\author{
Universidade de São Paulo \\ Instituto de Física
}

\title{
Estudos Teóricos do Espectro de Absorção de Porfirinas e Ftalocianinas
}

\author{
Vinícius Wilian Dias Cruzeiro
}

Orientadora: $\operatorname{Prof}^{\mathrm{a}}$. $\mathrm{Dr}^{\mathrm{a}}$. Kaline Rabelo Coutinho

\section{Banca Examinadora:}

Prof $^{\mathrm{a}}$. Dr ${ }^{\mathrm{a}}$. Kaline Rabelo Coutinho (IF-USP)

Prof $^{\mathrm{a}}$. Dr ${ }^{\mathrm{a}}$. Helena Maria Petrilli (IF-USP)

Prof. Dr. Antonio Carlos Borin (IQ-USP) 


\section{FICHA CATALOGRÁFICA}

Preparada pelo Serviço de Biblioteca e Informação do Instituto de Física da Universidade de São Paulo

Cruzeiro, Vinícius Wilian Dias

Estudos Teóricos do Espectro de Absorção

de Porfirinas e Ftalocianinas. São Paulo, 2014.

Dissertação de Mestrado - Universidade de São Paulo. Instituto de Física - Departamento de Física Geral. Grupo de Física Atômica e Molecular

Orientadora: Prof $\stackrel{\text { a }}{\text {. Dr }}$ a . Kaline Rabelo Coutinho

Área de Concentração: Física Atômica e Molecular

Unitermos:

1. Física Molecular;

2. Simulações Computacionais - Dinâmicas Moleculares;

3. Efeitos Térmicos;

4. Espectroscopia Eletrônica.

USP/IF/SBI-031/2014 
Dedico esta dissertação ao meu filho Pedro Wilian, e a todas as pessoas que, assim como eu, sonham alto. 

"Nem tudo que se enfrenta pode ser modificado, mas nada pode ser modificado até que seja enfrentado"

Albert Einstein

"Seja a mudança que você quer ver no mundo"

Mahatma Gandhi

"...and if we were to name the most powerful assumption of all [...] it is that all things are made of atoms, and that everything [...] can be understood in terms of the jigglings and wigglings of atoms"

Richard P. Feynman 



\section{Agradecimentos}

Com esta dissertação, mais uma etapa da minha carreira acadêmica chega ao fim. Eu não poderia deixar de aproveitar este espaço para agradecer aqueles que contribuíram para que isso pudesse acontecer.

Inicialmente eu gostaria de agradecer muito aos professores Sylvio e Kaline por terem me aberto as portas do grupo de Física Atômica e Molecular. Desde que cheguei a USP, além de muito bem recebido e tratado, tive oportunidade de estudar e trabalhar com tudo que tive vontade. Através disso considero que consegui alcançar um dos meus principais objetivos no mestrado, que era o de aprender o máximo que eu pudesse.

À minha orientadora, professora Kaline Coutinho, agradeço pela confiança depositada em mim, pela excelente orientação, pela amizade, e por ter me apoiado em todos os momentos do meu mestrado, inclusive nos momentos difíceis que passei. Agradeço também pela atenção, pelos ensinamentos (tanto científicos quanto pessoais), que com certeza vou levar comigo pelo decorrer de toda minha carreira acadêmica.

Eu não poderia deixar de agradecer também aos professores Benedito Cabral e Sylvio Canuto pelas conversas que contribuíram imensamente no meu mestrado.

Ao fazer meu mestrado na USP tive a oportunidade de fazer parte de um ambiente acadêmico extremamente enriquecedor e frutífero. Portanto eu não poderia deixar de agradecer aos meus colegas de universidade, que hoje se tornaram amigos. Agradeço particularmente aos amigos Marcus Damasceno, Evanildo Lacerda, Carlos Bistafa, George Barbosa, Lucas Modesto, Fernando da Silva, Marcel Dorta e Paula 
Jaramillo pelas conversas e pelo suporte, ao amigo Antonio Cunha por ter me ensinado a manusear os equipamentos no laboratório para medidas do espectro de absorção, ao amigo Fábris Kossoski pelos conselhos acerca desta dissertação, e a amiga Cíntia Suplicy por ter me ajudado a montar uma máquina com GPU's. Agradeço também aos funcionários Valdir e Sérgio pelo suporte técnico.

Gostaria de agradecer também aos ex-alunos do grupo que deixaram boas dissertações ou teses que ajudaram bastante na minha formação principalmente quando cheguei ao grupo. Espero que esta dissertação possa também ser útil para futuros alunos assim como várias teses e dissertações foram úteis para mim.

Agradeço também a agência de fomento CNPq pelo suporte financeiro.

A vida me trouxe uma excelente surpresa durante o período de mestrado: meu filho, Pedro Wilian. Ele mal chegou ao mundo e já trouxe muita alegria para mim e para toda minha família, além de me mostrar um novo e intenso significado do que é o amor. Agradeço ao meu filho pois, mesmo sem saber, me deu incentivo para continuar na árdua tarefa que foi escrever esta dissertação. Agradeço profundamente aos meus amados pais, André e Zenilda, que cuidaram e acolheram a minha esposa em Goiânia desde a gravidez e agora também o meu filho até que eu pudesse concluir o meu mestrado. Mãe, muito obrigado por suas palavras de carinho. Pai, muito obrigado por seu meu maior apoiador. Eu não chegaria até aqui sem o apoio de vocês.

Por fim, eu gostaria de agradecer imensamente a minha companheira, minha esposa Fabiana. Agradeço por ter me dado um filho maravilho, pela compreensão com os meus estudos, e por ter estado ao meu lado me apoiando e incentivando em todos momentos. Agradeço por ser uma mamãe excelente, e por ter cuidado do nosso filho tão bem. O seu carinho e o seu amor foram essenciais para que eu chegasse até aqui.

A todos, o meu muito obrigado!

Vinícius Wilian Dias Cruzeiro 


\section{Sumário}

Resumo $\quad x$

Abstract $\quad$ xii

1 Introdução 1

1.1 Comentários gerais . . . . . . . . . . . . . . 1

1.2 Organização desta dissertação . . . . . . . . . . . . . . 8

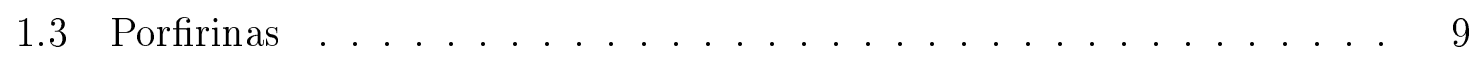

1.3.1 Revisão da literatura sobre o espectro da $H_{2}$-Porfirina $\ldots . . .9$

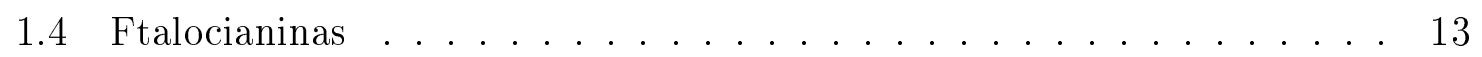

1.4.1 Revisão da literatura sobre o espectro da $H_{2}$-Ftalocianina . . 13

2 Revisão de Conceitos e Métodos Teóricos $\quad 17$

2.1 A Luz e o Espectro Eletromagnético . . . . . . . . . . . . . . . . 17

2.2 O Espectro de Absorção . . . . . . . . . . . . . . . . . . . . 19

2.2 .1 Conceitos gerais . . . . . . . . . . . . . 19

2.2 .2 Espectro de Absorção Eletrônica . . . . . . . . . . . 20

2.2.3 Níveis de Energia Eletrônica: Orbitais Moleculares . . . . . . . 23

2.2.4 Energia de Excitação . . . . . . . . . . . . . 27

2.2.5 Absorbância, Lei de Lambert-Beer e Força de oscilador . . . . . 27

2.2.6 Convolução dos picos teóricos por Lorentzianas . . . . . . . . 31

2.3 Métodos para Cálculos de Mecânica Quântica . . . . . . . . . . . 34

2.3.1 Aproximação de Born-Oppenheimer . . . . . . . . . . . 37

2.3.2 Aproximação de Hartree-Fock . . . . . . . . . . . . . . . . . 39 
2.3.3 Aproximação LCAO: Conjuntos de Funções-base . . . . . . . . 44

2.3.4 Métodos Semi-empíricos: ZINDO/CIS . . . . . . . . . 47

2.3.5 Teoria do Funcional da Densidade . . . . . . . . . . . . 49

2.3.5.1 Formalismo de Kohn-Sham . . . . . . . . . . . 51

2.3.5.2 Implementação computacional de métodos DFT . . . 53

2.3.5.3 Por que a versão dependente do tempo de DFT deve ser usada no cálculo do espectro de absorção? ... 55

2.3.6 Métodos de Mecânica Molecular: campo de força GROMOS . . 57

2.4 Inclusão de Efeitos Térmicos através de Dinâmicas Moleculares . . . . 61

2.4.1 Optimização de Geometria . . . . . . . . . . . . . . . 61

2.4.2 Simulações Moleculares: Dinâmicas Moleculares . . . . . . . . . 62

2.4.3 Equação de Movimento Nuclear . . . . . . . . . . . . . . . . 64

2.4.3.1 Algoritmo de integração: algoritmo Leap-Frog . . . 65

2.4.4 Termalização: termostato Velocity-Rescale . . . . . . . . . . . 66

2.4.5 Mudanças nas Dinâmicas ab initio com o uso de GPUs . . . . . 68

3 Resultados e Discussões $\quad 69$

3.1 Estudos de Porfirinas isoladas . . . . . . . . . . . . . . . 70

3.1.1 Comparação entre as estruturas optimizada e cristalina . . . 71

3.1.2 Discussão acerca do modelo de Gouterman ...... 73

3.1.3 Discussão sobre as forças de oscilador na região do visível . . 83

3.1.3.1 As excitações são proibidas por simetria? . . . . . . 83

3.1.3.2 Espectro de uma estrutura distorcida . . . . . . . 86

3.1.4 Comparação de resultados para estruturas optimizadas . . . . . 89

3.1.4.1 Resultados para monômero . . . . . . . . . . . 89

3.1.4.2 Resultados para dímeros . . . . . . . . . . 93

3.1.5 Resultados de Dinâmicas Moleculares de Monômero . . . . . . 105

3.1.5.1 Descrição das dinâmicas . . . . . . . . . . . . 106

3.1.5.2 Termalização: escolha da região de produção . . . . 108

3.1.5.3 Análises das estruturas geradas . . . . . . . . . . 109

3.1.5.4 Alteração de parâmetros do campo de forças clássico . 114

3.1.5.5 Influência de um hidrogênio central na estrutura . . . 118 
3.1.5.6 Análise de convergência para o espectro de absorção 120

3.1.5.7 Detalhamento do espectro de absorção . . . . . . . . . 124

3.1.5.8 Espectro de absorção em diferentes temperaturas . . . 130

3.1.6 Sumário de Conclusões . . . . . . . . . . . . . . 135

3.2 Estudos de Ftalocianinas isoladas . . . . . . . . . . . . 137

3.2.1 Comparação entre as estruturas optimizada e cristalina . . 138

3.2 .2 Teste de convergência de funções-base . . . . . . . . . . . . 140

3.2.3 O modelo de Gouterman é válido para Ftalocianinas? . . . . . 142

3.2.4 Desdobramento das bandas $Q$ da $H_{2}$-Ftalocianina . . . . . 152

3.2.5 Comparação de resultados para estruturas optimizadas . . . . 155

3.2.5.1 Resultados para monômero . . . . . . . . . 155

3.2.5.2 Resultados para dímeros . . . . . . . . . 159

3.2.6 Resultados de Dinâmicas Moleculares de Monômero . . . . . 169

3.2.6.1 Descrição das dinâmicas . . . . . . . . . . . . . 170

3.2.6.2 Termalização: escolha da região de produção ... 171

3.2.6.3 Análises das estruturas geradas . . . . . . . . . . 172

3.2.6.4 Influência do posicionamento dos hidrogênios centrais 177

3.2.6.5 Análise de convergência para o espectro de absorção 180

3.2.6.6 Análise do espectro de absorção . . . . . . . . . . 182

3.2.6.7 Espectro de absorção em diferentes temperaturas . . . 188

3.2.7 Resultados adicionais . . . . . . . . . . . . . . . . . 194

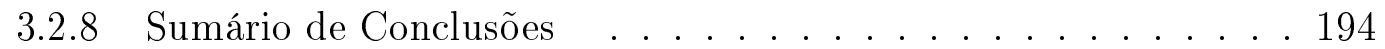

4 Conclusões e Perspectivas $\quad 199$

$\begin{array}{ll}\text { Referências Bibliográficas } & 203\end{array}$

$\begin{array}{ll}\text { Apêndices } & 210\end{array}$

A Estudos do Espectro de Absorção de Moléculas Modelo Isoladas 211

B Resultados Adicionais para Porfirinas Isoladas 223

$\begin{array}{ll}\text { C Resultados Adicionais para Ftalocianinas } & 241\end{array}$ 
C.1 Ftalocianinas com Eugenóis substituintes . . . . . . . . . . . 242

C.2 Resultados referenciados durante a dissertação . . . . . . . . . . . 248

D Parametrizações das Dinâmicas Clássicas $\quad 263$

D.1 Parametrização da $H_{2}$-Porfirina . . . . . . . . . . . . . . . . . 263

D.1.1 Arquivo de topologia . . . . . . . . . . . . . . 263

D.1.2 Arquivo de inicialização da dinâmica . . . . . . . . . . 268

D.2 Parametrização da $H_{2}$-Ftalocianina . . . . . . . . . . . . 269

D.2.1 Arquivo de topologia . . . . . . . . . . . . . . 269

D.2.2 Arquivo de inicialização da dinâmica . . . . . . . . . . 276

$\begin{array}{ll}\text { E Publicação } & \mathbf{2 7 7}\end{array}$ 


\section{Resumo}

Esta dissertação está focada no estudo do espectro de absorção em fase gasosa de Porfirinas e Ftalocianinas. O estudo dessas moléculas é de grande interesse científico e tem sido tema em diversos trabalhos na literatura.

São apresentados resultados o espectro de absorção teórico das Porfirinas Base Livre $\left(\mathrm{H}_{2}\right.$-Porfirina), complexada com Zinco, e complexada com Magnésio, e das Ftalocianinas Base Livre ( $H_{2}$-Ftalocianina) e complexada com Zinco. Espectros de absorção dos monômeros optimizados dessas moléculas são calculados com vários métodos e uma análise das transições eletrônicas é feita junto com uma discussão do modelo de Gouterman. São apresentados espectros para estruturas optimizadas de dímeros de $\mathrm{H}_{2}$-Porfirina e $\mathrm{H}_{2}$-Ftalocianina. A inclusão de efeitos térmicos no espectro dos monômeros de $\mathrm{H}_{2}$-Porfirina e $\mathrm{H}_{2}$-Ftalocianina é estudada usando dinâmicas moleculares.

Após comparação entre resultados de dinâmicas clássica e ab initio, propomos novos parâmetros para o campo de força da $H_{2}$-Porfirina que fornece resultados mais compatíveis, mas o mesmo não precisou ser feito para $H_{2}$-Ftalocianina. Mostramos que para $\mathrm{H}_{2}$-Porfirina a inclusão de efeitos térmicos aumenta com a temperatura as forças de oscilador médias das bandas $Q$ e gera um deslocamento das bandas para o vermelho, e para $H_{2}$-Ftalocianina um aumento do desdobramento das bandas $Q$. Esses resultados fornecem uma explicação para observações experimentais e mostram que efeitos térmicos são importantes para uma descrição mais completa do espectro. 


\section{Abstract}

This work aims at studing the gas phase absorption spectrum of Porphyrins and Phthalocyanines. The study of these molecules is of immense cientific interest and has been topic for several works at the literature.

Results are presented for the theoretical absorption spectrum of Free Base $\left(\mathrm{H}_{2^{-}}\right.$ Porphyrin), Zinc and Magnesium Porphyrins and of Free Base $\left(H_{2}\right.$-Phythalocyanine) and Zinc Phthalocyanines. The absorption spectra of these molecules' optimized monomers are calculated with several methods and eletronic transitions analysis is done together with a discussion of Gouterman model. Spectra are presented for optimized dimers of $\mathrm{H}_{2}$-Porphyrin and $\mathrm{H}_{2}$-Phthalocyanine. The inclusion of thermal effects on the $H_{2}$-Porphyrin's and $H_{2}$-Phthalocyanine's monomer spectra is studied through molecular dynamics.

After comparing results of classical and ab initio molecular dynamics we proposed new force field parameters for $\mathrm{H}_{2}$-Porphyrin that provides more consistent results, but the same didn't need to be done for $H_{2}$-Phthalocyanine. We showed that the inclusion of thermal effects increases with temperature the $Q$ bands average oscillator strengths and implies in a red shift of the $\mathrm{H}_{2}$-Porphyrin bands, and increases the $H_{2}$-Phthalocyanine's $Q$ bands splitting. There results provide an explanation to the experimental observations and shows that thermal effects are important to a more complete description of the spectrum. 


\section{Capítulo 1}

\section{Introdução}

\subsection{Comentários gerais}

Dentre as diversas áreas de estudos em Física, a Física Atômica e Molecular é uma área que se dedica ao estudo do comportamento da matéria em nível atômico-molecular. Estudos são feitos envolvendo, por exemplo, a compreensão de estruturas moleculares, ligações químicas, reações químicas, da interação entre as moléculas, da interação entre moléculas e radiações, e de propriedades que as moléculas apresentam sozinhas, em aglomerados ou até mesmo em fase condensada. Para isso se utiliza conhecimentos de Física como Mecânica Quântica, Eletromagnetismo e Mecânica Estatística. Entretanto, apesar de as teorias envolvidas nestes conhecimentos estarem bem estabelecidas dentro da física, existe uma grande complexidade na interação entre átomos e moléculas, bem como no tratamento teórico para lidar com essas interações.

Através do estudo da estrutura eletrônica de um sistema molecular é possível entender, calcular e prever inúmeras propriedades, como sua estabilidade estrutural, reatividade, centro de atividade biológica, propriedades elétricas, respostas a campo, mecanismos de reação, dentre outras. Desde o desenvolvimento da mecânica quântica, no início do século passado, muitos trabalhos teóricos têm sido desenvolvidos com o intuito de compreender a estrutura eletrônica de moléculas e/ou materiais. Muito 
conhecimento foi gerado nesta área mas ainda há muitos problemas em aberto para se estudar. Os problemas e as moléculas que serão estudados nesta dissertação tem relação com o processo fotossintético, que discorreremos brevemente a seguir.

Para a manutenção da vida em nosso planeta, seja ela humana ou não, é preciso energia [1,2]. Em nosso planeta essa energia é principalmente provida pelo Sol. A luz solar é capturada e convertida em energia química em um processo conhecido como fotossintese $e^{1,2}$. Esse processo não ocorre somente em plantas, mas também em algas e em muitas bactérias.

A fotossíntese é um dos mais importantes processos da natureza, sendo responsável pela existência de vida em nosso planeta [1]. Nesse processo físico-químico radiação solar é absorvida e utilizada em uma complexa reação química que converte dióxido de carbono e água em carboidrato com a subsequente liberação de oxigênio; oxigênio esse que necessitamos em nossa respiração. A equação química mínima e balanceada para a descrição da fotossíntese é [1]:

$$
\mathrm{CO}_{2}+\mathrm{H}_{2} \mathrm{O} \stackrel{\text { Absorção de Luz }}{\longrightarrow}\left(\mathrm{CH}_{2} \mathrm{O}\right)+\mathrm{O}_{2}
$$

onde $\left(\mathrm{CH}_{2} \mathrm{O}\right)$ representa um carboidrato. Um exemplo de carboidrato é a Glicose. A Glicose é um dos carboidratos mais importantes da biologia porque as células a usam como fonte de energia e intermediário metabólico. No caso da Glicose a equação fica [1]:

$$
6 \mathrm{CO}_{2}+6 \mathrm{H}_{2} \mathrm{O} \stackrel{\text { Absorção de Luz }}{\longrightarrow}\left(\mathrm{C}_{6} \mathrm{H}_{12} \mathrm{O}_{6}\right)+6 \mathrm{O}_{2}
$$

\footnotetext{
${ }^{1}$ A palavra fotossíntese vem do grego. "Foto" vem da palavra Photo que significa luz, e "síntese" vem da palavra synthesis que significa unir, ou colocar junto.

${ }^{2}$ Uma curiosidade sobre fotossíntese é que ela é tão importante para a preservação de um ambiente propício para a existência de vida em nosso planeta que a maior causa do catastrófico evento que causou a extinção dos dinossauros e de outras espécies a cerca de 65 milhões de anos atrás não foi o impacto do asteroide em si, mas sim os efeitos que ele causou ao ejetar imensas quantidades de poeira na atmosfera [1]. Esta poeira bloqueou a luz solar e com isso encerrou todos os processos fotossintéticos por toda Terra por um período de meses ou até anos. Essa interrupção teve efeitos catastróficos na biosfera da Terra, levando a extinções.
} 
Além de prover uma fonte de energia para as plantas e também fornecer oxigênio para a respiração, a fotossíntese está ligada a maior parte das cadeias alimentares na Terra. Sem ela os animais e muitos outros seres heterotróficos ${ }^{3}$ seriam incapazes de sobreviver porque a base da sua alimentação está em outros seres vivos autótrofos ${ }^{4}$, direta ou indiretamente.

A primeira etapa do processo de fotossíntese é a absorção de luz solar, principalmente na região do visível - de aproximadamente 400 a $700 \mathrm{~nm}$, de uma forma extraordinariamente eficiente. A região do visível corresponde ao máximo da radiação solar, portanto é natural conceber que houve uma adaptação natural dos seres que realizam fotossíntese para absorver luz com mais eficiência nesta região espectral.

Os pigmentos fotossintéticos, também chamados de fotorreceptores, são moléculas que são usadas como antenas para captar e absorver luz no processo fotossintético. Nas plantas os pigmentos ativos na fotossíntese se encontram dentro dos cloroplastos [1]. Essa eficiente absorção de luz visível dos pigmentos fotossintéticos pode ser observada nas características do espectro de absorção desses pigmentos.

Existe um extraordinário número de pigmentos encontrados em diferentes organismos fotossintéticos, que servem para uma variedade de funções. Dentre os pigmentos estão as Clorofilas (nomeadas de $a$ a $d$ ) e as Bacterioclorofilas (nomeadas de $a$ a $g$ ), que foram nomeadas na ordem de seu descobrimento, e também os Carotenoides e as Ficobilinas. Na figura 1.1 a seguir ilustramos a estrutura química de um pigmento de cada um desses tipos.

\footnotetext{
${ }^{3}$ Em biologia, seres heterotróficos são seres que não conseguem sintetizar o seu próprio alimento por não possuírem a capacidade de produzir glicose a partir da fotossíntese, por isso estes seres necessitam de se alimentar a partir dos outros compostos inorgânicos ou orgânicos.

${ }^{4}$ Em biologia, seres autótrofos são seres que conseguem sintetizar o seu próprio alimento, ao contrário de seres heterotróficos.
} 

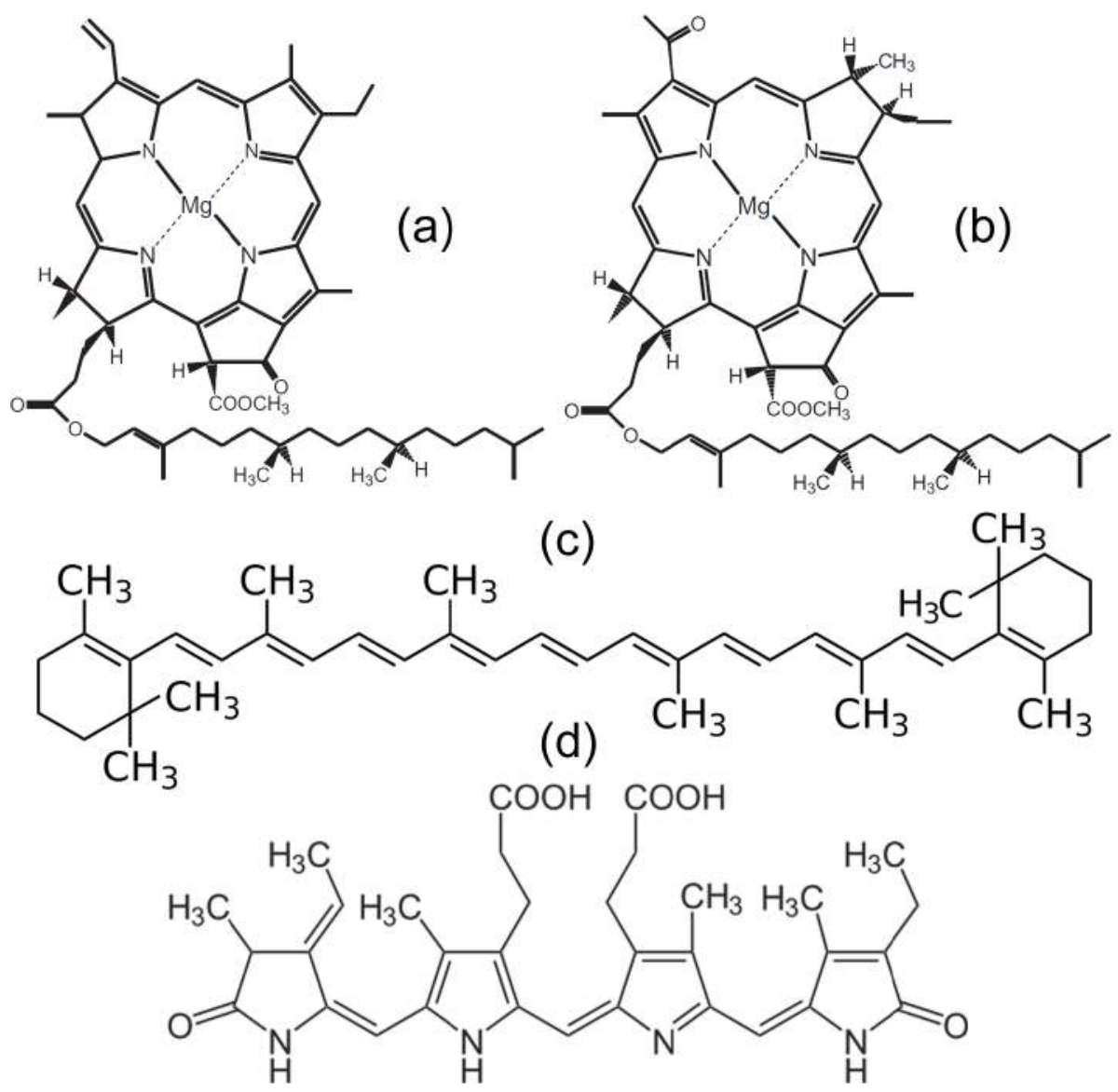

Figura 1.1: Ilustrações das estruturas químicas de alguns pigmentos fotossintéticos. Essas ilustrações foram baseadas em figuras da referência [1]. (a) Clorofila $a$, (b) Bacterioclorofila $a$, (c) $\beta$-Caroteno e (d) Ficocianobilina.

De uma forma geral o espectro de absorção desses pigmentos é caracterizado por uma absorção intensa na região de aproximadamente 400 a $450 \mathrm{~nm}$ (conhecida como banda de Soret) e também por absorções de menor intensidade na região de aproximadamente 500 a $700 \mathrm{~nm}$ (conhecidas como bandas Q). Todas as Clorofilas apresentam essas características no espectro de absorção, e uma interessante implicação disto é que a subtração das cores azul e vermelho, correspondentes a essas absorções de luz, confere a cor verde às plantas. Já os Carotenos apresentam apenas uma intensa banda de Soret e por isso são alaranjados.

Além dos pigmentos fotossintéticos existem outros pigmentos importantes pela 
sua capacidade de absorver de luz. Dentre esses pigmentos estão as Porfirinas $e$ Ftalocianinas, que são os tipos de moléculas estudas nesta dissertação. Porfirinas e Ftalocianinas são bastante estudas na literatura (tanto experimentalmente como teoricamente), são encontradas na natureza em diversas formas, e possuem varias aplicações (que serão mencionadas posteriormente nas seções 1.3 e 1.4). Essas moléculas têm estruturas semelhantes à estrutura do macrociclo das Clorofilas. As estruturas químicas delas são ilustradas na figura 1.2.
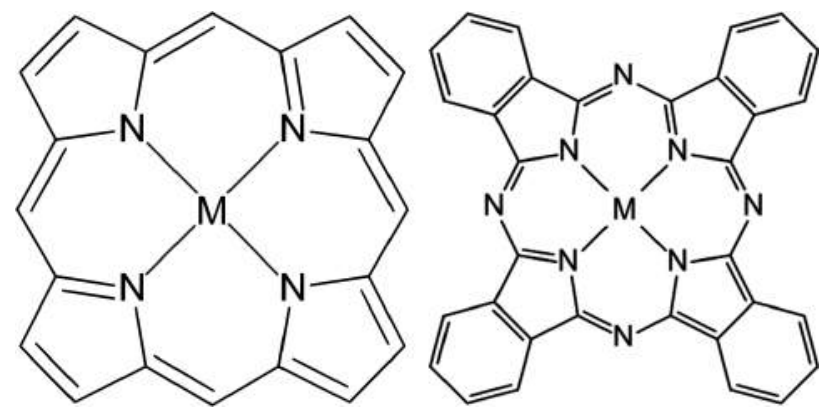

Figura 1.2: Ilustrações das estruturas químicas de Porfirinas (esquerda) e Ftalocianinas (direita). M pode ser substituído por algum íon metálico ou por dois átomos de hidrogênio.

Os quatro átomos de nitrogênio presentes no centro das Porfirinas e Ftalocianinas são capazes de acomodar um íon metálico ou dois hidrogênios. Quando dois hidrogênios são acomodados a molécula é chamada de Base Livre. Como a figura 1.2 mostra as Porfirinas são uma classe de moléculas orgânicas com uma estrutura formada por um macrociclo tetrapirrólico (ou seja, formada por quatro anéis pirrólicos ${ }^{5}$ ), ligados por ligações metílicas (-CH-). Nesta classe de compostos estão a Hemeporfirina - que contém um íon de ferro no seu centro e é o pigmento vermelho das células sanguíneas - e uma simplificação da estrutura da Clorofila a mostrada na figura 1.1 leva a Porfirina complexada com Magnésio. Como a figura 1.2 mostra as Ftalocianinas são estruturalmente relacionadas com Porfirinas. Em comparação com as Porfirinas, nas Ftalocianinas um anel benzênico ${ }^{6}$ se une a cada anel pirrol e as ligações metílicas

\footnotetext{
${ }^{5} \mathrm{Um}$ anel pirrol - $\mathrm{C}_{4} H_{5} \mathrm{~N}$ - é um composto orgânico constituído por 4 carbonos e 1 nitrogênio em forma de um anel de 5 lados.

${ }^{6} \mathrm{Um}$ anel benzênico - $\mathrm{C}_{6} \mathrm{H}_{6} \mathrm{~N}$ - também chamado anel aromático, é um composto orgânico cons-
} 
passam a ser intermediadas por um nitrogênio. Essas diferenças estruturais entre Clorofilas, Porfirinas e Ftalocianinas resultam em diferenças no espectro de absorção, mas algumas características gerais são mantidas já que todas essas moléculas apresentam bandas $Q$ e também apresentam banda de Soret.

Pela enorme importância desses pigmentos, o seu processo de absorção e emissão de luz tem sido objeto de muitas investigações teóricas e experimentais. A compreensão do espectro de absorção de pigmentos abre portas para a concepção de novos pigmentos artificiais com uma resposta ainda mais adequada para absorção de luz [3]. Portanto o estudo do espectro de absorção dessas moléculas também está na linha de desenvolvimento de células solares [4,5], por exemplo, e também no desenvolvimento de sensores para o tratamento de câncer através da Terapia Fotodinâmica [6,7]. Estudos do tipo desses mencionados estão dentro de uma linha de pesquisa conhecida como "Light Harvest" e tem adquirido enorme interesse nos últimos anos [3].

Dada a importância do estudo do processo de absorção de moléculas desse tipo, nesta dissertação vamos apresentar estudos relacionados com a descrição do espectro de absorção em fase gasosa de Porfirinas e Ftalocianinas. Este tipo de estudo está na mesma linha de diversos trabalhos teóricos encontrados na literatura [8-27]. A compreensão do espectro de absorção em fase gasosa é importante pois serve como base para a compreensão do espectro em outras situações, como em solução e/ou com a presença de substituintes na molécula.

$\mathrm{Na}$ literatura existem vários resultados experimentais envolvendo Porfirinas e Ftalocianinas, dentre eles medidas do espectro de absorção. Dentre essas medidas estão o espectro em fase gasosa de várias Porfirinas - reportado em um trabalho de Edwards, Dolphin, Gouterman e Adler de 1971 [28] - e o espectro em fase gasosa de várias Ftalocianinas - reportado em um trabalho de Edwards e Gouterman de 1970 [29]. Nestes trabalhos algumas observações experimentais chamam a atenção, como a 
baixa absorção de luz na região do visível pela Porfirina Base Livre em temperaturas não muito elevadas, e a observação de um maior desdobramento das bandas $Q$ da Ftalocianina Base Livre em comparação com o desdobramento observado em solução.

Nesta dissertação serão apresentados resultados para o espectro de absorção teórico das Porfirinas Base Livre, complexada com Zinco, e complexada com Magnésio, e das Ftalocianinas Base Livre e complexada com Zinco. Os espectros de absorção dos monômeros dessas moléculas obtidos após a optimização de geometria serão apresentados utilizando vários métodos - teoria do funcional da densidade com vários funcionais, semi-empírico com parametrização espectroscópica e interação de configuração no caso das Porfirinas - e uma análise dos orbitais moleculares e das transições eletrônicas envolvidas nas excitações dos espectros será feita juntamente com uma discussão acerca o modelo de Gouterman [9]. Os espectros obtidos com diferentes métodos para estruturas de dímeros optimizados da Porfirina Base Livre e da Ftalocianina Base Livre também serão apresentados e discutidos. No caso dos monômeros de Porfirina Base Livre e Ftalocianina Base Livre a influência da inclusão de efeitos térmicos no espectro de absorção será estuda através da realização de dinâmicas moleculares, e uma análise desses resultados será feita em conexão com as observações experimentais mencionadas no final do parágrafo anterior com o intuito de fornecer uma descrição teórica para esses fenômenos.

A inclusão de efeitos térmicos no tratamento teórico do espectro de absorção é importante porque o resultado para uma estrutura optimizada sem correções vibracionais corresponde ao resultado em uma temperatura nula $(0 \mathrm{~K})$ enquanto os resultados experimentais são obtidos em temperaturas elevadas. Com o uso de dinâmicas moleculares podemos gerar configurações acessíveis a uma dada condição termodinâmica, condição essa que pode ser compatível com a experimental. Por isso efeitos térmicos incluem efeitos vibracionais e de ensemble no tratamento teórico e podem ser importantes para uma correta descrição dos resultados experimentais. Nesta dissertação 
apresentaremos resultados de dinâmicas moleculares ab initio, e confrontaremos os seus resultados, tanto estruturais como os espectros, com os de dinâmicas clássicas. Esse tipo de comparação é importante pois serve como teste para o campo de forças utilizado nas dinâmicas clássicas.

\subsection{Organização desta dissertação}

Esta dissertação está organizada em quatro capítulos, onde este capítulo de Introdução é o primeiro deles. O segundo capítulo é chamado de Revisão de Conceitos e Métodos Teóricos, o terceiro capítulo é chamado Resultados e Discussões, e o quarto capítulo é chamado de Conclusões e Perspectivas. Esta dissertação também contém cinco apêndices nomeados de A a E cujos nomes são autoexplicativos. O apêndice A é chamado Estudos do Espectro de Absorção de Moléculas Modelo Isoladas, o apêndice B é chamado Resultados Adicionais para Porfirinas Isoladas, o apêndice C é chamado Resultados Adicionais para Ftalocianinas, o apêndice D é chamado Parametrizações das Dinâmicas Clássicas, e o apêndice E é chamado Publicação.

Nas duas seções restantes deste capítulo falaremos um pouco mais sobre Porfirinas e Ftalocianinas, e apresentaremos o espectro de absorção da Porfirina Base Livre e da Ftalocianina Base Livre juntamente com uma revisão de trabalhos da literatura e com uma explanação dos problemas de origem experimental que serão tratados nesta dissertação. No capítulo 2 faremos uma revisão teórica sobre o espectro de absorção, sobre métodos de mecânica quântica, e sobre simulação computacional com enfoque nos pontos considerados relevantes para esta dissertação. No capítulo 3 o foco das discussões é nos resultados para a Porfirina e Ftalocianina Livres de Base, e os resultados para as demais moléculas são mencionados durante o texto e se encontram nos apêndices. E no capítulo 4 serão apresentadas as conclusões e as perspectivas que surgem desta dissertação. 


\subsection{Porfirinas}

As porfirinas são pigmentos de coloração roxa [30]. Este nome, Porfirina, vem da palavra grega "porfyró" que significa roxo. Porfirinas são importantes em diversos processos biológicos como na absorção e no transporte de oxigênio, e no transporte eletrônico na etapa inicial do processo fotossintético $[1,9,10]$. Recentemente Porfirinas têm sido empregadas em diversas aplicações, como em indústrias de tintas, na conversão de energia solar, em fotossíntese artificial, em terapia fotodinâmica, em eletro-óptica e em óptica não linear, dentre outras [11]. Porfirinas são tão importantes que já foram rotuladas como "os pigmentos da vida" [11] e no livro "The Colours of Life: An introduction to the Chemistry of Porphyrins and Related Compounds" de L. R. Milgrom [31] existe uma frase no último parágrafo do capítulo final que diz "Truly, where there is life, there are porphyrins" (Verdadeiramente, onde há vida, há porfirinas).

\subsubsection{Revisão da literatura sobre o espectro da $H_{2}$-Porfirina}

Porfirinas, em suas mais variadas formas, já veem sendo alvo de estudos teóricos [9-11, 14, 15, 17, 25-27, 32, 33] e experimentais [28, 34, 35] há muitas décadas. O espectro de Porfirinas é tema para muitas discussões e interpretações teóricas, algumas dessas muito bem estabelecidas na literatura. O estudo de Porfirinas e sistemas relacionados é de tamanha importância a ponto de existirem duas excelentes séries de livros na literatura com um condensado de diversos resultados, tanto teóricos quanto experimentais, olhando para diferentes propriedades dos sistemas de Porfirinas e sistemas relacionados. A série mais antiga é chamada "The Porphyrins" [30], foi editada por David Dolphin, e contém sete volumes. A série mais recente é chamada de "The Porphyrin Handbook" [36], foi editada por Karl Kadish, Kevin Smith e Roger Guilard, e contém vinte volumes. Alguns dos volumes destas duas séries foram consultados durante a escrita desta dissertação. 
Gouterman, em um de seus trabalhos de 1961 sobre o espectro de absorção de Porfirinas [9], afirma que todas as Porfirinas apresentam aproximadamente as mesmas características no espectro de absorção: cerca de quadro bandas visíveis de intensidade moderada na região de aproximadamente 500 a $660 \mathrm{~nm}$, seguidas por uma banda de intensidade extremamente forte no início da região ultravioleta, chamada de banda de Soret, em torno de $400 \mathrm{~nm}$. As bandas na região do visível Gouterman rotulou de bandas $Q$, e a banda de Soret de banda $B$.

O espectro experimental da molécula de $H_{2}$-Porfirina em fase gasosa, amplamente citado na literatura, foi obtido por Edwards e coautores em 1971 [28] e é apresentado na figura 1.3. Neste trabalho, onde Gouterman é coautor, outros rótulos são dados para as bandas além da banda de Soret, como pode ser visto na figura.

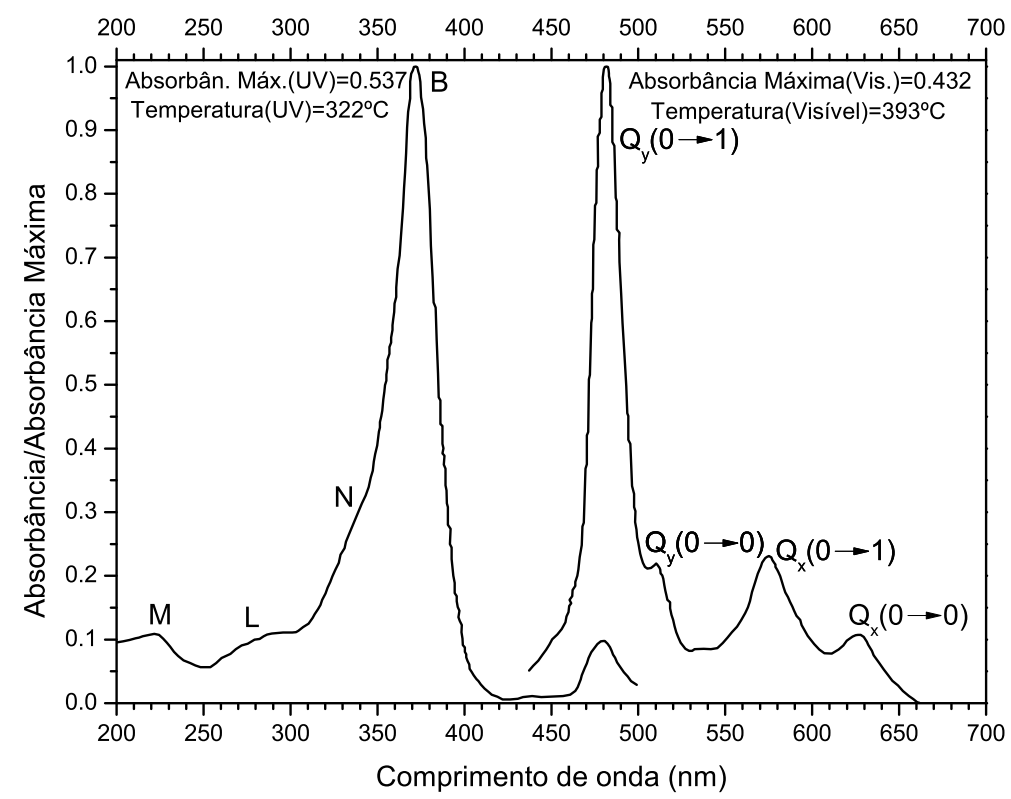

Figura 1.3: Espectro de absorção experimental da $H_{2}$-Porfirina em fase gasosa, retirado da referência [28].

Como vemos pela figura 1.3 o espectro experimental da $H_{2}$-Porfirina é composto por quatro bandas na região do visível. Gouterman em seu artigo de 1961 [9] afirma, com base em cálculos semi-empíricos disponíveis na época [37], que duas das bandas 
do espetro nessa região são na verdade picos vibracionais. Essa afirmação, segundo Gouterman, é feita com base no fato de haver uma constância na separação de energia de cada uma dessas bandas em relação ao pico principal (pico relacionado puramente a transições eletrônicas) assim como devido à uma constância na intensidade relativa entre esse picos, observada em várias medidas experimentais. Essa hipótese de que duas das bandas na região do visível são picos vibracionais foi investigada teoricamente em vários trabalhos, dentre eles em um excelente trabalho de B. Minaev e H. Ågren [11] utilizando DFT, e está muito bem consolidada na literatura.

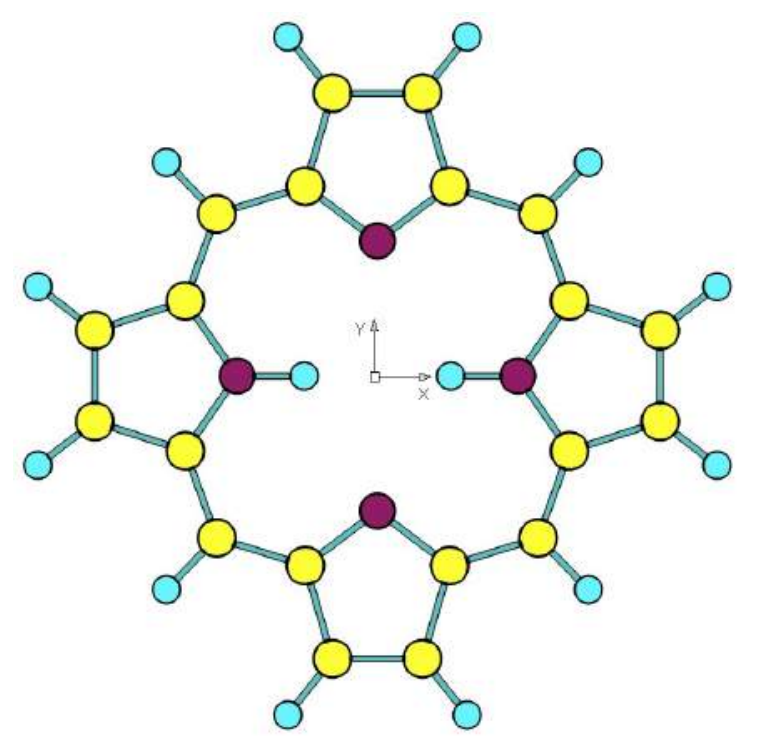

Figura 1.4: Estrutura da $\mathrm{H}_{2}$-Porfirina com a escolha de eixos de Gouterman.

Portanto, como mostrado na figura 1.3, o espectro de absorção da $H_{2}$-Porfirina é caracterizado pelas bandas: $Q_{x}(0 \rightarrow 0)$ em torno de $628 \mathrm{~nm}, Q_{x}(0 \rightarrow 1)$ em torno de $575 \mathrm{~nm}, Q_{y}(0 \rightarrow 0)$ em torno de $512 \mathrm{~nm}, Q_{y}(0 \rightarrow 1)$ em torno de $484 \mathrm{~nm}, B$ em torno de $373 \mathrm{~nm}, N$ em torno de $340 \mathrm{~nm}, L$ em torno de $292 \mathrm{~nm}$, e $M$ em torno de $225 \mathrm{~nm}$. Essa nomenclatura x e y tem relação com os momentos de dipolo de transição das excitações e com a escolha de eixos feita por Gouterman. Esses eixos são ilustrados na figura 1.4 juntamente com a estrutura da $H_{2}$-Porfirina. Portanto a excitação $Q_{x}(0 \rightarrow 0)$ é polarizada ao longo do eixo central N-H...H-N, chamado de eixo x, e $Q_{y}(0 \rightarrow 0)$ ao 
longo do eixo central N...N, chamado de eixo y, perpendicular ao eixo x. As bandas $Q_{x}$ e $Q_{y}$ têm componentes vibracionais fortes, e por isso os picos vibracionais $(0 \rightarrow 1)$ são mais intensos que os picos principais $(0 \rightarrow 0)$ correspondentes.

Todos essas interpretações mencionadas aqui, inicialmente propostas a partir das primeiras tentativas de explicar o espectro de Porfirinas utilizando o modelo de quatro orbitais desenvolvido por Gouterman e coautores apresentado em trabalhos na década de 60 [38-40], foram checadas em trabalhos teóricos mais recentes [11,15], e as nomenclaturas e escolha de eixos feitas por Gouterman são ainda utilizadas em muitos trabalhos $[10,11,13-15,27]$. Os estados excitados da Porfirina Base Livre, $\mathrm{H}_{2}$-Porfirina, já foram reportados utilizando uma variedade de métodos, desde métodos semi-empíricos utilizando o modelo de quatro orbitais de Gouterman, até cálculos mais recentes utilizando, como por exemplo, teoria multiconfiguracional de perturbação de segunda ordem (CASPT2, do Inglês "Complete Active-Space second-order Perturbation Theory") [27], método de configuração de interação adaptado à simetria (SAC-CI, do Inglês "Symmetry Adapted Cluster/Configuration Interaction") [32], e uma abordagem de "Similarity-Transformed Equation-Of-Motion Coupled-Cluster" (STEOM-CC) [33].

Apesar desses vários trabalhos, pouca atenção foi dada na literatura para um fato interessante com relação as bandas visíveis do espectro da $H_{2}$-Porfirina em fase gasosa. No artigo em que o espectro de absorção experimental da $H_{2}$-Porfirina é reportado [28], os autores em um ponto do texto dão a entender que é necessário que a temperatura esteja alta o suficiente para que ocorra absorção de luz na região do visível. Além disso, o resultado reportado para o espectro, apresentado na figura 1.3, também mostra o efeito da temperatura nas bandas visíveis. O espectro reportado é constituído por duas medidas: uma feita na região ultravioleta e visível próximo ao violeta à uma temperatura de $322^{\circ} \mathrm{C}$, e a outra na região do visível à uma temperatura de $393^{\circ} \mathrm{C}$. Na medida feita à $322^{\circ} \mathrm{C}$ a banda $Q_{y}(0 \rightarrow 1)$ aparece no espectro e podemos ver que ela é 
10 vezes menos intensa que a banda de Soret, o que corresponde a uma absorbância de 0,054 (já que a absorbância da banda de Soret é de 0,537). Porém na medida feita à $393^{\circ} \mathrm{C}$, uma temperatura $71^{\circ} \mathrm{C}$ mais elevada que a primeira, a absorbância da banda $Q_{y}(0 \rightarrow 1)$ passa a ser 0,432 , uma absorbância comparável a absorbância da banda $B$ à $322^{\circ} \mathrm{C}$. Portanto isso mostra que com esse aumento de temperatura a absorção de luz visível passa a ser maior. Atenção será dada a isso nos resultados apresentados para a $\mathrm{H}_{2}$-Porfirina no capítulo 3 de resultados.

Apesar de não ser tópico dessa dissertação, vale registrar aqui que a fosforescência de Porfirinas também foi alvo de estudos teóricos [11,15] e experimentais [41].

\subsection{Ftalocianinas}

Ftalocianinas são compostos macrocíclicos aromáticos de coloração intensamente azul ou verde (ver volume 17 da referência [36]), que são amplamente utilizados para tingimento e pintura principalmente em industrias automobilísticas [42]. Ftalocianinas, além de serem utilizadas como corantes, possuem diversas outras aplicações, tanto médicas como na terapia fotodinâmica, em oftalmologia e também na área cardiovascular, como na área do desenvolvimento de materiais como filmes finos, cristais líquidos e materiais semicondutores, e também na área de óptica não linear, dentre outras (ver volume 19 da referência [36]).

\subsubsection{Revisão da literatura sobre o espectro da $H_{2}$-Ftalocianina}

Assim como as Porfirinas, Ftalocianinas já veem sendo alvo de estudos teóricos [8,4348] e experimentais $[29,42,49]$ durante muitas décadas. O espectro de absorção de Ftalocianinas, principalmente na região do visível, é tema para muitas discussões teóricas e experimentais. Como mencionado no início da subseção 1.3.1, existem duas séries 
de livros voltadas apenas para o estudo de Porfirinas e sistemas relacionados $[30,36]$. Os seis últimos volumes da série "The Porphyrin Handbook" [36] são especialmente focados em Ftalocianinas.

O espectro experimental da $\mathrm{H}_{2}$-Ftalocianina em fase gasosa foi obtido e reportado em um trabalho de L. Edwards e M. Gouterman de 1970 [29]. Esse espectro é apresentado na figura 1.5.

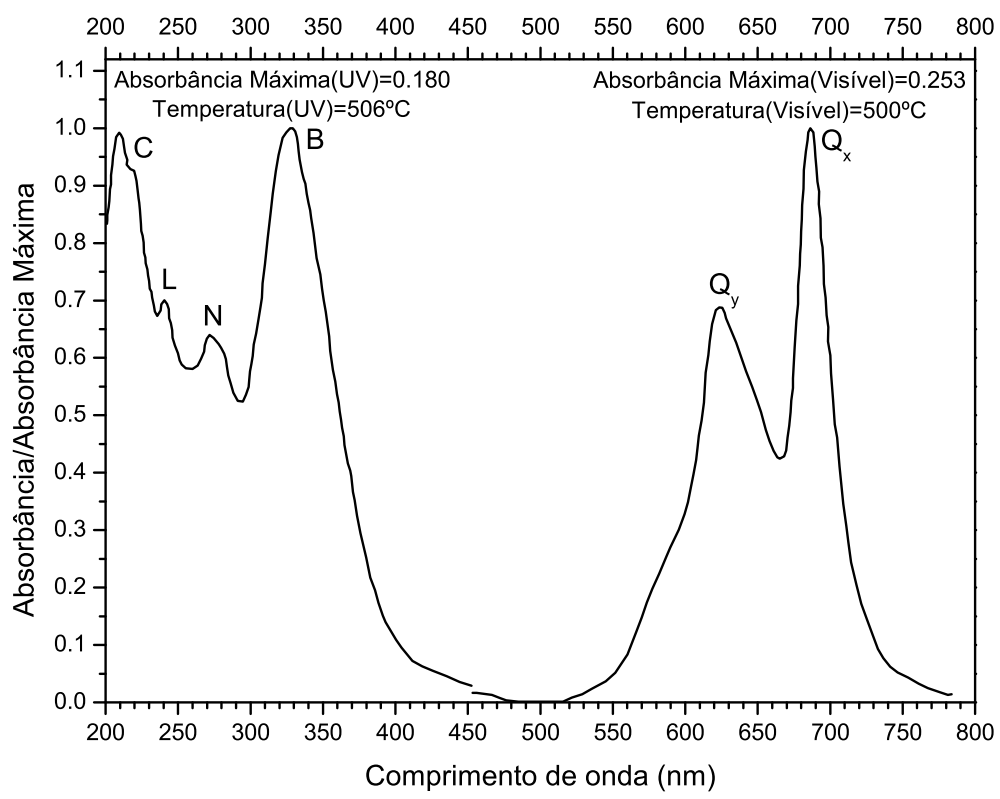

Figura 1.5: Espectro de absorção experimental da $H_{2}$-Ftalocianina em fase gasosa, retirado da referência [29].

Como pode ser visto na figura 1.5, ao contrário do espectro para a $H_{2}$-Porfirina em fase gasosa (ver figura 1.3), o espectro de absorção da $H_{2}$-Ftalocianina apresenta duas bandas na região do visível. Além disso, outras diferenças que podemos notar são o fato de que para a $\mathrm{H}_{2}$-Ftalocianina, ao contrário da $\mathrm{H}_{2}$-Porfirina, a absorbância das bandas na região do visível é maior do que a banda de Soret (ou banda $B$ ) e o fato de que a banda de Soret tem aproximadamente a mesma intensidade das demais bandas da região ultravioleta.

Como mostrado na figura 1.5, o espectro de absorção da $H_{2}$-Ftalocianina em 
fase gasosa é caracterizado pelas bandas: $Q_{x}$ em torno de $686 \mathrm{~nm}, Q_{y}$ em torno de $622 \mathrm{~nm}, B$ em torno de $327 \mathrm{~nm}, N$ em torno de $280 \mathrm{~nm}, L$ em torno de $240 \mathrm{~nm}$, e $C$ em torno de $220 \mathrm{~nm}$. Essa nomenclatura x e y tem relação com os momentos de dipolo de transição das excitações e com a escolha de eixos feita por Gouterman para a $H_{2}$-Porfirina (ver subseção 1.3.1). Esses eixos são ilustrados na figura 1.6 juntamente com a estrutura da $\mathrm{H}_{2}$-Ftalocianina.

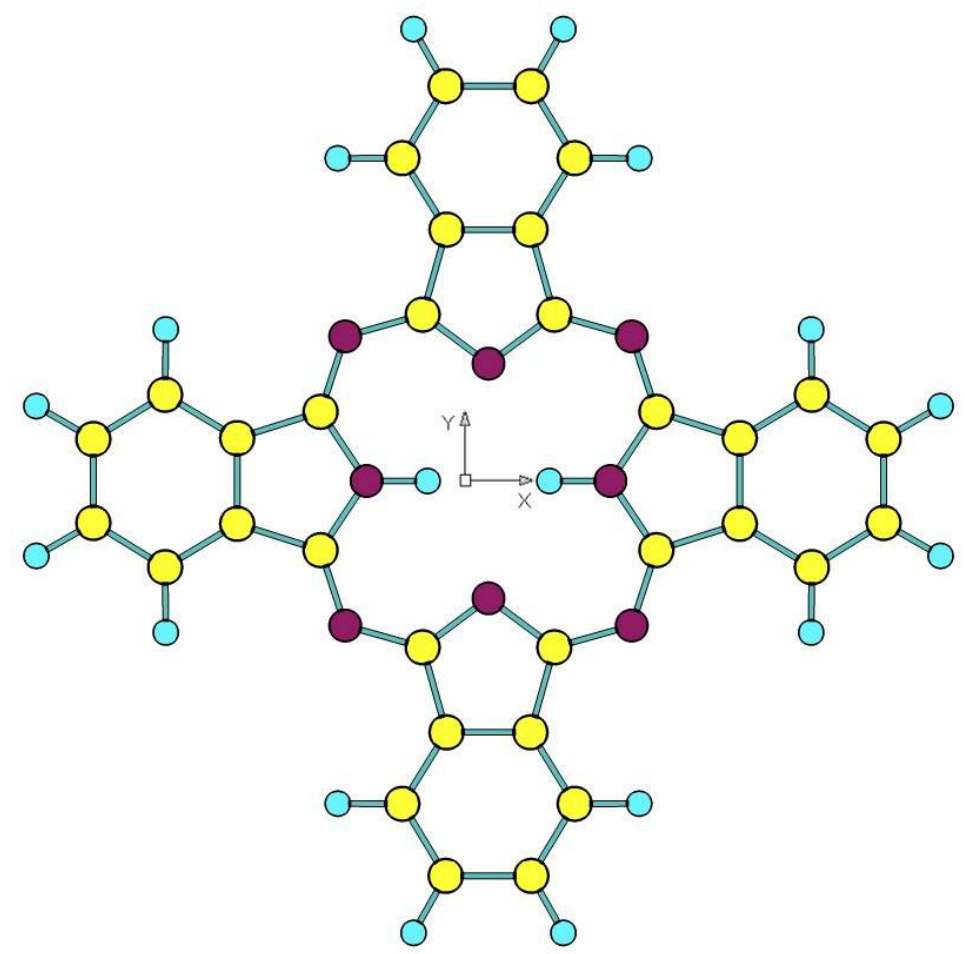

Figura 1.6: Estrutura da $\mathrm{H}_{2}$-Ftalocianina com a escolha de eixos de Gouterman. Na figura está representado apenas a orientação dos eixos. A origem dos eixos está obviamente no centro dos quatro nitrogênios centrais.

Os estados excitados da Ftalocianina Base Livre, $\mathrm{H}_{2}$-Ftalocianina, já foram obtidos teoricamente utilizando vários métodos reportados em trabalhos na literatura, desde trabalhos mais antigos como o de Schaffer e Gouterman do início da década de 70 [47] até em trabalhos um pouco mais recentes como o de Toyota et. al. de 1997 utilizando o método de configuração de interação adaptado a simetria (SAC-CI) [44] e o trabalho de Lu et. al. de 2008 utilizando TD-DFT [45]. Um trabalho de autoria 
de B. J. C. Cabral, V. W. D. Cruzeiro, K. Coutinho e S. Canuto com estudos levando em consideração efeitos térmicos e também de dimerização no espectro de absorção da $H_{2}$-Ftalocianina também está reportado na literatura $[8]^{7}$.

No artigo em que o espectro de absorção em fase gasosa da $H_{2}$-Ftalocianina é reportado [29] são listadas uma série de anomalias do espectro desta molécula observadas em comparação com medidas feitas em solução. Dentre as anomalias listadas destaca-se a observação de uma separação (ou desdobramento) das bandas $Q$ em fase gasosa significativamente maior que em solução. No artigo é abordada uma hipótese para explicar esse desdobramento. De acordo com essa hipótese o surgimento do desdobramento das bandas $Q$ seria devido ao posicionamento dos prótons (hidrogênios centrais) em uma "posição de ponte" entre os nitrogênios centrais. Nesta posição de ponte, um hidrogênio central, ao invés de ficar ligado a um único nitrogênio como na figura 1.6 ficaria em uma posição intermediária entre dois nitrogênios centrais, portanto nesse caso não seriam formadas ligações N-H convencionais. No artigo experimental são citados dois trabalhos $[50,51]$ que suportam essa hipótese de que esse posicionamento em forma de ponte produz o desdobramento das bandas $Q^{8}$. Esse é um problema que gera muitas controvérsias. Um fato interessante a respeito disso é que existem estruturas cristalinas nas quais a $H_{2}$-Ftalocianina tem uma estrutura bem semelhante a da estrutura da figura 1.6 [49] e também existem outras em que os hidrogênios centrais aparecem formando pontes [52]. Uma outra possibilidade a se levar em consideração é que o posicionamento em forma de ponte dos hidrogênios centrais poderia corresponder à conformação média molécula. Atenção a essa problemática envolvendo o desdobramento das bandas $Q$ e o posicionamento dos hidrogênios centrais será dada nos resultados apresentados para a $H_{2}$-Ftalocianina no capítulo 3 de resultados.

\footnotetext{
${ }^{7}$ Este artigo é integralmente apresentado no apêndice E.

${ }^{8}$ Observamos em [8] um desdobramento das bandas $Q$ significativamente maior para as configurações de $H_{2}$-Ftalocianina isolada (obtidas através de dinâmica molecular) que tem os hidrogênios centrais aproximadamente em posição de ponte.
} 


\section{Capítulo 2}

\section{Revisão de Conceitos e Métodos Teóricos}

Neste capítulo discutiremos os métodos e conceitos considerados mais relevantes para esta dissertação. Dentre os tópicos abordados estão uma revisão de conceitos relacionados com o espectro de absorção, uma revisão de métodos de química quântica, e uma revisão do funcionamento de dinâmicas moleculares tanto ab initio como clássicas. As abordagens são feitas de uma forma sucinta, onde várias referências são apresentadas. Isso precisou ser feito devido ao extenso número de métodos utilizados nesta dissertação. Referências às seções deste capítulo são feitas durante as discussões dos resultados feita no capítulo 3 .

\subsection{A Luz e o Espectro Eletromagnético}

Nesta dissertação estamos interessados em estudos sobre o espectro de absorção de Porfirinas e Ftalocianinas. Portanto nada mais apropriado do que iniciar falando sobre luz e sobre o espectro eletromagnético.

Luz nada mais é do que uma perturbação eletromagnética que se propaga pelo espaço como uma onda. Propriedades características como comprimento de onda $(\lambda)$, frequência $(\nu)$ e velocidade $(c)$ de outros tipos de onda, como as ondas que se propagam 
em uma corda, na superfície de um lago e as ondas sonoras, também se aplicam a ondas de luz (ondas eletromagnéticas). O comprimento de onda é a distância entre dois pontos equivalentes consecutivos da onda (como duas cristas de onda consecutivas), a frequência é o número de pontos correspondentes da onda que passam por um ponto observado dentro de um intervalo de tempo, e a velocidade é a taxa na qual cada ponto da onda se propaga. A relação entre essas três propriedades é:

$$
c=\lambda \nu
$$

A velocidade da luz no vácuo é uma constante e o seu valor é cerca de $2,99 \times 10^{8} \mathrm{~m} / \mathrm{s}$. Em um dado meio, a velocidade da luz é constante e por isso os valores de $\lambda$ e $\nu$ estão diretamente relacionados uma com o outro.

As regiões mais importantes do espectro eletromagnético para Porfirinas, Ftalocianinas, Clorofilas e outros pigmentos relacionados são as regiões do ultra violeta próximo, do visível e do infravermelho próximo [1], que absorvem bastante radiação eletromagnética (ou luz) nesta faixa de frequências. Apenas uma pequena parte do espectro eletromagnético é visível aos olhos humanos. A parte visível do espectro se estende em torno $400 \mathrm{~nm}$ até $700 \mathrm{~nm}$. Na fronteira destes valores a capacidade de captação de luz pelo olho humano se reduz até que a radiação se torne invisível aos nossos olhos (o que não quer dizer que ela não exista). A região ultravioleta do espectro se estende aproximadamente de $100 \mathrm{~nm}$ até $400 \mathrm{~nm}$, e a região infravermelha de cerca de $400 \mathrm{~nm}$ até $1000 \mathrm{~nm}$. A figura 2.1 ilustra o espectro visível e fornece os valores das regiões onde se encontram as cores.

Outro conceito importante associado a luz é o conceito de fóton, que nada mais é do que um quantum de radiação eletromagnética, uma partícula de luz. A energia de um fóton é dada pela equação de Planck, e depende da frequência da radiação:

$$
E=h \nu=\frac{h c}{\lambda}
$$

onde $h$ é a constante de Planck e vale $6,63 \times 10^{-34} \mathrm{Js}$. 


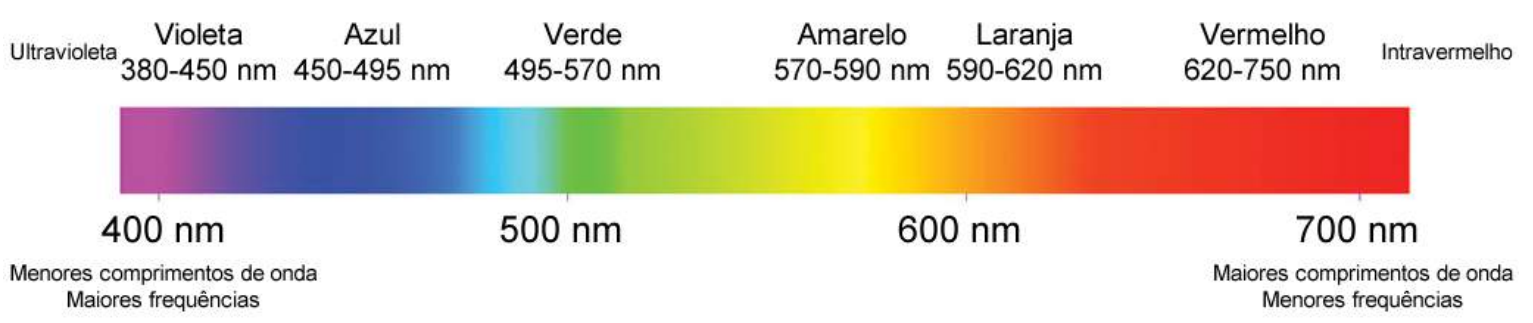

Figura 2.1: Ilustração do espectro visível.

\subsection{O Espectro de Absorção}

\subsubsection{Conceitos gerais}

As cores de Porfirinas, Ftalocianinas, Clorofilas, dentre outras substâncias, são praticamente devidas à absorção luz, que devem ser distinguidas das cores relacionadas a emissão e a incandescência [53]. De modo geral, a luz pode ser monocromática (composta de uma única cor) ou policromática (composta por uma mistura de cores). A luz que erradia do Sol comumente chamamos de "luz branca", e se removermos alguma cor da luz branca a luz então se transformará em "luz colorida" [53]. A cor que se resulta da remoção de uma cor da luz branca é a cor complementar desta cor removida. Na figura 2.2 apresentamos um disco de cores em que as cores complementares estão diametralmente opostas. Podemos ver que na figura as duas pontas do espectro visível se encontram.

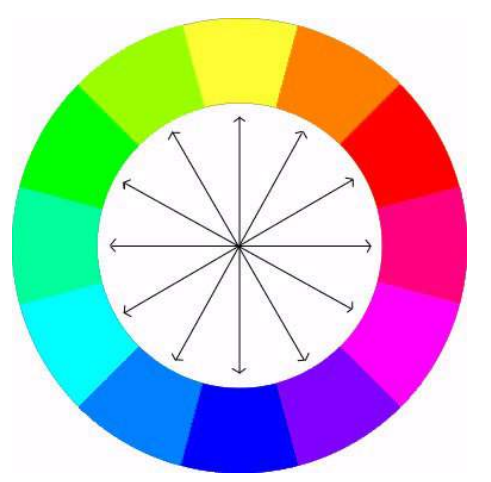

Figura 2.2: Disco de cores. Cores complementares estão diametralmente opostas. 
Na figura 2.2 um fato chama atenção. Na região de junção das duas pontas do espectro visível, correspondente as cores violeta e vermelho, podemos ver que a cor complementar é o verde. A cor verde portanto é o resultado da subtração das luzes vermelha (de mais baixa energia e de mais alto comprimento de onda) e violeta (de mais alta energia e de mais baixo comprimento de onda) da luz branca.

As substâncias somente podem absorver certos comprimentos de onda da luz, e a capacidade de absorção (ou absorbância) de um certo comprimento de onda pode ser maior ou menor do que outro. Desse modo, a medida da absorbância como função da frequência ou do comprimento de onda da radiação incidente na amostra da origem ao espectro de absorção da substância. A cor da substância é a cor resultante da subtração de todas as cores absorvidas pela substância.

Cada substância possui um espectro de absorção distinto. Por isso o espectro de absorção é extremamente útil em análises químicas e pode ser usado como ferramenta para determinar a presença de uma dada substância em uma amostra e até mesmo para quantificar a quantidade desta substância que está presente na amostra. Uma aplicação importante de medidas do espectro de absorção é em astronomia [54]. Como os objetos de interesse astronômico, como planetas e estrelas, estão tão distantes da Terra que apenas radiação eletromagnética é o que se encontra disponível para medidas deles [54]. O espectro de absorção tem sido particularmente importante para o entendimento de nuvens interestelares e na determinação das moléculas que as compõem, e também no estudo de planetas extrasolares [54].

\subsubsection{Espectro de Absorção Eletrônica}

O espectro de absorção é classificado pela natureza da mudança que ocorre no estado de uma molécula (ou um átomo), e essa mudança tem essência em mecânica quântica. A parte do espectro devida a mudanças no estado rotacional da molécula se encontra tipicamente na região espectral de micro-ondas. Já a parte devida a mudanças 
no estado vibracional se encontra caracteristicamente na região de infravermelho do espectro. A parte devida a mudanças no estado eletrônico da molécula (ou átomo) é normalmente encontrada na região do visível e ultravioleta do espectro. Absorções de raios X estão associadas com a excitação de elétrons das camadas mais internas dos átomos. Algumas dessas mudanças podem ser combinadas gerando novas absorções (como, por exemplo, transições vibracionais-rotacionais). A região espectral de maior interesse para pigmentos como Porfirinas, Ftalocianinas e Clorofilas é a região devida a excitações eletrônicas.

Quando uma molécula absorve um fóton e passa do seu estado eletrônico fundamental para um estado excitado, ou então quando emite um fóton passando de um estado excitado para um de menor excitação, a distribuição de elétrons muda praticamente instantaneamente [1]. A figura 2.3 ilustra esse processo, que resulta nos espectros de absorção e de emissão. A nova distribuição de elétrons no estado excitado define uma nova função de energia potencial para o estado excitado da molécula. Os núcleos não se ajustam instantaneamente a essa nova função de energia potencial porque eles se movem muito mais lentamente que os elétrons ${ }^{1}$. Por causa dessa diferença nas escalas de tempo de movimento as transições são frequentemente descritas como verticais, ou seja, a mudança no estado eletrônico acontece enquanto os núcleos estão praticamente paralisados.

Na figura 2.3 são ilustradas as curvas de energia potencial do estado fundamental e de um estado excitado e também os níveis vibracionais associados a cada estado. Como ilustrado em (a) na figura, usualmente o estado inicial (estado eletrônico fundamental) da absorção se encontra no estado fundamental vibracional, enquanto o estado final (estado eletrônico excitado) pode ser vibracionalmente excitado. No caso da emissão, como ilustrado em (b) na figura, o estado inicial, que é eletronicamente excitado, geralmente se encontra em um estado vibracionalmente fundamental, enquanto

\footnotetext{
${ }^{1}$ Discutiremos mais a respeito disso na subseção 2.3.1 sobre a aproximação de Born-Oppenheimer.
} 
(a) Absorção

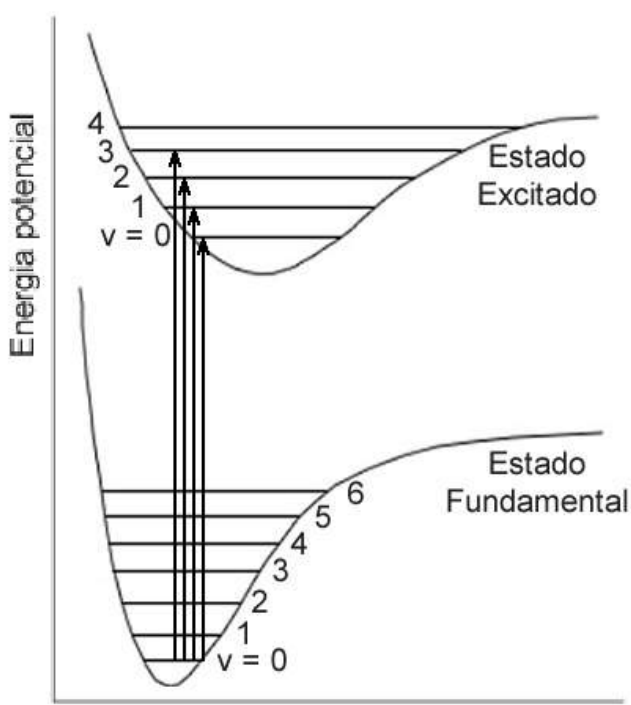

(b) Emissäo

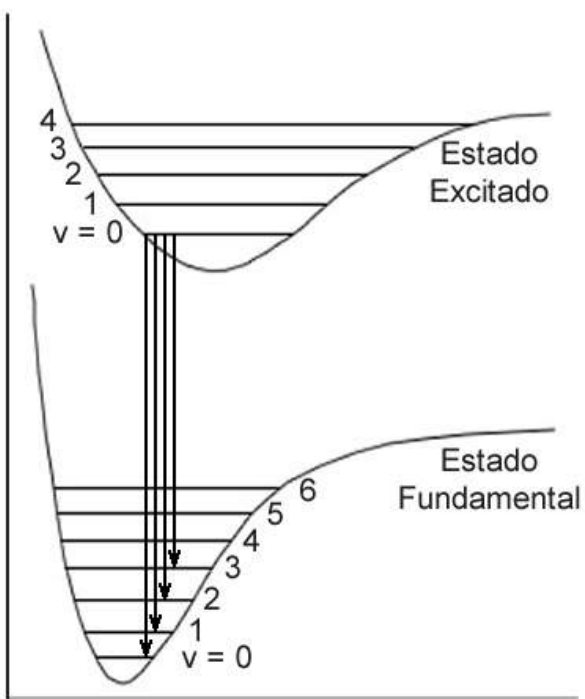

Comprimento de uma ligação

(c) Absorção Emissão

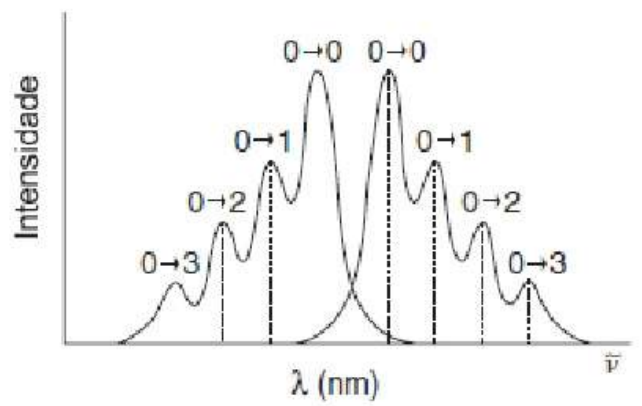

Figura 2.3: Diagramas de energia potencial e os respectivos espectros de absorção e emissão. Esta figura foi baseada em figura da referência [1].

o estado final (que no caso da figura é o estado eletrônico fundamental) pode ser vibracionalmente excitado. Os espectros que surgem destas transições são ilustrados em (c) na figura, onde o espectro de emissão comumente se encontra em uma região de maiores comprimentos de onda que a região onde o espectro de absorção se situa. O caso mostrado na figura 2.3, por exemplo, ilustra um caso onde transições de origens vibracionais e eletrônicas aparecem combinadas no espectro. 


\subsubsection{Níveis de Energia Eletrônica: Orbitais Moleculares}

Na subseção anterior mostramos como os estados eletrônicos interferem na origem dos espectros de absorção e também de emissão. Vamos agora discutir com mais detalhes como esses estados são formados.

O estado eletrônico de menor energia é chamado de estado fundamental e os de maior energia são chamados de estados excitados. No estado fundamental os elétrons preenchem os orbitais moleculares de menor energia da molécula de acordo com o princípio de Pauli. Segundo o princípio de Pauli cada orbital pode possuir no máximo dois elétrons com os spins opostos (ou emparelhados). Ou seja, para ambos elétrons ocuparem o mesmo orbital um deve ter spin para cima (up) e o outro spin para baixo (down). No estado fundamental os orbitais moleculares são preenchidos desde o de menor energia até o de maior energia. O último dos orbitais preenchidos, automaticamente o de energia mais alta entre os ocupados, é chamado de $H O M O$, que vem do inglês "Highest Occupied Molecular Orbital", e o orbital seguinte é chamado de $L U M O$, que vem do inglês "Lowest Unoccupied Molecular Orbital". A nomenclatura dos demais orbitais é dada de acordo com as suas energias em relação ao HOMO e ao $L U M O$. O orbital logo abaixo do $H O M O$ é rotulado como $H O M O-1$, e o que fica logo abaixo de $H O M O-1$ é rotulado como $H O M O-2$, e assim por diante. O mesmo raciocínio é aplicado para rotular os orbitais desocupados. O orbital logo acima de $L U M O$ é rotulado como $L U M O+1$, e o que fica logo acima de $L U M O+1$ é rotulado como $L U M O+2$, e assim por diante. Tudo que discutimos neste parágrafo esta ilustrado na figura 2.4 para a molécula de Formaldeído.

Caso o número de elétrons da molécula seja par, no estado fundamental todos os orbitais até HOMO estão preenchidos e cada orbital tem dois elétrons que têm spins opostos. Este estado é portanto um estado singleto, isso porque a soma dos spins de todos os elétrons é nula. Como mostrado na figura 2.4, um estado excitado 

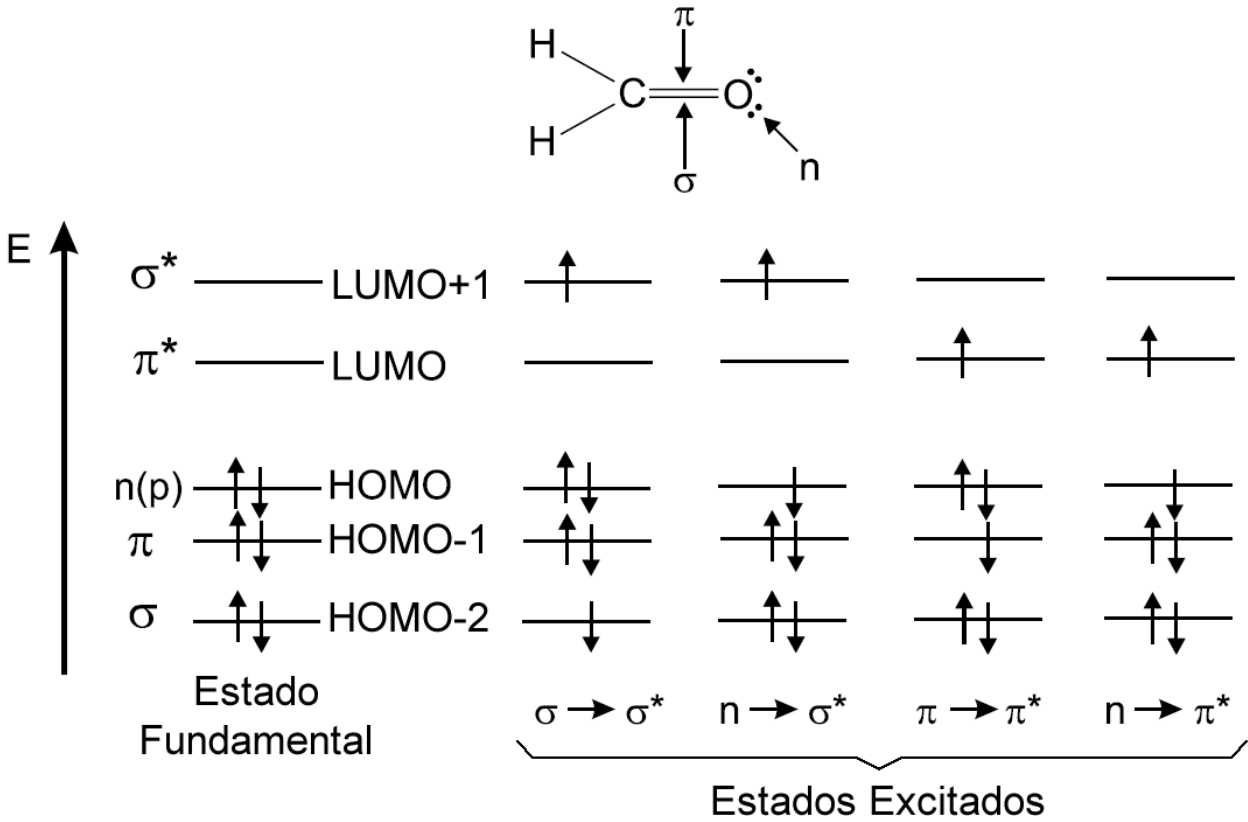

Figura 2.4: Ilustrações dos níveis de energia eletrônica, dos orbitais moleculares e da composição de alguns estados eletrônicos, para uma molécula de Formaldeído (também chamada de Metanal). Esta figura foi retirada de [55] e adaptada.

pode ser formado pela transição de um elétron de um orbital ocupado para um orbital desocupado. Mesmo que este novo estado tenha dois orbitais ocupados por apenas um elétron cada esse estado pode ser singleto, porém outros estados podem ser obtidos (como estados tripletos) caso os elétrons se arranjem, sem violar o princípio de Pauli, de maneira que a soma dos spins não seja nula.

Em uma interpretação grotesca podemos pensar que uma excitação eletrônica (ou estado excitado) de uma molécula é composta pela transição de um elétron de um orbital ocupado para um orbital desocupado, porém isto nem sempre é o que acontece. As leis físicas que regem a formação de estados excitados são de natureza quântica, por isso muitas vezes um dado estado excitado é composto por várias transições eletrônicas, onde cada transição pode contribuir com um peso diferente para o estado excitado. Nas seções 3.1.2 e 3.2.3 do capítulo 3 de resultados discutiremos sobre como são as transições eletrônicas que compõem o espectro de absorção de Porfirinas e Ftalociani- 
nas, e la mostraremos que vários estados são compostos por diversas transições. Como veremos, as características principais do espectro destas moléculas estão relacionadas com transições entre orbitais de fronteira, ou seja, com os orbitais mais próximos de HOMO е LUMO.

Os orbitais podem ser classificados como orbitais de caroço, de valência e de Rydberg [56]. Essa classificação, aproximada, é baseada nas energias dos orbitais e em suas extensões espaciais. Em Mecânica Quântica existe uma função de onda associada a cada orbital molecular. Em muitos trabalhos teóricos vemos ilustrações de orbitais. Essas ilustrações na verdade estão relacionadas com as funções de onda dos orbitais. Assim como nas figuras para orbitais moleculares a serem mostradas nesta dissertação, o que essas ilustrações geralmente mostram são uma superfície de densidade eletrônica constante (ou seja, uma superfície em que todos os pontos possuem a mesma densidade eletrônica) obtida a partir da função de onda do orbital, e geralmente uma coloração é dada para a região de sinal positivo da função e outra coloração para a região de sinal negativo da função.

Uma maneira de se explicar as propriedades das moléculas é através da Teoria dos Orbitais Moleculares [57], desenvolvida em meados de 1930 por Mulliken e outros. Segundo esta teoria, a descrição de ligações covalentes é feita em termos dos orbitais moleculares, que resultam da interação entre os orbitais atômicos dos átomos envolvidos nas ligações e estão associados a molécula como um todo. A combinação de dois orbitais atômicos leva a um orbital molecular ligante - que está relacionado a uma interferência construtiva e tem menor energia e maior estabilidade que os orbitais atômicos que o formaram - e a um orbital molecular não ligante - que está relacionado a uma interferência destrutiva e tem maior energia e menor estabilidade que os orbitais atômicos que o formaram. Um asterisco é utilizado para representar um orbital antiligante na notação dos orbitais moleculares. Como exemplo, a figura 2.5 ilustra como combinação de dois orbitais atômicos dá origem a orbitais moleculares. 

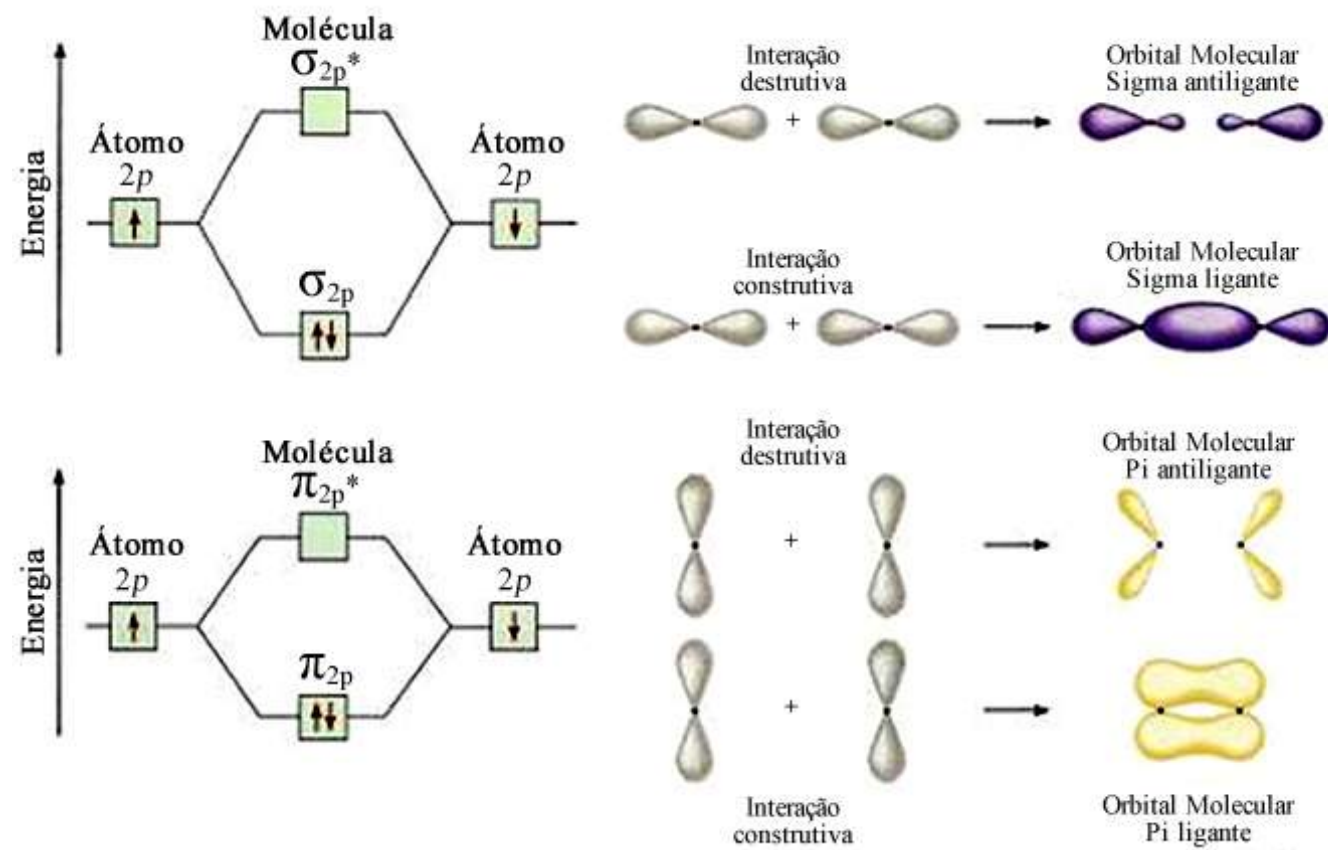

Figura 2.5: Combinação de dois orbitais $p$ equivalentes na formação de orbitais moleculares. Esta figura foi adaptada de [57].

Os orbitais moleculares também podem ser distinguidos com relação aos seus tipos. Em um orbital do tipo $\sigma$ a densidade eletrônica está concentrada simetricamente em torno das linhas que unem os núcleos dos átomos. Em um orbital do tipo $\pi$ a densidade eletrônica se concentra acima e abaixo das linhas que unem os núcleos dos átomos. Orbitais moleculares do tipo $\sigma$ e do tipo $\pi$ são ilustrados na figura 2.5. Existem também orbitais do tipo $n$ que são relacionados com por pares isolados de elétrons de átomos como o oxigênio, o nitrogênio ou o flúor.

Maiores detalhes sobre orbitais moleculares podem ser encontrados na literatura. Uma revisão de conceitos relacionados a orbitais mais voltada para a física é dada na referência [56], e uma visão mais química é dada no capítulo 10 da referência [57]. Na subseção 2.3.2 voltaremos a falar de orbitais moleculares e de como eles surgem dentro da aproximação de Hartree-Fock. 


\subsubsection{Energia de Excitação}

Como mencionamos na subseção 2.2.2, uma molécula passa de seu estado fundamental para um estado estado excitado ao absorver um fóton. De acordo com a Mecânica Quântica, a energia deste fóton deve ser igual a diferença de energia dos estados antes e depois da absorção do fóton ${ }^{2}$. A energia deste fóton é a chamada Energia de Excitação, e correspondente portanto a energia necessária para trazer sistema do estado fundamental para um dado estado excitado. A frequência deste fóton absorvido pode ser calculada utilizando a equação 2.2 :

$$
\nu_{i f}=\frac{E_{f}-E_{i}}{h}
$$

onde $E_{i}$ é a energia do estado inicial (antes da absorção do fóton) e $E_{f}$ é a energia do estado final (depois da absorção do fóton).

Utilizando métodos para cálculos de Mecânica Quântica podemos calcular as energias de excitação de uma molécula [58]. No decorrer da seção 2.3 discutiremos melhor como isso é feito.

\subsubsection{Absorbância, Lei de Lambert-Beer e Força de oscilador}

Vamos nesta subseção tentar dar uma ideia do que são e de como se relacionam as grandezas chamadas de Absorbância ${ }^{3}$ e de Força de oscilador. As interpretações e a ordem com que as deduções são apresentadas nesta subseção representam as impressões do autor com relação a este tema, que são baseadas na referência [59] e também complementarmente na referência [60]. Estas referências contém maiores detalhes como as deduções de algumas equações que apresentamos aqui.

A figura 2.6 ilustra simplificadamente como o espectro de absorção é medido.

\footnotetext{
${ }^{2}$ Não confundir as energias dos estados com as energias dos orbitais moleculares, que apesar de serem ambas propriedades que podem ser expressas nas mesmas unidades, são propriedades com conceitos distintos e que aparecem em diferentes contextos.

${ }^{3}$ Em alguns artigos, principalmente os mais antigos, a absorbância é chamada de densidade óptica.
} 
Uma luz incidente de intensidade $I_{0}$ chega até a amostra, percorre uma distância $\ell$ dentro dela, e depois sai com uma intensidade $I$.

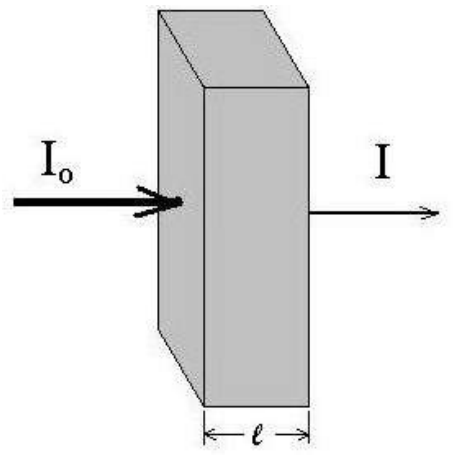

Figura 2.6: Ilustração simplificada de como o espectro de absorção é medido.

Os valores das intensidades dependem ambos da frequência da luz incidente. A absorbância é definida como [59]:

$$
A(\nu)=\log \left(\frac{I_{0}(\nu)}{I(\nu)}\right)
$$

A absorbância consequentemente depende da frequência da luz incidente. Como vemos, a absorbância pode ser determinada experimentalmente a partir das medidas das intensidades inicial e final, e o gráfico da absorbância em função da frequência (ou em função do comprimento de onda, por exemplo) fornece o espectro de absorção da molécula e é o que comumente vemos sendo reportado na literatura.

Existe uma lei, chamada Lei de Lambert-Beer, que relaciona a absorbância com a concentração $C$ de espécies absorvedoras na amostra em que a medida está sendo realizada e com o comprimento $\ell$, comumente chamado de caminho óptico. Por essa lei temos que [59]:

$$
A(\nu)=\varepsilon(\nu) C \ell
$$

onde $\varepsilon$ é chamado de coeficiente de absorção molar e é uma propriedade que depende das características das moléculas absorvedoras, das características do meio onde essas moléculas estão, e também da frequência da radiação incidente. Vamos guardar em 
mente que a equação 2.5 mostra que $A(\nu)$ e $\varepsilon(\nu)$ são proporcionais, esta relação será importante ao final desta subseção.

Retomando a Mecânica Quântica, pode-se mostrar que a probabilidade de transição entre dois estados, induzida por um campo elétrico oscilante de uma onda eletromagnética (luz), é proporcional ao quadrado da integral de momento de transição, denotada como $\vec{M}$. Para uma dada excitação eletrônica de um estado inicial $\left|\psi_{i}\right\rangle$ para um estado final $\left|\psi_{i}\right\rangle$, a integral de momento de transição é dada por [60]:

$$
\vec{M}_{i f}=\int \psi_{f}^{*} \overrightarrow{\widehat{\mu}}_{t} \psi_{i} d \tau=\left\langle\psi_{f}\left|\overrightarrow{\widehat{\mu}}_{t}\right| \psi_{i}\right\rangle
$$

onde $\vec{\mu}_{t}$ é um operador vetorial chamado de momento de dipolo de transição.

Apesar de a Lei de Lambert-Beer da equação 2.5 ter um viés empírico e a equação 2.6 ter fundamentos teóricos em Mecânica Quântica, pode-se mostrar que o coeficiente de absorção molar $\varepsilon$ e $\vec{M}_{i f}$ se relacionam da seguinte maneira [59]:

$$
\int_{\text {Sobre uma banda }} \varepsilon\left(\nu^{\prime}\right) d \nu^{\prime}=\frac{8 \pi^{3}}{3 h^{2}} \frac{N h \nu}{2303 c}\left|\vec{M}_{i f}\right|^{2}
$$

onde a integral é feita apenas sobre uma única banda do espectro de absorção, $\nu$ é a frequência do fóton absorvido relacionado a esta banda, e a excitação $\left|\psi_{i}\right\rangle \longmapsto\left|\psi_{f}\right\rangle$ é a excitação relacionada com esta banda.

A força de uma excitação eletrônica é geralmente expressa em termos de uma quantidade chamada força de oscilador. No caso experimental, a força de oscilador de uma dada banda associada a absorção de um fóton de frequência $\nu$ é definida como [59]:

$$
f_{\nu}=\frac{\left[\int_{\text {Sobre uma banda }} \varepsilon\left(\nu^{\prime}\right) d \nu^{\prime}\right]_{\text {experimental }}}{\left[\int_{\text {Sobre uma banda }} \varepsilon\left(\nu^{\prime}\right) d \nu^{\prime}\right]_{\text {ideal }}}
$$

onde ambas as integrais são feitas sobre uma única banda. Essa integral chamada de ideal é inserida para que a força de oscilador se torne uma grandeza adimensional. 
Esta integral ideal é comumente feita para a excitação do estado fundamental para o primeiro estado excitado de um oscilador harmônico em uma dimensão. Na referência [59] existe uma demonstração que mostra que o valor desta integral para este caso é:

$$
\left[\int_{\text {Sobre uma banda }} \varepsilon\left(\nu^{\prime}\right) d \nu^{\prime}\right]_{\text {ideal }} \simeq 2,309 \times 10^{8} \mathrm{~J} \mathrm{~mol}^{-1} \mathrm{~cm}^{-1}
$$

Portanto é comum vermos a equação 2.8 reescrita em alguns livros texto na seguinte forma:

$$
f_{\nu}=\left(4,33 \times 10^{-9} J^{-1} \text { mol cm }\right) \times\left[\int_{\text {Sobre uma banda }} \varepsilon\left(\nu^{\prime}\right) d \nu^{\prime}\right]_{\text {experimental }}
$$

Na equação 2.7 mostramos que existe uma proporcionalidade entre a integral do coeficiente de absorção molar e o quadrado da integral de momento de transição. Portanto, de maneira análoga ao caso experimental, no caso teórico podemos definir a força de oscilador $f_{\text {if }}$ de uma transição do estado $i$ para o estado $f$ como:

$$
f_{i f}=\frac{\left|\vec{M}_{i f}\right|^{2}}{\left|\vec{M}_{01}\right|_{\text {ideal }}^{2}}
$$

$\left|\vec{M}_{01}\right|_{\text {ideal }}^{2}$ é resolvido para o caso da transição de um único elétron do estado fundamental para o primeiro estado excitado de um oscilador harmônico simples. A força de oscilador $f_{\text {if }}$ fica portanto igual a [59]:

$$
f_{i f}=\frac{8 \pi^{2} m_{e} c}{3 h \nu_{i f}}\left|\vec{M}_{i f}\right|^{2}
$$

onde $m_{e}$ é a massa de um elétron e $\nu_{i f}$ é calculado segundo a equação 2.3 .

A partir das equações 2.5, 2.7 e 2.12 podemos então retirar um resultado extremamente interessante ao concluir que a absorbância de uma banda, que é uma medida experimental, e a força de oscilador da excitação correspondente a esta banda, que é um valor teórico, se relacionam da seguinte maneira:

$$
f_{\text {if }} \propto \int_{\text {Sobre uma banda }} A\left(\nu^{\prime}\right) d \nu^{\prime}
$$


A equação 2.13 mostra portanto que em um gráfico obtido experimentalmente para a absorbância em função da frequência da radiação incidente, a área abaixo da curva correspondente a uma banda é proporcional a força de oscilador teórica obtida para a excitação correspondente a essa banda.

\subsubsection{Convolução dos picos teóricos por Lorentzianas}

Com relação ao espectro de absorção, o resultado experimental nos fornece a absorbância em função da frequência (ou do comprimento de onda) da radiação incidente, enquanto o cálculo teórico nos fornece as energias de excitação ${ }^{4}$ e as forças de oscilador correspondentes dos estados excitados da molécula. As energias de excitação podem ser diretamente relacionadas com as posições dos picos das bandas do espectro experimental, porém, como mostramos na equação 2.13, força de oscilador e absorbância são grandezas que não se relacionam diretamente mas sim por intermédio de uma integração. Deste modo, como podemos comparar resultados teóricos com resultados experimentais?

Apesar de força de oscilador e absorbância não serem grandezas diretamente proporcionais, podemos entender que onde a força de oscilador for maior, maior deve ser também a absorbância naquela região já que a área abaixo da curva desta banda tem que necessariamente ser maior. O oposto também é válido, já que caso a força de oscilador de uma excitação seja nula isso quer dizer que a curva abaixo da curva da banda associada a essa excitação tem que ser zero, e por isso a banda não apareceria no espectro experimental. Deste modo então, apesar não podermos fazer uma comparação direta entre essas duas grandezas, podemos ver que elas estão relacionadas.

É importante frisar que este tipo de análise é apenas de cunho qualitativo, isso porque elas somente seriam completamente válidas em um caso ideal onde as energias

\footnotetext{
${ }^{4}$ Como mostramos na seção 2.1, energia, frequência e comprimento de onda estão relacionados, portanto é possível calcular a frequência ou o comprimento de onda associado a uma dada energia de excitação.
} 
de excitação e as forças de oscilador pudessem ser calculadas com extrema exatidão, porém, como veremos na seção 2.3 posteriormente, nestes cálculos estão embutidas uma série de aproximações que implicam em imprecisões nos resultados. Na verdade, como veremos no capítulo 3 , diferentes métodos de cálculo geralmente fornecem diferentes valores para as energias de excitação e para as forças de oscilador.

Uma vez tendo em mente como se diferenciam e como se relacionam absorbância e força de oscilador, um procedimento comum em estudos teóricos é a convolução do picos teóricos (correspondentes as forças de oscilador e energias de excitação). A curva convoluida corresponde a um gráfico da força de oscilador em função da energia de excitação (ou da frequência, que é linearmente proporcional a energia) onde, em vez de mostram apenas traços verticais correspondentes aos picos, se dá uma forma a cada pico para se obter uma curva que se assemelhe mais a forma de uma banda. Duas formas são comumente utilizadas para descrever o formato de uma banda, são elas funções Gaussianas e Lorentzianas. Ambas as funções tem um formato similar ao formato descrito na figura 2.7.

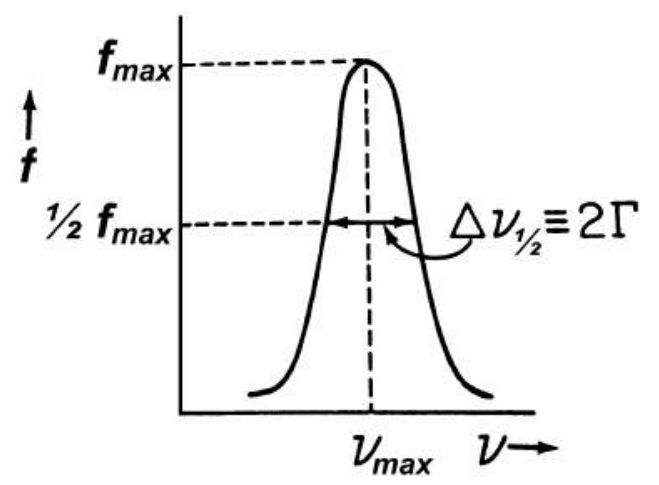

Figura 2.7: Ilustração de uma curva Gaussiana ou Lorentzianas.

Uma Gaussiana é descrita pela seguinte equação:

$$
f_{\text {gau }}(\nu)=f_{\text {max }} \exp \left[-\frac{(\ln 2)\left(\nu-\nu_{\max }\right)^{2}}{\Gamma^{2}}\right]
$$


E uma Lorentziana pela seguinte equação:

$$
f_{\text {lor }}(\nu)=f_{\max } \frac{\Gamma^{2}}{\Gamma^{2}+\left(\nu-\nu_{\max }\right)^{2}}
$$

onde $\Gamma$ possui a mesma dimensão de $\nu$ e é igual a $\Gamma=\frac{1}{2} \Delta \nu_{1 / 2}$, e $\Delta \nu_{1 / 2}$ (chamado de largura de linha) é a largura da curva na metade da altura máxima, como mostra a figura 2.7 .

Nesta dissertação optamos pelo formato de Lorentzianas. Portanto a curva formada pela convolução de todos os picos teóricos calculados é:

$$
f(\nu)=\sum_{n} f_{n} \frac{\Gamma_{n}^{2}}{\Gamma_{n}^{2}+\left(\nu-\nu_{n}\right)^{2}}
$$

onde $\nu_{n}$ é calculado a partir da energia de excitação entre o estado fundamental e o estado $n$ com a equação $2.3, f_{n}$ é a força de oscilador desta excitação, e a somatória é feita sobre todos estados excitados calculados.

A escolha dos valores dos $\Gamma_{n}$ é arbitraria. Nesta dissertação geralmente escolhemos um valor único para todos os $\Gamma_{n}$ dos estados na região do visível e outro valor para todos os $\Gamma_{n}$ dos demais estados. Nos gráficos que apresentaremos para as convoluções, em vez de plotar em função da frequência, optamos por plotar em função do comprimento de onda. A curva convoluída é obtida exatamente da maneira que é mostrada na equação 2.16, em função da frequência (ou seja, a convolução é feita no espaço das frequências), e depois os valores das frequências são convertidos para comprimentos de onda.

Em muitas análises nesta dissertação faremos uso de curvas convoluídas de forças de oscilador para facilitar a comparação dos resultados entre si e também com o experimental. Como dissemos, ao fazer isso as diferenças entre força de oscilador e absorvidade discutidas nesta subseção devem estar claras. O eixo y dos gráficos que contém as convoluções e muitas vezes o resultado experimental é rotulo como "Intensidade", porém a curva teórica representa valores de força de oscilador e a curva 
experimental representa absorbância. Como essas grandezas, absorbância e força de oscilador, não podem ser comparadas quantitativamente entre si, o intuito desses gráficos é compararmos tendências, da maneira discutida no segundo parágrafo desta subseção. Vale ressaltar que o mesmo não é válido no eixo x, já que as energias de excitação podem ser comparadas quantitativamente com as posições dos picos experimentais nesses gráficos. Este rotulo dado ao eixo y nesses gráficos, Intensidade, não deve ser confundido com a intensidade da radiação incidente.

\subsection{Métodos para Cálculos de Mecânica Quântica}

Para descrição do comportamento fundamental da matéria em escala molecular se faz uso de Mecânica Quântica. Cálculos de Mecânica Quântica podem ser aplicados para resolver problemas de interesse em física e química. Em princípio se pode descrever todos os sistemas moleculares usando Mecânica Quântica. Porém, na prática, somente os sistemas mais simples podem ser investigados com maior exatidão devido à imensa dificuldade matemática no tratamento teórico de sistemas mais complexos. Por isso, como veremos no decorrer desta seção, aproximações são feitas para possibilitar o tratamento teórico. A inclusão de aproximações implica em imprecisões no resultados. Diferentes métodos de cálculos quânticos, pelo fato de utilizarem diferentes aproximações, fornecem diferentes resultados. Por isso então cabe ao pesquisador escolher com sabedoria os melhores métodos para aplicar em cada tipo de estudo, buscando sempre um equilíbrio entre viabilidade de cálculo e precisão dos resultados.

Os métodos para cálculos de Mecânica Quântica são incorporados em programas de computador para realizar diversos tipos de cálculo que envolvem propriedades de sistemas moleculares. Dentre esses tipos de cálculo estão cálculos de estruturas moleculares, cálculos de cargas parciais, cálculos de propriedades magnéticas, cálculos de energias de excitação, dentre diversos outros. Os resultados obtidos com esses progra- 
mas complementam as informações obtidas a partir de experimentos, e podem também, em alguns casos, até prever fenômenos não observados no experimento. Os métodos implementados nestes programas se baseiam na resolução da equação de Schrödinger associada a um Hamiltoniano molecular, tem diferentes abordagens para essa resolução e utilizam diferentes aproximações. Esses métodos são classificados de acordo com o tipo de abordagem utilizada para a resolução da equação de Schrödinger. Os quatro principais grupos de métodos são: métodos ab initio, métodos semi-empíricos, métodos de teoria do funcional da densidade, e métodos de mecânica molecular (também chamados de métodos clássicos).

Métodos ab initio (ou de primeiros princípios) são os métodos mais sofisticados para a solução da equação de Schrödinger. Esses métodos não usam nenhum dado experimental (a não ser as contantes físicas fundamentais) no tratamento teórico. Este fato não implica que a solução da equação é exata, pois os resultados são sempre resultados aproximados de Mecânica Quântica. O método ab initio mais simples para o cálculo de estruturas eletrônicas é o Hartree-Fock (HF), que é utilizado como base para vários outros métodos mais elaborados.

Métodos semi-empíricos, em comparação com métodos ab initio, realizam algumas simplificações no tratamento teórico ao negligenciar ou parametrizar determinados termos durante a resolução da equação de Schrödinger. Os parâmetros tem seus valores ajustados para que os resultados produzidos pelos cálculos correspondam a dados experimentais ou a resultados de cálculos ab initio. Devido a suas simplificações, métodos semi-empíricos são muito mais viáveis computacionalmente do que métodos $a b$ initio, porém eles contém mais aproximações.

Métodos baseados na Teoria do Funcional da Densidade (ou métodos DFT, do Inglês "Density Functional Theory") atacam a resolução da equação de Schrödinger por um caminho em que, em vez de obter diretamente a função de onda do sistema, busca obter a densidade eletrônica $\rho$ do sistema. As propriedades do sistema são calculadas 
a partir de $\rho$. Existe uma grande controvérsia a respeito de se determinados métodos DFT podem ser considerados como $a b$ initio ou não. Alguns métodos DFT não utilizam nenhum tipo de parâmetro (a não ser as contantes físicas fundamentais) e por isso são definitivamente $a b$ initio. Porém outros métodos, denominados métodos híbridos de DFT, utilizam o resultado de um cálculo Hartree-Fock como ponto de partida e na hora de montar o resultado final dão pesos para o resultado Hartree-Fock e para resultados de DFT. Esses pesos são portanto parâmetros e são comumente ajustados para melhor reproduzir resultados de cálculos ab initio ou experimentais para certas propriedades. Por fazer uso desses parâmetros esses métodos perderiam a classificação de métodos $a b$ initio e se enquadrariam como métodos semi-empíricos. Entretanto alguns pesquisadores não gostam desta denominação porque métodos híbridos de DFT tem uma "artilharia pesada" de Mecânica Quântica. Por outro lado, pelo fato dessa parametrização ser feita, esses métodos perdem a sua "universalidade" e por isso um dado método híbrido de DFT pode produzir bons resultados para uma dada propriedade de um determinado sistema e resultados ruins para outras propriedades ou sistemas ${ }^{5}$.

Os métodos de mecânica molecular na verdade não se baseiam de forma direta em Mecânica Quântica e por isso não fazem uma descrição do sistema em termos da função de onda. Em vez disso a molécula é tratada como uma coleção de partículas mantidas juntas por ligações que são representadas por funções analíticas. Essas funções analíticas modelam as interações moleculares e expressam elas em termos de constantes de força e outros parâmetros (obtidos empiricamente ou derivados de cálculos ab initio). Dos métodos listados, esses métodos são os mais eficientes computacionalmente mas também são os que descrevem as interações do sistema de maneira mais aproximada.

\footnotetext{
${ }^{5}$ Os métodos $a b$ initio, por conterem aproximações, não estão livres dessa problemática pois um dado método $a b$ initio pode ser mais apropriado que um outro método $a b$ initio para uma determinada aplicação. A questão levantada sobre métodos híbridos de DFT diz respeito ao fato de eles serem parametrizados para aplicação em determinadas propriedades e/ou sistema, enquanto em métodos $a b$ initio nenhuma parametrização é feita.
} 
No decorrer desta dissertação faremos uso de métodos de todos os tipos mencionados acima, em diferentes tipos de cálculos. Buscaremos no decorrer desta seção, dentre outras coisas, mostrar com um pouco mais de detalhes como esses tipos de métodos funcionam e como são as aproximações realizadas.

\subsubsection{Aproximação de Born-Oppenheimer}

O estudo teórico de sistemas moleculares se baseia fundamentalmente na solução da equação de Schrödinger para se obter as informações desejadas a respeito das propriedades do sistema. A aproximação de Born-Oppenheimer tem um papel central em química teórica e é uma das aproximações mais importantes.

O Hamiltoniano de uma sistema molecular é dado pela energia cinética dos elétrons e núcleos, e pela energia de interação entre os núcleos, entre os elétrons e entre núcleos e elétrons. Dessas interações, as duas primeiras são repulsivas e a última é atrativa. Desprezando os termos relativísticos, o Hamiltoniano que descreve um sistema molecular de $M$ núcleos e $N$ elétrons, escrito em unidades atômicas, é [61]:

$$
\mathcal{H}(\mathbf{r}, \mathbf{R})=-\sum_{i=1}^{N} \frac{1}{2} \nabla_{i}^{2}-\sum_{A=1}^{M} \frac{1}{2 M_{A}} \nabla_{A}^{2}-\sum_{i=1}^{N} \sum_{A=1}^{M} \frac{Z_{A}}{r_{i A}}+\sum_{i<j}^{N} \frac{1}{r_{i j}}+\sum_{A<B}^{M} \frac{Z_{A} Z_{B}}{R_{A B}}
$$

onde $\mathbf{r}$ é o conjunto das coordenadas dos elétrons, $\mathbf{R}$ é o conjunto das coordenadas dos núcleos, $i$ e $j$ se referem a elétrons e $A$ e $B$ se referem a núcleos, e $M_{A}$ e $Z_{A}$ são a massa do núcleo e o número atômico do átomo A.

A equação de Schrödinger, em sua forma independente do tempo (aplicável quando o Hamiltoniano não dependem explicitamente do tempo), é escrita como:

$$
\mathcal{H}(\mathbf{r}, \mathbf{R}) \Psi_{n}(\mathbf{r}, \mathbf{R})=\mathscr{E}_{n} \Psi_{n}(\mathbf{r}, \mathbf{R})
$$

onde $\Psi_{n}$ é a função de onda e $\mathscr{E}_{n}$ a energia do $n$-ésimo estado da molécula.

Esta equação só pode ser resolvida de maneira exata para átomos hidrogenoides (ou seja, átomos que tenham apenas um elétron). Para qualquer outro sistema é 
preciso fazer aproximações.

A massa de um núcleo é muito maior que a massa de um elétron ${ }^{6}$, por isso os núcleos se movem mais devagar que os elétrons. Nos tratamentos teóricos a primeira aproximação comumente feita é a separação dos movimentos nuclear e eletrônico. Esta é a aproximação chamada de aproximação de Born-Oppenheimer (ou separação de Born-Oppenheimer). Nessa separação inicialmente consideramos que os elétrons se movem em um campo de forças gerado pelos núcleos fixos, que funcionam como cargas pontuais, por isso o termo que representa a energia cinética dos núcleos na equação (2.17) é negligenciado.

A partir desta aproximação tomamos a função de onda do sistema dada pela equação (2.18) como o produto de uma função de onda eletrônica que depende apenas parametricamente das posições $\mathbf{R}$ nucleares e outra função de onda nuclear que depende explicitamente de $\mathbf{R}[61,62]$ :

$$
\Psi_{n}(\mathbf{r}, \mathbf{R})=\Psi_{n}^{e l}(\mathbf{r} ; \mathbf{R}) \Psi_{n}^{n u c}(\mathbf{R})
$$

Podemos selecionar os termos da equação (2.17) relacionado a descrição dos elétrons e escrever um Hamiltoniano, chamado de Hamiltoniano eletrônico, que descreve esses elétrons para uma configuração fixa dos núcleos:

$$
\mathcal{H}^{e l}(\mathbf{r} ; \mathbf{R})=-\sum_{i=1}^{N} \frac{1}{2} \nabla_{i}^{2}-\sum_{i=1}^{N} \sum_{A=1}^{M} \frac{Z_{A}}{r_{i A}}+\sum_{i<j}^{N} \frac{1}{r_{i j}}
$$

A parte da energia relacionada a esse Hamiltoniano é obtida pela seguinte equação:

$$
\mathcal{H}^{e l}(\mathbf{r} ; \mathbf{R}) \Psi_{n}^{e l}(\mathbf{r} ; \mathbf{R})=\mathscr{E}_{n}^{e l}(\mathbf{R}) \Psi_{n}^{e l}(\mathbf{r} ; \mathbf{R})
$$

A equação 2.21 é portanto a equação que descreve o movimento eletrônico. Pela equação (2.17) vemos que a energia total do sistema para uma posição fixa dos núcleos (núcleos parados) deve incluir, além da energia eletrônica, a energia de repulsão

\footnotetext{
${ }^{6} \mathrm{~A}$ massa de um único próton é cerca de 1836 vezes maior que a massa de um elétron.
} 
nuclear:

$$
\mathscr{E}_{n}^{t o t}(\mathbf{R})=\mathscr{E}_{n}^{e l}(\mathbf{R})+\sum_{A<B}^{M} \frac{Z_{A} Z_{B}}{R_{A B}}
$$

Como os elétrons se movem mais rápido do que os núcleos, é uma aproximação razoável substituir as coordenadas eletrônicas na equação (2.17) pelos seus valores médios calculados sobre a função de onda eletrônica. Portanto pela equação (2.17) podemos obter o Hamiltoniano do sistema para o movimento dos núcleos no campo médio dos elétrons, e como portanto as coordenadas eletrônicas não vão aparecer este Hamiltoniano está relacionado apenas com a descrição dos núcleos, por isso ele é chamado de Hamiltoniano nuclear:

$$
\begin{aligned}
\mathcal{H}_{n}^{\text {nuc }}(\mathbf{R}) & =-\sum_{A=1}^{M} \frac{1}{2 M_{A}} \nabla_{A}^{2}+\left\langle-\sum_{i=1}^{N} \frac{1}{2} \nabla_{i}^{2}-\sum_{i=1}^{N} \sum_{A=1}^{M} \frac{Z_{A}}{r_{i A}}+\sum_{i<j}^{N} \frac{1}{r_{i j}}\right\rangle+\sum_{A<B}^{M} \frac{Z_{A} Z_{B}}{R_{A B}} \\
& =-\sum_{A=1}^{M} \frac{1}{2 M_{A}} \nabla_{A}^{2}+\mathscr{E}_{n}^{e l}(\mathbf{R})+\sum_{A<B}^{M} \frac{Z_{A} Z_{B}}{R_{A B}} \\
& =-\sum_{A=1}^{M} \frac{1}{2 M_{A}} \nabla_{A}^{2}+\mathscr{E}_{n}^{\text {tot }}(\mathbf{R})
\end{aligned}
$$

onde o Hamiltoniano agora tem uma dependência com o estado eletrônico, isso porque em cada estado eletrônico a energia $\mathscr{E}_{n}^{e l}(\mathbf{R})$ terá um valor diferente.

Este resultado, extremamente interessante, mostra que a energia $\mathscr{E}_{n}^{t o t}(\mathbf{R})$ fornece um potencial para o movimento nuclear. Esta é portanto a consequência da aproximação de Born-Oppenheimer: os núcleos se movem em um potencial obtido ao resolver apenas o problema eletrônico.

\subsubsection{Aproximação de Hartree-Fock}

No Hamiltoniano eletrônico apresentado na equação 2.21, o termo $\sum_{i<j}^{N} \frac{1}{r_{i j}}$ é o termo que correlaciona o movimento dos elétrons da molécula. Devido a esta correlação entre os elétrons a equação de Schrödinger se torna inviável de se resolver exatamente. A aproximação de Hartree-Fock surge como opção para a obtenção da função de onda 
e da energia do estado fundamental. Na aproximação de Hartree-Fock, que é uma aproximação de campo médio, cada elétron interage apenas com o potencial médio gerado pelos demais elétrons.

Para descrevermos a função de onda eletrônica de um sistema com muitos elétrons a aproximação comumente utilizada é consideramos que a função de onda é formada por uma combinação linear de produtos de funções de onda que descrevem apenas um elétron. A função de onda que descreve o estado de um elétron recebe o nome de orbital (ver subseção 2.2.3). A parte desta função de onda, $\psi_{i}(\mathbf{r})$, que descreve o estado espacial do elétron é chamada de orbital espacial, de tal forma que $\left|\psi_{i}(\mathbf{r})\right|^{2} d \mathbf{r}$ é a probabilidade de se encontrar o elétron em um elemento de volume infinitesimal $d \mathbf{r}$ em torno da posição $\mathbf{r}$.

O elétron também possui spin, que é uma característica intrínseca da matéria, e os possíveis estados de spin de um elétron são: spin up ou spin down. Esses estados de spin são descritos pelas funções $\alpha(\omega)$ e $\beta(\omega)$ para os estados up e down respectivamente, onde $\omega$ representa uma coordenada de spin. Se define como spin-orbital $\chi(\mathbf{x})$ a função de onda que descreve tanto o estado espacial quanto o estado de spin de um elétron. Pelo princípio de Pauli dois ou mais elétrons não podem ter o mesmo estado quântico, por isso em cada orbital espacial podemos ter apenas dois elétrons ${ }^{7}$, um com spin up e outro com spin down. Assim dado um conjunto com $W$ orbitais espaciais podemos formar um conjunto de $2 W$ spin-orbitais da seguinte maneira [61]:

$$
\left.\begin{array}{rl}
\chi_{2 i-1}(\mathbf{x}) & =\psi_{i}(\mathbf{r}) \alpha(\omega) \\
\chi_{2 i}(\mathbf{x}) & =\psi_{i}(\mathbf{r}) \beta(\omega)
\end{array}\right\} i=1,2, \ldots, W
$$

O ponto de partida da aproximação de Hartree-Fock é escrever a função de onda do estado fundamental através de um determinante de Slater. A função de onda eletrônica do estado fundamental para um sistema com $N$ elétrons obtida através do

\footnotetext{
${ }^{7}$ Os orbitais moleculares que rotulamos como HOMO, LUMO e etc na subseção 2.2 .3 correspondem a orbitais espaciais.
} 
determinante de Slater é [58]:

$$
\Psi_{0}^{e l}\left(\mathbf{x}_{1}, \mathbf{x}_{2}, \ldots, \mathbf{x}_{N}\right)=\frac{1}{\sqrt{N !}}\left|\begin{array}{cccc}
\chi_{1}\left(\mathbf{x}_{1}\right) & \chi_{2}\left(\mathbf{x}_{1}\right) & \cdots & \chi_{N}\left(\mathbf{x}_{1}\right) \\
\chi_{1}\left(\mathbf{x}_{2}\right) & \chi_{2}\left(\mathbf{x}_{2}\right) & \cdots & \chi_{N}\left(\mathbf{x}_{2}\right) \\
\vdots & \vdots & & \vdots \\
\chi_{1}\left(\mathbf{x}_{N}\right) & \chi_{2}\left(\mathbf{x}_{N}\right) & \cdots & \chi_{N}\left(\mathbf{x}_{N}\right)
\end{array}\right|
$$

Neste determinante $N$ elétrons ocupam $N$ spin-orbitais $\left(\chi_{1}, \chi_{2}, \ldots, \chi_{N}\right)$ sem especificar qual elétron está em qual spin-orbital. Este determinante obedece ao princípio de anti-simetria da função de onda: $\Psi^{e l}\left(\ldots, \mathbf{x}_{\mathbf{i}-\mathbf{1}}, \mathbf{x}_{\mathbf{i}}, \mathbf{x}_{\mathbf{i}+\mathbf{1}}, \ldots, \mathbf{x}_{\mathbf{j}-\mathbf{1}}, \mathbf{x}_{\mathbf{j}}, \mathbf{x}_{\mathbf{j}+\mathbf{1}}, \ldots\right)=$ $-\Psi^{e l}\left(\ldots, \mathbf{x}_{\mathbf{i}-\mathbf{1}}, \mathbf{x}_{\mathbf{j}}, \mathbf{x}_{\mathbf{i}+\mathbf{1}}, \ldots, \mathbf{x}_{\mathbf{j}-\mathbf{1}}, \mathbf{x}_{\mathbf{i}}, \mathbf{x}_{\mathbf{j}+\mathbf{1}}, \ldots\right)$. Além disso o princípio de Pauli é obedecido pois se dois elétrons ocuparem o mesmo spin-orbital teremos duas colunas do determinante iguais, e isso faz com que o determinante seja zero.

Com a função de onda escrita em termos dos spin-orbitais, pode-se mostrar que a energia eletrônica do estado fundamental é dada por:

$$
\mathscr{E}_{0}^{e l}=\left\langle\Psi_{0}^{e l}\left|\mathcal{H}^{e l}\right| \Psi_{0}^{e l}\right\rangle=\sum_{a=1}^{N} \int \chi_{a}^{*}(\mathbf{x}) h(\mathbf{x}) \chi_{a}(\mathbf{x}) d \mathbf{x}+\frac{1}{2} \sum_{a=1}^{N} \sum_{b=1}^{N}\langle a b|| a b\rangle
$$

Onde:

$$
\begin{aligned}
h\left(\mathbf{x}_{i}\right) & =-\frac{1}{2} \nabla_{i}^{2}-\sum_{A=1}^{M} \frac{Z_{A}}{r_{i A}} \\
\langle a b|| a b\rangle & =\langle a b \mid a b\rangle-\langle a b \mid b a\rangle \\
\langle a b \mid a b\rangle & =\int \chi_{a}^{*}\left(\mathbf{x}_{1}\right) \chi_{b}^{*}\left(\mathbf{x}_{2}\right) \frac{1}{r_{12}} \chi_{c}\left(\mathbf{x}_{1}\right) \chi_{d}\left(\mathbf{x}_{2}\right) d \mathbf{x}_{1} d \mathbf{x}_{2}
\end{aligned}
$$

De acordo com o Princípio Variacional a energia eletrônica do estado fundamental dada pela equação 2.26 só terá seu valor mínimo quando a função de onda for a função de onda exata. Portanto a exatidão do valor de $\mathscr{E}_{0}^{e l}$ depende da escolha dos spin-orbitais moleculares. A expressão para $\mathscr{E}_{0}^{e l}$ da equação 2.26 pode ser minimizada utilizando o método dos multiplicadores de Lagrange com o intuito de procurar o melhor conjunto 
de spin-orbitais moleculares, e pode-se mostrar que o resultado dessa minimização leva a equação de Hartree-Fock [58]:

$$
\mathcal{F}(\mathbf{x}) \chi_{a}(\mathbf{x})=\epsilon_{a} \chi_{a}(\mathbf{x})
$$

onde $\epsilon_{a}$ é a energia do $a$-ésimo orbital molecular ${ }^{8}$ e $\mathcal{F}(\mathbf{x})$ é o operador de Fock. A solução desta equação fornece os orbitais moleculares que fornecem o menor valor para a energia eletrônica do estado fundamental da equação 2.26. Temos que [58]:

$$
\begin{aligned}
\mathcal{F}(\mathbf{x}) & =h(\mathbf{x})+\sum_{b=1}^{N}\left[\mathcal{J}_{b}(\mathbf{x})-\mathcal{K}_{b}(\mathbf{x})\right] \\
\mathcal{J}_{b}\left(\mathbf{x}_{\mathbf{1}}\right) \chi_{a}\left(\mathbf{x}_{1}\right) & =\left[\int \chi_{b}^{*}\left(\mathbf{x}_{2}\right) \frac{1}{r_{12}} \chi_{b}\left(\mathbf{x}_{2}\right) d \mathbf{x}_{2}\right] \chi_{a}\left(\mathbf{x}_{1}\right) \\
\mathcal{K}_{b}\left(\mathbf{x}_{\mathbf{1}}\right) \chi_{a}\left(\mathbf{x}_{1}\right) & =\left[\int \chi_{b}^{*}\left(\mathbf{x}_{2}\right) \frac{1}{r_{12}} \chi_{a}\left(\mathbf{x}_{2}\right) d \mathbf{x}_{2}\right] \chi_{b}\left(\mathbf{x}_{1}\right)
\end{aligned}
$$

Utilizando a equação 2.27 a equação 2.31 para o operador de Fock pode ser reescrita da seguinte maneira:

$$
\begin{aligned}
\mathcal{F}\left(\mathbf{x}_{i}\right) & =-\frac{1}{2} \nabla_{i}^{2}-\sum_{A=1}^{M} \frac{Z_{A}}{r_{i A}}+v^{H F}\left(\mathbf{x}_{i}\right) \\
v^{H F}\left(\mathbf{x}_{i}\right) & =\sum_{b=1}^{N}\left[\mathcal{J}_{b}(\mathbf{x})-\mathcal{K}_{b}(\mathbf{x})\right]
\end{aligned}
$$

Podemos ver que o operador de Fock como escrito na equação 2.34 é um operador de um elétron e se compararmos a equação 2.34 com a equação 2.20 podemos ver que $v^{H F}(\mathbf{x})$ representa o potencial eletrostático médio sentido pelo elétron descrito pelo operador de Fock. Essa observação a respeito de $v^{H F}(\mathbf{x})$ mostra que, de fato, a aproximação de Hartree-Fock é uma aproximação de campo médio. Porém, como podemos ver, $v^{H F}(\mathbf{x})$ depende não somente do spin-orbital que este elétron ocupa mas também de todos os outros spin-orbitais. Por esse motivo a equação de Hartree-Fock

\footnotetext{
${ }^{8}$ Essas são as energias usadas para rotular os orbitais moleculares da maneira discutida na subseção 2.2.3.
} 
deve ser resolvida iterativamente, e o procedimento utilizado para se fazer isso envolve a escolha de uma forma inicial para os spin-orbitais que gera um $v^{H F}(\mathbf{x})$ inicial. Com esse conjunto inicial de spin-orbitais e com o $v^{H F}(\mathbf{x})$ a equação de Hartree-Fock é resolvida e um novo conjunto de spin-orbitais e consequentemente um novo $v^{H F}(\mathbf{x})$ são obtidos. Este processo é repetido até que uma convergência seja alcançada. Este procedimento é chamado de Campo Auto-Consistente (ou SCF, do Inglês "Self-Consistent Field").

Pode-se mostrar que a energia eletrônica do estado fundamental é dada por [58]:

$$
\mathscr{E}_{0} e l=\sum_{a=1}^{N} \epsilon_{a}-\frac{1}{2} \sum_{a=1}^{N} \sum_{b=1}^{N}\langle a b|| a b\rangle
$$

É importante notarmos que a energia eletrônica do estado fundamental não é igual a soma das energias dos spin-orbitais moleculares. Maiores informações e detalhes sobre o método de Hartree-Fock (inclusive detalhes sobre o procedimento SCF) podem ser encontradas no capítulo 1 da referência [58] escrito por M. A. Castro e S. Canuto.

A aplicação da aproximação de Hartree-Fock da origem ao método Hartree-Fock, que é um método ab initio. Como a aproximação de Hartree-Fock é uma aproximação de campo médio, isso porque como mostramos a interação elétron-elétron $\sum_{i<j}^{N} \frac{1}{r_{i j}}$ do sistema é substituída por um potencial eletrostático médio, parte dessa interação elétron-elétron não é considerada. A diferença de energia entre a energia exata e a energia obtida utilizando Hartree-Fock é chamada de energia de correlação eletrônica, e se deve justamente ao fato de que parte da interação elétron-elétron não é considerada na aproximação de Hartree-Fock. Existem métodos ab initio, chamados de métodos pós Hartree-Fock, que utilizam a Teoria da Perturbação ou outras abordagens para buscar incluir a correlação eletrônica desconsiderada em Hartree-Fock (que é importante para diversos sistemas) no tratamento teórico. 


\subsubsection{Aproximação LCAO: Conjuntos de Funções-base}

Os orbitais espaciais (ver equação 2.24) podem ser expandidos em combinações lineares de $M$ funções conhecidas $\left(\varphi_{j}\right)$, que são chamadas de funções-base. As funções $\varphi_{j}(\mathbf{r})$ são funções de um elétron e cada função representa um orbital atômico e é centrada em um núcleo atômico específico. Ao fazermos esta expansão estamos aproximando os orbitais moleculares por uma combinação linear de orbitais atômicos, e esta aproximação é chamada de LCAO (do Inglês "Linear Combination of Atomic Orbitals"). A expansão de um orbital molecular espacial em termos de orbitais atômicos é:

$$
\psi_{i}(\mathbf{r})=\sum_{j=1}^{M} c_{i j} \varphi_{j}(\mathbf{r})
$$

onde os $c_{i j}$ representam os coeficientes da combinação, ou seja, representam o quanto o $j$-ésimo orbital atômico contribui para o $i$-ésimo orbital molecular espacial. O conjunto de todas as funções $\varphi_{j}(\mathbf{r})$ é chamado de conjunto de funções-base.

Apesar de o conjunto de funções-base ser conhecido, os coeficientes $c_{i j}$ são desconhecidos. Esses coeficientes podem ser determinados através de cálculos computacionais que utilizam algum método de química quântica em sua formulação. No caso do método Hartree-Fock a equação 2.37 pode ser utilizada e portanto a equação de Hartree-Fock (ver equação 2.30) pode ser escrita não mais em função dos orbitais moleculares mas em função dos coeficientes $c_{i j}$ (ver referência [58] para maiores detalhes). A dependência das coordenadas de spin pode ser eliminada da equação de Hartree-Fock, e essa equação escrita em termos dos coeficientes $c_{i j}$ e transformada na forma matricial é chamada de equação de Hartree-Fock-Roothaan [58]. A solução desta equação leva ao conjunto de coeficientes $c_{i j}$ que fornecem os orbitais moleculares que minimizam a energia do estado fundamental.

O número $M$ de funções-base é finito. Caso o conjunto de funções-base fosse completo teríamos um exato para função de onda dentro da formulação de teórica do método utilizado. Porém um conjunto completo (como o conjunto composto por 
todos orbitais de um átomo de hidrogênio) é comumente infinito e por isso inviável de ter tratado computacionalmente. Em princípio, quanto maior for o número de funções-base melhor é a descrição da função de onda do sistema e consequentemente das propriedades do sistema, mas por outro lado maior é o custo computacional envolvido. Portanto, devido as limitações computacionais, nos estudos teóricos há sempre uma busca por um conjunto de funções-base que equilibre eficiência computacional e resultados satisfatórios.

Além do número de funções-base, a escolha do conjunto de funções também é de grande relevância para a precisão do cálculo. Existem diversos tipos de conjuntos de funções-base que foram propostos na literatura, e as discussões a cerca desses tipos e os detalhes de sua composição são temas bastante extensos e que ocupam várias páginas de livros-texto. Vamos no restante desta subseção abordar superficialmente e resumidamente esses temas apenas com o intuito de dar uma ideia sobre os conjuntos de funções-base usados nesta dissertação. Para maiores informações recomendamos as referências [61] e [63], que foram as referências utilizadas para o apresentado a seguir.

Os dois tipos de funções-base mais comumente utilizados são funções do tipo Slater (ou STO, do Inglês "Slater Type of Orbital") e funções do tipo Gaussiana (ou GTO, do Inglês "Gaussian Type of Orbital"). Funções do tipo Slater são melhores do que funções Gaussianas no sentido de que a precisão fornecida por um conjunto de funções Gaussianas pode ser alcançada utilizando um conjunto de funções Gaussianas de tamanho menor. Por outro lado computacionalmente se pode resolver integrais de dois elétrons (como por exemplo a integral da equação 2.29) mais rapidamente com funções Gaussianas do que com funções de Slater. Na tentativa de se contornar essas limitação foram propostas na literatura os chamados conjuntos de funções-base Gaussianas contraídas. Em um conjunto desses cada função-base é escrita como uma combinação linear fixa de funções Gaussianas, que nesse contexto recebem o nome de funções primitivas. Essas funções contraídas podem ser escolhidas, por exemplo, de 
modo a se parecerem com funções de Slater ou com orbitais moleculares de HartreeFock. Apesar de cada função-base contraída ser uma combinação fixa de algumas funções Gaussianas, a escolha desse conjunto contraído é vantajosa porque o número de funções-base da equação 2.37 reduz em comparação com o caso em que consideramos todas as funções primitivas como o conjunto de funções-base, e a consequência disso é uma maior eficiência computacional com resultados compatíveis aos que seriam gerados pelo conjunto formado pelas primitivas. Esse ganho em eficiência ocorre porque o número de integrais de dois-elétrons cresce com a quarta potência em relação ao número de funções de base [63].

Na literatura existem disponíveis diferentes conjuntos de funções-base Gaussianas contraídas. Os conjuntos mais comumente usados e que se encontram implementados em diversos programas de computador são as bases do tipo Dunning-Huzinaga e as bases do tipo Pople [63]. Nesta dissertação em praticamente todos os cálculos optamos por trabalhar com as bases de Pople. Existem vários tipos de bases de Pople, por isso vamos a seguir buscar comentar apenas sobre as bases de Pople utilizadas nesta dissertação.

Vamos inicialmente falar dos conjuntos de funções-base de Pople do tipo k-nlmG. Essas bases são do tipo "valência desdobrada". $k$ representa o número de funções primitivas a serem usadas para representar orbitais de caroço ${ }^{9} . n l m$ indica em quantas funções (ou partes) os orbitais de valência são partidos e também quantas funções primitivas são usadas na representação de cada função. Caso na base de Pople apareçam os três números $n l m$ isso significa que os orbitais são partidos em três funções, e caso apareçam apenas dois números $n l$ isso significa que os orbitais são partidos em duas funções. No caso da base 6-31G os orbitais de caroço são uma contração de seis funções primitivas, os orbitais de valência são partidos em duas funções (por isso 6-31G é uma base "Double-Zeta"), a parte interna dos orbitais de valência é uma contração de três

\footnotetext{
${ }^{9}$ Orbitais de caroço são orbitais mais fortemente ligados ao núcleo atômico e não fazem parte dos orbitais de valência.
} 
funções primitivas, e a parte externa dos orbitais de valência é representada por uma função primitiva. No caso da base 6-311G os orbitais de caroço são uma contração de seis funções primitivas e os orbitais de valência são partidos em três funções (por isso 6-311G é uma base "Tiple-Zeta"), representadas respectivamente por três, uma e uma funções primitivas.

Nos conjuntos de funções-base do tipo $k$-nlm $\mathrm{G}$ podem ser adicionadas funções difusas e/ou de polarização. Funções difusas são denotadas por + ou ++ que devem vir imediatamente antes de $G$, onde o primeiro + indica que um conjunto de funções difusas $s$ e $p$ são adicionadas aos átomos pesados, e o segundo + indica que um conjunto de funções difusas $s$ são adicionadas aos átomos de hidrogênio. Funções de polarização são denotadas na forma $(\xi, \varsigma)$ que deve vir imediatamente após de $\mathrm{G}$, onde $\xi$ representa as funções de polarização dos átomos pesados e $\varsigma$ representa as funções de polarização dos átomos de hidrogênio. No caso da base 6-31G(d) apenas uma função de polarização do tipo $d$ é adicionada nos átomos pesados. No caso da base 6-31G(2df,2pd) duas funções de polarização do tipo $d$ e uma do tipo $f$ são adicionadas aos átomos pesados e duas funções de polarização do tipo $p$ e uma do tipo $d$ são adicionadas aos átomos de hidrogênio. Em vez de usar anotação do tipo $(\xi, \varsigma)$, existe uma notação alternativa que utiliza asteriscos. Nessa notação um asterisco * representa (d) e dois asteriscos $* *$ representam $(\mathrm{d}, \mathrm{p})$, portanto 6-31G* é equivalente a 6-31G(d) e $6-311++\mathrm{G}^{* *}$ é equivalente a $6-311++\mathrm{G}(\mathrm{d}, \mathrm{p})$.

Vale aqui esclarecer que conjuntos de funções primitivas (funções-base Gaussianas contraídas) se encontram disponíveis na literatura para cada tipo de base de Pople (como 6-31G ou 6-31+G*) e para vários elementos da tabela periódica.

\subsubsection{Métodos Semi-empíricos: ZINDO/CIS}

Existem vários métodos semi-empíricos utilizados na literatura, como os métodos INDO/S, CNDO/S, AM1, PM3, dentre outros. Nesta subseção buscaremos dar uma 
ideia geral acerca do funcionamento e das aproximações de alguns métodos semiempíricos. O livro-texto utilizado com base para escrita desta subseção é a referência [63], portanto para maiores informações sobre a formulação de métodos semiempíricos recomendamos a leitura das seções 3.11 e 3.12 desta referência.

Métodos semi-empíricos são geralmente construídos em cima das bases teóricas de métodos ab initio, e a sua essência consiste em negligenciar o cálculo de algumas integrais e compensar as imprecisões causadas por isso com a inclusão de parâmetros escolhidos nas demais integrais. A redução do número de integrais reduz o custo computacional.

Outro procedimento adotado pelos métodos semi-empíricos para reduzir o custo computacional é considerar apenas os elétrons de valência explicitamente, e nesse caso geralmente o efeito dos elétrons de caroço são incluídos apenas com a modificação do número atômico do núcleo para um número atômico efetivo. Além disso, apenas uma base mínima é utilizada na descrição dos orbitais moleculares.

A conjectura central feita pelos métodos semi-empíricos é a chamada aproximação de Superposição de Diferencial Nulo (ZDO, do Inglês "Zero Differential Overlap"), e consiste em negligenciar todos os produtos de funções-base localizadas em diferentes átomos mas que dependam das mesmas coordenadas [63]. Reescrevendo as funçõesbase $\varphi_{j}(\mathbf{r})$ da equação 2.37 em uma notação em que o núcleo do átomo no qual a base está centrada apareça de força explicita, a aproximação ZDO implica em:

$$
\varphi_{A}^{c}(\mathbf{r}) \varphi_{B}^{d}(\mathbf{r})=0, \text { para } A \neq B
$$

onde $A$ e $B$ representam os núcleos atômicos aos quais as bases estão centradas e $c$ e $d$ diferenciam as bases de acordo com o seu tipo.

Como dissemos, para contornar os erros cometidos ao negligenciar integrais parâmetros são incluídos nas demais integrais. Essas parâmetros ajustados de modo que os resultados produzidos reproduzam alguns resultados experimentais ou cálculos 
$a b$ initio. A maneira como a parametrização é feita e o número de integrais que são desprezadas é o que define os diversos métodos semi-empíricos [63].

Todas as aproximações já mencionadas dão origem ao método NDDO (do Inglês "Neglect of Diatomic Differential Overlap"). O método INDO (do Inglês "Intermediate Neglect of Differential Overlap") utiliza todas as aproximações de NDDO e adicionalmente negligencia todas integrais de dois centros e de dois elétrons que não sejam integrais Coulomb [63].

Uma das maneiras de se obter os parâmetros leva o método INDO ao método INDO/S. O método INDO/S com a parametrização usada por Zerner et al. para reproduzir resultados empíricos espectroscópicos é o que implementado no programa ZINDO [64], que é bastante utilizado nos cálculos desta dissertação. A aplicação do método INDO/S com a parametrização de Zerner et al. para o cálculo do espectro de absorção juntamente com o método Interação de Configuração (CI, do Inglês "Configuration Interaction") considerando apenas excitações simples da origem ao que chamamos nesta dissertação de método ZINDO/CIS para o cálculo do espectro. Uma explicação a respeito da metodologia de parametrização juntamente com uma revisão das teorias (e suas implementações) utilizadas na construção do programa ZINDO é feita no excelente apêndice A da referência [65]. Maiores informações sobre o método CI podem ser encontradas no capítulo 5 da referência [58].

\subsubsection{Teoria do Funcional da Densidade}

Os métodos que fazem uso da Teoria do Funcional da Densidade (DFT, do Inglês "Density-Functional Theory") surgem como alternativa ao método Hartree-Fock e aos métodos pós Hartree-Fock. Dentro da abordagem de DFT a correlação eletrônica perdida na aproximação de Hartree-Fock é considerada. Na verdade, do ponto de vista teórico, DFT provém resultados exatos pois ela fornece uma alternativa para a solução direita da equação de Schrödinger. A ideia básica por trás de DFT é que é 
possível, em princípio, obter todas as informações sobre um sistema de $N$ elétrons sem ter que calcular a função de onda eletrônica desse sistema. Em vez disso as informações podem ser obtidas a partir da densidade eletrônica. DFT é uma teoria de estado fundamental, e, como veremos na subseção 2.3.5.3, o ponto de partida para a determinação dos estado excitados através da versão dependente do tempo de DFT é a determinação do estado fundamental.

A densidade de probabilidade $n_{0}(\mathbf{r})$ de se encontrar um elétron na posição $\mathbf{r}$ no estado estado fundamental de um sistema de $N$ elétrons ${ }^{10}$ pode ser escrita em função da função de onda eletrônica do sistema da seguinte maneira [66]:

$$
n_{0}(\mathbf{r})=N \int \ldots \int\left|\Psi_{0}^{e l}\left(\mathbf{r}, \mathbf{r}_{2}, \ldots, \mathbf{r}_{N}\right)\right|^{2} d \mathbf{r}_{2} \ldots d \mathbf{r}_{N}
$$

A forma de $\Psi_{0}^{e l}$ está intimamente relacionada com a forma do potencial da equação de Schrödinger (ou seja, a equação 2.20 sem o termo cinético), e desse modo a forma desse potencial implica também na forma de $n_{0}(\mathbf{r})$. Um dos pilares de DFT é o teorema de Hohenberg-Kohn, e segundo esse teorema é impossível que dois potenciais diferentes produzam a mesma densidade $n_{0}(\mathbf{r})$ no estado fundamental. Vamos denotar o potencial exato sentido por um elétron, cuja expressão pode ser deduzida a partir da equação 2.20, como $v^{e l}(\mathbf{r})$. Pelo teorema de Hohenberg-Kohn podemos conceber que existe então um relação de um para um da seguinte maneira: $n_{0}(\mathbf{r}) \leftrightarrow v^{e l}(\mathbf{r})$, ou seja, para cada $n_{0}(\mathbf{r})$ existe somente um $v^{e l}(\mathbf{r})$ associado. Esse tipo de relação estabelece uma relação chamada funcional, e por esse motivo DFT é chamado de Teoria do Funcional da Densidade. Dentro da abordagem de DFT a maneira de se escrever essa relação funcional é escrever todas as funções como funcional de $n_{0}(\mathbf{r})$, de modo que uma alteração em $n_{0}(\mathbf{r})$ implica em mudanças nas demais propriedades. A função de onda escrita como funcional de $n_{0}(\mathbf{r})$ é denotada como $\Psi_{0}^{e l}\left[n_{0}\right]$. A energia do estado fundamental pode ser escrita como funcional de $n_{0}(\mathbf{r})$, e com base no princípio

\footnotetext{
${ }^{10}$ Como um elétron tem carga $-e$, a densidade eletrônica do estado fundamental é: $\rho_{0}(\mathbf{r})=-e n_{0}(\mathbf{r})$
} 
variacional se pode mostrar que:

$$
\begin{aligned}
& \mathscr{E}_{0}^{e l}\left[n_{0}\right]>E_{0}^{e l} \text { para } n_{0}(\mathbf{r}) \neq n_{0}^{\text {exato }}(\mathbf{r}) \\
& \mathscr{E}_{0}^{e l}\left[n_{0}\right]=E_{0}^{e l} \text { para } n_{0}(\mathbf{r})=n_{0}^{\text {exato }}(\mathbf{r})
\end{aligned}
$$

onde nessa notação $E_{0}^{e l}$ e $n_{0}^{\text {exato }}(\mathbf{r})$ representam respectivamente a energia e a densidade de probabilidade exatas do estado fundamental. Desse modo a equação 2.40 expressa que a energia exata do estado fundamental só é alcançada para a densidade de probabilidade exata do estado fundamental.

\subsubsection{Formalismo de Kohn-Sham}

O fato de que todos os observáveis são funcionais de $n_{0}(\mathbf{r})$ abre caminho para uma enorme simplificação, uma vez que $n_{0}(\mathbf{r})$ é uma função de apenas 3 variáveis enquanto a função de onda eletrônica possui $3 N$ variáveis. A ideia por trás do formalismo de KohnSham, que funciona como uma alternativa para resolver a equação de Schrödinger diretamente, é substituir o sistema real de elétrons interagentes por um sistema não interagente mas que reproduza a densidade eletrônica do sistema real. Isso é feito da seguinte maneira, primeiramente se escreve $n_{0}(\mathbf{r})$ como [66]:

$$
n_{0}(\mathbf{r})=\sum_{i}\left|\varphi_{i}(\mathbf{r})\right|^{2}
$$

onde $\varphi_{i}(\mathbf{r})$ é chamado de orbital de Kohn-Sham e obedece uma equação de Schrödinger de uma partícula. O potencial para essa equação, $v^{K S}\left[n_{0}\right](\mathbf{r})$, é chamado de potencial de Kohn-Sham. Portanto:

$$
\left[-\frac{\nabla^{2}}{2}+v^{K S}\left[n_{0}\right](\mathbf{r})\right] \varphi_{i}(\mathbf{r})=\epsilon_{i}^{K S} \varphi_{i}(\mathbf{r})
$$

Esta equação é chamada de equação de Kohn-Sham. O sistema de Kohn-Sham é considerado não interagente porque $v^{K S}\left[n_{0}\right](\mathbf{r})$ é um potencial de um elétron, ou seja, cada elétron do sistema de comporta de acordo com esse potencial que depende apenas de suas coordenadas. 
O sucesso do formalismo de Kohn-Sham se deve ao fato de que caso $v^{K S}\left[n_{0}\right](\mathbf{r})$ forneça orbitais de Kohn-Sham (via a equação 2.42) de modo que esses orbitais forneçam a densidade de probabilidade exata $n_{0}^{\text {exato }}(\mathbf{r})$ (via a equação 2.41 ), então pela equação 2.40 vemos que a energia exata do estado fundamental é obtida. Desse modo com isso conseguimos mostrar que todas as informações do sistema podem ser obtidas de forma exata através do formalismo de Kohn-Sham sem ter que resolver diretamente a equação de Schrödinger de muitos elétrons mostrada na equação 2.21. Portanto no formalismo de Kohn-Sham o problema a ser resolvido passa ser o seguinte: como determinar o potencial $v^{K S}\left[n_{0}\right](\mathbf{r})$ que fornece a densidade $n_{0}^{\text {exato }}$ exata? Os resultados fornecidos pelo formalismo de Kohn-Sham deixam de ser exatos e passam a ser aproximados caso $v^{K S}\left[n_{0}\right](\mathbf{r})$ forneça uma densidade aproximada.

O passo seguinte dentro do formalismo de Kohn-Sham é escrever $v^{K S}\left[n_{0}\right](\mathbf{r})$ de uma forma inteligente. Vamos atribuir para primeira parte desse potencial um potencial $v_{0}(\mathbf{r})$, que é um potencial externo que age no sistema não interagente de KohnSham (como é um potencial externo, então não é um funcional de $n_{0}$ ). No caso do Hamiltoniano eletrônico da equação 2.20 é natural conceber que esse potencial é o potencial eletrostático causado pelos núcleos atômicos, e portanto nesse caso teríamos:

$$
v_{0}(\mathbf{r})=-\sum_{A=1}^{M} \frac{Z_{A}}{\left|\mathbf{r}-\mathbf{r}_{A}\right|} \text {, onde } \mathbf{r}_{A} \text { é a posição do núcleo do átomo } A
$$

Como $v_{0}(\mathbf{r})$ é um potencial externo, a diferença $v^{K S}\left[n_{0}\right](\mathbf{r})-v_{0}(\mathbf{r})$ representa efeitos de muitos corpos, e grande parte desses efeitos pode ser considerada em um potencial $v_{H}\left[n_{0}\right](\mathbf{r})$ do tipo Coulomb associado com a densidade eletrônica, chamado de potencial de Hartree, que é expresso como:

$$
v_{H}\left[n_{0}\right](\mathbf{r})=\int \frac{n_{0}\left(\mathbf{r}^{\prime}\right)}{\left|\mathbf{r}-\mathbf{r}^{\prime}\right|} d \mathbf{r}^{\prime}
$$

O restante do potencial de Kohn-Sham, denotado como $v_{x c}\left[n_{0}\right](\mathbf{r})$, é chamado de potencial de troca-correlação (exchange-correlation potential). Portanto podemos 
escrever $v^{K S}\left[n_{0}\right](\mathbf{r})$ como:

$$
v^{K S}\left[n_{0}\right](\mathbf{r})=v_{0}(\mathbf{r})+v_{H}\left[n_{0}\right](\mathbf{r})+v_{x c}\left[n_{0}\right](\mathbf{r})
$$

A energia do estado fundamental associada a densidade $n_{0}(\mathbf{r})$, mostrada na equação 2.40, pode ser determinada a partir do Hamiltoniano $H^{e l}$ do sistema: $\mathscr{E}_{0}^{e l}\left[n_{0}\right]=$ $\left\langle\Psi_{0}^{e l}\left[n_{0}\right]\left|H^{e l}\right| \Psi_{0}^{e l}\left[n_{0}\right]\right\rangle$. Pode-se mostrar que essa energia e os termos da equação 2.45 se relacionam da seguinte maneira [66]:

$$
\mathscr{E}_{0}^{e l}\left[n_{0}\right]=T^{K S}\left[n_{0}\right]+\int v_{0}(\mathbf{r}) n_{0}(\mathbf{r}) d \mathbf{r}+E_{H}\left[n_{0}\right]+E_{x c}\left[n_{0}\right]
$$

Onde:

$$
\begin{aligned}
T^{K S}\left[n_{0}\right] & =-\frac{1}{2} \sum_{i} \varphi_{i}^{*}(\mathbf{r}) \nabla^{2} \varphi_{i}(\mathbf{r}) \\
E_{H}\left[n_{0}\right] & =\frac{1}{2} \iint \frac{n_{0}(\mathbf{r}) n_{0}\left(\mathbf{r}^{\prime}\right)}{\left|\mathbf{r}-\mathbf{r}^{\prime}\right|} d \mathbf{r} d \mathbf{r}^{\prime} \\
v_{x c} & =\frac{\delta E_{x c}\left[n_{0}\right]}{\delta n_{0}(\mathbf{r})}
\end{aligned}
$$

\subsubsection{Implementação computacional de métodos DFT}

Como mencionamos na subseção anterior, o problema central dentro do formalismo de Kohn-Sham é determinar o potencial de Kohn-Sham que fornece a densidade de probabilidade exata via as equações 2.41 e 2.42. Quando um potencial de Kohn-Sham que fornece a densidade aproximada é utilizado, então o valor obtido para energia do estado fundamental (e consequentemente para as outras propriedades) também é aproximado. Quando o potencial de Kohn-Sham é reescrito da maneira apresentada na equação 2.45 então toda a indeterminação desse potencial recai somente no potencial de troca-correlação $v_{x c}\left[n_{0}\right](\mathbf{r})$, já que $v_{0}(\mathbf{r})$ é conhecido e $v_{H}\left[n_{0}\right](\mathbf{r})$ pode ser determinado a partir de $n_{0}(\mathbf{r})$ via a equação 2.44 .

Se conhecêssemos o potencial de troca-correlação exato do sistema poderíamos determinar a densidade de probabilidade exata e a energia do estado fundamental 
exata iterativamente. Isso pode ser feito porque, como mostramos na equação 2.40 , a energia exata do estado fundamental é um mínimo e só é obtida para a densidade de probabilidade exata do sistema. O procedimento para fazer essa resolução iterativa é através do SCF (Campo Auto-Consistente), e se aplica de maneira semelhante a utilizada para se resolver a equação de Hartree-Fock iterativamente (ver subseção 2.3.2). O procedimento SCF aplicado a métodos DFT pode ser sumarizado nos seguintes passos:

1. Inicialmente se escolhe um conjunto de orbitais de Kohn-Sham. Uma escolha comumente utilizada são os orbitais de Hartree-Fock. Essa escolha implica em um chute inicial para $n_{0}(\mathbf{r})$ via a equação 2.41 .

2. Com essa densidade $n_{0}(\mathbf{r})$ inicial se resolve a equação de Kohn-Sham (equação 2.42).

3. A solução da equação de Kohn-Sham fornece um novo conjunto de orbitais KohnSham. Com esse novo conjunto uma nova densidade $n_{0}(\mathbf{r})$ é obtida via a equação 2.41. Com a nova densidade $n_{0}(\mathbf{r})$ a energia do estado fundamental pode ser calculada via a equação 2.46 .

4. Com o novo conjunto de orbitais de Kohn-Sham este processo pode ser realizado novamente e novos valores para os orbitais, para a densidade e para a energia serão obtidos. Esse processo é repetido até que a energia do estado fundamental convirja dentro de uma precisão desejada.

Se o potencial de troca-correlação fosse exato, os resultados obtidos para a densidade $n_{0}(\mathbf{r})$ e para a energia do estado fundamental através do procedimento SCF seriam exatos apenas dentro de uma cerca tolerância ${ }^{11}$. Porém uma forma exata para o potencial de troca-correlação não é conhecida e por isso esse potencial precisa ser

\footnotetext{
${ }^{11}$ Estritamente falando, a densidade $n_{0}(\mathbf{r})$ e para a energia do estado fundamental exatas só seriam obtidas com infinitos passos SCF, isso porque, por exemplo, as infinitas casas decimais da energia teriam que ser todas determinadas.
} 
aproximado. Desse modo, devido ao fato da solução computacional da equação de Kohn-Sham introduzir imprecisões numéricas e devido ao fato de o potencial de trocacorrelação ser aproximado, na prática os resultados providos por métodos DFT são aproximados.

Na literatura diversos potenciais de troca-correlação foram propostos, onde alguns deles usam argumentos físicos em sua elaboração (como por exemplo os funcionais PBE e LDA) enquanto outros utilizam parametrizações (como por exemplo os funcionais B3LYP, O3LYP, CAM-B3LYP e M06-2X, e funcionais desse tipo são conhecidos como funcionais híbridos) que são ajustadas para reproduzir resultados de referência (por exemplo, resultados experimentais e resultados de cálculos pós Hartree-Fock). Uma discussão sobre a formulação de cada funcional utilizado nesta dissertação é bastante extensa e por isso foge do escopo desta dissertação. Em vez dessa discussão, no capítulo de resultados apresentamos uma comparação dos resultados obtidos para cálculos do espectro de absorção onde se é possível ver as características de cada funcional utilizado no espectro dos sistemas estudos. Uma explanação de cunho geral sobre alguns conceitos envolvidos na formulação de alguns tipos de funcionais pode ser consultada na referência [66].

\subsubsection{Por que a versão dependente do tempo de DFT deve ser usada no cálculo do espectro de absorção?}

Esse é um questionamento interesse: se estamos interessado em calcular estados excitados de uma molécula em estrutura fixa, porque temos que utilizar a Teoria do Funcional da Densidade em sua versão Dependente do Tempo (TD-DFT, onde TD vem do Inglês "Time Dependent")? DFT é uma teoria que fornece resultados para o estado fundamental, e TD-DFT fornece um mecanismo no qual se é possível sair do estado fundamental e chegar nos estados exitados. Vamos buscar fornecer uma breve explanação a cerca disso nesta subseção. 
A equação que regula a evolução temporal dos estados é a equação de Schrödinger na versão dependente do tempo:

$$
i \frac{\partial}{\partial t} \Psi_{j}^{e l}\left(\mathbf{r}_{1}, \ldots, \mathbf{r}_{N}, t\right)=\mathcal{H}^{e l} \Psi_{j}^{e l}\left(\mathbf{r}_{1}, \ldots, \mathbf{r}_{N}, t\right)
$$

Em TD-DFT o Hamiltoniano dependente do tempo é escrito na seguinte forma:

$$
\mathcal{H}^{e l}=T+V(t)+W
$$

onde $T$ é o operador de energia cinética, $W$ representa a interação entre os elétrons do sistema, e $V(t)$ representa o potencial externo sentido pelos elétrons e carrega a dependência temporal do Hamiltoniano. A repulsão Colombiana causada pelos núcleos atômicos nos elétrons está incluída em $V(t)$, mas uma perturbação dependente do tempo também é incluída. Essa perturbação dependente do tempo é o que torna possível a evolução de um estado inicial (que pode ser o estado fundamental) para um outro estado final (que pode ser um estado excitado), e é por isso que se precisa utilizar a versão dependente do tempo de DFT para o cálculo dos estados excitados. Em TD-DFT $V(t)$ é escrito como:

$$
\begin{aligned}
V(t) & =\sum_{j=1}^{N} v\left(\mathbf{r}_{j}, t\right) \\
v(\mathbf{r}, t) & =v_{0}(\mathbf{r})+\theta\left(t-t_{0}\right) v_{1}(\mathbf{r}, t)
\end{aligned}
$$

onde $\theta(x)=1$ para $x \geq 0$ e $\theta(x)=0$ para $x<0$. Portanto a perturbação dependente do tempo $v_{1}(\mathbf{r}, t)$ é ligada no instante $t_{0}$.

A essência de TD-DFT está no teorema de Runge-Gross que é uma generalização do teorema de Hohenberg-Kohn mencionado no início desta seção. Segundo o teorema de Runge-Gross existe uma relação unívoca entre $v(\mathbf{r}, t)$ e a densidade de probabilidade $n_{j}(\mathbf{r}, t)$ de se encontram um elétron em um dado estado $j$ para um sistema que evolui de um estado inicial bem definido (que pode ser o estado fundamental).

A maneira mais comumente utilizada para se aplicar TD-DFT é através da Teoria de Resposta Linear. Dentro dessa teoria a perturbação $v_{1}(\mathbf{r}, t)$ pode ser escrita, por 
exemplo, como um campo elétrico oscilante no tempo e que aponta na direção z:

$$
v_{1}(\mathbf{r}, t)=E z \sin (\omega t)
$$

Um passo central dentro da Teoria de Resposta Linear é escrever a mudança na densidade $n_{j}(\mathbf{r}, t)$ que ocorre devido a perturbação do sistema em termos da mudança que acontece no potencial $v(\mathbf{r}, t)$. Nesta relação a coordenada temporal é submetida a uma transição de Fourier e a relação é escrita da seguinte forma:

$$
\partial n_{j}(\mathbf{r}, w)=\int \chi\left(\mathbf{r}, \mathbf{r}^{\prime}, \omega\right) \partial v(\mathbf{r}, w) d \mathbf{r}^{\prime}
$$

Pode-se mostra que $\chi\left(\mathbf{r}, \mathbf{r}^{\prime}, \omega\right)$, chamada função de resposta linear, é dada por [66]:

$\chi\left(\mathbf{r}, \mathbf{r}^{\prime}, \omega\right)=\lim _{\eta \rightarrow 0^{+}} \sum_{k=1}^{\infty}\left[\frac{\left\langle\Psi_{0}^{e l}|\hat{n}(\mathbf{r})| \Psi_{k}^{e l}\right\rangle\left\langle\Psi_{k}^{e l}\left|\hat{n}\left(\mathbf{r}^{\prime}\right)\right| \Psi_{0}^{e l}\right\rangle}{\omega-\left(\mathscr{E}_{k}^{e l}-\mathscr{E}_{0}^{e l}\right)+i \eta}-\frac{\left\langle\Psi_{0}^{e l}\left|\hat{n}\left(\mathbf{r}^{\prime}\right)\right| \Psi_{k}^{e l}\right\rangle\left\langle\Psi_{k}^{e l}|\hat{n}(\mathbf{r})| \Psi_{0}^{e l}\right\rangle}{\omega+\left(\mathscr{E}_{k}^{e l}-\mathscr{E}_{0}^{e l}\right)+i \eta}\right]$

onde $\hat{n}(\mathbf{r})$ é o operador de densidade de probabilidade, e $\left|\Psi_{k}^{e l}\right\rangle$ e $\mathscr{E}_{k}^{e l}$ correspondem a função de onda e a energia do estado $k$ do sistema não perturbado. Podemos ver que a função de onda e a energia do estado fundamental do sistema não perturbado aparecem nessa expressão, o que mostra que o primeiro passo em TD-DFT é a determinação do estado fundamental utilizando DFT. Os polos da função $\chi\left(\mathbf{r}, \mathbf{r}^{\prime}, \omega\right)$ fornecem as energias dos estados excitados do sistema não perturbado $\left(E_{k}\right)$, e é assim então que as energias de excitação são determinadas em TD-DFT.

\subsubsection{Métodos de Mecânica Molecular: campo de força GRO- MOS}

Mesmo fazendo aproximações, a complexidade computacional dos métodos apresentados nas subseções anteriores desta seção 2.3 muitas vezes é um fator limitante que inviabiliza diversos estudos teóricos, principalmente de moléculas grandes. Assim então, métodos de Mecânica Molecular, também denotados como métodos clássicos, 
surgem como uma alternativa para a descrição das interações moleculares de uma forma computacionalmente mais eficiente e onde sistemas maiores podem ser tratados de forma mais factível. Apesar desses métodos produzirem resultados satisfatórios em alguns casos, esses são os métodos que mais contém aproximações dentre os métodos apresentados nesta seção. Métodos de Mecânica Molecular são comumente aplicados na realização de simulações computacionais, como dinâmicas moleculares (falaremos sobre dinâmicas moleculares na seção 2.4).

Na seção 2.3.1 mostramos que a energia eletrônica para uma configuração fixa dos núcleos fornece juntamente com o potencial de repulsão nuclear o potencial $\mathscr{E}_{n}^{t o t}(\mathbf{R})$ para o movimento dos núcleos (ver equação 2.23). Esse potencial $\mathscr{E}_{n}^{\text {tot }}(\mathbf{R})$ pode ser determinado com métodos dos tipos já mencionados nesta seção, mas a abordagem dos métodos de Mecânica Molecular é tratar esse potencial como um conjunto de funções que juntamente com um grande conjunto de parâmetros descrevem os diferentes termos das interações moleculares. Esses parâmetros, quando colocados nessas funções, fornecem valores numéricos para as interações moleculares. Esses parâmetros são determinados de maneira a melhor reproduzir propriedades experimentais - como densidade, entalpia de vaporização e função de distribuição radial. Quando dados experimentais não estão disponíveis, é comum se usar cálculos ab initio para realizar a parametrização. O conjunto das formas escolhidas para essas funções juntamente com o conjunto de parâmetros é chamado de campo de força.

Os campos de força são usualmente determinados para o estado fundamental, por isso vamos considerar apenas o estado fundamental e a partir de agora utilizar nesta subseção uma notação simplificada para $\mathscr{E}_{0}^{\text {tot }}(\mathbf{R})$, que será $V^{n u c}(\mathbf{R})$.

Supondo que existam $S$ moléculas no sistema, a primeira etapa adotada pelos campos de força é escrever $V^{n u c}(\mathbf{R})$ da seguinte maneira:

$$
V^{n u c}(\mathbf{R})=\sum_{\mathcal{D}<\mathcal{G}}^{S} V_{\text {Inter }}^{(\mathcal{D}, \mathcal{G})}\left(\mathbf{R}^{(\mathcal{D})}, \mathbf{R}^{(\mathcal{G})}\right)+\sum_{\mathcal{D}=1}^{S} V_{\text {Intra }}^{(\mathcal{D})}\left(\mathbf{R}^{(\mathcal{D})}\right)
$$


onde $\mathbf{R}^{(\mathcal{D})}$ representa as coordenadas dos núcleos da molécula $\mathcal{D}, V_{\text {Inter }}^{(\mathcal{D}, \mathcal{G})}\left(\mathbf{R}^{(\mathcal{D})}, \mathbf{R}^{(\mathcal{G})}\right)$ é o potencial de interação intermolecular entre as moléculas $\mathcal{D}$ e $\mathcal{G}$, e $V_{\text {Intra }}^{(\mathcal{D})}\left(\mathbf{R}^{(\mathcal{D})}\right)$ é o potencial intramolecular da molécula $\mathcal{D}$.

Na literatura existem vários campos de força disponíveis, como OPLS, AMBER, CHARMM e GROMOS. Nesta dissertação, como estamos interessados em estudar Porfirinas e Ftalocianinas, optamos por usar o campo de forças GROMOS [67,68] com o conjunto de parâmetros 53A6 [69], que é recomendado para a simulação de biomoléculas em água explícita.

No campo de forças GROMOS 53A6 o potencial $V_{\text {Inter }}^{(\mathcal{D}, \mathcal{G})}\left(\mathbf{R}^{(\mathcal{D})}, \mathbf{R}^{(\mathcal{G})}\right)$ da equação 2.57 é escrito como [67]:

$$
V_{\text {Inter }}^{(\mathcal{D}, \mathcal{G})}\left(\mathbf{R}^{(\mathcal{D})}, \mathbf{R}^{(\mathcal{G})}\right)=\sum_{A \in \mathcal{D}} \sum_{B \in \mathcal{G}}\left[V_{A B}^{L J}\left(R_{A B}\right)+V_{A B}^{I E}\left(R_{A B}\right)\right]
$$

onde $A$ é um núcleo da molécula $\mathcal{D}, B$ é um núcleo da molécula $\mathcal{G}, R_{A B}$ é a distância entre os núcleos $A$ e $B, V_{A B}^{L J}\left(R_{A B}\right)$ é o potencial de Lennard-Jones (também chamado de potencial de van der Waals), e $V_{A B}^{I E}\left(R_{A B}\right)$ é um potencial de interações eletrostáticas. Esses potenciais são dados por [67]:

$$
\begin{aligned}
& V_{A B}^{L J}\left(R_{A B}\right)=4 \varepsilon_{A B}\left[\left(\frac{\sigma_{A B}}{R_{A B}}\right)^{12}-\left(\frac{\sigma_{A B}}{R_{A B}}\right)^{6}\right] \\
& V_{A B}^{I E}\left(R_{A B}\right)=\frac{q_{A} q_{B}}{4 \pi \epsilon}\left[\frac{1}{R_{A B}}-\frac{\left(R_{A B}\right)^{2} \mathcal{C}^{R F}}{2\left(\mathcal{R}^{R F}\right)^{3}}-\frac{\left(2-\mathcal{C}^{R F}\right)}{2 \mathcal{R}^{R F}}\right]
\end{aligned}
$$

onde $\varepsilon_{A B}=\sqrt{\varepsilon_{A}^{\prime} \varepsilon_{B}^{\prime}}$ e $\sigma_{A B}=\sqrt{\sigma_{A}^{\prime} \sigma_{B}^{\prime}}, q_{A}$ é a carga do átomo $A, \epsilon$ é a permissividade do meio, $\mathcal{R}^{R F}$ é chamado de raio de corte do campo de reação (RF, do Inglês "ReactionField"), e $\mathcal{C}^{R F}$ é uma contante do campo de reação. Podemos ver que todos $\varepsilon^{\prime}, \sigma^{\prime}$, e $q$ juntamente com $\mathcal{R}^{R F}$ e $\mathcal{C}^{R F}$ são parâmetros do campo de força. A expressão para $\mathcal{C}^{R F}$ e maiores informações sobre o potencial $V_{A B}^{I E}\left(R_{A B}\right)$ podem ser consultadas no manual do GROMOS [67].

O potencial $V_{\text {Intra }}^{(\mathcal{D})}\left(\mathbf{R}^{(\mathcal{D})}\right)$ da equação 2.57 no campo de forças GROMOS 53A6 é 
dado por [67]:

$$
\begin{aligned}
& V_{\text {Intra }}^{(\mathcal{D})}\left(\mathbf{R}^{(\mathcal{D})}\right)=\sum_{\substack{\operatorname{Ligações}_{(\mathcal{D})}(C, E) \\
C E}} V_{C E}^{l i g}\left(R_{C E}\right)+\sum_{\substack{\text { Ângulos }(\mathcal{D}) \\
(C, E, F)}} V_{C E F}^{a n g}\left(\theta_{C E F}\right) \\
& +\sum_{\substack{\text { Angulos de Torção( })(D) \\
(C, E, F, H)}} V_{C E F H}^{\text {tor }}\left(\varphi_{C E F H}\right) \\
& +\sum_{\text {Ângulos de Diedro Impróprio }}^{(\mathcal{D})} V_{C E F H}^{i m p}\left(\xi_{C E F H}\right) \\
& (C, E, F, H) \\
& +\sum_{\substack{\text { Átomos que são mais que terceiros vizinhos } \\
(A, B)}}\left[V_{A B}^{L J}\left(R_{A B}\right)+V_{A B}^{I E}\left(R_{A B}\right)\right]
\end{aligned}
$$

onde o último somatório é feito sobre todos os pares de átomos que não sejam nem primeiros, nem segundos e nem terceiros vizinhos (alguns desses pares podem ser incluídos "na mão" no somatório). Os demais somatórios são feitos sobre todas ligações, todos ângulos, todos ângulos de torção (diedro próprio) e todos ângulos de diedro improprio, onde todos esses são formados por átomos ligados pertencentes a molécula D. $V_{C E}^{l i g}\left(R_{C E}\right)$ é o potencial que descreve a ligação $R_{C E}$ formada pelos átomos $C$ e $E$, $V_{C E F}^{a n g}\left(\theta_{C E F}\right)$ é o potencial que descreve o ângulo $\theta_{C E F}$ formado pelos átomos $C, E$ e $F$, $V_{C E F H}^{t o r}\left(\varphi_{C E F H}\right)$ é o potencial que descreve o ângulo de torção $\varphi_{C E F H}$ formado pelos átomos $C, E, F$ e $H$, e $\left.V_{C E F H}^{i m p}\left(\xi_{C E F H}\right)\right)$ é o potencial que descreve o ângulo de torção $\xi_{C E F H}$ formado pelos átomos $C, E, F$ e $H$. E esses potenciais são dados por [67]:

$$
\begin{aligned}
V_{C E}^{l i g}\left(R_{C E}\right) & =\frac{1}{4} k_{C E}^{l i g}\left[\left(R_{C E}\right)^{2}-\left(R_{C E}^{e q}\right)^{2}\right]^{2} \\
V_{C E F}^{a n g}\left(\theta_{C E F}\right) & =\frac{1}{2} k_{C E F}^{a n g}\left[\cos \left(\theta_{C E F}\right)-\cos \left(\theta_{C E F}^{e q}\right)\right]^{2} \\
V_{C E F H}^{t o r}\left(\varphi_{C E F H}\right) & =k_{C E F H}^{t o r}\left[1+\cos \left(\varphi_{C E F H}^{e q}\right) \cos \left(m_{C E F H} \varphi_{C E F H}\right)\right] \\
V_{C E F H}^{i m p}\left(\xi_{C E F H}\right) & \left.=\frac{1}{2} k_{C E F H}^{i m p}\left(\xi_{C E F H}-\xi_{C E F H}^{e q}\right)\right)^{2}
\end{aligned}
$$

onde $-\pi<\xi_{C E F H}-\xi_{C E F H}^{e q} \leq \pi$, e também $\varphi_{C E F H}^{e q}=0$ ou $\pi$, e todos os valores com $e q$ correspondem a valores de equilíbrio. Podemos ver que todos $k_{C E}^{l i g}, R_{C E}^{e q}, k_{C E F}^{a n g}, \theta_{C E F}^{e q}$, $k_{C E F H}^{\text {tor }}, \varphi_{C E F H}^{e q}, m_{C E F H}, k_{C E F H}^{i m p}$ e $\xi_{C E F H}^{e q}$ são parâmetros do campo de força. 


\subsection{Inclusão de Efeitos Térmicos através de Dinâmi- cas Moleculares}

\subsubsection{Optimização de Geometria}

Antes de falar sobre a inclusão de efeitos térmicos através de dinâmicas moleculares, vamos falar brevemente sobre optimização de geometria, que corresponderia ao caso em que nenhum efeito térmico é adicionado.

Como mostramos na equação 2.23 a energia eletrônica para uma configuração fixa dos núcleos juntamente com o potencial de repulsão nuclear geram o potencial para a movimentação dos núcleos, denotado como $\mathscr{E}_{n}^{\text {tot }}(\mathbf{R})$. $\mathscr{E}_{n} t o t(\mathbf{R})$ é uma função das coordenadas nucleares, e por isso fornece uma Superfície de Energia Potencial (PES, do Inglês "Potential Energy Surface") para a movimentação dos núcleos. A proposta de uma optimização de geometria é obter um conjunto de coordenadas nucleares $\mathbf{R}$ - ou seja, uma estrutura molecular - que forneçam a menor energia $\mathscr{E}_{n}^{t o t}(\mathbf{R})$ possível. A medida que se vai abaixando a temperatura de uma molécula ela vai deixando cada vez mais de vibrar e com isso a energia da molécula, em média, também abaixa. Quando a molécula chega a uma temperatura igual a zero Kelvin ${ }^{12}$ ela atinge a menor energia possível correspondente ao fundo de um poço na PES. Quando isso ocorre, apesar de a molécula ter uma energia de vibração de ponto zero que tem origem apenas em Mecânica Quântica, ela praticamente fica na mesma geometria. Por isso que podemos interpretar a geometria optimizada da molécula como a correspondente com uma temperatura de zero Kelvin.

Os procedimentos para optimização de geometria geralmente envolvem o cálculo das forças atômicas, correspondentes as primeiras derivadas de $\mathscr{E}_{n}$ tot $(\mathbf{R})$ com relação as coordenadas nucleares, e também o cálculo da Hessiana, correspondente as segundas

\footnotetext{
${ }^{12}$ Essa temperatura, zero Kelvin, também é chamada de zero absoluto e seria a menor temperatura possível. Essa temperatura é aproximadamente $-273,15^{\circ} \mathrm{C}$.
} 
derivadas de $\mathscr{E}_{n}^{\text {tot }}(\mathbf{R})$ com relação as coordenas nucleares. Considerando que o sistema tenha $M$ núcleos, as forças atômicas e a Hessiana são dadas por:

$$
\begin{aligned}
F_{i} & =\frac{\partial \mathscr{E}_{n}^{t o t}}{\partial X_{i}}(\mathbf{X}) \\
H_{i j} & =\frac{\partial^{2} \mathscr{E}_{n}^{t o t}}{\partial X_{i} \partial X_{j}}(\mathbf{X})
\end{aligned}
$$

onde $X_{3 A-2}=R_{A}^{(x)}$ é a coordenada $x$ do núcleo $A, X_{3 A-1}=R_{A}^{(y)}$ é a coordenada $y$, $X_{3 A}=R_{A}^{(z)}$ é a coordenada $z$, e $A=1, \ldots, M$.

Pode-se mostrar que um novo conjunto de coordenadas $\mathbf{X}^{\text {novo }}$ cuja energia está mais próxima de um mínimo na PES é dado por [61]:

$$
\mathbf{X}^{\text {novo }}=\mathbf{X}-\mathbf{H}^{-1}(\mathbf{X}) \mathbf{F}(\mathbf{X})
$$

onde $\mathbf{F}(\mathbf{X})$ e $\mathbf{H}(\mathbf{X})$ são matrizes com as componentes mostradas nas equações 2.66 e 2.67 .

Um outro novo conjunto de coordenadas pode ser obtido de $\mathbf{X}^{\text {novo }}$ através da equação 2.68, e esse processo é repetido até que a energia $\mathscr{E}_{n}^{\text {tot }}$ convirja. Como mostramos esse procedimento é válido para qualquer estado excitado, mas geralmente os cálculos de optimização de geometria são feitos no estado fundamental. Para maiores informações sobre o funcionamento de optimizações de geometria recomendamos a leitura do apêndice C da referência [61] chamado "Analytic Derivative Methods and Geometry Optimization".

\subsubsection{Simulações Moleculares: Dinâmicas Moleculares}

Como mencionamos no final da seção 1.1 do capítulo 1 (e como veremos no capítulo 3 de resultados), a inclusão de efeitos térmicos pode ser importante para uma descrição mais correta de propriedades moleculares (como o espectro de absorção), já que os resultados experimentais são obtidos em laboratório, portanto em uma temperatura finita. Uma forma confiável, eficiente e sistemática de gerar configurações 
moleculares acessíveis a uma dada condição termodinâmica é através das simulações computacionais [63,70-72]. Essas simulações utilizam modelos para descrever as interações moleculares e são baseadas em resolver equações de movimento ou em amostrar distribuições probabilísticas para gerar configurações moleculares acessíveis. A sua implementação computacional leva a Dinâmica Molecular e a simulação de Monte Carlo com amostragem de Metropolis, respectivamente. Em princípio, utilizando o mesmo modelo para as interações moleculares, esses métodos são equivalentes para simulações infinitamente longas. Sendo assim, a escolha do método de simulação está fortemente ligada ao problema que se deseja estudar.

Sem sombra de dúvidas um ponto crucial das simulações é a escolha do modelo para descrever as interações moleculares. A escolha mais usada é a de campos de força (ver subseção 2.3.6). Dinâmicas Moleculares que utilizam campos de força na descrição das interações moleculares são chamadas de Dinâmicas Moleculares Clássicas. Devido as limitações naturais dos campos de força, o seu uso no estudo de algumas propriedades e sistemas é inadequado, e existe uma forte necessidade de modelos quânticos para as interações moleculares.

Sem dúvidas a escolha que descreve os sistemas moleculares mais precisamente é baseada em um Hamiltoniano quântico, onde as interações moleculares são descritas usando métodos $a b$ initio, que dispensam a necessidade de parametrizações. Dinâmicas Moleculares que usam métodos ab initio para as interações moleculares são conhecidas como Dinâmicas Moleculares ab initio. Atualmente tais dinâmicas são os métodos mais sofisticados para se gerar configurações moleculares acessíveis a uma dada condição termodinâmica, e exigem um grande custo computacional, o que torna impraticável muitos estudos teóricos.

Nesta dissertação optamos por realizar Dinâmicas Moleculares em vez de utilizar simulação de Monte Carlo. Um dos objetivos deste trabalho é testar o campo de forças GROMOS 53A6 utilizado nas dinâmicas clássicas dos monômeros de $H_{2}$-Porfirina e $H_{2^{-}}$ 
Ftalocianina em comparação com os resultados de dinâmicas ab initio. Os resultados obtidos são apresentados no capítulo 3 de resultados, nas seções 3.1.5 e 3.2.6. Um campo de forças que produza resultados em dinâmicas clássicas compatíveis com o de dinâmicas $a b$ initio é de grande interesse para estudos teóricos pois dinâmicas clássicas são extremamente mais viáveis computacionalmente do que dinâmicas ab initio.

\subsubsection{Equação de Movimento Nuclear}

Além de separarmos o movimento dos núcleos e dos elétrons com a aproximação de Born-Oppenheimer, vamos também considerar que os núcleos são partículas clássicas de tal modo que podemos portanto estabelecer as suas posições e velocidades simultaneamente.

O potencial $\mathscr{E}_{n}^{\text {tot }}(\mathbf{R})$ da equação 2.23 , que é o potencial para a movimentação dos núcleos, pode ser obtido tanto classicamente através de campos de força (ver subseção 2.3.6) ou quanticamente (como através de métodos ab initio e métodos DFT, ver seção 2.3). Porém os conceitos por trás Dinâmicas Moleculares, sejam clássicas ou ab initio, são os mesmo.

A energia $\mathscr{E}_{n}^{\text {tot }}(\mathbf{R})$ depende das coordenadas de todos os átomos do sistema ${ }^{13}$. Assim então para calcularmos a força resultante sobre um átomo $i$ basta calcularmos o gradiente de $\mathscr{E}_{n}^{\text {tot }}(\mathbf{R})$ em relação às coordenadas do núcleo do átomo $i$ da seguinte forma:

$$
\mathbf{F}_{i}^{(n)}=-\nabla_{i} \mathscr{E}_{n}{ }_{n}
$$

Apesar da equação 2.69 ser válida para qualquer estado excitado, as dinâmicas moleculares são comumente realizadas no estado fundamental. Por isso vamos escrever:

$$
\mathbf{F}_{i} \equiv \mathbf{F}_{i}^{(0)}=-\nabla_{i} \mathscr{E}_{0}^{t o t}
$$

\footnotetext{
${ }^{13}$ Quando nos referimos as coordenas de um átomo, estamos nos referindo as coordenadas de seu núcleo.
} 
A aceleração instantânea sobre o átomo $i$ pode ser calculada da seguinte maneira:

$$
\mathbf{a}_{i}=\mathbf{F}_{i} / m_{i}
$$

onde $m_{i}$ é a massa do átomo $i$. A equação 2.71 é chamada de Equação de Movimento Nuclear (já que estamos na prática é tratando as coordenas nucleares). A partir da posição e da velocidade instantâneas deste átomo podemos determinar a sua posição e a sua velocidade em um instante posterior. O problema que surge nisso é que a aceleração que obtemos pela equação 2.71 não é constante, pois uma variação na posição de qualquer átomo muda a energia potencial do sistema.

Para resolver este problema imaginamos que em um intervalo de tempo $\Delta t$ muito pequeno $^{14}$ as posições variaram tão pouco a ponto de as forças atômicas terem se mantido aproximadamente constantes. Fazendo essa suposição partindo das posições, velocidades e forças do instante inicial podemos determinar as posições e as velocidades em logo após $\Delta t$. Esse procedimento é chamado de integração das equações de movimento. Com o novo conjunto de posições e velocidades, após o cálculo das forças novamente para o novo conjunto de posições, um outro novo conjunto de posições e velocidades é obtido correspondente ao final de mais um intervalo de tempo $\Delta t$. Esse processo pode ser repetido quantas vezes quisermos, e é assim que as dinâmicas moleculares são realizadas.

\subsubsection{Algoritmo de integração: algoritmo Leap-Frog}

Como exemplo de um algoritmo para a integração da equação de movimento dos núcleos atômicos (equação 2.71), vamos mostrar o algoritmo Leap-Frog (onde LeapFrog significa "Pulo de Sapo") que é o algoritmo padrão do programa GROMACS [73-75] e é também o algoritmo usado nas dinâmicas clássicas desta dissertação.

\footnotetext{
${ }^{14}$ Os valores típicos para $\Delta t$, que é chamado de timestep ou intervalo de integração, são da ordem de femtosegundos ( 1 femtosegundo $=10^{-15}$ segundos) em simulações moleculares.
} 
Seja $\mathbf{r}_{i}(t)$ a posição de um átomo $i$ em um instante $t$. A velocidade e a aceleração instantâneas desse átomo são $\mathbf{v}_{i}(t)=\frac{d \mathbf{r}_{i}(t)}{d t}$ e $\mathbf{a}_{i}(t)=\frac{d^{2} \mathbf{r}_{i}(t)}{d^{2} t}$. De acordo com o algoritmo Leap-Frog temos [74]:

$$
\begin{aligned}
\mathbf{v}_{i}\left(t+\frac{1}{2} \Delta t\right) & =\mathbf{v}_{i}\left(t-\frac{1}{2} \Delta t\right)+\Delta t \mathbf{a}_{i}(t) \\
\mathbf{r}_{i}(t+\Delta t) & =\mathbf{r}_{i}(t)+\Delta t \mathbf{v}_{i}\left(t+\frac{1}{2} \Delta t\right)
\end{aligned}
$$

onde a aceleração $\mathbf{a}_{i}(t)$ é calculada com a equação 2.71. O algoritmo Leap-Frog também pode ser escrito em uma versão em que as velocidades são determinadas nos mesmos instantes que as posições:

$$
\begin{aligned}
\mathbf{r}_{i}(t+\Delta t) & =\mathbf{r}_{i}(t)+\Delta t \mathbf{v}_{i}(t)+\frac{1}{2} \Delta t^{2} \mathbf{a}_{i}(t) \\
\mathbf{v}_{i}(t+\Delta t) & =\mathbf{v}_{i}(t)+\frac{1}{2} \Delta t\left(\mathbf{a}_{i}(t)+\mathbf{a}_{i}(t+\Delta t)\right)
\end{aligned}
$$

\subsubsection{Termalização: termostato Velocity-Rescale}

Supondo que estejamos simulando um sistema que está isolado no espaço, a integração da equação de movimento 2.71 ocorre de forma adiabática, já que não há troca de calos com o meio externo, e por isso a energia do sistema deve se conservar. Porém os resultados experimentais são obtidos em uma determinada temperatura, por isso é importante podermos fazer simulações com o sistema em equilíbrio térmico nessa temperatura. Existem vários algoritmos que possibilitam que isso seja feito, que por fazerem um controle da temperatura recebem o nome de termostato. Vamos nesta subseção exemplificar o termostato Velocity-Rescale (ou somente V-Rescale), que é o termostato usado nas dinâmicas clássicas desta dissertação.

Supondo que o sistema tenha $M$ átomos, podemos usar o teorema da equipartição para determinar a temperatura do sistema através do valor médio da energia cinética 
dos átomos do sistema:

$$
\begin{array}{r}
\left\langle\frac{1}{2} m|\mathbf{v}|^{2}\right\rangle=\frac{3}{2} K_{b} T \\
T=\frac{1}{3 K_{b}}\left\langle m|\mathbf{v}|^{2}\right\rangle=\frac{1}{3 K_{b}} \frac{1}{M} \sum_{i=1}^{M} m_{i}\left|\mathbf{v}_{i}\right|^{2}
\end{array}
$$

onde $K_{b}$ é a constante de Boltzmann.

Podemos levar o sistema para uma temperatura $T^{\prime}$ multiplicando o módulo de todas as velocidades por um fator $\alpha=\sqrt{\frac{T^{\prime}}{T}}$ de tal modo que as novas velocidades sejam $\mathbf{v}_{i}^{\prime}=\alpha \mathbf{v}_{i}$, pois utilizando a equação 2.76 temos:

$$
\frac{1}{3 K_{b}} \frac{1}{M} \sum_{i=1}^{M} m_{i}\left|\mathbf{v}_{i}^{\prime}\right|^{2}=\alpha^{2} \frac{1}{3 K_{b}} \frac{1}{M} \sum_{i=1}^{M} m_{i}\left|\mathbf{v}_{i}\right|^{2}=\frac{T^{\prime}}{T} T=T^{\prime}
$$

Em vez de levar o sistema diretamente à temperatura $T_{\text {alvo }}$ desejada ao final de cada passo, podemos ir trazendo o sistema até a temperatura alvo aos poucos utilizando o termostato Velocity-Rescale [76]. Pelo termostato Velocity-Rescale levamos o sistema em cada passo a uma temperatura mais próxima da temperatura alvo da seguinte maneira $[74,76]$ :

$$
\begin{aligned}
\alpha^{2}=\frac{T^{\prime}}{T}= & e^{-\Delta t / \tau}+\frac{T_{\text {alvo }}}{T}\left(1-e^{-\Delta t / \tau}\right) \frac{\left(\mathscr{R}_{1}^{2}+\mathscr{R}_{2}^{2}+\mathscr{R}_{3}^{2}\right)}{3} \\
& +2 e^{-\Delta t / 2 \tau} \sqrt{\frac{T_{\text {alvo }}}{T}\left(1-e^{-\Delta t / \tau}\right) \frac{\mathscr{R}_{1}}{3}}
\end{aligned}
$$

onde $\tau$ é chamado de tempo de amortecimento e é um parâmetro a ser escolhido, e $\mathscr{R}_{1}$, $\mathscr{R}_{2}$ e $\mathscr{R}_{3}$ são números aleatórios independentes obtidos de uma distribuição Gaussiana com variância unitária. Maiores informações sobre o termostato Velocity-Rescale e uma dedução para a equação 2.78 podem ser encontradas na referência [76].

Como estamos trazendo o sistema "à força" para a temperatura alvo, os resultados da simulação utilizando um termostato têm como objetivo gerar configurações correspondentes a um sistema em equilíbrio térmico na temperatura alvo. Com o uso do termostato Velocity-Rescale pretendemos levar o sistema a uma situação em que 
esteja próximo do equilíbrio, ou seja, em que a temperatura oscile em torno da temperatura alvo. Após o inicio da simulação é preciso que se passe um determinado número de passos até que se observe a flutuação da temperatura em torno da temperatura alvo, e esse período é chamado de período de termalização. A amplitude da flutuação de temperatura está intimamente relacionada com o tempo de amortecimento $\tau$, de modo que quanto maior é $\tau$ maior é a flutuação ${ }^{15}$.

\subsubsection{Mudanças nas Dinâmicas ab initio com o uso de GPUs}

Recentemente novas placas de vídeo com Unidades de Processamento Gráfico (GPUs, do Inglês "Graphics Processing Units") com grande poder de processamento foram desenvolvidas. Tais placas têm performance de cálculo muitas vezes maior do que CPUs convencionais (comparações de resultado entre cálculos com GPUs e CPUs podem ser encontrados na internet, como em [77]). Deste modo, por exemplo, simulações que demorariam da ordem de meses passam a poder ser feitas em semanas. Essa nova tecnologia é extremamente importante para aplicações científicas, e abre muitas possibilidades para estudos teóricos que até então seriam inviáveis.

Vários programas que realizam cálculos quânticos estão sendo ou já foram adaptados para trabalhar com GPUs, e outros novos programas foram desenvolvidos para trabalhar exclusivamente com GPUs [77]. Dentre esses novos programas está o TeraChem [78], que faz dinâmicas moleculares ab initio completamente baseadas em GPUs e com alta performance de cálculo. Este foi o programa utilizado nesta dissertação para realizar dinâmicas moleculares ab initio. Testes de performance e de precisão dos resultados em comparação com outros programas são mostrados no site do programa [78]. Os testes mostram que o programa é cada vez mais eficiente à medida que se aumenta o tamanho do sistema ou o nível de cálculo.

\footnotetext{
${ }^{15}$ Pela equação 2.78 vemos que no limite em que $\tau \rightarrow \infty$ temos que $\alpha \rightarrow 1$, o que indica que $T^{\prime}=T$ e portanto que as velocidades não são reescaladas.
} 


\section{Capítulo 3}

\section{Resultados e Discussões}

Neste capítulo serão apresentados os resultados mais relevantes obtidos para esta dissertação. Serão apresentados resultados para Porfirinas e Ftalocianinas isoladas. Dentro dos resultados serão apresentadas comparações de resultados utilizando diferentes métodos de química teórica. Além de resultados para estruturas optimizadas, também serão apresentados resultados obtidos a partir de dinâmicas moleculares clássicas e $a b$ initio juntamente com discussões dos resultados. Resultados adicionais e/ou complementares aos apresentados nesse capítulo serão apresentados nos apêndices.

Estudos das primeiras bandas do espectro de absorção de moléculas isoladas foram feitos como preparação para este trabalho. Essas moléculas são: Água, Amônia, Fenol, Uracil, 5-Fluorouracil e Acroleína. O intuito desses estudos é fornecer uma primeira visão a cerca das diferenças nos métodos teóricos para o cálculo do espectro de absorção e de optimização de geometria, e também das dificuldades teóricas encontradas neste tipo de estudo. Quando disponíveis, uma simples comparação com resultados experimentais em fase gasosa é feita. Este estudo é apresentado no apêndice A. 


\subsection{Estudos de Porfirinas isoladas}

Nesta seção apresentaremos resultados para Porfirinas isoladas. Estudos foram feitos para a Porfirina Base Livre (Free Base Porphyrin - $\mathrm{H}_{2}$-Porfirina), a Porfirina complexada com Magnésio (Magnesium Porphyrin - Mg-Porfirina), e a Porfirina complexada com Zinco (Zinc Porphyrin - Zn-Porfirina) cujas estruturas estão ilustradas na figura 3.1 abaixo. Podemos ver que a $H_{2}$-Porfirina tem simetria $D_{2 h}$ e que a Mg-Porfirina e a Zn-Porfirina tem simetria $D_{4 h}{ }^{1}$. Nesta seção estaremos focados na análise e discussão apenas dos resultados para a $\mathrm{H}_{2}$-Porfirina. Os resultados para $\mathrm{Mg}$-Porfirina e para a Zn-Porfirina são apresentados no apêndice B e serão apenas mencionados no decorrer do texto desta seção.

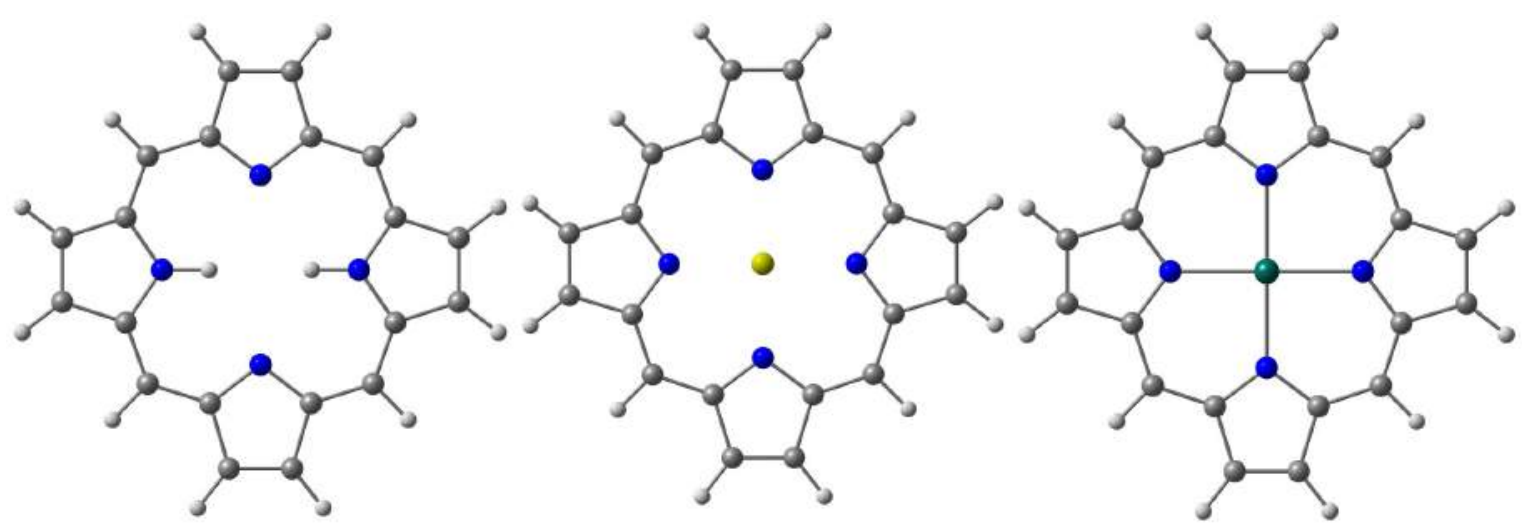

Figura 3.1: Porfirina Base Livre ( $H_{2}$-Porfirina) com simetria $D_{2 h}$ a esquerda, Porfirina complexada com Magnésio (Mg-Porfirina) com simetria $D_{4 h}$ ao centro, e Porfirina complexada com Zinco (Zn-Porfirina) com simetria $D_{4 h}$ a direita.

Com base no estudo realizado para moléculas modelo apresentado no apêndice A onde é mostrado que as estruturas obtidas com B3LYP foram capazes de reproduzir as estruturas obtidas com MP2 (que é um método pós Hartree-Fock) das moléculas estudas (e por isso não fornecerem diferenças significativas no espectro de absorção), e devido ao fato de B3LYP ser popularmente usado na literatura para cálculos de geometrias optimizadas $[79,80]$, as estruturas dos monômeros de Porfirina ( $H_{2}$-Porfirina,

\footnotetext{
${ }^{1}$ Para maiores informações sobre simetrias moleculares recomendamos a excelente referência [60].
} 
Mg-Porfirina e Zn-Porfirina) foram obtidas através de optimização de geometria (ver subseção 2.4.1) no nível B3LYP/6-31+G(d,p) ${ }^{2}$ com o programa Gaussian 09 [81].

\subsubsection{Comparação entre as estruturas optimizada e cristalina}

A estrutura cristalina da $\mathrm{H}_{2}$-Porfirina foi resolvida experimentalmente através da difração de raios-X por Chen e Tulinsky em um trabalho de 1972 [35]. Neste trabalho são reportados os valores para todas distâncias e todos ângulos de átomos ligados. Na figura 3.2 apresentamos os rótulos que escolhemos para os átomos da $H_{2}$-Porfirina, e na tabela 3.1 apresentamos uma comparação entre os valores de algumas ligações e ângulos na estrutura optimizada e na estrutura cristalina obtida experimentalmente. Essa escolha de rótulos será mencionada posteriormente quando tratarmos de resultados para dinâmicas moleculares na subseção 3.1.5. Os valores apresentados na tabela 3.1 para a estrutura cristalina (Experimental) correspondem aos valores médios com seus respectivos desvios padrão para todas ligações ou ângulos equivalentes da molécula na geometria optimizada.

Tabela 3.1: Comparação de valores de ligações e ângulos para a estrutura optimizada no nível B3LYP $/ 6-31+\mathrm{G}(\mathrm{d}, \mathrm{p})$ e a estrutura cristalina [35] da $H_{2}$-Porfirina. Os valores reportados para a estrutura cristalina (Experimental) correspondem aos valores médios com seus respectivos desvios padrão para todas ligações ou ângulos equivalentes na molécula. Os valores para as ligações são dados em Angstroms e para os ângulos em Graus.

\begin{tabular}{|c|c:c|c|c:c|}
\hline Ligação & Optimizada & Experimental & Ângulo & Optimizada & Experimental \\
\hline C1A-NA & 1,365 & $1,377 \pm 0,012$ & C1B-NB-C4B & 110,8 & $108,6 \pm 1,1$ \\
C1A-C2A & 1,462 & $1,452 \pm 0,011$ & NB-C1B-C2B & 106,6 & $107,9 \pm 0,8$ \\
C1A-C5D & 1,400 & $1,376 \pm 0,004$ & C1B-C2B-C3B & 108,0 & $107,8 \pm 0,3$ \\
C2A-C3A & 1,358 & $1,345 \pm 0,001$ & C1B-C5A-C4A & 127,2 & $127,1 \pm 0,6$ \\
C2A-H1A & 1,082 & $1,060 \pm 0,045$ & C5A-C1B-C2B & 127,9 & $126,9 \pm 0,6$ \\
C5A-H3A & 1,086 & $1,083 \pm 0,100$ & C1B-NB-HC1 & 124,6 & $125,5 \pm 4,8$ \\
C1B-NB & 1,374 & $1,380 \pm 0,003$ & C1A-NA-C4A & 105,6 & $106,1 \pm 0,3$ \\
NB-HC1 & 1,014 & $0,860 \pm 0,000$ & C1A-C2A-C3A & 106,2 & $107,2 \pm 0,9$ \\
\hline
\end{tabular}

\footnotetext{
${ }^{2}$ As coordenadas do monômero optimizado de $H_{2}$-Porfirina estão na tabela B.8 do apêndice B.
} 


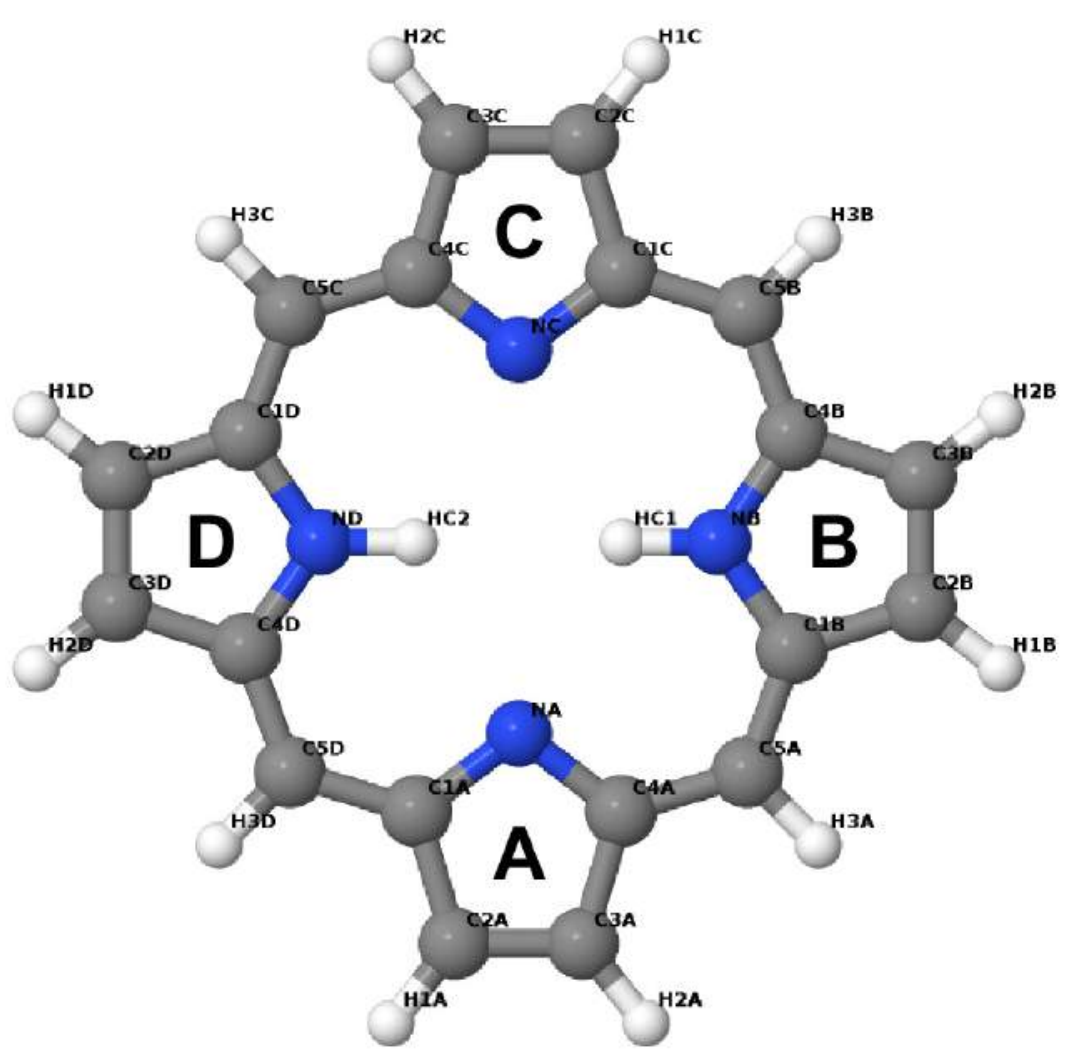

Figura 3.2: Escolha de rótulos para cada átomo da $H_{2}$-Porfirina.

Pela tabela 3.1 vemos que os valores obtidos através da optimização de geometria feita no nível B3LYP $/ 6-31+\mathrm{G}(\mathrm{d}, \mathrm{p})$ está de acordo com a estrutura cristalina experimental. Podemos ver que as diferenças obtidas são pequenas. Com relação a essas diferenças podemos dizer que a estrutura optimizada foi obtida para a molécula isolada enquanto a estrutura cristalina foi determinada em estado sólido (sofrendo portanto interações devido ao meio), portanto é esperado que existam diferenças entre essas duas estruturas. Os resultados da tabela 3.1 são um indicativo de que o método de cálculo utilizado está fornecendo uma boa geometria para a $\mathrm{H}_{2}$-Porfirina isolada. 


\subsubsection{Discussão acerca do modelo de Gouterman}

Em um excepcional e pioneiro trabalho sobre o espectro de absorção de Porfirinas publicado em 1961 [9], Gouterman expõem que as características essenciais do espectro das Porfirinas podem ser consideravelmente compreendidas em termos de um modelo de quatro orbitais [38-40], que nesta dissertação daremos o nome de modelo de Gouterman. De acordo com esse modelo, as características do espectro de absorção estão relacionadas essencialmente com as propriedades dos dois orbitais mais altos ocupados (HOMO e HOMO-1) e dos dois orbitais mais baixos desocupados (LUMO e $L U M O+1)$. Desse modo, as transições características do espectro se enquadrariam entre transições envolvendo promoções dos orbitais $H O M O$ e $H O M O-1$ para os orbitais $L U M O$ e $L U M O+1$. Vamos agora, a partir dos nossos resultados, verificar essa hipótese.

Na figura 3.3 mostramos esses quatro orbitais de interesse no modelo de Gouterman e alguns outros, para a $H_{2}$-Porfirina ${ }^{3}$. Esses orbitais foram obtidos a partir de cálculo no nível B3LYP/6-311++G(d,p) utilizando o programa Gaussian 09 [81]. Uma questão que pode surgir aqui é a de que os orbitais obtidos através do cálculo DFT(B3LYP) são na verdade orbitais de Kohn-Sham (ver subseção 2.3.5.1) e que por isso podem não representar os orbitais moleculares "propriamente ditos" do sistema. Porém, no cálculo B3LYP feito pelo programa Gaussian 09, escolha inicial para os orbitais de Kohn-Sham são os orbitais Hartree-Fock, então por isso esperamos que os orbitais convergidos de Kohn-Sham obtidos nesse cálculo tenham a forma muito semelhante à dos orbitais Hartree-Fock ${ }^{4}$.

\footnotetext{
${ }^{3}$ Esses orbitais moleculares também são apresentados para Zn-Porfirina e a Mg-Porfirina no apêndice B. Ver figuras B.1 e B.2.

${ }^{4}$ Essa afirmação foi checada para os orbitais do modelo de Gouterman para $\mathrm{H}_{2}$-Porfirina. Os orbitais Hartree-Fock são mostrados na figura B.3 do apêndice B. De fato vemos que a forma dos orbitais é idêntica a dos orbitais da figura 3.3. Ocorre apenas uma troca de posições entre os orbitais $H O M O$ e $H O M O-1$, devido a diferenças nas energias calculadas para cada um desses orbitais nos métodos HF e DFT(B3LYP).
} 
Vale aqui frisar que os orbitais moleculares são numerados de acordo com a energia calculada para cada orbital. O valor calculado para energia de um orbital pode variar para diferentes métodos, portanto é possível, por exemplo, que um orbital que receba uma determinada numeração (como $H O M O)$ por um dado método seja identificado com uma outra numeração (como HOMO-1) por outro método.

Pela figura 3.3 vemos que os orbitais $H O M O, H O M O-1$, $L U M O$ e $L U M O+1$ estão de acordo com os orbitais para o monômero de $H_{2}$-Porfirina apresentados por Gouterman [9], a partir de um cálculo apresentado em um trabalho de Longuet-Higgins et al. publicado no ano de 1950 [82]. Essa citação é muito interessante pois nos dá uma ideia de há quanto tempo sistemas como Porfirinas já vem sendo alvos de estudos teóricos. É interessante também que nossos resultados para os orbitais moleculares corroboram com as previsões feitas nesses trabalhos, onde as transições eletrônicas entre os orbitais de Gouterman são presumidas serem do tipo $\pi \rightarrow \pi^{*}$. Podemos ver que os orbitais $H O M O, H O M O-1, L U M O$ e $L U M O+1$ são de fato todos do tipo $\pi$ ou $\pi^{* 5}$.

A partir das estruturas optimizadas, calculamos o espectro de absorção teórico para os 12, 16 ou 32 primeiros estados excitados utilizando vários métodos com o conjunto de funções-base 6-311++G(d,p), utilizando o programa Gaussian 09 [81]. O espectro também foi cálculo para os 49 primeiros estados excitados utilizando o método ZINDO/CIS como implementado no programa ZINDO [64] onde o conjunto de funções-base já é predeterminado (ver subseção 2.3.4). Neste cálculo consideramos apenas transições dos 25 orbitais mais altos ocupados para os 25 orbitais mais baixos desocupados. Nos cálculos consideramos a carga da molécula é nula e a multiplicidade é 1 (singleto).

Na tabela 3.2 apresentamos os resultados obtidos para os dois primeiros estados excitados, correspondentes a região visível do espectro (ou das bandas $Q$ ), e na tabela

\footnotetext{
${ }^{5}$ Maiores informações sobre tipos de orbitais moleculares podem ser consultadas na subseção 2.2.3.
} 
3.3 mostramos os resultados de algumas excitações não nulas na região ultravioleta, para a $H_{2}$-Porfirina ${ }^{6}$. O cálculo CIS(D) é integralmente apresentado na tabela 3.4

6. Dentre outras informações, as tabelas mostram as transições envolvidas e a sua contribuição para cada uma das excitações.

${ }^{6}$ Resultados equivalentes são apresentados para a Mg-Porfirina e a Zn-Porfirina no apêndice B. Ver tabelas de B.1 a B.6. 

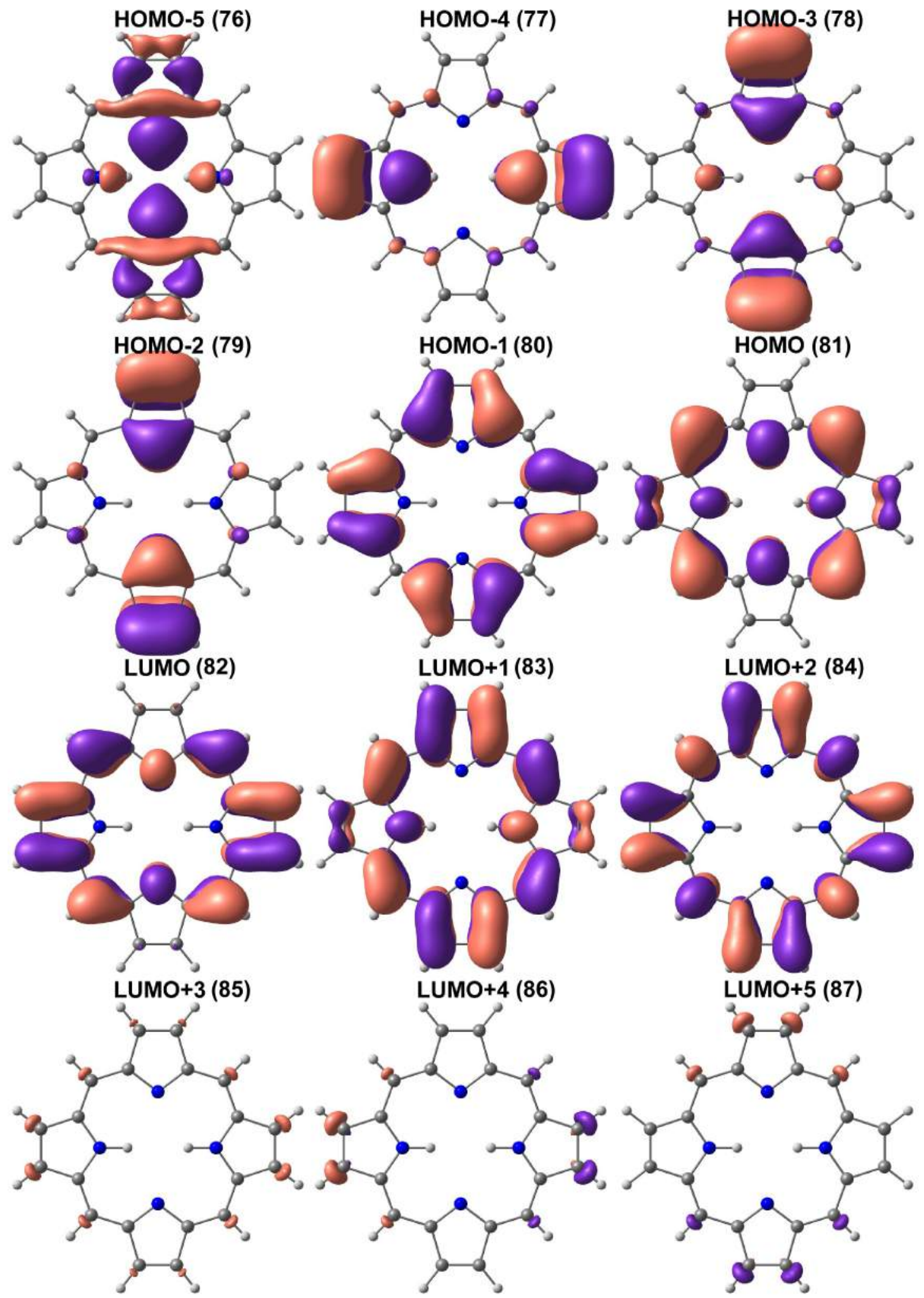

Figura 3.3: Alguns orbitais moleculares da $H_{2}$-Porfirina. Esses orbitais foram obtidos a partir do cálculo B3LYP/6-311++G(d,p). 
Tabela 3.2: Dois primeiros estados excitados da molécula $H_{2}$-Porfirina isolada calculados utilizando vários métodos com a base $6-311++\mathrm{G}(\mathrm{d}, \mathrm{p})$ (exceto ZINDO/CIS). $\Delta E$ é a energia de excitação dada em eV, $\lambda$ é o comprimento de onda correspondente dado em nm, e $f$ é a força de oscilador. As transições envolvidas são mostradas, e a contribuição delas para cada excitação é mostrada em parênteses. O orbital HOMO é numerado como 81.

\begin{tabular}{|c|cccc|}
\hline Método & $\Delta E$ & $\lambda$ & $f$ & Transições envolvidas \\
\hline TD-DFT & 2,2580 & 549,1 & 0 & $80 \rightarrow 82(42 \%), 81 \rightarrow 83(57 \%)$ \\
(B3LYP) & 2,4073 & 515,0 & 0,0001 & $80 \rightarrow 83(46 \%), 81 \rightarrow 82(53 \%)$ \\
\hline TD-DFT & 2,1610 & 573,7 & 0,0018 & $80 \rightarrow 82(47 \%), 81 \rightarrow 83(53 \%)$ \\
(CAM-B3LYP) & 2,3728 & 522,5 & 0,0016 & $80 \rightarrow 83(50 \%), 81 \rightarrow 82(49 \%)$ \\
\hline TD-DFT & 2,2334 & 555,1 & 0,0001 & $80 \rightarrow 82(40 \%), 81 \rightarrow 83(59 \%)$ \\
(O3LYP) & 2,3756 & 521,9 & 0 & $80 \rightarrow 83(44 \%), 81 \rightarrow 82(55 \%)$ \\
\hline TD-DFT & 2,1674 & 572,0 & 0,0008 & $80 \rightarrow 82(38 \%), 81 \rightarrow 83(62 \%)$ \\
(BP86) & 2,2937 & 540,5 & 0,0004 & $80 \rightarrow 83(42 \%), 81 \rightarrow 82(58 \%)$ \\
\hline TD-DFT & 2,2405 & 553,4 & 0,0015 & $80 \rightarrow 82(47 \%), 81 \rightarrow 83(53 \%)$ \\
\hline (M06-2X) & 2,4686 & 502,2 & 0,0015 & $80 \rightarrow 83(50 \%), 81 \rightarrow 82(50 \%)$ \\
\hline TD-DFT & 1,8458 & 671,7 & 0,0048 & $80 \rightarrow 83(48 \%), 81 \rightarrow 82(48 \%)$ \\
\hline CINC-wPBE) & 2,1700 & 571,4 & 0,0032 & $80 \rightarrow 82(46 \%), 81 \rightarrow 83(51 \%)$ \\
\hline TD-HF & 2,3760 & 521,8 & 0,0369 & $80 \rightarrow 83(40 \%), 81 \rightarrow 82(55 \%)$ \\
\hline & 2,4854 & 498,9 & 0,0273 & $80 \rightarrow 82(40 \%), 81 \rightarrow 83(56 \%)$ \\
\hline & 2,4629 & 503,4 & 0,0369 & $80 \rightarrow 83(40 \%), 81 \rightarrow 82(55 \%)$ \\
\hline & 2,8912 & 428,8 & 0,0273 & $80 \rightarrow 82(40 \%), 81 \rightarrow 83(56 \%)$ \\
\hline CIND) & 1,6941 & 731,8 & 0,0222 & $80 \rightarrow 83(44 \%), 81 \rightarrow 82(52 \%)$ \\
\hline
\end{tabular}


Analisando a tabela 3.2 vemos que para os dois primeiros estados excitados da $H_{2}$-Porfirina, correspondentes a região das bandas $Q$, as transições envolvidas nas excitações são dominantemente transições que envolvem os quatro orbitais de interesse no modelo de Gouterman (HOMO, HOMO-1, LUMO e $L U M O+1)^{7}$. Pela tabela observamos que as forças de oscilador para esses estados é muito baixa, e em alguns casos é até nula ${ }^{7}$. Esse curioso fato levanta um questionamento: por que as forças de oscilador são tão baixas na região visível do espectro sendo que o espectro experimental [28] indica que existem absorções nessa região? Esse tema será abordado posteriormente, porém ainda assim vale aqui observar que todos os cálculos foram feitos para a mesma estrutura optimizada, que tem simetria $D_{2 h}$, e que nos cálculos Hartree-Fock e CIS(D) obtivemos forças de oscilador baixas porém algumas ordens de grandeza maior que as obtidas com os outros métodos utilizados ${ }^{7}$.

Analisando a tabela 3.3 para os estados excitados de força de oscilador não nula fora região do visível da $\mathrm{H}_{2}$-Porfirina, vemos que os orbitais de interesse no modelo de Gouterman tem uma participação importante nas transições envolvidas nas excitações, porém não são os únicos envolvidos ${ }^{8}$. Podemos ver que, em algumas excitações, alguns orbitais que não são de Gouterman tem um papel fundamental nas transições ${ }^{8}$. Dessa forma, para uma descrição mais correta dessas bandas, outros orbitais além dos de Gouterman devem ser considerados.

Analisando a tabela 3.4 para o cálculo CIS(D) para a molécula $H_{2}$-Porfirina isolada podemos ver que para os estados excitados com força de oscilador nula, conhecidos como estados escuros por serem inacessíveis a partir estado fundamental, os orbitais de interesse no modelo de Gouterman tem uma participação pequena nas transições envolvidas nessas excitações ${ }^{9}$. Além disso, transições envolvendo apenas os orbitais de

\footnotetext{
${ }^{7} \mathrm{O}$ mesmo ocorre para as moléculas Mg-Porfirina e Zn-Porfirina, como pode ser visto nas tabelas B. 1 e B.4.

${ }^{8}$ Esse mesmo comportamento acontece com as moléculas Mg-Porfirina e Zn-Porfirina, como mostrado nas tabelas B.2 e B.5.

${ }^{9} \mathrm{O}$ mesmo se observa para as moléculas Mg-Porfirina e Zn-Porfirina nas tabelas B.3 e B.6.
} 
Gouterman não existem. Essas conclusões não ficam restritas somente para o cálculo CIS(D), elas podem ser estendidas para os outros cálculos feitos.

Portanto, a partir dos nossos resultados e das análises discutidas nos parágrafos anteriores, podemos concluir que para a $\mathrm{H}_{2}$-Porfirina o modelo de quatro orbitais proposto por Gouterman se mostra completamente válido para descrever os estados excitados na região do visível, parcialmente válido para descrever estados com força de oscilador não nula na região ultravioleta, e praticamente inválido para descrever estados escuros ${ }^{10}$. Assim então, de modo geral, podemos concluir que o modelo de Gouterman, apesar de não ser completamente válido, é capaz de descrever satisfatoriamente algumas das características mais essenciais do espectro de absorção da $H_{2^{-}}$ Porfirina ${ }^{10}$. Essas conclusões com relação aos nossos resultados, entretanto, são apenas confirmações de afirmações já conhecidas desde um trabalho de Weiss, Kobayashi, e Gouterman [40] de 1965, utilizando métodos disponíveis na época, que mostrou que o modelo de quatro orbitais é justificável para as transições de baixa energia (bandas Q) mas menos justificável para as transições no ultravioleta próximo (banda de Soret) da $\mathrm{H}_{2}$-Porfirina.

\footnotetext{
${ }^{10}$ Essa mesma conclusão pode ser estendida para as moléculas Mg-Porfirina e Zn-Porfirina, a partir de análise dos resultados mostrados no apêndice B.
} 
Tabela 3.3: Algumas excitações não nulas na região ultravioleta da molécula $H_{2}$-Porfirina isolada calculadas utilizando vários métodos com a base 6-311++G(d,p) (exceto ZINDO/CIS). Os estados que estão entre os apresentados e não aparecem na tabela tem força de oscilador nula. $\Delta E$ é a energia de excitação dada em eV, $\lambda$ é o comprimento de onda correspondente dado em nm, e $f$ é a força de oscilador. As transições envolvidas são mostradas, e a contribuição delas para cada excitação é mostrada em parênteses. O orbital HOMO é numerado como 81.

\begin{tabular}{|c|c|c|c|c|c|}
\hline Método & Estado & $\Delta E$ & $\lambda$ & $f$ & Transições envolvidas \\
\hline $\begin{array}{l}\text { TD-DFT } \\
\text { (B3LYP) }\end{array}$ & $\begin{array}{c}3^{\underline{O}} \\
--- \\
5^{\underline{0}} \\
--- \\
7^{0} \\
--- \\
8^{0}\end{array}$ & $\begin{array}{l}3,2953 \\
----- \\
3,4404 \\
----- \\
3,7170 \\
----- \\
3,7892\end{array}$ & $\begin{array}{l}376,3 \\
--- \\
360,4 \\
---- \\
333,6 \\
--- \\
327,2\end{array}$ & $\begin{array}{l}0,4816 \\
----- \\
0,7337 \\
----- \\
0,4433 \\
----- \\
0,7287\end{array}$ & 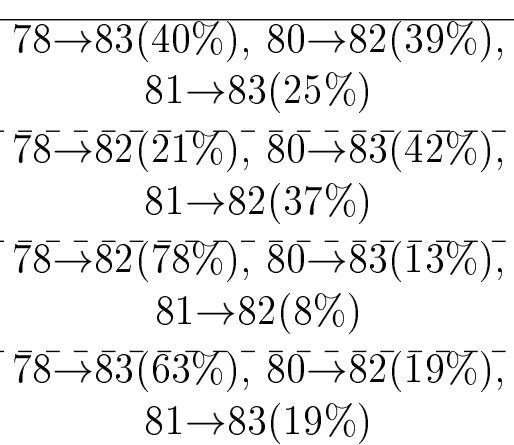 \\
\hline $\begin{array}{c}\text { TD-DFT } \\
\text { (CAM-B3LYP) }\end{array}$ & $\begin{array}{c}3^{\mathrm{O}} \\
--- \\
4^{\mathrm{O}} \\
---- \\
6^{\mathrm{O}} \\
--- \\
8^{\mathrm{O}}\end{array}$ & $\begin{array}{l}3,4966 \\
---- \\
3,6068 \\
----- \\
4,2045 \\
---- \\
4,4268\end{array}$ & $\begin{array}{c}354,6 \\
--- \\
343,8 \\
---- \\
294,9 \\
280,1\end{array}$ & \begin{tabular}{c}
0,8747 \\
$-1,1895$ \\
----- \\
0,5296 \\
\hdashline 0,0788
\end{tabular} & 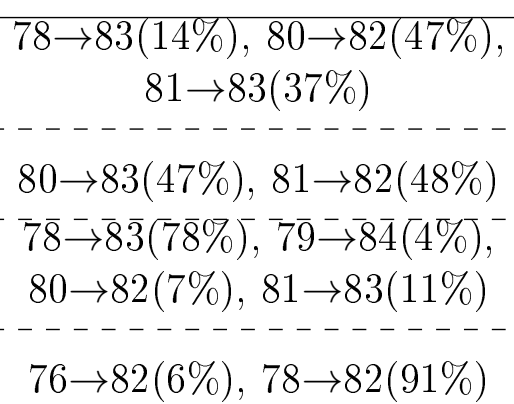 \\
\hline $\begin{array}{l}\text { TD-DFT } \\
\text { (O3LYP) }\end{array}$ & $\begin{array}{c}3^{\underline{0}} \\
--- \\
5^{\underline{0}} \\
--- \\
7^{\underline{0}} \\
--- \\
8^{0}\end{array}$ & $\begin{array}{l}3,1943 \\
----- \\
3,3178 \\
----- \\
3,5654 \\
---- \\
3,6713\end{array}$ & $\begin{array}{r}388,1 \\
--- \\
373,7 \\
--- \\
347,7 \\
--- \\
337,7\end{array}$ & $\begin{array}{l}0,3245 \\
---- \\
0,3053 \\
----- \\
0,8066 \\
---- \\
0,7910\end{array}$ & 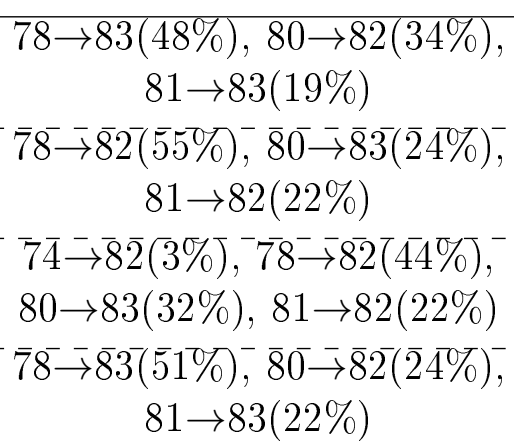 \\
\hline $\begin{array}{l}\text { TD-DFT } \\
(\mathrm{BP} 86)\end{array}$ & $\begin{array}{c}4^{\underline{0}} \\
--- \\
6^{0} \\
--- \\
10^{0} \\
--- \\
11^{0}\end{array}$ & $\begin{array}{l}3,0195 \\
3,3519 \\
- \\
3,4120\end{array}$ & $\begin{array}{c}410,6 \\
369,9 \\
- \\
363,4\end{array}$ & $\begin{array}{c}0,1326 \\
----- \\
0,0428 \\
----- \\
0,0007 \\
----- \\
0,9141\end{array}$ & 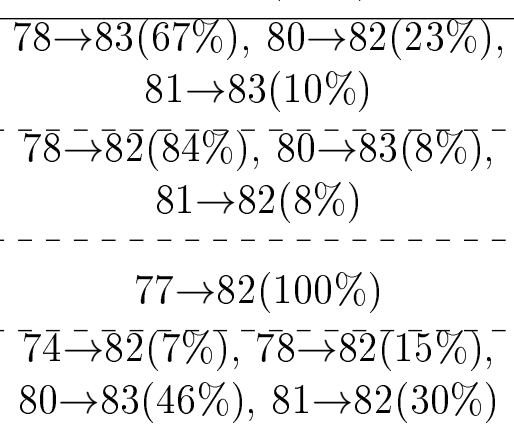 \\
\hline
\end{tabular}




\begin{tabular}{|c|c|c|c|c|c|}
\hline Método & Estado & $\Delta E$ & $\lambda$ & $f$ & Transições envolvidas \\
\hline \multirow{4}{*}{$\begin{array}{l}\text { TD-DFT } \\
(\mathrm{M} 06-2 \mathrm{X})\end{array}$} & $3^{\underline{O}}$ & 3,5165 & 352,6 & 0,9005 & $\begin{array}{c}78 \rightarrow 83(13 \%), 80 \rightarrow 82(47 \%), \\
81 \rightarrow 83(37 \%)\end{array}$ \\
\hline & $4^{0}$ & 3,6110 & 343,4 & 1,1740 & $80 \rightarrow 83(48 \%), 81 \rightarrow 82(48 \%)$ \\
\hline & $6^{0}$ & 4,2122 & 294,4 & 0,4764 & $\begin{array}{l}7 \overline{8} \stackrel{-}{\rightarrow} \overline{3}(8 \overline{1} \%),{ }_{7}{ }^{-} \rightarrow 85(4 \%), \\
80 \rightarrow 82(6 \%), 81 \rightarrow 83(10 \%)\end{array}$ \\
\hline & $8^{0}$ & 4,4357 & 279,5 & 0,0980 & $76 \rightarrow 82(4 \%), 78 \rightarrow 82(93 \%)$ \\
\hline \multirow{4}{*}{$\begin{array}{c}\text { TD-DFT } \\
\text { (LC-wPBE) }\end{array}$} & $3^{0}$ & 3,6055 & 343,9 & 1,0276 & $\begin{array}{c}78 \rightarrow 83(9 \%), 80 \rightarrow 83(42 \%) \\
81 \rightarrow 82(45 \%)\end{array}$ \\
\hline & $4^{\mathrm{O}}$ & 3,6973 & 335,3 & 1,2615 & $80 \rightarrow 82(51 \%), 81 \rightarrow 83(45 \%)$ \\
\hline & $6^{0}$ & 4,5311 & 273,6 & 0,4700 & $\begin{array}{c}\overline{7} \overline{8} \rightarrow 8 \overline{3}(\overline{7} \overline{8} \%), \overline{7} \overline{9} \rightarrow 8 \overline{7}(9 \%) \\
80 \rightarrow 83(8 \%), 81 \rightarrow 82(4 \%)\end{array}$ \\
\hline & $10^{\mathrm{o}}$ & 4,9770 & 249,1 & 0,0147 & $\begin{array}{c}\overline{76} \stackrel{-}{\rightarrow} \overline{2}(2 \overline{4} \%), \overline{7} \overline{7} \rightarrow 8 \overline{7}(4 \%), \\
78 \rightarrow 82(67 \%)\end{array}$ \\
\hline \multirow{4}{*}{ TD-HF } & $3^{0}$ & 4,4312 & 279,8 & 1,7374 & $\begin{array}{l}78 \rightarrow 83(23 \%), 79 \rightarrow 94(4 \%), \\
80 \rightarrow 83(39 \%), 81 \rightarrow 82(29 \%)\end{array}$ \\
\hline & $4^{\underline{0}}$ & 4,6143 & 268,7 & 2,8608 & $\begin{array}{c}\overline{7} \overline{8} \rightarrow \overline{8} \overline{2}(\overline{2} \%), \overline{80} \rightarrow 8 \overline{2}(53 \%) \\
81 \rightarrow 83(37 \%)\end{array}$ \\
\hline & $9^{\underline{0}}$ & 5,2354 & 236,8 & 1,7801 & $\begin{array}{l}7 \overline{8} \rightarrow 8 \overline{3}(6 \overline{2} \%), 7 \overline{9} \rightarrow 94(5 \%)^{-} \\
80 \rightarrow 83(16 \%), 81 \rightarrow 82(10 \%)\end{array}$ \\
\hline & $10^{\mathrm{O}}$ & 5,2543 & 236,0 & 0,0095 & $\begin{array}{c}8 \overline{0} \rightarrow \overline{8} \overline{4}(6 \overline{9} \%), 8 \overline{0} \rightarrow 9 \overline{2}(8 \%) \\
80 \rightarrow 95(5 \%), 80 \rightarrow 110(2 \%), \\
81 \rightarrow 87(11 \%)\end{array}$ \\
\hline \multirow{3}{*}{ CIS(D) } & $3^{\mathrm{O}}$ & 3,3639 & 368,6 & 1,7374 & $\begin{array}{l}78 \rightarrow 83(23 \%), 79 \rightarrow 94(4 \%), \\
80 \rightarrow 83(39 \%), 81 \rightarrow 82(29 \%)\end{array}$ \\
\hline & $4^{0}$ & 3,4353 & 360,9 & 2,8609 & $\begin{array}{c}\overline{7} \overline{8} \rightarrow \overline{8} \overline{2}(2 \%), 80 \rightarrow 8 \overline{2}(53 \%) \\
81 \rightarrow 83(37 \%)\end{array}$ \\
\hline & $\begin{array}{r}9^{0} \\
----\end{array}$ & 4,1454 & 299,1 & 1,7799 & $\begin{array}{c}\overline{7} \overline{8} \rightarrow \overline{8} \overline{3}(6 \overline{2} \%), \overline{7} \overline{9} \rightarrow 9 \overline{4}(5 \%), \\
80 \rightarrow 83(16 \%), 81 \rightarrow 82(10 \%) \\
\overline{8} \overline{0} \rightarrow \overline{4} \overline{4}(\overline{6} \overline{9} \%), \overline{8} \overline{0} \rightarrow \overline{2} \overline{2}(8 \%), \\
80 \rightarrow 95(5 \%), 80 \rightarrow 110(2 \%), \\
81 \rightarrow 87(11 \%)\end{array}$ \\
\hline
\end{tabular}




\begin{tabular}{|c|ccccc|}
\hline Método & Estado & $\Delta E$ & $\lambda$ & $f$ & Transições envolvidas \\
\hline \multirow{5}{*}{ ZINDO/CIS } & $3^{0}$ & 3,3211 & 373,3 & 1,6651 & $81 \rightarrow 82(35 \%)$ \\
& $4^{-0}$ & 3,4704 & 357,3 & 2,3592 & $80 \rightarrow 82(57 \%), 81 \rightarrow 83(37 \%)$ \\
\hline & $7^{0}$ & 4,0401 & 306,9 & 1,3767 & $79 \rightarrow 83(77 \%), 80 \rightarrow 84(11 \%)$ \\
& $10^{-}$ & 4,3937 & 282,2 & 0,3337 & $81 \rightarrow 85(19 \%)$ \\
\hline
\end{tabular}

Tabela 3.4: Estados excitados da molécula $H_{2}$-Porfirina isolada no nível CIS(D)/6$311++\mathrm{G}(\mathrm{d}, \mathrm{p}) . \Delta E$ é a energia de excitação dada em eV, $\lambda$ é o comprimento de onda correspondente dado em nm, e $f$ é a força de oscilador. As transições envolvidas são mostradas, e a contribuição delas para cada excitação é mostrada em parênteses. O orbital HOMO é numerado como 81.

\begin{tabular}{|c|c|c|c|c|}
\hline & $\Delta E$ & $\lambda$ & $f$ & Transições envolvidas \\
\hline $1^{0}$ Estado & 2,4629 & 503,4 & 0,0369 & $80 \rightarrow 83(40 \%), 81 \rightarrow 82(55 \%)$ \\
\hline $2^{\underline{O}}$ Estado & 2,8912 & 428,8 & 0,0273 & $80 \rightarrow 82(40 \%), 81 \rightarrow 83(56 \%)$ \\
\hline $3^{0}$ Estado & 3,3639 & 368,6 & 1,7374 & $\begin{array}{r}78 \rightarrow 8 \overline{3}(2 \overline{3} \%), 7 \overline{9} \rightarrow 9 \overline{4}(4 \%), \\
80 \rightarrow 83(39 \%), 81 \rightarrow 82(29 \%)\end{array}$ \\
\hline $4^{0}$ Estado & 3,4353 & 360,9 & 2,8609 & 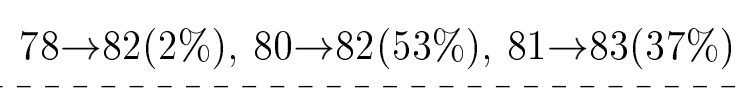 \\
\hline $5^{0}$ Estado & 3,7184 & 333,4 & $\begin{array}{c}0 \\
----\end{array}$ & $78 \rightarrow 94(7 \%), 78 \rightarrow 102(2 \%), 79 \rightarrow 83(85 \%)$ \\
\hline $6^{0}$ Estado & 5,0953 & 243,3 & 0 & $81 \rightarrow 84(84 \%), 81 \rightarrow 92(6 \%), 81 \rightarrow 95(5 \%)$ \\
\hline $7^{0}$ Estado & 5,2793 & 234,9 & $\begin{array}{c}0 \\
---\end{array}$ & 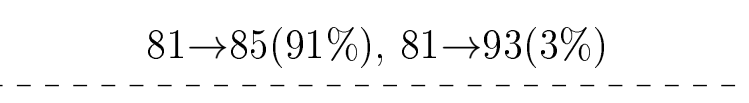 \\
\hline $8^{0}$ Estado & 5,3475 & 231,9 & 0 & $81 \rightarrow 86(92 \%)$ \\
\hline $9^{0}$ Estado & 4,1454 & 299,1 & 1,7799 & $\begin{aligned} & 78 \rightarrow 83(62 \%), 79 \rightarrow 94(5 \%), \\
& 80 \rightarrow 83(16 \%), 81 \rightarrow 82(10 \%)\end{aligned}$ \\
\hline $10^{\mathrm{o}}$ Estado & 4,8830 & 253,9 & 0,0097 & $\begin{array}{l}8 \overline{0} \rightarrow 8 \overline{4}(6 \overline{9} \%), 8 \overline{0} \rightarrow 92(8 \%), 80 \rightarrow 95(5 \%), \\
\quad 80 \rightarrow 110(2 \%), 81 \rightarrow 87(11 \%)\end{array}$ \\
\hline $11^{0}$ Estado & 5,4995 & 225,4 & 0,0011 & $80 \rightarrow 84(9 \%), 81 \rightarrow 87(84 \%)$ \\
\hline $12^{0}$ Estado & 4,1773 & 296,8 & 0 & $\begin{array}{l}7 \overline{4} \rightarrow 8 \overline{2}(3 \%), \overline{7} 9 \rightarrow \overline{2}(39 \%), \\
81 \rightarrow 94(48 \%), 81 \rightarrow 102(2 \%)\end{array}$ \\
\hline
\end{tabular}




\subsubsection{Discussão sobre as forças de oscilador na região do visível}

Vamos agora retomar a questão das forças de oscilador das bandas $Q$ que como vimos na tabela 3.2 são muito baixas ou até nulas. Esse resultado, um tanto curioso, chama a atenção porque no espectro experimental [28] a molécula apresenta absorções nessa região. Como discutido na subseção 1.3.1, o espectro experimental da $H_{2}$-Porfirina em fase gasosa foi obtidos nas temperaturas de $322^{\circ} \mathrm{C}($ ou $595 \mathrm{~K}$ ) para a região ultravioleta e $393{ }^{\circ} \mathrm{C}$ (ou $666 \mathrm{~K}$ ) para a região visível. Por outro lado, os resultados apresentados na subseção 3.1.2 são para uma estrutura optimizada, o que corresponderia a uma temperatura de $0 \mathrm{~K}$. No artigo que reporta o espectro experimental [28] durante o texto os autores dão a entender que para que a $H_{2}$-Porfirina começasse a absorver na região do visível era necessário que ela fosse aquecida até altas temperaturas. Partindo desse pressuposto, em princípio os nossos resultados para forças de oscilador não estão em desacordo com o resultado experimental. Do ponto de vista teórico uma hipótese que levantamos para explicar o que pode estar acontecendo é que com o aumento da temperatura a molécula passa a ganhar energia suficiente para ter conformações mais distorcidas em comparação com a estrutura optimizadas tais que as absorções na região do visível ganhem intensidade. Essa hipótese será inicialmente estudada e avaliada nesta subseção 3.1.3, e será também discutida no decorrer da subseção 3.1.5.

\subsubsection{As excitações são proibidas por simetria?}

Antes de tratar diretamente a discussão do parágrafo anterior, uma questão pode ser levantada: do ponto de vista teórico, por que a molécula praticamente não absorve na região do visível quando está na estrutura optimizada? Uma possibilidade para que isso ocorra é a de que essas excitações possam ser proibidas devido a simetria da molécula na geometria optimizada. Vamos aqui buscar checar se isso ocorre.

Uma primeira observação que coloca essa hipótese em cheque é a de que, indepen- 
dente do método de cálculo ou da função base utilizada, apenas utilizando argumentos baseados na simetria dos orbitais moleculares é possível determinar quais são as transições proibidas. Portanto, supondo que as excitações sejam proibidas por simetria, o que deveríamos observar na tabela 3.2, já que o programa Gaussian 09 [81] reconhece a simetria da estrutura optimizada em todos os cálculos feitos, é que as forças de oscilador fossem todas nulas em todos os casos, o que não acontece. Mesmo com esse argumento vamos utilizar conhecimentos de Teoria de Grupos para checar se as bandas $Q$ são proibidas por simetria ou não. O caso que escolhemos analisar é o do cálculo B3LYP, pois é o método que apresenta as menores forças de oscilador na tabela 3.2 .

A Teoria de Grupos é uma teoria que tem muitas implicações em problemas de física e química. Existem vários livros na literatura que simplesmente abordam aplicações de Teoria de Grupos, a partir de simetrias, para problemas moleculares. Este é um tema bastante extenso. Como utilizaremos nessa dissertação esses argumentos somente para a análise mostrada a seguir, este tema não será discutido mais a fundo nessa dissertação. Para maiores informações sobre implicações de simetrias em espectroscopia recomendamos os excelentes livros de D. C. Harris e M. D. Bertolucci [60], e de I. N. Levine [83], que foram as referências utilizadas para a análise mostrada a seguir.

Na figura 3.3 são apresentados os orbitais moleculares obtidos pelo cálculo B3LYP, e na tabela 3.2 as transições envolvidas em cada um dos estados excitados na região das bandas $Q$. Como a molécula $H_{2}$-Porfirina tem simetria $D_{2 h}{ }^{11}$, uma vez feita a escolha de eixos de Gouterman (ver subseção 1.3.1) a simetria do orbital HOMO-1 é $A_{u}$, do $H O M O$ é $B_{1 u}$, do $L U M O$ é $B_{3 g}$, e do $L U M O+1$ é $B_{2 g}{ }^{11}$.

Para que a excitação de um estado inicial $i$ para um estado final $f$ seja proibida,

\footnotetext{
${ }^{11}$ Para maiores informações sobre simetrias moleculares e simetrias de orbitais recomendamos a referência [60].
} 
o produto $\left\langle\psi_{i}\left|\mu_{s}\right| \psi_{f}\right\rangle$ deve ser nulo [60,83], onde $\left|\psi_{i}\right\rangle$ e $\left|\psi_{f}\right\rangle$ são as funções de onda dos estados inicial e final, respectivamente, $\mu_{s}$ é uma componente do momento de dipolo de transição da excitação, e $s=x, y$ ou $z$. Partindo disso, pode-se mostrar que, do ponto de vista dos orbitais moleculares, para que uma dada transição de uma excitação seja permitida por simetria o produto $\Gamma_{O M i} \oplus \Gamma_{\mu_{s}} \oplus \Gamma_{O M f}$ deve corresponder a representação totalmente simétrica do grupo pontual [60,83], onde $\Gamma_{O M i}$ e $\Gamma_{O M f}$ são as representações das simetrias dos orbitais moleculares inicial e final, respectivamente, e $\Gamma_{\mu_{s}}$ é a representação da simetria do momento de dipolo de transição.

Para a primeira excitação da $H_{2}$-Porfirina, correspondente a banda $Q_{x}$, o cálculo B3LYP mostra que o momento de dipolo de transição dessa excitação tem componente apenas na direção $x$ (como esperado, ver subseção 1.3.1), portanto com simetria $B_{3 u}$. A tabela 3.2 mostra que a banda $Q_{x}$ é composta por transições eletrônicas envolvendo promoções de $H O M O-1$ para $L U M O$ e de $H O M O$ para $L U M O+1$. Para a transição HOMO-1 $\rightarrow$ LUMO temos ${ }^{12}:$

$$
A_{u} \oplus B_{3 u} \oplus B_{3 g}=B_{3 g} \oplus B_{3 g}=A_{g}
$$

Como $A_{g}$ é a representação totalmente simétrica do grupo $D_{2 h}$, a transição $H O M O-1$ $\rightarrow L U M O$ é permitida por simetria. Para a transição $H O M O \rightarrow L U M O+1$ temos $^{12}$ :

$$
B_{1 u} \oplus B_{3 u} \oplus B_{2 g}=B_{2 g} \oplus B_{2 g}=A_{g}
$$

Portanto a transição $H O M O-1 \rightarrow L U M O$ é permitida por simetria.

Para a segunda excitação da $H_{2}$-Porfirina, correspondente a banda $Q_{y}$, como esperado o cálculo B3LYP mostra que o momento de dipolo de transição dessa excitação tem componente apenas na direção $y$, portanto com simetria $B_{2 u}$. A tabela 3.2 mostra que a banda $Q_{y}$ é composta por transições eletrônicas envolvendo promoções de $H O M O-1$ para $L U M O+1$ e de $H O M O$ para $L U M O$. Para a transição HOMO-1

\footnotetext{
${ }^{12}$ Este produto foi feito utilizando a tabela de multiplicação do grupo $D_{2 h}$. Esta tabela pode ser consultada na referência [60].
} 
$\rightarrow L U M O+1$ temos $^{12}:$

$$
A_{u} \oplus B_{2 u} \oplus B_{2 g}=B_{2 g} \oplus B_{2 g}=A_{g}
$$

Portanto a transição $H O M O-1 \rightarrow L U M O+1$ é permitida por simetria. Para a transição $H O M O \rightarrow L U M O$ temos $^{12}:$

$$
B_{1 u} \oplus B_{2 u} \oplus B_{3 g}=B_{3 g} \oplus B_{3 g}=A_{g}
$$

Portanto a transição $H O M O-1 \rightarrow L U M O$ é permitida por simetria.

Assim então podemos concluir que as excitações correspondentes as bandas $Q_{x} \mathrm{e}$ $Q_{y}$ da $H_{2}$-Porfirina não são proibidas por simetria. Portanto a causa para que as forças de oscilador das bandas $Q$ sejam baixas para a estrutura optimizada da $H_{2}$-Porfirina não é devido a simetria da molécula.

\subsubsection{Espectro de uma estrutura distorcida}

Seguindo com a hipótese levantada no início desta subseção 3.1.3, calculamos o espectro de absorção para uma estrutura distorcida a partir da estrutura optimizada da molécula $\mathrm{H}_{2}$-Porfirina. Essa estrutura é apresentada, sobre duas perspectivas diferentes, na figura 3.4. Como pode ser visto pela figura, a molécula teve a sua planaridade e o alinhamento dos hidrogênios centrais distorcidos, dentre outros fatores. O cálculo do espectro foi feito para essa estrutura no nível B3LYP $/ 6-311++G(d, p)$ utilizando o programa Gaussian 09 [81] e na tabela 3.5 apresentamos os resultados para este cálculo. TD-DFT(B3LYP) foi escolhido aqui por ser, dos métodos mostrados na tabela 3.2 , o que tem as menores forças de oscilador.

Podemos ver que para essa estrutura distorcida as forças de oscilador na região do visível permanecem baixas porém aumentam consideravelmente em comparação com as da estrutura optimizada. Podemos ver que elas deixam de ser quase nulas, como é o caso para a estrutura optimizada como mostrado na tabela 3.2. Esse aumento das forças de oscilador na região do visível está de acordo com a nossa hipótese 

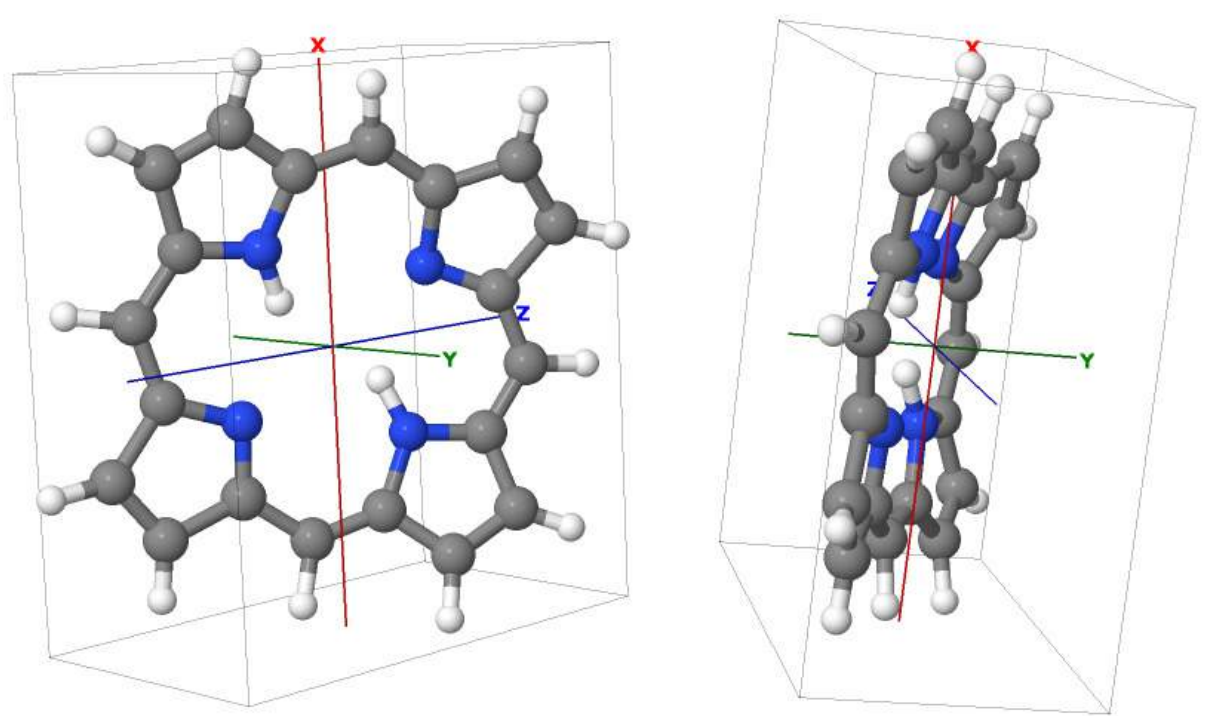

Figura 3.4: Molécula distorcida de $H_{2}$-Porfirina, vista de duas perspectivas diferentes.

levantada para explicar a observação experimental de que a absorção de luz visível pela $H_{2}$-Porfirina só é pronunciável em altas temperaturas. Como dissemos, essa questão também será discutida no decorrer da subseção 3.1.5.

É interessante notar pela tabela 3.5 que as conclusões feitas na subseção 3.1 .2 a cerca do modelo de Gouterman para a estrutura optimizada de $H_{2}$-Porfirina também podem ser estendidas para esta estrutura distorcida. 
Tabela 3.5: Estados excitados da molécula $H_{2}$-Porfirina na conformação apresentada na figura 3.4 no nível B3LYP/6-311++G(d,p). $\Delta E$ é a energia de excitação dada em eV, $\lambda$ é o comprimento de onda correspondente dado em nm, e $f$ é a força de oscilador. As transições envolvidas são mostradas, e a contribuição delas para cada excitação é mostrada em parênteses. O orbital HOMO é numerado como 81.

\begin{tabular}{|c|c|c|c|c|}
\hline & $\Delta E$ & $\lambda$ & $f$ & Transições envolvidas \\
\hline $1^{0}$ Estado & 2,1607 & 573,8 & 0,0108 & $80 \rightarrow 83(41 \%), 81 \rightarrow 82(56 \%)$ \\
\hline $2^{0}$ Estado & 2,3145 & 535,7 & 0,0019 & $80 \rightarrow 82(50 \%), 81 \rightarrow 83(48 \%)$ \\
\hline $3^{0}$ Estado & 3,1512 & 393,4 & 0,5002 & $\begin{array}{c}-\overline{78} \rightarrow \overline{8} 2(\overline{6} \%), \overline{7} \overline{8} \rightarrow \overline{3}(\overline{6} \%), \overline{79}^{-} \bar{\rightarrow} 82(14 \%), \\
79 \rightarrow 83(2 \%), 80 \rightarrow 82(33 \%), 80 \rightarrow 83(3 \%), \\
81 \rightarrow 82(4 \%), 81 \rightarrow 83(32 \%)\end{array}$ \\
\hline $4^{0}$ Estado & 3,3011 & 375,6 & 0,6275 & $\begin{array}{l}7 \overline{8} \rightarrow 8 \overline{2}(14 \%), \overline{-}{ }^{-} \rightarrow 83(1 \overline{3} \%), \overline{80} \rightarrow 8 \overline{2}(3 \%), \\
80 \rightarrow 83(39 \%), 81 \rightarrow 82(27 \%), 81 \rightarrow 83(3 \%)\end{array}$ \\
\hline $5^{\underline{O}}$ Estado & 3,4026 & 364,4 & 0,1729 & $\begin{array}{c}78 \rightarrow 82(8 \%), 78 \rightarrow 83(11 \%), \overline{7} 9 \rightarrow \overline{7} 2(55 \%), \\
79 \rightarrow 83(8 \%), 80 \rightarrow 83(8 \%), 81 \rightarrow 82(6 \%)\end{array}$ \\
\hline $6^{0}$ Estado & 3,5439 & 349,8 & 0,0410 & $78 \rightarrow 82(33 \%), 79 \rightarrow 82(5 \%), 79 \rightarrow 83(56 \%)$ \\
\hline $7^{0}$ Estado & 3,5957 & 344,8 & 0,4186 & $\begin{array}{c}78 \rightarrow 82(3 \overline{8} \%), 78 \rightarrow 83(5 \%), \overline{9} \rightarrow \overline{8} 2(\overline{17 \%}), \\
79 \rightarrow 83(17 \%), 80 \rightarrow 82(4 \%), 80 \rightarrow 83(5 \%), \\
81 \rightarrow 82(4 \%), 81 \rightarrow 83(7 \%)\end{array}$ \\
\hline $8^{0}$ Estado & 3,6899 & 336,0 & 0,3309 & $\begin{array}{c}\overline{78} \rightarrow \overline{8} 3(\overline{7} \%)^{-}, \overline{79} \rightarrow \overline{8} 2(5 \%), 8 \overline{0} \rightarrow 8 \overline{2}(7 \%) \\
81 \rightarrow 83(7 \%), 81 \rightarrow 84(72 \%)\end{array}$ \\
\hline $9^{0}$ Estado & 3,8651 & 320,8 & 0,0187 & $\begin{array}{c}75 \rightarrow 82(1 \overline{2} \%), 76 \rightarrow 82(6 \%), \overline{7} \rightarrow \overline{8} 2(\overline{1} 9 \%), \\
80 \rightarrow 84(9 \%), 81 \rightarrow 84(45 \%)\end{array}$ \\
\hline $10^{\mathrm{O}}$ Estado & 3,8908 & 318,7 & 0,0310 & $\begin{array}{c}75 \stackrel{\rightarrow}{ } 8 \overline{2}(36 \%), 76 \rightarrow 82(9 \%), \overline{7} \bar{\rightarrow} \rightarrow \overline{8} 2(\overline{13 \%}), \\
80 \rightarrow 84(2 \%), 81 \rightarrow 84(31 \%)\end{array}$ \\
\hline $11^{0}$ Estado & 3,9332 & 315,2 & 0,0196 & $\begin{array}{c}\overline{7} \overline{3} \rightarrow \overline{8} \overline{2}(\overline{3} \%), \overline{74} \rightarrow 8 \overline{2}(7 \%), \overline{7} 5 \rightarrow \overline{8} 2(\overline{9} \%), \\
76 \rightarrow 82(16 \%), 76 \rightarrow 83(3 \%), 77 \rightarrow 82(37 \%), \\
77 \rightarrow 83(5 \%), 80 \rightarrow 84(15 \%)\end{array}$ \\
\hline $12^{0}$ Estado & 3,9650 & 312,7 & 0,0108 & 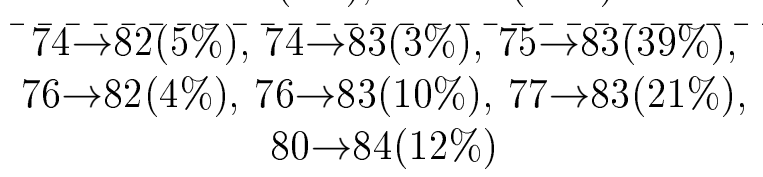 \\
\hline
\end{tabular}




\subsubsection{Comparação de resultados para estruturas optimizadas}

Nesta subseção vamos fazer uma comparação dos resultados obtidos com resultados experimentais e também com outros trabalhos teóricos encontrados na literatura. Resultados para dímeros optimizados também serão apresentados. Esses resultados para dímeros são importantes, não apenas com intuito de inferir sobre a possibilidade de ocorrência de dimerização no espectro experimental da $H_{2}$-Porfirina ${ }^{13}$, mas também porque a agregação de Porfirinas já vem sendo estuda há várias décadas e aparece no espectro experimental, por exemplo, ao se mudar a concentração de soluções que contenham Porfirinas, em alguns $\operatorname{casos}^{14}$. Esse tipo de estudo também é de interesse para a área de desenvolvimento de filmes finos [42].

\subsubsection{Resultados para monômero}

Com relação aos resultados mostrados na subseção 3.1.2, como não estamos incluindo efeitos de acoplamentos vibracionais nos cálculos para o espectro da geometria optimizada, as bandas $Q_{x}(0 \rightarrow 1)$ e $Q_{y}(0 \rightarrow 1)$, presentes no espectro experimental, ficam ausentes no espectro teórico, como pode ser visto na tabela 3.2. Na tabela 3.6 apresentamos uma comparação dos nossos resultados, inicialmente apresentados na subseção 3.1.2, com o resultado experimental e com resultados de outros trabalhos teóricos para as energias de excitação das bandas $Q$ e para a banda de Soret ${ }^{15}$. Na tabela reportamos apenas os picos principais $Q_{x}$ e $Q_{y}$, já que acoplamentos vibracionais não são incluídos nos cálculos, e $B_{x}$ e $B_{y}$, que são duas excitações teóricas correspondentes a banda de Soret. Esse assinalamento x e y para as bandas $B$ teóricas também é devido

\footnotetext{
${ }^{13} \mathrm{O}$ vapor de $\mathrm{H}_{2}$-Porfirina em que as medidas do espectro foram realizadas é obtido a partir de uma vaporização deste sistema em solução, portanto caso as moléculas se encontrem agregadas em solução é possível que eles continuem agregadas no vapor.

${ }^{14} \mathrm{O}$ capítulo 7, escrito por W. I. White, do volume V parte $\mathrm{C}$ da série de livros "The Porphyrins" [30] é devotado apenas a discussões sobre agregação de Porfirinas e Metaloporfirinas. Para maiores informações sobre agregação de Porfirinas recomendamos inicialmente a leitura deste capítulo.

${ }^{15}$ Uma comparação equivalente para a molécula Mg-Porfirina é apresentada na tabela B.7 do apêndice B.
} 
a polarização das excitações [15, 28].

Como já dito anteriormente, os primeiros esforços para o estudo teórico do espectro da $\mathrm{H}_{2}$-Porfirina ocorreram em meados de 1960 através do desenvolvimento do modelo de quatro orbitais. Somente em torno de 1980 é que métodos ab initio puderam, com limitações, ser utilizados para calcular os estados excitados da $\mathrm{H}_{2}$-Porfirina. Os primeiros cálculos ab initio mais pesados, com tratamento completo da correlação eletrônica, começaram a surgir na literatura em torno de 1994. Alguns desses cálculos são apresentaremos em nossa comparação na tabela 3.6.

Pela tabela 3.6 vemos que os diferentes métodos, incluindo os apresentados em outros trabalhos, fornecem diferentes resultados para as energias de excitação. Com relação aos outros trabalhos, não é mencionada nas tabelas detalhes dos cálculos como o conjunto de funções-base utilizada, a estrutura utilizada ou o programa utilizado nos cálculos. Desse modo, uma comparação direta desses resultados com os nossos é impraticável sem essa análise prévia. A menção a esses trabalhos aqui ainda assim é importante para estressar o esforço teórico que tem se dedicado ao estudo da Porfirina Base Livre em fase gasosa, e um fato curioso sobre esses e outros trabalhos é que, apesar de muitas discussões em torno das energias de excitação, pouca atenção é dada a questão das forças de oscilador, principalmente na região do visível.

Os nossos resultados também são mostrados na figura 3.5, onde são comparados mais diretamente com o espectro experimental através da convolução por Lorentzianas dos picos teóricos (ver subseção 2.2.6).

Como os nossos resultados foram obtidos utilizando o mesmo conjunto de funções base e a mesma estrutura (optimizada e que tem simetria $D_{2 h}$ ) eles podem ser comparados entre si. Analisando a figura 3.5 vemos que os métodos que forneceram uma descrição para o espectro que mais se aproxima do resultado experimental são TD-DFT(CAM-B3LYP) seguido por TD-DFT(M06-2X). 
Tabela 3.6: Comparação de resultados para as energias de excitação da $H_{2}$-Porfirina, que são dadas em eV, para as bandas $Q$ e a banda de Soret. O resultado experimental inclui um range de valores de onde o pico se encontra no espectro. Os valores experimentais apresentados para as bandas $Q$ são referentes as componentes $(0 \rightarrow 0)$ (ver subseção 1.3.1).

\begin{tabular}{|c|c|c|c|c|c|}
\hline Método & Referência & $Q_{x}$ & $Q_{y}$ & $B_{x}$ & $B_{y}$ \\
\hline Experimental & {$[28]$} & 1,98 & 2,42 & 3,33 & 3,33 \\
\hline TD-DFT (B3LYP) & Este Trabalho & 2,26 & 2,41 & 3,30 & 3,44 \\
\hline TD-DFT (CAM-B3LYP) & Este Trabalho & 2,16 & 2,37 & 3,50 & 3,61 \\
\hline TD-DFT (O3LYP) & Este Trabalho & 2,23 & 2,38 & 3,19 & 3,32 \\
\hline TD-DFT (BP86) & Este Trabalho & 2,17 & 2,29 & 2,99 & 3,02 \\
\hline TD-DFT (M06-2X) & Este Trabalho & 2,24 & 2,47 & 3,52 & 3,61 \\
\hline TD-DFT (LC-wPBE) & Este Trabalho & 1,85 & 2,17 & 3,61 & 3,70 \\
\hline TD-HF & Este Trabalho & 2,38 & 2,49 & 4,43 & 4,61 \\
\hline CIS(D) & Este Trabalho & 2,46 & 2,89 & 3,36 & 3,44 \\
\hline ZINDO/CIS & Este Trabalho & 1,69 & 2,04 & 3,32 & 3,47 \\
\hline $\mathrm{GW}+\mathrm{BSE}$ & {$[15]$} & 1,98 & 2,30 & 3,30 & 3,50 \\
\hline TD-DFT (LDA) & {$[15]$} & 1,97 & 2,10 & 3,00 & 3,00 \\
\hline CASPT2 & {$[27]$} & 1,63 & 2,11 & 3,08 & 3,12 \\
\hline NEVPT2 & {$[84]$} & 2,04 & 2,51 & 3,22 & 3,30 \\
\hline $\mathrm{SAC}-\mathrm{CI}$ & {$[32]$} & 1,81 & 2,10 & 3,47 & 3,69 \\
\hline STEOM-CC & {$[33]$} & 1,70 & 2,59 & 3,63 & 3,74 \\
\hline TD-DFT (B3LYP) & {$[11]$} & 2,27 & 2,44 & 3,33 & 3,41 \\
\hline
\end{tabular}

A figura 3.5 nos da uma ideia melhor dos resultados apresentados na tabela 3.6, além de ilustrar as outras bandas obtidas após a banda de Soret. Os cálculos com 


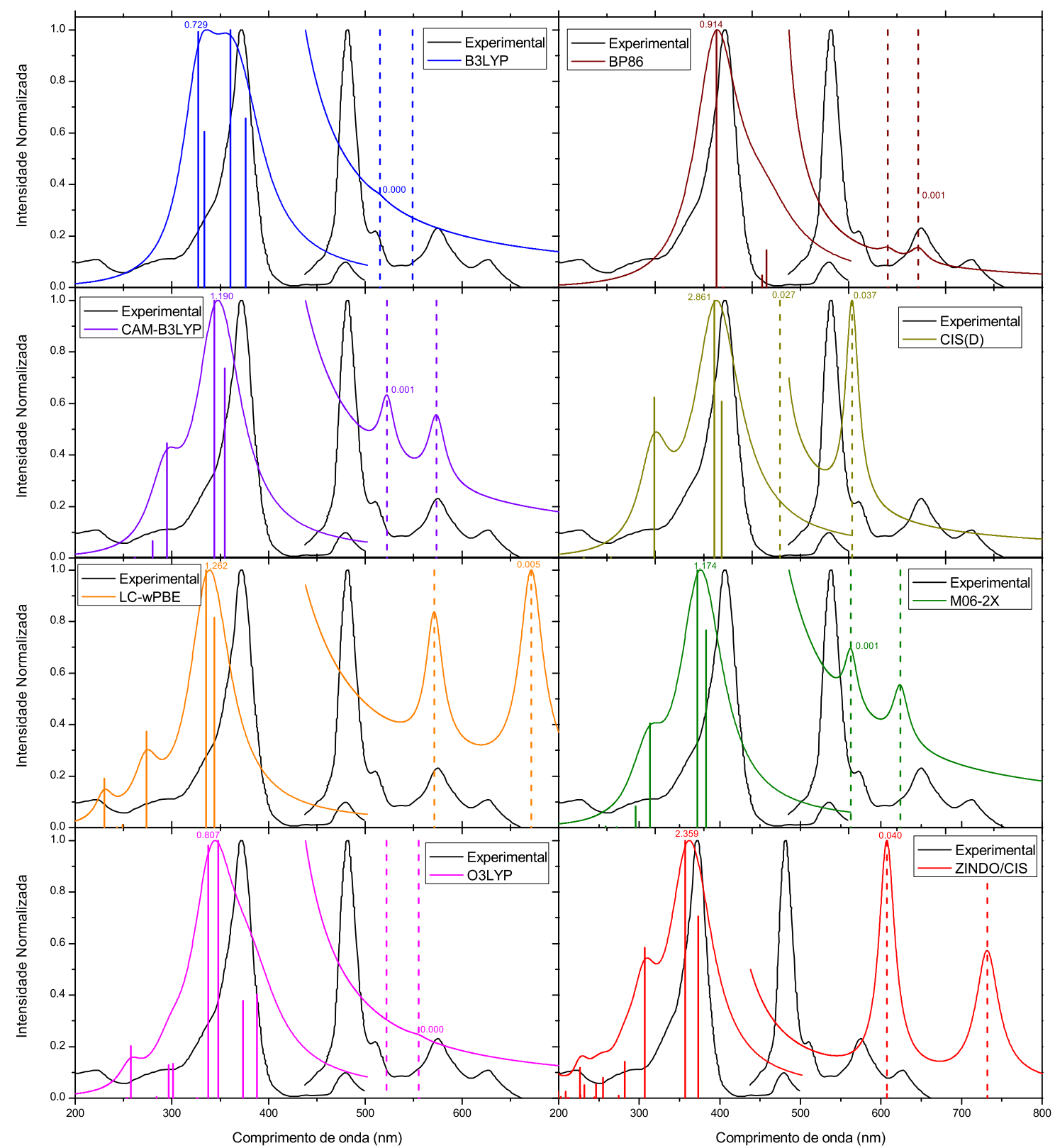

Figura 3.5: Comparação de resultados para a $\mathrm{H}_{2}$-Porfirina isolada. O espectro experimental foi retirado de [28]. Mostramos os picos teóricos e a convolução dos picos utilizando Lorentzianas. O conjunto de funções-base utilizado em todos os cálculos é o 6-311++G(d,p) (exceto ZINDO/CIS). Na região do visível amplificamos as curvas. Como os picos teóricos relacionados com as bandas $Q$ tem intensidade muito baixa, eles são mostrados separadamente nas linhas tracejadas. Os números mostrados correspondem as forças de oscilador. 
B3LYP, BP86, CAM-B3LYP, e CIS(D) foram feitos para os 12 primeiros estados excitados, LC-wPBE e M06-2X para 16 estados, O3LYP para 32 estados, e ZINDO/CIS para 49 estados. Desses estados, apenas os estados com força de oscilador não nula aparecem na figura 3.5.

Como podemos ver pela figura 3.5, dos métodos utilizados apenas CIS(D) fornece um posicionamento das bandas $Q$ mais a direita das bandas $Q$ experimentais.

Vale ressaltar que, como não estamos incluindo efeitos de acoplamentos vibracionais nos cálculos, as bandas $Q_{x}(0 \rightarrow 1)$ e $Q_{y}(0 \rightarrow 1)$ do espectro experimental ficam ausentes no espectro teórico (ver subseção 1.3.1), como pode ser visto na figura 3.5 e também na tabela 3.6.

\subsubsection{Resultados para dímeros}

Vamos agora apresentar resultados para dímeros de $H_{2}$-Porfirina. Os cálculos de dímeros envolvem uma complicação adicional em relação ao cálculo de monômeros devido ao tamanho do sistema, que dobra. Com isso o custo computacional dos cálculos aumenta significativamente. Por isso, nos cálculos para dímeros apresentados aqui, o número de estados excitados considerados foi escolhido de modo a dar uma maior atenção apenas as bandas na região visível do espectro de absorção.

Foram obtidos dois dímeros, chamados de (a) e (b), através de optimização de geometria no nível wB97XD/6-31G* utilizando o programa Gaussian 09 [81]. O funcional wB97XD foi escolhido por conter correções para incluir interações de dispersão, que são importantes para estruturação de dímeros de moléculas aromáticas como o benzeno $^{16}[85,86]$. Os dímeros obtidos são ilustrados na figura 3.6. Um fato que vale aqui registrar é que uma tentativa para obtenção de um dímero com uma estrutura na forma de $\mathrm{T}$ foi feita, mas essa optimização levou ao dímero (b).

\footnotetext{
${ }^{16}$ Compostos aromáticos são compostos cíclicos (em forma de anel ou anéis) em que todos átomos dos anéis participação de uma rede de ligações do tipo pi, resultando em uma estabilidade para a estrutura.
} 

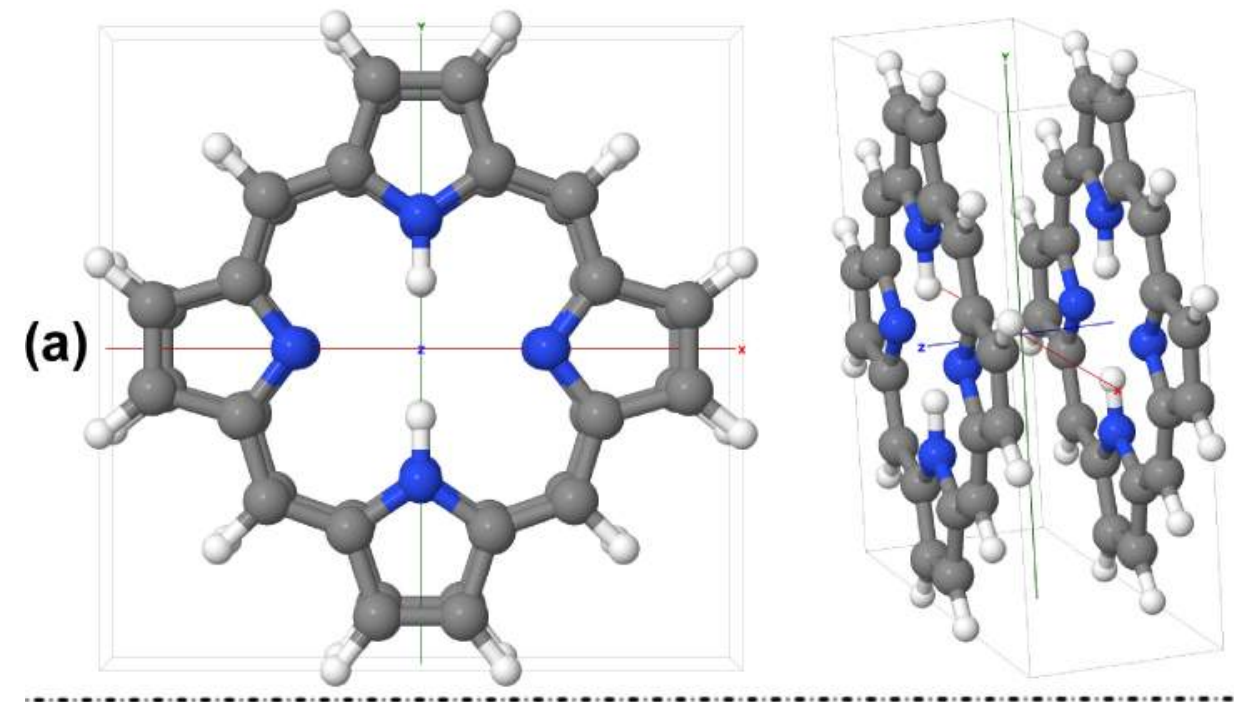

(b)
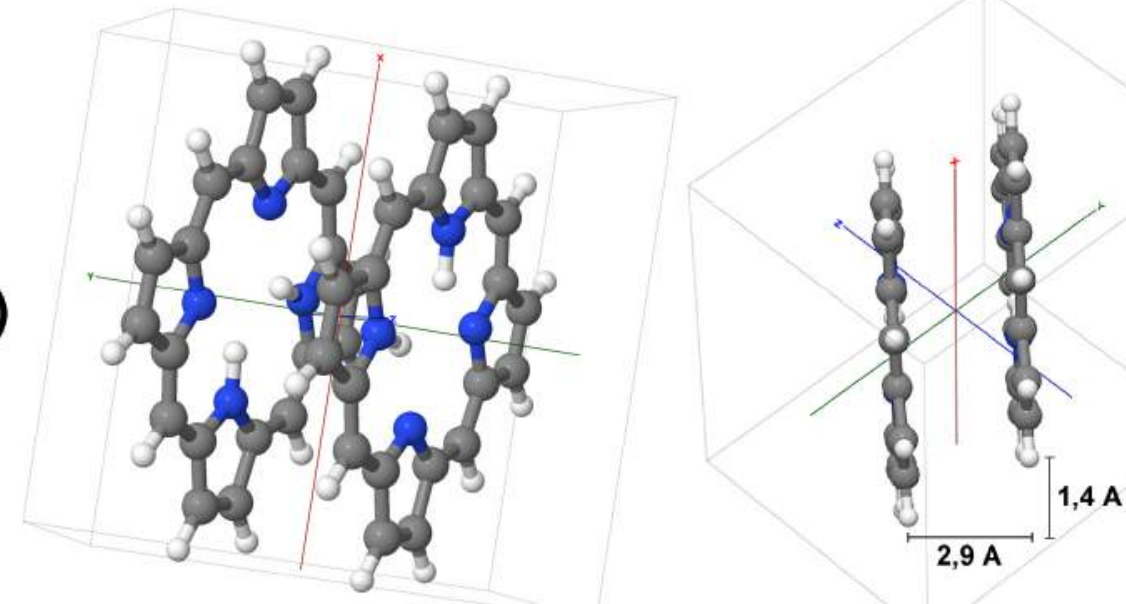

Figura 3.6: Dímeros de $H_{2}$-Porfirina, obtidos a partir de optimizações de geometria no nível wB97XD $/ 6-31 \mathrm{G}^{*}$, ilustrados sobre duas perspectivas diferentes. Eixos e uma caixa limitante que contém a molécula são incluídos para facilitar a compreensão das estruturas das moléculas.

Como pode ser visto pela figura 3.6, o dímero (a) é composto, aproximadamente, por duas moléculas transladadas no eixo perpendicular ao plano de uma delas. A palavra "aproximadamente"é muito apropriada aqui porque a distância entre as moléculas é de 3,5 A na região dos hidrogênios centrais e de 3,6 A nas extremidades. Deste modo identificamos que as moléculas saem da planaridade, estando mais próximas (e por isso interagindo mais) na região dos hidrogênios centrais e menos próximas nas 
extremidades.

Pela figura 3.6 vemos que as moléculas que compõem o dímero (b) não estão sobre o mesmo eixo, como é o caso para o dímero (a), por isso a visualização delas apenas nas duas perspectivas apresentadas é bem difícil. Por isso, na tentativa de dar uma ideia adicional sobre a estrutura do dímero (b), algumas medidas são apresentadas na figura. Existe uma separação de cerca de 2,9 $\AA$ entre as moléculas, como mostrado na figura, seguido de um deslocamento na direção perpendicular de cerca de 1,4 A. A distância entre os centros dos nitrogênios centrais das moléculas é de 3,7 A. Como vemos pela figura, os hidrogênios centrais de cada molécula individualmente não fazem mais ligação com nitrogênios centrais opostos, e comparando a posição desses hidrogênios em cada molécula vemos que eles estão em lados opostos em cada molécula.

As coordenadas das estruturas optimizadas dos dímeros (a) e (b) são apresentadas na tabela B.8 do apêndice B. Maiores informações sobre a estruturas desses dímeros podem ser obtidas a partir dessas coordenadas.

A energia de ligação desses dímeros também foi determinada no nível wB97XD / 631G* utilizando o programa Gaussian 09 [81] utilizando o método Counterpoise (ver manual do Gaussian) na tentativa de reduzir erros de superposição de bases. A energia de ligação é definida como a diferença de energia entre as energias de cada monômero isolado somadas e a energia do dímero. Essa energia portanto dá uma ideia de quão fortemente interagente estão os monômeros que compõem o dímero e também da estabilidade da estrutura em dímero em comparação com os monômeros isolados. Uma vez definida dessa maneira, caso a energia de ligação seja positiva isso significa que a interação entre os monômeros é atrativa. Um problema que surge nesse tipo de cálculo é o chamado de erro de superposição de bases. Esse erro é devido ao fato de que no cálculo da energia do dímero o número de funções-base é o dobro do número de funções-base no cálculo da energia de um monômero, devido ao tamanho do sistema ser duas vezes maior para o dímero. Como o número de funções-base é maior para o 
dímero, a energia calculada é mais precisa para o dímero do que para o monômero, e por isso o resultado para a energia de ligação pode ser alterada por essa maior imprecisão no cálculo dos monômeros. Para reduzir esse erro de superposição de bases uma opção é a utilização do método Counterpoise. No método Counterpoise no cálculo da energia de um monômero se coloca, além das funções-base que já estariam naturalmente nos sítios atômicos deste monômero, funções-base adicionais centradas nos sítios correspondentes as posições atômicas do outro monômero. Essa mudança influencia a função de onda do sistema mas não o Hamiltoniano, já que permanecemos tratando as interações de um único monômero, porém o erro de superposição de base é reduzido no cálculo das energias dos monômeros ao se fazer isso. A tabela 3.7 mostra a energia de ligação dos dois dímeros, como também as energias dos dímeros e de cada monômero que compõem os dímeros com e sem Counterpoise.

Tabela 3.7: Energias envolvidas nos dímeros de $H_{2}$-Porfirina mostrados na figura 3.6, obtidas no nível wB97XD/6-31G*. São apresentados os valores das energias de ligação dadas em $\mathrm{kcal} / \mathrm{mol}$, e os valores para as energias dos dímeros e de cada monômero que compõem os dímeros dadas em Hartree. Os valores para as energias de ligação e energias dos monômeros são apresentados com a utilização de Counterpoise e também sem Counterpoise em parenteses.

\begin{tabular}{|c|c|c|}
\hline & Dímero (a) & Dímero (b) \\
\hline Energia de Ligação & $11,218(17,199)$ & $20,191(28,068)$ \\
\hline $\begin{array}{r}\text { Dímero } \\
-\ldots-\ldots\end{array}$ & $-1978,42877249$ & $-1978,41806655$ \\
\hline \multirow[t]{2}{*}{$1^{\underline{0}}$ Monômero } & $-989,205447726$ & $-989,192945043$ \\
\hline & $(-989,200681996)$ & $(-989,186668999)$ \\
\hline \multirow[t]{2}{*}{$2^{\underline{O}}$ Monômero } & $-989,205447726$ & $-989,192944723$ \\
\hline & $(-989,200681996)$ & $(-989,186668361)$ \\
\hline
\end{tabular}

A tabela 3.7 mostra, a partir dos resultados para as energias de ligação, que o dímero (b) está mais fortemente ligado que o dímero (a), indicando que o dímero (b) é mais estável que o dímero (a). Pode-se chegar a esta mesma conclusão a partir dos 
valores para as energias dos dímeros. Analisando os valores para os monômeros vemos que os monômeros do dímero (a) com os hidrogênios centrais opostos são mais estáveis que os monômeros do dímero (b) onde os hidrogênios centrais não são opostos. Outra observação que podemos fazer pela tabela 3.7 é a cerca da relevância da utilização de Counterpoise, que implica em diferenças significativas nos valores das energias de ligação.

A temperatura em que o espectro de absorção experimental foi obtido para as bandas $Q$ (666 K, ver figura 1.3) fornece uma energia térmica ${ }^{17}$ de $1,324 \mathrm{kcal} / \mathrm{mol}$. Pela tabela 3.7 vemos que essa energia pode não ser suficiente para desfazer os dímeros uma vez que a energia de ligação dos dímeros é bem maior que a energia térmica. Esse é um indicativo de que esses dímeros podem existir na temperatura experimental. Porém, para uma indicação mais concreta a respeito disso, deveríamos olhar para as energias livres de ligação, entretanto este é um calculo muito custoso de se fazer pois envolve o cálculo da Hessiana (ver subseção 2.4.1) do sistema.

O espectro de absorção teórico foi calculado, utilizando o programa Gaussian 09 [81], para esses dois dímeros utilizando vários métodos ab initio com o conjunto de funções-base $6-31+\mathrm{G}^{* 18}$ para os quatorze primeiros estados excitados. O espectro também foi calculado para os quarenta e nove primeiros estados utilizando o método ZINDO/CIS com o programa [64] (ver subseção 2.3.4) considerando apenas transições dos 25 orbitais mais altos ocupados para os 25 mais baixos desocupados. Nos cálculos a carga dos dímeros foi considerada neutra e a multiplicidade 1 (singleto). Os resultados obtidos são apresentados na tabela 3.8. Na figura 3.7 para cada método é apresentado os picos teóricos e a convolução dos picos por Lorentzianas (ver subseção 2.2.6) na

\footnotetext{
${ }^{17} \mathrm{~A}$ energia térmica é dada pela constante de Boltzmann multiplicada pela temperatura.

${ }^{18} \mathrm{~A}$ base $6-311++\mathrm{G}(\mathrm{d}, \mathrm{g})$ utilizada anteriormente nos cálculos de espectro para monômeros sobrecarrega muito o custo computacional para o cálculo de dímeros, por isso a necessidade da escolha de uma base menor. Na subseção 3.2.2 mostraremos que a base $6-31+\mathrm{G}^{*}$ reproduz os resultados da base $6-311++\mathrm{G}(\mathrm{d}, \mathrm{g})$ para espectro de absorção teórico do monômero de $H_{2}$-Ftalocianina, por isso utilizaremos essa base aqui.
} 
região de $380 \mathrm{~nm}$ até $750 \mathrm{~nm}$.

Em um dímero onde as moléculas estão suficientemente distantes a ponto de não interagirem uma com a outra, o espectro de ambas é aproximadamente igual (será igual caso elas estejam na mesma conformação). Por isso o espectro do dímero que veríamos nesse caso seria simplesmente a soma do espectro de dois monômeros isolados. No caso da $H_{2}$-Porfirina, o monômero tem duas bandas na região visível, portanto no caso de um dímero em que não exista interação entre as moléculas se esperaria ver no espectro quatro bandas na região visível, duas devido a cada monômero. Caso as moléculas estejam próximas ocorre uma interação (ou seja, um efeito em que uma realiza uma pertubação sobre a outra), e essa interação pode ser suficientemente forte de tal modo que o espectro do dímero não seja mais simplesmente a soma do espectro dos monômeros. Esse espectro pode apresentar mudanças significativas em relação ao espectro do monômero, como deslocamentos ou surgimento de novas bandas, escuras ou não. Por isso na tabela 3.8 e na figura 3.7 incluímos os resultados para monômero para fazermos uma comparação entre os resultados obtidos para monômero e dímero, e também na figura 3.7 mostramos os picos dos estados escuros.

Analisando a tabela 3.8 e a figura 3.7 vários aspectos chamam a atenção. Um deles é que no espectro de ambos os dímeros aparecem diversos estados que não existem no espectro de monômero. Como discutimos no parágrafo anterior, isso é um indício de que a interação entre as moléculas do dímero é grande o suficiente para observamos o surgimento de bandas, mesmo que escuras, em regiões onde no espectro do monômero não existiam bandas. Desse modo, para ambos os dímeros analisados, vemos que as características do espectro de dímeros optimizados de $H_{2}$-Porfirina diferem bastante do espectro de monômero optimizado.

Outro fato que chama a atenção é que as forças de oscilador na região das bandas $Q$ para os dímeros ainda são baixas, e muitos estados até escuros. Vale aqui fazer um comentário sobre esses estados escuros (ou dark states) [18]. É concebível a hipótese 


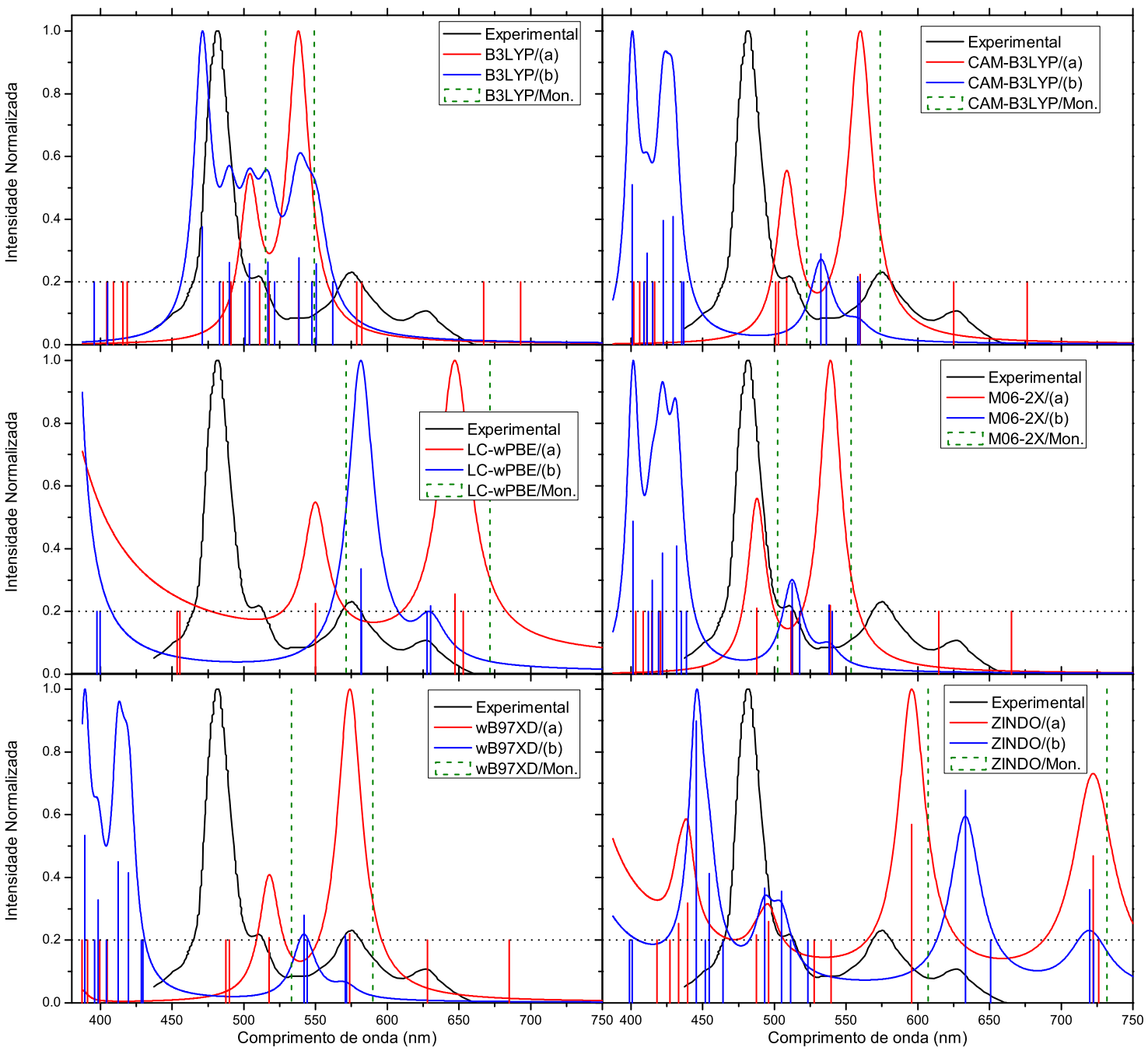

Figura 3.7: Comparação de resultados para dímeros de $H_{2}$-Porfirina isolada. O espectro experimental foi retirado de [28]. Mostramos os picos teóricos e a convolução dos picos em duas regiões utilizando Lorentzianas. O conjunto de funções-base utilizado em todos os cálculos é o 6-31+G* (exceto ZINDO/CIS). Como muitos dos picos tem intensidade muito baixa ou nulas, eles foram renormalizados tal que 0,2 corresponda ao valor 0 da força de oscilador. As bandas de monômero também são apresentadas.

de hajam outros estados excitados além dos estados observados a partir do espectro de absorção (como a banda de Soret e as bandas $Q$ ), tais estados não seriam observados por serem transições proibidas a partir do estado fundamental. Tais estados, como pode ser visto pelos nossos resultados apresentados, podem ser calculados te- 
oricamente, e não somente para Porfirinas como também para outros sistemas como por exemplo a Clorofila C2 [16]. A existência de tais estados é muito importante. Por um lado para a compreensão dos estados excitados de pigmentos fotossintéticos e, com isso, para concepção e o design de pigmentos sintéticos com uma resposta mais adequada para absorção de luz solar, por exemplo [4,5]. Por outro lado estes estados podem ter um significado muito importante em fotossíntese, pois eles seriam responsáveis pela dissipação de energia e, também, permitiriam transferência de energia através do efeito antena com carotenos [87]. É importante mencionar que tais estados escuros não são mais especulações teóricas uma vez que foram observados experimentalmente. Mesmo sendo inacessíveis a partir do estado fundamental, O. Schalk et. al. [88] obtiveram tais estados experimentalmente como transições no infravermelho próximo a partir das bandas $Q$ para Tetratolil-Porfirinas Base Livre e complexada com Zinco. Nesse caso a observação desses estados se torna possível pois as transições ocorrem a partir de estados excitados mais baixos, o que muda a regra de seleção e torna os estados escuros acessíveis. A avenida aberta por essa recente observação abre portas para a determinação e a caracterização de estados escuros em outros pigmentos fotossintéticos.

Para lidar com a questão do aparecimento de bandas no espectro dos dímeros que não estão apresentes no espectro de monômero, olhamos para os orbitais moleculares dos dímeros. A figura 3.8 ilustra alguns dos orbitais obtidos para os dímeros (a) e (b) a partir do cálculo no nível B3LYP $/ 6-31+\mathrm{G}^{*}$.

O que vemos nos orbitais apresentados na figura 3.8, como também em diversos outros não mostrados na figura, tanto em orbitais ocupados como desocupados, é a delocalização dos orbitais nas duas moléculas pertencentes ao dímero. Desse modo as transições eletrônicas que compõem o espectro do dímero são transições que estão também delocalizadas em ambas moléculas do dímero. Assim então esse tipo de transições não podem ser observadas no monômero pois são características de dímero. Portanto 


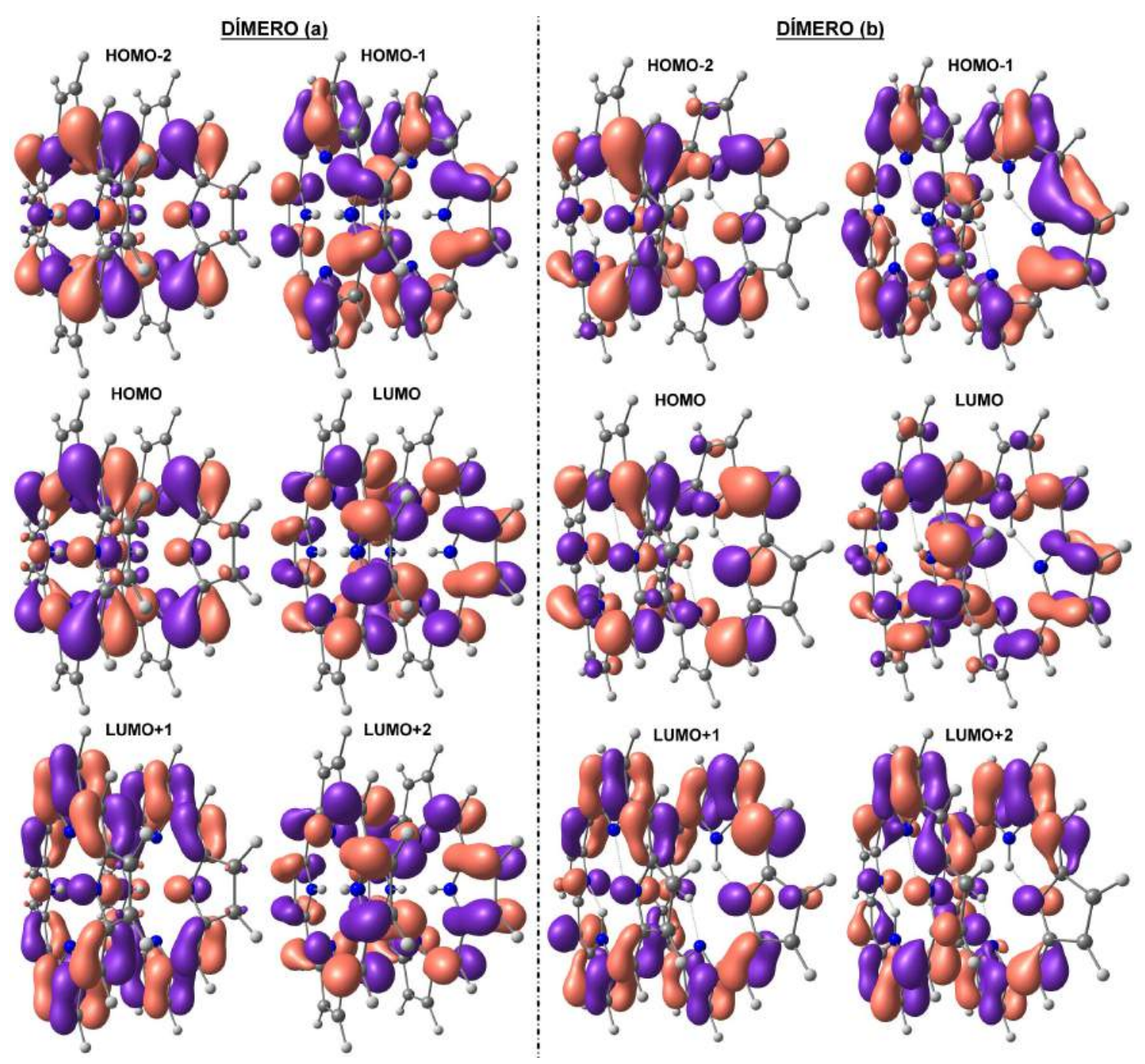

Figura 3.8: Alguns orbitais moleculares dos dímeros (a) e (b) de $H_{2}$-Porfirina apresentados na figura 3.6. Esses orbitais foram obtidos a partir de cálculo no nível B3LYP/6-31+G*.

essa observação a cerca dos orbitais moleculares corrobora com o fato de observamos características bem distintas no espectro do dímero em comparação com o espectro do monômero. Esse fato corrobora também com outro fato que podemos observar que é o "desaparecimento" das bandas de monômero no espectro de dímero, mesmo para o dímero (a), onde as moléculas guardam bastante semelhante conformacional com a estrutura do monômero optimizado.

Com relação ao espectro experimental, o espectro para monômero aparenta ser 
mais condizente com o resultado experimental devido ao posicionamento dos picos e ao fato de possuir apenas duas bandas na região do visível, $Q_{x}$ e $Q_{y}$. Além disso outros trabalhos teóricos já mostraram que os dois picos mais intensos e vizinhos aos picos principais de $Q_{x}$ e $Q_{y}$ podem ser descritos ao se incluir correções vibracionais no cálculo do espectro da geometria monomérica optimizada (ver subseção 1.3.1).

Um outro fato que vemos a partir dos resultados da tabela 3.8 e na figura 3.7 é uma significante diferença nos espectros obtidos para os dímeros (a) e (b). Essa é uma observação interessante que mostra que o espectro tem características diferentes nas duas estabilizações conformacionais. Essa é uma informação importante que poderia ser utilizada, por exemplo, na determinação da estrutura mais estável do sistema em uma dada temperatura a partir da medida experimental do espectro de absorção. 
Tabela 3.8: Onze primeiros estados excitados dos dímeros de $H_{2}$-Porfirina apresentados na figura 3.6 calculados utilizando vários métodos com a base 6-31+G* (exceto ZINDO/CIS). $\lambda$ é o comprimento de onda dado em $\mathrm{nm}$, e $f$ é a força de oscilador. Resultados para as bandas $Q(0 \rightarrow 0)$ do monômero e experimental, retirados da tabela 3.2 e de [28], são apresentados. O cálculo de monômero com wB97XD foi feito a parte apenas para esta análise.

\begin{tabular}{|c|c|c|c|c|c|c|c|}
\hline & \\
\hline & & Dímero (a) & \multicolumn{2}{|c|}{ Dímero (b) } & \multicolumn{2}{|c|}{ Monômero } & \multirow{2}{*}{$\frac{\text { Experimental }}{\lambda}$} \\
\hline Método & Estado & $\lambda \quad 1$ & $\lambda$ & $f$ & $\lambda$ & $f$ & \\
\hline \multirow{13}{*}{$\begin{array}{l}\text { TD-DFT } \\
\text { (B3LYP) }\end{array}$} & $1^{\underline{O}}$ & $\begin{array}{l:l}692,9 & 0,0000\end{array}$ & 561,9 & 0,0000 & 549,1 & 0,0000 & 627,5 \\
\hline & $2^{Q}$ & $667,2: 0,0000$ & 550,6 & 0,0073 & 515,0 & 0,0001 & 511,5 \\
\hline & $\begin{array}{c}---- \\
3^{-0}\end{array}$ & $\begin{array}{c:c} & \\
582,2 & 0,0000\end{array}$ & $\begin{array}{l}--- \\
547,4\end{array}$ & 0,0000 & $---\frac{1}{1}$ & & \\
\hline & $\begin{array}{c}---- \\
4^{-}\end{array}$ & $\begin{array}{c:c} & \\
578,8 & 0,0000\end{array}$ & $\begin{array}{l}--- \\
538,4\end{array}$ & 0,0096 & $---\frac{1}{1}$ & & \\
\hline & $\begin{array}{l}---- \\
5^{\underline{0}}\end{array}$ & $\begin{array}{c:c} & - \\
538,1 & 0,0002\end{array}$ & $\begin{array}{l}--- \\
521,3\end{array}$ & $\begin{array}{l}--- \\
0,0000\end{array}$ & $\begin{array}{r}---1 \\
\vdots \\
1\end{array}$ & $\tau_{--1}-1$ & \\
\hline & $6^{0}$ & $517,7,0,0000$ & 516,7 & : & $\begin{array}{r}--1 \\
1\end{array}$ & & \\
\hline & $\begin{array}{c}---- \\
7^{0}\end{array}$ & $\begin{array}{c}--1--- \\
511,0\end{array}$ & $\begin{array}{l}---- \\
503,9\end{array}$ & $:---$ & ---+ & & ------ \\
\hline & ---- & $---1---$ & --- & $\vdash--$ & ---+ & +-- & ------- \\
\hline & $\begin{array}{l}8^{0} \\
----\end{array}$ & $\begin{array}{cccc}504,0 & \mathrm{I} & 0,0001 \\
- & - & -\end{array}$ & $\begin{array}{l}500,9 \\
-\ldots-\end{array}$ & $\begin{array}{r}0,0000 \\
-\end{array}$ & $\begin{array}{r}1 \\
\ldots \\
-\ldots\end{array}$ & & \\
\hline & $9^{\underline{0}}$ & $491,0 \quad$ । 0,0000 & 490,0 & 0,0000 & & & \\
\hline & $\begin{array}{c}---- \\
10^{0}\end{array}$ & $\begin{array}{c}-1---- \\
485,5 \\
\end{array}$ & $\begin{array}{l}--- \\
489,8\end{array}$ & $\begin{array}{l}\llcorner--- \\
0,0078\end{array}$ & $---\frac{1}{1}$ & & --- \\
\hline & ---- & $-{ }_{-} I_{-},-$ & --- & $1---$ & $---\frac{1}{1}$ & & ---- \\
\hline & $11^{0}$ & $418,6: 0,0000$ & 483,0 & 0,0000 & । & & \\
\hline \multirow{12}{*}{$\begin{array}{c}\text { TD-DFT } \\
\text { (CAM-B3LYP) }\end{array}$} & $1^{0}$ & $676,3 \quad 0,0000$ & 559,4 & 0,0000 & 573,7 & 0,0018 & 627,5 \\
\hline & $2^{0}$ & $625,0,0,0000$ & 558,2 & 0,0021 & 522,5 & 0,0016 & 511,5 \\
\hline & $\begin{array}{l}---- \\
3^{-}\end{array}$ & \begin{tabular}{c|c}
- & - \\
559,9 & 0,0030
\end{tabular} & $\begin{array}{l}--- \\
536,1\end{array}$ & {$\left[\begin{array}{l}--- \\
0,0000\end{array}\right.$} & $\begin{aligned} &--1 \\
& 1\end{aligned}$ & & \\
\hline & & 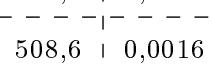 & $\begin{array}{l}--- \\
532,5\end{array}$ & $\begin{array}{l}\ulcorner--- \\
0,0112\end{array}$ & ---1 & & ---- \\
\hline & $-\frac{--}{5^{0}}$ & $\begin{array}{l}--1---- \\
502,7 \quad 1 \quad 0,0000\end{array}$ & $\begin{array}{l}--- \\
436,8\end{array}$ & $\begin{array}{l}--- \\
0,0000\end{array}$ & ---+ & & ---- \\
\hline & $\begin{array}{c}---- \\
6^{0}\end{array}$ & $\begin{array}{ccc}-1- & -1- \\
500,8 & 1 & 0,0000\end{array}$ & $\begin{array}{l}--- \\
435,3\end{array}$ & $\begin{array}{l}---- \\
0,0000\end{array}$ & ---+ & & \\
\hline & & $\begin{array}{c}--1---- \\
416,4\end{array}$ & --- & $\begin{array}{l}---- \\
0,0260\end{array}$ & $---\frac{1}{1}$ & -- & ------- \\
\hline & $\begin{array}{c}---- \\
8^{0}\end{array}$ & $\begin{array}{c}------ \\
410,9\end{array}$ & $\begin{array}{l}--- \\
422,4\end{array}$ & $\begin{array}{l}\llcorner---- \\
0,0245\end{array}$ & $---\frac{1}{1}$ & & ------- \\
\hline & --- & ${ }_{-}^{410,9} I_{-}, 0,0000$ & $\begin{array}{l}4 \angle 2,4 \\
---\end{array}$ & $1-0,0240$ & $---\frac{1}{1}$ & & ---- \\
\hline & $9^{0}$ & $406,0 \quad 0,0000$ & 415,0 & 0,0000 & & & \\
\hline & $10^{0}$ & $\begin{array}{c:c} & 0,0000\end{array}$ & 411,2 & 0,0115 & & & \\
\hline & $\begin{array}{c}-{ }^{-}- \\
11^{0}\end{array}$ & $\begin{array}{c:c} & \\
367,6 & 0,0000\end{array}$ & $\begin{array}{l}--- \\
409,1\end{array}$ & & - & & --- \\
\hline \multirow{11}{*}{$\begin{array}{c}\text { TD-DFT } \\
\text { (LC-wPBE) }\end{array}$} & $1^{0}$ & 765,6 । 0,0000 & 630,2 & 0,0023 & 671,7 & 0,0048 & 627,5 \\
\hline & $\begin{array}{l}---- \\
2^{Q}\end{array}$ & 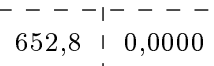 & $\begin{array}{l}--- \\
627,8\end{array}$ & $\begin{array}{l}\vdash-- \\
0,0000\end{array}$ & \begin{tabular}{l|l}
--- & + \\
571,4
\end{tabular} & 0,0032 & $\begin{array}{c}------- \\
511,5\end{array}$ \\
\hline & $\begin{array}{c}--- \\
3^{0}\end{array}$ & $\begin{array}{ccc}--1 & ---1 \\
647,1 & \mathbf{1} & 0,0070\end{array}$ & $\begin{array}{l}--- \\
582,1\end{array}$ & 0,0000 & & & \\
\hline & $\begin{array}{c}---- \\
4^{\mathrm{O}}\end{array}$ & $\begin{array}{c}--1---- \\
549,9 \text { । } 0,0032\end{array}$ & $\begin{array}{l}--- \\
581,6\end{array}$ & 0,0169 & -- & & --- \\
\hline & $--^{-{ }^{Q}}--$ & $\begin{array}{c}--1---- \\
455,4\end{array}$ & $\begin{array}{l}--- \\
399,6\end{array}$ & 0,0000 & $---\frac{1}{1}$ & & \\
\hline & --- & $\begin{array}{l:l} & \\
453,5 & 0,0000\end{array}$ & 397,5 & 0,0000 & & & \\
\hline & $\begin{array}{c}--- \\
7^{0}\end{array}$ & $\begin{array}{c:c} & \\
358,8 & 0,0000\end{array}$ & $\begin{array}{l}--- \\
374,8\end{array}$ & 0 & & & \\
\hline & $\begin{array}{c}--^{-}- \\
8^{Q}\end{array}$ & $\begin{array}{c:c} & \\
357,8 & 0,0001\end{array}$ & $\begin{array}{l}--- \\
372,9\end{array}$ & 0,0624 & & & \\
\hline & $9^{-}-$ & $\begin{array}{c:c} & - \\
348,3 & 0,0002\end{array}$ & 362,9 & 0,0000 & & & \\
\hline & $\begin{array}{c}---- \\
10^{\underline{Q}}\end{array}$ & $\begin{array}{c:c}- & - \\
347,8 & 0,0002\end{array}$ & 357,5 & 0,0384 & & & \\
\hline & $--^{-}--$ & 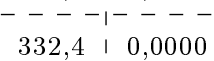 & 357,3 & 0,0000 & i & & -- \\
\hline
\end{tabular}




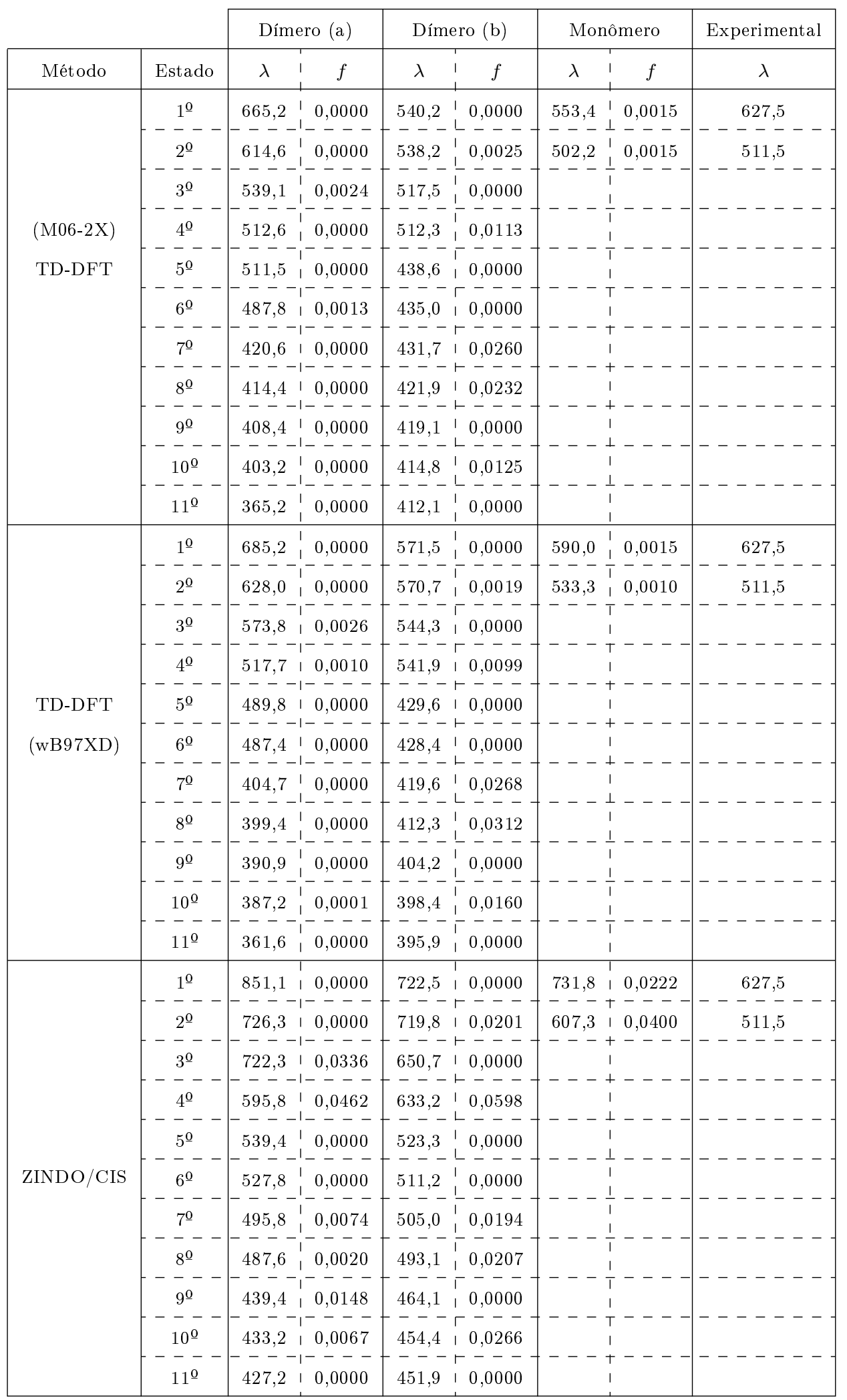




\subsubsection{Resultados de Dinâmicas Moleculares de Monômero}

Os resultados apresentados até aqui são para estruturas optimizadas. Como falamos na subseção 1.3.1 e discutimos na subseção 3.1.3, no artigo onde o espectro experimental da $H_{2}$-Porfirina é obtido [28] os autores mencionam e os resultados apresentados mostram que é necessário que a temperatura seja elevada até altos valores para que se observe absorção de luz visível pela $H_{2}$-Porfirina. Portanto, a inclusão de efeitos térmicos no tratamento teórico pode ser de grande importância para uma descrição teórica de tal fenômeno. Além disso na literatura pouca atenção é dada para a questão das baixas forças de oscilador na região do visível para estruturas optimizadas da $\mathrm{H}_{2^{-}}$ Porfirina. Por isso nesta subseção apresentaremos resultados e análises de dinâmicas moleculares, e do respectivo espectro de absorção, para o monômero de $H_{2}$-Porfirina.

Serão apresentados resultados para dinâmicas clássicas e $a b$ initio, com intuito de inferir sobre a validade da parametrização utilizada. Esse tipo de estudo é importante pois serve de base para futuros trabalhos envolvendo dinâmicas clássicas da $H_{2}$-Porfirina ou de moléculas que "contenham" a $H_{2}$-Porfirina (como mostramos na seção 1.1 a Porfirina tem um papel central na estruturação de alguns pigmentos fotossintéticos). Além disso uma comparação dos espectros teóricos, obtidos via dinâmica molecular, é feita com o espectro experimental e com o espectro da geometria optimizada.

Como mencionado na subseção 2.3.6, os parâmetros dos campos de força clássicos são geralmente obtidos de tal modo que reproduzam propriedades experimentais, e quando dados experimentais não estão disponíveis se usa resultados de cálculos $a b$ initio como base. Deste modo vamos considerar a dinâmica ab initio como base e analisar se a dinâmica clássica reproduz razoavelmente bem os resultados estruturais e também o espectro de absorção obtidos através da dinâmica ab initio. Como será apresentado e discutido posteriormente nessa subseção, novos parâmetros para o campo 
de força serão propostos com o intuito de que a dinâmica clássica melhor reproduza a dinâmica $a b$ initio.

\subsubsection{Descrição das dinâmicas}

A dinâmica $a b$ initio realizada para o monômero de $H_{2}$-Porfirina foi feita com o programa TeraChem $[78,89]$. A dinâmica da molécula isolada foi realizada no nível de cálculo DFT(B3LYP) com o conjunto de funções-base STO-3G para os hidrogênios e 6-31G para os demais átomos da molécula. A carga da molécula é neutra e a multiplicidade singleto. O timestep ( $\Delta t$, ou intervalo de integração, ver subseção 2.4.3) utilizado foi de 0,25 fs. O ensamble da simulação é o NVT, e o termostato utilizado foi o termostato de Langevin (ver manual do TeraChem [78]) com tempo de amortecimento de $\tau=250$ fs. A temperatura alvo escolhida para a simulação foi a mesma temperatura em que os resultados experimentais foram obtidos para a região do visível (ver subseção 1.3.1), ou seja, $393{ }^{\circ} \mathrm{C}$ (ou 666,15 K). O número total de passos de dinâmica realizados foi de 200000 passos, portanto o tempo total simulado foi de 50 ps.

A dinâmica clássica foi feita utilizando o programa GROMACS [73-75]. O campo de força escolhido foi o GROMOS [67,68] com o conjunto de parâmetros 53A6 [69] (ver subseção 2.3.6), recomendado para a simulação de biomoléculas em água explícita. Os valores das cargas atômicas fornecidas pela parametrização foram substituídos por valores obtidos através de um cálculo para determinação de cargas atômicas na geometria optimizada com CHelpG ${ }^{19}$ no nível B3LYP $/ 6-31+\mathrm{G}^{* *}$. Os valores dos comprimentos de ligação, ângulos, e diedros de equilíbrio também foram modificados para os valores obtidos para a estrutura optimizada da $\mathrm{H}_{2}$-Porfirina, que como dissemos nos primeiros parágrafos desta seção 3.1 foi obtida no nível B3LYP $/ 6-31+\mathrm{G}(\mathrm{d}, \mathrm{p})$. Os rótulos dados para os átomos na parametrização que realizamos são mostrados na figura 3.2

\footnotetext{
${ }^{19}$ Maiores informações sobre CHelpG podem ser encontradas na referência [61].
} 
da subseção 3.1.1, e o arquivo *.top, que contém informações da topologia e do campo de força já no formato do programa GROMACS com os valores numéricos dos parâmetros, é apresentado na subseção D.1.1 do apêndice D. O timestep utilizado foi o mesmo da dinâmica $a b$ initio, 0,25 fs. O ensamble da simulação é o NVT, e o termostato utilizado foi o V-Rescale (ver subseção 2.4.4) com tempo de amortecimento de $\tau$ $=250$ fs. A temperatura alvo escolhida para a simulação foi a mesma da simulação $a b$ initio: $393{ }^{\circ} \mathrm{C}$ (ou 666,15 K). A simulação foi feita em uma caixa cúbica com 20 nm de lado. O número total de passos de dinâmica realizados foi de 120 milhões de passos, portanto o tempo total simulado foi de $30 \mathrm{~ns}$. Demais detalhes a respeito dessa simulação podem ser consultados no arquivo *.mdp, que contém informações sobre a inicialização da dinâmica, apresentado na subseção D.1.2 do apêndice D.

O valor do timestep (0,25 fs) utilizado em ambas as simulações foi escolhido especialmente para uma melhor descrição das ligações N-H centrais, que tem um período de oscilação estimado a partir do campo de força clássico em cerca de 1,4 fs (os períodos de oscilação para as outras ligações da molécula são maiores que para as ligações N-H centrais). O parâmetro $\tau$, ou tempo de amortecimento, tem naturalmente relação direta com as flutuações de temperatura do sistema. O calor específico é uma propriedade que tem relação com as flutuações de temperatura do sistema ${ }^{20}$ e pode ser determinado através de dinâmica molecular [70]. A partir da medida experimental do calor específico do sistema seria possível determinar um parâmetro $\tau$ para o qual a dinâmica forneceria esse valor. Como no artigo experimental que reporta o espectro de absorção experimental da $H_{2}$-Porfirina não se encontra informações referentes ao calor específico, a escolha que fizemos neste trabalho para o parâmetro $\tau$ foi arbitrária. Apesar da escolha arbitrária o parâmetro $\tau$ utilizado nas dinâmicas (250fs) foi escolhido assim, um valor alto em comparação com o timestep, para tornar a dinâmica "menos artificial" pelo fato de trazer o sistema para a temperatura alvo de uma forma

\footnotetext{
${ }^{20} \mathrm{O}$ calor específico a volume constante no ensamble NVT é dado por $c_{v}=\frac{1}{N}\left(\frac{\delta U}{\delta T}\right)_{V, N}$ [90], onde $U$ é a energia do sistema, $N$ é o número de partículas, e $T$ é a temperatura.
} 
menos abrupta, ou seja, "menos agressiva". Ao fazer isso é esperado que a flutuação da temperatura em torno da temperatura alvo seja mais pronunciável, porém isso é algo aceitável e que se espera que aconteça na realidade para uma molécula isolada (apesar de não sabermos quão grande deve ser a magnitude dessa flutuação). A razão $\tau / \Delta t$ que utilizamos é a mesma que é sugerida como "default" pelo programa TeraChem. Um fato que vale aqui registrar é que realizamos dinâmicas clássicas para o monômero de $H_{2}$-Porfirina com $\tau \simeq \Delta t$ e observamos que a molécula ficava sempre planar no decorrer de toda a simulação.

\subsubsection{Termalização: escolha da região de produção}

A primeira análise feita em cima das dinâmicas foi separar as configurações geradas em duas partes: termalização e produção (ver subseção 2.4.4). Esse passo é importante porque somente as configurações da região de produção serão levadas em consideração nas análises posteriores. A figura 3.9 mostra a temperatura do sistema no decorrer dos passos para ambas dinâmicas realizadas. A figura também mostra as regiões escolhidas como termalização e produção, e o valor médio da temperatura na região de produção.
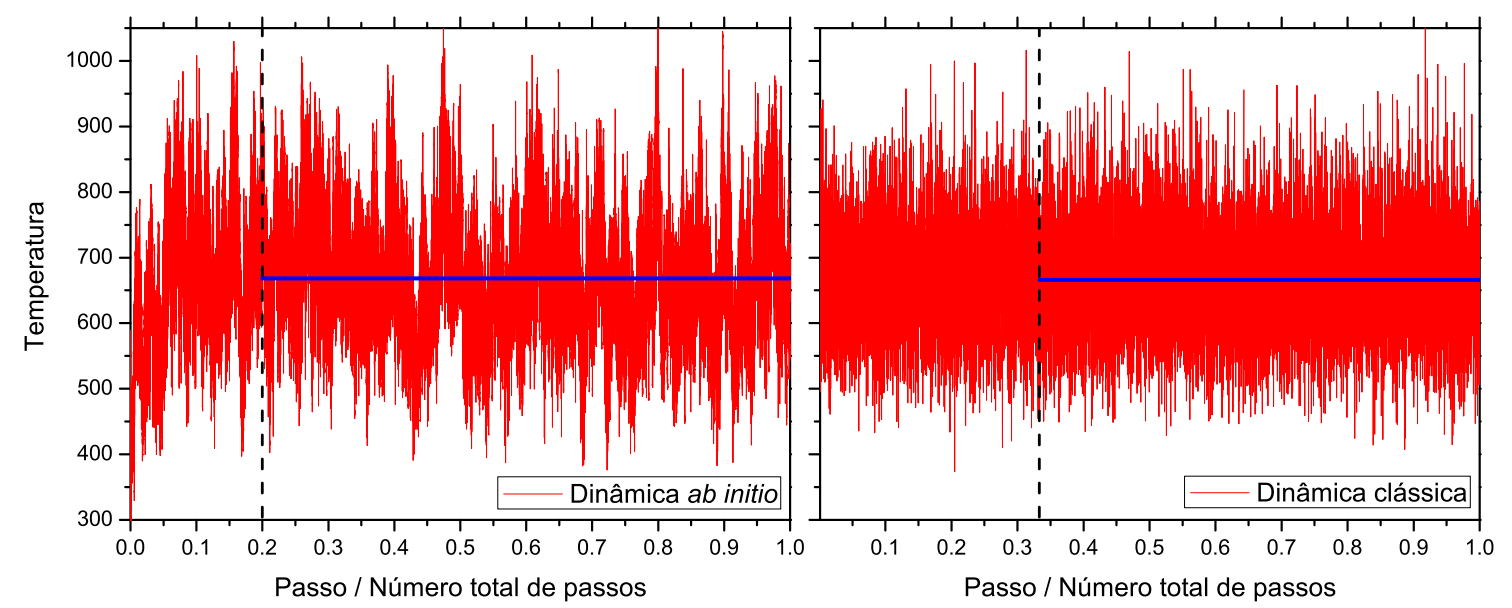

Figura 3.9: Temperatura do sistema com o passar dos passos, para as dinâmicas ab initio e clássica do monômero de $\mathrm{H}_{2}$-Porfirina. A linha tracejada separa as regiões escolhidas como termalização e como produção. A linha azul representa a temperatura média da região de produção. 
Analisando a figura 3.9 podemos ver que, para ambas dinâmicas, o comportamento inicial da temperatura é levemente diferente do restante da simulação. Podemos ver que esse comportamento diferente permanece até em torno de $15 \%$ de simulação para ambas dinâmicas. A região de termalização foi escolhida em ambos casos de tal modo que esses primeiros $15 \%$ de simulação sejam incluídos nela.

Portanto como mostrado na figura 3.9, para a dinâmica ab initio separamos os primeiros 10 ps de simulação como termalização e os 40 ps restantes como produção, e a temperatura média na região de produção foi de $(668,44 \pm 90,68) \mathrm{K}$, onde 90,68 é o desvio padrão. Para a dinâmica clássica separamos os primeiros 10 ns como termalização e os 20 ns restantes como produção, e a temperatura média na região de produção foi de $(665,78 \pm 86,89)$ K. Podemos ver que esses valores médios estão ambos em bom acordo com a temperatura alvo escolhida, de 666,15 K.

\subsubsection{Análises das estruturas geradas}

Uma vez selecionadas as configurações de produção, a etapa seguinte de análise é com relação as estruturas geradas em ambas dinâmicas. Uma pergunta que buscaremos responder é: será que as configurações geradas pela dinâmica clássica estão de acordo com as geradas pela dinâmica $a b$ initio? Na figura 3.10, apresentada a seguir, pegamos 100 configurações igualmente espaçadas a partir de toda região de produção das dinâmicas ab initio e clássica e sobrepomos. Para realizarmos a sobreposição colocamos, em todas as configurações, três átomos escolhidos no mesmo plano. Isso é feito da seguinte maneira: a molécula é transladada em cada configuração de modo que o primeiro dos átomos passe a ficar na origem em todas as configurações, depois a molécula é rotacionada em todas as configurações de modo que o segundo dos átomos fique sempre em um mesmo eixo, e por fim a molécula é rotacionada novamente em todas as configurações de modo que o terceiro dos átomos fique sempre em um mesmo plano com os outros dois átomos. 

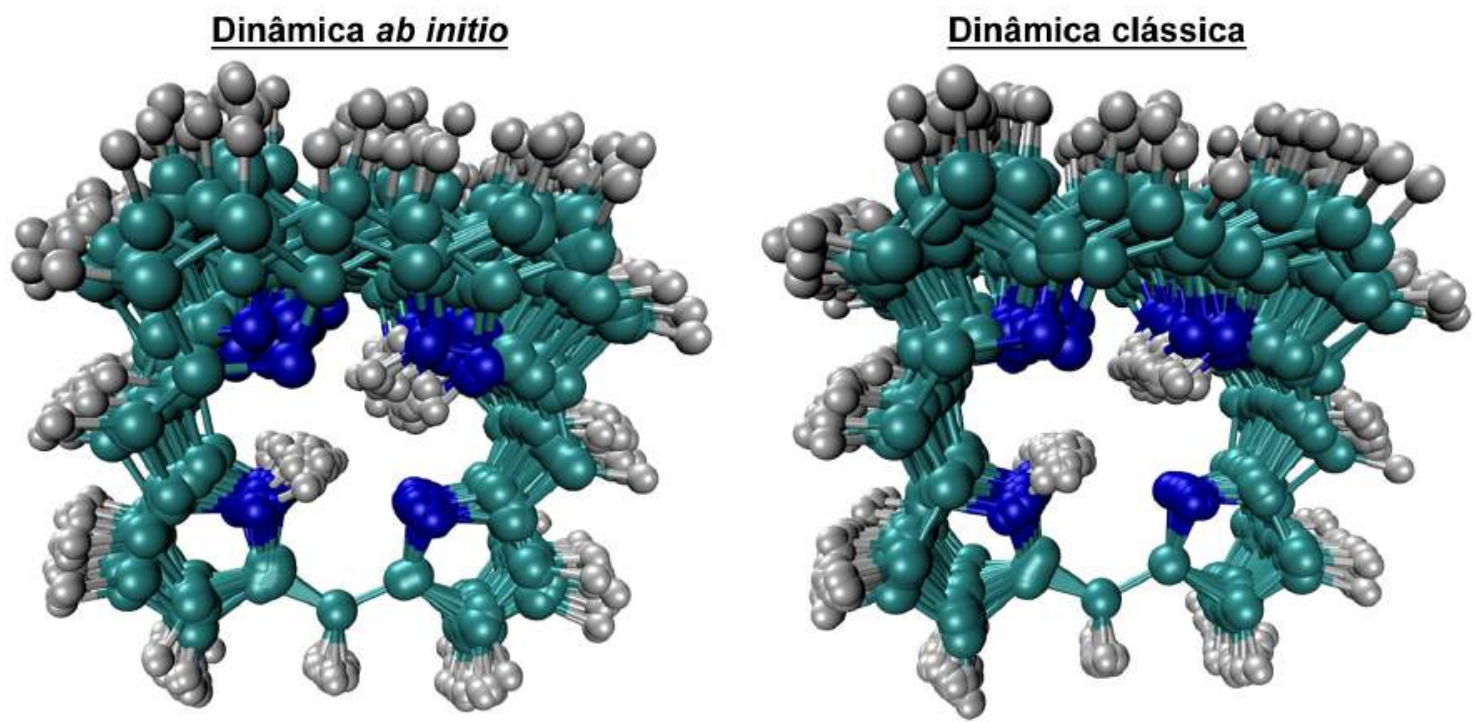

Figura 3.10: Sobreposição de 100 configurações igualmente espaçadas a partir de todas as configurações da região de produção das dinâmicas ab initio e clássica da $H_{2}$-Porfirina.

A figura 3.10 já nos da uma ideia preliminar de como são as estruturas geradas em ambas as dinâmicas. Para uma análise mais detalhada um questionamento surge: como comparar 20 ns da dinâmica clássica com 40 ps da dinâmica ab initio? A maneira que optamos para fazer isso é através da análise da distribuição de valores (ou histograma) normalizada (ou percentual) para distâncias atômicas, ligações, ângulos e diedros. Esse tipo de análise se faz necessária pois nossas capacidades computacionais para a dinâmica $a b$ initio não nos permitem simular muito além dos 50 ps simulados. Já na dinâmica clássica a simulação pode ser feita extremamente mais rápida, e por isso simulamos 30 ns. A figura 3.11 apresenta as distribuições de valores considerados relevantes para algumas distâncias atômicas de átomos não ligados e ligados, ângulos e diedros, obtidos através de 8000 configurações igualmente espaçadas da região de produção das dinâmicas ab initio e clássica. 

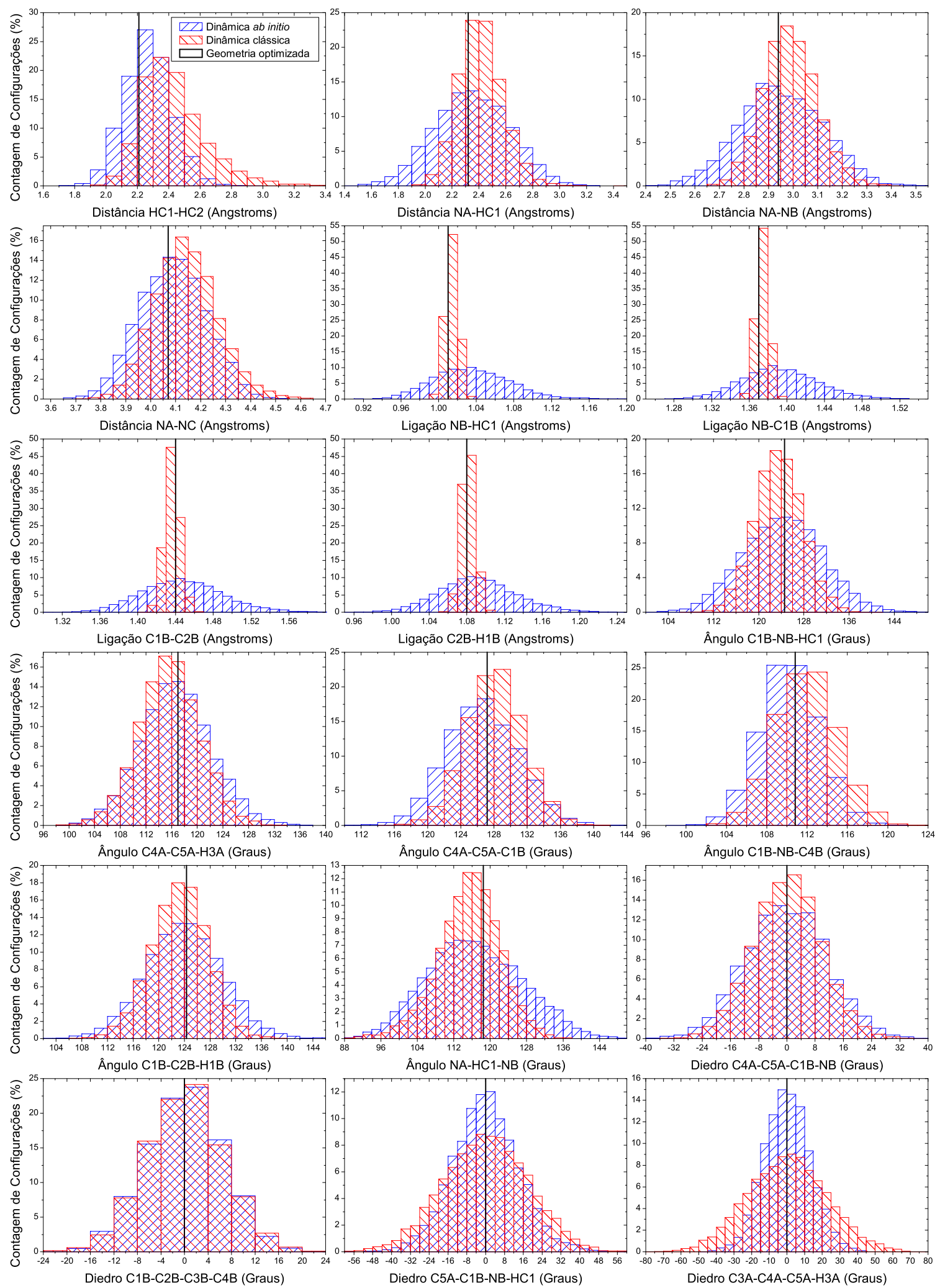

Figura 3.11: Distribuição de valores de distâncias atômicas, ligações, ângulos e diedros, obtidos a partir de 8000 configurações igualmente espaçadas da região de produção das dinâmicas $a b$ initio e clássica da $H_{2}$-Porfirina. Os rótulos dos átomos são mostrados na figura 3.2. 
Como mencionado na subseção 2.3.6, pela própria natureza de sua construção os campos de força clássicos possuem limitações por serem uma aproximação para descrever as interações moleculares, que sem dúvidas são mais corretamente descritas com um Hamiltoniano quântico. Desse modo não esperamos que a dinâmica clássica reproduza detalhadamente os mesmo resultados da dinâmica $a b$ initio, apenas esperamos que os resultados produzidos sejam concordantes.

Tendo isso em mente, analisando a figura 3.11 vemos que os valores mais prováveis das distâncias entre átomos que não se ligam divergem da ordem de $\sim 0,1 \AA$ entre as duas dinâmicas e que a distribuição de valores em boa parte dos casos é não simétrica. Podemos ver também que a distribuição de valores para as distâncias de átomos ligados está bem mais concentrada na dinâmica clássica do que na ab initio. Isso indica que na dinâmica $a b$ initio os átomos tem uma elasticidade maior do que a que foi dada aos átomos pelo campo de força utilizado na dinâmica clássica. Não podemos deixar de observar as ordens de grandeza dos valores envolvidos nessas ligações. Por exemplo, para ligação NB-HC1 os valores variam dentro de uma faixa de $\sim 0,05 \AA$ na dinâmica clássica e em um faixa de $\sim 0,17 \AA$ na dinâmica $a b$ initio. Mesmo esses valores sendo pequenos essas diferenças podem ser relevantes, e o fato de os átomos estarem mais fortemente ligados na dinâmica clássica do que na dinâmica ab initio pode levar também a outros tipos de diferenças estruturais que podem ser relevantes, como será discutido na subseção 3.1.5.5, e também a diferenças no espectro de absorção, como será discutido nas subseções 3.1.5.6 e 3.1.5.7.

Podemos ver que os valores de distâncias, ângulos e diedros de átomos ligados estão distribuídos na mesma região em que se encontram os valores para a geometria optimizada. Na dinâmica $a b$ initio existe um pequeno deslocamento dos valores médios das ligações em relação a estrutura optimizada da ordem de $\sim 0,03 \AA$, mas essa é uma diferença pequena pois é bem menor do que o valor da ligação na geometria optimizada. Portanto, sobre essa perspectiva, os valores médios obtidos em ambas as 
dinâmicas para as distâncias de átomos ligados são concordantes e as diferenças entre eles é tolerável, mas a mesma conclusão não é válida para a distribuição de valores (veja que os valores são distribuídos de forma mais concentrada na dinâmica clássica). Para os gráficos dos ângulos e diedros podemos ver que existe uma concordância razoável entre os valores mais prováveis e as distribuições de valores entre as duas dinâmicas (com exceção da distribuição para o ângulo C1B-NB-HC1). No caso dos ângulos as diferenças entre os valores mais prováveis são da ordem de $\sim 2^{\circ}$. Para diedros os valores mais prováveis coincidem entre si e com o valor da geometria optimizada, e como as distribuições são aproximadamente simétricas, esse é um indicativo de que em média a molécula fica planar durante ambas dinâmicas ${ }^{21}$.

Com relação a distância de átomos não ligados podemos ver que a distribuição de valores não ocorre de maneira homogênea em relação aos valores para a geometria optimiza. No caso da distância NA-NC, por exemplo, quando os átomos se afastam um do outro mais do que o valor na geometria optimizada eles se aproximam mais dos carbonos com os quais estão ligados e quando se aproximam mais um do outro eles se distanciam desses carbonos indo para uma região onde não há átomos ligados, portanto o ambiente presenciado nas duas situações é distinto. Por isso a distribuição de valores não simétrica mostrada na figura 3.11 para essas distâncias é esperada.

Com base nas análises realizadas, de uma maneira geral, podemos concluir que os valores médios (ou mais prováveis) obtidos para as distâncias atômicas, ângulos e diedros analisados são concordantes nas dinâmicas ab initio e clássica, e também estão de acordo com os valores para a geometria optimizada. Mas o fato de os valores das ligações estarem bem mais concentrados na dinâmica clássica, indicando que os átomos estão mais fortemente ligados do que na dinâmica $a b$ initio, pode ser significativo e acarretar em outros tipos de diferenças estruturais como também em diferenças no

\footnotetext{
${ }^{21}$ Esse é apenas um indicativo pois olhamos apenas para a distribuição de valores de alguns diedros. Para uma conclusão mais concreta seria necessário olhar para todos os diedros. Ainda assim os gráficos apresentados para esses diedros são fortes indicativos.
} 
espectro de absorção. Portanto na subseção 3.1.5.4 a seguir apresentaremos resultados para uma nova dinâmica clássica feita com parâmetros modificados com o intuito de melhor reproduzir as distribuições de valores da dinâmica $a b$ initio, principalmente para as ligações.

\subsubsection{Alteração de parâmetros do campo de forças clássico}

Visando reproduzir melhor as distribuições de valores da dinâmica $a b$ initio, alteramos algumas constantes de força da parametrização que utilizamos inicialmente e realizamos uma nova dinâmica clássica. As novas constantes de força foram obtidas a partir de uma estimativa onde a energia de vibração de uma ligação na dinâmica clássica é considerada como uma equação do tipo $E \propto k_{r}\left(r-r_{e q}\right)^{2}$, e portanto a força da ligação entre os átomos é proporcional a $-k_{r} r$. Essa interação permite que a ligação assuma valores apenas dentro de um certo intervalo, como pode ser visto na figura 3.11. A largura deste intervalo está naturalmente associada com a constante de força $k_{r}$, e portanto quanto maior é $k_{r}$ mais concentrada é a distribuição de valores e quanto menor é $k_{r}$ mais espalhada é a distribuição. Pelas distribuições de valores das ligações na dinâmica $a b$ initio é possível extrair qual é o menor $\left(r_{\min }\right)$ e o maior $\left(r_{\max }\right)$ valor assumido pela ligação (ou seja, o intervalo de valores assumidos pela ligação) e também a distância de equilíbrio $\left(r_{e q}\right)$, que deve corresponder ao valor mais provável da distribuição. Com essas informações é possível estimar uma nova constante de força $k_{r}^{\prime}$ para a dinâmica clássica que tenha os valores de $\Delta r_{\min }$ e $\Delta r_{\max }$ (onde $\Delta r=r-r_{e q}$ ) mais compatíveis com a dinâmica ab initio (ou seja, que o alargamento da distribuição seja mais compatível) da seguinte maneira:

$$
k_{r}^{\prime}=k_{r} \frac{\left(r_{\min }^{(c)}-r_{e q}^{(c)}\right)^{2}+\left(r_{\max }^{(c)}-r_{e q}^{(c)}\right)^{2}}{\left(r_{\min }^{(q)}-r_{e q}^{(q)}\right)^{2}+\left(r_{\max }^{(q)}-r_{e q}^{(q)}\right)^{2}}
$$

onde os valores com $(c)$ são tirados dos histogramas da dinâmica clássica e os valores com $(q)$ da dinâmica quântica ( $a b$ initio) da figura 3.11. Os valores de $r_{\min }$ e $r_{\max }$ 
são escolhido de modo que o número de configurações com valores neste intervalo seja aproximadamente o mesmo nas duas dinâmicas. Por exemplo, para a ligação NB-C1B os valores escolhidos são $r_{\min }^{(c)}=1,36 \AA, r_{\max }^{(c)}=1,39 \AA, r_{\min }^{(q)}=1,31 \AA$ e $r_{\max }^{(c)}=1,49$ $\AA$, e os valores de equilíbrio são $r_{e q}^{(c)}=1,374 \AA$ e $r_{e q}^{(q)}=1,393 \AA$. Utilizando esses valores e a equação 3.1 temos que $k_{r}^{\prime} / k_{r}=2,773 \cdot 10^{-2}$. Como esperado obtemos uma nova constante de força $k_{r}^{\prime}$ que deixa os átomos mais fracamente ligados, e podemos ver que $k_{r}^{\prime}$ é duas ordens de grandeza menor que $k_{r}$. Razões em torno dessa ordem de grandeza também são obtidas para as outras novas constantes de força, como pode ser visto em D.1.1.

Calculamos novas constantes de força para as ligações NB-HC1, NB-C1B, C1BC2B e C2B-H1B, e também para o ângulo de átomos ligados $\mathrm{C} 1 \mathrm{~B}-\mathrm{NB}-\mathrm{HC}^{22}$. A nova constante de força obtida para NB-HC1 foi utilizada para todas as ligações $\mathrm{N}-\mathrm{H}$ na nova parametrização, assim como a nova constante para NB-C1B em todas ligações $\mathrm{N}-\mathrm{C}$, a de C1B-C2B em todas ligações C-C, e a de C2B-H1B em todas as ligações C-H. Portanto, como pode ser checado na figura 3.2, os valores das constantes de força de todas as ligações foram alterados. A nova constante de força obtida para o ângulo C1B-NB-HC1 foi utilizada apenas nos ângulos equivalentes para dos dois hidrogênios centrais, portanto apenas quatro constantes de força para os ângulos foram modificadas. Os valores originais e os modificados para as constantes de força estão apresentados na subseção D.1.1 do apêndice D.1, juntamente com todos os demais outros parâmetros. Vale aqui frisar que as distância e ângulos de equilíbrio não foram alterados nesta nova parametrização, permanecendo ainda os da geometria optimizada.

A nova dinâmica clássica com os parâmetros modificados foi feita com os mesmos parâmetros de simulação anunciados na subseção 3.1.5.1 e apresentados na subseção D.1.2 do apêndice D.1. Novamente os $10 \mathrm{~ns}$ iniciais de simulação foram escolhidos como região de termalização, e portanto a região de produção é composta pelos 20 ns

\footnotetext{
${ }^{22} \mathrm{O}$ raciocínio para obter a constante de força nesse caso é o mesmo, basta trocar $r$ e $k_{r}$ por $\theta$ e $k_{\theta}$ na equação 3.1 .
} 
restantes. A temperatura média obtida na região de produção é $(667,12 \pm 90,66) \mathrm{K}$, compatível com a temperatura alvo do termostato que é de $666,15 \mathrm{~K}$.

Utilizando a nova dinâmica clássica a figura 3.11 que contem as distribuições de valores nas dinâmicas $a b$ initio e clássica foi refeita e é apresentada na figura 3.12.

Analisando a figura 3.12 podemos ver que a dinâmica clássica com os parâmetros modificados fornece distribuições de valores muito mais condizentes com a dinâmica $a b$ initio do que a dinâmica clássica feita com a parametrização GROMOS 53A6 original (cujos resultados são apresentados na figura 3.11). Podemos ver que agora o alargamento das distribuições de valores para as ligações e para o ângulo C1B-NBHC1, que tiveram as constantes de força corrigidas, são bastante concordantes. Desse modo podemos concluir que a dinâmica clássica com o campo de forças modificado produz resultados estruturais bem mais compatíveis com a dinâmica ab initio do que a dinâmica clássica utilizando o campo de força com as constantes de força originais GROMOS 53A6. Esse já é um primeiro indicativo da relevância da modificação de parâmetros realizada. 

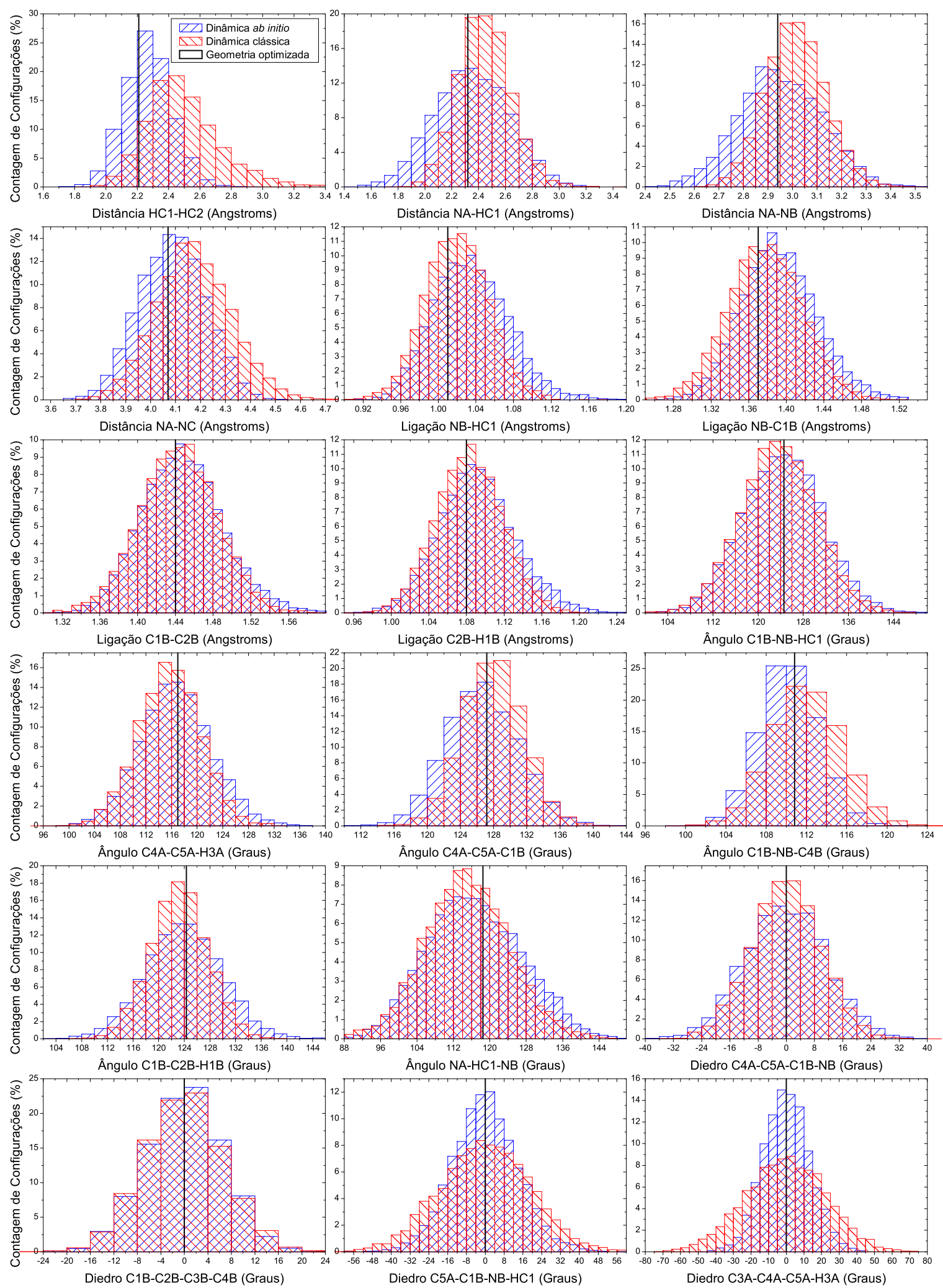

Figura 3.12: Distribuição de valores de distâncias atômicas, ligações, ângulos e diedros, obtidos a partir de 8000 configurações igualmente espaçadas da região de produção das dinâmicas $a b$ initio e clássica (com parâmetros modificados) da $\mathrm{H}_{2}$-Porfirina. Os parâmetros desta dinâmica clássica são apresentados na subseção D.1.1. Os rótulos dos átomos são mostrados na figura 3.2. 


\subsubsection{Influência de um hidrogênio central na estrutura}

Uma vez estabelecido esse novo conjunto de parâmetros para o campo de força da dinâmica clássica, analisamos um outro aspecto estrutural: como a posição dos hidrogênios centrais altera a estruturação central da $H_{2}$-Porfirina. Na estrutura optimizada o átomo HC1 está ligado ao nitrogênio NB. O hidrogênio $\mathrm{HC} 1$ pode se deslocar na direção dos outros hidrogênios centrais que não tem um hidrogênio ligados a eles. Nas figuras 3.11 e 3.12 a partir das distribuições de distâncias entre os átomos NA e HC1 podemos ver que o átomo $\mathrm{HC} 1$ se aproxima de NA mais na dinâmica $a b$ initio do que na dinâmica clássica, mas por poucas configurações. O valor de uma ligação $\mathrm{N}-\mathrm{H}$ central, como pode ser visto nas figuras, é de 1,01 $\AA$ na geometria optimizada, e a distância NA-HC1 chega até $~ 1,5$ Å na dinâmica ab initio, porem essa distância possui valores entre 1,4 e 1,8 $\AA$ em apenas aproximadamente $3 \%$ das configurações.

Ainda em cima da discussão do parágrafo anterior, apresentamos na figura 3.13 o gráfico da razão entre as distâncias NB-NC e NA-NB em função da razão entre as distâncias NB-HC1 e NA-HC1 para as dinâmicas ab initio e clássica, e geometria optimizada. Na figura são apresentados os gráficos para a primeira dinâmica clássica feita com a parametrização GROMOS 53A6 para as constantes de força, que a partir de agora também será chamada de dinâmica clássica/G, e para a segunda dinâmica clássica feita com os parâmetros modificados que a partir de agora também será chamada de dinâmica clássica/Gm. Os gráficos apresentados foram feitos a partir de 8000 configurações igualmente espaçadas da região de produção das duas dinâmicas clássicas e da dinâmica $a b$ initio.

Pela figura 3.13 vemos que a razão NB-NC/NA-NB entre as distâncias dos nitrogênios centrais muda dependendo do posicionamento do hidrogênio HC1. A figura mostra que a medida que HC1 começa a se afastar do nitrogênio NB no qual estava ligado para o nitrogênio NA vizinho (ou seja, a medida que a razão NB-HC1/NA-HC1 

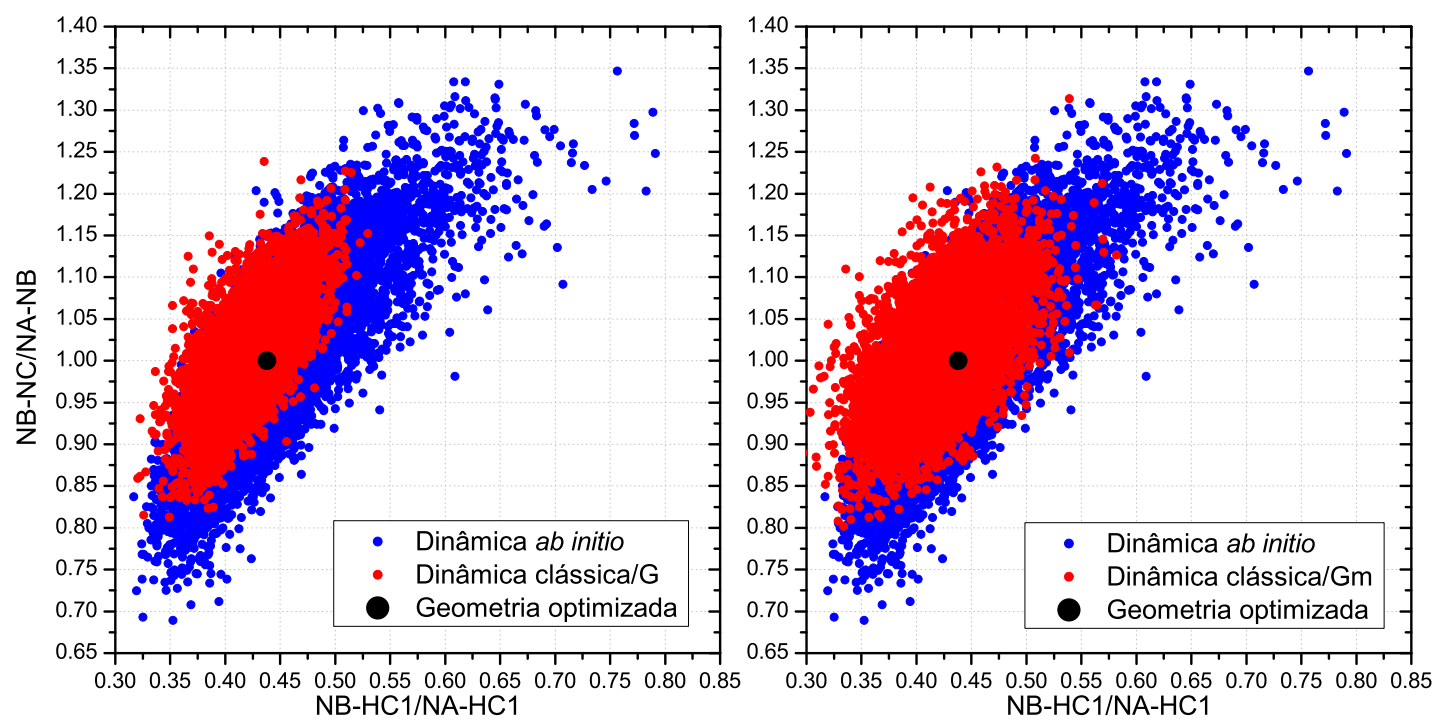

Figura 3.13: Influência da posição de um hidrogênio central na estrutura central da $H_{2^{-}}$ Porfirina. O gráfico da esquerda foi feito com a primeira dinâmica clássica (ver figura 3.11) e o gráfico da direita com a segunda dinâmica clássica utilizando parâmetros modificados (ver figura 3.12). Nos gráficos é apresentada a razão entre as distâncias NB-NC e NA-NB em função da razão entre as distâncias NB-HC1 e NA-HC1 para as dinâmicas ab initio e clássica, obtidos a partir de 8000 configurações igualmente espaçadas da região de produção de ambas dinâmicas. O ponto correspondente a geometria optimizada também é apresentado. Os rótulos dos átomos são mostrados na figura 3.2.

aumenta em relação ao valor da geometria optimizada) a distância NB-NC aumenta em relação a distância NA-NB, chegando a estar até mais de 30\% maior em algumas configurações da dinâmica ab initio. Quando HC1 se afasta de NA (ou seja, quando a razão NB-HC1/NA-HC1 diminui em relação ao valor da geometria optimizada) ficando portanto mais próximo de NC, a distância NB-NC diminui em relação a distância NANB, chegando a ficar até cerca de $30 \%$ menor em algumas configurações da dinâmica $a b$ initio. Os pontos que vemos nos gráficos não são simétricos em relação ao ponto da geometria optimizada porque quando $\mathrm{HC} 1$ se afasta de NA se aproximando da região onde NC está, não sabemos ao certo o quão próximo de NC o átomo HC1 está.

Como podemos ver na figura 3.13 as dinâmicas clássicas, apesar de descreverem as mesmas tendências da dinâmica $a b$ initio, não visitam todos os pontos visitadas pela 
dinâmica $a b$ initio nos gráficos, ficando mais restritas apenas as regiões mais próximas da geometria optimizada. Como pode ser visto na figura, a dinâmica clássica/G, cujas constantes de força para as ligações e para os ângulos do tipo C-N-H são mais altas, a movimentação da molécula é mais restrita. Para a dinâmica clássica/Gm com os parâmetros modificados a amostragem é notavelmente melhor, pois os átomos estão mais "soltos", se assemelhando mais ao comportamento dos átomos na dinâmica $a b$ initio.

Após analise da figura 3.13, como todas as dinâmicas realizadas indicam, podemos concluir que o posicionamento dos hidrogênios centrais influencia na estruturação central da $H_{2}$-Porfirina, ou seja, na estruturação do macrociclo. Podemos concluir também que a dinâmica clássica feita com parâmetros modificados é capaz de descrever isso de uma forma mais condizente com a dinâmica $a b$ initio do que a dinâmica feita com a parametrização GROMOS 53A6 para as constantes de força.

A partir das análises estruturais apresentadas aqui e também nas duas subseções anteriores fica claro que existem diferenças entre os resultados providos pelas dinâmicas clássicas e pela dinâmica $a b$ initio. Porém uma questão fundamental é: as diferenças estruturais entre dinâmicas clássicas e $a b$ initio são relevantes para uma correta descrição do espectro de absorção? Ou então: as diferenças estruturais entre dinâmicas clássicas e $a b$ initio são grandes o suficiente para gerarem espectros de absorção não concordantes? Vamos buscar analisar isso a seguir.

\subsubsection{Análise de convergência para o espectro de absorção}

O número de configurações de produção geradas nas dinâmicas é bem elevado, 160 mil configurações na dinâmica $a b$ initio e 80 milhões configurações em cada dinâmica clássica. Tratar todas essas configurações exigiria um altíssimo custo computacional. Além disso configurações sucessivas guardam ainda muitas semelhanças entre si e por isso geram valores muito próximos, ou estatisticamente correlacionados, para o espec- 
tro de absorção. Portanto realizar cálculos em configurações sucessivas acaba sendo um desperdício de tempo computacional e acrescenta pouca informação estatística nos resultados.

Para contornar essa dificuldade apresentamos aqui resultados obtidos a partir de conjuntos de configurações igualmente espaçadas (também chamadas de configurações descorrelacionadas) retiradas da região de produção das dinâmicas. Dessa maneira analisando os resultados para conjuntos com tamanhos diferentes é possível analisar a convergência das propriedades associadas ao espectro de absorção, como as energias de excitação, forças de oscilador, e também a convolução do espectro.

O cálculo do espectro de absorção utilizando TD-DFT para uma molécula grande como a $\mathrm{H}_{2}$-Porfirina é extremamente mais computacionalmente custoso do que utilizando o método semi-empírico ZINDO/CIS. Como foi mostrado na figura 3.5 apresentada na subseção 3.1.4.1 o ZINDO/CIS fornece em relação ao espectro experimental uma concordância razoável para as posições dos picos na região fora do visível, enquanto os picos na região do visível, correspondentes as bandas $Q$, estão bastante deslocados para maiores comprimentos de onda (ou seja, deslocados para o vermelho). Mesmo assim utilizar o ZINDO/CIS é uma boa opção aqui para as análises que pretendemos fazer, como análise de convergência, análise das diferenças entre os espectros para as diferentes dinâmicas, e como as bandas são compostas. As conclusões qualitativas que chegarmos devem ser independentes do método de cálculo escolhido. A palavra "qualitativa" aqui é extremamente apropriada pois, como a figura 3.5 mostra claramente, as posições dos picos e as respectivas forças de oscilador sofrem muitas diferenças para os diferentes métodos.

A figura 3.14 mostra resultados obtidos através das duas dinâmicas clássicas e da dinâmica $a b$ initio para o espectro de absorção para diferentes números de configurações descorrelacionadas. São apresentados os valores médios e os respectivos desvios padrão para as energias de excitação e as forças de oscilador. É importante mencio- 
nar aqui que os valores médios e os desvios padrão para as energias de excitação são ponderados pelas forças de oscilador, enquanto os valores médios e os desvios padrão para as forças de oscilador não são ponderados. Também é apresentada a convolução dos picos teóricos utilizando Lorentzianas (ver subseção 2.2.6) para diferentes números de configurações descorrelacionadas. Os cálculos de espectro para cada configuração foram feitos utilizando o método ZINDO/CIS considerando apenas transições dos 25 orbitais mais altos ocupados para os 25 mais baixos desocupados. O cálculo foi feito para as 49 primeiras excitações.

Como pode ser visto a partir dos gráficos para as convoluções do espectro apresentados na figura 3.14, a convergência para as excitações além das bandas $Q$ é bem mais rápida, por isso nos gráficos à esquerda focamos apenas nas duas primeiras excitações correspondentes as bandas $Q$.

Analisando a figura podemos ver que a partir de 200 configurações já temos razoavelmente a mesma descrição para a posição dos picos, os alargamentos das bandas, e as intensidades relativas entre as bandas. Apesar de ainda termos algumas diferenças em comparação com um número maior de configurações, isso quer dizer que as conclusões que chegarmos a partir da descrição feita com 200 configurações devem ser essencialmente as mesmas se usarmos um número maior de configurações descorrelacionadas. Desse modo podemos concluir que uma convergência razoável das propriedades do espectro de absorção já é alcançada utilizando 200 configurações descorrelacionadas.

Pela figura podemos ver que os espectros obtidos para a dinâmica clássica/G são mais concentrados em relação aos obtidos com as outras dinâmicas, e por isso os desvios padrão também são menores. Podemos associar esse comportamento as questões levantadas na subseção 3.1.5.3 com relação as constantes de força utilizadas na parametrização do campo de força. As altas constantes de força deixaram os átomos mais presos e com isso vibrando menos. Essa menor vibração molecular distorce menos a estrutura molecular em relação a geometria optimizada e por isso os picos do espectro 

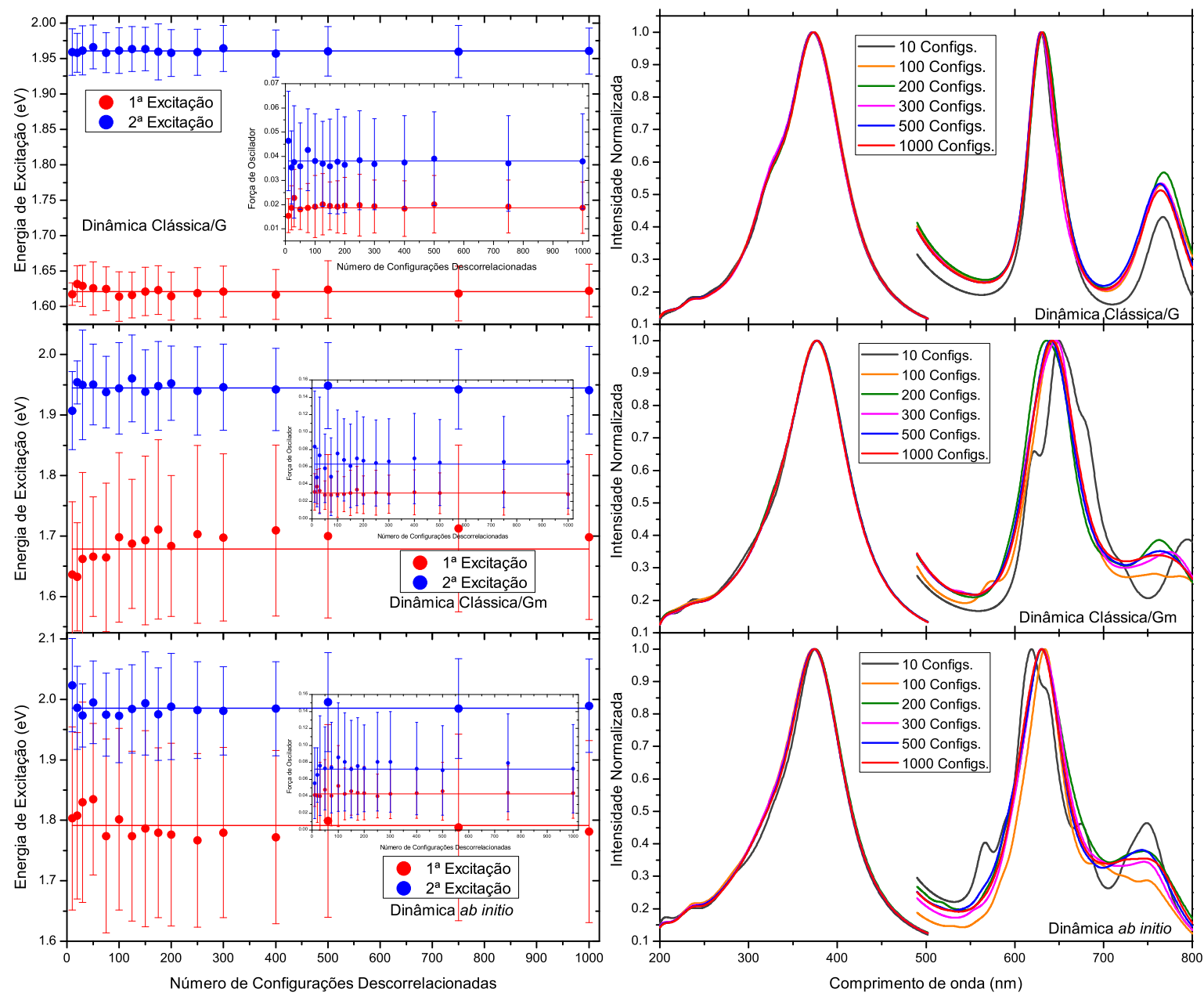

Figura 3.14: Convergência do espectro de absorção para a primeira dinâmica clássica $(\mathrm{G})$, para a segunda dinâmica clássica ( $\mathrm{Gm}$, com parâmetros modificados) e para a dinâmica $a b$ initio da $\mathrm{H}_{2}$-Porfirina. Os gráficos à esquerda mostram a convergência das duas primeiras energias de excitação e das forças de oscilador correspondentes, e os gráficos à direita a convolução utilizando Lorentzianas de todos os picos teóricos obtidos. Os cálculos do espectro foram feitos utilizando o método ZINDO/CIS.

teóricos permanecem mais concentrados. Essa discussão será melhor detalhada na próxima subseção.

A figura 3.14 também mostra que os desvios padrão da dinâmica clássica/Gm são bem mais compatíveis com a dinâmica ab initio do que os desvios padrão da dinâmica clássica/G. Essa mesma conclusão se estende para as convoluções do espectro na região 
das bandas $Q$. Podemos ver que a concordância com a dinâmica $a b$ initio é melhor na dinâmica clássica/Gm que na dinâmica clássica/G.

Assim então, a figura 3.14 já mostra claramente a influência da nova parametrização no espectro de absorção. Podemos concluir que a nova parametrização foi relevante e que as diferenças estruturais encontradas na dinâmica clássica/G em comparação com a dinâmica $a b$ initio são significativas para a descrição e a caracterização do espectro de absorção. A figura também indica claramente que a inclusão de efeitos vibracionais através de dinâmica molecular influencia principalmente as bandas $Q$. Esse e outros aspectos do espectro serão discutidos em mais detalhes a seguir.

\subsubsection{Detalhamento do espectro de absorção}

Seguindo com as discussões da última subseção, apresentaremos aqui comparações dos resultados obtidos para 200 configurações descorrelacionadas. As comparações serão feitas entre os resultados em si e também com o espectro da geometria optimizada e o experimental. A composição dos espectros teóricos também será discutida.

Na figura 3.15 mostramos a convolução dos picos teóricos e os valores médios de cada excitação. Os valores médios para as energias de excitação são ponderados pela força de oscilador, e depois são convertidos para nm e apresentados na figura. Os resultados para geometria optimizada e também o espectro experimental são apresentados. É importante frisar que uma largura de linha diferente foi utilizada na região das bandas $Q$ e que as convoluções foram renormalizadas nessa região, porém as excitações médias não foram renormalizadas, por isso linhas tracejadas são incluídas para mostrar melhor o posicionamento das bandas na região do visível.

Além do cálculo com ZINDO/CIS feito para quarenta e nove estados excitados, realizamos também um cálculo com TD-DFT(M06-2X) com a base 6-31G* os seis primeiros estados excitados para as dinâmicas clássica/Gm e ab initio. O método TD-DFT(M06-2X) foi escolhido por ser para estrutura optimizada, dos métodos que 
utilizamos, juntamente com o TD-DFT(CAM-B3LYP), o método que fornece a melhor concordância com o resultado experimental, como pode ser visto na tabela 3.6 e 3.5. A escolha da base $6-31 \mathrm{G}^{*}$ e de calcular apenas os seis primeiros estados excitados foi feita unicamente com o intuito de reduzir o custo computacional dos cálculos ${ }^{23}$.

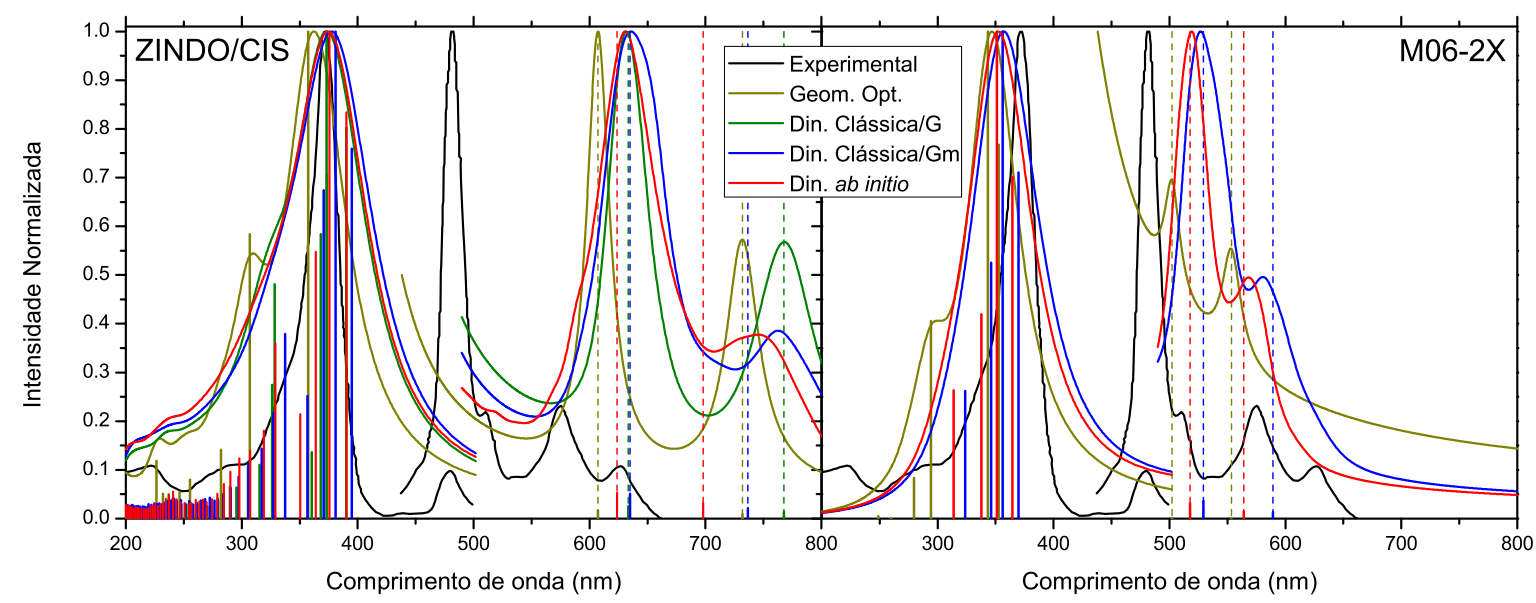

Figura 3.15: Comparação de resultados para os espectros de absorção teóricos de 200 configurações descorrelacionadas obtidos através da primeira dinâmica clássica $(\mathrm{G})$, da segunda dinâmica clássica (Gm, com parâmetros modificados) e da dinâmica ab initio da $H_{2}$-Porfirina. O espectro da estrutura optimizada e o espectro experimental também são apresentados. As linhas verticais apresentadas representam os valores médios das excitações, e as linhas tracejadas são uma ampliação desses valores para as bandas $Q$. Os cálculos do espectro foram feitos utilizando o método ZINDO/CIS e também com M06-2X/6-31G* para duas das dinâmicas.

A figura 3.15 indica que, para ambos métodos de cálculo utilizados, as forças de oscilador médias das bandas $Q$ em comparação com a banda de Soret obtidas via dinâmica molecular são maiores do que para a geometria optimizada. Utilizando o ZINDO/CIS, na dinâmica clássica/G as forças de oscilador médias para as duas primeiras excitações e para a excitação mais intensa na banda de Soret são respectivamente 0,0197, 0,0365 e 1,4336, na dinâmica clássica/Gm são 0,0279, 0,0671 e 1,3212, na dinâmica $a b$ initio são 0,0435, 0,0726 e 1,3572, e na geometria optimizada são

\footnotetext{
${ }^{23}$ Como será mostrado na subseção 3.2 .2 , para a $H_{2}$-Ftalocianina o custo computacional com a base $6-31 G^{*}$ é bem menor que com outras bases maiores, mas os resultados fornecidos possuem diferenças. Como estamos lidando com esse número elevado de 200 configuração, para que o cálculo se torne viável dentro das nossas capacidades computacionais essas escolhas visando a redução do custo computacional tiverem que ser priorizadas.
} 
0,0222, 0,0400 e 2,3592. Podemos ver portanto que, em comparação com a geometria optimizada, a inclusão de efeitos térmicos via dinâmica molecular tende em média a diminuir a força de oscilador na região de Soret e aumentar na região do visível.

Com relação a posição dos picos, a figura mostra que na região do visível os picos sofrem um deslocamento para maiores comprimentos de onda (para o vermelho) em relação aos picos da estrutura optimizada. Podemos ver que, assim como para a estrutura optimizada, os picos da região do visível obtidos via dinâmica molecular permanecem ainda a direita (muito a direita no caso de ZINDO/CIS) do espectro experimental para as bandas $Q$. Com relação a banda de Soret, assim como para a geometria optimizada, os espectros obtidos via dinâmica molecular tem uma boa concordância com o valor experimental. Assim como para a estrutura optimizada, os resultados obtidos com TD-DFT(M06-2X) se mostraram mais compatíveis o espectro experimental que com ZINDO/CIS.Além desses fatos, os resultados também mostram a importância do alargamento das bandas obtido via inclusão de efeitos térmicos através de dinâmica molecular para a descrição e caracterização do espectro de absorção.

Assim como indicado na figura 3.14, a figura 3.15 mostra que existem diferenças nos valores médios das energias de excitação e das forças de oscilador, bem como na forma do espectro convoluido, entre as diferentes dinâmicas. A figura mostra que essas diferenças são mais pronunciáveis para a primeira excitação, e também, mas em um grau menor, para a segunda excitação. A concordância entre as diferentes dinâmicas para as demais bandas é bem melhor.

Como fica claro pela figura 3.15, é importante olhar além do valor médio. Por isso na figura 3.15 abaixo apresentamos um detalhamento do espectro teórico obtido para todas dinâmicas, e através dessa figura é possível ver como o espectro é composto. A figura mostra cada um dos picos de cada uma das 200 configurações utilizadas para compor o espectro, e cada excitação é apresentada com uma coloração diferente (os picos referentes a primeira excitação tem coloração vermelha, os referentes a segunda 
tem coloração azul, e assim por diante). A figura também mostra os valores médios das excitações (onde os valores das energias de excitação são ponderados pelas forças de oscilador) e a convolução por Lorentzianas (ver seção 2.2.6). Nessa figura as convoluções não foram normalizadas, mas uma largura de linha diferente foi utilizada na região das bandas $Q$.

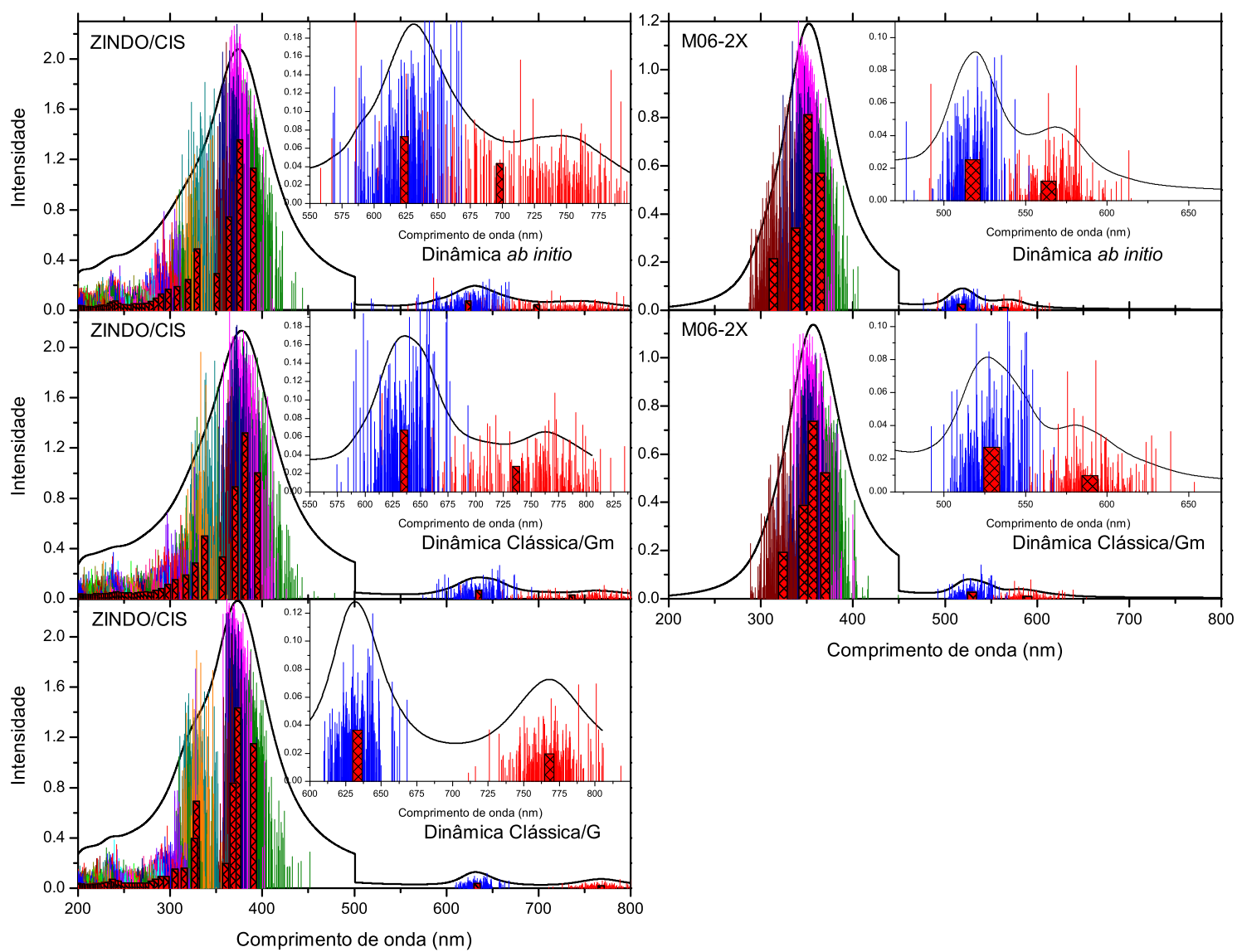

Figura 3.16: Detalhamento das excitações dos espectros de absorção teóricos de 200 configurações descorrelacionadas obtidos através da primeira dinâmica clássica $(\mathrm{G})$, da segunda dinâmica clássica ( $\mathrm{Gm}$, com parâmetros modificados) e da dinâmica ab initio da $\mathrm{H}_{2}$-Porfirina. São apresentados os picos de cada uma das configurações e também os valores médios nas barras vermelhas riscadas. Cada excitação é apresentada na figura com uma coloração diferentes. A convolução por Lorentzianas, utilizando uma largura de linha diferente na região das bandas $Q$ em relação as outras regiões, também é apresentada. Os cálculos do espectro foram feitos utilizando o método ZINDO/CIS e também com M06-2X/6-31G* para duas das dinâmicas. 
Analisando a figura 3.16 podemos ver que tanto a posição quanto a intensidade (força de oscilador) dos picos teóricos variam bastante para as diferentes configurações. Por exemplo, podemos ver que os comprimentos de onda correspondentes a primeira excitação na dinâmica $a b$ initio com ZINDO/CIS assumem valores no intervalo de 560 até $800 \mathrm{~nm}$, e as forças de oscilador assumem valores variáveis. Essa variação de valores de energia de excitação e de força de oscilador nas diferentes configurações está em acordo com a hipótese levantada na subseção 3.1.3 de que distorções conformacionais induzidas por efeitos térmicos seriam responsáveis pelo surgimento de absorção na região do visível, já que as forças de oscilador nessa região são baixíssimas para a estrutura optimizada. Como discutido também na subseção 1.3.1 o resultado experimental aponta que absorção no visível só ocorre em altas temperaturas.

Dos métodos utilizados para o cálculo do espectro da geometria optimizada, um dos que fornece os maiores valores para as forças de oscilador das bandas $Q$ é o ZINDO/CIS, como mostrado na tabela 3.2. Os valores de força do oscilador para geometria optimizada obtidos com o ZINDO/CIS são 0,0222 para a banda $Q_{x}$ e 0,0400 para a banda $Q_{y}$. Olhando os gráficos com foco nas bandas $Q$ da figura 3.16 podemos ver que para várias configurações os valores das forças de oscilador obtidos com ZINDO/CIS são maiores que esses. O método TD-DFT(M06-2X), por outro lado, fornece valores bem baixos para as forças de oscilador das bandas $Q$ para a geometria optimizada, como pode ser visto na tabela 3.2. Esses valores são de 0,0015 para as bandas $Q_{x}$ e $Q_{y}$. A figura 3.16 que ao menos a maior parte das 200 configurações selecionadas em cada dinâmicas fornecem valores maiores que esses. Ambos os métodos mostram também que os valores médios para as forças de oscilador são maiores que os valores para a geometria optimizada. Portanto podemos concluir que, em acordo com o já apontado na análise apresentada na subseção 3.1.3.2 para uma estrutura distorcida, as distorções estruturais induzidas através da inclusão de efeitos térmicos é de fato responsável pelo aumento das forças de oscilador na região do visível, o que 
leva ao aumento de absorção nessa região.

Seguindo com as discussões da subseção 3.1.5.6 a respeito do espectro da dinâmica clássica/G em relação as outras, analisando a figura 3.16 vemos que na dinâmica clássica/G os picos se distribuem mais concentradamente em torno dos valores médios. Esse comportamento deve estar intimamente relacionado com a parametrização, pois para a dinâmica clássica/Gm com constantes de força mais relaxadas a distribuição dos picos no espectro é muito mais condizente com a dinâmica $a b$ initio, como mostrado na figura. Portanto a figura mostra em detalhes que a modificação de parâmetros realizada se mostrou relevante para a descrição e caracterização do espectro de absorção.

Para a dinâmica clássica/G vemos que existe uma separação entre os picos correspondentes a primeira e a segunda excitação. O mesmo não acontece nos espectros obtidos via as demais dinâmicas. A figura mostra que nas dinâmicas clássica/Gm e $a b$ initio existem picos da primeira excitação na região onde os picos da segunda excitação estão situados. Ao fazer a convolução, uma Lorentziana é atribuída para cada pico (ver seção 2.2.6), por isso esses picos da primeira excitação situados na região típica da segunda contribuem para a forma da convolução do espectro nessa região. Por essa razão os valores médios das primeiras excitação se encontram deslocados em relação aos picos nas convoluções.

Outro fato interessante que a figura 3.16 mostra é que as bandas $Q$, em especial a banda $Q_{x}$ correspondente a primeira excitação, são mais sensíveis a distorções devidas a efeitos vibracionais que as demais bandas. Na subseção 1.3.1 falamos que os primeiros trabalhos teóricos utilizando métodos semi-empíricos já mostravam que parte dos picos na região do visível do espectro de absorção experimental são devidos a efeitos vibracionais. Como falado na subseção 1.3.1, trabalhos mais recentes na literatura utilizando métodos quânticos com correções vibracionais a partir da geometria optimizada são capazes de descrevem esses "picos vibracionais". Desse modo a partir 
de todos esses resultados se pode esperar que os picos referentes as bandas $Q$ sejam bastante sensíveis a deformações conformacionais decorrentes de efeitos vibracionais (que podem ser induzidos termicamente). Esse comportamento de fato é observado em nossos resultados.

Os resultados apresentados aqui mostram a importância da inclusão de efeitos térmicos para o estudo teórico do espectro de absorção. As deformações estruturais causadas pela inclusão de efeitos térmicos estão diretamente relacionadas com a temperatura do sistema, por isso na próxima subseção apresentaremos resultados para dinâmicas moleculares realizadas com diferentes temperaturas alvo.

\subsubsection{Espectro de absorção em diferentes temperaturas}

Nesta subseção apresentaremos resultados obtidos através de dinâmicas clássicas feitas com a parametrização modificada para três temperaturas diferentes: temperatura ambiente $(300,00 \mathrm{~K})$, temperatura na qual o espectro experimental na região ultravioleta foi medido $(595,15 \mathrm{~K})$, e temperatura na qual a região do visível do espectro foi medida $(666,15 \mathrm{~K})$. As novas dinâmicas clássicas/Gm (para 300,00 K e 595,15 K) foram feitas exatamente da mesma maneira que a dinâmica clássica/Gm apresentada anteriormente (para 666,15 K), mudando apenas a temperatura alvo. Novamente escolhemos os primeiros $10 \mathrm{~ns}$ como termalização e consideramos os $20 \mathrm{~ns}$ restantes como região de produção. Os valores médios com os respectivos desvios padrão das temperaturas nas dinâmicas são respectivamente $(299,71 \pm 40,75) \mathrm{K},(594,87 \pm 80,15) \mathrm{K}$ e $(667,12 \pm 90,66) \mathrm{K}$. Podemos ver que esses valores estão em bom acordo com as temperaturas alvo escolhidas.

O gráfico da figura 3.15 mostra comparações dos resultados obtidos nas diferentes dinâmicas entre si e também em comparação com os espectros experimental e da geometria optimizada. Na figura 3.17 apresentamos essas mesmas comparações para as dinâmicas feitas nas três diferentes temperaturas. Os resultados apresentados para 
as dinâmicas são para 200 configurações descorrelacionadas e o cálculo do espectro foi feito apenas com ZINDO/CIS. Os valores médios cálculos para as energias de excitação foram ponderados pela força de oscilador e depois convertidos para nm e apresentados na figura.

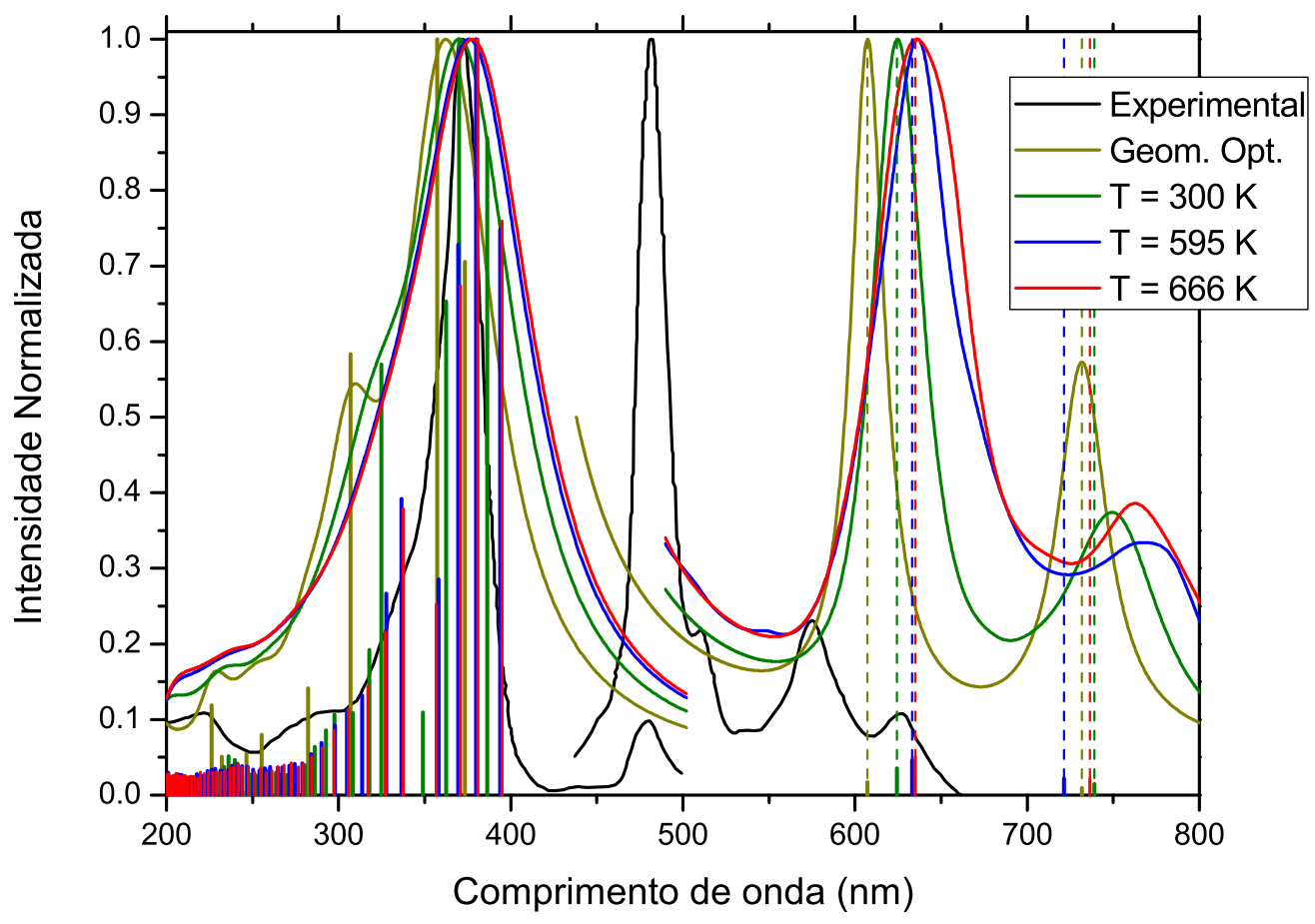

Figura 3.17: Comparação de resultados para os espectros de absorção teóricos de 200 configurações descorrelacionadas obtidos através de dinâmicas moleculares clássicas com a parametrização modificada da $H_{2}$-Porfirina, para três temperaturas diferentes. O espectro da estrutura optimizada e o espectro experimental também são apresentados. As linhas verticais apresentadas representam os valores médios das excitações, e as linhas tracejadas são uma ampliação desses valores para as bandas $Q$. Os cálculos do espectro foram feitos utilizando o método ZINDO/CIS.

Analisando a figura 3.17 vemos que a posição dos valores médios varia para as diferentes temperaturas assim como a posição dos picos das convoluções. Um fato interessante é que o espectro para as dinâmicas está deslocado para maiores comprimentos de onda (deslocado para o vermelho) em relação ao espectro da geometria optimizada. 
Esse deslocamento é cerca de $31 \mathrm{~nm}$ para a banda $Q_{x}$ e $28 \mathrm{~nm}$ para banda $Q_{y}$ para a temperatura mais elevada, $666 \mathrm{~K}$. O espectro para $300 \mathrm{~K}$, que é a mais baixa das temperaturas utilizadas nas dinâmicas, é o que mais se aproxima do espectro da geometria optimizada. O espectro para $595 \mathrm{~K}$ e $666 \mathrm{~K}$ apresentam diferenças relevantes apenas nas posições dos picos na região da banda $Q_{x}$.

Como foi mostrado na subseção 3.1.4.1, dos resultados para o espectro de absorção obtidos para a estrutura optimizada apenas CIS(D) apresenta as bandas $Q$ mais a direita das bandas $Q$ experimentais. Portanto uma observação curiosa é que o deslocamento para maiores comprimentos de onda causado pela inclusão de efeitos térmicos colocaria o resultado CIS(D) na direção do resultado experimental. Como o cálculo CIS(D) é extremamente pesado, as nossas capacidades computacionais não nos permitem fazer este cálculo para as 200 configurações selecionadas de cada uma das dinâmicas moleculares.

Outro comportamento interessante mostrado na figura 3.17 é o comportamento das forças de oscilador na região do visível nas diferentes temperaturas. Na figura as barras verticais correspondentes as excitações médias estão normalizadas pela força de oscilador mais alta, que está na banda de Soret. Pela figura podemos ver que existe um crescimento das forças de oscilador na região do visível em relação a banda de Soret em comparação com o espectro da geometria optimizada. Esse crescimento está de acordo com a hipótese levantada na subseção 3.1.3.2 para explicar o fato experimental de que a absorção de luz visível pela $H_{2}$-Porfirina em fase gasosa só é claramente observada em altas temperaturas.

Na figura 3.18 apresentamos um detalhamento do espectro teórico obtido para as dinâmicas nas diferentes temperaturas. Esta figura foi feita da mesma maneira que a figura 3.16 .

Pela figura 3.17 observamos que os picos das 200 configurações descorrelacionadas da dinâmica para $300 \mathrm{~K}$ estão mais concentrados em torno dos valores médios na região 
do visível em comparação com os resultados para 595 e 666 K. Esse comportamento é esperado devido ao fato de que na temperatura de $300 \mathrm{~K}$ a energia cinética do sistema não é suficiente para causar deformações na molécula tão pronunciáveis quanto nas dinâmicas para 595 ou $666 \mathrm{~K}$.

Com relação as forças de oscilador na região das bandas $Q$, olhando as configurações individualmente podemos ver que existem configurações com forças de oscilador maiores para 595 e $666 \mathrm{~K}$ que as para $300 \mathrm{~K}$. Vemos que os valores médios das forças de oscilador tentem a aumentar com o aumento da temperatura e também aumentam em relação as bandas na região de Soret. Os valores médios das forças de oscilador das bandas $Q_{x}$ e $Q_{y}$ e da banda mais intensa na região de Soret são respectivamente 0,0221, 0,0505 e 1,4265 para $300 \mathrm{~K}, 0,0280,0,0593$ e 1,2904 para $595 \mathrm{~K}$, e 0,0279, 0,0671 e 1,3212 para 666 K. Esse aumento com a temperatura está de acordo com a hipótese levantada na subseção 3.1.3.

Podemos concluir que a temperatura alvo influencia na distribuição de valores dos picos que compõem o espectro de absorção e que também influencia nas forças de oscilador, que tendem em média a aumentar com a temperatura devido a deformações estruturais causadas via a inclusão de efeitos térmicos através de dinâmica molecular. 


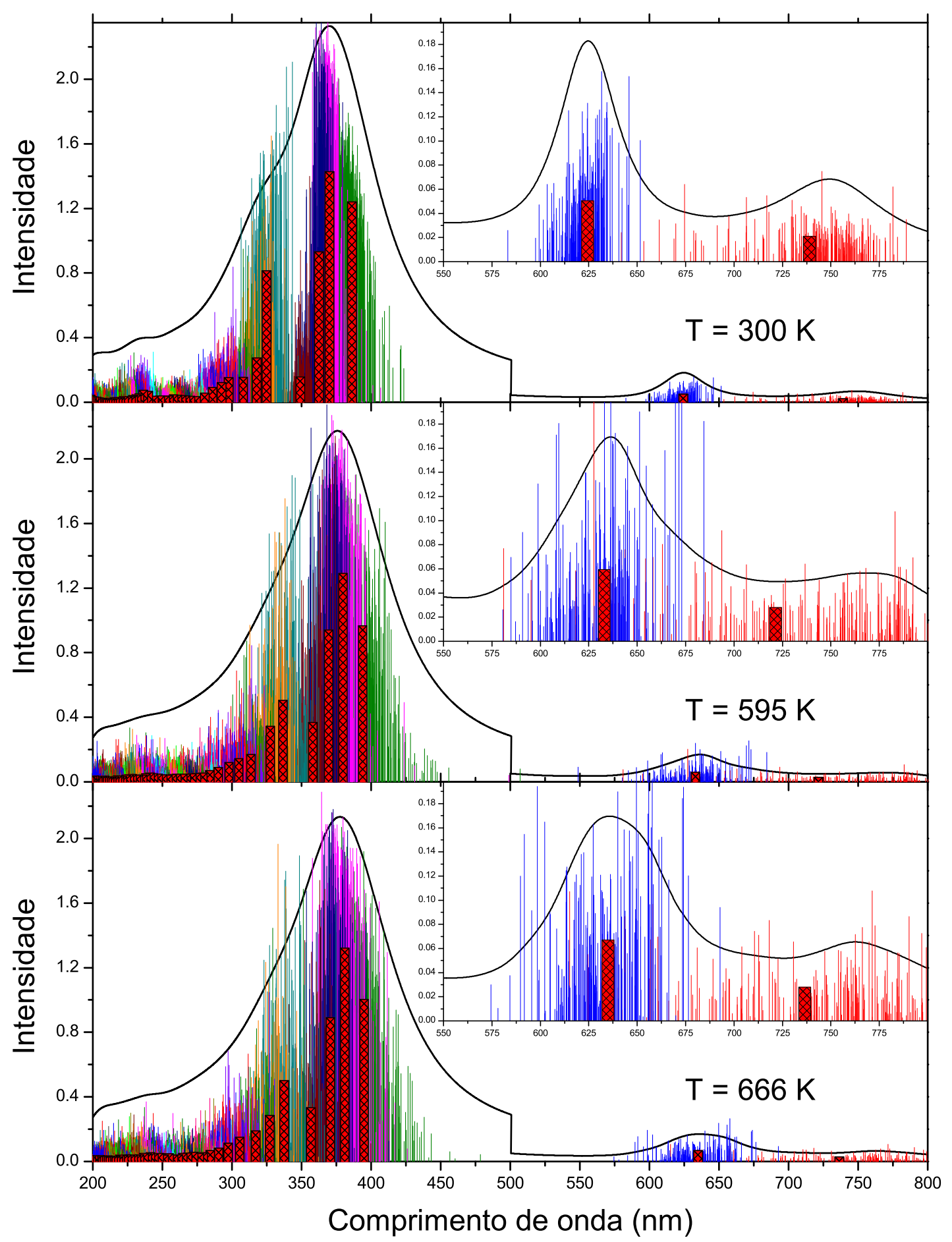

Figura 3.18: Detalhamento das excitações dos espectros de absorção teóricos de 200 configurações descorrelacionadas obtidos através de dinâmicas moleculares clássicas com a parametrização modificada $(\mathrm{Gm})$ da $H_{2}$-Porfirina, para três temperaturas diferentes. São apresentados os picos de cada uma das configurações e também os valores médios nas barras vermelhas riscadas. Cada excitação é apresentada na figura com uma coloração diferentes. A convolução por Lorentzianas, utilizando uma largura de linha diferente na região das bandas $Q$ em relação as outras regiões, também é apresentada. Os cálculos do espectro foram feitos utilizando o método ZINDO/CIS. 


\subsubsection{Sumário de Conclusões}

Com relação aos estudos de Porfirinas, algumas conclusões que podem ser tiradas desta dissertação são:

1. A estrutura optimizada do monômero de $H_{2}$-Porfirina obtida no nível B3LYP/6$31+\mathrm{G}(\mathrm{d}, \mathrm{p})$ está em bom acordo com a estrutura cristalina experimental.

2. O modelo de Gouterman para as Porfirinas analisadas ( $H_{2}$-Porfirina, Mg-Porfirina e Zn-Porfirina) se mostra válido para descrever os estados excitados na região do visível (bandas Q) e parcialmente válido para descrever estados na região ultravioleta (banda de Soret e demais bandas). A descrição de estados escuros necessita de mais do que os orbitais propostos por Gouterman. Verificamos que essas conclusões também se aplicam para uma estrutura distorcida da $H_{2}$-Porfirina.

3. Os métodos utilizados para o cálculo do espectro do monômero optimizado de $H_{2}$-Porfirina fornecem forças de oscilador baixíssimas para as bandas $Q$.

4. As transições envolvidas nas excitações correspondentes às bandas $Q$ da $H_{2^{-}}$ Porfirina não são proibidas por simetria, por isso as baixas forças de oscilador dessas bandas na geometria optimizada não são devidas à simetria da molécula.

5. Dos cálculos feitos para o espectro com a geometria optimizada do monômero de $\mathrm{H}_{2}$-Porfirina, os métodos que forneceram resultados mais condizentes com o experimental foram TD-DFT(CAM-B3LYP) e TD-DFT(M06-2X).

6. Os resultados para o espectro e para os orbitais dos dímeros de $H_{2}$-Porfirina mostram que as características do espectro dos dímeros são bem distintas em comparação com o espectro do monômero. No espectro dos dímeros observamos o surgimento de várias novas bandas na região do visível, mesmo que escuras. 
7. A modificação de parâmetros que descrevem as interações atômicas na dinâmica clássica da $\mathrm{H}_{2}$-Porfirina se mostrou relevante para uma melhor descrição das estruturas geradas e do espectro de absorção em comparação com os resultados obtidos pela dinâmica $a b$ initio.

8. O posicionamento de um hidrogênio central influencia na estruturação do macrociclo da $\mathrm{H}_{2}$-Porfirina.

9. As características do espectro de absorção da $H_{2}$-Porfirina se mostram razoavelmente convergidas para cálculos realizados com 200 configurações estatisticamente descorrelacionadas.

10. As bandas $Q$ da $H_{2}$-Porfirina, em especial a banda $Q_{x}$, são mais sensíveis a distorções estruturais que as demais bandas. Esse fato está em acordo com trabalhos na literatura $[11,15]$ que apontam uma grande influência de efeitos vibracionais nessas bandas (na verdade, dois dos picos na região do visível do espectro experimental são interpretados como picos de origens vibracionais).

11. A medida que se aumenta a temperatura nas dinâmicas para a $H_{2}$-Porfirina se observa um deslocamento para o vermelho do espectro em comparação com o espectro calculado para estrutura optimizada.

12. O deslocamento para o vermelho causado pela inclusão de efeitos térmicos colocaria o resultado CIS(D) para geometria optimizada da $H_{2}$-Porfirina na direção do resultado experimental.

13. Efeitos térmicos no espectro teórico da $H_{2}$-Porfirina tendem a aumentar em média as forças de oscilador das bandas $Q$ com o aumento da temperatura. 


\subsection{Estudos de Ftalocianinas isoladas}

Vamos agora apresentar resultados para Ftalocianinas isoladas. Estudos foram feitos para a Ftalocianina Base Livre (Free Base Phthalocyanine - $\mathrm{H}_{2}$-Ftalocianina) e para a Ftalocianina complexada com Zinco (Zinc Phthalocyanine - Zn-Ftalocianina) cujas estruturas estão ilustradas na figura 3.19 abaixo. Pela figura podemos ver que a $\mathrm{H}_{2^{-}}$ Ftalocianina tem simetria $D_{2 h}$ e que a Zn-Ftalocianina tem simetria $D_{4 h}{ }^{24}$. Nesta seção estaremos focados na discussão e análise dos resultados para a $H_{2}$-Ftalocianina. Resultados para a Zn-Ftalocianina são apresentados no apêndice C e mencionados no decorrer desta seção.

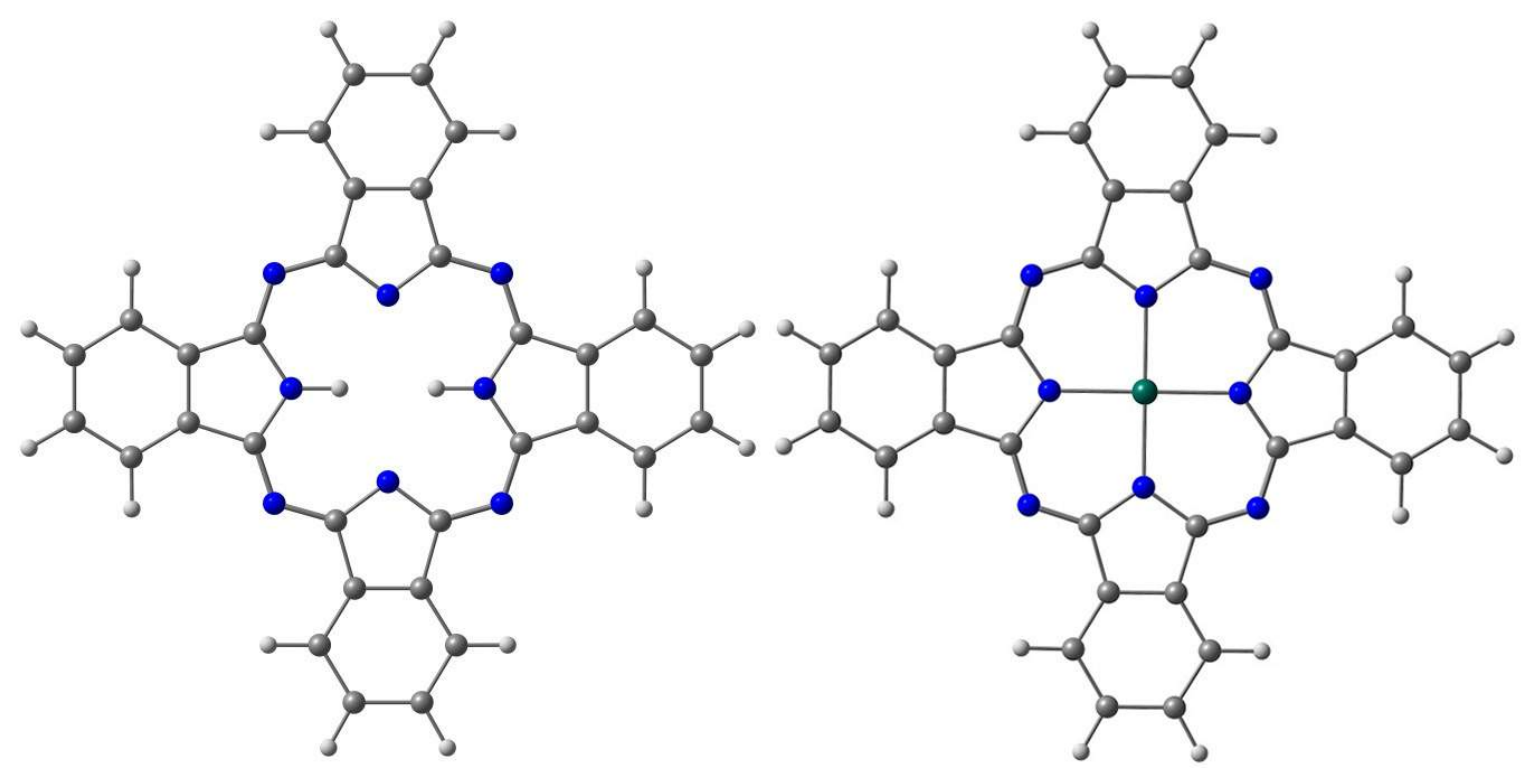

Figura 3.19: Ftalocianina Base Livre $\left(H_{2}\right.$-Ftalocianina $)$ com simetria $D_{2 h}$ a esquerda, e Ftalocianina complexada com Zinco (Zn-Ftalocianina) com simetria $D_{4 h}$ a direita.

As estruturas dos monômeros de Ftalocianina ( $\mathrm{H}_{2}$-Ftalocianina e Zn-Ftalocianina) foram obtidas através de optimização de geometria (ver subseção 2.4.1) no nível B3LYP /6-31G* 25 com o programa Gaussian 09 [81].

\footnotetext{
${ }^{24}$ Para maiores informações sobre simetrias moleculares recomendamos a excelente referência [60].

${ }^{25} \mathrm{Na}$ tabela C.4 do apêndice $\mathrm{C}$ apresentamos as coordenadas do monômero optimizado de $H_{2^{-}}$ Ftalocianina.
} 
Na subseção 1.1 do capítulo 1 comentamos sobre as diferenças estruturais entre Porfirinas e Ftalocianinas. Como veremos no decorrer desta seção, apesar de algumas características gerais se manterem, essas mudanças implicam em diferenças significativas nos espectros de absorção de ambas as moléculas.

\subsubsection{Comparação entre as estruturas optimizada e cristalina}

A estrutura cristalina da $\mathrm{H}_{2}$-Ftalocianina foi resolvida experimentalmente através de difração de raios-X em um trabalho de 1999 [49] de autoria de S. Matsumoto, K. Matsuhama e J. Mizuguch. Nesta estrutura os hidrogênios centrais estão ligados a nitrogênios centrais opostos, assim como na estrutura optimizada. Um fato curioso reportado nesse trabalho é que no cristal a estrutura da $H_{2}$-Ftalocianina deixa de ter a simetria $D_{2 h}$ de uma molécula livre e passa a ter simetria $C_{i}$. Nesse trabalho são reportados valores para algumas distâncias e ângulos de átomos ligados da estrutura estrutura cristalina. Na figura 3.20 apresentamos os rótulos que escolhemos para os átomos da $\mathrm{H}_{2}$-Ftalocianina, e na tabela 3.9 apresentamos uma comparação entre os valores de algumas ligações e ângulos na estrutura optimizada e na estrutura cristalina (experimental). Essa escolha de rótulos será mencionada posteriormente quando tratarmos de resultados para dinâmicas moleculares na subseção 3.2.6.

Um fato interessante apontado pelo resultado experimental é que existem diferenças nos anéis benzênicos que estão mais próximos a um hidrogênio central em comparação com os anéis benzênicos que não estão próximos a um hidrogênio central. Essas diferenças são observadas na estrutura optimizada também, como pode ser visto na tabela 3.9 .

Podemos ver pela tabela 3.9 que os valores estruturais obtidos para a geometria optimizada obtida no nível B3LYP/6-31G* estão em acordo com a estrutura cristalina experimental. A estrutura cristalina experimental é obtida em estado sólido enquanto a optimizada é obtida para a molécula isolada, portanto diferenças são naturalmente 


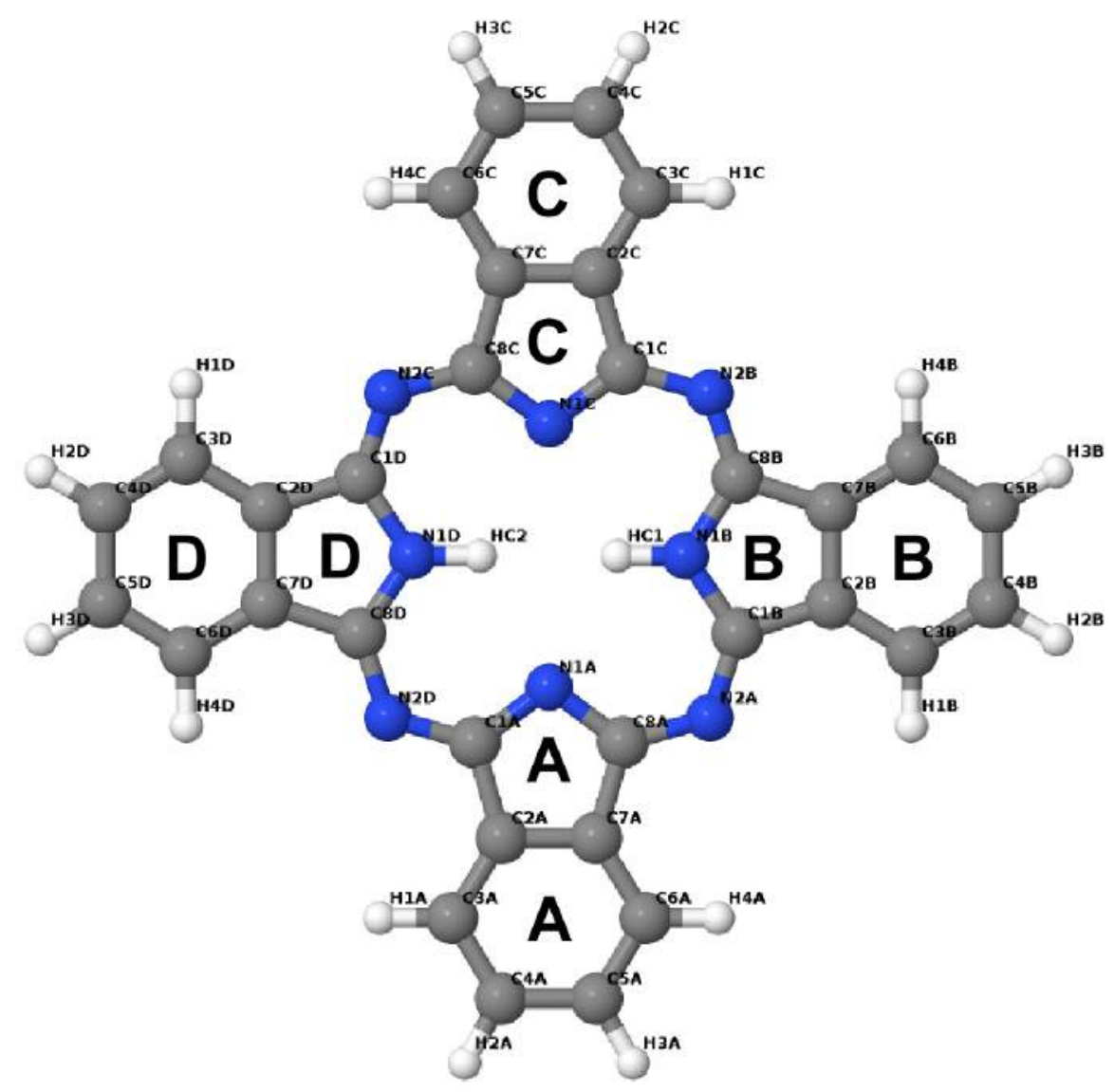

Figura 3.20: Escolha de rótulos para cada átomo da $H_{2}$-Ftalocianina.

Tabela 3.9: Comparação de valores de ligações e ângulos entre a estrutura optimizada no nível B3LYP/6-31G* e a estrutura cristalina [49] de $H_{2}$-Ftalocianina. Os valores para as ligações são dados em Angstroms e para os ângulos em Graus.

\begin{tabular}{|c|c:c|c|c:c|}
\hline Ligação & Optimizada & Experimental & Ângulo & Optimizada & Experimental \\
\hline C2A-C3A & 1,397 & $1,383 \pm 0,003$ & C3A-C2A-C7A & 121,7 & $120,9 \pm 0,2$ \\
C2A-C7A & 1,394 & $1,395 \pm 0,003$ & C2A-C3A-C4A & 117,2 & $117,6 \pm 0,2$ \\
C3A-C4A & 1,397 & $1,387 \pm 0,003$ & C3A-C4A-C5A & 121,1 & $121,4 \pm 0,2$ \\
C4A-C5A & 1,422 & $1,392 \pm 0,004$ & C4A-C5A-C6A & 121,1 & $121,3 \pm 0,2$ \\
C2B-C3B & 1,397 & $1,392 \pm 0,003$ & C3B-C2B-C7B & 121,1 & $121,6 \pm 0,2$ \\
C2B-C7B & 1,424 & $1,399 \pm 0,003$ & C2B-C3B-C4B & 117,2 & $117,4 \pm 0,2$ \\
C3B-C4B & 1,401 & $1,380 \pm 0,003$ & C3B-C4B-C5B & 121,7 & $121,1 \pm 0,2$ \\
C4B-C5B & 1,394 & $1,399 \pm 0,004$ & C4B-C5B-C6B & 121,7 & $121,6 \pm 0,2$ \\
\hline
\end{tabular}


esperadas. Podemos ver que os resultados estruturais providos pela optimização de geometria fornecem valores razoavelmente próximos dos experimentais e que prevê as mesmas tendências observadas no resultado experimental, o que indica que os resultados obtidos são compatíveis. Esse é um indicativo de que o cálculo de optimização está fornecendo uma boa geometria para a $\mathrm{H}_{2}$-Ftalocianina isolada.

\subsubsection{Teste de convergência de funções-base}

Como mencionado na seção 3.1.2, para as Porfirinas o cálculo do espectro de absorção foi feito com o conjunto de funções-base 6-311++G(d,p) para todos os métodos, com exceção obviamente do cálculo ZINDO/CIS que é um método semi-empírico cujas funções-base já são previamente estabelecidas (ver subseção 2.3.4). A $H_{2}$-Porfirina possui 38 átomos e a $\mathrm{H}_{2}$-Ftalocianina possui 58 átomos. Portanto, caso fizéssemos os cálculos do espectro de absorção para as Ftalocianinas utilizando o robusto conjunto de funções-base utilizado para as Porfirinas, o tempo computacional envolvido tornaria tais cálculos inviáveis. Por isso um teste de convergência de funções-base foi feito para a escolha de um conjunto menor para o cálculo do espectro de absorção da $H_{2}$-Ftalocianina ${ }^{26}$. Neste teste o espectro teórico foi calculado para os 46 primeiros estados excitados com TD-DFT (ver subseção 2.3.5.3) no nível O3LYP com os seguintes conjuntos de funções-base: $6-31 \mathrm{G}^{*}, 6-31+\mathrm{G}^{*}, 6-31+\mathrm{G}^{* *}, 6-31++\mathrm{G}^{*}, 6-31++\mathrm{G}^{* *}$ e $6-311++\mathrm{G}^{* *}$. Como estamos interessados apenas em observar os efeitos da base no espectro de absorção, para este teste a escolha do funcional O3LYP foi puramente arbitrária. A figura 3.21 mostra a convolução dos picos teóricos utilizando Lorentzianas (ver subseção 2.2.6) e o tempo de cálculo para cada conjunto, e é acompanhada por uma tabela com os valores para os comprimentos de onda das bandas $Q_{x}$ e $B$ (Soret).

A partir dos resultados da figura 3.21, buscando um equilíbrio entre precisão dos resultados e eficiência computacional nos cálculos, vemos que o conjunto de funções-

\footnotetext{
${ }^{26} \mathrm{O}$ mesmo teste foi feito para a Zn-Ftalocianina e é apresentado na figura C.5 do apêndice C.
} 


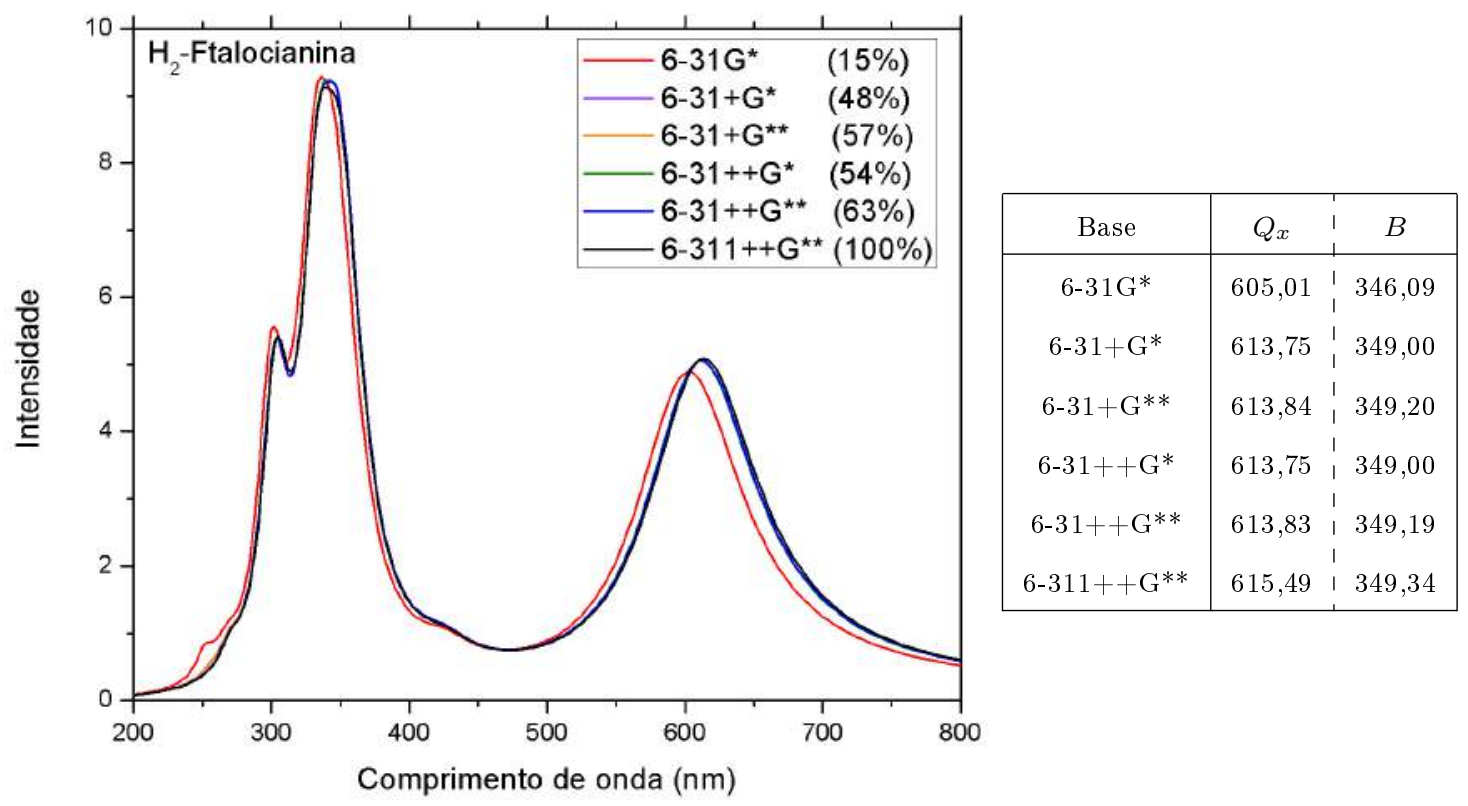

Figura 3.21: Teste de conjuntos de funções-base para o cálculo do espectro de absorção da molécula $H_{2}$-Ftalocianina isolada, utilizando o método TD-DFT(O3LYP) e as seguintes bases: $6-31 \mathrm{G}^{*}, 6-31+\mathrm{G}^{*}, 6-31+\mathrm{G}^{* *}, 6-31++\mathrm{G}^{*}, 6-31++\mathrm{G}^{* *}$, e $6-311++\mathrm{G}^{* *}$. No gráfico é apresentado a convolução dos 46 picos teóricos para cada base, utilizando Lorentzianas (ver subseção 2.2.6). Nas legendas das figuras também se encontra o tempo de cálculo de cada caso, em comparação com o tempo obtido com o conjunto de funções-base maior. A direita da figura se encontra uma tabela com os valores dos comprimentos de onda para as bandas $Q_{x}$ e $B$ (Soret).

base $6-31+\mathrm{G}^{*}$ reproduz satisfatoriamente os resultados dos conjuntos maiores nos cálculos do espectro de absorção em um tempo menor ${ }^{27}$. Portanto, esse é o conjunto de funções-base que vamos utilizar em cálculos do espectro de absorção que serão apresentados no decorrer dessa seção 3.2.

\footnotetext{
${ }^{27}$ Esse mesmo conjunto pode ser escolhido a partir do teste de convergência feito para a ZnFtalocianina, mostrado na figura C.5 do apêndice C.
} 


\subsubsection{O modelo de Gouterman é válido para Ftalocianinas?}

Na subseção 3.1.2 discutimos a respeito do modelo de quatro orbitais de Gouterman [9] proposto para Porfirinas. Como dissemos, em um trabalho de 1963, Gouterman e Wagnière [39] mostraram que este modelo podia explicar muitas das características observadas no espectro de Porfirinas, e de fato pudemos ver a significância desses orbitais em nossos resultados (ver subseção 3.1.2). Dada a semelhança estrutural entre Porfirinas e Ftalocianinas, uma pergunta pode ser levantada: o modelo de Gouterman é capaz de descrever as características do espectro de absorção de Ftalocianinas? Vamos agora, a partir dos nossos resultados, buscar responder esta pergunta.

Na figura 3.22 mostramos os quatro orbitais de interesse no modelo de Gouterman e alguns outros para a $H_{2}$-Ftalocianina ${ }^{28}$. Esses orbitais foram obtidos a partir de cálculo no nível B3LYP/6-31+G* utilizando o programa Gaussian 09 [81].

Pela figura 3.22 um fato que chama a atenção é que muitos dos orbitais estão delocalizados nos anéis benzênicos, nas extremidades da $\mathrm{H}_{2}$-Ftalocianina. Portanto, como esses anéis não existem na $H_{2}$-Porfirina, somente a partir desta análise de orbitais já podemos esperar que existam diferenças no espectro de absorção da $H_{2}$-Ftalocianina em relação ao espectro da $H_{2}$-Porfirina ${ }^{29}$. Além disso, no caso da $H_{2}$-Porfirina os orbitais estão delocalizados em outras regiões devido a inexistência dos anéis benzênicos - como pode ser visto na figura 3.3 -, o que reforça a expectativa levantada em relação ao espectro da $\mathrm{H}_{2}$-Ftalocianina.

Analisando a figura 3.22 vemos que todos os orbitais apresentados são do tipo $\pi^{30,31}$, portanto esse é um indicativo de que ao menos boa parte das transições que compõe o espectro da $H_{2}$-Ftalocianina sejam do tipo $\pi \rightarrow \pi^{*}$.

\footnotetext{
${ }^{28}$ Orbitais moleculares da Zn-Ftalocianina também são apresentados na figura C.6 do apêndice C.

${ }^{29}$ Essa mesma expectativa é feita para o espectro da Zn-Ftalocianina em relação ao espectro da Zn-Porfirina, pois, como mostrado na figura C.6, muitos orbitais moleculares da Zn-Ftalocianina também estão delocalizados nos anéis benzênicos.

${ }^{30}$ Uma descrição dos tipos de orbitais moleculares foi apresentada na subseção 2.2.3.

${ }^{31}$ A figura 3.22 mostra que boa parte dos orbitais da Zn-Ftalocianina também são do tipo $\pi$.
} 

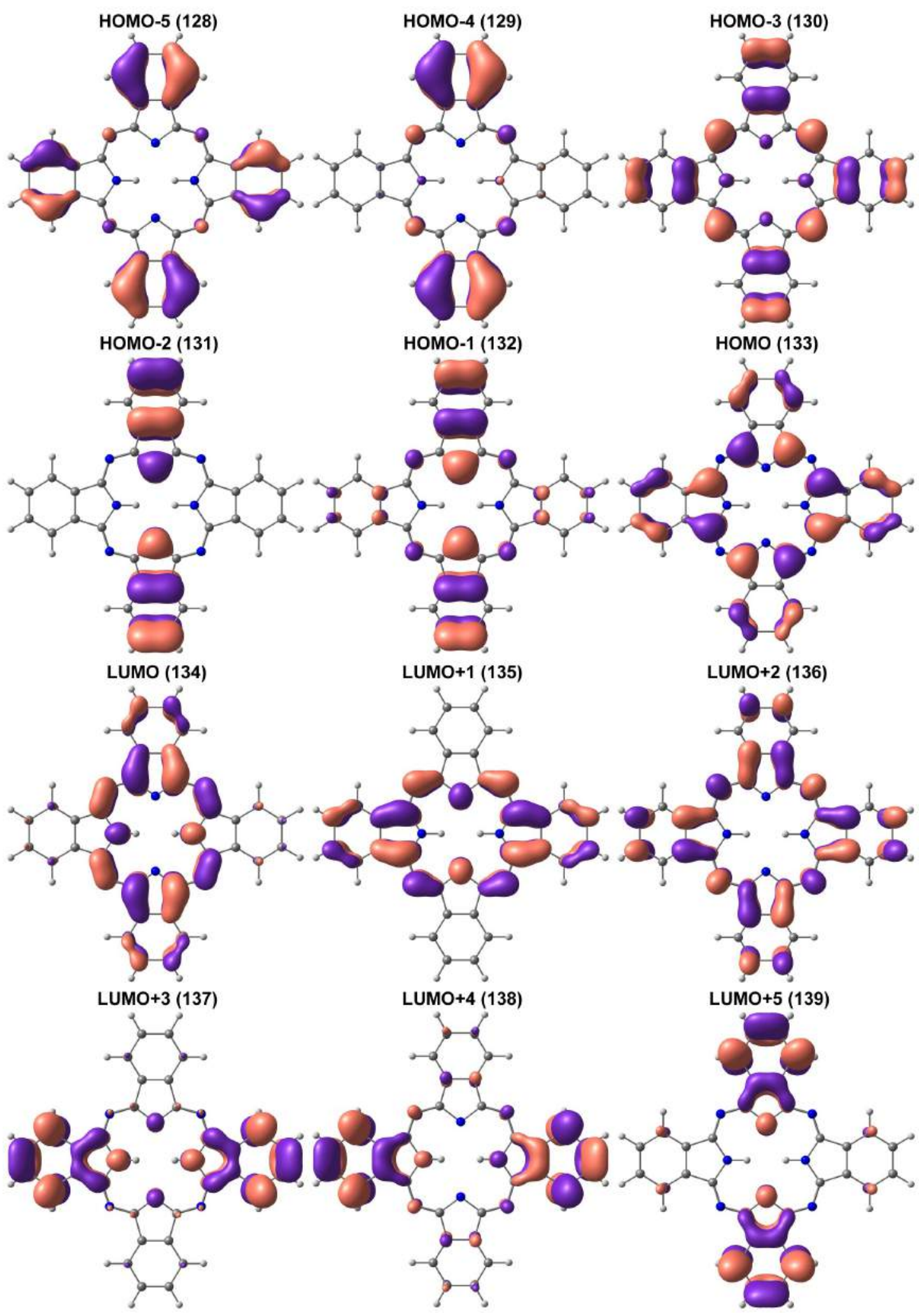

Figura 3.22: Alguns orbitais moleculares da $H_{2}$-Ftalocianina isolada, obtidos no nível B3LYP $/ 6-31+\mathrm{G}^{*}$. 
A partir das estruturas optimizadas calculamos o espectro de absorção teórico para os 46 primeiros estados excitados utilizando o método TD-DFT com vários funcionais (ver subseção 2.3.5.3) com o conjunto de funções-base $6-31+\mathrm{G}^{*}$ utilizando o programa Gaussian 09 [81]. O cálculo CIS(D), feito para a $H_{2}$-Porfirina, é inviável para a $\mathrm{H}_{2}$-Ftalocianina dentro dos nossos recursos computacionais devido ao tamanho da molécula e por isso não pode ser feito. O espectro também foi cálculo para os 49 primeiros estados excitados utilizando o método ZINDO/CIS como implementado no programa ZINDO [64] (ver seção 2.3.4). Neste cálculo consideramos apenas transições dos 25 orbitais moleculares mais altos ocupados para os 25 orbitais mais baixos desocupados. Em todos os cálculos consideramos a carga da molécula como neutra e a multiplicidade 1 (singleto). Na tabela 3.10 apresentamos os resultados obtidos para os dois primeiros estados excitados, correspondentes a região visível do espectro (ou das bandas $Q$ ), e na tabela 3.11 mostramos os resultados de algumas excitações não nulas na região ultravioleta para a $H_{2}$-Ftalocianina ${ }^{32}$. O cálculo TD-DFT(LC-wPBE) é integralmente apresentado na tabela $3.12^{32}$. Dentre outras informações, as tabelas mostram as transições envolvidas e a sua contribuição em cada uma das excitações.

\footnotetext{
${ }^{32}$ Resultados equivalentes são apresentados para a Zn-Ftalocianina nas tabelas C.1, C.2 e C.3 do apêndice $\mathrm{C}$.
} 
Tabela 3.10: Dois primeiros estados excitados da molécula $H_{2}$-Ftalocianina isolada calculados utilizando vários funcionais TD-DFT com a base $6-31+\mathrm{G}^{*}$ e ZINDO/CIS. $\Delta E$ é a energia de excitação dada em eV,$\lambda$ é o comprimento de onda correspondente dado em $\mathrm{nm}, \Delta \lambda$ é a diferença entre os comprimentos de onda das duas primeiras excitações (correspondente ao desdobramento das bandas $Q$ ), e $f$ é a força de oscilador. As transições envolvidas são mostradas, e a contribuição delas para cada excitação é mostrada em parênteses. O orbital HOMO é numerado como 133.

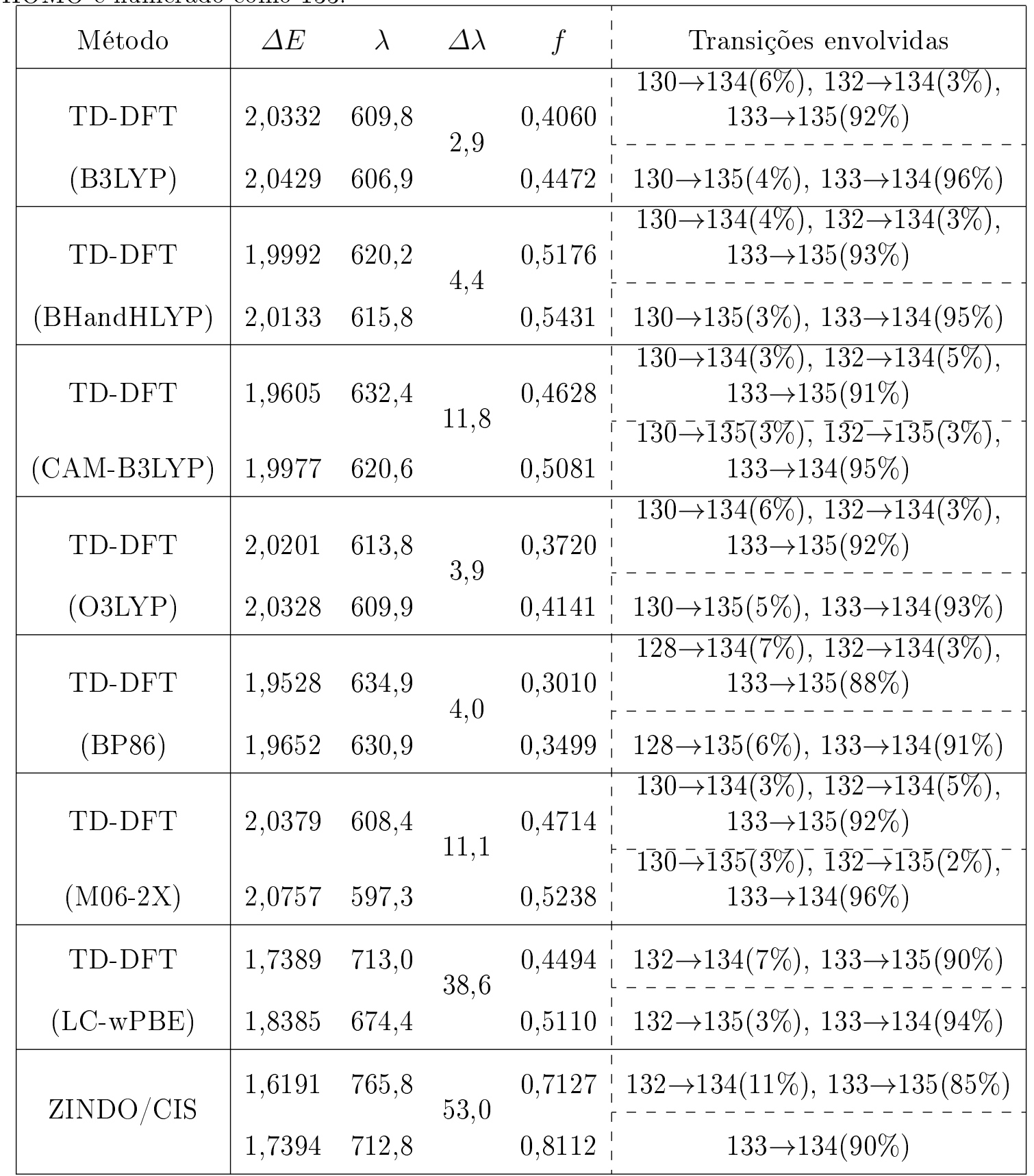


Como discutido na subseção 1.4.1, o espectro experimental em fase gasosa da $H_{2}$-Ftalocianina apresenta uma separação (ou desdobramento) de cerca de $64 \mathrm{~nm}$ para as duas bandas $Q$. Analisando a tabela 3.10 para as bandas $Q$ da $H_{2}$-Ftalocianina vemos que vários dos métodos falham em descrever esse desdobramento. Os que mais se aproximam são o método ZINDO/CIS seguido por TD-DFT(LC-wPBE). Como dissemos na subseção 1.4.1, no artigo onde o espectro experimental é apresentado [29] é abordada uma hipótese de que o posicionamento dos hidrogênios centrais poderia ser o responsável pelo desdobramento das bandas $Q$. Está hipótese será discutida no decorrer desta seção 3.2 juntamente com a hipótese de que este desdobramento seja devido a efeitos térmicos, já que o espectro experimental na região do visível foi obtido em uma temperatura de $500^{\circ} \mathrm{C}$ enquanto a nossa estrutura optimizada corresponderia a uma situação de temperatura igual a $0 \mathrm{~K}$ (ver seção 2.4).

Com relação as transições do espectro, a tabela 3.10 mostra que as transições envolvidas nas bandas $Q$ são majoritariamente transições que envolvem os orbitais de Gouterman (HOMO, HOMO-1, LUMO e $L U M O+1$ ), porém (ao contrário do que acontece com a $H_{2}$-Porfirina) com contribuições pequenas de outros orbitais ${ }^{33}$. Um outro fato que chama a atenção ao analisar a tabela é que, apesar de a $H_{2}$-Ftalocianina ter semelhanças estruturais com a $H_{2}$-Porfirina, as forças de oscilador na região das bandas $Q$ para a estrutura optimizada da $H_{2}$-Ftalocianina não são tão baixas quanto são as da $\mathrm{H}_{2}$-Porfirina. Esse fato corrobora com as análises feitas a partir dos orbitais moleculares, discutida anteriormente, que indicava diferenças entre os espectros da $H_{2}$-Porfirina e da $H_{2}$-Ftalocianina. Apesar da tabela 3.10 já evidenciar diferenças nas posições dos picos e nas forças de oscilador entre os espectros dos monômeros optimizados de $\mathrm{H}_{2}$-Ftalocianina e de $H_{2}$-Porfirina, podemos ver que em ambos os casos temos somente duas bandas na região do visível.

Uma outra observação que pode ser feita a partir da tabela 3.10 sobre os dois

\footnotetext{
${ }^{33} \mathrm{O}$ mesmo ocorre para a molécula Zn-Ftalocianina, como pode ser visto na tabela C.1.
} 
primeiros estados excitados da $H_{2}$-Ftalocianina é que esses estados são compostos praticamente por apenas uma única transição eletrônica ${ }^{34}$. A tabela mostra que, para todos os métodos utilizados, a contribuição de uma única transição eletrônica em cada estado excitado correspondente a uma banda $Q$ é de no mínimo $85 \%$.

Analisando a tabela 3.11 para os estados excitados de força de oscilador não nula na região ultravioleta da $\mathrm{H}_{2}$-Ftalocianina, podemos ver que os orbitais de interesse no modelo de Gouterman tem uma participação importante nas transições envolvidas nas excitações, porém não são os únicos envolvidos, e além disso vemos que a participação dos orbitais de Gouterman nas transições é menor que para as bandas $Q^{35}$. Podemos ver que, em algumas excitações, alguns orbitais além dos de Gouterman tem um papel fundamental nas transições ${ }^{35}$.

Analisando a tabela 3.12 podemos ver que para os estados que tem força de oscilador nula (estados escuros, inacessíveis a partir do estado fundamental) os orbitais de Gouterman tem uma participação muito pequena nas transições, e que transições envolvendo apenas os orbitais de Gouterman não existem ${ }^{36}$. Essa conclusão pode ser estendida para os outros cálculos feitos, não ficando restrita somente ao cálculo TD-DFT(LC-wPBE) apresentado na tabela.

Assim então, a partir dos nossos resultados e das análises discutidas nos parágrafos anteriores, podemos concluir que para a $\mathrm{H}_{2}$-Ftalocianina o modelo de quatro orbitais proposto por Gouterman para Porfirinas se mostra praticamente válido para descrever os estados excitados na região do visível (ao contrário do que acontece para a $H_{2}$-Porfirina, onde o modelo é completamente válido nessa região), parcialmente válido para descrever estados com força de oscilador não nula na região ultravioleta, e prati-

\footnotetext{
${ }^{34}$ Como podemos ver pela tabela C.1, esse efeito também se manifesta nos resultados para a Zn-Ftalocianina mas de uma maneira diferente. Como as bandas $Q$ são degeneradas para a ZnFtalocianina, o que vemos é ambas bandas $Q$ são cada isoladamente praticamente compostas meioa-meio por duas únicas transições eletrônicas, onde essas duas transições são as mesmas para as duas bandas $Q$.

${ }^{35} \mathrm{O}$ mesmo comportamento é observado para a Zn-Ftalocianina, como mostrado na tabela C.2.

${ }^{36} \mathrm{O}$ mesmo é concluído para a Zn-Ftalocianina a partir de análise da tabela C.3.
} 
camente inválido para descrever estados escuros ${ }^{37}$. Portanto, de modo geral, podemos concluir que para uma descrição satisfatória e mais correta das bandas do espectro da $H_{2}$-Ftalocianina, outros orbitais além dos de Gouterman devem ser considerados, até mesmo para a descrição das bandas $Q^{37}$.

\footnotetext{
${ }^{37}$ Essa mesma conclusão pode ser estendida para a Zn-Ftalocianina, a partir de análise dos resultados mostrados no apêndice $\mathrm{C}$.
} 
Tabela 3.11: Algumas excitações não nulas na região ultravioleta da molécula $H_{2^{-}}$ Ftalocianina isolada calculadas utilizando vários funcionais TD-DFT com a base $6-31+\mathrm{G}^{*}$ e ZINDO/CIS. Os estados que estão entre os apresentados e não aparecem na tabela tem força de oscilador nula. $\Delta E$ é a energia de excitação dada em eV,$\lambda$ é o comprimento de onda correspondente dado em nm, e $f$ é a força de oscilador. As transições envolvidas são mostradas, e a contribuição delas para cada excitação é mostrada em parênteses. O orbital HOMO é numerado como 133.

\begin{tabular}{|c|c|c|c|c|c|}
\hline Método & Estado & $\Delta E$ & $\lambda$ & $f$ & Transições envolvidas \\
\hline \multirow{4}{*}{ TD-DFT } & $4^{\mathrm{O}}$ & 3,0578 & 405,5 & 0,0547 & $130 \rightarrow 134(4 \%), 132 \rightarrow 134(93 \%)$ \\
\hline & $5^{\mathrm{O}}$ & 3,2693 & 379,2 & 0,0020 & $130 \rightarrow 135(4 \%), 132 \rightarrow 135(93 \%)$ \\
\hline & $12^{\mathrm{O}}$ & 3,6096 & 343,5 & 0,1559 & $\begin{array}{c}128 \rightarrow 13 \overline{4}(\overline{70} \%), \overline{130 \rightarrow} 335(6 \%), \\
133 \rightarrow 138(23 \%)\end{array}$ \\
\hline & $14^{\mathrm{O}}$ & 3,6363 & 341,0 & 0,1362 & $\begin{array}{c}124 \rightarrow 13 \overline{4}(\overline{6} \%), 12 \overline{8} \rightarrow 135(52 \%), \\
130 \rightarrow 134(38 \%)\end{array}$ \\
\hline \multirow{4}{*}{ (BHandHLYP) } & $3^{\underline{0}}$ & 3,5984 & 344,6 & 0,1101 & $\begin{array}{c}130 \rightarrow 134(4 \%), 131 \rightarrow 136(4 \%) \\
132 \rightarrow 134(87 \%)\end{array}$ \\
\hline & $7^{0}$ & 4,0064 & 309,5 & $-x^{-1-1}$ & $\begin{array}{c}\overline{1} 28 \rightarrow \overline{1} 34(5 \%), \overline{1} 30 \rightarrow 135(2 \%), \\
132 \rightarrow 135(83 \%), 133 \rightarrow 134(2 \%), \\
133 \rightarrow 138(2 \%)\end{array}$ \\
\hline & $9^{\mathrm{o}}$ & 4,2092 & 294,6 & 0,0006 & $\begin{array}{c}135 \rightarrow 138(91 \%) \\
133(4 \%), 132 \rightarrow 135(3 \%)\end{array}$ \\
\hline & $10^{\underline{0}}$ & 4,2541 & 291,5 & 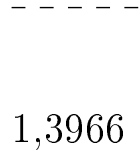 & $\begin{array}{c}\overline{1} \overline{2} 4 \overline{1} \overline{5}(3 \%), \overline{1} 25 \rightarrow 13 \overline{4}(\overline{3} \%), \\
130 \rightarrow 134(83 \%), 132 \rightarrow 134(3 \%), \\
133 \rightarrow 135(5 \%)\end{array}$ \\
\hline \multirow{4}{*}{ (CAM-B3LYP) } & $3^{0}$ & 3,5226 & 352,0 & 0,1733 & $\begin{array}{l}130 \rightarrow 134(11 \%), 131 \rightarrow 136(4 \%), \\
132 \rightarrow 134(78 \%), 133 \rightarrow 135(3 \%)\end{array}$ \\
\hline & $6^{\underline{0}}$ & 3,9580 & 313,3 & 0,3208 & $\begin{array}{c}12 \overline{8} \rightarrow 13 \overline{4}(\overline{5} \%), 13 \overline{2} \rightarrow \overline{1} \overline{3} 5(\overline{8} 6 \%), \\
133 \rightarrow 134(3 \%)\end{array}$ \\
\hline & $9^{\underline{0}}$ & 4,1535 & 298,5 & ( & $\begin{array}{c}\overline{1} 23 \rightarrow 135(2 \%), 125 \rightarrow 13 \overline{4}(3 \%) \\
130 \rightarrow 134(76 \%), 132 \rightarrow 134(9 \%), \\
133 \rightarrow 135(5 \%)\end{array}$ \\
\hline & $13^{\mathrm{O}}$ & 4,2589 & 291,1 & 0,1484 & $\begin{array}{c}125 \rightarrow 135(38 \%), 130 \rightarrow 135(9 \%), \\
133 \rightarrow 138(46 \%)\end{array}$ \\
\hline \multirow{4}{*}{ TD-DFT } & $4^{\mathrm{O}}$ & 2,9098 & 426,1 & 0,0442 & $130 \rightarrow 134(4 \%), 132 \rightarrow 134(93 \%)$ \\
\hline & $12^{\mathrm{O}}$ & 3,4080 & 363,8 & 0,0999 & $127 \rightarrow 134(77 \%), 133 \rightarrow 138(20 \%)$ \\
\hline & $13^{0}$ & 3,4175 & 362,8 & 0,0121 & $\begin{array}{c}124 \rightarrow 13 \overline{4}(\overline{6} \%), 1 \overline{2} \rightarrow \overline{1} \overline{3} 5(\overline{7} 1 \%), \\
130 \rightarrow 134(21 \%)\end{array}$ \\
\hline & $17^{\underline{0}}$ & 3,4979 & 354,5 & 0,1933 & $\begin{array}{l}124 \rightarrow 135(40 \%), 127 \rightarrow 134(5 \%), \\
130 \rightarrow 135(23 \%), 133 \rightarrow 138(29 \%)\end{array}$ \\
\hline
\end{tabular}




\begin{tabular}{|c|c|c|c|c|c|}
\hline Método & Estado & $\Delta E$ & $\lambda$ & $f$ & Transições envolvidas \\
\hline \multirow{4}{*}{ TD-DFT } & $4^{\mathrm{O}}$ & 2,6360 & 470,3 & 0,0265 & $128 \rightarrow 134(4 \%), 132 \rightarrow 134(93 \%)$ \\
\hline & $5^{\underline{0}}$ & 2,6927 & 460,4 & 0,0016 & $128 \rightarrow 135(7 \%), 132 \rightarrow 135(91 \%)$ \\
\hline & $13^{\mathrm{O}}$ & 3,0360 & 408,4 & 0,0001 & $\begin{array}{c}12 \overline{3} \rightarrow 1 \overline{3}(\overline{6} \%), 1 \overline{2} \overline{7} \overline{1} \overline{3} 5(\overline{7} 5 \%), \\
128 \rightarrow 134(17 \%)\end{array}$ \\
\hline & $14^{\underline{0}}$ & 3,0496 & 406,6 & 0,0762 & $127 \rightarrow 134(89 \%), 133 \rightarrow 138(8 \%)$ \\
\hline \multirow{4}{*}{ TD-DFT } & $3^{0}$ & 3,5302 & 351,2 & 0,1778 & $\begin{array}{l}130 \rightarrow 134(7 \%), 131 \rightarrow 136(3 \%), \\
132 \rightarrow 134(83 \%), 133 \rightarrow 135(3 \%)\end{array}$ \\
\hline & $6^{\underline{0}}$ & 3,9709 & 312,2 & 0,2747 & $\begin{array}{c}128 \rightarrow 134(5 \%), 132 \rightarrow 135(88 \%), \\
133 \rightarrow 134(2 \%)\end{array}$ \\
\hline & $9^{\underline{0}}$ & 4,1591 & 298,1 & 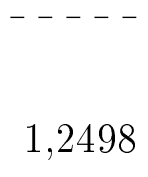 & $\begin{array}{c}\overline{1} 23 \rightarrow 13 \overline{5}(2 \%), \overline{1} 25 \rightarrow 1 \overline{3} \overline{4}(\overline{2} \%), \\
130 \rightarrow 134(81 \%), 132 \rightarrow 134(5 \%), \\
133 \rightarrow 135(5 \%)\end{array}$ \\
\hline & $13^{\underline{0}}$ & 4,2565 & 291,3 & 0,0923 & $\begin{array}{c}125 \rightarrow 135(\overline{2} 3 \%), \overline{1} 30 \rightarrow 135(8 \%) \\
133 \rightarrow 138(64 \%)\end{array}$ \\
\hline \multirow{5}{*}{$\begin{array}{c}\text { TD-DFT } \\
\text { (LC-wPBE) }\end{array}$} & $3^{0}$ & 3,7910 & 327,1 & 0,3654 & $\begin{array}{c}125 \rightarrow 134(3 \%), 130 \rightarrow 134(21 \%), \\
131 \rightarrow 136(6 \%), 132 \rightarrow 134(61 \%), \\
133 \rightarrow 135(6 \%)\end{array}$ \\
\hline & $6^{\underline{0}}$ & 4,2782 & 289,8 & 0,7797 & $\begin{array}{c}1 \overline{8} \rightarrow 1 \overline{3} \overline{4}(\overline{5} \%), 1 \overline{3} \overline{2} \rightarrow \overline{1} \overline{3} 5(\overline{8} 3 \%) \\
133 \rightarrow 134(3 \%)\end{array}$ \\
\hline & & & & & $12 \overline{5} \rightarrow \overline{1} \overline{4} \overline{3}(\overline{3} \%), 1 \overline{3} \overline{0} \rightarrow \overline{1} \overline{3} 4(\overline{6} 1 \%)$, \\
\hline & $7^{0}$ & 4,4369 & 279,4 & 1,1782 & $\begin{array}{c}131 \rightarrow 136(3 \%), 132 \rightarrow 134(19 \%), \\
133 \rightarrow 135(4 \%)\end{array}$ \\
\hline & $12^{\underline{0}}$ & 4,6200 & 268,4 & 0,0875 & $\begin{array}{l}125 \rightarrow 135(\overline{6} \%), \overline{1} 26 \rightarrow 136(6 \%), \\
130 \rightarrow 135(8 \%), 133 \rightarrow 138(14 \%)\end{array}$ \\
\hline \multirow{4}{*}{$\mathrm{ZINDO} / \mathrm{CIS}$} & $5^{-0}$ & 3,3366 & 371,6 & 0,04438 & $133 \rightarrow 138(97 \%)$ \\
\hline & $6^{0}$ & 3,4008 & 364,6 & 0,67120 & $130 \rightarrow 134(30 \%), 132 \rightarrow 134(52 \%)$ \\
\hline & $8^{0}$ & 3,6120 & 343,3 & 0,06373 & $133 \rightarrow 139(94 \%)$ \\
\hline & $10^{\mathrm{o}}$ & 3,8555 & 321,6 & 0,89343 & $132 \rightarrow 135(66 \%), 133 \rightarrow 143(12 \%)$ \\
\hline
\end{tabular}


Tabela 3.12: Estados excitados da molécula $H_{2}$-Ftalocianina isolada no nível LC-wPBE/6$31+\mathrm{G}^{*} . \Delta E$ é a energia de excitação dada em eV, $\lambda$ é o comprimento de onda correspondente dado em nm, e $f$ é a força de oscilador. As transições envolvidas são mostradas, e a contribuição delas para cada excitação é mostrada em parênteses. O orbital HOMO é numerado como 133.

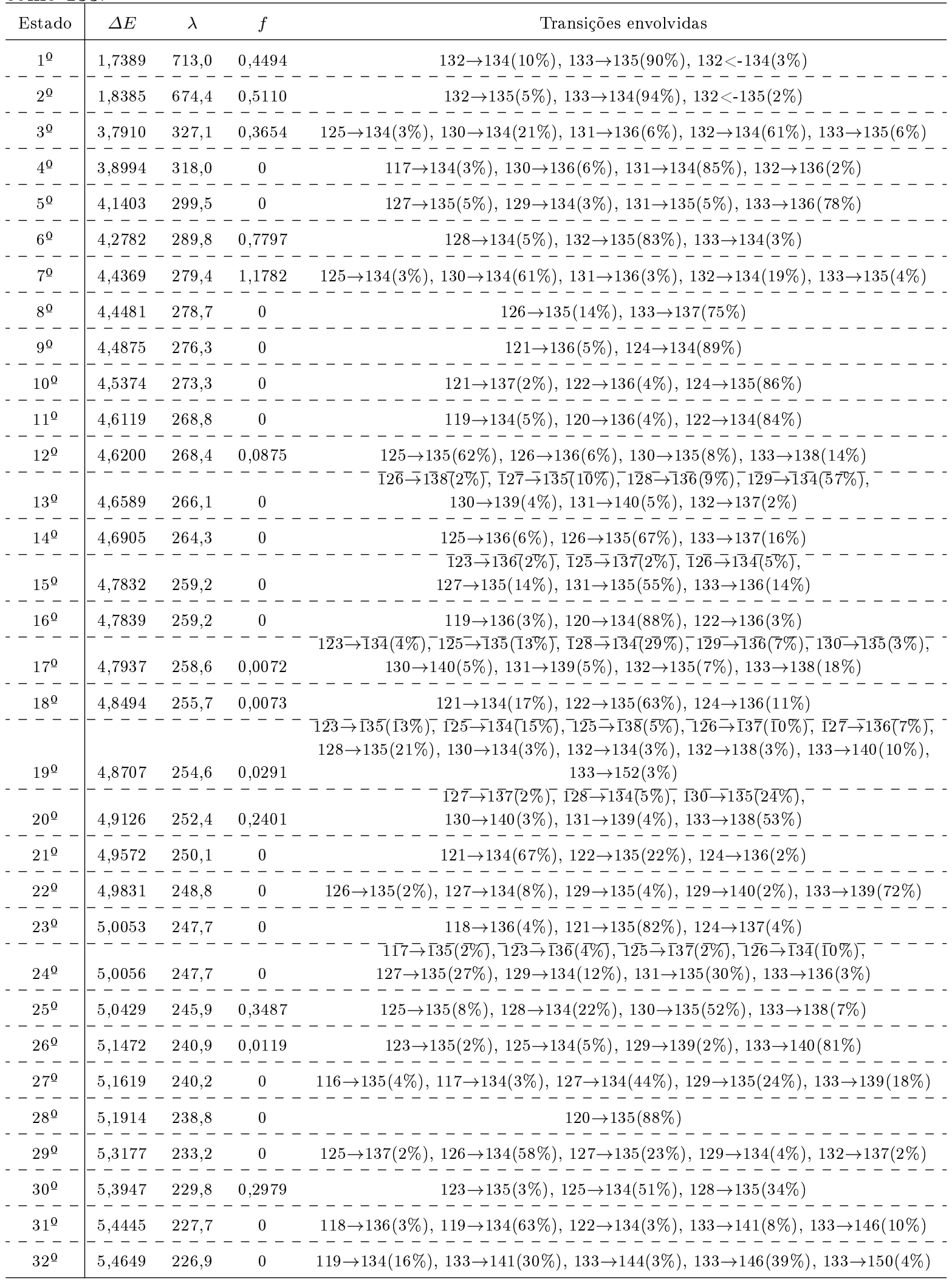




\subsubsection{Desdobramento das bandas $Q$ da $H_{2}$-Ftalocianina}

Seguindo com o que foi mencionado na subseção anterior e com o que foi apresentado na subseção 1.4.1, no artigo no qual o espectro experimental da $H_{2}$-Ftalocianina é reportando [29] é mencionada a hipótese de que o desdobramento das bandas $Q$ observado no espectro experimental da $\mathrm{H}_{2}$-Ftalocianina pode ser causado devido ao posicionamento dos hidrogênios centrais numa região intermediaria aos nitrogênios centrais (chamado posicionamento em ponte). No artigo é apresentado uma figura que representa essa situação. Realizamos diversas tentativas para obter uma estrutura optimizada desse tipo no nível B3LYP/6-31G* utilizando o programa Gaussian 09 [81] partindo de diversos chutes iniciais para essa estrutura, mas em todas tentativas a optimização, mesmo as em que a simetria era reconhecida pelo programa desde o chute inicial, levava sempre para estrutura da forma apresentada na figura 3.20. Porém percebemos que em algumas optimizações, antes de cada hidrogênio central migrar para ficar ligado com apenas um nitrogênio, a estrutura passava alguns passos de optimização em conformações semelhantes as que buscamos. Uma dessas conformações estruturais foi selecionada e é mostrada na figura 3.23. Mesmo esta estrutura tendo simetria $C_{2 h}$, a figura mostra que a distância entre os hidrogênios centrais e os nitrogênios próximos não é igual e que existem diferenças estruturais entre as partes não opostas da molécula.

Vamos nesta subseção mostrar resultados para o espectro de absorção da estrutura da figura 3.23. O cálculo do espectro foi feito no nível B3LYP $/ 6-31+\mathrm{G}^{*}$ utilizando o programa Gaussian 09 [81]. O método TD-DFT(B3LYP) foi escolhido por ser o que fornece o menor desdobramento para as bandas $Q$ dentre os resultados mostrados na tabela 3.10. Os resultados obtidos para essa estrutura são mostrados na tabela 3.13.

Como a tabela 3.13 mostra para essa estrutura com os hidrogênios em posição de ponte ocorre um desdobramento das bandas $Q$ de 61,1 nm que curiosamente está 


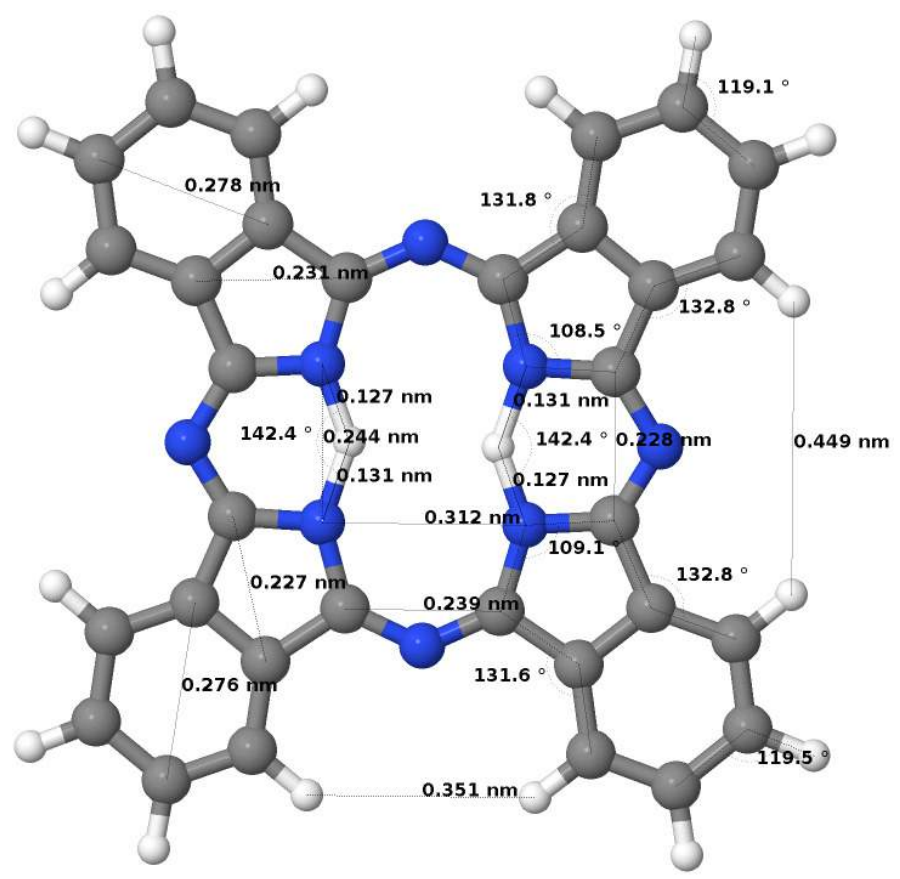

Figura 3.23: Estrutura da $H_{2}$-Ftalocianina com cada hidrogênio central posicionado intermediariamente entre dois nitrogênios centrais.

em bom acordo com a separação experimental e também em acordo com a hipótese abordada em [29], mas esse bom acordo não ocorre com a posição dos picos ${ }^{38}$. A discussão em torno desse problema será retomada na subseção 3.2.6.1, mas é curioso observarmos aqui que, como dissemos, a estrutura da figura 3.23 não é uma estrutura optimizada e por isso não corresponde a um mínimo na superfície de energia potencial da molécula (ver subseção 2.4.1). Mesmo assim existe uma possibilidade de que essa estrutura corresponda aproximadamente a algo como uma estrutura média da molécula, caso migrações dos hidrogênios centrais entre os nitrogênios centrais ocorram de tal modo que em média os hidrogênios fiquem em posição de ponte.

Um outro fato que chama a atenção pela tabela 3.13 é que alguns estados excitados permanecem escuros para essa estrutura. Isso pode estar acontecendo devido ao fato de essa estrutura ter simetria $C_{2 h}$.

\footnotetext{
${ }^{38}$ Como pode ser visto na subseção 1.4 .1 as posições dos picos das bandas $Q$ no espectro experimental são $686 \mathrm{~nm}$ e $622 \mathrm{~nm}$, e a separação entre os picos é de $64 \mathrm{~nm}$.
} 
Tabela 3.13: Estados excitados da molécula $H_{2}$-Ftalocianina na conformação apresentada na figura 3.23 obtidos no nível B3LYP /6-31+ $\mathrm{G}^{*}$. $\Delta E$ é a energia de excitação dada em eV, $\lambda$ é o comprimento de onda correspondente dado em nm, e $f$ é a força de oscilador.

\begin{tabular}{|c|c|c|c|}
\hline & $\Delta E$ & $\lambda$ & $f$ \\
\hline $1^{0}$ Estado & 1,9317 & 641,8 & 0,3989 \\
\hline $2^{0}$ Estado & 2,1351 & 580,7 & 0,4204 \\
\hline $3^{0}$ Estado & 3,2288 & 384,0 & 0,0311 \\
\hline $4^{0}$ Estado & 3,2362 & 383,1 & 0,0000 \\
\hline $5^{0}$ Estado & 3,3729 & 367,6 & 0,0000 \\
\hline $6^{0}$ Estado & 3,4026 & 364,4 & 0,0013 \\
\hline $7^{0}$ Estado & 3,4036 & 364,3 & 0,0000 \\
\hline $8^{0}$ Estado & 3,4364 & 360,8 & 0,0000 \\
\hline $9^{0}$ Estado & 3,5368 & 350,6 & 0,0000 \\
\hline $10^{0}$ Estado & 3,5407 & 350,2 & 0,0000 \\
\hline $11^{0}$ Estado & 3,5479 & 349,5 & 0,0902 \\
\hline $12^{\underline{O}}$ Estado & 3,5597 & 348,3 & 0,0000 \\
\hline $13^{0}$ Estado & 3,5924 & 345,1 & 0,0000 \\
\hline $14^{0}$ Estado & 3,5971 & 344,7 & 0,3248 \\
\hline $15^{\mathrm{O}}$ Estado & 3,6268 & 341,9 & 0,0000 \\
\hline $16^{0}$ Estado & 3,6331 & 341,3 & 0,0000 \\
\hline $17^{0}$ Estado & 3,6636 & 338,4 & 0,0000 \\
\hline $18^{0}$ Estado & 3,7111 & 334,1 & 0,0170 \\
\hline $19^{0}$ Estado & 3,7586 & 329,9 & 0,2814 \\
\hline $20^{0}$ Estado & 3,7693 & 328,9 & 0,0000 \\
\hline
\end{tabular}




\subsubsection{Comparação de resultados para estruturas optimizadas}

Nesta subseção vamos fazer uma comparação dos resultados obtidos com resultados experimentais e também com outros trabalhos teóricos encontrados na literatura. Resultados para dímeros optimizados também serão apresentados. Esses resultados para dímeros são importantes, não apenas com intuito de inferir sobre a possibilidade de ocorrência de dimerização no espectro experimental da $H_{2}$-Ftalocianina ${ }^{39}$, mas também porque a agregação de Ftalocianinas já vem sendo estuda há várias décadas. Estudos de dímeros de Ftalocianina são de interesse, por exemplo, para as áreas de fabricação de filmes finos e de cristais líquidos ${ }^{40}$.

\subsubsection{Resultados para monômero}

Na tabela 3.14 apresentamos uma comparação dos resultados obtidos, inicialmente apresentados na subseção 3.2.3, com o resultado experimental e com resultados de outros trabalhos teóricos para as energias de excitação das bandas $Q_{x}$ e $Q_{y}$ e para a banda de Soret $B$.

Pela tabela 3.14 podemos ver que os diferentes métodos, incluindo os apresentados em outros trabalhos, fornecem diferentes resultados para as energias de excitação. Com relação aos outros trabalhos, não é mencionada nas tabelas detalhes dos cálculos como o conjunto de funções-base utilizada, a estrutura utilizada ou o programa utilizado nos cálculos. Desse modo, uma comparação direta desses resultados com os nossos é impraticável sem essa análise prévia ${ }^{41}$. A menção a esses trabalhos aqui ainda

\footnotetext{
${ }^{39} \mathrm{O}$ vapor de $\mathrm{H}_{2}$-Ftalocianina em que as medidas do espectro foram realizadas é obtido a partir de uma vaporização deste sistema em solução, portanto caso as moléculas se encontrem agregadas em solução é possível que eles continuem agregadas no vapor.

${ }^{40}$ A seção III do capítulo 118 da série "The Porphyrin Handbook" [36] fala sobre dímeros de Ftalocianina. Este capítulo está presente no volume 19 da série.

${ }^{41}$ Pela tabela 3.14 é notável a concordância dos resultados de [8] e [43] com o resultado experimental. No caso de [8] os cálculos com LC-PBE foram feitos com o programa ORCA [91]. O funcional LC-PBE não está disponível no programa Gaussian 09 [81], que foi o programa utilizado nessa dissertação (juntamente com o ZINDO [64]). É importante registrarmos que realizamos cálculos TD-DFT utilizando o mesmo funcional, a mesma base e a mesma estrutura com o Gaussian e o com ORCA e
} 
Tabela 3.14: Comparação de resultados para as energias de excitação da $H_{2}$-Ftalocianina, que são dadas em eV, para as bandas $Q$ e a banda de Soret.

\begin{tabular}{ccccc}
\hline Método & Referência & $Q_{x}$ & $Q_{y}$ & $B$ \\
\hline Experimental & {$[29]$} & 1,81 & 1,99 & 3,79 \\
TD-DFT (B3LYP) & Este Trabalho & 2,03 & 2,04 & 3,73 \\
TD-DFT (BHandHLYP) & Este Trabalho & 2,00 & 2,01 & 4,25 \\
TD-DFT (CAM-B3LYP) & Este Trabalho & 1,96 & 2,00 & 4,15 \\
TD-DFT (O3LYP) & Este Trabalho & 2,02 & 2,03 & 3,55 \\
TD-DFT (BP86) & Este Trabalho & 1,95 & 1,96 & 3,77 \\
TD-DFT (M06-2X) & Este Trabalho & 2,04 & 2,08 & 4,16 \\
TD-DFT (LC-wPBE) & Este Trabalho & 1,74 & 1,84 & 4,44 \\
ZINDO/CIS & Este Trabalho & 1,62 & 1,74 & 4,06 \\
TD-TDF (B3LYP) & {$[45]$} & 2,06 & 2,09 & 3,78 \\
TD-TDF (LC-PBE) & {$[8]$} & 1,86 & 1,96 & 3,86 \\
VEH & {$[43]$} & 1,81 & 1,98 & 3,90 \\
SAC-CI & {$[44]$} & 1,30 & 1,51 & 3,96 \\
\hline & & & &
\end{tabular}

assim é importante para mostrar outros estudos teóricos que tem se dedicado ao estudo do espectro de absorção da Ftalocianina Base Livre em fase gasosa. Ainda assim podemos ver que a controvérsia com relação a separação das bandas $Q$ se mantém em outros trabalhos teóricos, assim como em nossos resultados, já que alguns resultados

obtivemos diferenças significativas nos resultados. Algumas possíveis causas para isso são possíveis diferenças nas grelhas utilizadas nos cálculos e diferenças nos critérios de convergência nos cálculos das energias, porém não estamos certos de quais são as razões para essas diferenças. Como todos os cálculos utilizando o Gaussian já se encontravam prontos ao nos depararmos com esse problema, seguimos no decorrer de toda dissertação fazendo uso do Gaussian em vez de usar o ORCA, mesmo sem saber qual dos dois estaria fornecendo os resultados mais corretos. 
indicam a separação enquanto outros não.

Os nossos resultados também são mostrados na figura $3.5^{42}$, onde são comparados mais diretamente com o espectro experimental através da convolução por Lorentzianas dos picos teóricos (vale lembrar que essa comparação tem que ser feita com cuidado, ver seções 2.2.5 e 2.2.6).

A figura 3.24 nos da uma ideia melhor dos resultados apresentados na tabela 3.14, além de ilustrar as outras bandas obtidas após a banda de Soret. Como mencionado na subseção 3.2.3, os cálculos com B3LYP, BP86, CAM-B3LYP, BHandHLYP, O3LYP, LC-wPBE e M06-2X foram feitos para os 46 primeiros estados excitados, e cálculo ZINDO/CIS para 49 estados. Vale aqui ressaltar que os estados escuros não são ilustrados na figura 3.24 .

Devido a essa problemática envolvendo a separação das bandas $Q$, analisando a tabela 3.14 e principalmente a figura 3.24 é difícil dizer qual dos métodos fornece uma concordância melhor com o resultado experimental. Com relação a banda de Soret, vemos que dos nossos resultados a melhor concordância é obtida com o método TDDFT(B3LYP). Com relação as bandas $Q$ os métodos que fornecem a maior separação são os métodos TD-DFT(LC-wPBE) e ZINDO/CIS, porém essa separação e a posição dos picos não estão de acordo com o resultado experimental assim como a posição do pico da banda de Soret.

Na subseção 3.2 .3 a partir de análise dos orbitais moleculares da $H_{2}$-Ftalocianina expressamos nossa expectativa de que, apesar de terem estruturas semelhantes, os espectros da $\mathrm{H}_{2}$-Ftalocianina e da $\mathrm{H}_{2}$-Porfirina apresentariam diferenças. Essa expectativa, de fato, se mostrou verdadeira. Se compararmos os espectros dessas duas moléculas nas figuras 3.24 e 3.5 podemos ver que existem diferenças significativas nas posições dos picos e nas forças de oscilador. Diferenças também se manifestam no

\footnotetext{
${ }^{42}$ Uma figura equivalente foi feita com os resultados para a Zn-Ftalocianina e é apresentada na figura C.7 do apêndice C
} 


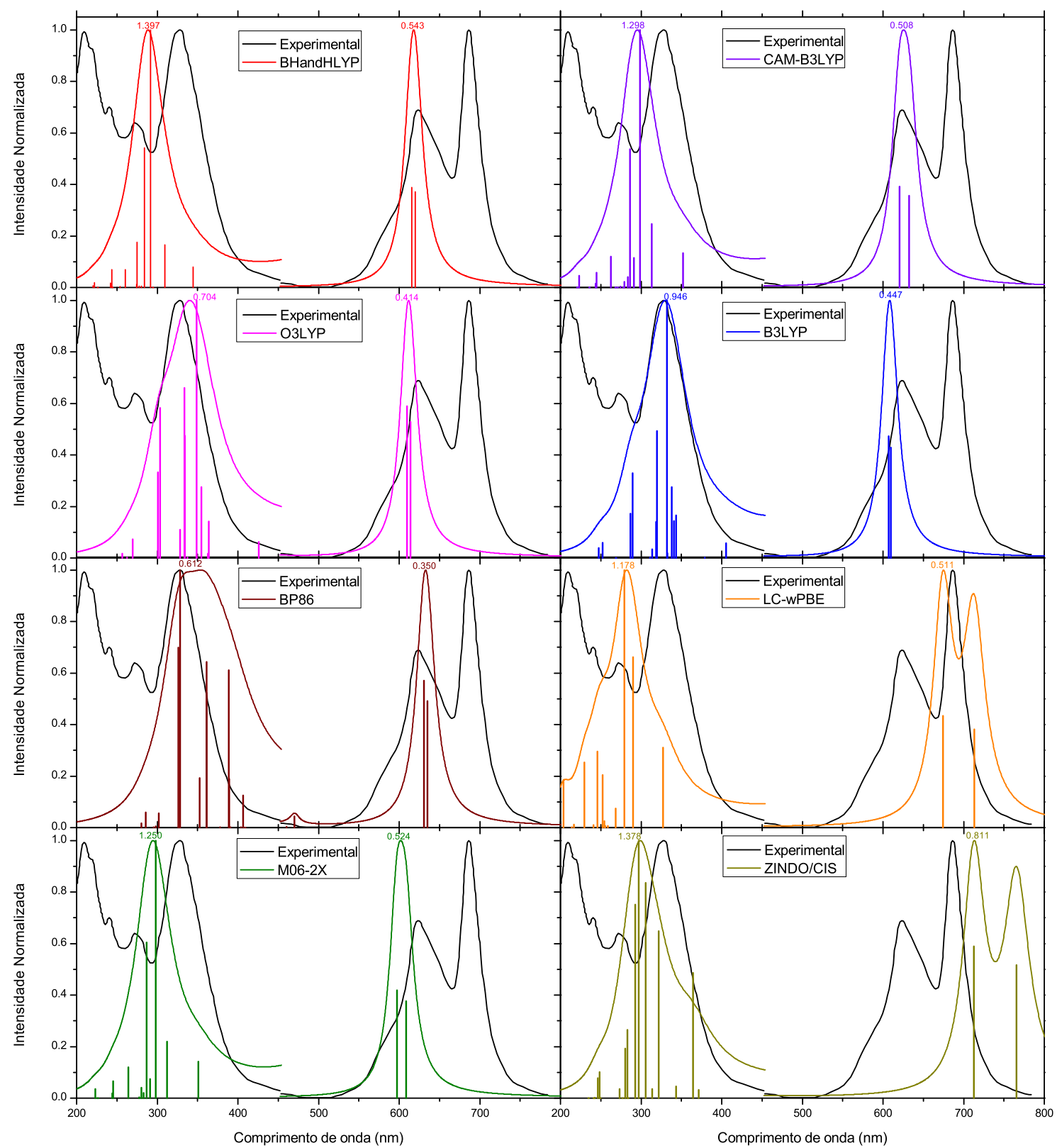

Figura 3.24: Comparação de resultados para a $H_{2}$-Ftalocianina isolada. O espectro experimental foi retirado de [29]. Mostramos os picos teóricos e a convolução dos picos obtidos utilizando. Veja que amplificamos as curvas na região de 420 a $800 \mathrm{~nm}$, porém os picos teóricos não foram amplificados.

espectro experimental como nas posições e nas absorbâncias dos picos. 


\subsubsection{Resultados para dímeros}

Vamos agora apresentar resultados para dímeros de $H_{2}$-Ftalocianina. Foram obtidos dois dímeros, chamados de (a) e (b), através de optimização de geometria no nível wB97XD/6-31G* utilizando o programa Gaussian 09 [81]. Assim como no caso dos dímeros de $H_{2}$-Porfirina apresentados na subseção 3.2.5.2, o funcional wB97XD foi escolhido por conter correções para incluir interações de dispersão. Os dímeros obtidos são ilustrados na figura 3.25, sobre duas perspectivas diferentes. Um fato que vale aqui registrar é que, assim como no caso dos dímeros de $H_{2}$-Porfirina, uma tentativa para obtenção de um dímero de $\mathrm{H}_{2}$-Ftalocianina com uma estrutura na forma de $\mathrm{T}$ foi feita, mas essa optimização levou ao dímero (b).

Como pode ser visto pela figura 3.25, o dímero (a) é composto, aproximadamente, por duas moléculas transladadas no eixo perpendicular ao plano de uma delas seguida de uma translação paralela a primeira mais ou menos na direção formada por dois nitrogênios mais externos à esquerda e à direita de uma molécula. A figura mostra que o deslocamento perpendicular é de aproximadamente $4,36 \AA$ e que o deslocamento paralelo é de aproximadamente 2,43 A. A figura da esquerda mostra que praticamente as mesmas distâncias são encontradas em regiões simétricas, indicando que as moléculas praticamente não estão rotacionadas uma em relação a outra. A figura da direita evidencia os deslocamentos observados na figura da esquerda. Caso as moléculas estivessem estivessem transladadas apenas sobre o mesmo eixo, o ângulo mostrado na figura da direita deveria ser $90^{\circ}$.

Como a figura 3.25 evidencia, a descrição do dímero (b) é um pouco mais complicada. A visualização dele apenas nas duas perspectivas apresentadas é bem mais difícil que para o dímero (a). Isso acontece porque, além de transladadas, as moléculas também estão rotacionadas uma em relação a outra. Isso pode ser deduzido pelas medidas apresentadas na figura da esquerda, que apresentam valores diferentes em 

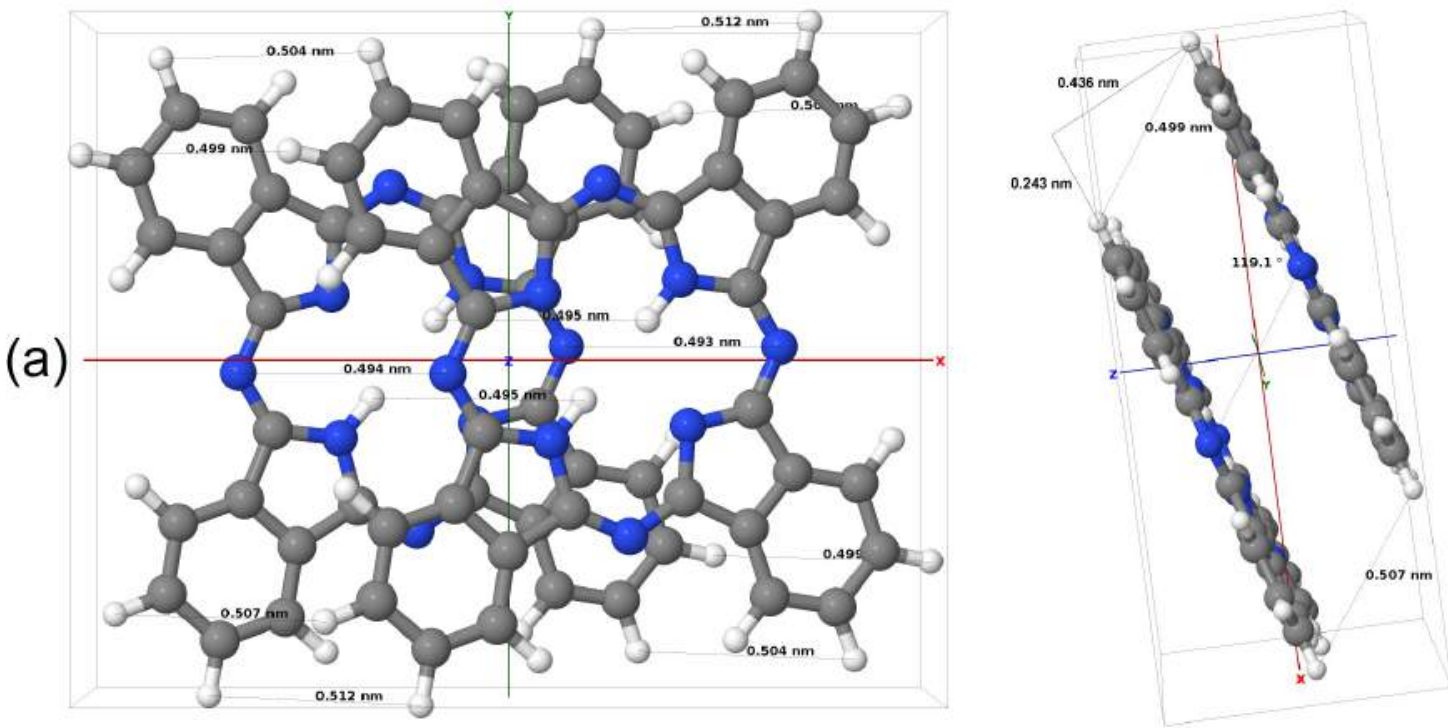

(b)
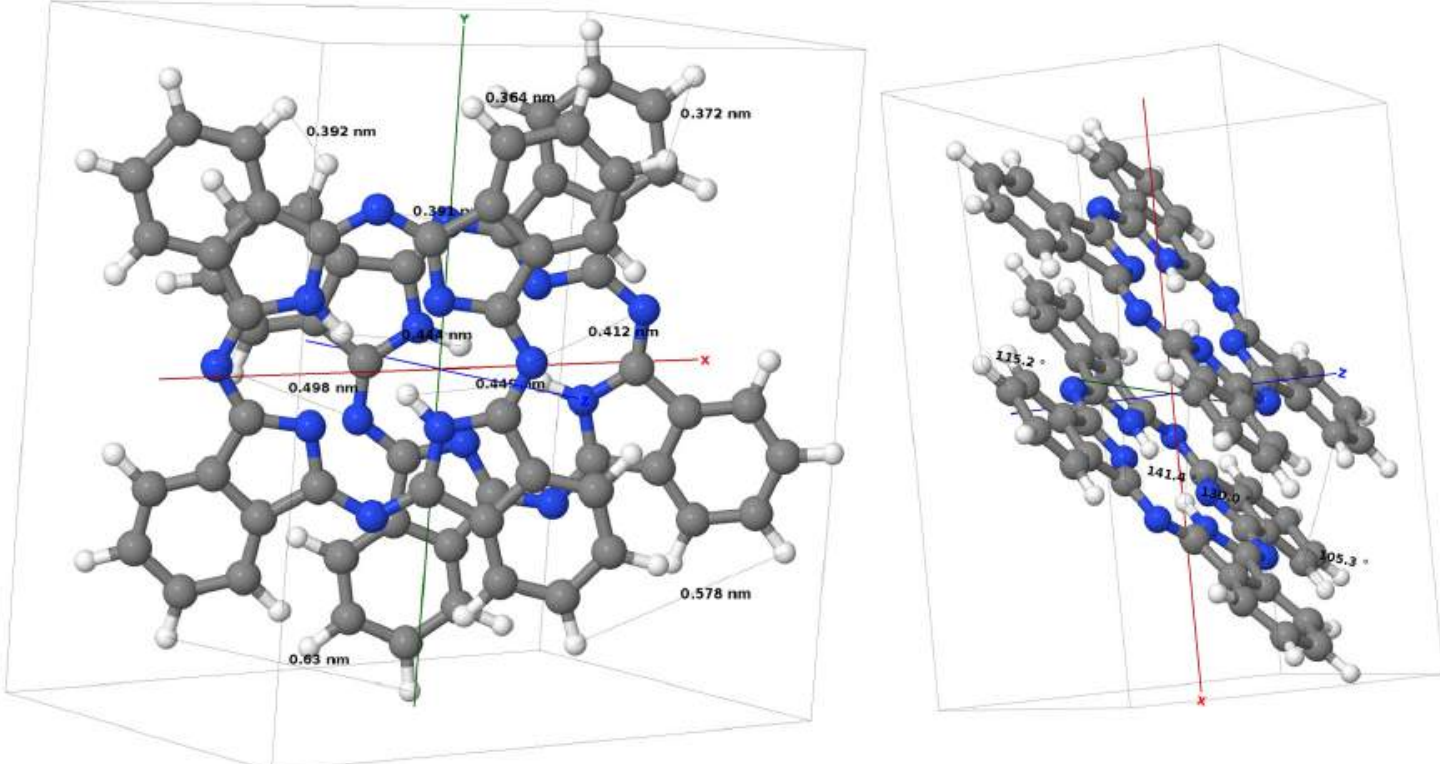

Figura 3.25: Dímeros de $\mathrm{H}_{2}$-Ftalocianina, obtidos a partir de optimizações de geometria no nível wB97XD/6-31G*, ilustrados sobre duas perspectivas diferentes. Eixos e uma caixa limitante que contém a molécula são incluídos para facilitar a compreensão das estruturas das moléculas.

regiões simétricas, e também na figura da direita que mostra vários valores diferentes para ângulos. Caso houvesse apenas translações como é praticamente o caso para o dímero (a), esses ângulos deveriam ser todos iguais. Como a figura da esquerda mostra, 
a distância para átomos equivalentes nas duas moléculas difere em diferentes regiões. Podemos ver que os hidrogênios centrais das duas moléculas estão distanciados cerca de 4,4 $\AA$ uns dos outros, e que um dos anéis benzênicos está mais próximo do seu equivalente, cerca de $3,7 \AA$ distante, enquanto outro anel benzênico está bem mais distanciado de seu equivalente, cerca de $6,3 \AA$.

Mais detalhes a respeitos da estruturas dos dímeros (a) e (b) podem ser encontrados na tabela C.4 do apêndice C que contém as coordenadas dessas estruturas.

A energia de ligação desses dímeros também foi determinada no nível wB97XD / 631G* utilizando o programa Gaussian 09 [81] utilizando o método Counterpoise (ver manual do Gaussian) na tentativa de reduzir erros de superposição de bases. Uma explicação sobre a definição de energia de ligação e sobre o funcionamento do método Counterpoise foi feita na subseção 3.1.4.2, portanto para maiores informações sobre esses assuntos recomendamos a leitura desta subseção. A tabela 3.15 mostra a energia de ligação dos dois dímeros, como também as energias dos dímeros e de cada monômero que compõem os dímeros com e sem a utilização de Counterpoise.

A tabela 3.15 mostra, a partir dos resultados para as energias de ligação, que o dímero (b) está mais fortemente ligado que o dímero (a), indicando que o dímero (b) é mais estável que o dímero (a). Pode-se chegar a esta mesma conclusão a partir dos valores para as energias dos dímeros. Podemos ver pela tabela 3.15 a relevância da utilização de Counterpoise, que implica em diferenças significativas nos valores das energias de ligação.

O espectro experimental na região do visível da $H_{2}$-Ftalocianina foi obtido na temperatura de $773 \mathrm{~K}$ (ver figura 1.5). Nesta temperatura, a energia térmica ${ }^{43}$ é de $1,536 \mathrm{kcal} / \mathrm{mol}$. Pela tabela 3.15 vemos que essa energia pode não ser suficiente para desfazer os dímeros de $H_{2}$-Ftalocianina uma vez que a energia de ligação dos dímeros é bem maior que a energia térmica. Esse é um indicativo de que esses dímeros podem

\footnotetext{
${ }^{43} \mathrm{~A}$ energia térmica é dada pela constante de Boltzmann multiplicada pela temperatura.
} 
Tabela 3.15: Energias envolvidas nos dímeros de $H_{2}$-Ftalocianina mostrados na figura 3.25 , obtidas no nível wB97XD/6-31G*. São apresentados os valores das energias de ligação dadas em $\mathrm{kcal} / \mathrm{mol}$, e os valores para as energias dos dímeros e de cada monômero que compõem os dímeros dadas em Hartree. Os valores para as energias de ligação e energias dos monômeros são apresentados com a utilização de Counterpoise e também sem Counterpoise em parenteses.

\begin{tabular}{|c|c|c|}
\cline { 2 - 3 } \multicolumn{1}{c|}{} & Dímero (a) & Dímero (b) \\
\hline Energia de Ligação & $18,362(22,175)$ & $33,452(44,026)$ \\
\hline Dímero & $-3335,54721907$ & $-3335,58036130$ \\
\hline $1^{0}$ Monômero & $-1667,75897873$ & $-1667,76354175$ \\
& $(-1667,75594039)$ & $(-1667,75503893)$ \\
\hline $2^{0}$ Monômero & $-1667,75897894$ & $-1667,76351053$ \\
& $(-1667,75594064)$ & $(-1667,75516238)$ \\
\hline
\end{tabular}

existir na temperatura experimental. Para uma indicação mais concreta a respeito disso, deveríamos olhar não só as energias de ligação mas sim para as energias livres de ligação. Porém este é um cálculo muito custoso para sistemas tão grandes como os dímeros de $\mathrm{H}_{2}$-Ftalocianina.

O espectro de absorção teórico foi calculado, utilizando o programa Gaussian 09 [81], para esses dois dímeros utilizando vários métodos ab initio com o conjunto de funções-base $6-31+\mathrm{G}^{*}$ para os doze primeiros estados excitados. Esse número reduzido de estados foi considerado devido aos custos computacionais altos envolvidos nos cálculos devido ao tamanho do sistema (um dímero de $H_{2}$-Ftalocianina tem 116 átomos e 532 elétrons). O espectro também foi calculado para os quarenta e nove primeiros estados utilizando o método ZINDO/CIS com o programa [64] (ver subseção 2.3.4) considerando apenas transições dos 25 orbitais mais altos ocupados para os 25 mais baixos desocupados. Nos cálculos a carga dos dímeros foi considerada neutra e a multiplicidade 1 (singleto). Os resultados obtidos são apresentados na tabela 3.16. 
Na figura 3.26 para cada método é apresentado os picos teóricos e a convolução dos picos por Lorentzianas (ver seção 2.2.6).

Na subseção 3.1.4.2 discutimos sobre o efeito da interação entre as moléculas de um dímero no espectro de absorção. Como dissemos, esses efeitos podem acarretar em mudanças significativas em relação ao espectro de monômero, não somente diferenças nas posições dos picos e nas forças de oscilador mas também no surgimento de novas bandas que podem ser escuras ou não. No decorrer do texto da subseção 3.1.4.2 também foi feito um comentário a respeito da relevância dos estados escuros do espectro de absorção. Por essas razões na tabela 3.16 e na figura 3.26 incluímos resultados para monômero para fazermos uma comparação entre os resultados obtidos para monômero e dímeros. Na figura 3.26 ilustramos os estados escuros.

Analisando a tabela 3.16 e a figura 3.26 vários aspectos chamam a atenção. Um deles é que na região do visível do espectro de ambos os dímeros aparecem estados escuros que não existem no espectro de monômero. A aparição destes estados escuros é um indício da interação entre as moléculas do dímero, que é forte o suficiente para a aparição desses novos estados na região do visível (que são típicos de dímero, já que não aparecem no espectro de monômero). Um outro fato que podemos observar é que, ao contrário do que observamos para os dímeros $H_{2}$-Porfirina, para ambos os dímeros de $H_{2}$-Ftalocianina analisados vemos que as características do espectro fornecidas pelos estados de força de oscilador não nula não diferem drasticamente do espectro de monômero optimizado. Analisando a figura 3.26 vemos que na região do visível os espectros dos dímeros apresentam duas bandas com relações de intensidade entre elas compatíveis com o espectro do monômero, mas essas bandas se encontram deslocadas para o azul (menores comprimentos de onda) em relação ao espectro do monômero. As separações entre as bandas $Q$ se mantém na mesma ordem de grandeza que a separação para monômero, e por isso na figura 3.26 vemos que os métodos que não fornecem uma grande separação das bandas $Q$ para o monômero também não fornecem 


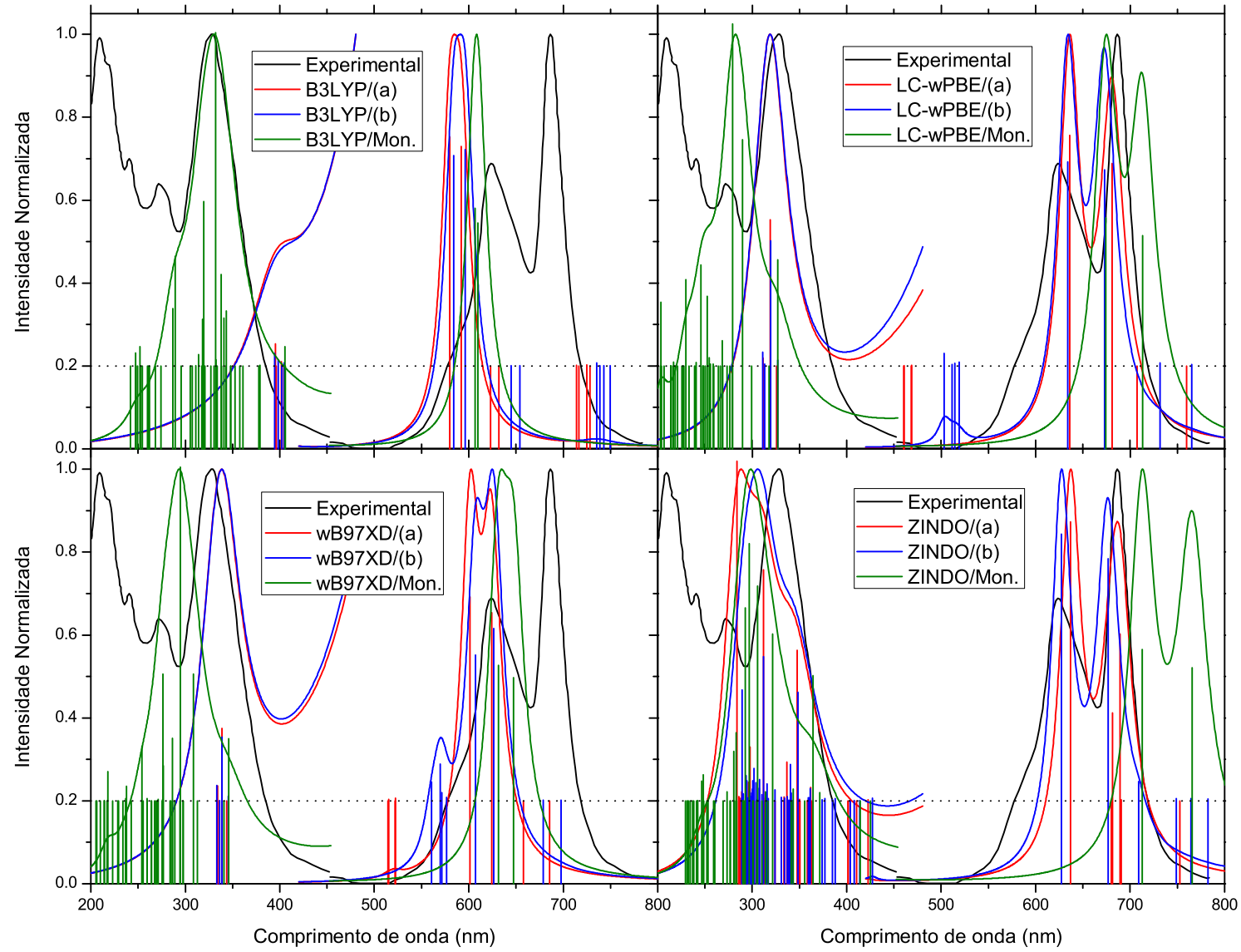

Figura 3.26: Comparação de resultados para dímeros de $H_{2}$-Ftalocianina isolada. O espectro experimental foi retirado de [29]. Resultados para monômeros também são apresentadas. Mostramos os picos teóricos e a convolução dos picos em duas regiões utilizando Lorentzianas. O conjunto de funções-base utilizado em todos os cálculos é o 6-31+G* (exceto ZINDO/CIS). Como muitos dos picos tem intensidade muito baixa ou nula, eles foram renormalizados tal que 0,2 corresponda ao valor 0 da força de oscilador.

uma grande separação para os dímeros. O curioso é que nos casos em que os métodos fornecem uma maior separação para as bandas $Q$ os espectros dos dímeros, que são deslocados para o azul, fornecem uma boa concordância para as posições dos picos em relação as bandas $Q$ experimentais. Com relação a banda de Soret não podemos fazer nenhuma análise porque os doze estados excitados calculados não foram suficientes para descrevem todos os estados excitados nessa região, mas o mesmo não acontece no cálculo ZINDO/CIS onde 49 estados foram calculados. O cálculo ZINDO/CIS mostra 
o surgimento de alguns estados escuros na região do ultravioleta próximo em relação ao espectro do monômero, e as bandas com força de oscilador não nula apontam para uma banda $Q$ com as mesmas características do espectro de monômero com o pico da banda na mesma região.

Para tentar entender uma pouco melhor essa questão do aparecimento de bandas no espectro dos dímeros que não estão apresentes no espectro de monômero, olhamos para os orbitais moleculares dos dímeros. A figura 3.27 ilustra alguns dos orbitais obtidos para os dímeros (a) e (b) a partir do cálculo no nível B3LYP/6-31+G*.

O que vemos nos orbitais apresentados na figura 3.27, como também em diversos outros não mostrados na figura, tanto em orbitais ocupados como desocupados, é a delocalização dos orbitais nas duas moléculas pertencentes ao dímero. Desse modo as transições eletrônicas que compõem o espectro do dímero são transições que estão também delocalizadas em ambas moléculas do dímero. Portanto essas transições são características de dímero. Deste modo essa observação corrobora com o fato de observamos o surgimento de bandas no espectro do dímero que não estão presentes no espectro do monômero. Esse fato corrobora também com o deslocamento dos picos observado na região do visível, característico do espectro de dímeros.

Com relação ao espectro experimental fica difícil dizer se o resultado mais condizente com o resultado experimental é o de monômero ou o de dímero. O que podemos ver é que, mesmo com o surgimento de novas bandas escuras, o espectro de dímero apresenta duas bandas intensas na região do visível, assim como o espectro do monômero. Apesar de que para os métodos que preveem uma separação maior das bandas $Q$ para o monômero após o deslocamento do espectro de dímero termos uma boa concordância com o espectro experimental, não podemos afirmar com certeza que o espectro de dímero é mais compatível com o experimental que o de monômero, ficando portanto essa possibilidade em aberto. Isso acontece porque esse bom acordo foi encontrado apenas alguns casos, e como mostramos na tabela 3.14 existem resultados 

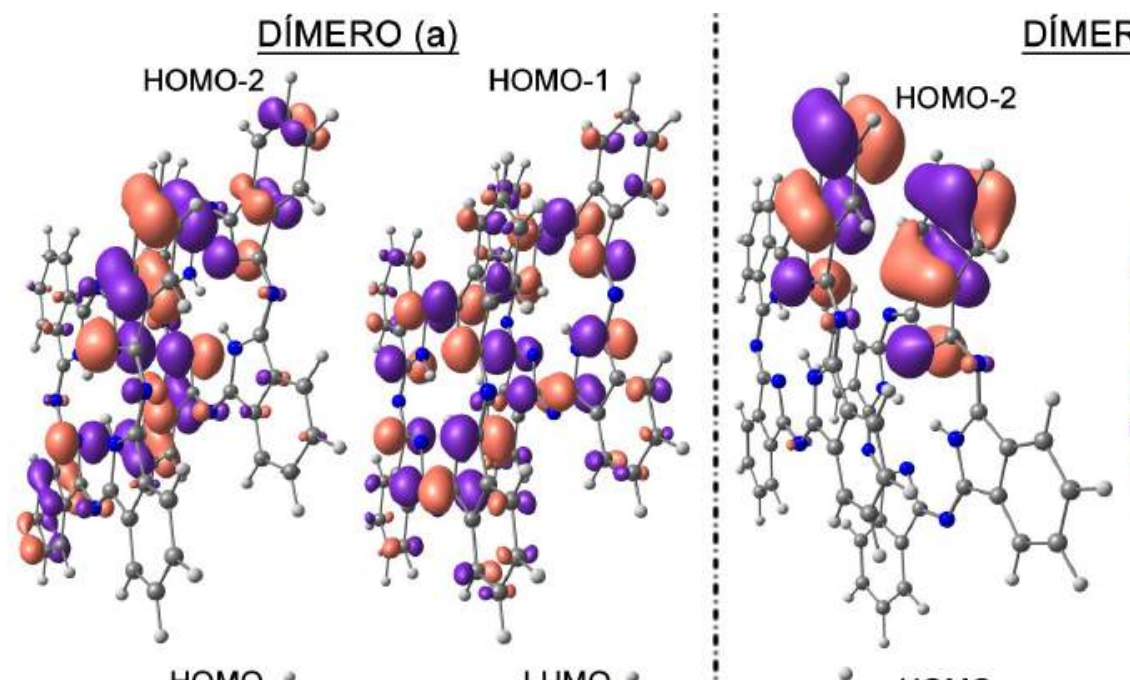

DÍMERO (b)
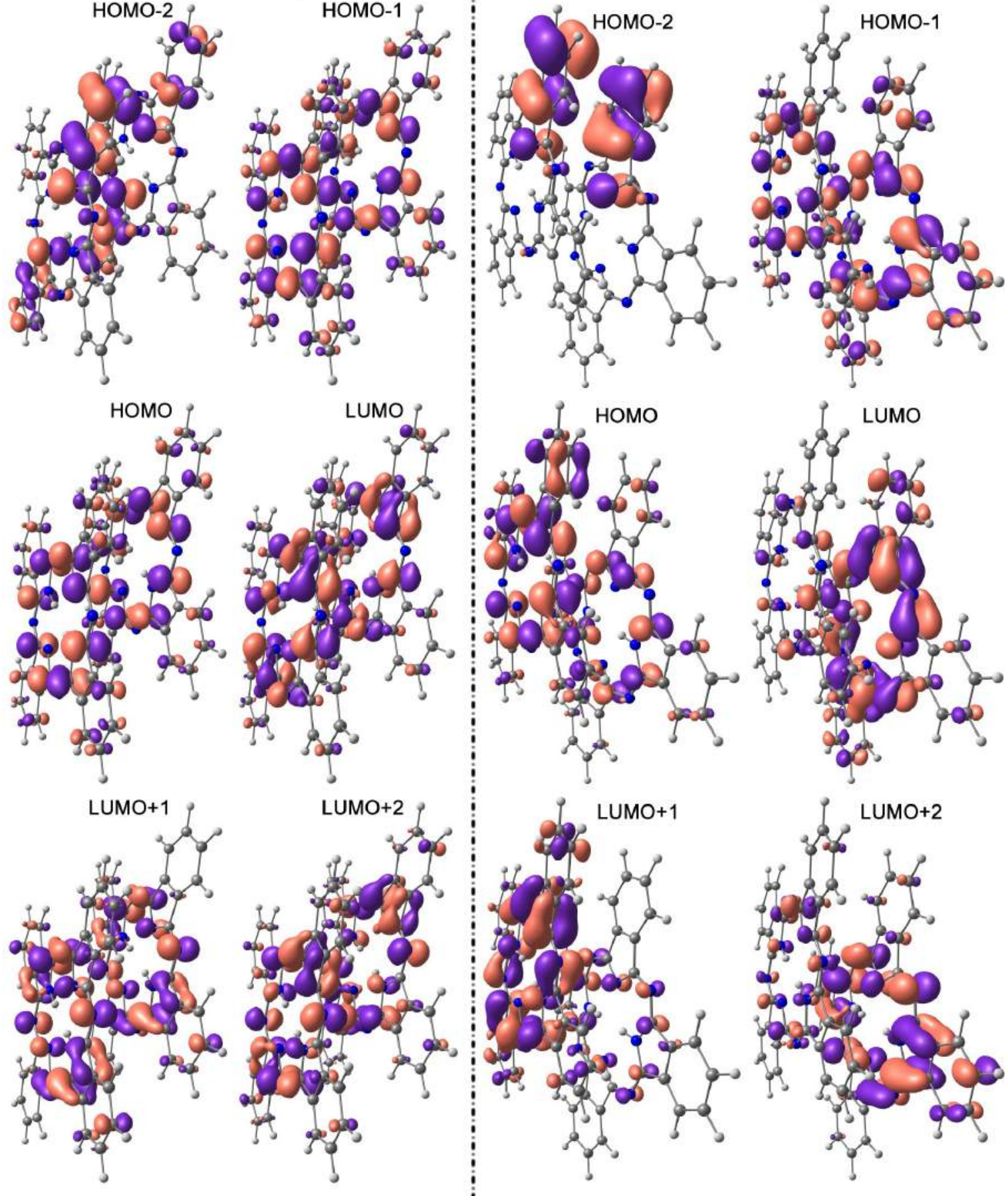

Figura 3.27: Alguns orbitais moleculares dos dímeros (a) e (b) de $H_{2}$-Ftalocianina apresentados na figura 3.25. Esses orbitais foram obtidos a partir de cálculo no nível B3LYP/6-31+G*. 
reportados na literatura que fornecem uma boa concordância do espectro teórico com o experimental para a estrutura monomérica. É possível que essa concordância, em qualquer um desses casos, possa ser simplesmente fortuita.

Um outro fato interessante que vemos a partir dos resultados da tabela 3.16 e na figura 3.26 é que, ao contrário do que aconteceu para os dímero de $H_{2}$-Porfirina na subseção 3.1.4.2, não observamos uma diferença significante nos espectros obtidos para os dímeros (a) e (b). 
Tabela 3.16: Doze primeiros estados excitados dos dímeros de $\mathrm{H}_{2}$-Ftalocianina apresentados na figura 3.25 calculados utilizando vários funcionais TD-DFT com a base $6-31+\mathrm{G}^{*} \mathrm{e}$ ZINDO/CIS. $\lambda$ é o comprimento de onda dado em nm, e $f$ é a força de oscilador. Resultados para as bandas $Q$ do monômero e experimental, retirados da tabela 3.10 e de [29], são apresentados. O cálculo de monômero com wB97XD foi feito a parte apenas para esta análise.

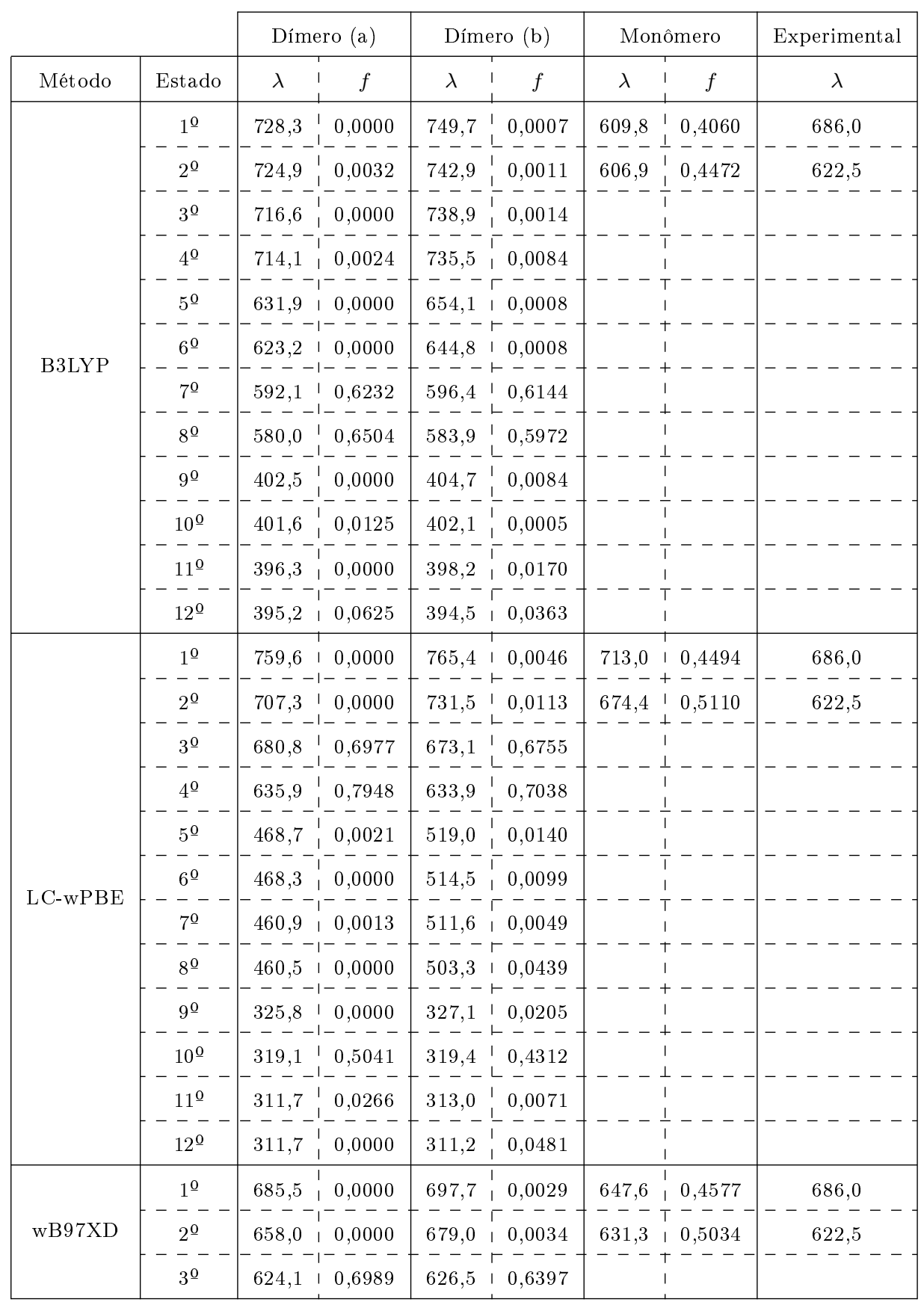




\begin{tabular}{|c|c|c|c|c|c|c|}
\hline \multirow[b]{2}{*}{ Método } & \multirow[b]{2}{*}{ Estado } & Dímero (a) & Dímero (b) & \multicolumn{2}{|c|}{ Monômero } & \multirow{2}{*}{$\frac{\text { Experimental }}{\lambda}$} \\
\hline & & 1 & 1 & $\lambda$ & $f$ & \\
\hline \multirow{12}{*}{ wB97XD } & $4^{0}$ & $601,4 \quad 0,7575$ & $607,0^{\prime} \quad 0,5415$ & \multirow{12}{*}{\multicolumn{2}{|c|}{ 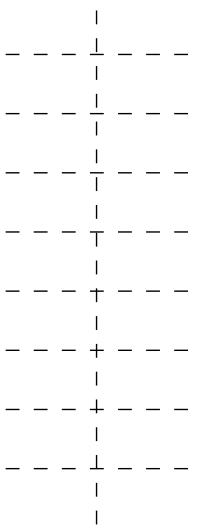 }} & \multirow{12}{*}{$\begin{array}{l}------ \\
------- \\
------- \\
------- \\
------- \\
------- \\
------- \\
-------\end{array}$} \\
\hline & --- & $----I_{-}-$ & $---1--$ & & & \\
\hline & $5^{0}$ & $\begin{array}{l:l}522,3 & 0,0101\end{array}$ & $\begin{array}{l:l}576,5 & 0,0136\end{array}$ & & & \\
\hline & $6^{0}$ & \begin{tabular}{c|c}
521,8 & 0,0000
\end{tabular} & $571,5: 0,0311$ & & & \\
\hline & & $\begin{array}{c:c} & - \\
515,2 & 0,0059\end{array}$ & $\begin{array}{c:c} & - \\
569,9 & 0,1373\end{array}$ & & & \\
\hline & $\begin{array}{l}--- \\
8^{0}\end{array}$ & $\begin{array}{c:c} & -\cdots, 0000 \\
514,7 & 0,000\end{array}$ & $\begin{array}{l:c}--10 \\
560,5 & 0,0699\end{array}$ & & & \\
\hline & $-\overline{9}^{0}--$ & $---1---$ & $\begin{array}{c}--r-- \\
3454\end{array}$ & & & \\
\hline & --- & 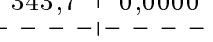 & 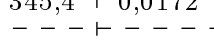 & & & \\
\hline & $10^{\mathrm{O}}$ & $338,7 \quad 0,2694$ & 338,9 । 0,2373 & & & \\
\hline & ---- & $---1---$ & $\begin{array}{l}--ー \vdash--- \\
3363100018\end{array}$ & & & \\
\hline & ---- & $\begin{array}{l}304,0 \\
-\end{array}$ & $\begin{array}{l}350,3 \\
-\end{array}$ & & & \\
\hline & $12^{\mathrm{O}}$ & $334,0: 0,0560$ & $\begin{array}{l:l}333,5 & 0,0567 \\
\end{array}$ & & & \\
\hline \multirow{15}{*}{ ZINDO/CIS } & $1^{0}$ & $\begin{array}{l:l}821,5 & 0,0000\end{array}$ & $\begin{array}{l:l}839,7 & 0,0032\end{array}$ & \multirow{15}{*}{\multicolumn{2}{|c|}{ 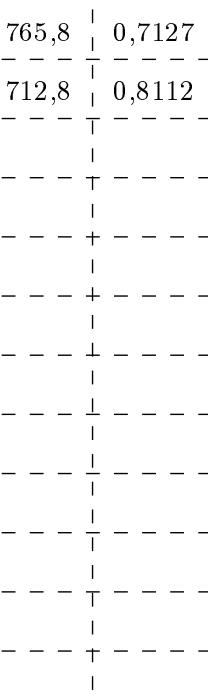 }} & \multirow{15}{*}{$\begin{array}{c}686,0 \\
--\frac{--}{622,5}-- \\
------- \\
------- \\
------- \\
------- \\
------- \\
------- \\
------- \\
------- \\
------- \\
-------\end{array}$} \\
\hline & --- & $\begin{array}{c:c}- & - \\
752,6 & 0,0000\end{array}$ & $\begin{array}{c:c}-0,0133 \\
808,6 & 0,0\end{array}$ & & & \\
\hline & & $\begin{array}{c:c}-6,0055 & 0,0050\end{array}$ & & & & \\
\hline & $-\frac{-}{4^{0}}$ & $\begin{array}{c:c}----- \\
6896 & 0.0002\end{array}$ & $\begin{array}{c:c}----- \\
7645 & 0.0115\end{array}$ & & & \\
\hline & & $---1---$ & & & & \\
\hline & $5^{\mathrm{Q}}$ & $689,4 \quad 0,8937$ & $749,0 \quad$ । 0,0130 & & & \\
\hline & $6^{0}$ & $681,2 \quad 0,4707$ & \begin{tabular}{l|l}
708,9 & । \\
0,1048
\end{tabular} & & & \\
\hline & ---- & & & & & \\
\hline & $\begin{array}{c}7^{0} \\
----\end{array}$ & $679,9: 0,0000$ & $676,6 \quad 1,2980$ & & & \\
\hline & $8^{0}$ & $\begin{array}{l:l}637,0 & 1,4960\end{array}$ & $\begin{array}{l:l}627,4 & 1,4300\end{array}$ & & & \\
\hline & $9^{0}$ & \begin{tabular}{c|c} 
& - \\
422,5 & 0,0070
\end{tabular} & $\begin{array}{l:c} & 0,0149 \\
427,3 & 0,014\end{array}$ & & & \\
\hline & --- & 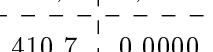 & $---1--$ & & & \\
\hline & & 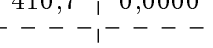 & 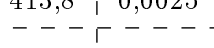 & & & \\
\hline & $11^{0}$ & \begin{tabular}{l|l}
403,3 & 0,0019
\end{tabular} & $408,1 \quad 0,0025$ & & & \\
\hline & $12^{\mathrm{O}}$ & $401,1 \quad 0,0000$ & $403,6 \quad 0,0005$ & & & \\
\hline
\end{tabular}




\subsubsection{Resultados de Dinâmicas Moleculares de Monômero}

Os resultados apresentados até aqui são para estruturas optimizadas. Nas subseções 1.4.1 e 3.2.4 argumentamos sobre a questão abordada no artigo experimental [29] a respeito do desdobramento das bandas $Q$ e da hipótese levantada para explicar esse desdobramento. Vamos aqui nesta subseção 3.2.6 analisar resultados de dinâmicas moleculares do monômero de $H_{2}$-Ftalocianina e resultados para o espectro de absorção obtido através dessas dinâmicas. Esse tipo de análise é interessante para inferirmos sobre como a inclusão de efeitos térmicos influência nas distorções estruturais da molécula e consequentemente qual é a interferência disso no espectro. Discussões a respeito do desdobramento das bandas $Q$ e da hipótese do artigo experimental serão realizadas.

Como mencionamos na subseção 1.4.1, um trabalho [8], de autoria de B. J. C. Cabral, V. W. D. Cruzeiro, K. Coutinho e S. Canuto, foi publicado neste ano de 2014. Neste trabalho estudos são apresentados para o espectro de absorção da $H_{2^{-}}$ Ftalocianina. O enfoque do trabalho é na influência de efeitos térmicos e dimerização no espectro teórico. Este trabalho é apresentado no apêndice E. Neste trabalho são apresentados resultados para dinâmicas moleculares do monômero e do dímero de $\mathrm{H}_{2^{-}}$ Ftalocianina. Essas dinâmicas são ab initio e foram feitas com o programa CP2K [92], com um conjunto de funções-base que contém ondas planas, para 14 ps com timestep de 0,5 fs, e os cálculos do espectro foram feitos com o programa ORCA [91]. Nesta dissertação utilizamos outros programas para fazer dinâmicas moleculares do monômero de $H_{2}$-Ftalocianina, utilizamos um conjunto de funções-base completamente gaussianas na dinâmica $a b$ initio, realizamos simulações significativamente maiores com o timestep reduzido, e o programa Gaussian 09 [81] para fazer os cálculos de espectro.

Serão apresentados resultados para dinâmicas clássicas e ab initio, com intuito de inferir sobre a validade da parametrização utilizada. Esse tipo de estudo, que podemos interpretar que funciona como um teste da parametrização realizada, é im- 
portante pois serve de base para futuros trabalhos envolvendo dinâmicas clássicas da $\mathrm{H}_{2}$-Ftalocianina ou até mesmo da $\mathrm{H}_{2}$-Ftalocianina com substituintes. Como mencionado na subseção 2.3.6, quando dados experimentais não estão disponíveis se usa resultados de cálculos ab initio como base para a parametrização dos campos de força clássicos. Deste modo, assim como fizemos para a $H_{2}$-Porfirina na subseção, vamos considerar a dinâmica $a b$ initio como base e analisar se a dinâmica clássica reproduz razoavelmente bem os resultados estruturais e também o espectro de absorção obtidos através da dinâmica $a b$ initio. Além disso uma comparação dos espectros teóricos, obtidos via dinâmica molecular, é feita com o espectro experimental e com o espectro da geometria optimizada.

\subsubsection{Descrição das dinâmicas}

A dinâmica $a b$ initio realizada para o monômero de $H_{2}$-Porfirina foi feita com o programa TeraChem [78,89]. A dinâmica da molécula isolada foi realizada no nível B3LYP/6-31G. A carga da molécula é neutra e a multiplicidade singleto. O timestep ( $\Delta t$, ou intervalo de integração, ver seção 2.4.3) utilizado foi de 0,25 fs. O ensamble da simulação é o NVT, e o termostato utilizado foi o termostato de Langevin (ver manual do TeraChem [78]) com tempo de amortecimento de $\tau=250$ fs. A temperatura alvo escolhida para a simulação foi de $549,85{ }^{\circ} \mathrm{C}$ ( ou $823,00 \mathrm{~K}$ ) em torno de $44{ }^{\circ} \mathrm{C}$ acima da temperatura em que os resultados experimentais foram obtidos na região do visível (ver subseção 1.4.1). O número total de passos de dinâmica realizados foi de 200000 passos, portanto o tempo total simulado foi de $50 \mathrm{ps}$.

A dinâmica clássica foi feita utilizando o programa GROMACS [73-75]. O campo de força escolhido foi o GROMOS [67,68] com o conjunto de parâmetros 53A6 [69] (ver subseção 2.3.6), recomendado para a simulação de biomoléculas em água explícita. Os valores das cargas atômicas fornecidas pela parametrização foram substituídos por valores obtidos através de um cálculo para determinação de cargas atômicas na geometria 
optimizada com CHelpG ${ }^{44}$ no nível B3LYP $/ 6-31+\mathrm{G}^{* *}$. Os valores dos comprimentos de ligação, ângulos, e diedros de equilíbrio também foram modificados para os valores obtidos para a estrutura optimizada da $H_{2}$-Ftalocianina, que como dissemos nos primeiros parágrafos desta seção 3.2 foi obtida no nível B3LYP/6-31G*. Os rótulos dados para os átomos na parametrização que realizamos são mostrados na figura 3.20 da subseção 3.2.1, e o arquivo *.top, que contém informações da topologia e do campo de força já no formato do programa GROMACS com os valores numéricos dos parâmetros, é apresentado na subseção D.2.1 do apêndice D. O timestep utilizado foi o mesmo da dinâmica $a b$ initio, 0,25 fs. O ensamble da simulação é o NVT, e o termostato utilizado foi o V-Rescale (ver subseção 2.4.4) com tempo de amortecimento de $\tau$ $=250$ fs. A temperatura alvo escolhida para a simulação foi a mesma da simulação ab initio: $549,85^{\circ} \mathrm{C}$ ( ou 823,00 K). A simulação foi feita em uma caixa cúbica com 20 nm de lado. O número total de passos de dinâmica realizados foi de 120 milhões de passos, portanto o tempo total simulado foi de $30 \mathrm{~ns}$. Demais detalhes a respeito desta simulação podem ser consultados no arquivo *.mdp, que contém informações sobre a inicialização da dinâmica, apresentado na subseção D.2.2 do apêndice D.

As razões que nos levaram as escolhas dos valores para o timestep e para o tempo de amortecimento são as mesmas que no caso da $\mathrm{H}_{2}$-Porfirina. Portanto a justificativa para estas escolhas pode ser consultada na subseção 3.2.6.1.

\subsubsection{Termalização: escolha da região de produção}

A figura 3.28 mostra a temperatura do sistema no decorrer dos passos para ambas dinâmicas realizadas. A figura também mostra as regiões escolhidas como termalização e produção, e o valor médio da temperatura na região de produção.

Analisando a figura 3.28 podemos ver que, para ambas dinâmicas, o comportamento inicial da temperatura é levemente diferente do restante da simulação. Podemos

\footnotetext{
${ }^{44}$ Maiores informações sobre CHelpG podem ser encontradas na referência [61].
} 

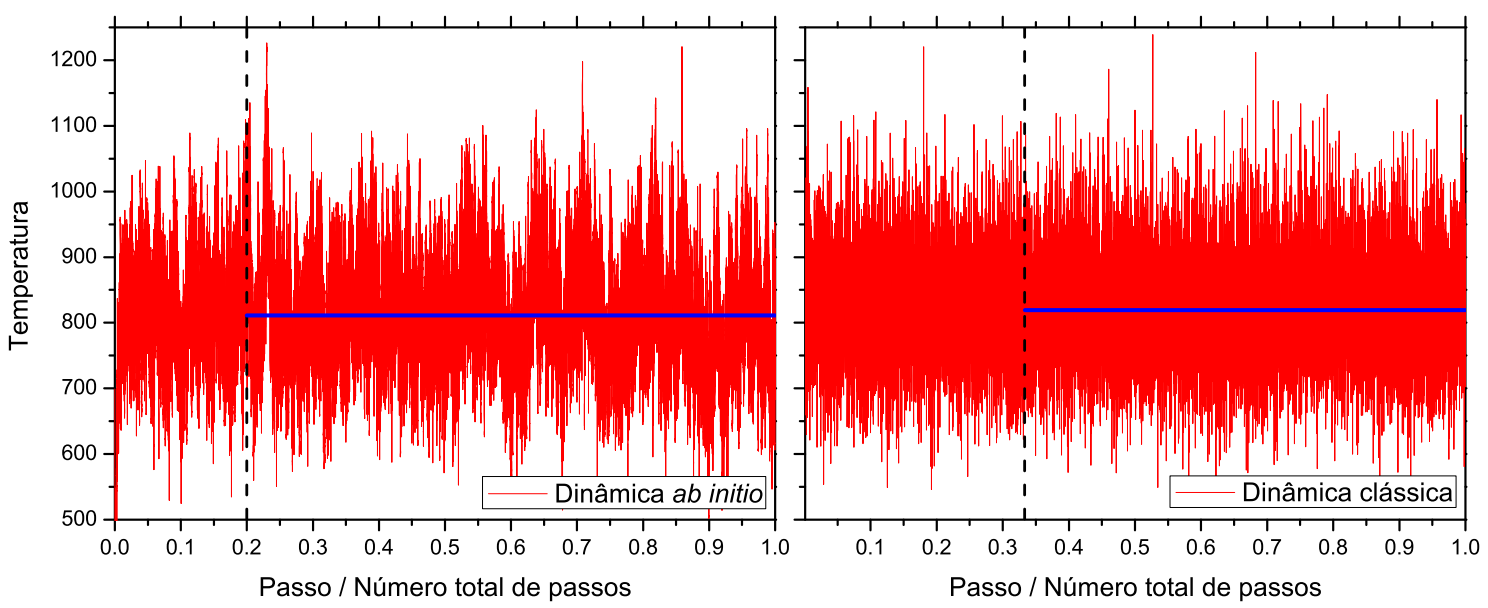

Figura 3.28: Temperatura do sistema com o passar dos passos, para as dinâmicas ab initio e clássica do monômero de $H_{2}$-Ftalocianina. A linha tracejada separa as regiões escolhidas como termalização e como produção. A linha azul representa a temperatura média da região de produção.

ver que esse comportamento diferente permanece até em torno de $15 \%$ de simulação para ambas dinâmicas. A região de termalização foi escolhida em ambos casos de tal modo que esses primeiros $15 \%$ de simulação sejam incluídos nela.

Como mostrado na figura 3.28, para a dinâmica $a b$ initio separamos os primeiros 10 ps de simulação como termalização e os 40 ps restantes como região de produção, e a temperatura média na região de produção foi de $(814,68 \pm 85,38) \mathrm{K}$, onde 85,38 é o desvio padrão. Na simulação clássica separamos os primeiros 10 ns como termalização e os 20 ns restantes como região de produção, e a temperatura média na região de produção foi de $(819,38 \pm 90,13) \mathrm{K}$. Dada que a temperatura alvo é elevada, $823 \mathrm{~K}$, podemos considerar que esses valores médios estão em acordo com este valor.

\subsubsection{Análises das estruturas geradas}

Com as configurações de produção selecionadas, analisamos as estruturas geradas em ambas dinâmicas. Assim como fizemos para a $H_{2}$-Porfirina na subseção 3.1.5.3, aqui buscaremos analisar se as configurações geradas pela dinâmica clássica estão de acordo 
com as geradas pela dinâmica $a b$ initio. Na figura 3.29, apresentada a seguir, pegamos 100 configurações igualmente espaçadas a partir de toda região de produção das dinâmicas $a b$ initio e clássica e sobrepomos ${ }^{45}$.
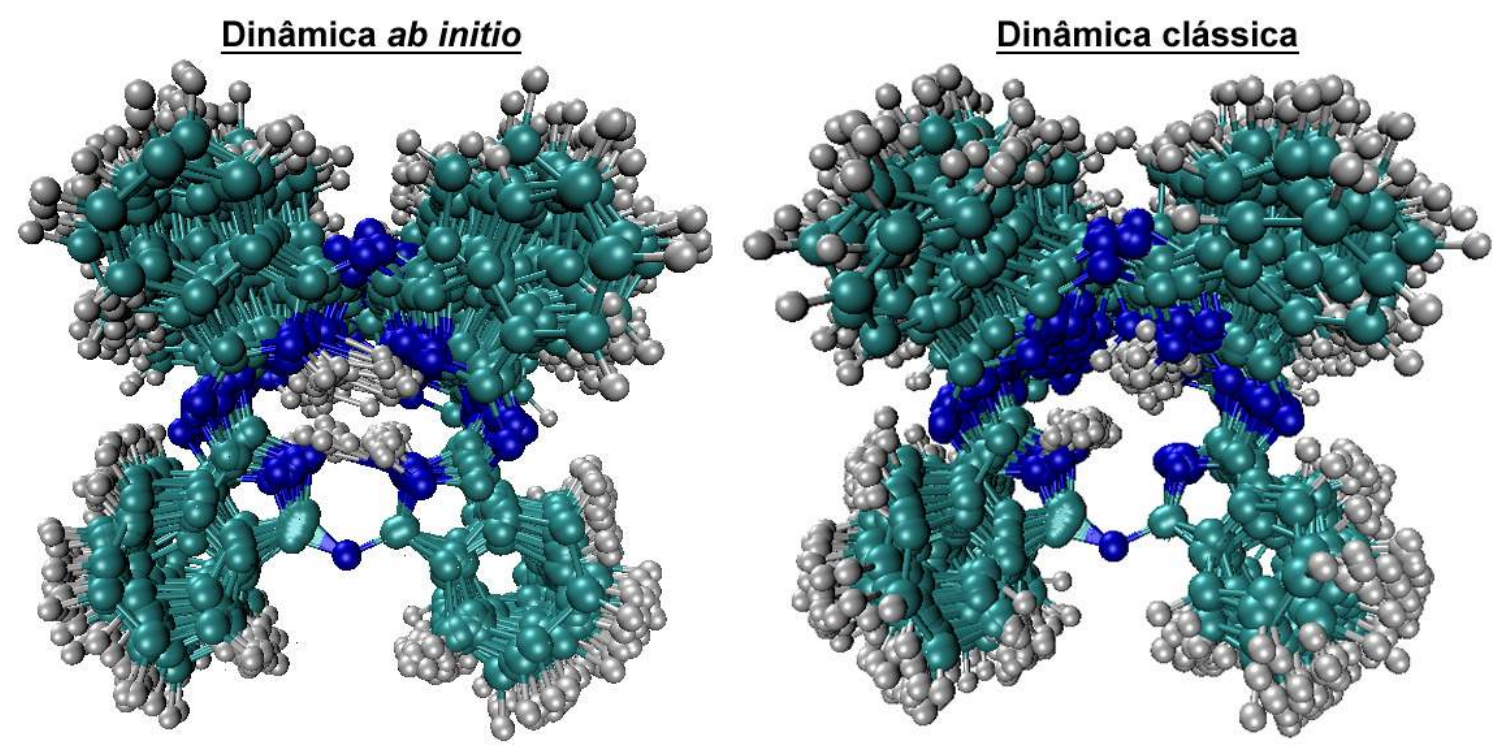

Figura 3.29: Sobreposição de 100 configurações igualmente espaçadas a partir de todas as configurações da região de produção das dinâmicas ab initio e clássica da $H_{2}$-Ftalocianina.

A figura 3.29 já nos da uma ideia preliminar de como são as estruturas geradas em ambas as dinâmicas. Por ela já podemos ver algo interessante: ocorre uma migração dos hidrogênios centrais para outros nitrogênios centrais na dinâmica $a b$ initio. Essa observação remete imediatamente a hipótese abordada no artigo experimental e discutida nas subseções 1.4.1 e 3.2.4. Sendo esta migração frequente, a conformação mostrada no artigo experimental com os hidrogênios centrais em posição de ponte poderia corresponder a estrutura média adquirida pela $H_{2}$-Ftalocianina? Voltaremos a tratar disso no decorrer desta seção.

Para uma análise mais detalhada das estruturas geradas vamos analisar a distribuição de valores (ou histograma) normalizada (ou percentual) para distâncias atômicas, ligações, ângulos e diedros, assim como foi feito para $H_{2}$-Porfirina na subseção

\footnotetext{
${ }^{45}$ Uma explicação de como essa superposição é feita é dada no inicio da subseção 3.1.5.3
} 
3.1.5.3. A figura 3.30 apresenta as distribuições de valores considerados relevantes para algumas distâncias atômicas de átomos não ligados e ligados, ângulos e diedros, obtidos através de 8000 configurações igualmente espaçadas da região de produção das dinâmicas $a b$ initio e clássica.

Como mencionado na subseção 2.3.6, pela própria natureza de sua construção os campos de força clássicos possuem limitações por serem uma aproximação para descrever as interações moleculares, que sem dúvidas são mais corretamente descritas com um Hamiltoniano quântico. Desse modo não esperamos que a dinâmica clássica reproduza detalhadamente os mesmo resultados da dinâmica ab initio, apenas esperamos que os resultados produzidos sejam concordantes. Como podemos ver nas figuras 3.29 e 3.30, a migração dos hidrogênios centrais só é observada na dinâmica ab initio. Não esperamos que esse fenômeno seja observado na dinâmica clássica porque na parametrização feita só é colocada uma constante de força de ligação em cada hidrogênio central com apenas um nitrogênio central, e a inclusão de uma constante de força para cada um dos outros nitrogênios centrais se tornaria complicada primeiro por causa da escolha do valor para essas constantes - teria essa constante de força um valor quando o nitrogênio e o hidrogênio estão próximos e formam ligação e outro valor quando estão longe e não formam ligação? - e também devido ao fato de que o modelo para tratar as interações de ligações no campo de força, que é uma aproximação (ver subseção 2.3.6), pode não ser uma boa aproximação neste caso de átomos distantes e que não formam ligação. Portanto este acaba sendo um exemplo das limitações dos campos de força clássicos e um exemplo também de um caso onde com uso de dinâmica ab initio se é capaz de observar um fenômeno não observado em dinâmicas clássicas. 

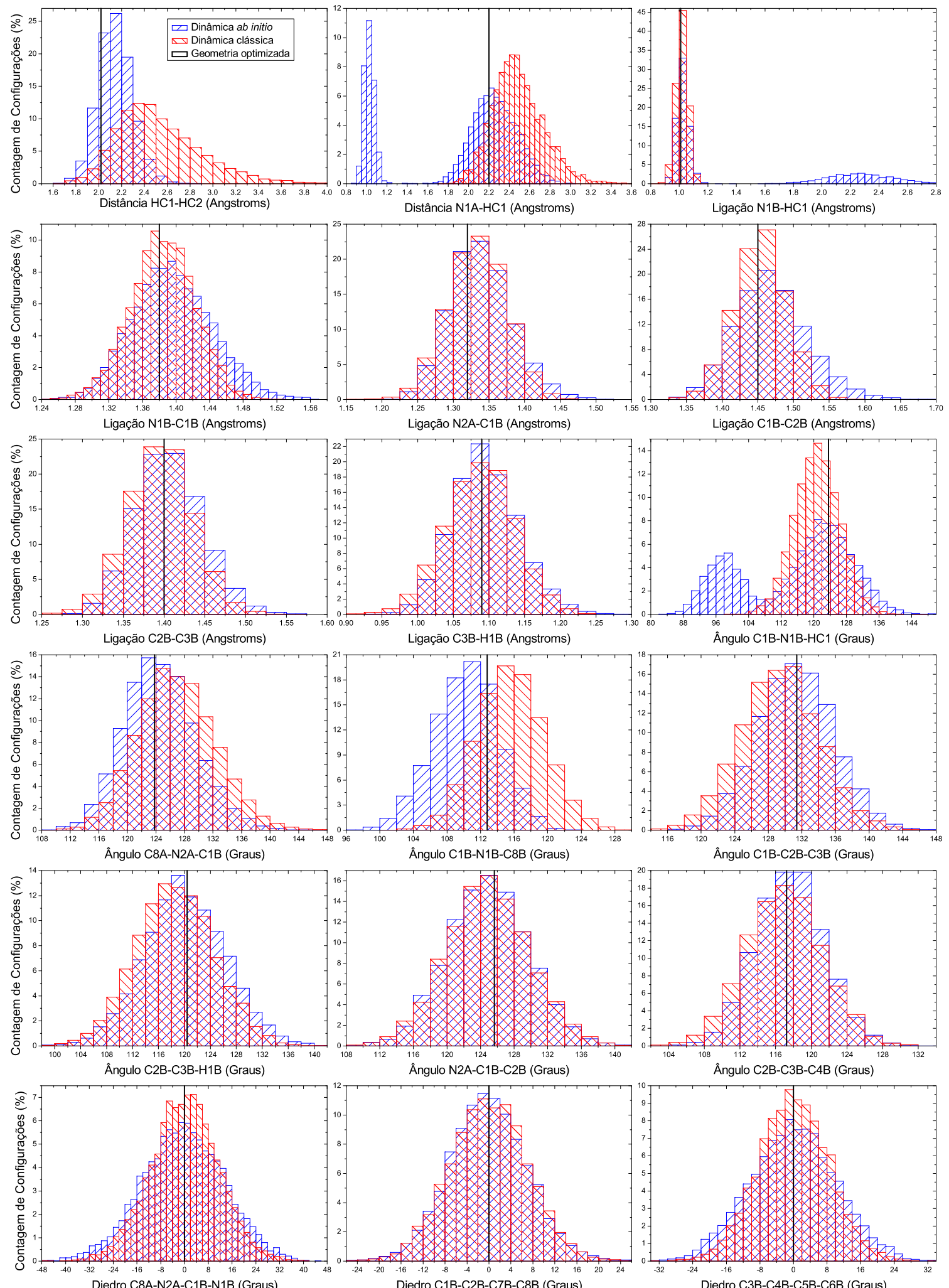

Figura 3.30: Distribuição de valores de distâncias atômicas, ligações, ângulos e diedros, obtidos a partir de 8000 configurações igualmente espaçadas da região de produção das dinâmicas $a b$ initio e clássica da $\mathrm{H}_{2}$-Ftalocianina. Os rótulos dos átomos são mostrados na figura 3.20. 
Analisando a figura 3.30 vemos que a migração dos hidrogênios centrais aparece nos gráficos da distância N1A-HC1, da ligação N1B-HC1 e do ângulo C1B-N1B-HC1. Pela figura vemos que os valores mais prováveis das distâncias entre átomos que não se ligam divergem da ordem de $\sim 0,25 \AA$ entre as duas dinâmicas. Podemos ver também que as distribuições de valores para as distâncias de átomos ligados estão concordantes na dinâmicas clássica e $a b$ initio. Podemos ver que os valores de distâncias, ângulos e diedros de átomos ligados estão distribuídos na mesma região em que se encontram os valores para a geometria optimizada ${ }^{46}$. Na dinâmica $a b$ initio vemos uma pequena diferença dos valores médios das ligações em ambas dinâmicas da ordem de $\sim 0,01 \AA$, mas podemos ver que essa é uma diferença pequena e tolerável levando em comparação a ordem dos valores envolvidos nas distribuições de valores dessas ligações. Para os gráficos dos ângulos e diedros podemos ver que existe uma concordância razoável entre os valores mais prováveis e as distribuições de valores entre as duas dinâmicas ${ }^{46}$. No caso dos ângulos essas diferenças entre os valores mais prováveis são no máximo da ordem de $\sim 4^{\circ}$. Para diedros os valores mais prováveis coincidem entre si e com o valor da geometria optimizada, e como as distribuições são aproximadamente simétricas, esse é um indicativo de que em média a molécula fica planar durante ambas dinâmicas ${ }^{47}$.

Um fato que pode chamar a atenção na figura 3.30 é que em alguns casos a distribuição de valores de ligações, ângulos ou diedros de átomos ligados na dinâmica clássica não ocorreu em torno do valor da geometria optimizada, que como dissemos na subseção 3.2.6.1 corresponde aos valores de equilíbrio no campo de forças clássico. Essa ocorrência porém não é nenhum absurdo, isso porque nos casos em que isso acontece o que estamos vendo nada mais é do que um "efeito combinado" já que, por exemplo, no caso de uma ligação existem no campo de forças outras interações além

\footnotetext{
${ }^{46}$ Mesmo com a migração dos hidrogênios centrais podemos fazer uma comparação de resultados olhando apenas para a região dos histogramas da dinâmica $a b$ initio referentes a antes de a migração acontecer.

${ }^{47}$ Esse é apenas um indicativo pois olhamos apenas para a distribuição de valores de alguns diedros. Para uma conclusão mais concreta seria necessário olhar para todos os diedros.
} 
da interação de ligação que interferem nessa ligação. Além disso, o fato de estarmos fazendo a dinâmica em uma temperatura elevada $(823 \mathrm{~K})$ pode também influenciar para essa ocorrência.

Com base nas análises realizadas, de uma maneira geral, podemos concluir que as distribuições de valores mostradas na figura 3.30 obtidas para as distâncias atômicas, os ângulos e os diedros analisados são concordantes nas dinâmicas ab initio e clássica, e também estão na mesma região que os valores para a geometria optimizada. Esse fato é um tanto quanto surpreendente porque, como mostrando na subseção 3.11, essa mesma concordância não ocorre no caso da $H_{2}$-Porfirina quando a dinâmica clássica é feita utilizando as constantes de força GROMOS 53A6. Essa observação é extremamente interessante pois mostra um exemplo em que, mesmo para sistemas com bastantes semelhanças estruturais, a mesma parametrização não foi capaz de prover resultados concordantes nas dinâmicas clássicas em relação aos resultados das dinâmicas ab initio.

\subsubsection{Influência do posicionamento dos hidrogênios centrais}

Nesta subseção vamos analisar como a posição dos hidrogênios centrais altera a estruturação central da $\mathrm{H}_{2}$-Ftalocianina. Vamos também analisar como se da a migração dos hidrogênios centrais através da evolução de algumas distâncias atômicas.

Na figura 3.31 apresentamos o gráfico da razão entre as distâncias N1C-N1B e N1A-N1B em função da razão entre as distâncias N1C-HC1 e N1A-HC1 para as dinâmicas ab initio e clássica, e geometria optimizada. N1A, N1B e N1C são os nitrogênios centrais mais próximos de HC1, que é o hidrogênio sobre análise no gráfico da esquerda da figura 3.31. A dinâmica clássica, feita com a parametrização GROMOS 53A6 para as constantes de força, é chamada de dinâmica clássica/G. Os gráficos apresentados foram feitos a partir de 8000 configurações igualmente espaçadas da região de produção das dinâmicas.

Pela figura 3.31 vemos que a razão N1C-N1B/N1A-N1B entre as distâncias dos 

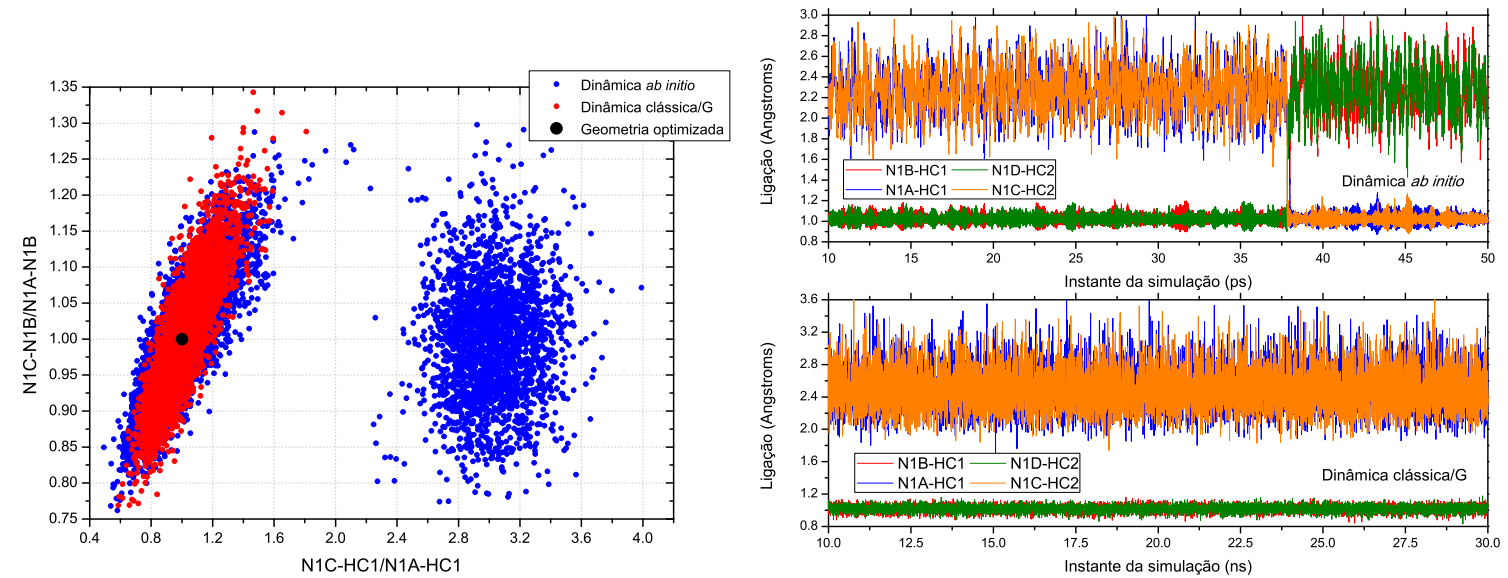

Figura 3.31: O gráfico da esquerda mostra a influência da posição de um hidrogênio central na estrutura central da $\mathrm{H}_{2}$-Ftalocianina, obtido a partir de 8000 configurações igualmente espaçadas da região de produção das dinâmicas. Os outros dois gráficos mostram a evolução da posição dos dois hidrogênios centrais em relação aos quatro nitrogênios centrais no decorrer da região de produção das dinâmicas. Os rótulos dos átomos são mostrados na figura 3.20.

nitrogênios centrais muda dependendo do posicionamento do hidrogênio HC1. A figura mostra que a medida que $\mathrm{HC1}$ começa a se afastar do nitrogênio N1B no qual estava ligado e se aproximar do nitrogênio N1C vizinho (ou seja, a medida que a razão N1CHC1/N1A-HC1 diminui em relação ao valor da geometria optimizada) a distância N1C-N1B diminui em relação a distância N1A-N1B, chegando a estar até mais de $20 \%$ menor em algumas configurações das dinâmicas. Quando HC1 se aproxima de N1A (ou seja, quando a razão N1C-HC1/N1A-HC1 aumenta em relação ao valor da geometria optimizada), a distância N1C-N1B aumenta em relação a distância N1AN1B, chegando a ficar até cerca de $20 \%$ maior em algumas configurações. Podemos ver que a distribuição de valores é simétrica enquanto o átomo HC1 ainda permanece ligado ao átomo N1B, indicando que, como esperado, esse efeito é equivalente quando HC1 se aproxima de N1C ou de N1C. Os pontos no gráfico para a dinâmica ab initio que se encontram mais distantes dos pontos para a dinâmica clássica e para a geometria optimizada correspondem as configurações após a migração do hidrogênio central HC1. Como podemos ver na figura 3.31 a dinâmica clássica no gráfico da esquerda descreve 
bem as mesmas tendências da dinâmica $a b$ initio, mas não visita todos os pontos visitadas pela dinâmica $a b$ initio. Ainda assim a concordância entre os resultados gerados em ambas dinâmicas é boa.

Nos gráficos à direita da figura 3.31 podemos ver que o átomo $\mathrm{HC} 1$ migra de $\mathrm{N} 1 \mathrm{~B}$ para N1A e que o átomo HC2 migra de N1D para N1C. Podemos ver também que essa migração dos átomos $\mathrm{HC} 1$ e $\mathrm{HC} 2$ ocorre de maneira praticamente instantânea e que eles permanecem opostos, já que N1A e N1C são opostos. Vemos que essa migração ocorre em torno de 38 ps segundos após o inicio da simulação. A observação desse fenômeno aos 38 ps é indicativo de que a dinâmica ab initio tem que ser longa o suficiente para que essa observação seja feita. Como dissermos na subseção 2.4.5, o TeraChem [78] tem uma arquitetura computacional baseada no uso de GPU's, o que torna este programa muito mais eficiente computacionalmente do que programas convencionais baseados no uso de CPU's. A dinâmica feita com o TeraChem para o monômero de $\mathrm{H}_{2}$-Ftalocianina (que tem 58 átomos e 266 elétrons) no nível B3LYP/631G para 200 mil passos (50 ps) foi feita em uma máquina utilizando duas placas de vídeo, uma GeForce GTX 780 e uma GeForce GTX 680, e durou aproximadamente 22 dias e meio, fazendo portanto 1 passo a cada 9,8 segundos em média. Uma dinâmica em um programa convencional (como o Gaussian 09 [81]) desse mesmo sistema, no mesmo nível, e também para 200 mil passos demoraria vários meses, mesmo em uma máquina com quatro bons processadores rodando em paralelo. Assim então podemos ver que o uso de um programa eficiente como o TeraChem é vantajoso e abre portas para muitos estudos teóricos que de outro modo seriam inviáveis.

Podemos concluir que, como todas as dinâmicas realizadas indicam, o posicionamento dos hidrogênios centrais influência na estruturação central da $H_{2}$-Ftalocianina, ou seja, na estruturação do macrociclo. Essa conclusão teórica é importante pois, como mencionado na subseção 1.4.1, uma estrutura cristalina experimental da $H_{2^{-}}$ Ftalocianina com os hidrogênios centrais formando pontes se encontra reportada na 
literatura [52], e nessa estrutura podemos ver que o arranjo dos nitrogênios centrais se dá da mesma maneira que os nossos resultados teóricos predizem. A partir das análises estruturais apresentadas aqui e também na subseção anteriores podemos ver que existem diferenças entre os resultados providos pela dinâmica clássica e pela dinâmica $a b$ initio. Vamos a seguir buscar analisar se essas diferenças são relevantes para uma correta descrição do espectro de absorção.

\subsubsection{Análise de convergência para o espectro de absorção}

Vamos nessa subseção analisar resultados para conjuntos de configurações descorrelacionadas com tamanhos diferentes para, assim como foi feito para a $\mathrm{H}_{2}$-Porfirina na subseção 3.2.6.5, analisar a convergência das propriedades associadas ao espectro de absorção, como as energias de excitação, forças de oscilador, e também a convolução do espectro. Esse tipo de analise é importante pois é inviável tratar todas as configurações geradas nas dinâmicas nos cálculos do espectro além do fato de que configurações sucessivas possuem muitas semelhanças e por isso incluem pouca informação estatística nos cálculos. Os cálculos de espectro para está análise foram feitos com o método ZINDO/CIS pelo fato deste método ter um custo computacional baixíssimo em comparação com um cálculo TD-DFT que é mais rigoroso. As conclusões qualitativas que chegarmos, como a cerca do número de configurações necessárias para uma convergência aceitável do espectro de absorção, devem ser independentes do método de cálculo escolhido.

A figura 3.32 mostra os resultados obtidos através das dinâmicas clássica e $a b$ initio para o espectro de absorção para diferentes números de configurações descorrelacionadas. São apresentados os valores médios e os respectivos desvios padrão para as energias de excitação e as forças de oscilador. É importante mencionar aqui que os valores médios e os desvios padrão para as energias de excitação são ponderados pelas forças de oscilador, enquanto os valores médios e os desvios padrão para as forças de 
oscilador não são ponderados. Também é apresentada a convolução dos picos teóricos utilizando Lorentzianas (ver subseção 2.2.6) para diferentes números de configurações descorrelacionadas. Os cálculos de espectro para cada configuração foram feitos utilizando o método ZINDO/CIS considerando apenas transições dos 25 orbitais mais altos ocupados para os 25 mais baixos desocupados. Os cálculos foram feitos para as 49 primeiras excitações.
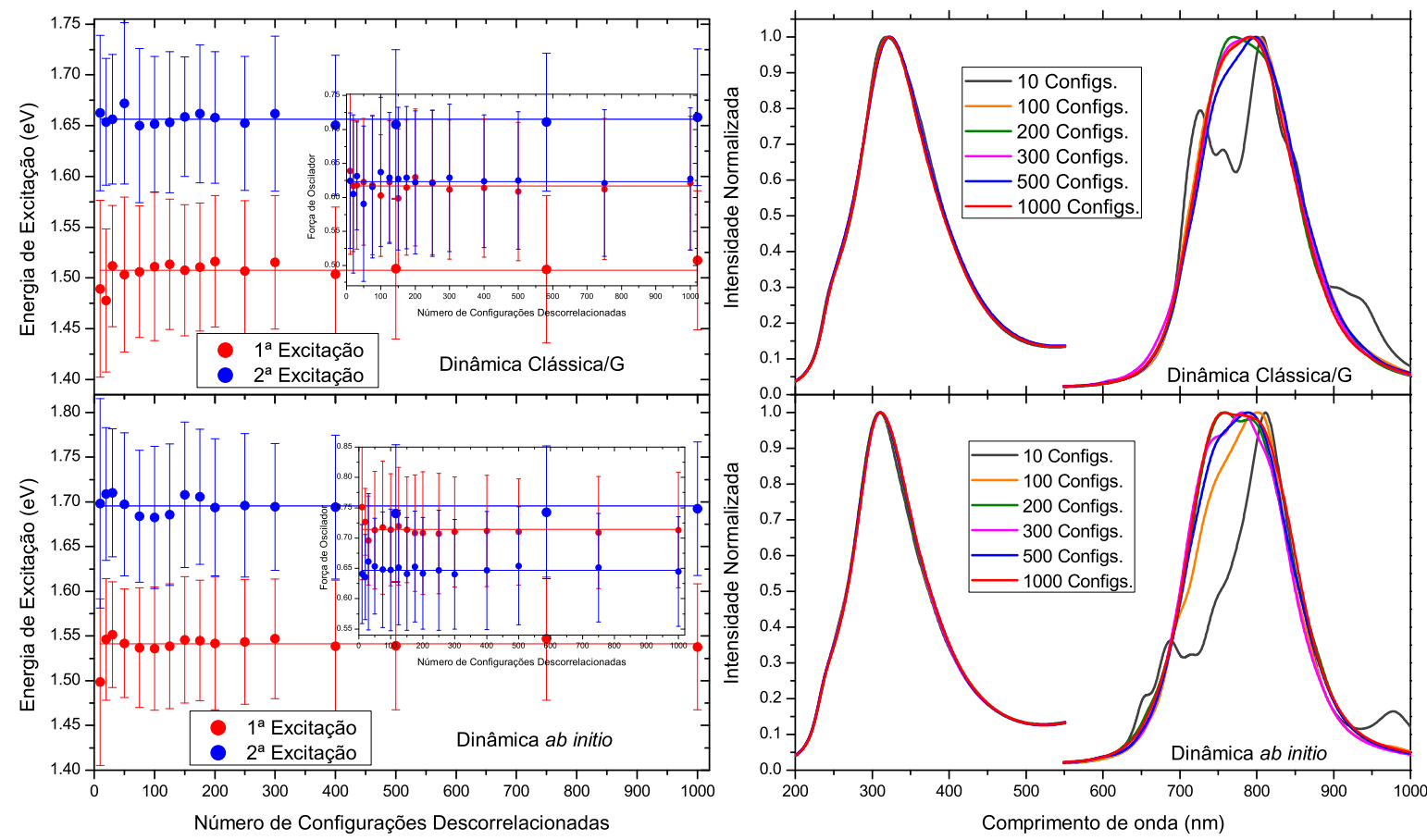

Figura 3.32: Convergência do espectro de absorção para a dinâmica clássica e para a dinâmica $a b$ initio da $H_{2}$-Ftalocianina. Os gráficos à esquerda mostram a convergência das duas primeiras energias de excitação e das forças de oscilador correspondentes, e os gráficos à direita a convolução utilizando Lorentzianas de todos os picos teóricos obtidos. Os cálculos do espectro foram feitos utilizando o método ZINDO/CIS.

Como pode ser visto a partir dos gráficos para as convoluções do espectro apresentados na figura 3.32, a convergência para as excitações na região ultravioleta é bem mais rápida que na região do visível, por isso nos gráficos à esquerda focamos apenas nas duas primeiras excitações correspondentes as bandas $Q$.

Analisando a figura podemos ver que a partir de 200 configurações já temos 
aproximadamente a mesma descrição para a posição dos picos, os alargamentos das bandas, e as intensidades relativas entre as bandas. Apesar de ainda termos algumas diferenças em comparação com um número maior de configurações, isso quer dizer que as conclusões que chegarmos a partir da descrição feita com 200 configurações devem ser essencialmente as mesmas se usarmos um número maior de configurações descorrelacionadas. Podemos portanto concluir que uma convergência razoável das propriedades do espectro de absorção já é alcançada utilizando 200 configurações descorrelacionadas.

A figura 3.32 também mostra uma concordância entre os resultados providos por ambas as dinâmicas para valores das energias de excitação e para os desvios padrão. Resultados compatíveis também são obtidos nas convoluções dos espectros.

\subsubsection{Análise do espectro de absorção}

Apresentaremos aqui comparações de resultados obtidos para 200 configurações descorrelacionadas. As comparações serão feitas entre os resultados em si e também com o espectro da geometria optimizada e o experimental. A composição dos espectros teóricos também será discutida.

Na figura 3.33 mostramos a convolução dos picos teóricos e os valores médios de cada excitação. Os valores médios para as energias de excitação são ponderados pela força de oscilador, e depois são convertidos para nm e apresentados na figura. É importante frisar que uma largura de linha diferente foi utilizada na região das bandas $Q$ e que as convoluções foram renormalizadas nessa região, porém as excitações médias não foram renormalizadas. Além do cálculo com ZINDO/CIS feito para 49 excitados, realizamos também o cálculo no nível B3LYP/6-31G* os seis primeiros estados excitados. O método TD-DFT(B3LYP) foi escolhido por ser, dos métodos que utilizamos para o cálculo do espectro para a estrutura optimizada, o método que fornece o menor desdobramento para as bandas $Q$, como pode ser visto na tabela 3.10. 
Com o TD-DFT(B3LYP) uma discussão a respeito do desdobramento das bandas $Q$ com a inclusão de efeitos térmicos via dinâmica molecular pode ficar mais direta já que para a estrutura optimizada este desdobramento é muito pequeno. As escolhas da base 6-31G* e de calcular apenas os seis primeiros estados excitados foi feita unicamente com o intuito de reduzir o custo computacional dos cálculos ${ }^{48}$.

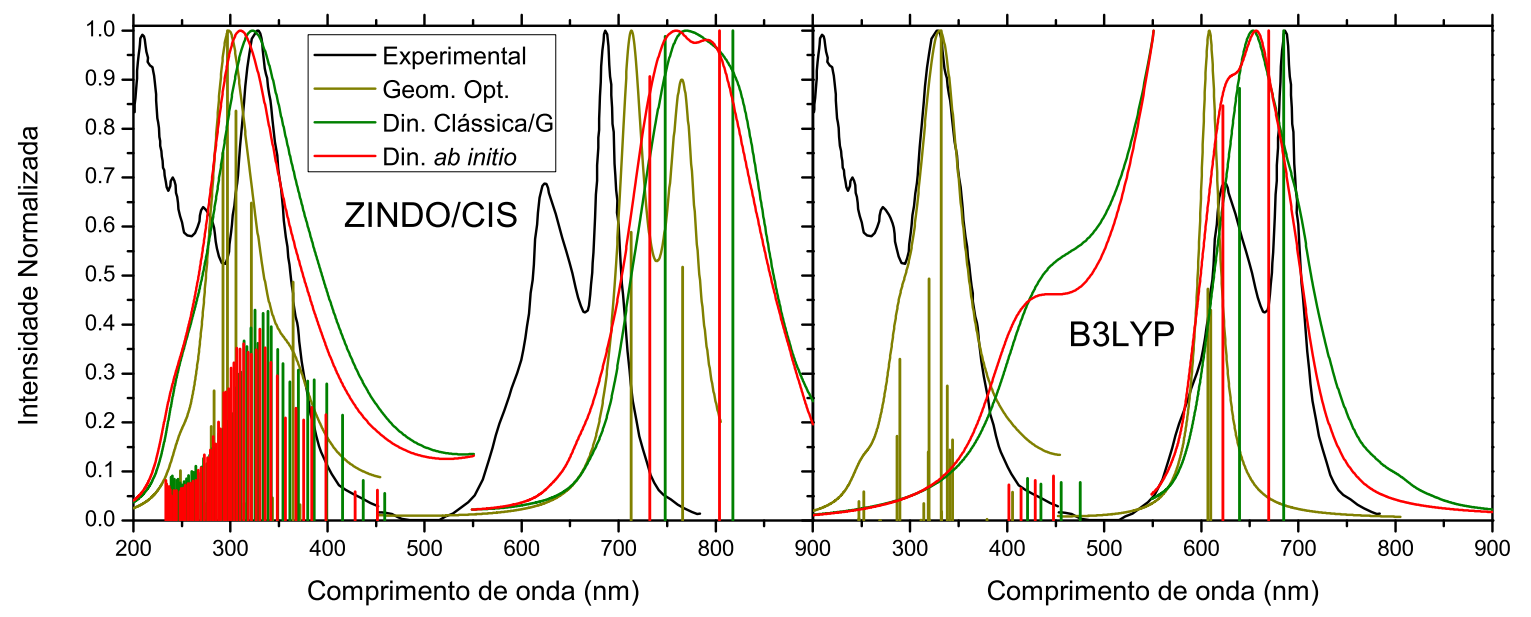

Figura 3.33: Comparação de resultados para os espectros de absorção teóricos de 200 configurações descorrelacionadas obtidos através da dinâmica clássica e da dinâmica $a b$ initio da $\mathrm{H}_{2}$-Ftalocianina. Resultados para a estrutura optimizada e o espectro experimental também são apresentados. As linhas verticais apresentadas representam os valores médios das excitações. Os cálculos do espectro foram feitos utilizando o ZINDO/CIS e também com o $\mathrm{B} 3 \mathrm{LYP} / 6-31 \mathrm{G}^{*}$.

A figura 3.33 indica que, para ambos métodos de cálculo utilizados, o desdobramento médio das bandas $Q$ obtido via dinâmica molecular é maior do que o valor para a geometria optimizada. Na dinâmica clássica esse desdobramento é de 69,9 nm com ZINDO/CIS e 45,4 nm com TD-DFT(B3LYP), na dinâmica ab initio é de 72,2 nm com ZINDO/CIS e 47,4 nm com TD-DFT(B3LYP), e na geometria optimizada é de 53,0 nm com ZINDO/CIS e 2,9 nm com TD-DFT(B3LYP). Para ZINDO/CIS podemos ver que o desdobramento aumenta em média cerca de $18 \mathrm{~nm}$ e para TD-DFT(B3LYP)

\footnotetext{
${ }^{48} \mathrm{Na}$ subseção 3.2.2 mostramos que o custo computacional usando a base $6-31 \mathrm{G} *$ é bem menor que com outras bases maiores, mas os resultados fornecidos possuem diferenças. Como estamos lidando com esse número elevado de 200 configuração, para que o cálculo se torne viável dentro das nossas capacidades computacionais a redução do custo computacional tive que ser priorizada.
} 
cerca de $43 \mathrm{~nm}$. Podemos ver portanto que a inclusão de efeitos térmicos via dinâmica molecular tende em média a aumentar o desdobramento das bandas $Q$ em comparação com a geometria optimizada.

Com relação a posição dos picos, a figura mostra que na região do visível os picos sofrem um deslocamento para maiores comprimentos de onda (para o vermelho) em relação aos picos da estrutura optimizada. Podemos ver que, assim como para a estrutura optimizada, os picos da região do visível obtidos via dinâmica molecular permanecem ainda a direita (muito a direita no caso de ZINDO/CIS) do espectro experimental para as bandas $Q$. Uma observação extremamente interessante é que o espectro com TD-DFT(B3LYP) não fornecia boa concordância com o experimental para a geometria optimizada, mas após a inclusão de efeitos térmicos passa a fornecer uma boa concordância para as posições médias dos picos com o espectro experimental.

Com relação a banda de Soret, assim como para a geometria optimizada, os espectros obtidos com ZINDO/CIS via dinâmica molecular tem uma boa concordância com o valor experimental e possuem um modesto deslocamento para o vermelho. Com relação aos espectros obtidos com TD-DFT(B3LYP) nada pode ser afirmado com relação a banda de Soret já que os seis estados calculados não foram suficientes para descrever essa região.

Outra fato curiosíssimo observado na figura é que com a inclusão de efeitos térmicos as bandas $Q$ passaram a ter forças de oscilador médias significativamente maiores que as demais bandas, ao contrário do que acontece na geometria optimizada onde excitações na banda de Soret possuem as maiores forças de oscilador. Com ZINDO/CIS os valores médios para as forças de oscilador das bandas $Q_{x}$ e $Q_{y}$ e da excitação mais intensa na região da banda de Soret são respectivamente 0,6294, 0,6222 e 0,2702 na dinâmica clássica, 0,7083, 0,6418 e 0,2767 na dinâmica ab initio, e na geometria optimizada são 0,7127, 0,8112 e 1,37826. Podemos portanto ver que a inclusão de efeitos térmicos via dinâmica molecular tende a diminuir significativamente 
as forças de oscilador das bandas na região ultravioleta que no espectro da estrutura optimizada eram bastante intensas mas aumenta as forças de oscilador de transições que eram nulas na geometria optimizada. Essa observação com relação a intensidade das bandas $Q$ é interessante pois está de acordo com resultado experimental que, como falado na subseção 1.4.1, mostra que a absorbância no pico da banda $Q_{x}$ é maior que nos demais picos. Podemos ver que, após a inclusão de efeitos térmicos via dinâmica molecular, $Q_{x}$ passa a ser mais intensa que $Q_{y}$ ao contrário do que ocorre na estrutura optimizada e em acordo com o resultado experimental.

Assim como indicado na figura 3.32, a figura 3.33 mostra que existem diferenças nos valores médios das energias de excitação e das forças de oscilador, bem como na forma do espectro convoluido, entre as diferentes dinâmicas. A figura mostra que essas diferenças são mais pronunciáveis para a primeira excitação, e também, mas em um grau menor, para a segunda excitação. A concordância entre as diferentes dinâmicas para as demais bandas é bem melhor.

Como fica claro pela figura 3.33, é importante olhar além do valor médio. Por isso na figura 3.33 apresentamos um detalhamento do espectro teórico obtido para todas dinâmicas, para vermos como o espectro é composto. A figura mostra cada um dos picos de cada uma das 200 configurações utilizadas para compor o espectro, e cada excitação é apresentada com uma coloração diferente (os picos referentes a primeira excitação tem coloração vermelha, os referentes a segunda tem coloração azul, e assim por diante). A figura também mostra os valores médios das excitações (onde os valores das energias de excitação são ponderados pelas forças de oscilador) e a convolução por Lorentzianas (ver seção 2.2.6). Nessa figura as convoluções não foram normalizadas, mas uma largura de linha diferente foi utilizada na região das bandas $Q$.

Analisando a figura 3.34 podemos ver que tanto a posição quanto a intensidade (força de oscilador) dos picos teóricos variam bastante para as diferentes configurações, assim como também ocorreu para a $H_{2}$-Porfirina como mostrado na figura 3.16. Esse 
comportamento ocorre nos cálculos utilizando ZINDO/CIS e também nos cálculos com TD-DFT(B3LYP). Um outro fato observado na figura é que as bandas $Q$, em especial a banda $Q_{x}$ correspondente a primeira excitação, são mais sensíveis a distorções devidas a efeitos vibracionais que as demais bandas.

Podemos ver pela figura 3.34 que os resultados fornecidos pela dinâmica clássica apresentam as mesmas características do resultado para a dinâmica ab initio. Podemos ver que existem diferenças, como por exemplo no posicionamento dos picos médios na região do visível, porém, como já mencionamos anteriormente, não esperamos que a dinâmica clássica seja capaz de reproduzir em detalhes os resultados da dinâmica $a b$ initio, esperamos apenas que os resultados sejam compatíveis. Além disso, apesar de pegarmos o mesmo número de configurações descorrelacionadas da região de produção em ambas dinâmicas, a dinâmica clássica foi feita para um total de 30 ns enquanto a dinâmica $a b$ initio para somente 50 ps. Essa pode ser portanto uma possível razão adicional para as diferenças observadas na figura 3.34.

Retomando as discussões das subseções 1.4 .1 e 3.2.4 a respeito de que o posicionamento dos hidrogênios centrais em forma de ponte seria o responsável pelo desdobramento das bandas $Q$, na figura 3.35 apresentamos os gráficos dos valores das bandas $Q$ em cada uma das 200 configurações descorrelacionadas utilizadas nos cálculos de espectro em função da razão entre as distâncias N1B-HC1 e N1A-HC1.

A figura 3.35 mostra vários aspectos interessantes. Um deles é que, como mostrado no gráfico para a evolução das posições dos hidrogênios centrais em relação aos nitrogênios centrais na figura 3.31, a migração dos hidrogênios centrais ocorre de maneira rápida, tão rápida que nas 200 configurações descorrelacionadas selecionadas não vemos o hidrogênio central HC1 em uma posição intermediaria aos nitrogênios N1B e N1A. Os gráficos mostram que existem duas regiões de valores, uma correspondente a quando HC1 está ligado a N1B (à esquerda) e outra quando HC1 está ligado a N1A (à direita). É interessante observar que o comportamento das bandas $Q$ nessas duas 
situações é equivalente, o que é esperado já que após a migração a molécula passa ter uma conformação completamente equivalente a anterior, já que os hidrogênios centrais migram juntos e ficam sempre opostos (como mostrado na figura 3.31).

Outro aspecto que vemos é que, apesar de na subseção 3.2.4 termos mostrado que uma configuração com os hidrogênios em forma de ponte fornece um desdobramento compatível com o experimental em um cálculo utilizando TD-DFT(B3LYP), a figura 3.35 mostra a inclusão de efeitos térmicos através de dinâmica molecular também é capaz de causar o desdobramento das bandas $Q$, mesmo com os hidrogênios centrais não ficando em posição de ponte. Podemos ver que isso também acontece no cálculo TD-DFT(B3LYP), que prevê um baixo desdobramento das bandas na geometria optimizada. Podemos ver na figura 3.35 que TD-DFT(B3LYP) fornece resultados mais concordantes com o experimental do que ZINDO/CIS.

Nos 50 ps da dinâmica quântica vimos a ocorrência da migração dos hidrogênios centrais uma única vez, após 38 ps. Obviamente para uma estatística correta da frequência com que essa migração ocorre seria necessário observamos ela diversas vezes. Mesmo assim podemos utilizar a nossa observação, 1 migração em 38 ps, para fazer uma estimativa dessas ocorrências. Levando este valor em consideração teríamos da ordem de 26 bilhões de ocorrências por segundo. Esse número nos da uma ideia de que, caso essa migração ocorra realmente na escala de tempo observada na dinâmica, este é um fenômeno muito frequente. Mesmo assim, como os gráficos da figura 3.31 mostram, a migração ocorre de maneira tão rápida que praticamente não vemos os hidrogênios centrais em posição de ponte. Por esse motivo, ao contrário da hipótese levantada no artigo experimental, acreditamos que o posicionamento dos hidrogênios centrais não é a causa para explicar o desdobramento das bandas $Q$ da $\mathrm{H}_{2}$-Ftalocianina em fase gasosa já que não corresponde a estrutura média adquirida pela molécula, que praticamente não fica com os hidrogênios centrais em forma de ponte. A observação de que a inclusão de efeitos térmicos por si só já é suficiente para observamos o desdobramento 
das bandas $Q$ também corrobora com esta nossa opinião. A nossa opinião, de certo modo, também corrobora com a observação comentada no artigo experimental [29] de que o desdobramento da bandas $Q$ é menor em solução que em vapor, isso porque acreditamos que o desdobramento em solução deve ser menor que em gás devido a temperatura ser mais baixa em solução do que em gás.

Os resultados apresentados aqui mostram a importância da inclusão de efeitos térmicos para o estudo teórico do espectro de absorção. As deformações estruturais causadas pela inclusão de efeitos térmicos estão diretamente relacionadas com a temperatura do sistema, por isso na próxima subseção apresentaremos resultados para dinâmicas moleculares realizadas com diferentes temperaturas alvo.

\subsubsection{Espectro de absorção em diferentes temperaturas}

Nesta subseção apresentaremos resultados obtidos através de dinâmicas clássicas feitas para três temperaturas diferentes: $20 \mathrm{~K}, 400 \mathrm{~K}$, e $823 \mathrm{~K}$. As novas dinâmicas clássicas/G (para $20 \mathrm{~K}$ e $400 \mathrm{~K}$ ) foram feitas exatamente da mesma maneira que a dinâmica clássica/G apresentada anteriormente (para $823 \mathrm{~K}$ ), mudando a temperatura alvo e na dinâmica à $20 \mathrm{~K}$ também o tempo de amortecimento para $\tau=2 \mathrm{fs}$. Novamente escolhemos os primeiros 10 ns como termalização e consideramos os 20 ns restantes como região de produção. Os valores médios com os respectivos desvios padrão das temperaturas nas dinâmicas são respectivamente $(19,98 \pm 2,20) \mathrm{K},(400,16 \pm 43,91)$ K e $(819,38 \pm 90,13) \mathrm{K}$. Podemos ver que esses valores estão em bom acordo com as temperaturas alvo escolhidas.

O gráfico da figura 3.33 mostra comparações dos resultados obtidos nas diferentes dinâmicas entre si e também em comparação com os espectros experimental e da geometria optimizada. Na figura 3.36 apresentamos essas mesmas comparações para as dinâmicas feitas nas três diferentes temperaturas. Os resultados apresentados para as dinâmicas são para 200 configurações descorrelacionadas e o cálculo do espectro 
foi feito com ZINDO/CIS para os primeiros quarenta e nove estado excitados e com B3LYP /6-31G* para os seis primeiros estados. Os valores médios cálculos para as energias de excitação foram ponderados pela força de oscilador e depois convertidos para nm e apresentados na figura.

Analisando a figura 3.36 vemos que a posição dos valores médios varia para as diferentes temperaturas assim como a posição dos picos das convoluções. Um fato interessante é que o espectro para as dinâmicas está deslocado para maiores comprimentos de onda (deslocado para o vermelho) em relação ao espectro da geometria optimizada. Esse deslocamento é cerca de 51,9 nm com ZINDO/CIS e 74,9 nm com TD-DFT(B3LYP) para a banda $Q_{x}$ e cerca de 35,0 nm com ZINDO/CIS e 32,41 nm com TD-DFT(B3LYP) para banda $Q_{y}$ para a temperatura mais elevada, $823 \mathrm{~K}$. O espectro para $20 \mathrm{~K}$, que é a mais baixa das temperaturas utilizadas nas dinâmicas, é o que mais se aproxima do espectro da geometria optimizada.

Outro comportamento interessante mostrado na figura 3.36 é o comportamento do desdobramento das bandas $Q$ nas diferentes temperaturas. Vemos que esse desdobramento é de 63,1 nm com ZINDO/CIS e 9,0 nm com TD-DFT(B3LYP) à 20 K, 59,8 nm com ZINDO/CIS e 27,0 nm com TD-DFT(B3LYP) à $400 \mathrm{~K}$, e 69,9 nm com ZINDO/CIS e 45,4 nm com TD-DFT(B3LYP) à $823 \mathrm{~K}$. Podemos ver portanto que a inclusão de efeitos térmicos aumenta o desdobramento das bandas $Q$ e que o desdobramento cresce com a temperatura.

Na figura 3.37 apresentamos um detalhamento do espectro teórico obtido para as dinâmicas nas diferentes temperaturas. Esta figura foi feita da mesma maneira que a figura 3.34 .

Pela figura 3.36 observamos que os picos das 200 configurações descorrelacionadas da dinâmica para $20 \mathrm{~K}$ estão extremamente mais concentrados em torno dos valores médios em comparação com os resultados para 400 e $823 \mathrm{~K}$. Podemos ver que a forma do espectro convoluido ainda é muito próxima da forma para a geometria optimizada. 
Esse comportamento é esperado devido ao fato de que na temperatura de $20 \mathrm{~K}$ a energia cinética do sistema não é suficiente para causar deformações na molécula tão pronunciáveis quanto nas demais dinâmicas. Podemos ver também que quanto maior a temperatura, maior é a flutuação dos valores dos picos em torno dos valores médios. Todos esses comportamentos são observados para ambos os métodos de cálculo do espectro utilizados, ZINDO/CIS e TD-DFT(B3LYP).

Podemos portanto concluir que a temperatura alvo influencia na distribuição de valores dos picos que compõem o espectro de absorção e que também influencia no desdobramento das bandas $Q$, que tende em média a aumentar com a temperatura devido a deformações estruturais causadas via a inclusão de efeitos térmicos através de dinâmica molecular. 
Figura 3.34: Detalhamento das excitações dos espectros de absorção teóricos de 200 configurações descorrelacionadas obtidos através da dinâmica clássica (acima) e da dinâmica $a b$ initio (abaixo) da $\mathrm{H}_{2}$-Ftalocianina. São apresentados os picos de cada uma dessas configurações e também o valor médio nas barras vermelhas riscadas. Cada excitação é apresentada na figura com uma coloração diferentes. A convolução por Lorentzianas, utilizando uma largura de linha diferente na região das bandas $Q$ em relação as outras regiões, também é 

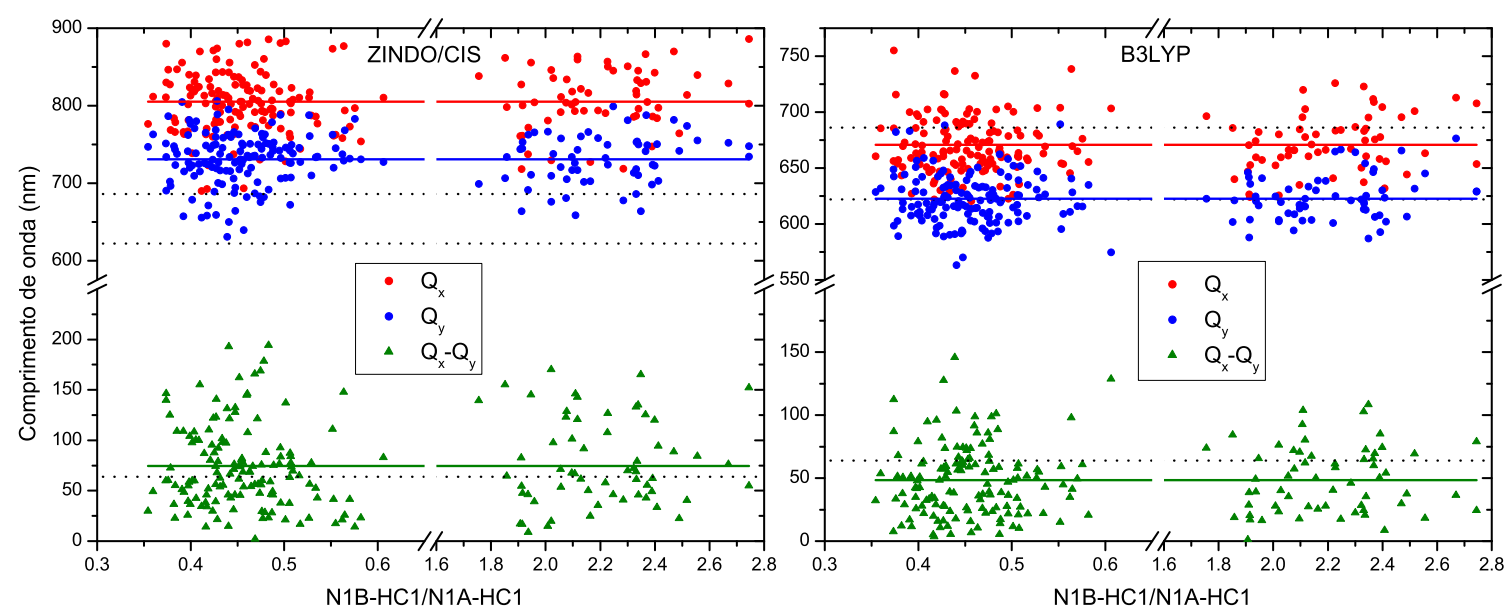

Figura 3.35: Influência da posição de um hidrogênio central no posicionamento das bandas $Q$ para a dinâmica $a b$ initio. São mostrados os valores das bandas $Q$ e do desdobramento em cada uma das 200 configurações descorrelacionadas em função da razão entre as distâncias N1B-HC1 e N1A-HC1. Os traços pontilhados representam os valores experimentais e as linhas verticais os valores médios.

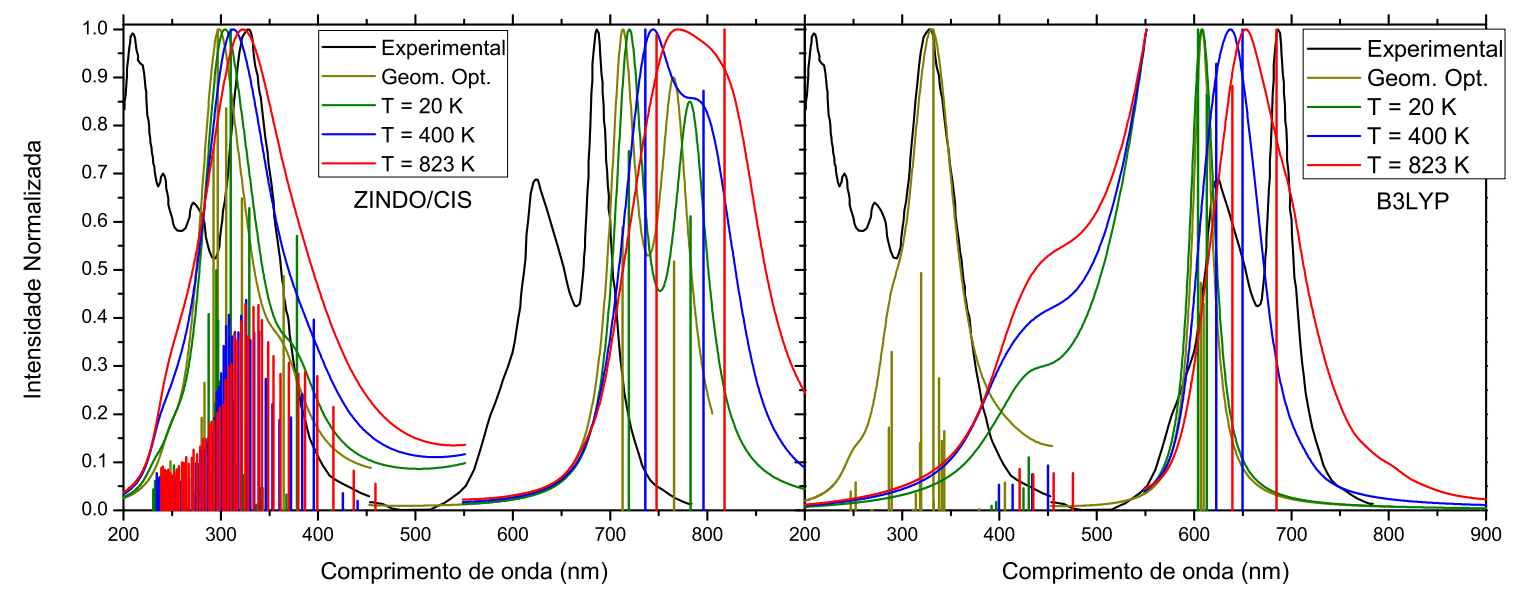

Figura 3.36: Comparação de resultados para os espectros de absorção teóricos de 200 configurações descorrelacionadas obtidos através de dinâmicas moleculares clássicas da $\mathrm{H}_{2^{-}}$ Ftalocianina, para três temperaturas diferentes. O espectro da estrutura optimizada e o espectro experimental também são apresentados. As linhas verticais apresentadas representam os valores médios das excitações. Os cálculos do espectro foram feitos utilizando o método ZINDO/CIS e também B3LYP/6-31G*. 


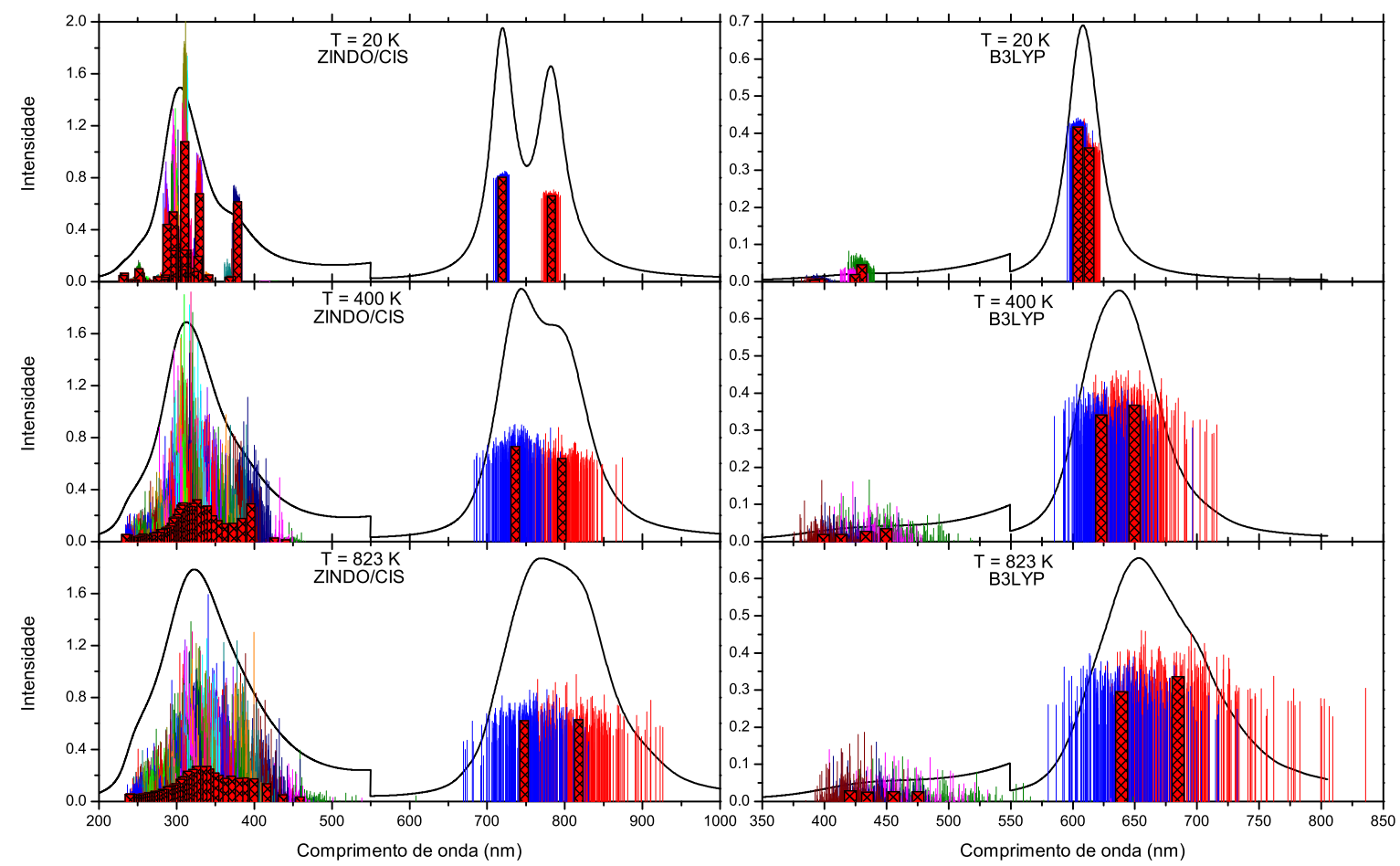

Figura 3.37: Detalhamento das excitações dos espectros de absorção teóricos de 200 configurações descorrelacionadas obtidos através de dinâmicas moleculares clássicas da $H_{2^{-}}$ Ftalocianina, para três temperaturas diferentes. São apresentados os picos de cada uma das configurações e também os valores médios nas barras vermelhas riscadas. Cada excitação é apresentada na figura com uma coloração diferentes. A convolução por Lorentzianas, utilizando uma largura de linha diferente na região das bandas $Q$ em relação as outras regiões, também é apresentada. Os cálculos do espectro foram feitos utilizando o método ZINDO/CIS e também B3LYP/6-31G*. 


\subsubsection{Resultados adicionais}

Além dos resultados adicionais do apêndice $\mathrm{C}$ mencionados no decorrer desta seção 3.2, apresentamos na seção C.1 deste apêndice resultados teóricos que obtemos para Ftalocianinas com Eugenóis como substituintes em solução e em fase isolada. Este estudo é interessante pois mostra a influência dos substituintes e da inclusão de efeitos de solvente no espectro de absorção. O espectro experimental dessas Ftalocianinas em solvente (clorofórmio) se encontra reportado na literatura [93].

\subsubsection{Sumário de Conclusões}

Com relação aos estudos de Ftalocianinas, algumas conclusões que podem ser tiradas desta dissertação são:

1. Os parâmetros estruturais do monômero optimizado de $H_{2}$-Ftalocianina, obtido no nível B3LYP/6-31G*, estão em bom acordo com os da estrutura cristalina experimental. A estrutura optimizada possui simetria $D_{2 h}$ enquanto a cristalina possui simetria $C_{i}$.

2. Mesmo as estruturas de Ftalocianinas sendo parecidas com as de Porfirinas, mostramos que o espectro de absorção e os orbitais moleculares de ambas possuem diferenças significativas. No caso do espectro de absorção, mostramos que existem diferenças nas posições dos picos e nas forças de oscilador mas que as características gerais de certa forma ainda se mantém, já que em ambos os casos observamos duas bandas $Q$ e também a banda de Soret.

3. Os métodos utilizados para o cálculo do espectro de absorção da geometria optimizada de $H_{2}$-Ftalocianina não preveem o desdobramento das bandas $Q$ de 64 nm observado no resultado experimental, obtido à $506{ }^{\circ} \mathrm{C}$. A maior parte dos métodos utilizados fornece um desdobramento menor que $12 \mathrm{~nm}$. 
4. Cada um dos dois primeiros estados excitados da $H_{2}$-Ftalocianina é praticamente composto por apenas uma única transição eletrônica (uma transição para a banda $Q_{x}$ e outra para a banda $Q_{y}$ ). Na Zn-Ftalocianina esse efeito se manifesta de uma forma diferente. Devido as bandas $Q$ serem degeneradas cada estado é praticamente composto meio-a-meio por duas únicas transições eletrônicas (essas duas transições descrevem então as duas bandas $Q$ ).

5. O modelo de Gouterman para a $H_{2}$-Ftalocianina e Zn-Ftalocianina se mostra praticamente válido para descrever as bandas $Q$ e parcialmente válido para descrever bandas com força de oscilador não nula na região ultravioleta. Para descrição dos estados escuros são necessários mais orbitais do que os de Gouterman.

6. Dos resultados para $\mathrm{H}_{2}$-Ftalocianina, o que fornece a melhor concordância com a banda de Soret experimental é o TD-DFT(B3LYP). Os cálculos TD-DFT(LCwPBE) e ZINDO/CIS fornecem as maiores separações para as bandas $Q$, porém essas separações como também as posições dos picos não estão de acordo com o resultado experimental.

7. O método TD-DFT(B3LYP) é o que fornece a menor separação para as bandas $Q$ da estrutura optimizada de $H_{2}$-Ftalocianina. Porém mostramos que esse mesmo método fornece uma separação compatível com a experimental para uma estrutura não optimizada com os hidrogênios centrais em posição de ponte (mas não fornece boa concordância nas posições dos picos). Essa observação está de acordo com a hipótese abordada no artigo experimental [28] para explicar a separação das bandas $Q$.

8. O espectro de dímero da $H_{2}$-Ftalocianina é deslocado para o azul na região do visível (bandas $Q$ ) em relação ao espectro de monômero, e para alguns dos cálculos realizados fornece boa concordância com o resultado experimental nas posições dos picos das bandas $Q$. Observamos o surgimento de estados escuros na 
região do visível. Os nossos resultados não são conclusivos a ponto de podermos afirmar que o espectro de dímero é mais compatível com o espectro experimental que o espectro de monômero.

9. Na dinâmica $a b$ initio da $\mathrm{H}_{2}$-Ftalocianina observamos a ocorrência de uma migração dos hidrogênios centrais entre os nitrogênios centrais de forma praticamente sincronizada e de modo que os hidrogênios permaneceram opostos. Essa migração ocorreu após 38 ps de simulação. Pudemos ver também que o posicionamento dos hidrogênios centrais influencia na estruturação do macrociclo.

10. As características do espectro de absorção da $H_{2}$-Ftalocianina se mostram razoavelmente convergidas para 200 configurações estatisticamente descorrelacionadas geradas nas dinâmicas.

11. Ao contrário do que acontece para a $H_{2}$-Porfirina, a dinâmica clássica da $H_{2^{-}}$ Ftalocianina com o campo de força GROMOS 53A6 fornece resultados compatíveis com os da dinâmica ab initio para as estruturas geradas e para o espectro.

12. A medida que se aumenta a temperatura, a inclusão de efeitos via dinâmica molecular aumenta o desdobramento das bandas $Q$ da $H_{2}$-Ftalocianina em comparação com a geometria optimizada, e as bandas na região do visível sofrem um deslocamento para o vermelho. Observamos também que após a inclusão de efeitos térmicos as forças de oscilador médias passam a ser maiores para as bandas $Q$ do que para as demais bandas e a banda $Q_{x}$ passa ser em média mais intensa que a $Q_{y}$, ao contrário do que acontece para a geometria optimizada e em acordo com o resultado experimental.

13. Embora a migração dos hidrogênios centrais aparente ocorrer frequentemente na dinâmica $a b$ initio da $H_{2}$-Ftalocianina, vemos que essa migração ocorre de maneira tão rápida que praticamente não identificamos os hidrogênios centrais 
em uma posição intermediaria entre os nitrogênios centrais (posição de ponte). Portanto, acreditamos que o desdobramento das bandas $Q$ se deve majoritariamente a inclusão de efeitos térmicos que deformam a molécula como um todo, não unicamente ao posicionamento em ponte dos hidrogênios centrais. Essas observações corroboram com as observações experimentais [29] mencionadas na introdução de que o desdobramento das bandas $Q$ é menor em solução do que em vapor, isso porque a temperatura em gás é mais alta que em solução. 


\section{Capítulo 4}

\section{Conclusões e Perspectivas}

Nesta dissertação apresentamos estudos teóricos com enfoque na descrição do espectro de absorção em fase gasosa de Porfirinas e Ftalocianinas. Dentre os resultados e análises desta dissertação, apresentamos discussões sobre as transições envolvidas nas excitações do espectro de absorção em conexão com o modelo de Gouterman (bastante conhecido na literatura), comparações de resultados para monômeros e dímeros optimizados, e resultados para o espectro de monômero com a inclusão de efeitos térmicos através de diferentes dinâmicas moleculares.

Algumas observações experimentais foram discutidas e analisadas com base em resultados teóricos nesta dissertação. No artigo, onde o espectro experimental da $H_{2}$-Porfirina em fase gasosa é reportado, é apresentado que para que a amostra absorva significativamente na região do visível é necessário que a temperatura seja alta. Em nossos resultados para $H_{2}$-Porfirina mostramos que a inclusão de efeitos térmicos através de dinâmica molecular é capaz de aumentar em média as forças de oscilador na região do visível em comparação com o espectro da geometria optimizada. Além disso nossos resultados para dinâmicas feitas em diferentes temperaturas apontam a tendencia experimental do aumento de absorção de luz (através do aumento das forças de oscilador) na região do visível com o aumento da temperatura, indicando que distorções estruturais são importantes para descrição desses fenômenos. Para a $H_{2^{-}}$ 
Ftalocianina o espectro experimental em fase gasosa aponta um desdobramento das bandas $Q$, porém os nossos cálculos para estruturas optimizadas não são capazes de descrever corretamente esse desdobramento. Uma hipótese apresentada na literatura para explicar esse fenômeno é de que os hidrogênios centrais ficariam em média em uma região intermediaria aos nitrogênios centrais, o que seria responsável pela ocorrência do desdobramento. Na dinâmica ab initio que realizamos para a $\mathrm{H}_{2}$-Ftalocianina fomos capazes de observar a migração dos hidrogênios centrais e vimos que ela ocorre de maneira muito rápida, por isso os hidrogênios praticamente não ficam em posições intermediarias aos nitrogênios centrais. Portanto, concluímos nesta dissertação que o desdobramento das bandas $Q$ não decorre apenas do posicionamento dos hidrogênios centrais mas sim de todas as deformações geométricas causadas pelos efeitos térmicos. Nossos resultados para dinâmicas feitas em diferentes temperaturas apontam que o desdobramento das bandas $Q$ aumenta com a temperatura.

Com relação às dinâmicas moleculares, além de uma extensa discussão a respeito de efeitos térmicos no espectro de absorção, apresentamos comparações de resultados obtidos com as estruturas geradas nas diferentes simulações. Os resultados que obtivemos podem servir como um alerta para a questão da validade das dinâmicas clássicas. No caso da $H_{2}$-Porfirina constatamos que as estruturas geradas pela dinâmica clássica utilizando as constantes de força do campo de força GROMOS 53A6 são mais rígidas que as geradas com a dinâmica $a b$ initio, mais especificamente nas ligações e nos ângulos C-N-H. Por esse motivo propomos um novo conjunto de constantes de força cujos resultados estruturais e do espectro são mais condizentes com os da dinâmica $a b$ initio. Curiosamente o mesmo não ocorre para a $H_{2}$-Ftalocianina, onde a dinâmica clássica com GROMOS 53A6 já fornece resultados satisfatórios em comparação com a dinâmica $a b$ initio. Portanto esses resultados mostram que a mesma parametrização deve ser utilizada com cautela mesmo para sistemas que guardam muitas semelhanças entre si. 
De maneira geral podemos concluir que nossos resultados mostram a importância da inclusão de efeitos térmicos no tratamento teórico para a descrição do espectro de absorção. Em outras palavras, nossos resultados expõem a importância de se olhar além da estrutura optimizada.

Como fruto desta dissertação, algumas perspectivas de aplicações podem ser apontadas. Ter um campo de força que produz resultados condizentes com uma dinâmica $a b$ initio é importante para estudos teóricos. Deste modo uma dessas perspectivas é a utilização das parametrizações testadas e/ou propostas em outros estudos, até mesmo em solução. Outra perspectiva surge dos resultados apresentados nos apêndices para Ftalocianinas com Eugenóis substituintes, que servem como base, juntamente com os demais resultados desta dissertação, para um estudo da Ftalocianina Base Livre com Eugenóis substituintes em que efeitos térmicos e de solvente explicito poderiam ser incluídos através de dinâmica molecular, e o cálculo do espectro poderia ser feito com ZINDO/CIS de maneira viável mesmo para este grande sistema que tem 146 átomos e 610 elétrons. Uma outra perspectiva seria com relação a utilização do programa TeraChem para a realização de dinâmicas moleculares ab initio. A aquisição deste programa foi feita para este trabalho, que é portanto o primeiro trabalho do nosso grupo a utilizar este programa. Nesta dissertação este programa foi bastante utilizado e se mostrou bastante prático e eficiente em relação a outros programas mais comumente utilizados, portanto recomendamos a utilização dele em trabalhos futuros.

Como fica claro a partir desta dissertação, estudos teóricos de sistemas como Porfirinas e Ftalocianinas envolvem uma série de complexidades e problemas, tanto de origem teóricas quanto experimentais. Além disso esses sistemas acabam sendo mais difíceis de serem tratados teoricamente do que outros sistemas estudados na literatura devido aos seus tamanhos. Porém, como esperamos que esta dissertação tenha mostrado, essas sistemas são interessantes e importantes de serem estudados. Apesar desta dissertação apresentar algumas percepções interessantes a respeitos dos 
problemas relacionados aos espectros de absorção de Porfirinas e Ftalocianinas, muitos aspectos relacionados a esses sistemas ainda não são completamente compreendidos e por isso muitas questões ainda estão em aberto. Deste modo esperamos que esta dissertação sirva de base para estudos futuros envolvendo Porfirinas e Ftalocianinas. 


\section{Referências Bibliográficas}

[1] R. E. Blankenship. Molecular Mechanisms of Photosynthesis. Blackwell Science, Tempe, (2002).

[2] D. S. Ginley (Ed.) e D. Cahen (Ed.). Fundamentals of Materials for Energy and Environmental Sustainability. Cambridge University Press, New York, (2012).

[3] C. König e J. Neugebauer. Phys. Chem. Chem. Phys. 13, 10475 (2011).

[4] A. Kay, R. Humphry-Baker e M. J. Grätzel. J. Phys. Chem. 98, 952 (1994).

[5] D. Wu, Z. Shen e Z. L. Zue. Chin. J. Inorg. Chem. 23, 1 (2007).

[6] H. Wu, P. L. Micca, M. S. Makar e M. Miura. Bioorg. Med. Chem. 14, 5083 (2006).

[7] A. E. H. Machado. Química Nova 23, 237 (2000).

[8] B. J. C. Cabral, V. W. D. Cruzeiro, K. Coutinho e S. Canuto. Chem. Phys. Lett. 595.

[9] M. Gouterman. J. Mol. Spec. 6, 138 (1961).

[10] S. J. A. van Gisbergen, A. Rosa, G. Ricciardi e E. J. Baerends. J. Chem. Phys. 111, 2499 (1999).

[11] B. Minaev e H. Ågren. Chem. Phys. 315, 215 (2005). 
[12] D. Sundholm. Chem. Phys. Lett. 317, 545 (2000).

[13] D. Sundholm. Chem. Phys. Lett. 317, 392 (2000).

[14] D. Sundholm. Phys. Chem. Chem. Phys. 2, 2275 (2000).

[15] M. Palummo, C. Hogan, F. Sottile, P. Bagalá e A. Rubio. J. Chem. Phys. 131, $084102(2009)$.

[16] P. Jaramillo, K. Coutinho, B. J. C. Cabral e S. Canuto. Chem. Phys. Lett. 516, 250 (2011).

[17] E. J. Baerends, G. Ricciardi, A. Rosa e S. J. A. Van Gisberg. Coord. Chem. Rev. 230, 5 (2002).

[18] J. Linnanto e J. Korppi-Tommola. Phys. Chem. Chem. Phys. 8, 663 (2006).

[19] L. Petit, A. Quartarolo, C. Adamo e N. Russo. J. Phys. Chem. B 110, 2398 (2006).

[20] H. Zheng wang Qu, V. May e R. Schinke. J. Phys. Chem. B 113, 4817 (2009).

[21] Z. Vokáčová e J. V. Burda. J. Phys. Chem. A 111, 5864 (2007).

[22] A. B. Fredj e M. F. Ruiz-Lopez. J. Phys. Chem. B 114, 681 (2010).

[23] A. B. Fredj, Z. B. Lakhdar e M. F. Ruiz-Lopez. Chem. Phys. Lett. 472, 243 (2009).

[24] J. Linnanto e J. Korppi-Tommola. J. Phys. Chem. A 105, 3855 (2001).

[25] X. Liu, E. K. L. Yeow, S. Velate e R. P. Steeer. 8, 1298 (2006).

[26] S. Tabita, Y. Kaizu, H. Kobayashi e I. Tanaka. J. Chem. Phys. 81, 2962 (1984). 
[27] L. Serrano-Andrés, M. Merchán, M. Rubio e B. O. Roos. Chem. Phys. Lett. 295, 195 (1998).

[28] L. Edwards, D. H. Dolphin, M. Gouterman e A. D. Adler. J. Mol. Spec. 38, 16 (1971).

[29] L. Edwards e M. Gouterman. J. Mol. Spec. 33, 292 (1970).

[30] D. Dolphin (Ed.). The Porphyrins. Academic Press, New York, (1978).

[31] L. R. Milgrom. The Colours of Life: An introduction to the Chemistry of Porphyrins and Related Compounds. Oxford University Press, New York, (1997).

[32] O. Kitao, H. Ushiyama e N. Miura. J. Chem. Phys. 110, 2936 (1999).

[33] S. R. Gwaltney e R. J. Bartlett. J. Chem. Phys. 108, 6790 (1998).

[34] G. D. Dorough, J. R. Miller e F. M. Huennekens. J. Am. Chem. Soc. 73, 4315 (1951).

[35] B. M. L. Chen e A. Tulinsky. J. Am. Chem. Soc. 94, 4144 (1972).

[36] K. M. Kadish (Ed.), K. M. Smith (Ed.) e R. Guilard (Ed.). The Porphyrin Handbook. Academic Press, San Diego, (2003).

[37] J. R. Platt. Radiation Biology, vol. 3. McGraw Hill, New York, (1956).

[38] M. Gouterman. J. Chem. Phys. 30, 1139 (1959).

[39] M. Gouterman, G. H. Wagnière e L. C. Snyder. J. Mol. Spec. 11, 108 (1963).

[40] C. Weiss, H. Kobayashi e M. Gouterman. J. Mol. Spec. 16, 415 (1965).

[41] M. Gouterman e G. Khalil. J. Mol. Spec. 53, 88 (1974).

[42] J. Mizuguchi e S. Matsumoto. J. Phys. Chem. A 103, 614 (1999). 
[43] E. Ortí, J. L. Brédas e C. Clarisse. J. Chem. Phys. 92, 1228 (1990).

[44] K. Toyota, J. Hasegawa e H. Nakatsuji. J. Phys. Chem. A 101, 446 (1997).

[45] T. Lu, M. Xiang, H. Wang, T. He e D. Chen. J. Mol. Struct. (Theochem) 860, $141(2008)$.

[46] N.S. Hush e I.S. Woolsey. Mol. Phys. 21, 465 (1971).

[47] A. M. Schaffer e M. Gouterman. Theoret. Chim. Acta 25, 62 (1972).

[48] R. Fukuda, M. Ehara e H. Nakatsuji. J. Chem. Phys. 133, 144316 (2010).

[49] S. Matsumoto, K. Matsuhama e J. Mizuguch. Acta Cryst. C 55, 131 (1999).

[50] I. Chen. J. Mol. Spec. 23, 131 (1967).

[51] B. D. Berezin. Russian J. Phys. Chem. (English Transl.) 39, 165 (1965).

[52] J. M. Robertson. J. Chem. Soc. S/V, 1195 (1936).

[53] P. W. Atkins. Molecules. W. H. Freeman and Company, New York, (1987).

[54] J. Wit e S. Seage. Science 342, 1473 (2013).

[55] B. Valeur. Molecular Fluorescence: Principles and Applications. Wiley-VCH, Paris, (2001).

[56] K. Wittel e S. P. McGlynn. Chem. Rev. 77, 745 (1977).

[57] R. Chang. Quimica Geral: Conceitos Essenciais, fourth edition. McGraw Hill, $4^{\mathrm{a}}$ edição, (2006).

[58] N. H. Morgon (Ed.) e K. Coutinho (Ed.). Métodos de Química Teórica e Modelagem Molecular. Livraria da Física, São Paulo, (2007). 
[59] K. K. Rohatgi-Mukherjee. Fundamentals of Photochemistry. New Age International, Calcutta, (1978).

[60] D. C. Harris e M. D. Bertolucci. Symmetry and Spectroscopy: An Introduction to Vibrational and Electronic Spectroscopy. Dover Publications, New York, (1989).

[61] A. Szabo e N. S. Ostlund. Modern Quantum Chemistry. Dover, Mineola, (1996).

[62] Ira N. Levine. Quantum Chemistry. Prentice-Hall, New Jersey, 5ª edição, (2000).

[63] F. Jensen. Introduction to Computational Chemistry. Wiley, Chichester, (1999).

[64] M. C. Zerner. ZINDO: A Semiempirical Program Package. University of Florida, Gainesville, (1996).

[65] C. C. V. Suplicy. Estudos experimentais e teóricos dos espectros eletrônicos das sondas fluorescentes Prodan e Laurdan em solventes e bicamadas lipídicas. Tese de doutorado, Instituto de Física da USP, (2010).

[66] C. A. Ullrich e Z. Yang. Braz. J. Phys. 44, 154 (2014).

[67] The GROMOS Software for (Bio)Molecular Simulation. Volume 3: Force Field and Topology Data Set. www.gromos.net, (2011).

[68] L. D. Schuler, X. Daura e W. F. Gunsteren. J. Comp. Chem. 22, 1205 (2001).

[69] C. Oostenbrink, A. Villa, A. E. Mark e W. F. Gunsteren. J. Comp. Chem. 25, 1656 (2004).

[70] M. P. Allen e D. J. Tildesley. Computer Simulation of Liquids. Oxford, New York, (1989).

[71] C. J. Cramer. Essentials of Computational Chemistry: Theories and Models. Wiley, West Sussex, $2^{\mathrm{a}}$ edição, (2004). 
[72] D. Frenkel e B. Smith. Understanding Molecular Simulation: From Algorithm to Applicaions. Academic Press, San Diego, $2^{\text {a }}$ edição, (2002).

[73] M. Abraham, E. Apol, R. Apostolov, H. J. C. Berendsen, A. Buuren, P. Bjelkmar, R. Drunen, A. Feenstra, G. Groenhof, C. Junghans, P. Kasson, C. Kutzner, P. Larsson, P. Meulenhoff, T. Murtola, S. Pall, S. Pronk, R. Schulz, M. Shirts, A. Sijbers, P. Tieleman, B. Hess, D. Spoel e E. Lindahl. GROMACS: GROningen MAchine for Chemical Simulation. Royal Institute of Technology and Uppsala University, Sweden, 4.6.5 edição, (2013).

[74] D. Spoel, E. Lindahl, B. Hess, A. R. Buuren, E. Apol, P. J. Meulenhoff, D. P. Tieleman, A. L. T. M. Sijbers, K. A. Feenstra, R. Drunen e H. J. C. Berendsen. Gromacs User Manual version 4.6-beta1. www.gromacs.org, (2010).

[75] E. Lindahl, B. Hess e D. Spoel. J. Mol. Model. 7, 306 (2001).

[76] G. Bussi, D. Donadio e M. Parrinello. J. Chem. Phys. 126, 014101 (2007).

[77] M. Berger. NVIDIA Computational Chemistry and Biology. www.nvidia.com/docs/IO/122634/computational-chemistry-benchmarks.pdf, (2013).

[78] PetaChem, www.petachem.com. TeraChem User's Guide Version 1.5K, (2012).

[79] V. N. Staroverov, G. E. Scuseria, J. Tao e J. P. Perdew. J. Chem. Phys. 119, 12129 (2003).

[80] K. Burke. J. Chem. Phys. 136, 150901 (2012).

[81] M. J. Frisch, G. W. Trucks, H. B. Schlegel, G. E. Scuseria, M. A. Robb, J. R. Cheeseman, G. Scalmani, V. Barone, B. Mennucci, G. A. Petersson, H. Nakatsuji, M. Caricato, X. Li, H. P. Hratchian, A. F. Izmaylov, J. Bloino, G. Zheng, J. L. Sonnenberg, M. Hada, M. Ehara, K. Toyota, R. Fukuda, J. Hasegawa, 
M. Ishida, T. Nakajima, Y. Honda, O. Kitao, H. Nakai, T. Vreven, J. A. Montgomery, Jr., J. E. Peralta, F. Ogliaro, M. Bearpark, J. J. Heyd, E. Brothers, K. N. Kudin, V. N. Staroverov, R. Kobayashi, J. Normand, K. Raghavachari, A. Rendell, J. C. Burant, S. S. Iyengar, J. Tomasi, M. Cossi, N. Rega, J. M. Millam, M. Klene, J. E. Knox, J. B. Cross, V. Bakken, C. Adamo, J. Jaramillo, R. Gomperts, R. E. Stratmann, O. Yazyev, A. J. Austin, R. Cammi, C. Pomelli, J. W. Ochterski, R. L. Martin, K. Morokuma, V. G. Zakrzewski, G. A. Voth, P. Salvador, J. J. Dannenberg, S. Dapprich, A. D. Daniels, O. Farkas, J. B. Foresman, J. V. Ortiz, J. Cioslowski, e D. J. Fox. Gaussian 09 Revision A.02. Gausssian Inc., Wallingford, (2009).

[82] H. C. Longuet-Higgins, C. W. Rector e J. R. Platt. J. Chem. Phys. 18, 1174 (1950).

[83] I. N. Levine. Molecular Spectroscopy. Wiley-Interscience, New York, (1975).

[84] C. Angeli, M. Pastore, e R. Cimiraglia. Theor. Chem. Acc. 117, 743 (2007).

[85] O. Bludský, M. Rubeš, P. Soldán e P. Nachtigall. J. Chem. Phys. 128, 114102 (2008).

[86] N. A. Seifert, A. L. Steber, J. L. Neill, C .Pérez, D. P. Zaleski, B. H. Pate e A. Lesarri. Phys. Chem. Chem. Phys. 15, 11468 (2013).

[87] T. Polivka e H. A. Frank. Acc. Chem. Res. 43, 1125 (2010).

[88] O. Schalk, H. Brands, T. S. Balaban e A. Unterreiner. J. Phys. Chem. A 112, $1719(2008)$.

[89] I. S. Ufimtsev e T. J. Martinez. J. Chem. Theory Comput. 5, 2619 (2009).

[90] S. R. A. Salinas. Introdução à Fúsica Estatística, 2ª Edição. Edusp, São Paulo, (1999). 
[91] F. Neese. ORCA - An ab initio, Density Functional and Semiempirical Program Package, Version 2.9.1. University of Bonn, Bonn, (2012).

[92] J. Hutter (Adm.), M. Krack (Adm.), T. Laino (Adm.) e J. VandeVondele (Adm.) et. al. CP2K - Open Source Molecular Dynamics. www.cp2k.org, (2011).

[93] E. Ă̆ar, S. Şaşmaz e A. A ğar. Turk. J. Chem. 23, 131 (1999).

[94] A. Hermann, W. G. Schmidt e P. Schwerdtfeger. Phys. Rev. Lett. 100, 207403 (2008).

[95] K. Dressler e O. Schnepp. J. Chem. Phys. 33, 270 (1960).

[96] H. Baba e S. Suzuki. J. Chem. Phys. 35, 1118 (1961).

[97] L. B. Clark, G. G. Peschel e I. Tinoco Jr. J. Phys. Chem. 69, 3615 (1965).

[98] F. E. Blacet, W. G. Young e J. G. Roof. J. Am. Chem. Soc. 59, 608 (1937).

[99] A. Lüthy. Z. Phys. Chem. 107, 284 (1923).

[100] K. Inuzuka. 33, 678 (1960).

[101] R. Yalman e L. Spaulding. Porphin project final report, como citado na tabela 6 da referência [30], (1968).

[102] A. Starukhin, A. Shulga e J. Waluk. Chem. Phys. Lett. 272, 405 (1997).

[103] J. Šeda, J. V. Burda, V. Brázdová e V. Kapsa. Int. J. Mol. Sci. 5, 196 (2004).

[104] J. Šeda, J. V. Burda e J. Leszczynski. J. Comp. Chem. 26, 294 (2005).

[105] J. Tomasi, B. Mennucci e R. Cammi. Chem. Rev. 105, 2999 (2005).

[106] S. Miertus, E. Scrocco e J. Tomasi. Chem. Phys. 55, 117 (1981).

[107] M. T. Cancès, B. Mennucci e J. Tomasi. J. Chem. Phys. 107, 3032 (1997). 


\section{Apêndice A}

\section{Estudos do Espectro de Absorção de Moléculas Modelo Isoladas}

Neste estudo de moléculas modelo isoladas, calculamos o valor das energias de excitação dos três primeiros estados excitados e a força de oscilador correspondente das seguintes moléculas: Água $\left(\mathrm{H}_{2} \mathrm{O}\right)$, Amônia $\left(\mathrm{CH}_{3}\right)$, Fenol $\left(\mathrm{C}_{6} \mathrm{H}_{5} \mathrm{OH}\right)$, Uracil $\left(\mathrm{C}_{4} \mathrm{H}_{4} \mathrm{~N}_{2} \mathrm{O}_{2}\right)$, 5-Fluorouracil $\left(\mathrm{C}_{4} \mathrm{H}_{3} \mathrm{FN}_{2} \mathrm{O}_{2}\right)$, e Acroleína $\left(\mathrm{C}_{3} \mathrm{H}_{4} \mathrm{O}\right)$. A figura A.1 abaixo ilustra a estrutura dessas moléculas. Os cálculos do espectro e também os cálculos de optimização de geometria foram feitos utilizando o programa Gaussian 09 [81].

Para todas as moléculas realizamos duas optimizações de geometria. Uma no nível B3LYP/6-311++G(d,p) e outra no nível MP2/aug-cc-pVDZ. O método MP2 é um método pós-Hartree-Fock com o qual se espera que ele forneça bons resultados para estruturas optimizadas, enquanto B3LYP é um funcional do método DFT muito utilizado na literatura para o cálculo de geometrias optimizadas $[79,80]$. Os conjuntos de funções base utilizados em ambos os casos podem ser considerados robustos. Na tabela A.1 uma comparação entre ambas estruturas obtidas é feita para todas moléculas.

Pela tabela A.1 podemos ver que as estruturas geradas em ambos níveis são bastante semelhantes. Assim então, para as moléculas estudadas e para os conjuntos de funções bases utilizados, podemos concluir que as estruturas B3LYP puderam 


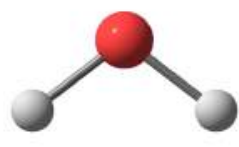

(a)

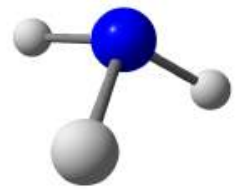

(b)

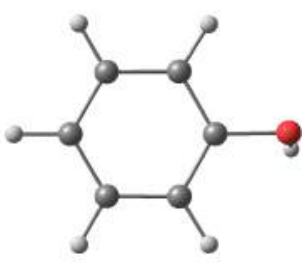

(c)

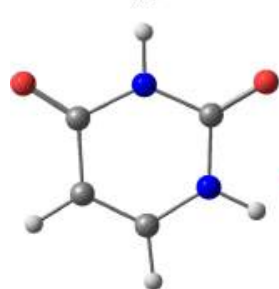

(d)

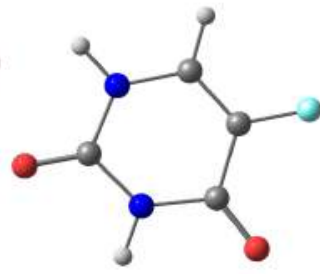

(e)

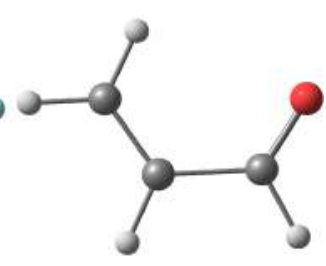

(f)

Figura A.1: Ilustração da estrutura das moléculas modelo estudadas. As moléculas são: (a) Água, (b) Amônia, (c) Fenol, (d) Uracil, (e) 5Fluorouracil, e (f) Acroleína.

Tabela A.1: Comparação entre as estruturas obtidas nos níveis B3LYP/6-311 $++\mathrm{G}(\mathrm{d}, \mathrm{p})$ e MP2/aug-cc-pVDZ das moléculas modelo estudadas. $R$ representa distâncias interatômicas, e é dado em Angstroms. $\theta$ e $\beta$ representam ângulos e diédros respectivamente, e são dados em graus. Os valores com traço em cima representam o valor médio e os com MAX o valor máximo.

\begin{tabular}{ccccccc} 
& $\overline{\Delta R}$ & $\Delta R_{M A X}$ & $\overline{\Delta \theta}$ & $\Delta \theta_{M A X}$ & $\overline{\Delta \beta}$ & $\Delta \beta_{M A X}$ \\
\hline Água & 0,0038 & 0,0038 & 1,1821 & 1,1821 & - & - \\
Amônia & 0,0057 & 0,0057 & 1,5893 & 1,5895 & 3,3537 & 3,3537 \\
Fenol & 0,0108 & 0,0141 & 0,1600 & 1,1593 & 0,0004 & 0,0012 \\
Uracil & 0,0079 & 0,0164 & 0,1707 & 0,6179 & 0,0001 & 0,0004 \\
5-Fluorouracil & 0,0080 & 0,0169 & 0,1710 & 0,4419 & 0,0002 & 0,0007 \\
Acroleína & 0,0107 & 0,0186 & 0,4971 & 0,8241 & 0,0001 & 0,0001 \\
\hline
\end{tabular}

reproduzir bem as estruturas obtidas utilizando o método MP2.

A partir das estruturas optimizadas calculamos, utilizamos vários métodos e conjunto de funções base 6-311++G(d,p), o espectro de absorção teórico. Os métodos 
utilizados foram: DFT com os funcionais B3LYP, CAM-B3LYP, e M06-2X; CIS e CIS(D); e EOM-CCSD. Os métodos CIS, CIS(D) e EOM-CCSD são métodos pósHartree-Fock, onde desses EOM-CCSD é o mais robusto, seguido por CIS(D) e CIS ${ }^{1}$. Nas tabelas de A.2 a A.7 mostramos os resultados obtidos para cada uma das moléculas modelo estudadas.

Tabela A.2: Estados excitados da molécula de Água isolada. Todos os cálculos foram feitos com o conjunto de funções base $6-311++\mathrm{G}(\mathrm{d}, \mathrm{p})$. $\Delta E$ é a energia de excitação dada em $\mathrm{eV}$, $f$ é a força de oscilador, e TE é o tempo de execução dado em \%, em relação ao cálculo com EOM-CCSD da estrutura correspondente. ${ }^{a}$ Referência [94].

\begin{tabular}{ccccccccc}
\hline & \multicolumn{2}{c}{$1^{\underline{0}}$ Estado } & \multicolumn{2}{c}{$2^{\underline{0}}$ Estado } & \multicolumn{2}{c}{$3^{0}$ Estado } \\
Estrutura/Método & $\Delta E$ & $f$ & $\Delta E$ & $f$ & $\Delta E$ & $f$ & TE \\
\hline B3LYP/B3LYP & 6,8780 & 0,0415 & 8,4096 & 0 & 9,0032 & 0,0886 & 32,1 \\
B3LYP/CAM-B3LYP & 7,0561 & 0,0428 & 8,6908 & 0 & 9,1805 & 0,0914 & 87,9 \\
B3LYP/M06-2X & 7,3206 & 0,0364 & 8,8281 & 0 & 9,4977 & 0,0875 & 56,6 \\
B3LYP/CIS & 8,6159 & 0,0428 & 10,307 & 0 & 10,898 & 0,1119 & - \\
B3LYP/CIS(D) & 6,9692 & 0,0428 & 8,7534 & 0 & 9,3388 & 0,1119 & 16,2 \\
B3LYP/EOM-CCSD & 7,3532 & 0,0461 & 9,1305 & 0 & 9,7325 & 0,1024 & 100 \\
MP2/B3LYP & 6,8574 & 0,0411 & 8,3988 & 0 & 9,0419 & 0,0900 & 32,7 \\
MP2/CAM-B3LYP & 7,0353 & 0,0424 & 8,6798 & 0 & 9,2173 & 0,0929 & 88,6 \\
MP2/M06-2X & 7,2982 & 0,0360 & 8,8143 & 0 & 9,5327 & 0,0890 & 57,0 \\
MP2/CIS & 8,5914 & 0,0423 & 10,285 & 0 & 10,926 & 0,1139 & - \\
MP2/CIS(D) & 6,9454 & 0,0423 & 8,7496 & 0 & 9,3770 & 0,1139 & 16,7 \\
MP2/EOM-CCSD & 7,3276 & 0,0457 & 9,1157 & 0 & 9,7670 & 0,1042 & 100 \\
\hline Experimental & $7,4{ }^{a}$ & - & - & - & - & - & - \\
\hline
\end{tabular}

\footnotetext{
${ }^{1}$ Para maiores informações sobre métodos pós-Hartree-Fock recomendamos a referência [58]
} 
Analisando a tabela A.2 para Água podemos ver que as diferentes estruturas obtidas (B3LYP/6-311++G(d,p) e MP2/aug-cc-pVDZ) fornecem resultados muito semelhantes, com diferenças nas energias de excitação entre elas da ordem de $\sim 0,03$ $\mathrm{eV}$. Vemos que o EOM-CCSD é o método que nos fornece o resultado mais próximo da primeira banda experimental, e que é também o cálculo mais custoso computacionalmente. Vemos que, para a Água, uma molécula relativamente pequena, o cálculo com o CIS(D), e também o CIS, que é precessor do cálculo CIS(D), são os menos custoso dentre os analisados. Podemos ver também que EOM-CCSD e M06-2X nos fornecem resultados razoavelmente concordantes para o cálculo da energia e da força de oscilador dos estados excitados calculados.

Na tabela A.3 para Amônia também vemos que as diferentes estruturas obtidas nos fornecem resultados semelhantes com diferenças nas energias de excitação calculadas a partir delas da ordem de $\sim 0,09 \mathrm{eV}$. Vemos que o segundo e o terceiro estados são degenerados. Aqui, o método que nos da o resultado mais próximo do experimental é o B3LYP. Podemos ver que EOM-CCSD, M06-2X e CIS(D) nos fornecem resultados moderadamente concordantes para os valores das energias de excitação. Vemos que o EOM-CCSD é o método mais custoso computacionalmente e o CIS(D) e também CIS são os menos custosos.

A molécula de Fenol, cujos resultados são mostrados na tabela A.4, é uma molécula consideravelmente maior que a Água e a Amônia, e uma das consequências que vemos disso é que o cálculo EOM-CCSD fica extremamente mais custoso em relação aos outros métodos utilizados. Vemos que aqui CIS(D) e CIS deixam de ser os métodos menos custosos, e B3LYP passa a ser o método menos custoso. Vemos que as diferentes estruturas obtidas nos fornecem resultados semelhantes com diferenças de energia entre elas da ordem de $\sim 0,1 \mathrm{eV}$. Vemos os métodos EOM-CCSD e M06-2X fornecem resultados aproximadamente concordantes. Os métodos que aqui fornecem o resultado mais próximo do experimental são o EOM-CCSD para a primeira excitação 
Tabela A.3: Estados excitados da molécula de Amônia isolada. Todos os cálculos foram feitos com o conjunto de funções base $6-311++\mathrm{G}(\mathrm{d}, \mathrm{p}) . \Delta E$ é a energia de excitação dada em $\mathrm{eV}$, $f$ é a força de oscilador, e TE é o tempo de execução dado em \%, em relação ao cálculo com EOM-CCSD da estrutura correspondente. ${ }^{a}$ Referência [95].

\begin{tabular}{cccccccc}
\hline & \multicolumn{2}{c}{$1^{\underline{0}}$ Estado } & \multicolumn{2}{c}{$2^{0}$ Estado } & \multicolumn{2}{c}{$3^{0}$ Estado } \\
Estrutura/Método & $\Delta E$ & $f$ & $\Delta E$ & $f$ & $\Delta E$ & $f$ & TE \\
\hline B3LYP/B3LYP & 5,8241 & 0,0705 & 7,2479 & 0,0034 & 7,2483 & 0,0034 & 24,2 \\
B3LYP/CAM-B3LYP & 6,0589 & 0,0729 & 7,5728 & 0,0028 & 7,5733 & 0,0028 & 53,0 \\
B3LYP/M06-2X & 6,2419 & 0,0657 & 7,5840 & 0,0025 & 7,5844 & 0,0025 & 48,5 \\
B3LYP/CIS & 7,3064 & 0,0839 & 8,8344 & 0,0058 & 8,8344 & 0,0058 & - \\
B3LYP/CIS(D) & 6,1033 & 0,0839 & 7,6803 & 0,0058 & 7,6803 & 0,0058 & 7,8 \\
B3LYP/EOM-CCSD & 6,3070 & 0,0810 & 7,9278 & 0,0032 & 7,9278 & 0,0032 & 100 \\
MP2/B3LYP & 5,9000 & 0,0722 & 7,3454 & 0,0041 & 7,3458 & 0,0041 & 46,0 \\
MP2/CAM-B3LYP & 6,1347 & 0,0747 & 7,6717 & 0,0034 & 7,6717 & 0,0034 & 105 \\
MP2/M06-2X & 6,3282 & 0,0677 & 7,6869 & 0,0030 & 7,6869 & 0,0030 & 86,6 \\
MP2/CIS & 7,4081 & 0,0864 & 8,9518 & 0,0071 & 8,9518 & 0,0071 & - \\
MP2/CIS(D) & 6,1874 & 0,0864 & 7,7888 & 0,0071 & 7,7888 & 0,0071 & 15,8 \\
MP2/EOM-CCSD & 6,3918 & 0,0831 & 8,0341 & 0,0040 & 8,0341 & 0,0040 & 100 \\
\hline Experimental & $5,82 a$ & - & - & - & - & - & - \\
\hline
\end{tabular}

experimental, e o CAM-B3LYP para a segunda.

Na tabela A.5 para a molécula de Uracil vemos que as diferentes estruturas obtidas nos fornecem resultados semelhantes com diferenças entre elas nas energias excitação da ordem de $\sim 0,12 \mathrm{eV}$. O B3LYP é o método que nos fornece um resultado que mais se aproxima do experimental para a primeira excitação experimental e EOM- 
Tabela A.4: Estados excitados da molécula de Fenol isolada. Todos os cálculos foram feitos com o conjunto de funções base $6-311++\mathrm{G}(\mathrm{d}, \mathrm{p}) . \Delta E$ é a energia de excitação dada em $\mathrm{eV}$, $f$ é a força de oscilador, e TE é o tempo de execução dado em \%, em relação ao cálculo com EOM-CCSD da estrutura correspondente. ${ }^{a}$ Referência [96].

\begin{tabular}{cccccccc}
\hline & \multicolumn{2}{c}{$1^{0}$ Estado } & \multicolumn{2}{c}{$2^{0}$ Estado } & \multicolumn{2}{c}{$3^{0}$ Estado } & \\
Estrutura/Método & $\Delta E$ & $f$ & $\Delta E$ & $f$ & $\Delta E$ & $f$ & TE \\
\hline B3LYP/B3LYP & 5,0486 & 0,0330 & 5,1839 & 0,0001 & 5,6386 & 0,0032 & 0,179 \\
B3LYP/CAM-B3LYP & 5,1884 & 0,0344 & 5,6060 & 0 & 5,9584 & 0,0325 & 0,315 \\
B3LYP/M06-2X & 5,2761 & 0,0363 & 5,5401 & 0 & 6,0312 & 0,0039 & 0,349 \\
B3LYP/CIS & 5,9031 & 0,0484 & 6,1377 & 0 & 6,1738 & 0,0031 & - \\
B3LYP/CIS(D) & 5,0771 & 0,0484 & 5,6213 & 0 & 6,4940 & 0,0031 & 0,246 \\
B3LYP/EOM-CCSD & 5,0060 & 0,0217 & 5,6399 & 0,0001 & 6,1576 & 0,0045 & 100 \\
MP2/B3LYP & 4,9597 & 0,0314 & 5,1815 & 0,0001 & 5,6266 & 0,0032 & 0,107 \\
MP2/CAM-B3LYP & 5,0980 & 0,0326 & 5,6047 & 0 & 5,8709 & 0,0286 & 0,192 \\
MP2/M06-2X & 5,1852 & 0,0343 & 5,5381 & 0 & 6,0171 & 0,0350 & 0,197 \\
MP2/CIS & 5,8099 & 0,0458 & 6,0728 & 0,0022 & 6,1362 & 0 & - \\
MP2/CIS(D) & 4,9698 & 0,0458 & 6,4206 & 0,0022 & 5,6271 & 0 & 0,119 \\
MP2/EOM-CCSD & 4,9022 & 0,0201 & 5,6374 & 0,0001 & 6,1444 & 0,0046 & 100 \\
\hline Experimental & $4,55{ }^{a}$ & - & - & - & $5,83{ }^{a}$ & - & - \\
\hline
\end{tabular}

CCSD para a segunda, que é um ombro pronunciado no espectro experimental [97]. Podemos ver aqui também que o método EOM-CCSD é o mais custoso computacionalmente. O cálculo com B3LYP é menos custoso. Vemos que EOM-CCSD, M06-2X e CIS(D) nos fornecem resultados relativamente concordantes para os valores calculados para as energias de excitação. 
Tabela A.5: Estados excitados da molécula de Uracil isolada. Todos os cálculos foram feitos com o conjunto de funções base $6-311++\mathrm{G}(\mathrm{d}, \mathrm{p}) . \Delta E$ é a energia de excitação dada em $\mathrm{eV}$, $f$ é a força de oscilador, e TE é o tempo de execução dado em \%, em relação ao cálculo com EOM-CCSD da estrutura correspondente. sh significa ombro, do inglês shoulder. ${ }^{a}$ Referência [97].

\begin{tabular}{cccccccc}
\hline & \multicolumn{2}{c}{$1^{\underline{0}}$ Estado } & \multicolumn{2}{c}{$2^{\underline{0}}$ Estado } & \multicolumn{2}{c}{$3^{\underline{0}}$ Estado } & \\
Estrutura/Método & $\Delta E$ & $f$ & $\Delta E$ & $f$ & $\Delta E$ & $f$ & TE \\
\hline B3LYP/B3LYP & 4,6766 & 0 & 5,1830 & 0,1320 & 5,6943 & 0,0020 & 0,116 \\
B3LYP/CAM-B3LYP & 5,0578 & 0 & 5,4385 & 0,1912 & 6,0803 & 0,0030 & 0,236 \\
B3LYP/M06-2X & 4,9480 & 0 & 5,4845 & 0,2022 & 5,9716 & 0,0023 & 0,258 \\
B3LYP/CIS & 6,3031 & 0 & 6,4635 & 0,4573 & 6,7444 & 0,0115 & - \\
B3LYP/CIS(D) & 5,0399 & 0 & 5,6779 & 0,4573 & 6,0660 & 0,0115 & 0,212 \\
B3LYP/EOM-CCSD & 5,1700 & 0 & 5,6654 & 0,2368 & 6,0571 & 0,0025 & 100 \\
MP2/B3LYP & 4,5490 & 0 & 5,0761 & 0,1296 & 5,6520 & 0,0001 & 0,118 \\
MP2/CAM-B3LYP & 4,9368 & 0 & 5,3337 & 0,1902 & 6,0672 & 0,0032 & 0,177 \\
MP2/M06-2X & 4,8297 & 0 & 5,3803 & 0,2014 & 5,9573 & 0,0025 & 0,207 \\
MP2/CIS & 6,1932 & 0 & 6,3467 & 0,4598 & 6,7290 & 0,0122 & - \\
MP2/CIS(D) & 4,8772 & 0 & 5,5720 & 0,4598 & 6,0621 & 0,0122 & 0,172 \\
MP2/EOM-CCSD & 5,0371 & 0 & 5,5595 & 0,2369 & 6,0429 & 0,0027 & 100 \\
\hline Experimental & - & - & $5,08 a$ & - & $6,05(\mathrm{sh})$ & $a$ & - \\
\hline
\end{tabular}

Para a molécula de 5-Fluorouracil, cujos resultados são mostrados na tabela A.6, não encontramos resultamos experimentais em fase gasosa reportados na literatura. Podemos ver que as diferentes estruturas obtidas novamente nos fornecem resultados semelhantes com diferenças entre elas nas energias de excitação chegando a ordem de $\sim 0,13 \mathrm{eV}$. Podemos ver que EOM-CCSD, M06-2X e CIS(D) nos fornecem resultados 
Tabela A.6: Estados excitados da molécula de 5-Fluorouracil isolada. Todos os cálculos foram feitos com o conjunto de funções base 6-311++G(d,p). $\Delta E$ é a energia de excitação dada em $\mathrm{eV}, f$ é a força de oscilador, e TE é o tempo de execução dado em \%, em relação ao cálculo com EOM-CCSD da estrutura correspondente.

\begin{tabular}{cccccccc}
\hline & $1^{0}$ Estado & \multicolumn{2}{c}{$2^{\underline{0}}$ Estado } & \multicolumn{2}{c}{$3^{0}$ Estado } \\
Estrutura/Método & $\Delta E$ & $f$ & $\Delta E$ & $f$ & $\Delta E$ & $f$ & TE \\
\hline B3LYP/B3LYP & 4,7338 & 0 & 4,9258 & 0,1276 & 5,6045 & 0,0001 & 0,316 \\
B3LYP/CAM-B3LYP & 5,0829 & 0 & 5,2048 & 0,1807 & 6,0043 & 0,0002 & 0,446 \\
B3LYP/M06-2X & 4,9678 & 0 & 5,2792 & 0,1911 & 5,8919 & 0,0002 & 0,577 \\
B3LYP/CIS & 6,2557 & 0 & 6,3597 & 0,4408 & 6,8265 & 0,0027 & - \\
B3LYP/CIS(D) & 5,0690 & 0 & 5,4712 & 0,4408 & 5,9498 & 0,0027 & 0,619 \\
B3LYP/EOM-CCSD & 5,2006 & 0 & 5,5433 & 0,2178 & 6,0148 & 0,0002 & 100 \\
MP2/B3LYP & 4,5931 & 0 & 4,8291 & 0,1241 & 5,6047 & 0,0001 & 0,387 \\
MP2/CAM-B3LYP & 4,9496 & 0 & 5,1108 & 0,1795 & 6,0104 & 0,0003 & 0,476 \\
MP2/M06-2X & 4,8378 & 0 & 5,1854 & 0,1902 & 5,8980 & 0,0002 & 0,620 \\
MP2/CIS & 6,1335 & 0 & 6,2513 & 0,4451 & 6,8374 & 0,0028 & - \\
MP2/CIS(D) & 4,8947 & 0 & 5,3775 & 0,4451 & 5,9650 & 0,0028 & 0,560 \\
MP2/EOM-CCSD & 5,0558 & 0 & 5,4486 & 0,2173 & 6,0218 & 0,0003 & 100 \\
\hline
\end{tabular}

relativamente concordantes para os valores calculados para as energias de excitação. Vemos que o EOM-CCSD é o método mais custoso computacionalmente e que B3LYP é o menos custoso.

Por fim, analisando a tabela A.7 para a molécula de Acroleína, que é uma molécula de tamanho intermediário dentre as moléculas estudadas, podemos ver que as diferentes estruturas obtidas também fornecem resultados muito semelhantes, com diferenças nas energias de excitação entre elas da ordem de $\sim 0,09 \mathrm{eV}$. Vemos que o 
Tabela A.7: Estados excitados da molécula de Acreleína isolada. Todos os cálculos foram feitos com o conjunto de funções base $6-311++\mathrm{G}(\mathrm{d}, \mathrm{p}) . \Delta E$ é a energia de excitação dada em $\mathrm{eV}, f$ é a força de oscilador, e TE é o tempo de execução dado em \%, em relação ao cálculo com EOM-CCSD da estrutura correspondente. ${ }^{a}$ Referência [98-100].

\begin{tabular}{cccccccc}
\hline & \multicolumn{2}{c}{$1^{0}$ Estado } & \multicolumn{2}{c}{$2^{0}$ Estado } & \multicolumn{2}{c}{$3^{0}$ Estado } \\
Estrutura/Método & $\Delta E$ & $f$ & $\Delta E$ & $f$ & $\Delta E$ & $f$ & TE \\
\hline B3LYP/B3LYP & 3,4245 & 0,0002 & 5,7148 & 0,2531 & 6,4430 & 0,0265 & 2,84 \\
B3LYP/CAM-B3LYP & 3,6110 & 0,0003 & 5,8877 & 0,2690 & 7,0035 & 0,0268 & 4,87 \\
B3LYP/M06-2X & 3,4354 & 0,0003 & 5,9518 & 0,2634 & 7,0690 & 0,0010 & 6,09 \\
B3LYP/CIS & 4,5691 & 0,0005 & 6,5175 & 0,4193 & 7,6367 & 0,0543 & - \\
B3LYP/CIS(D) & 3,7207 & 0,0005 & 6,4150 & 0,4193 & 6,4150 & 0,0543 & 0,991 \\
B3LYP/EOM-CCSD & 3,7455 & 0,0002 & 6,4811 & 0,2827 & 7,0389 & 0,0301 & 100 \\
MP2/B3LYP & 3,3409 & 0,0002 & 5,5545 & 0,2475 & 6,4537 & 0,0254 & 4,81 \\
MP2/CAM-B3LYP & 3,5273 & 0,0003 & 5,7182 & 0,2619 & 7,0281 & 0,0256 & 7,61 \\
MP2/M06-2X & 3,3519 & 0,0002 & 5,7785 & 0,2564 & 6,9794 & 0,0011 & 14,9 \\
MP2/CIS & 4,4884 & 0,0004 & 6,3302 & 0,4084 & 7,5351 & 0,0530 & - \\
MP2/CIS(D) & 3,6005 & 0,0004 & 6,2384 & 0,4084 & 7,4932 & 0,0530 & 1,6 \\
MP2/EOM-CCSD & 3,6437 & 0,0002 & 6,3150 & 0,2759 & 7,0413 & 0,0284 & 100 \\
\hline Experimental & $3,69-3,71$ & - & - & - & - & - & - \\
\hline
\end{tabular}

EOM-CCSD é o método que nos da o resultado mais próximo do experimental, e que é também o cálculo mais custoso computacionalmente. O cálculo com o CIS(D) é o menos custoso. Podemos ver também que EOM-CCSD e CIS(D) nos fornecem resultados razoavelmente concordantes para os valores calculados para as energias de excitação. 
O método EOM-CCSD, devido a sua construção teórica, é um método confiável. Todos os resultados apresentados nas tabelas A.2 a A.7 nos mostram que quanto maior é o tamanho da molécula maior é o custo computacional de EOM-CCSD em comparação com outros métodos estudados, assim então fica inviável utilizar EOMCCSD para sistemas ainda maiores do que os estudados aqui. Portanto, principalmente nesses casos, os métodos DFT se tornam as opções mais viáveis. O mesmo que acontece com EOM-CCSD também acontece com CIS(D), só que em uma escala menor. Isso está relacionado com um conceito conhecido como escalabilidade. A medida que aumentamos o tamanho do sistema (ou do conjunto de funções base) o custo computacional aumenta mas em uma taxa que é diferente para cada método, e essa taxa está relacionada com a escalabilidade do método. Como EOM-CCSD e CIS(D) são métodos pós-Hartree-Fock, a sua escalabilidade é pior do que a de métodos DFT, por isso que métodos DFT passam a ser mais computacionalmente eficientes a medida que aumentamos o tamanho do sistema em relação a esses outros.

Outra conclusão interessante é que as estruturas obtidas nos diferentes níveis de cálculo utilizados, B3LYP/6-311++G(d,p) e MP2/aug-cc-pVDZ, não fornecem diferenças significativas nos resultados calculados. Portanto este estudo comprova, para as moléculas estudadas, a razão para a popularidade do uso de B3LYP em cálculos de optimização de geometria $[79,80]$. Outro fato que chama a atenção é que CIS(D) e M06-2X, mesmo sendo métodos que em comparação com o EOM-CCSD são muito menos custosos computacionalmente, são capazes de produzir, em alguns dos casos estudados, resultados razoavelmente concordantes com o EOM-CCSD para os valores das três primeiras energias de excitação.

É importante aqui chamarmos atenção para o fato de que esta é apenas uma analise primária, onde estamos olhando apenas para os três primeiros estados excitados. As comparações feitas com os resultados experimentais são simples e rudimentares. Ao fazermos essas comparações imprecisões experimentais e outros fatores não foram 
levadas em consideração, o que não deve ser feito em uma comparação mais rigorosa, onde o maior número de fatores possíveis para justificar discrepâncias entre os resultados devem ser considerados. Além disso, os resultados experimentais são obtidos em uma determinada temperatura finita, e nossos cálculos teóricos foram feitos para estruturas fixas e optimizadas, o que corresponderia a uma temperatura de zero Kelvin. Portanto, para uma melhor comparação, o ideal seria realizar dinâmicas moleculares a uma temperatura compatível com a experimental para a inclusão de efeitos térmicos e de ensamble.

Apesar desses fatos, este estudo já nos fornece um bom panorama dos aspectos desse tipo de estudo teórico, incluindo imprecisões e limitações envolvidas. Por exemplo, podemos ver nos nossos resultados a ocorrência de algo comum em trabalhos teóricos: os diversos métodos utilizados fornecem diferentes resultados. Além disso, um método que fornece o melhor resultado para um sistema ou excitação pode não fornecer o melhor resultado para um outro sistema ou excitação. As razões para isso podem variar desde a maneira como a medida experimental é obtida ${ }^{2}$, também pelo fato de alguns efeitos relevantes poderem não estar sendo levados em consideração no tratamento e no modelo teórico ${ }^{3}$, e até mesmo devido a maneira como os métodos teóricos são concebidos ${ }^{4}$.

\footnotetext{
${ }^{2}$ É possível que o resultado experimental possua imprecisões ou incertezas associadas, que podem levar a melhor concordância com um resultado e, mudando essas imprecisões, levar a melhor concordância com um outro resultado.

${ }^{3}$ Assim então o resultado teórico pode não refletir a situação experimental. Exemplos de fatores que podem ocorrer e não estarem sendo levados em consideração no tratamento teórico são: a possível formação de agregados, a possível quebra ou formação de ligações químicas, e até mesmo a estrutura modelada teoricamente não corresponder a conformação preferencial que a molécula adquiri nas condições em que o resultado experimental é obtido.

${ }^{4}$ As aproximações utilizadas na construção de um dado método podem ser boas para o estudo de um dado sistema e propriedade, e não tão boas para outros casos. No caso de métodos híbridos DFT, por exemplo, essa problemática é ainda mais pronunciada devido a natureza da construção dos funcionais, que possuem parametrizações específicas e fixas para tratar a contribuição de cada interação (ver seção 2.3.5).
} 


\section{Apêndice B}

\section{Resultados Adicionais para Porfirinas Isoladas}

Neste apêndice apresentamos resultados adicionais para Porfirinas isoladas. Dentre os resultados apresentados estão resultados para a Porfirina complexada com Magnésio e para a Porfirina complexada com Zinco para orbitais moleculares, para valores das energias de excitação e forças de oscilador incluindo análise das transições eletrônicas para diferentes métodos. Também são apresentados outros resultados como as coordenadas das geometrias optimizadas do monômero e dos dímeros de $\mathrm{H}_{2}$-Porfirina. Os resultados apresentados neste apêndice são todos referenciados no decorrer da seção 3.1 do capitulo 3 de resultados. 


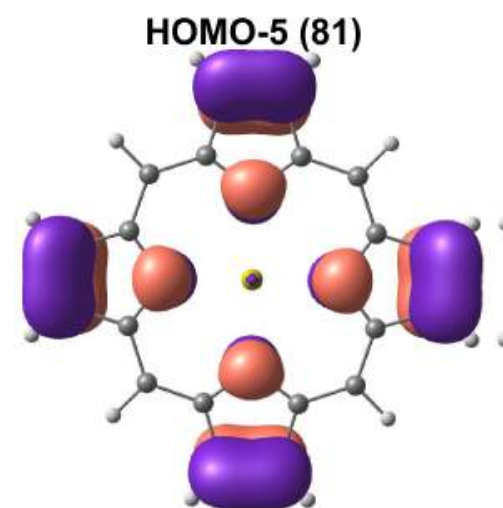

HOMO-2 (84)
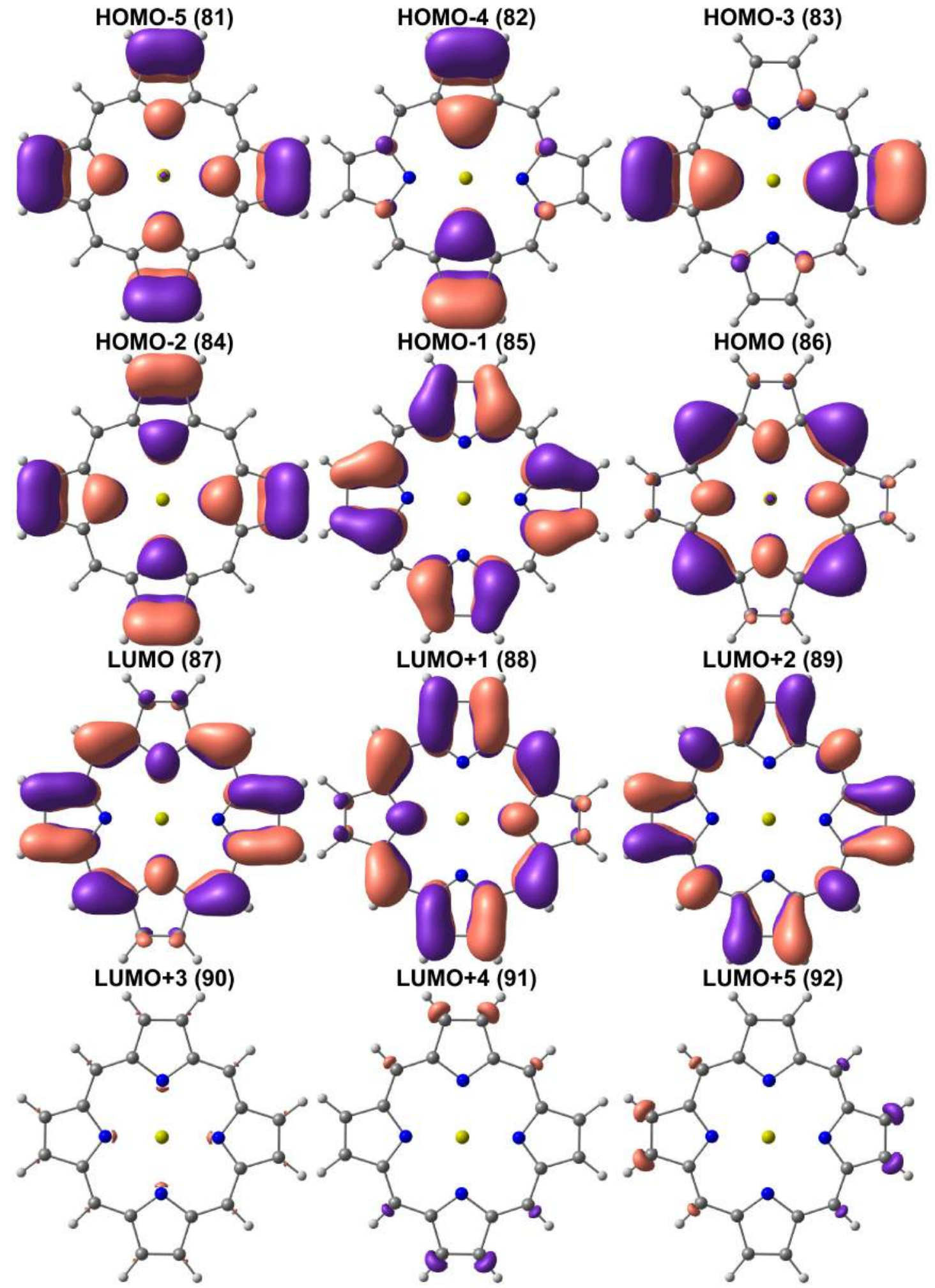

Figura B.1: Alguns orbitais moleculares da Mg-Porfirina. Esses orbitais foram obtidos a partir do cálculo B3LYP $/ 6-311++\mathrm{G}(\mathrm{d}, \mathrm{p})$. 

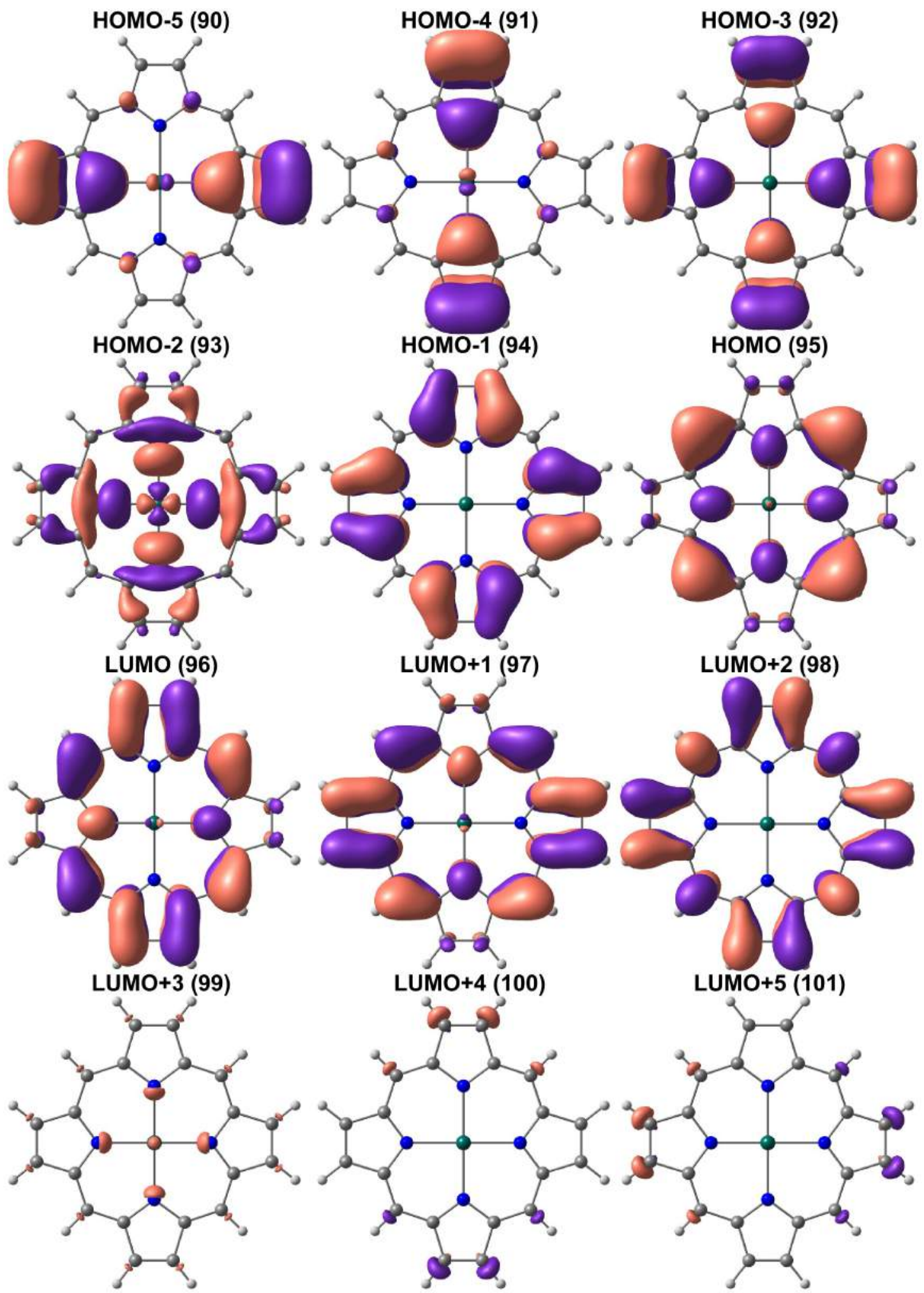

Figura B.2: Alguns orbitais moleculares da Zn-Porfirina. Esses orbitais foram obtidos a partir do cálculo B3LYP/6-311++G(d,p). 
Tabela B.1: Dois primeiros estados excitados da molécula Mg-Porfirina isolada utilizando vários métodos com a base 6-311++ $\mathrm{G}(\mathrm{d}, \mathrm{p})$ (exceto ZINDO/CIS). $\Delta E$ é a energia de excitação dada em eV,$\lambda$ é o comprimento de onda correspondente dado em $\mathrm{nm}$, e $f$ é a força de oscilador. As transições envolvidas são mostradas, e a contribuição delas para cada excitação é mostrada em parênteses. O orbital HOMO é numerado como 86 .

\begin{tabular}{|c|c|c|c|c|}
\hline Método & $\Delta E$ & $\lambda$ & $f$ & Transições envolvidas \\
\hline TD-DFT & 2,3488 & 527,9 & 0,0007 & $85 \rightarrow 87(46 \%), 86 \rightarrow 88(50 \%)$ \\
\hline (B3LYP) & 2,3488 & 527,9 & 0,0007 & $85 \rightarrow 88(46 \%), 86 \rightarrow 87(50 \%)$ \\
\hline TD-DFT & 2,2841 & 542,8 & 0,0034 & $85 \rightarrow 88(48 \%), 86 \rightarrow 87(52 \%)$ \\
\hline (CAM-B3LYP) & 2,2841 & 542,8 & 0,0034 & $85 \rightarrow 87(48 \%), 86 \rightarrow 88(52 \%)$ \\
\hline TD-DFT & 2,3209 & 534,2 & 0,0002 & $85 \rightarrow 87(46 \%), 86 \rightarrow 88(53 \%)$ \\
\hline (O3LYP) & 2,3209 & 534,2 & 0,0002 & $85 \rightarrow 88(46 \%), 86 \rightarrow 87(53 \%)$ \\
\hline TD-DFT & 2,2471 & 551,8 & 0 & $\begin{array}{l}85 \rightarrow 87(28 \%), 85 \rightarrow 88(16 \%), \\
86 \rightarrow 87(20 \%), 86 \rightarrow 88(35 \%)\end{array}$ \\
\hline (BP86) & $\begin{array}{l}----- \\
2,2471\end{array}$ & 551,8 & 0 & $\begin{array}{l}\overline{8} 5 \rightarrow \overline{8} 7(\overline{1} 6 \%), \overline{8} 5 \rightarrow \overline{8} 8(\overline{2} 8 \%), \\
86 \rightarrow 87(35 \%), 86 \rightarrow 88(20 \%)\end{array}$ \\
\hline TD-DFT & 2,3708 & 523,0 & 0,0033 & $\begin{array}{l}85 \rightarrow 87(4 \%), 85 \rightarrow 88(45 \%) \\
86 \rightarrow 87(47 \%), 86 \rightarrow 88(4 \%)\end{array}$ \\
\hline$(\mathrm{M} 06-2 \mathrm{X})$ & 2,3708 & 523,0 & 0,0033 & $\begin{array}{c}8 \overline{5} \stackrel{-}{\rightarrow} \overline{7}(45 \%), 8 \overline{5} \rightarrow \overline{8} \overline{8}(4 \%), \\
86 \rightarrow 87(4 \%), 86 \rightarrow 88(47 \%)\end{array}$ \\
\hline TD-DFT & 2,0307 & 610,5 & 0,0058 & $\begin{array}{l}85 \rightarrow 87(40 \%), 85 \rightarrow 88(4 \%), \\
86 \rightarrow 87(5 \%), 86 \rightarrow 88(47 \%)\end{array}$ \\
\hline (LC-wPBE) & 2,0307 & 610,5 & 0,0058 & $\begin{array}{l}85 \stackrel{-}{\rightarrow} 87(4 \%), 85 \rightarrow 88(40 \%) \\
86 \rightarrow 87(47 \%), 86 \rightarrow 88(5 \%)\end{array}$ \\
\hline \multirow[t]{2}{*}{ TD-HF } & & 508,5 & 0,0385 & $\begin{array}{c}85 \rightarrow 88(37 \%), 86 \rightarrow 87(55 \%), \\
86 \rightarrow 88(2 \%) \\
85-8 \overline{8}(2 \overline{7} \% 5-8 \overline{6}-8 \overline{7}(\sigma \%)-\end{array}$ \\
\hline & 2,4385 & 508,5 & & $86 \rightarrow 88(55 \%)$ \\
\hline \multirow{2}{*}{ CIS(D) } & 2,6895 & 461,0 & 0,0385 & $85 \rightarrow 88(38 \%), 86 \rightarrow 87(58 \%)$ \\
\hline & 2,6895 & 461,0 & 0,0385 & $85 \rightarrow 87(38 \%), 86 \rightarrow 88(58 \%)$ \\
\hline \multirow{2}{*}{ ZINDO/CIS } & 1,9475 & 636,6 & 0,0564 & $\begin{array}{c}85 \rightarrow 88(25 \%), 86 \rightarrow 87(44 \%), \\
86 \rightarrow 88(17 \%)\end{array}$ \\
\hline & 1,9475 & 636,6 & 0,0564 & $\begin{array}{c}85 \rightarrow \overline{8}(\overline{25 \%),}, \overline{8} \overline{6} \rightarrow \overline{8} 7(\overline{1} 7 \%), \\
86 \rightarrow 88(44 \%)\end{array}$ \\
\hline
\end{tabular}


Tabela B.2: Algumas excitações não nulas fora da região do visível da molécula Mg-Porfirina isolada utilizando vários métodos com a base 6-311++G(d,p) (exceto ZINDO/CIS). Os estados que estão no meio dos apresentados e não aparecem na tabela tem força de oscilador nula. $\Delta E$ é a energia de excitação dada em $\mathrm{eV}, \lambda$ é o comprimento de onda correspondente dado em nm, e $f$ é a força de oscilador. As transições envolvidas são mostradas, e a contribuição delas para cada excitação é mostrada em parênteses. O orbital HOMO é numerado como 86.

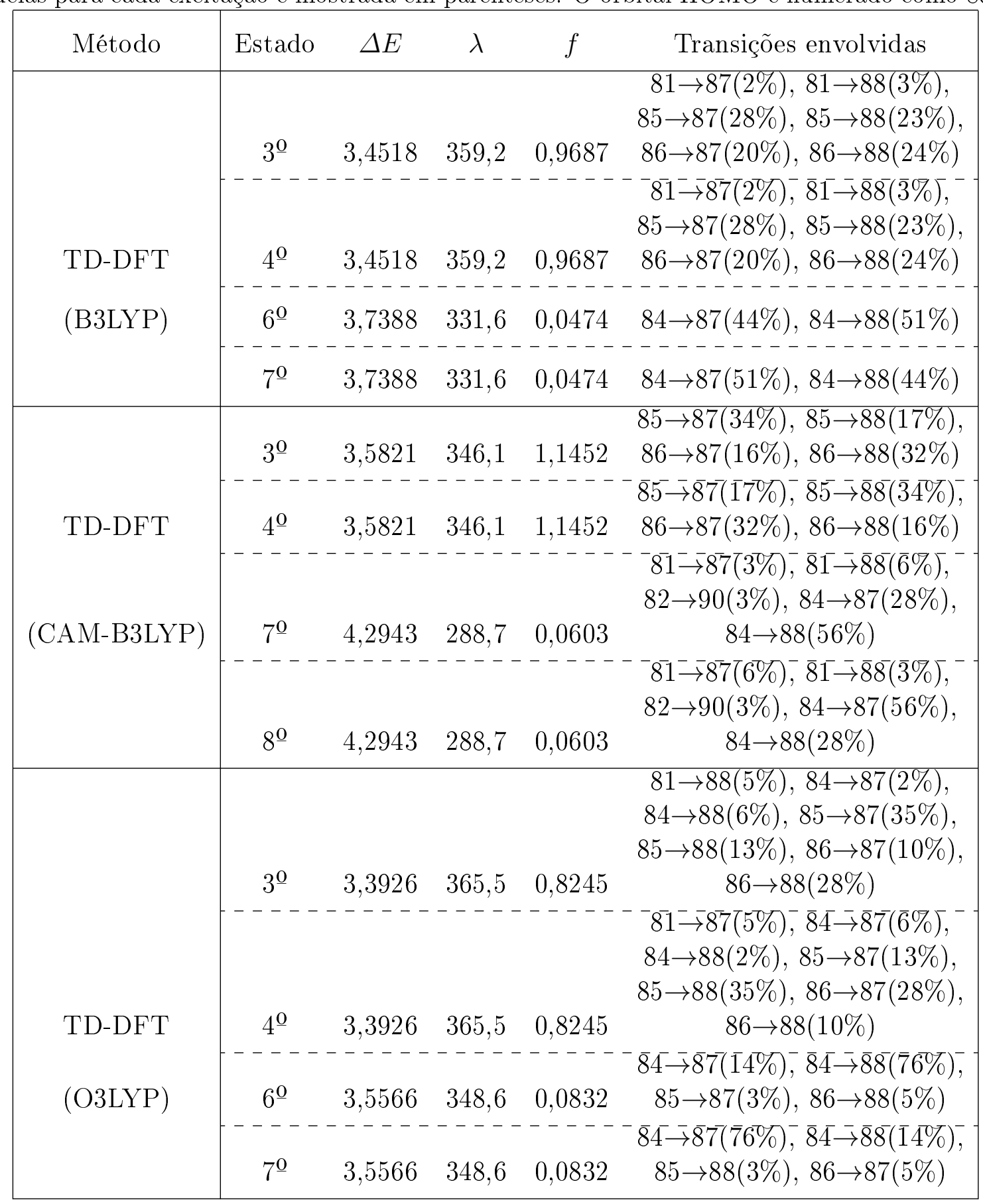




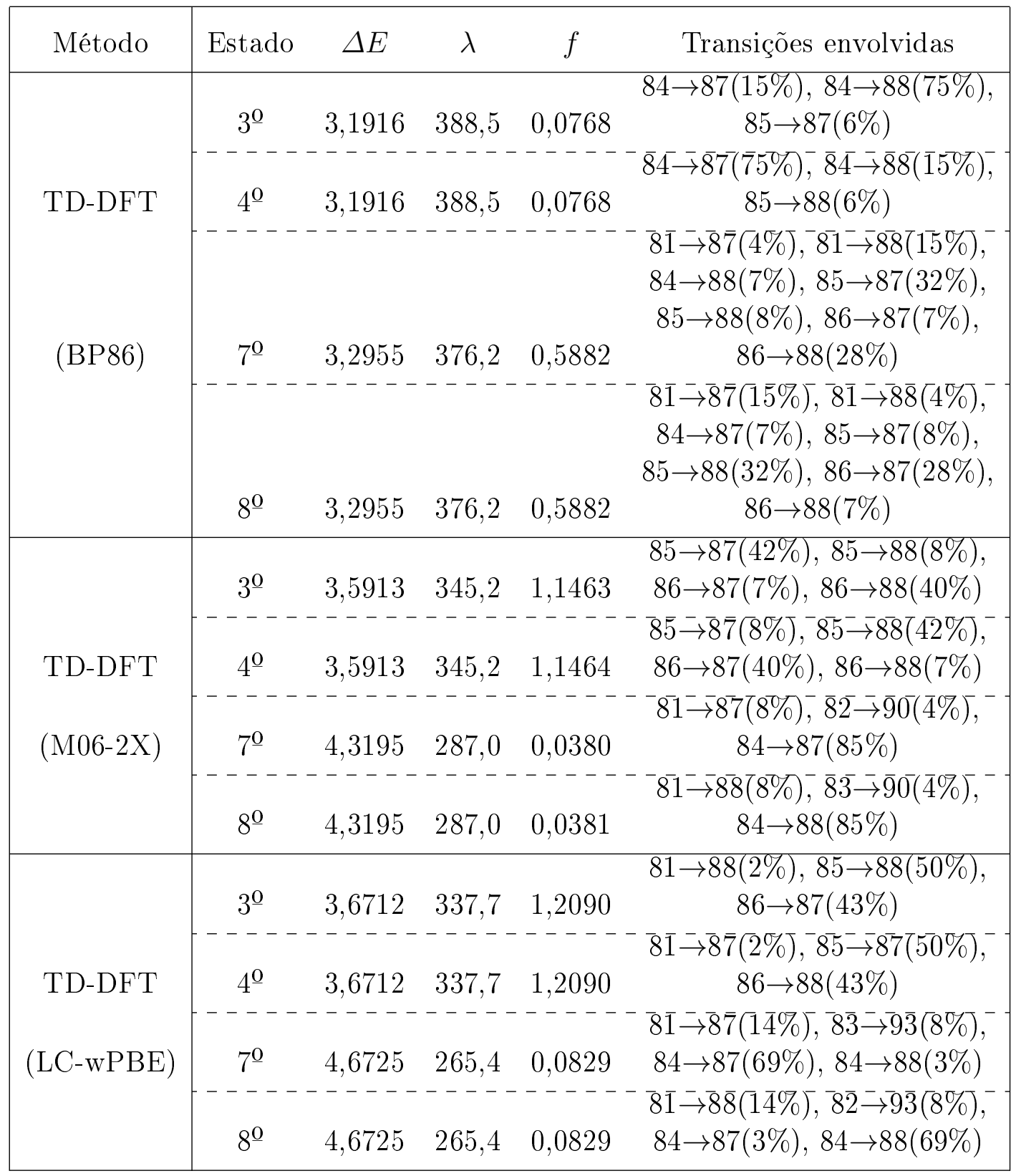




\begin{tabular}{|c|c|c|c|c|c|}
\hline Método & Estado & $\Delta E$ & $\lambda$ & $f$ & Transições envolvidas \\
\hline \multirow{4}{*}{ TD-HF } & $4^{\underline{0}}$ & 4,5865 & 270,3 & 2,7270 & $\begin{array}{c}81 \rightarrow 88(4 \%), 85 \rightarrow 87(4 \%), \\
85 \rightarrow 88(50 \%), 86 \rightarrow 87(32 \%) \\
86 \rightarrow 88(3 \%)\end{array}$ \\
\hline & & & & & $\overline{8} \overline{1} \rightarrow \overline{8} \overline{7}(4 \%), 85 \rightarrow 87(50 \%)$, \\
\hline & $5^{\mathrm{O}}$ & 4,5865 & 270,3 & 2,7270 & $86 \rightarrow 88(32 \%)$ \\
\hline & $9^{\underline{0}}$ & 4,9013 & 253,0 & 0,0018 & $\begin{array}{c}85 \rightarrow \overline{8} 9(67 \%), 85 \rightarrow \overline{9} 5(\overline{2} 1 \%), \\
85 \rightarrow 109(8 \%)\end{array}$ \\
\hline \multirow{3}{*}{ CIS(D) } & $4^{\underline{0}}$ & 3,3897 & 365,8 & 2,7265 & $\begin{array}{c}81 \rightarrow 87(4 \%), 85 \rightarrow 87(54 \%) \\
86 \rightarrow 88(35 \%)\end{array}$ \\
\hline & $5^{\mathrm{o}}$ & 3,3897 & 365,8 & 2,7265 & $\begin{array}{c}81 \rightarrow 8 \overline{8}(4 \%), 85 \rightarrow 88(54 \%) \\
86 \rightarrow 87(35 \%)\end{array}$ \\
\hline & $9^{\underline{0}}$ & 4,5068 & 275,1 & 0,0018 & $\begin{array}{c}85 \rightarrow 89(67 \%), 85 \rightarrow \overline{9} 5(21 \%), \\
85 \rightarrow 109(8 \%)\end{array}$ \\
\hline \multirow{4}{*}{ ZINDO/CIS } & $3^{0}$ & 3,5064 & 365,8 & 2,4019 & $85 \rightarrow 87(51 \%), 86 \rightarrow 88(30 \%)$ \\
\hline & $4^{0}$ & 3,5064 & 365,8 & 2,4019 & $85 \rightarrow 88(51 \%), 86 \rightarrow 87(30 \%)$ \\
\hline & $8^{0}$ & 4,2753 & 290,0 & 0,0786 & $82 \rightarrow 87(18 \%), 82 \rightarrow 88(56 \%)$ \\
\hline & $9^{\underline{0}}$ & 4,2753 & 290,0 & 0,0786 & $82 \rightarrow 87(56 \%), 82 \rightarrow 88(18 \%)$ \\
\hline
\end{tabular}


Tabela B.3: Estados excitados da molécula Mg-Porfirina isolada no nível CIS(D)/6$311++\mathrm{G}(\mathrm{d}, \mathrm{p}) . \Delta E$ é a energia de excitação dada em eV, $\lambda$ é o comprimento de onda correspondente dado em nm, e $f$ é a força de oscilador. As transições envolvidas são mostradas, e a contribuição delas para cada excitação é mostrada em parênteses. O orbital HOMO é numerado como 86.

\begin{tabular}{|c|c|c|c|c|}
\hline & $\Delta E$ & $\lambda$ & $f$ & Transições envolvidas \\
\hline $1^{0}$ Estado & 2,6895 & 461,0 & 0,0385 & $85 \rightarrow 88(38 \%), 86 \rightarrow 87(58 \%)$ \\
\hline $2^{\underline{O}}$ Estado & 2,6895 & 461,0 & 0,0385 & $85 \rightarrow 87(38 \%), 86 \rightarrow 88(58 \%)$ \\
\hline $3^{0}$ Estado & 4,7892 & 258,9 & 0 & $86 \rightarrow 89(72 \%), 86 \rightarrow 95(19 \%), 86 \rightarrow 109(6 \%)$ \\
\hline $4^{\underline{0}}$ Estado & 3,3897 & 365,8 & 2,7265 & $81 \rightarrow 87(4 \%), 85 \rightarrow 87(54 \%), 86 \rightarrow 88(35 \%)$ \\
\hline $5^{\underline{0}}$ Estado & 3,3897 & 365,8 & 2,7265 & $81 \rightarrow 88(4 \%), 85 \rightarrow 88(54 \%), 86 \rightarrow 87(35 \%)$ \\
\hline $6^{\underline{0}}$ Estado & 5,1940 & 238,7 & 0 & $86 \rightarrow 92(91 \%), 86 \rightarrow 108(7 \%)$ \\
\hline $7^{0}$ Estado & 5,1854 & 239,1 & 0 & $86 \rightarrow 90(90 \%), 86 \rightarrow 98(3 \%), 86 \rightarrow 115(3 \%)$ \\
\hline $8^{0}$ Estado & 5,1854 & 239,1 & 0 & $86 \rightarrow 91(90 \%), 86 \rightarrow 99(3 \%), 86 \rightarrow 116(3 \%)$ \\
\hline $9^{\underline{0}}$ Estado & 4,5068 & 275,1 & 0,0018 & $85 \rightarrow 89(67 \%), 85 \rightarrow 95(21 \%), 85 \rightarrow 109(8 \%)$ \\
\hline $10^{0}$ Estado & 5,5000 & 225,4 & 0 & $86 \rightarrow 89(22 \%), 86 \rightarrow 95(71 \%), 86 \rightarrow 109(2 \%)$ \\
\hline $11^{0}$ Estado & 4,8798 & 254,1 & 0 & $85 \rightarrow 92(87 \%), 85 \rightarrow 108(10 \%)$ \\
\hline $12^{\mathrm{O}}$ Estado & 5,5075 & 225,1 & 0 & $86 \rightarrow 93(95 \%)$ \\
\hline
\end{tabular}


Tabela B.4: Estados excitados correspondentes as bandas $Q$ da molécula Zn-Porfirina isolada calculados utilizando vários métodos com a base 6-311++G(d,p) (exceto ZINDO/CIS). $\Delta E$ é a energia de excitação dada em eV $\lambda$ é o comprimento de onda correspondente dado em $\mathrm{nm}$, e $f$ é a força de oscilador. As transições envolvidas são mostradas, e a contribuição delas para cada excitação é mostrada em parênteses. O orbital HOMO é numerado como 95.

\begin{tabular}{|c|c|c|c|c|}
\hline Método & $\Delta E$ & $\lambda$ & $f$ & Transições envolvidas \\
\hline TD-DFT & 2,3964 & 517,4 & 0,0022 & $94 \rightarrow 96(50 \%), 95 \rightarrow 97(50 \%)$ \\
\hline (B3LYP) & 2,3965 & 517,4 & 0,0022 & $94 \rightarrow 97(50 \%), 95 \rightarrow 96(50 \%)$ \\
\hline TD-DFT & 2,3371 & 530,5 & 0,0063 & $94 \rightarrow 97(46 \%), 95 \rightarrow 96(54 \%)$ \\
\hline (CAM-B3LYP) & 2,3372 & 530,5 & 0,0062 & $94 \rightarrow 96(46 \%), 95 \rightarrow 97(54 \%)$ \\
\hline TD-DFT & 2,3663 & 524,0 & 0,0011 & $94 \rightarrow 96(48 \%), 95 \rightarrow 97(51 \%)$ \\
\hline (O3LYP) & 2,3663 & 524,0 & 0,0011 & $94 \rightarrow 97(48 \%), 95 \rightarrow 96(51 \%)$ \\
\hline TD-DFT & 2,2978 & 539,6 & 0,0002 & $94 \rightarrow 96(46 \%), 95 \rightarrow 97(53 \%)$ \\
\hline (BP86) & 2,2985 & 539,4 & 0,0002 & $94 \rightarrow 97(46 \%), 95 \rightarrow 96(53 \%)$ \\
\hline TD-DFT & 2,4209 & 512,1 & 0,0064 & $94 \rightarrow 97(46 \%), 95 \rightarrow 96(53 \%)$ \\
\hline$(\mathrm{M} 06-2 \mathrm{X})$ & 2,4210 & 512,1 & 0,0063 & $94 \rightarrow 96(46 \%), 95 \rightarrow 97(53 \%)$ \\
\hline TD-DFT & 2,0960 & 591,5 & 0,0090 & $94 \rightarrow 97(42 \%), 95 \rightarrow 96(54 \%)$ \\
\hline (LC-wPBE) & 2,0962 & 591,5 & 0,0089 & $94 \rightarrow 96(42 \%), 95 \rightarrow 97(54 \%)$ \\
\hline \multirow{2}{*}{ TD-HF } & 2,4805 & 499,8 & 0,0452 & $94 \rightarrow 97(37 \%), 95 \rightarrow 96(59 \%)$ \\
\hline & 2,4806 & 499,8 & 0,0450 & $94 \rightarrow 96(37 \%), 95 \rightarrow 97(59 \%)$ \\
\hline \multirow{2}{*}{ CIS(D) } & 2,7444 & 451,8 & 0,0452 & $94 \rightarrow 97(37 \%), 95 \rightarrow 96(59 \%)$ \\
\hline & 2,7446 & 451,7 & 0,0450 & $94 \rightarrow 96(37 \%), 95 \rightarrow 97(59 \%)$ \\
\hline \multirow{2}{*}{ ZINDO/CIS } & 1,2344 & 1004,4 & 0,1667 & $95 \rightarrow 96(87 \%)$ \\
\hline & 1,2346 & 1004,3 & 0,1666 & $95 \rightarrow 97(87 \%)$ \\
\hline
\end{tabular}


Tabela B.5: Algumas excitações não nulas além das bandas $Q$ da molécula Zn-Porfirina isolada calculadas utilizando vários métodos com a base 6-311++G(d,p) (exceto ZINDO/CIS). Os estados que estão no meio dos apresentados e não aparecem na tabela tem força de oscilador nula. $\Delta E$ é a energia de excitação dada em eV, $\lambda$ é o comprimento de onda correspondente dado em nm, e $f$ é a força de oscilador. As transições envolvidas são mostradas, e a contribuição delas para cada excitação é mostrada em parênteses. O orbital HOMO é numerado como 95.

\begin{tabular}{|c|c|c|c|c|c|}
\hline Método & Estado & $\Delta E$ & $\lambda$ & $f$ & Transições envolvidas \\
\hline \multirow{4}{*}{$\begin{array}{l}\text { TD-DFT } \\
\text { (B3LYP) }\end{array}$} & $3^{\underline{0}}$ & 3,4711 & 357,2 & 0,9494 & $\begin{array}{c}89 \rightarrow 96(3 \%), 92 \rightarrow 96(3 \%), \\
94 \rightarrow 97(47 \%), 95 \rightarrow 96(45 \%)\end{array}$ \\
\hline & $4^{\mathrm{O}}$ & 3,4711 & 357,2 & 0,9496 & $\begin{array}{c}\overline{8} \overline{9} \rightarrow \overline{9} 7(\overline{3} \%), \overline{9}{ }^{-} \rightarrow 9 \overline{7}(3 \%), \\
94 \rightarrow 96(47 \%), 95 \rightarrow 97(45 \%)\end{array}$ \\
\hline & $9^{\underline{O}}$ & 3,7855 & 327,5 & 0,0374 & $92 \rightarrow 96(95 \%), 95 \rightarrow 96(3 \%)$ \\
\hline & $10^{\underline{0}}$ & 3,7859 & 327,5 & 0,0372 & $92 \rightarrow 97(95 \%), 95 \rightarrow 97(3 \%)$ \\
\hline \multirow{4}{*}{ (CAM-B3LYP) } & $3^{\underline{0}}$ & 3,6069 & 343,7 & 1,1025 & $\begin{array}{c}89 \rightarrow 96(2 \%), 94 \rightarrow 96(51 \%) \\
95 \rightarrow 97(45 \%)\end{array}$ \\
\hline & $4^{\underline{O}}$ & 3,6069 & 343,7 & 1,1026 & $\begin{array}{c}89 \rightarrow 97(2 \%), \overline{9} \rightarrow \overline{9} 7(51 \%) \\
95 \rightarrow 96(45 \%)\end{array}$ \\
\hline & $9^{\underline{0}}$ & 4,3444 & 285,4 & 0,0497 & $\begin{array}{c}\overline{8} \overline{9} \rightarrow(\overline{8} \%), \overline{9} \rightarrow \overline{9} \overline{9}(5 \%) \\
93 \rightarrow 96(83 \%)\end{array}$ \\
\hline & $10^{\underline{O}}$ & 4,3451 & 285,4 & 0,0496 & $\begin{array}{c}\overline{8} \overline{9} \rightarrow \overline{9}(\overline{8} \%), \overline{9} \rightarrow \overline{9} \overline{9}(5 \%) \\
93 \rightarrow 97(83 \%)\end{array}$ \\
\hline \multirow{4}{*}{ TD-DFT } & $5^{\underline{0}}$ & 3,4127 & 363,3 & 0,8352 & $\begin{array}{c}89 \rightarrow 96(5 \%), 92 \rightarrow 96(7 \%), \\
94 \rightarrow 97(46 \%), 95 \rightarrow 96(40 \%)\end{array}$ \\
\hline & $6^{-0}$ & 3,4128 & 363,3 & 0,8357 & $\begin{array}{c}\overline{8} \overline{9} \rightarrow \overline{9} 7(5 \%), \overline{9} \stackrel{-}{\rightarrow} \overline{9}(\overline{7} \%), \\
94 \rightarrow 96(46 \%), 95 \rightarrow 97(40 \%)\end{array}$ \\
\hline & $9^{\underline{0}}$ & 3,6002 & 344,4 & 0,0658 & $\begin{array}{c}92 \rightarrow 96(92 \%), 94 \rightarrow 97(2 \%) \\
95 \rightarrow 96(5 \%)\end{array}$ \\
\hline & $10^{\mathrm{O}}$ & 3,6005 & 344,4 & 0,0653 & $\begin{array}{c}92 \rightarrow 97(92 \%), 94 \rightarrow 96(2 \%) \\
95 \rightarrow 97(5 \%)\end{array}$ \\
\hline
\end{tabular}




\begin{tabular}{|c|c|c|c|c|c|}
\hline Método & Estado & $\Delta E$ & $\lambda$ & $f$ & \multirow{5}{*}{ 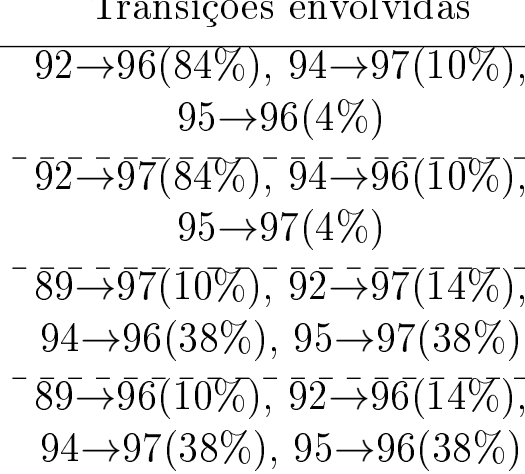 } \\
\hline \multirow{4}{*}{ TD-DFT } & $6^{\underline{0}}$ & 3,2330 & 383,5 & 0,1221 & \\
\hline & $7^{\underline{0}}$ & 3,2333 & 383,5 & 0,1228 & \\
\hline & $10^{\mathrm{O}}$ & 3,3310 & 372,2 & 0,6017 & \\
\hline & $11^{\underline{0}}$ & 3,3310 & 372,2 & 0,6018 & \\
\hline \multirow{4}{*}{$\begin{array}{l}\text { TD-DFT } \\
(\mathrm{M} 06-2 \mathrm{X})\end{array}$} & $3^{0}$ & 3,6197 & 342,5 & 1,1125 & \multirow{4}{*}{$\begin{array}{c}94 \rightarrow 96(53 \%), 95 \rightarrow 97(47 \%) \\
94 \leftarrow 96(2 \%), 95 \leftarrow 97(2 \%) \\
\overline{9} 4-\overline{9} 7(53 \%), \overline{9} 5 \rightarrow \overline{9} 6(\overline{4} 7 \%) \\
94 \leftarrow 97(2 \%), 95 \leftarrow 96(2 \%) \\
-\overline{89} \rightarrow \overline{9} \overline{6}(8 \%), \overline{9} \overline{2} \bar{\rightarrow} \overline{9} \overline{9}(\overline{4} \%), \\
93 \rightarrow 96(86 \%) \\
-\overline{89} \rightarrow 9 \overline{7}(8 \%), \overline{9} \overline{1} \rightarrow \overline{9} \overline{9}(\overline{4} \%), \\
93 \rightarrow 97(86 \%)\end{array}$} \\
\hline & $4^{\mathrm{O}}$ & 3,6198 & 342,5 & 1,1118 & \\
\hline & $9^{\underline{0}}$ & 4,3653 & 284,0 & 0,0321 & \\
\hline & $10^{\underline{O}}$ & 4,3660 & 284,0 & 0,0320 & \\
\hline \multirow{4}{*}{$\begin{array}{c}\text { TD-DFT } \\
\text { (LC-wPBE) }\end{array}$} & $3^{0}$ & 3,7045 & 334,7 & 1,1652 & $94 \rightarrow 96(53 \%), 95 \rightarrow 97(42 \%)$ \\
\hline & $4^{\mathrm{O}}$ & 3,7046 & 334,7 & 1,1651 & $94 \rightarrow 97(53 \%), 95 \rightarrow 96(42 \%)$ \\
\hline & $9^{\underline{O}}$ & 4,7258 & 262,4 & 0,0705 & \multirow{2}{*}{ 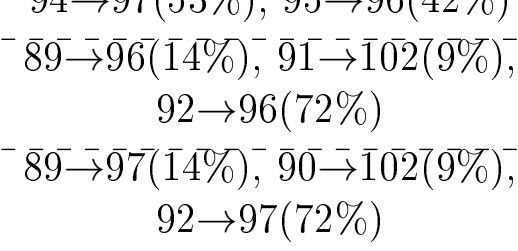 } \\
\hline & $10^{\underline{O}}$ & 4,7266 & & 0,0704 & \\
\hline
\end{tabular}




\begin{tabular}{|c|c|c|c|c|c|}
\hline Método & Estado & $\Delta E$ & $\lambda$ & $f$ & Transições envolvidas \\
\hline \multirow{4}{*}{ TD-HF } & $4^{\underline{0}}$ & 4.6149 & 268.7 & 2.6826 & $\begin{array}{c}90 \rightarrow 96(3 \%), 94 \rightarrow 96(55 \%), \\
95 \rightarrow 97(34 \%)\end{array}$ \\
\hline & $5^{\underline{0}}$ & 4,6150 & 268,7 & 2,6828 & $\begin{array}{c}\overline{90} \rightarrow \overline{9} 7(\overline{3 \%}), \overline{9} \overline{4} \rightarrow \overline{9} \overline{7}(5 \overline{5} \%), \\
95 \rightarrow 96(34 \%)\end{array}$ \\
\hline & $8^{\underline{0}}$ & 5,0229 & 246,8 & 0,0032 & $94 \rightarrow 119(7 \%)$ \\
\hline & $16^{\underline{\mathrm{O}}}$ & 5,4143 & 229,0 & 0,2123 & $\begin{array}{l}\overline{90} \rightarrow \overline{9} \overline{6}(1 \overline{5} \%),{ }^{-} \overline{9} \stackrel{-}{\rightarrow} 1 \overline{0} \overline{9}(6 \%) \\
92 \rightarrow 118(2 \%), 93 \rightarrow 96(68 \%)\end{array}$ \\
\hline \multirow{3}{*}{ CIS(D) } & $4^{\underline{0}}$ & 3,4135 & 363,2 & 2,6828 & $\begin{array}{c}90 \rightarrow 96(3 \%), 94 \rightarrow 96(55 \%), \\
95 \rightarrow 97(34 \%)\end{array}$ \\
\hline & $5^{\underline{\underline{O}}}$ & 3,4136 & 363,2 & 2,6828 & $\begin{array}{c}90 \rightarrow 97(3 \%), \overline{9} \rightarrow \overline{9} \overline{7}(55 \%), \\
95 \rightarrow 96(34 \%)\end{array}$ \\
\hline & $8^{\underline{0}}$ & 4,6164 & 268,6 & 0,0033 & $\begin{array}{c}\overline{94} \rightarrow 98(69 \%), 94 \rightarrow 103(20 \%), \\
94 \rightarrow 119(7 \%)\end{array}$ \\
\hline \multirow{3}{*}{ ZINDO/CIS } & $6^{\underline{0}}$ & 1,4620 & 848,1 & 0,0205 & $94 \rightarrow 98(88 \%)$ \\
\hline & $7^{0}$ & 1,4621 & 848,0 & 0,0204 & $93 \rightarrow 98(88 \%)$ \\
\hline & $11^{\mathrm{O}}$ & 2,2267 & 556,8 & 0,0023 & $92 \rightarrow 98(89 \%)$ \\
\hline
\end{tabular}


Tabela B.6: Estados excitados da molécula Zn-Porfirina isolada no nível CIS(D)/6$311++\mathrm{G}(\mathrm{d}, \mathrm{p}) . \Delta E$ é a energia de excitação dada em eV, $\lambda$ é o comprimento de onda correspondente dado em nm, e $f$ é a força de oscilador. As transições envolvidas são mostradas, e a contribuição delas para cada excitação é mostrada em parênteses. O orbital HOMO é numerado como 95.

\begin{tabular}{|c|c|c|c|c|}
\hline & $\Delta E$ & $\lambda$ & $f$ & Transições envolvidas \\
\hline $1^{0}$ Estado & 2,7444 & $\begin{array}{l}451,8 \\
----\end{array}$ & 0,0452 & 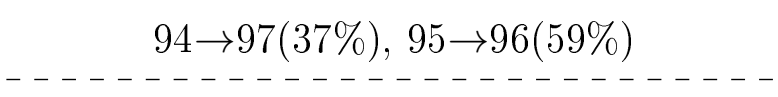 \\
\hline $2^{\mathrm{O}}$ Estado & 2,7446 & 451,7 & 0,0450 & $94 \rightarrow 96(37 \%), 95 \rightarrow 97(59 \%)$ \\
\hline $3^{\underline{0}}$ Estado & 4,8371 & 256,3 & 0 & $95 \rightarrow 98(73 \%), 95 \rightarrow 103(19 \%), 95 \rightarrow 119(6 \%)$ \\
\hline $4^{\mathrm{O}}$ Estado & 3,4135 & $\begin{array}{l}363,2 \\
---\ldots\end{array}$ & 2,6828 & $90 \rightarrow 96(3 \%), 94 \rightarrow 96(55 \%), 95 \rightarrow 97(34 \%)$ \\
\hline $5^{\mathrm{o}}$ Estado & 3,4136 & 363,2 & 2,6828 & $90 \rightarrow 97(3 \%), 94 \rightarrow 97(55 \%), 95 \rightarrow 96(34 \%)$ \\
\hline $6^{\underline{Q}}$ Estado & 5,2234 & 237,4 & 0 & 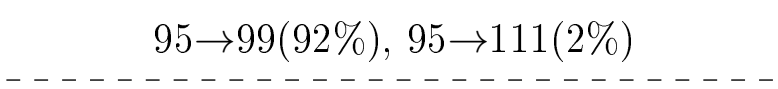 \\
\hline $\begin{array}{l}7^{0} \text { Estado } \\
------\end{array}$ & 5,2234 & 237,4 & 0 & 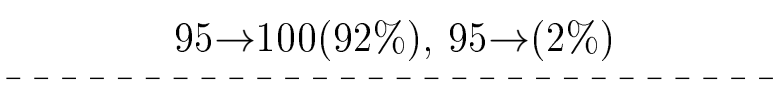 \\
\hline $8^{0}$ Estado & 4,6164 & $\begin{array}{l}268,6 \\
----\end{array}$ & 0,0033 & $94 \rightarrow 98(69 \%), 94 \rightarrow 103(20 \%), 94 \rightarrow 119(7 \%)$ \\
\hline $9^{0}$ Estado & 5,5460 & 223,6 & 0 & $95 \rightarrow 98(21 \%), 95 \rightarrow 103(72 \%)$ \\
\hline $10^{0}$ Estado & 5,5086 & 225,1 & 0 & $95 \rightarrow 101(95 \%)$ \\
\hline $11^{0}$ Estado & 4,2092 & 294,6 & 0 & $\begin{array}{l}\overline{9} \overline{1} \rightarrow \overline{9} \overline{7}(\overline{3} \overline{3} \%)^{-}, \overline{9} \overline{2} \rightarrow \overline{9} \overline{6}(3 \overline{5} \%) \\
93 \rightarrow 109(6 \%), 95 \rightarrow 108(21 \%)\end{array}$ \\
\hline $12^{\mathrm{O}}$ Estado & 4,0819 & 303,7 & 0 & $\begin{aligned} & \overline{9} \overline{0} \rightarrow \overline{1} \overline{0} 9(\overline{7} \%), \overline{9} \bar{\longrightarrow} \rightarrow \overline{1} \overline{1} \overline{2}(\overline{2} \%) \\
& 91 \rightarrow 97(44 \%), 92 \rightarrow 96(43 \%)\end{aligned}$ \\
\hline
\end{tabular}



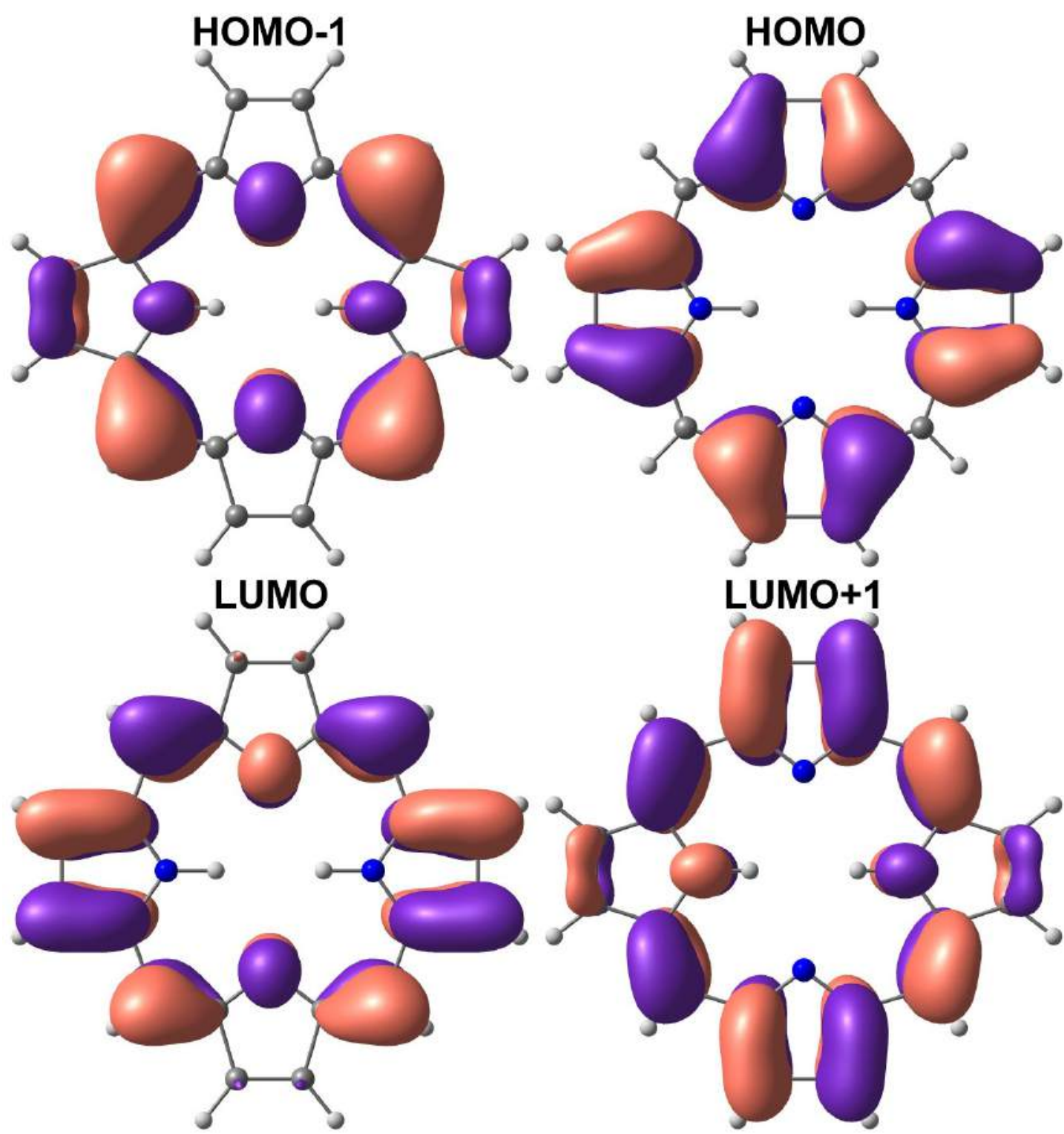

Figura B.3: Alguns orbitais moleculares Hartree-Fock da $H_{2}$-Porfirina obtidos a partir do cálculo HF /6-311++G(d,p). 
Tabela B.7: Comparação de resultados para as energias de excitação da Mg-Porfirina, que são dadas em eV, para as bandas $Q$, a banda de Soret e também a banda $N$. Devido a simetria da molécula, as bandas $Q, B$ e $N$ que são desdobradas para a $H_{2}$-Porfirina, aqui são degeneradas.

\begin{tabular}{|c|c|c|c|c|}
\hline Método & Referência & $Q$ & $B$ & $N$ \\
\hline Experimental & {$[30,101,102]^{a}$} & 2,2 & 3,1 & - \\
\hline TD-DFT (B3LYP) & Este Trabalho & 2,35 & 3,45 & 3,74 \\
\hline TD-DFT (CAM-B3LYP) & Este Trabalho & 2,28 & 3,58 & 4,29 \\
\hline TD-DFT (O3LYP) & Este Trabalho & 2,32 & 3,39 & 3,56 \\
\hline TD-DFT (BP86) & Este Trabalho & 2,24 & 3,19 & 3,29 \\
\hline TD-DFT (M06-2X) & Este Trabalho & 2,37 & 3,59 & 4,31 \\
\hline TD-DFT (LC-wPBE) & Este Trabalho & 2,03 & 3,67 & 4,67 \\
\hline TD-HF & Este Trabalho & 2,43 & 4,58 & 4,86 \\
\hline ZINDO/CIS & Este Trabalho & 1,95 & 3,51 & 4,27 \\
\hline CIS(D) & Este Trabalho & 2,69 & 3,39 & 4,51 \\
\hline CIS & [103] & 2,52 & 4,69 & 5,57 \\
\hline $\mathrm{RPA}$ & [103] & 1,89 & 4,06 & 5,42 \\
\hline TD-DFT (B3LYP) & [103] & 2,47 & 3,60 & 3,96 \\
\hline ZINDO/CIS & {$[103]$} & 1,97 & 3,63 & 4,50 \\
\hline SAC-CI & [104] & 1,68 & 3,29 & 3,81 \\
\hline CASPT2 & {$[104]$} & 2,15 & 3,41 & 3,61 \\
\hline
\end{tabular}

${ }^{a}$ Sundholm [13] diz que o espectro experimental da Mg-Porphyrin foi medido por Yalman e Spaulding $[30,101]$ nos anos 60 , mas nunca foi publicado, e os valores correspondentes aos primeiros picos são $572 \mathrm{~nm}, 539 \mathrm{~nm}$ e $401 \mathrm{~nm}$. Sundholm também cita um trabalho de Starukhin [102] onde é reportado um valor de $2.2 \mathrm{eV}$ para a primeira banda. 
Tabela B.8: Coordenadas das estruturas optimizadas de monômero e dímeros de $H_{2}$-Porfirina apresentados no decorrer da seção 3.1. O monômero foi obtido no nível B3LYP $/ 6-31+\mathrm{G}(\mathrm{d}, \mathrm{p})$ e os dímeros no nível wB97XD/6-31G*.

\begin{tabular}{|c|c|c|c|c|c|c|c|c|c|}
\hline \multirow[b]{2}{*}{ Átomo } & \multicolumn{3}{|c|}{ Monômero } & \multicolumn{3}{|c|}{ Dímero (a) } & \multicolumn{3}{|c|}{ Dímero (b) } \\
\hline & $\mathrm{X}$ & $\mathrm{Y}$ & I Z & $\mathrm{X}$ & $\mathrm{Y}$ & Z & $\mathrm{X}$ & Y & Z \\
\hline $\mathrm{C} 1$ & $\begin{array}{r}-2,8976968 \\
-\end{array}$ & | & 0,0 & $-1,122997$ & $\begin{array}{r}2,878145 \\
-\end{array}$ & 1,788092 & $-2,992645$ & 1,923617 & 1,154691 \\
\hline $\mathrm{C} 2$ & $-2,8976968$ & $-1,13096588$ & 0,0 & 1,123321 & 2,878015 & 1,788093 & $-2,744703$ & 0,505185 & $-0,456346$ \\
\hline $\mathrm{C} 3$ & $-4,2635654$ & $-0,68664721$ & 0,0 & 0,683005 & 4,239659 & 1,814020 & $-4,182546$ & 0,683396 & $-0,280583$ \\
\hline $\mathrm{C} 4$ & $-4,2635654$ & 0,68664721 & 0,0 & $-0,682523$ & ו 4,239738 & 1,814020 & $-4,337779$ & 1,569567 & 0,729633 \\
\hline N5 & $-2,1184659$ & | 0,00000000 & 0,0 & 0,000117 & 2,102171 & 1,769883 & $-2,058759$ & 1,269480 & 0,426338 \\
\hline $\mathrm{H} 6$ & $-5,1200249$ & 1,34778334 & 0 & $-1,345950$ & 5,093882 & 1,829144 & $-5,254548$ & 1,960194 & 1,152416 \\
\hline & & $-1-------$ & & & & & & & \\
\hline $\begin{array}{l}\mathrm{H} 7 \\
---\end{array}$ & $\begin{array}{l}-5,1200249 \\
--\ldots--~\end{array}$ & $\begin{array}{l}\mathbf{1}-1,34778334 \\
-\mid-\ldots-\ldots-\end{array}$ & $\begin{array}{rl}1 & 0,0 \\
-1 & -\end{array}$ & $\begin{array}{r}1,346529 \\
-\quad-\quad-\quad-\end{array}$ & $\begin{array}{r}1,093728 \\
+\quad--\end{array}$ & $\begin{array}{l}1,829144 \\
+ \\
+\end{array}$ & $\begin{array}{l}-4,949886 \\
--\ldots-\end{array}$ & $\begin{array}{r}0,181856 \\
-1-+-\end{array}$ & 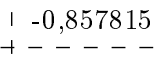 \\
\hline $\mathrm{C} 8$ & $-2,4239346$ & $\begin{array}{r}2,44365734 \\
-\end{array}$ & $\begin{array}{r}0,0 \\
- \\
-\end{array}$ & $-2,429593$ & $\begin{array}{r}2,410125 \\
+\quad-\end{array}$ & $\begin{array}{l}1,794780 \\
+\end{array}$ & $-2,674143$ & $\begin{array}{r}2,824073 \\
-\end{array}$ & $\begin{array}{r}2,177579 \\
-\end{array}$ \\
\hline $\begin{array}{l}\mathrm{H} 9 \\
--\ldots\end{array}$ & $-3,1820977$ & 3,22110740 & $\begin{array}{r}0,0 \\
- \\
-\end{array}$ & $\begin{array}{l}-3,207739 \\
-\ldots-\ldots\end{array}$ & $\begin{array}{r}3,167485 \\
+\ldots \\
-\end{array}$ & {$\left[\begin{array}{l}1,803145 \\
\perp\end{array}\right.$} & $-3,483364$ & $\begin{array}{r}3,313744 \\
-\end{array}$ & $\begin{array}{r}2,709171 \\
\perp\end{array}$ \\
\hline $\mathrm{C} 10$ & $-2,4239346$ & $\begin{array}{r}-2,44365734 \\
-\end{array}$ & \begin{tabular}{l}
0,0 \\
\hdashline
\end{tabular} & $\begin{array}{r}2,429865 \\
-\ldots-\ldots\end{array}$ & $\begin{array}{l}2,409847 \\
-\end{array}$ & $\begin{array}{l}1,794781 \\
-\end{array}$ & $\begin{array}{l}-2,208826 \\
-\ldots-\ldots-\end{array}$ & $\begin{array}{r}-0,341069 \\
\hdashline-\ldots\end{array}$ & $\begin{array}{l}-1,424999 \\
-\end{array}$ \\
\hline $\mathrm{C} 11$ & $-0,6790901$ & $\begin{array}{r}4,26452740 \\
-\end{array}$ & \begin{tabular}{l}
0,0 \\
\hdashline
\end{tabular} & $-4,237338$ & $\begin{array}{r}0,675020 \\
-\end{array}$ & $\begin{array}{l}1,808004 \\
-\end{array}$ & $-0,920562$ & $\begin{array}{r}4,012152 \\
-\end{array}$ & $\begin{array}{r}3,591595 \\
-\end{array}$ \\
\hline C12 & 1,08684316 & $\begin{array}{r}2,86114657 \\
-\end{array}$ & 0,0 & $-2,836929$ & $-1,077404$ & 1,793055 & 0,868856 & $\begin{array}{l}3,078881 \\
\end{array}$ & 2,552114 \\
\hline $\mathrm{C} 13$ & 0,67909013 & 4,26452740 & 0,0 & $-4,237413$ & $-0,674540$ & 1,808005 & 0,441251 & 3,973756 & 3,590647 \\
\hline $\mathrm{H} 14$ & $-1,3514955$ & 5,11327891 & 0,0 & $-5,082594$ & 1,351693 & $\begin{array}{l}T,---- \\
1,810302\end{array}$ & $-1,564999$ & 4,598369 & $\begin{array}{c}7---- \\
4,231271\end{array}$ \\
\hline $\mathrm{H} 15$ & 1,3514955 & I 5,11327891 & 0,0 & $\begin{array}{l}----- \\
-5,082746\end{array}$ & $\begin{array}{l}+----- \\
1-1,351118\end{array}$ & $\begin{array}{l}+------ \\
1,810302\end{array}$ & $\begin{array}{r}----- \\
1,117571\end{array}$ & 4,524471 & $\begin{array}{l}+----- \\
1 \quad 4,229405\end{array}$ \\
\hline $\mathrm{C} 16$ & $-1,0868431$ & $-2,86114657$ & 0,0 & 2,836929 & 1,077404 & I 1,793055 & $-0,875744$ & $-0,633$ & $\begin{array}{l}+---- \\
\\
-1,721361\end{array}$ \\
\hline $\mathrm{C} 17$ & 0,6790901 & $-4,26452740$ & 0,0 & 4,237338 & $-0,675020$ & 1,808004 & 0,855866 & $-1,581819$ & $-2,808203$ \\
\hline $\mathrm{C} 18$ & 1,08684316 & $-2,86114657$ & 0,0 & 2,836808 & $-1,077728$ & 1,793055 & 1,282372 & $-0,712111$ & $-1,724174$ \\
\hline $\mathrm{H} 19$ & $-3,1820977$ & $-3,22110740$ & 0,0 & 3,208096 & 3,167119 & 1,803146 & $-2,941001$ & $-0,854282$ & $-2,045729$ \\
\hline $\mathrm{N} 20$ & 0,00000000 & 2,03641593 & 0,0 & $-2,013518$ & 0,000116 & 1,785960 & $-0,265380$ & 2,608898 & 1,954702 \\
\hline $\mathrm{H} 21$ & $-1,1035989$ & : 0,00000000 & 0,0 & 0,000058 & 1,087696 & 1,743876 & $-0,407851$ & 1,948872 & 1,184633 \\
\hline $\mathrm{H} 22$ & 1,3514955 & $-5,11327891$ & 0,0 & 5,082594 & 1 $-1,351693$ & 1,810302 & 1,509297 & $-2,147588$ & $-3,460569$ \\
\hline $\mathrm{C} 23$ & $2,4239346 ?$ & $\begin{array}{l}- \\
\quad 2,44365734\end{array}$ & 0,0 & $-2,429865$ & ו $-2,409847$ & 1,794781 & 2,191098 & 2,765032 & $\begin{array}{c}----- \\
2,269826\end{array}$ \\
\hline $\mathrm{H} 24$ & 3,1820977 & 3,22110740 & 0,0 & $-3,208096$ & I $-3,167119$ & 1,803146 & 2,922643 & 3,291034 & 2,874115 \\
\hline $\mathrm{N} 25$ & 0,00000000 & | - $-2,03641593$ & 0,0 & 2,013518 & I $-0,000116$ & । 1,785960 & 0,220667 & । $-0,156393$ & $-1,091928$ \\
\hline $\mathrm{C} 26$ & $-0,6790901$ & । $-4,26452740$ & 0,0 & 4,237413 & 0,674540 & 1,808005 & $-0,496585$ & $-1,532612$ & $-2,806197$ \\
\hline $\mathrm{H} 27$ & $-1,3514955$ & $-5,11327891$ & 0,0 & 5,082746 & 1,351118 & 1,810302 & $-1,187406$ & $-2,051185$ & $-3,459900$ \\
\hline $\mathrm{C} 28$ & 2,8976968 & 1,13096588 & 0,0 & $-1,123321$ & $-2,878015$ & 1,788093 & 2,729823 & 1,897515 & 1,325853 \\
\hline $\mathrm{C} 29$ & 2,8976968 & $-1,13096588$ & 0,0 & 1,122997 & $-2,878145$ & $\begin{array}{l}1,788092 \\
1,4\end{array}$ & 2,978449 & 0,405279 & $-0,339284$ \\
\hline N30 & 2,11846598 & 0,00000000 & 0,0 & $-0,000117$ & $-2,102171$ & 1,769883 & 2,079321 & 1,110942 & 0,419935 \\
\hline H31 & 1,10359898 & 0,00000000 & | 0,0 & $-0,000058$ & I $-1,087696$ & 1,743876 & 1,083591 & & 0,212418 \\
\hline---- & & - - - - - - - - & & & & & & & \\
\hline C32 & 2,42393467 & | $-2,44365734$ & 0,0 & 2,429593 & I $-2,410125$ & | 1,794780 & 2,607753 & | $-0,456460$ & I -1,361090 \\
\hline
\end{tabular}




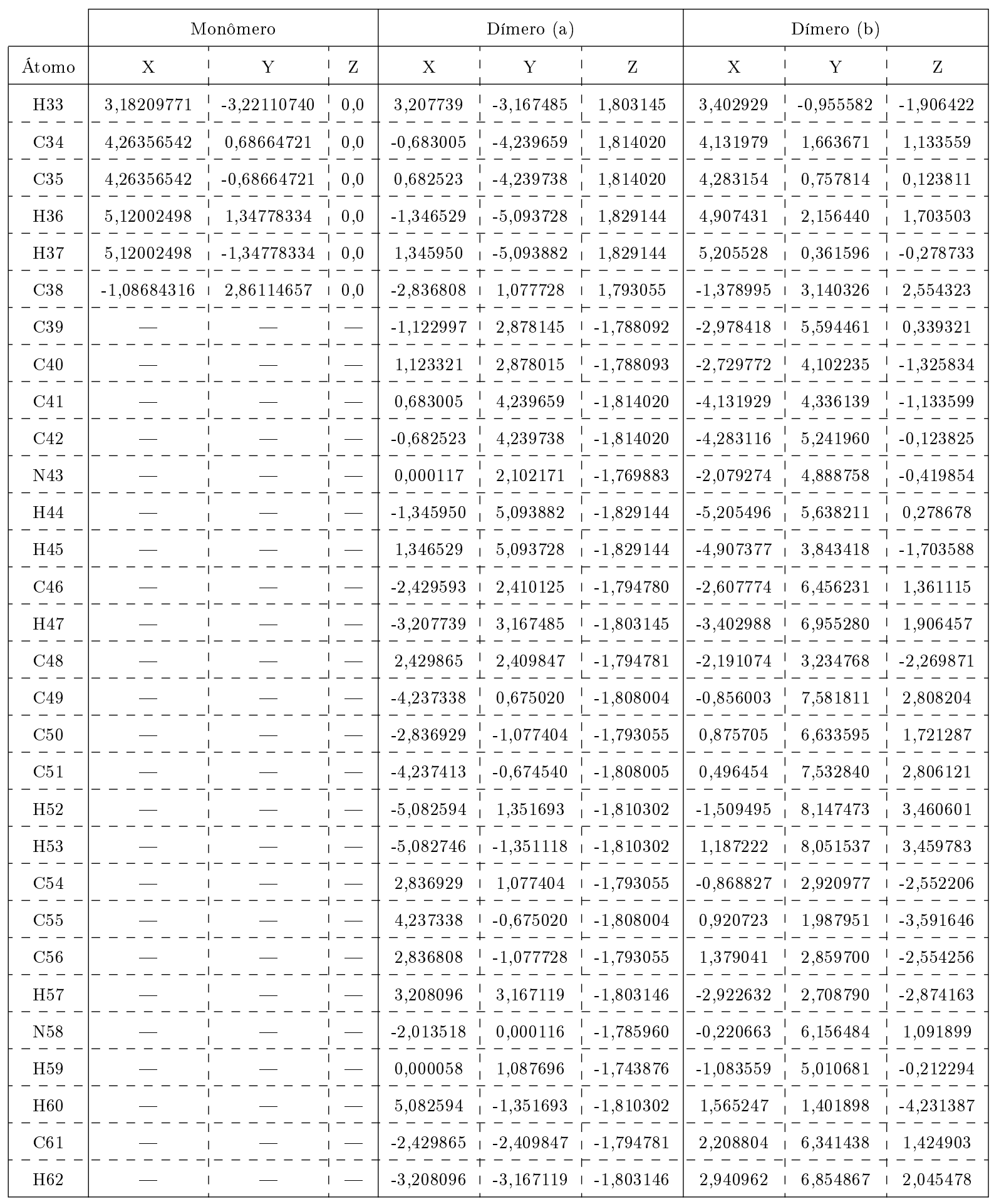




\begin{tabular}{|c|c|c|c|c|c|c|c|c|c|}
\hline \multirow[b]{2}{*}{ Átomo } & Monômero & \multicolumn{4}{|c|}{ Dímero (a) } & \multicolumn{4}{|c|}{ Dímero (b) } \\
\hline & $\begin{array}{l:l:l}X & Y & Z\end{array}$ & $\mathrm{X}$ & & $\mathrm{Y}$ & $\mathrm{Z}$ & $\mathrm{X}$ & $\mathrm{Y}$ & I & $\mathrm{Z}$ \\
\hline N63 & $-1-1-$ & 2,013518 & & $-0,000116$ & $-1,785960$ & 0,265335 & । 3,390999 & & $-1,954694$ \\
\hline & $--\frac{1}{1}--1-$ & & & & $\perp-----$ & & & & \\
\hline C64 & $-1-1-$ & 4,237413 & & 0,674540 & $-1,808005$ & $-0,441099$ & 2,026209 & & $-3,590770$ \\
\hline H65 & $-1-1-$ & 5,082746 & & 1,351118 & $-1,810302$ & $-1,117314$ & 1,475440 & & $-4,229591$ \\
\hline & $--\frac{1}{1}--\frac{1}{1}-$ & & & & $\frac{1}{1}----$ & ----- & ----- & & ----- \\
\hline C66 & $-1-1-$ & $-1,123321$ & & $-2,878015$ & $-1,788093$ & 2,744704 & 5,495016 & & 0,456404 \\
\hline---- & $--\frac{1}{1}-\Gamma-$ & ---- & & ----- & $T----$ & ----- & $1----$ & $\frac{1}{\top}$ & ---- \\
\hline C67 & $-1-1-$ & 1,122997 & & $-2,878145$ & | $-1,788092$ & 2,992612 & | 4,076313 & I & $-1,154382$ \\
\hline---- & $--\dagger--\vdash-$ & & & & +-- & & $1----$ & & \\
\hline N68 & $-1-1-$ & $-0,000117$ & I & $-2,1$ & । $-1,769883$ & 2,058747 & । 4,730432 & I & $-0,426014$ \\
\hline & $--+--1--$ & & & & & & $-1-$ & & \\
\hline H69 & $-1-1=$ & $-0,000058$ & 1 & $-1,087$ & $-1,74$ & 0,407484 & । 4,051135 & 1 & $-1,184$ \\
\hline-- & $\begin{array}{r}--1-1- \\
-1-1\end{array}$ & 2409503 & & -- & - & - - - - - & $\overline{1}--$ & & \\
\hline & $--\perp--\llcorner-$ & $\begin{array}{l}2,429593 \\
-----~\end{array}$ & & $-2,4$ & $\perp-1$ & $\begin{array}{l}2,674149 \\
-----\end{array}$ & -3, & 1 & $\begin{array}{l}-2,177331 \\
-\ldots-\ldots-\end{array}$ \\
\hline H71 & $-1-1-$ & 3,207739 & & $-3,167485$ & $-1,80$ & 3,483426 & 2,686324 & & $-2,708919$ \\
\hline & $--\frac{1}{1}--\frac{1}{1}-$ & & & & $\perp--$ & ----- & $1----$ & & ----- \\
\hline C72 & $-:-1-$ & $-0,683005$ & & $-4,239659$ & $-1,814020$ & 4,182554 & 5,316912 & & 0,280539 \\
\hline--- & $--\frac{1}{1}--$ & & & & $\frac{1}{1}---$ & --- & $--\cdots$ & & ----- \\
\hline C73 & $-1-1-$ & 0,682523 & & $-4,239738$ & $-1,814020$ & 4,337767 & 4,430539 & & $-0,729502$ \\
\hline & $-\tau--i$ & & & & $T--$ & & & & \\
\hline H74 & $-1-1-$ & $-1,346529$ & & $-5,093728$ & । $-1,829144$ & 4,949899 & । 5,818656 & & 0,857589 \\
\hline H75 & $-7--$ & & & --- & $T^{-}$ & ----- & $1----$ & & ----- \\
\hline $\mathrm{H} 75$ & $-1-$ & 1,345950 & & $-5,093882$ & | $-1,829144$ & 5,254524 & । 4,039903 & & $-1,152302$ \\
\hline $\mathrm{C} 76$ & $\begin{array}{r}-7--1- \\
-1-1-\end{array}$ & $\begin{array}{l}----- \\
-2,836808\end{array}$ & । & 0777 & $\begin{array}{ll}\top & - \\
1,79\end{array}$ & $-1,2824$ & 6,712050 & $\dagger$ & 24160 \\
\hline
\end{tabular}




\section{Apêndice C}

\section{Resultados Adicionais para Ftalocianinas}

Neste apêndice apresentamos resultados adicionais para Ftalocianinas. Inicialmente são apresentados na seção C.1 resultados teóricos para Ftalocianinas com Eugenóis como substituintes em solução, com análises acerca da influência dos substituintes e da inclusão de efeitos de solvente no espectro de absorção. Na seção C.2 apresentamos resultados referenciados no decorrer da seção 3.1 do capitulo 3 de resultados e também resultados referenciados na seção C.1 deste apêndice. Dentre os resultados apresentados nessa seção C.2 estão resultados para a Ftalocianina complexada com Zinco para orbitais moleculares, para valores das energias de excitação e forças de oscilador incluindo análise das transições eletrônicas para diferentes métodos, e também uma comparação de resultados incluindo com o resultado experimental. Também são apresentados outros resultados como as coordenadas das geometrias optimizadas do monômero e dos dimeros de $\mathrm{H}_{2}$-Ftalocianina. 


\section{C.1 Ftalocianinas com Eugenóis substituintes}

Apresentamos nesta seção uma análise para Ftalocianinas com Eugenóis substituintes. O espectro de absorção experimental em Clorofórmio para essas Ftalocianinas, complexadas de diferentes maneiras, foi obtido e reportado em um trabalho de E. A ğar et al. [93]. No artigo são apresentados os comprimentos de onda e as intensidades dos picos do espectro experimental. Na figura C.1 abaixo apresentamos a estrutura dessas moléculas, reportada em [93].

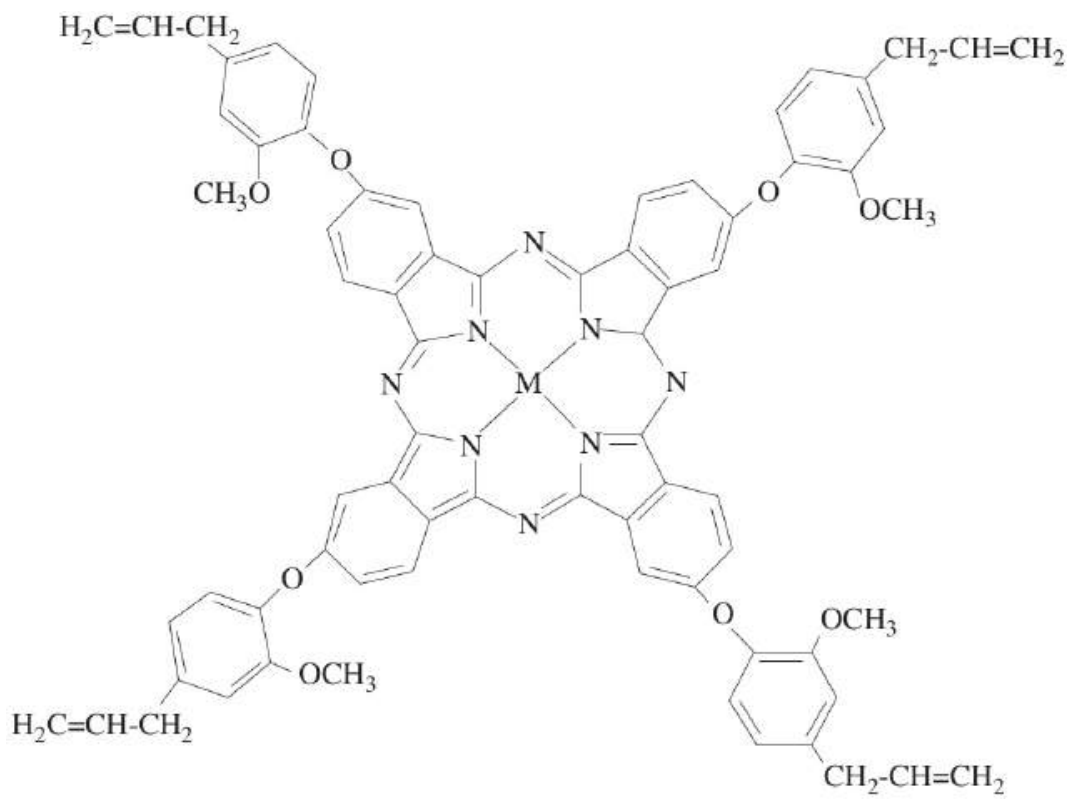

Figura C.1: Ftalocianinas com quatro moléculas de Eugenol como substituintes em suas extremidades, complexadas de diferentes maneiras. M representa o complexo. Esta figura foi retirada de [93]. No artigo existem resultados experimentais para M substituído por: dois átomos de hidrogênio, Cobre, Níquel, Cobalto, Zinco e Ferro.

Partindo dessa figura, construímos computacionalmente a estrutura dessa molécula na forma base livre (ou seja, quando M da figura C.1 é substituído por dois átomos de hidrogênio), chamada aqui de $H_{2}$-Ftalocianina-4Eug, e da molécula complexada com Zinco (quando M é substituído por Zn), chamada aqui de Zn-Ftalocianina-4Eug. Após construídas, as estruturas foram optimizadas no nível B3LYP/6-31G*. Esses 
cálculos foram feitos para as moléculas isoladas e também em meio Clorofórmio utilizando o modelo $\mathrm{PCM}^{1}$ para lidar com os efeitos de solvente. As estruturas dessas moléculas sem a presença de substituintes também foram obtidas, para uma análise da influência dos substituintes no espectro de absorção.

A primeira análise realizada para inferir sobre a influência dos eugenóis substituintes no espectro de absorção foi analisar o espectro de absorção, da $H_{2}$-Ftalocianina4Eug e da Zn-Ftalocianina-4Eug, com e sem os Eugenóis substituintes, e isoladas e em meio Clorofórmio. O nível de cálculo adotado foi o O3LYP $/ 6-31+\mathrm{G}^{*}$, onde o método O3LYP foi aqui uma escolha arbitrária. Nos cálculos feitos em meio Clorofórmio foi novamente utilizado o modelo PCM para tratar os efeitos de solvente no espectro de absorção. Nos cálculos de espectro com a inclusão de efeitos de solvente foram utilizadas as estruturas obtidas utilizando efeito de solvente na optimização, e nos cálculos de espectro para moléculas isoladas foram utilizadas as estruturas obtidas para as moléculas isoladas. Os resultados obtidos para a $H_{2}$-Ftalocianina-4Eug são mostrados na figura C.2 abaixo ${ }^{2}$.

A partir dos resultados mostrados na figura C.2 podemos ver que, para o caso da $H_{2}$-Ftalocianina-4Eug, a inclusão dos Eugenóis substituintes e também a inclusão de efeitos de solvente são relevantes para a caracterização do espectro de absorção ${ }^{3}$. Essa afirmação a cerca da importância da inclusão dos Eugenóis substituintes pode ser atestada ao analisarmos os orbitais moleculares da molécula com os substituintes. $\mathrm{Na}$ figura C.3 apresentamos alguns orbitais moleculares da $\mathrm{H}_{2}$-Ftalocianina-4Eug em meio Clorofórmio ${ }^{4}$.

Como podemos ver pela figura alguns dos orbitais importantes para a descrição

\footnotetext{
${ }^{1}$ Para maiores informações sobre o PCM e outros modelos de solvente contínuos recomendamos as referências [58, 105-107].

${ }^{2}$ Os resultados obtidos para a Zn-Ftalocianina-4Eug são mostrados na figura C.2 da seção C.2 deste apêndice.

${ }^{3} \mathrm{O}$ mesmo pode ser concluído a partir da figura C.8 para a Zn-Ftalocianina-4Eug.

${ }^{4}$ Orbitais para a Zn-Ftalocianina-4Eug também são apresentados na figura C.3.
} 


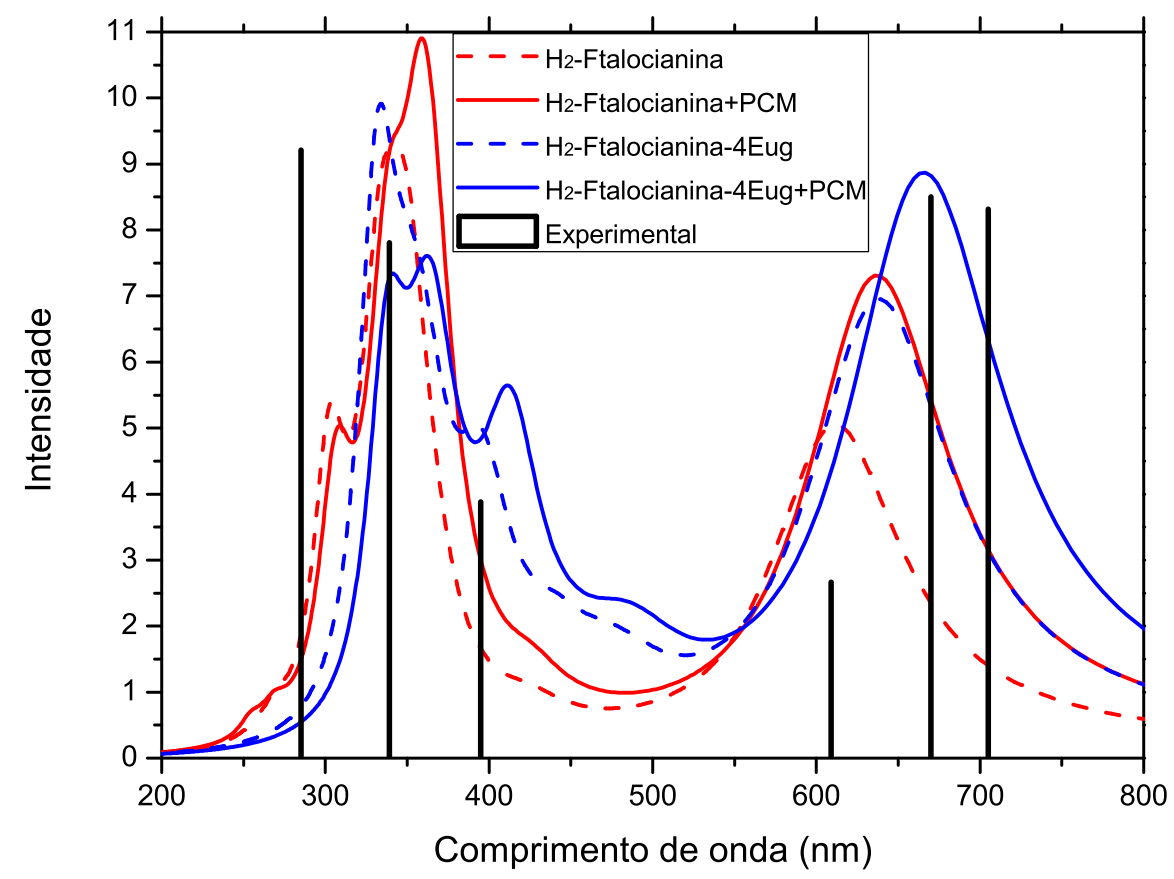

Figura C.2: Cálculo do espectro de absorção da molécula Ftalocianina Base Livre, com e sem os quatro Eugenóis substituintes, e com e sem a inclusão de efeitos de solvente. Os cálculos foram feitos no nível O3LYP /6-31+G*. Os efeitos de solvente em meio Clorofórmio, quando incluídos, foram incluídos utilizando o modelo PCM. O resultado experimental do espectro de absorção em Clorofórmio também é apresentado e foi retirado de [93]. Nesta figura optamos por não normalizar as curvas, apenas as barras referentes ao espectro experimental.

das transições eletrônicas do espectro de absorção da $H_{2}$-Ftalocianina-4Eug (orbitais mais próximos do HOMO e do LUMO) estão delocalizados nos Eugenóis substituintes, desse modo vemos que os substituintes tem realmente um papel fundamental na caracterização do espectro de absorção $0^{5}$.

Uma outra análise foi feita para inferir sobre a influência da rotação de um dos Eugenóis substituintes no espectro de absorção, no dipolo e na energia da molécula. Os cálculos foram feitos no nível O3LYP $/ 6-31+\mathrm{G}^{*}$, utilizando PCM em meio Cloro-

\footnotetext{
C.3.

${ }^{5}$ Essa conclusão pode ser estendida para a Zn-Ftalocianina-4Eug, a partir dos orbitais da figura
} 


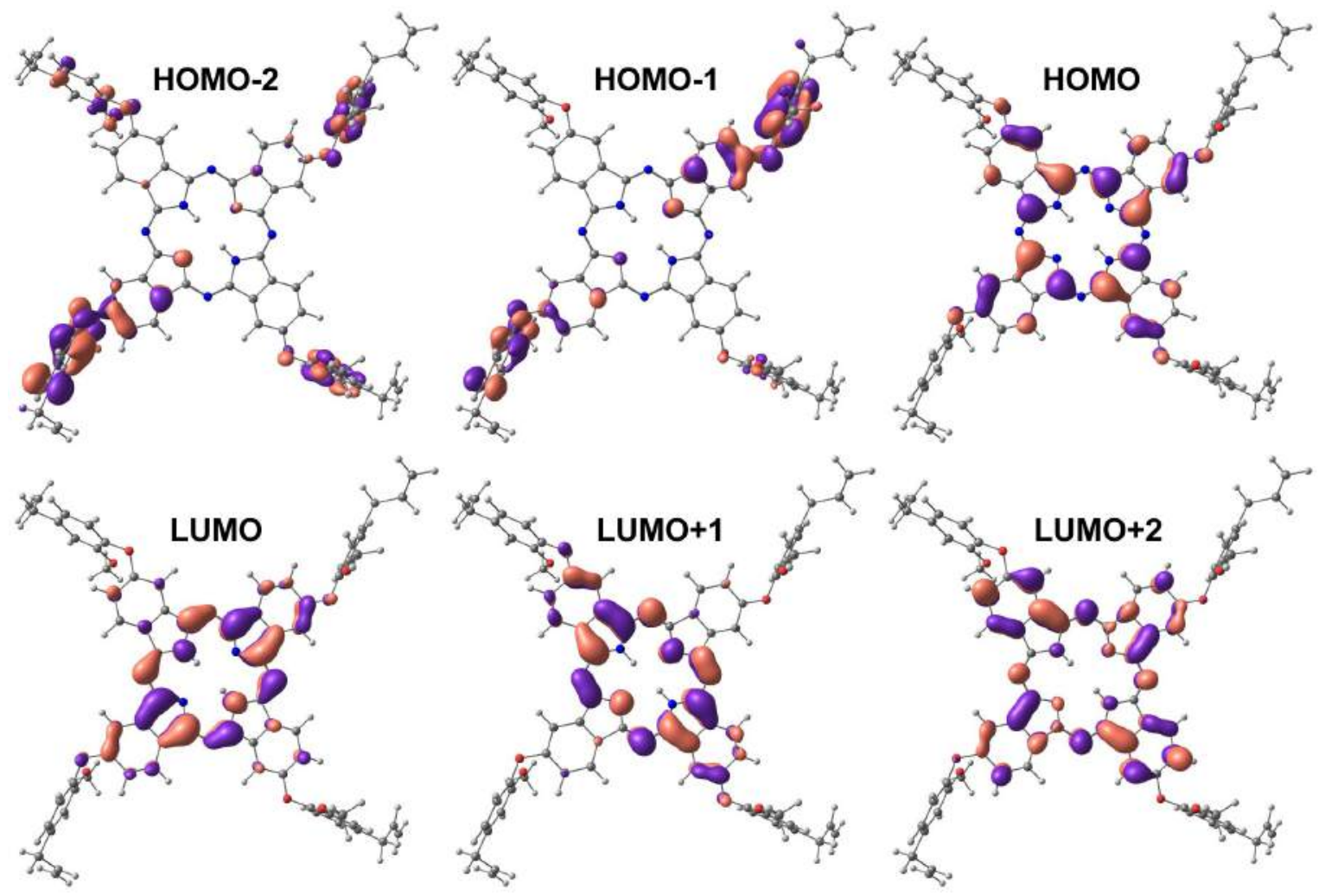

Figura C.3: Orbitais Moleculares da molécula Ftalocianina Base Livre com quatro Eugenóis substituintes, obtidos no nível O3LYP $/ 6-31+\mathrm{G}^{*}$, em meio Clorofórmio utilizando o modelo PCM.

fórmio. A rotação do Eugenol foi feita de duas maneiras diferentes. Como pode ser visto na figura C.1, existe um oxigênio intermediário entre um último carbono da Ftalocianina e o primeiro carbono de cada Eugenol. A primeira rotação, cujos resultados são apresentados na parte de cima da figura C.4, foi feita em torno do eixo que liga o último carbono da Ftalocianina e o oxigênio intermediário, e a segunda rotação, cujos resultados são apresentados na parte de baixo da figura C.4, foi feita em torno do eixo que liga o oxigênio intermediário e o primeiro carbono do Eugenol.

Analisando a figura C.4 vemos que a rotação de um dos Eugenóis substituintes é capaz de modificar bastante as características do espectro de absorção e o valor do dipolo, porém para a rotação acontecer é necessário superar uma barreira de energia 
correspondentes aos valores de $\Delta E$ apresentados, caso a molécula parta da geometria optimizada. Esses resultados apontam que a realização de, por exemplo, uma dinâmica molecular, para a inclusão de efeitos térmicos e de ensamble (amostragem) pode ser importante. A inclusão de efeitos de solvente explicito também pode ser importante e pode ser feita através de dinâmica molecular. Entretanto as análises feitas para este sistema nesta dissertação se encerraram aqui, devido ao tamanho do sistema. A $H_{2^{-}}$ Ftalocianina possui 58 átomos enquanto a $H_{2}$-Ftalocianina-4Eug possui 146 átomos, e esse tamanho grande da molécula implica em complicações relacionadas com altos custos computacionais nos cálculos envolvidos.

Uma sugestão fica aqui para trabalhos futuros envolvendo essas Ftalocianinas com Eugenóis substituintes é: realizar uma dinâmica molecular clássica usando como base para a parametrização do campo de força as constantes de força GROMOS 53A6 testadas e discutidas na subseção 3.2 do capítulo de resultados, e fazer os cálculos do espectro de absorção utilizando ZINDO/CIS. Infelizmente, devido ao tempo limitado de mestrado, essas contas não puderam ser feitas nesta dissertação. 


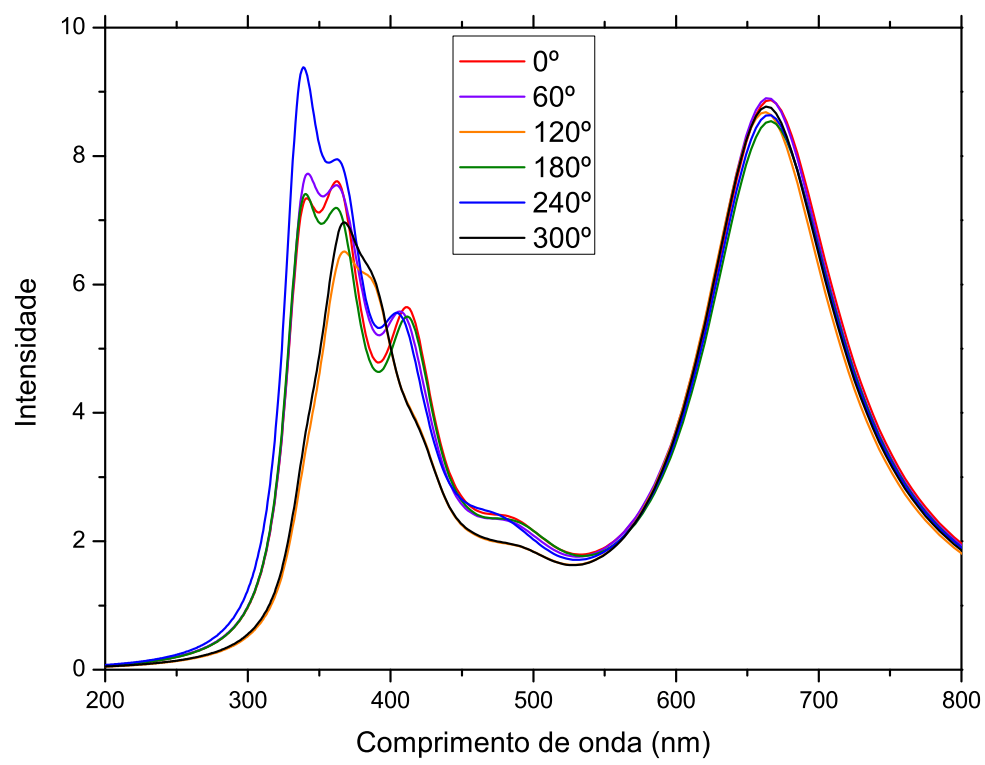

\begin{tabular}{ccc}
\hline Ângulo & Dipolo & $\Delta \mathrm{E}$ \\
\hline $0^{\underline{0}}$ & 0,19 & 0 \\
$60^{\underline{0}}$ & 5,57 & 5,40 \\
$120^{\underline{0}}$ & 6,15 & 3,37 \\
$180^{\underline{0}}$ & 5,67 & 24,10 \\
$240^{\underline{0}}$ & 3,68 & 4,79 \\
$300^{\underline{0}}$ & 3,14 & 11,39 \\
\hline
\end{tabular}

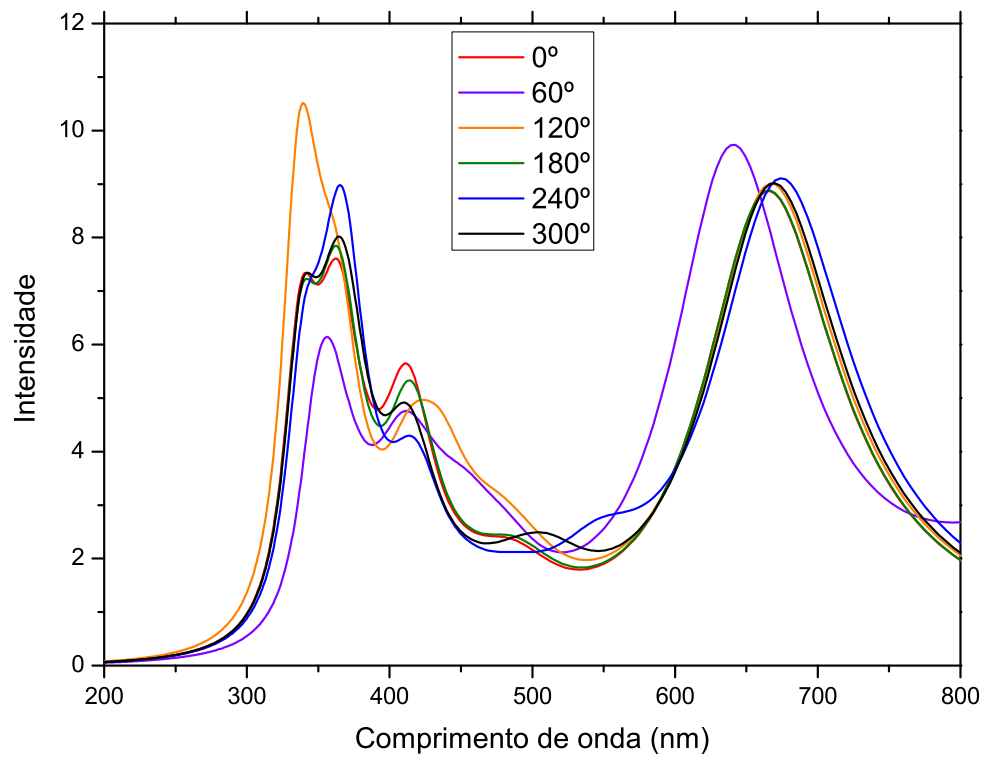

\begin{tabular}{ccc}
\hline Ângulo & Dipolo & $\Delta \mathrm{E}$ \\
\hline $0^{\underline{0}}$ & 0,19 & 0 \\
$60^{\underline{0}}$ & 9,85 & 189,26 \\
$120^{\mathrm{O}}$ & 3,18 & 189,26 \\
$180^{\mathrm{O}}$ & 2,67 & 1,32 \\
$240^{\mathrm{O}}$ & 2,31 & 45,24 \\
$300^{\mathrm{O}}$ & 1,16 & 10,23 \\
\hline & &
\end{tabular}

Figura C.4: Influência da rotação de um dos Eugenóis substituintes no espectro de absorção, no dipolo e na energia da molécula $H_{2}$-Ftalocianina-4Eug. Na parte de cima são apresentados resultados para a rotação em torno do eixo que liga o último carbono da Ftalocianina e o oxigênio intermediário entre a Ftalocianina e o Eugenol, e na parte de baixo para a rotação em torno do eixo que liga o primeiro carbono do Eugenol e o oxigênio intermediário. Os cálculos foram feitos no nível O3LYP/6-31+G* com PCM (Clorofórmio). O Dipolo é dado em Debye. $\Delta \mathrm{E}$ é a diferença de Energia em relação a estrutura mais estável, dada em $\mathrm{kcal} / \mathrm{mol}$. 


\section{C.2 Resultados referenciados durante a dissertação}

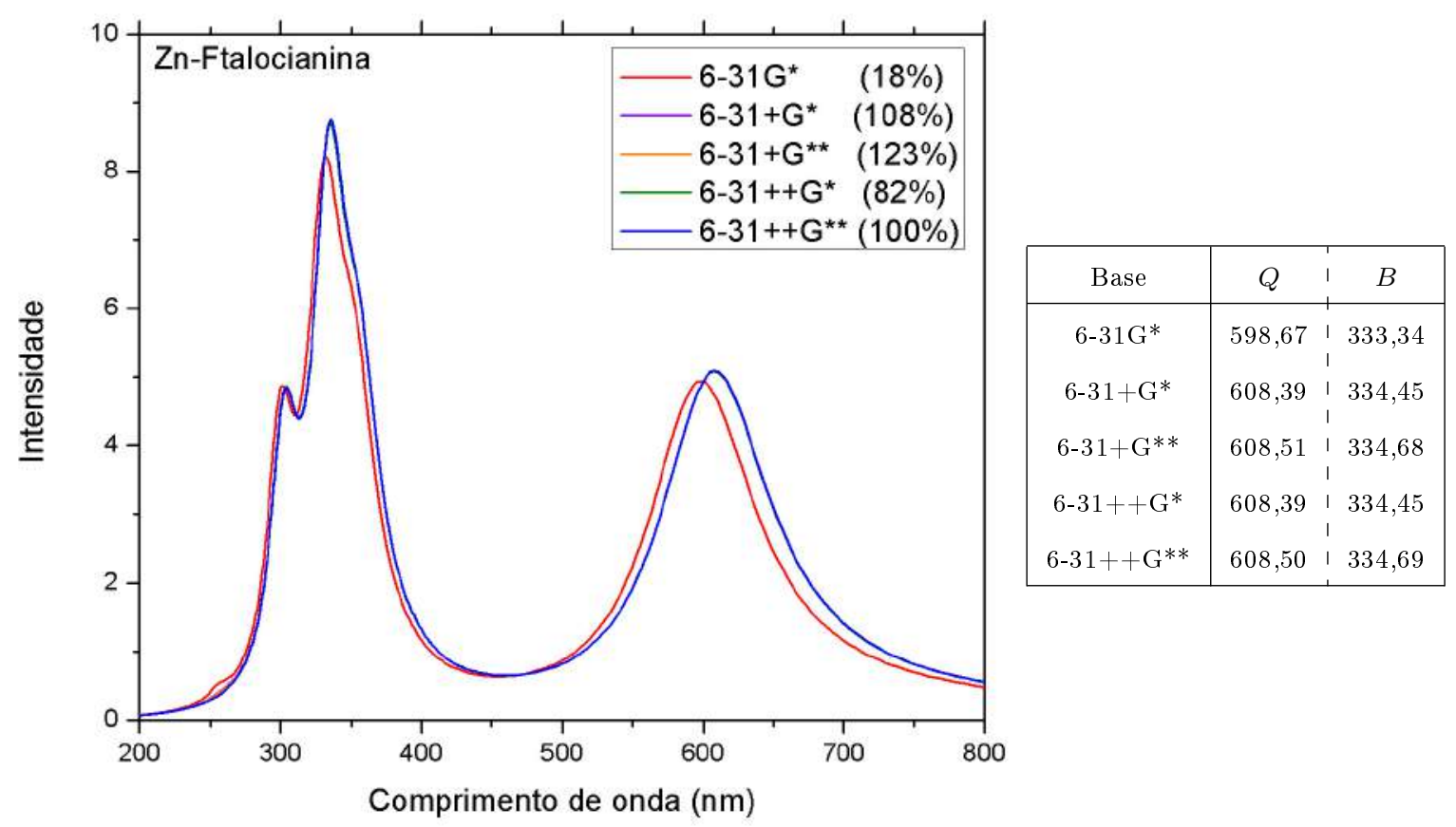

Figura C.5: Teste de conjuntos de funções-base para o cálculo do espectro de absorção da molécula Zn-Ftalocianina isolada, utilizando o método TD-DFT(O3LYP) e as seguintes bases: $6-31 \mathrm{G}^{*}, 6-31+\mathrm{G}^{*}, 6-31+\mathrm{G}^{* *}, 6-31++\mathrm{G}^{*}, 6-31++\mathrm{G}^{* *}$, e $6-311++\mathrm{G}^{* *}$. No gráfico é apresentado a convolução dos 46 picos teóricos para cada base, utilizando Lorentzianas (ver seção 2.2.6). Nas legendas das figuras também se encontra o tempo de cálculo de cada caso, em comparação com o tempo obtido com o conjunto de funções-base maior. A direita da figura se encontra uma tabela com os valores dos comprimentos de onda para as bandas $Q$ e $B$ (Soret). 

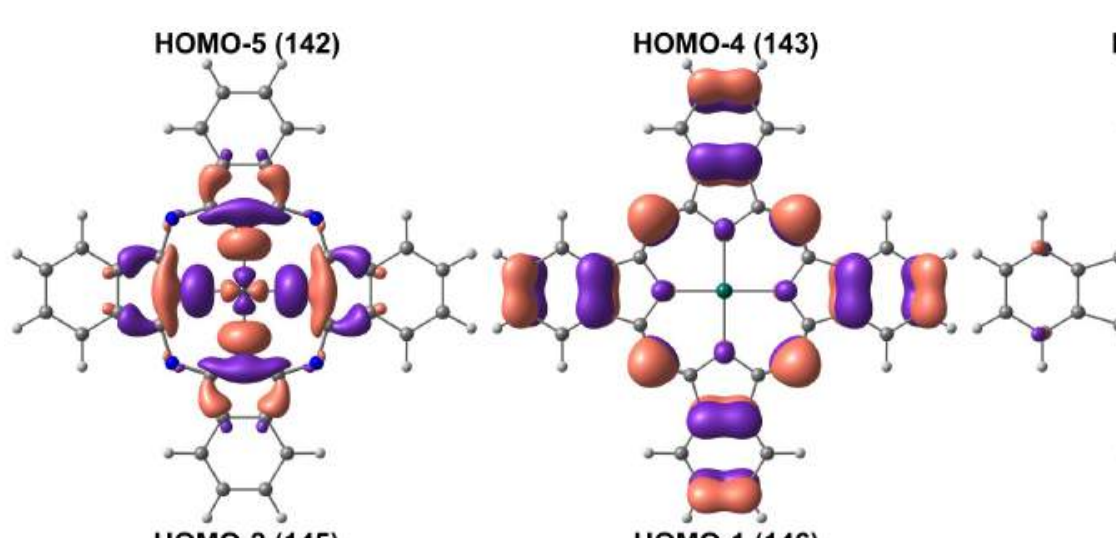

OMO-3 (144)

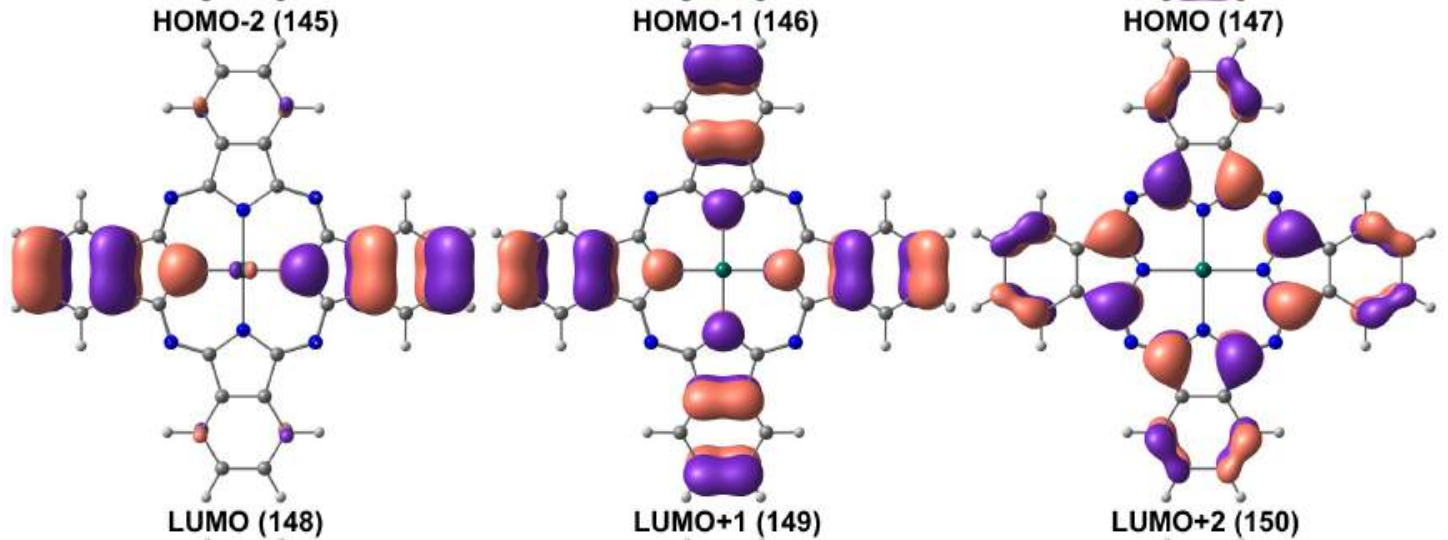

HOMO-1 (146)
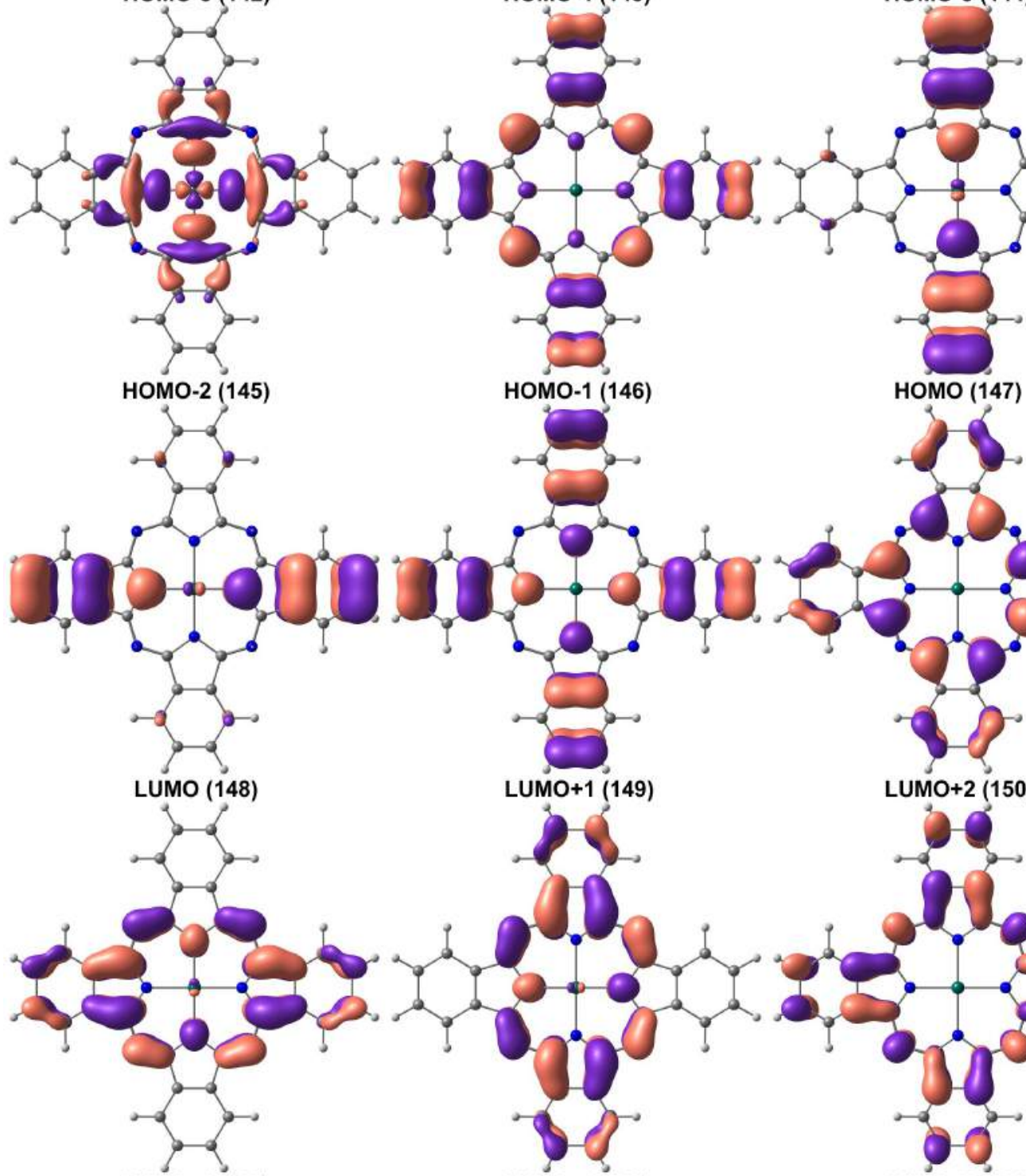

LUMO+1 (149)

LUMO+2 (150)
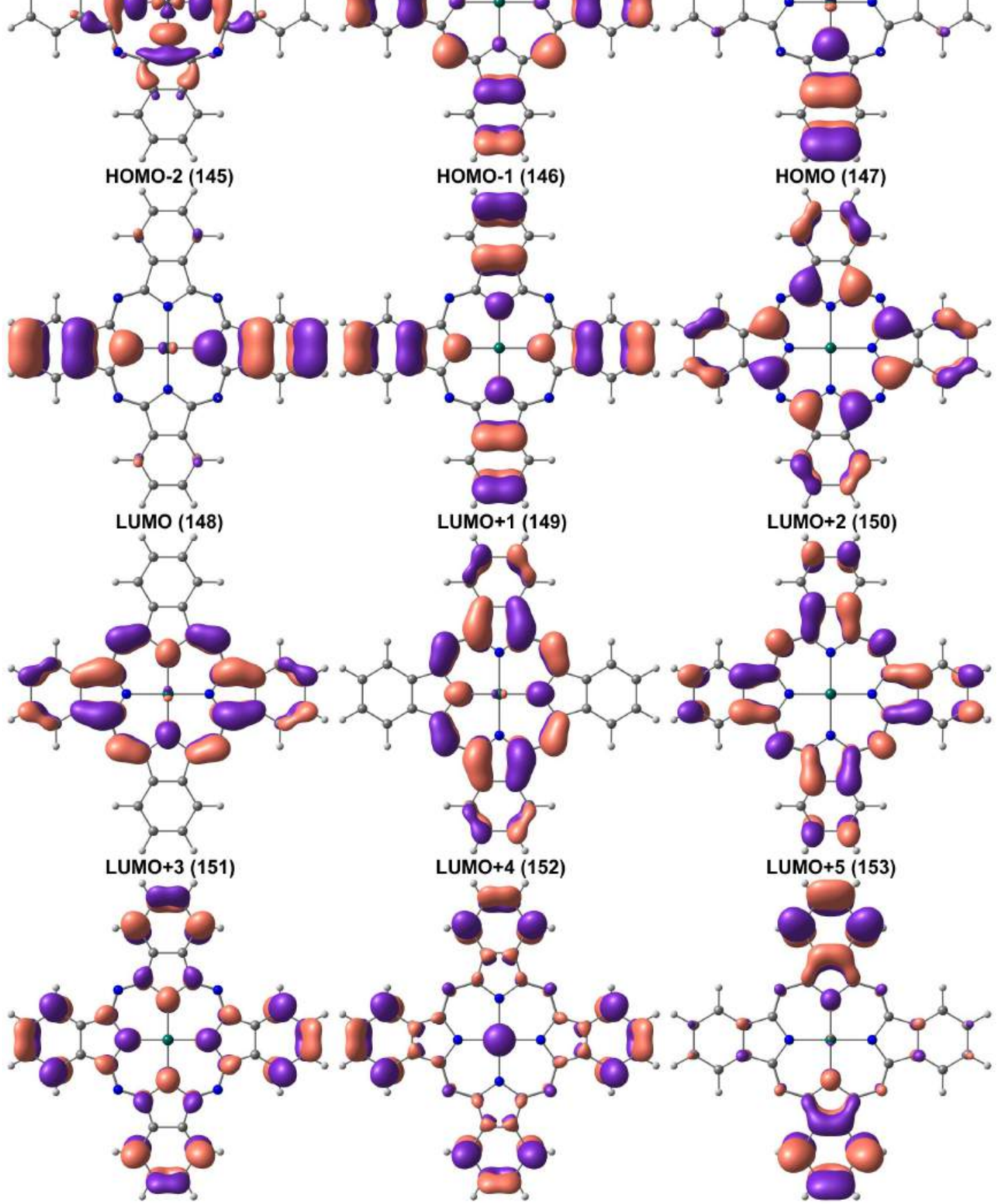

Figura C.6: Alguns orbitais moleculares da Zn-Ftalocianina isolada, obtidos a partir do cálculo B3LYP $/ 6-31+\mathrm{G}^{*}$. 
Tabela C.1: Dois primeiros estados excitados da molécula Zn-Ftalocianina isolada calculados utilizando vários funcionais TD-DFT com a base $6-31+\mathrm{G}^{*}$ e ZINDO/CIS. $\Delta E$ é a energia de excitação dada em eV, $\lambda$ é o comprimento de onda correspondente dado em $\mathrm{nm}$, e $f$ é a força de oscilador. As transições envolvidas são mostradas, e a contribuição delas para cada excitação é mostrada em parênteses. O orbital HOMO é numerado como 147. * As bandas na região do visível só aparecem nos estados 7 e 8 com o ZINDO/CIS, e são esses os estados mostrados na tabela.

\begin{tabular}{|c|c|c|c|c|}
\hline Método & $\Delta E$ & $\lambda$ & $f$ & Transições envolvidas \\
\hline $\begin{array}{l}\text { TD-DFT } \\
\text { (B3LYP) }\end{array}$ & $\begin{array}{l}2,0504 \\
---- \\
2,0504\end{array}$ & $\begin{array}{l}604,7 \\
604,7\end{array}$ & $\begin{array}{r}0,4280 \\
---- \\
0,4280\end{array}$ & $\begin{array}{c}143 \rightarrow 148(3 \%), 143 \rightarrow 149(2 \%), \\
147 \rightarrow 148(45 \%), 147 \rightarrow 149(50 \%) \\
{ }^{-} 14 \overline{3}-\bar{\rightarrow} 1 \overline{4} \overline{8}(\overline{2} \%), 1-1 \overline{3} \rightarrow \overline{1} \overline{4} \overline{4}(\overline{3} \%), \\
147 \rightarrow 148(50 \%), 147 \rightarrow 149(45 \%)\end{array}$ \\
\hline $\begin{array}{c}\text { TD-DFT } \\
\text { (BHandHLYP) }\end{array}$ & $\begin{array}{l}2,0178 \\
2,0178\end{array}$ & $\begin{array}{l}614,5 \\
614,5\end{array}$ & $\begin{array}{r}0,5268 \\
--- \\
0,5268\end{array}$ & $\begin{array}{c}146 \rightarrow 148(2 \%), 146 \rightarrow 149(2 \%), \\
147 \rightarrow 148(47 \%), 147 \rightarrow 149(48 \%) \\
{ }^{14} \overline{6}^{-} \rightarrow 14 \overline{8}(\overline{2} \%), 14 \overline{6} \rightarrow 1 \overline{4} 9(\overline{2} \%), \\
147 \rightarrow 148(48 \%), 147 \rightarrow 149(47 \%)\end{array}$ \\
\hline $\begin{array}{c}\text { TD-DFT } \\
\text { (CAM-B3LYP) }\end{array}$ & $\begin{array}{l}1,9973 \\
-\end{array}$ & $\begin{array}{l}620,8 \\
620,7\end{array}$ & $\begin{array}{r}0,4861 \\
0,4861\end{array}$ & $\begin{array}{c}146 \rightarrow 148(5 \%), 147 \rightarrow 148(3 \%) \\
147 \rightarrow 149(91 \%) \\
\overline{1} \overline{4} \overline{6} \rightarrow \overline{1} \overline{4} 9(5 \%), \overline{1} \overline{4} \bar{\rightarrow} \overline{1} \overline{148}(9 \overline{1} \%) \\
147 \rightarrow 149(3 \%)\end{array}$ \\
\hline $\begin{array}{l}\text { TD-DFT } \\
\text { (O3LYP) }\end{array}$ & $\begin{array}{l}2,0379 \\
---- \\
2,0379\end{array}$ & $\begin{array}{l}608,4 \\
--- \\
608,4\end{array}$ & $\begin{array}{r}0,3961 \\
---- \\
0,3961\end{array}$ & 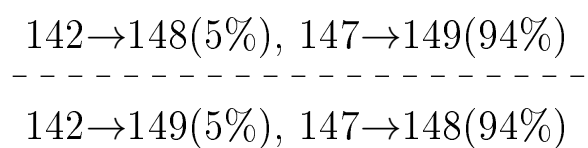 \\
\hline $\begin{array}{l}\text { TD-DFT } \\
(\mathrm{BP} 86)\end{array}$ & $\begin{array}{l}1,9721 \\
---1,9721\end{array}$ & $\begin{array}{l}628,7 \\
628,7\end{array}$ & $\begin{array}{r}0,3326 \\
----- \\
0,3325\end{array}$ & $\begin{array}{c}141 \rightarrow 148(6 \%), 147 \rightarrow 149(90 \%) \\
141 \rightarrow 149(6 \%), 147 \rightarrow 148(90 \%)\end{array}$ \\
\hline TD-DFT & 2,0717 & 598,5 & $\begin{array}{r}0,4979 \\
0,4979\end{array}$ & $\begin{array}{c}146 \rightarrow 148(3 \%), 147 \rightarrow 148(34 \%) \\
147 \rightarrow 149(61 \%) \\
\overline{1} \overline{4} \overline{6} \rightarrow \overline{1} \overline{4} 9(3 \%), \overline{1} \overline{4} 7 \rightarrow \overline{1} \overline{148}(6 \overline{1} \%) \\
147 \rightarrow 149(34 \%)\end{array}$ \\
\hline (LC-wPBE) & $\begin{array}{l}1,8201 \\
----\end{array}$ & 681,2 & $\begin{array}{r}0,4833 \\
---- \\
0,4833\end{array}$ & $\begin{array}{c}146 \rightarrow 148(4 \%), 147 \rightarrow 148(2 \%) \\
147 \rightarrow 149(91 \%) \\
\overline{1} \overline{4} \overline{6} \rightarrow \overline{1} \overline{4} 9(\overline{4} \%), \overline{1} \overline{4} \overline{7} \rightarrow \overline{1} \overline{148}(9 \overline{1} \%) \\
147 \rightarrow 149(2 \%)\end{array}$ \\
\hline ZINDO/CIS* & 2,2652 & 547,3 & 0,0464 & $\begin{array}{c}144 \rightarrow 151(14 \%), 145 \rightarrow 150(22 \%), \\
146 \rightarrow 149(22 \%), 147 \rightarrow 148(32 \%) \\
\overline{1} \overline{4} 4 \rightarrow \overline{1} \overline{1} \overline{9}(1 \overline{6} \%), 1 \overline{4} \overline{\mathrm{C}} \rightarrow \overline{1} \overline{4} 8(\overline{2} 3 \%), \\
146 \rightarrow 151(20 \%), 147 \rightarrow 149(17 \%), \\
\quad 147 \rightarrow 150(14 \%)\end{array}$ \\
\hline
\end{tabular}


Tabela C.2: Algumas excitações não nulas na região ultravioleta da molécula Zn-Ftalocianina isolada calculadas utilizando vários funcionais TD-DFT com a base 6-31+G* e ZINDO/CIS. Os estados que estão entre os apresentados e não aparecem na tabela tem força de oscilador nula. $\Delta E$ é a energia de excitação dada em eV,$\lambda$ é o comprimento de onda correspondente dado em nm, e $f$ é a força de oscilador. As transições envolvidas são mostradas, e a contribuição delas para cada excitação é mostrada em parênteses. O orbital HOMO é numerado como 147.

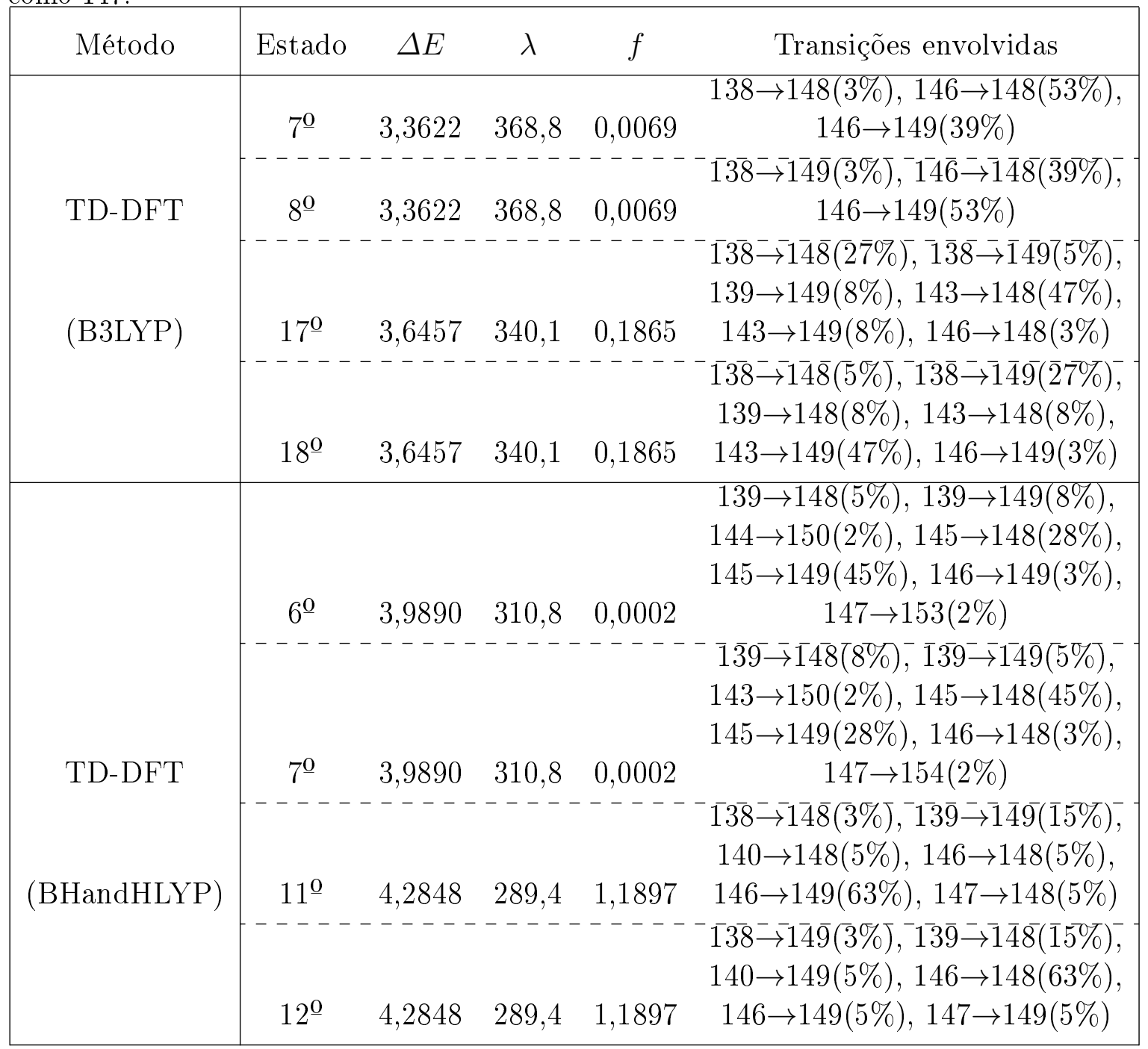




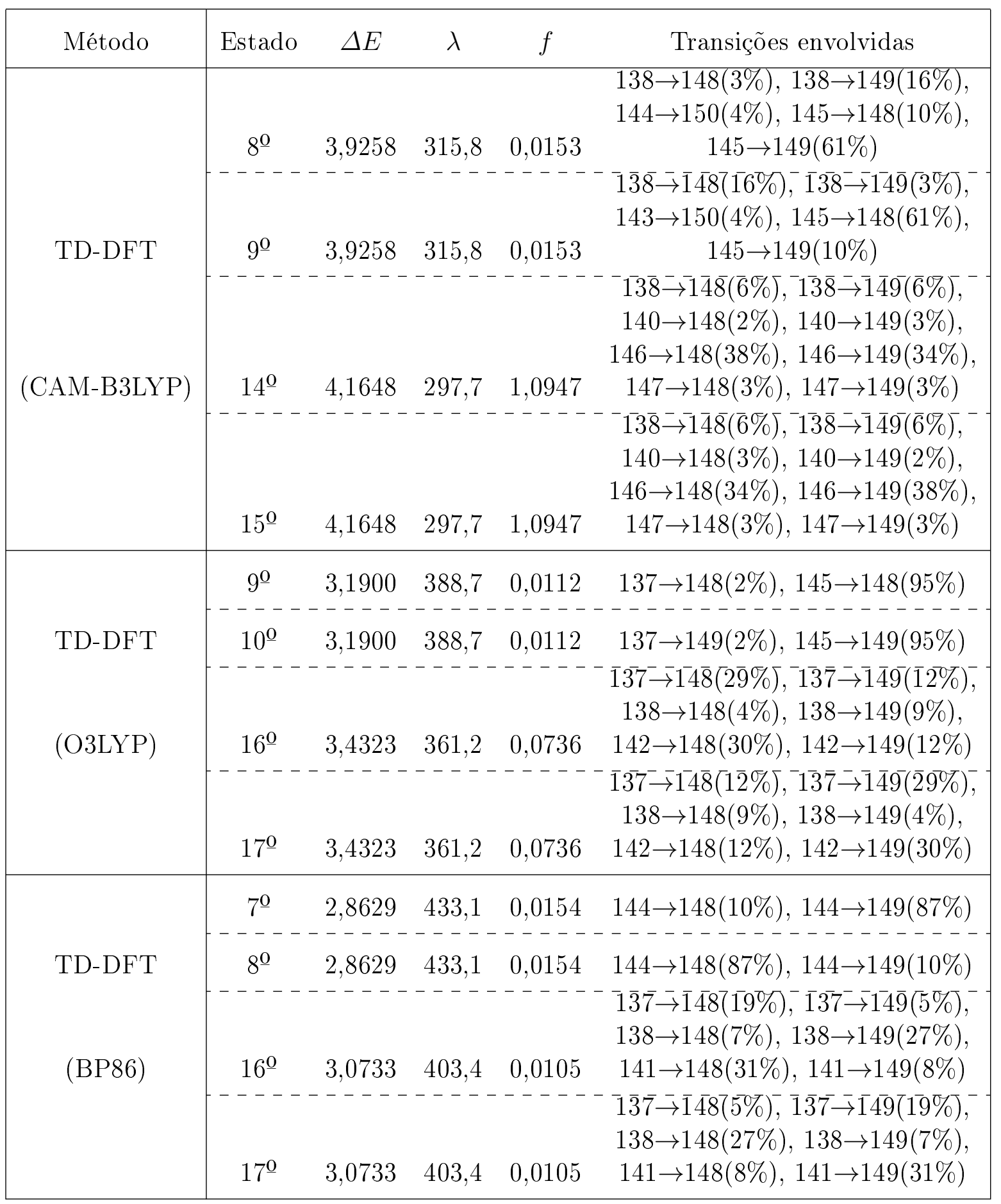




\begin{tabular}{|c|c|c|c|c|c|}
\hline Método & Estado & $\Delta E$ & $\lambda$ & $f$ & Transições envolvidas \\
\hline \multirow[t]{2}{*}{ TD-DFT } & $\begin{array}{c}6^{\underline{0}} \\
---\end{array}$ & 3,9408 & 314,6 & 0,0239 & $\begin{array}{c}139 \rightarrow 148(12 \%), 139 \rightarrow 149(6 \%), \\
144 \rightarrow 150(2 \%), 145 \rightarrow 148(48 \%), \\
145 \rightarrow 149(26 \%) \\
139 \rightarrow 148(6 \%), 139 \rightarrow 149(12 \%), \\
143 \rightarrow 150(2 \%), 145 \rightarrow 148(26 \%), \\
145 \rightarrow 149(48 \%)\end{array}$ \\
\hline & $14^{\mathrm{O}}$ & 4,1744 & 297,0 & 1,0602 & 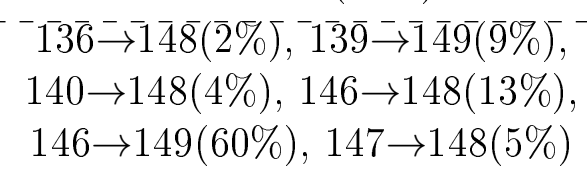 \\
\hline$(\mathrm{M} 06-2 \mathrm{X})$ & $15^{\mathrm{O}}$ & 4,1744 & 297,0 & 1,0602 & $\begin{array}{l}136 \rightarrow 149(\overline{2} \%), 13 \overline{9} \rightarrow 1 \overline{4} 8(\overline{9} \%), \\
140 \rightarrow 149(4 \%), 146 \rightarrow 148(60 \%), \\
146 \rightarrow 149(13 \%), 147 \rightarrow 149(5 \%)\end{array}$ \\
\hline \multirow{6}{*}{$\begin{array}{c}\text { TD-DFT } \\
\text { (LC-wPBE) }\end{array}$} & $8^{\underline{0}}$ & 4,2625 & 290,9 & 0,3487 & $\begin{array}{c}138 \rightarrow 148(30 \%), 138 \rightarrow 149(4 \%), \\
143 \rightarrow 150(5 \%), 145 \rightarrow 148(34 \%), \\
145 \rightarrow 149(4 \%), 146 \rightarrow 148(13 \%), \\
147 \rightarrow 149(3 \%)\end{array}$ \\
\hline & $9^{\underline{O}}$ & 4,2625 & 290,9 & 0,3487 & 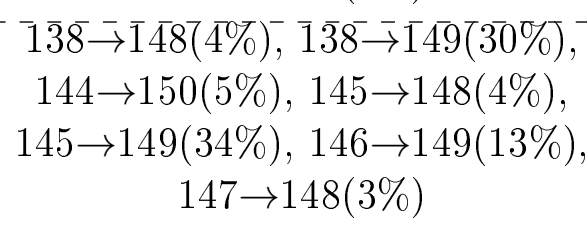 \\
\hline & & & & & $\overline{145} \rightarrow 14 \overline{8}(1 \overline{0} \%), 14 \overline{1} \rightarrow \overline{1} \overline{4}(\overline{1} 3 \%)$ \\
\hline & $10^{\underline{0}}$ & 4,4078 & 281,3 & 0,7773 & $\begin{array}{c}146 \rightarrow 148(25 \%), 146 \rightarrow 149(34 \%), \\
147 \rightarrow 148(3 \%), 147 \rightarrow 149(2 \%)\end{array}$ \\
\hline & & & & & $\begin{array}{l}145 \rightarrow 148(13 \%), 145 \rightarrow 1 \overline{4}(\overline{10 \%}), \\
146 \rightarrow 148(34 \%), 146 \rightarrow 149(25 \%)\end{array}$ \\
\hline & $11^{0}$ & 4,4078 & 281,3 & 0,7773 & $147 \rightarrow 148(2 \%), 147 \rightarrow 149(3 \%)$ \\
\hline \multirow{4}{*}{ ZINDO/CIS } & $12^{\mathrm{O}}$ & 2,6779 & 463,0 & 0,2102 & $\begin{array}{c}144 \rightarrow 149(21 \%), 147 \rightarrow 149(45 \%), \\
147 \rightarrow 150(12 \%)\end{array}$ \\
\hline & $13^{\underline{0}}$ & 2,6779 & 463,0 & 0,2102 & $\begin{array}{c}\overline{144 \rightarrow 150}(2 \overline{1} \%), 14 \overline{7} \rightarrow \overline{1} \overline{4} 9(\overline{1} 2 \%) \\
147 \rightarrow 150(45 \%)\end{array}$ \\
\hline & $20^{\underline{0}}$ & 2,8470 & 435,5 & 0,0782 & $\begin{array}{c}\overline{143 \rightarrow} \overline{1} \overline{4}(5 \overline{1} \%),{ }^{-14} \overline{3} \rightarrow \overline{1} \overline{1} \overline{0}(\overline{1} 1 \%) \\
145 \rightarrow 148(13 \%)\end{array}$ \\
\hline & $21^{\underline{0}}$ & 2,8470 & 435,5 & $\begin{array}{ll}---- \\
0,0782\end{array}$ & $\begin{array}{c}\overline{143 \rightarrow} 14 \overline{9}(1 \overline{1} \%), 14 \overline{3} \rightrightarrows \overline{1} \overline{1} 50(51 \%) \\
146 \rightarrow 148(13 \%)\end{array}$ \\
\hline
\end{tabular}


Tabela C.3: Estados excitados da molécula Zn-Ftalocianina isolada no nível LC-wPBE/6$31+\mathrm{G}^{*}$. $\Delta E$ é a energia de excitação dada em eV, $\lambda$ é o comprimento de onda correspondente dado em nm, e $f$ é a força de oscilador. As transições envolvidas são mostradas, e a contribuição delas para cada excitação são mostradas em parênteses. O orbital HOMO é numerado como 147.

\begin{tabular}{|c|c|c|c|c|}
\hline Estado & $\Delta E$ & $\lambda$ & $f$ & Transições envolvidas \\
\hline $1^{0}$ & 1,8201 & 681,2 & 0,4833 & $146 \rightarrow 148(4 \%), 147 \rightarrow$ \\
\hline--- & & & & --------------------------- \\
\hline $2^{Q}$ & 1,8201 & 681,2 & 0,4833 & $149(4 \%), 147 \rightarrow 148(91 \%), 147 \rightarrow 149(2 \%)$ \\
\hline---- & ---- & 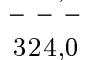 & ---- & 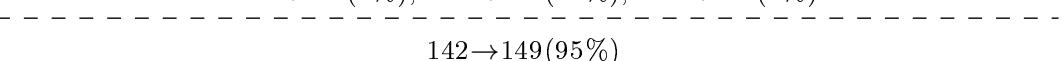 \\
\hline-- & & & ---- & -------------- \\
\hline $4^{\mathrm{O}}$ & 3,8273 & 324,0 & 0 & $142 \rightarrow 148(95$ \\
\hline $\begin{array}{l}--- \\
5^{0}\end{array}$ & ---- & --- & ---- & ---------------1 \\
\hline--- & -1234 & -- & --- & 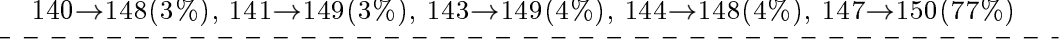 \\
\hline $6^{\underline{0}}$ & 4,1910 & 295,8 & 0 & $143 \rightarrow 148(41 \%), 144 \rightarrow 149(41 \%), 145 \rightarrow 150(8 \%)$ \\
\hline--- & & & --- & ----------------------- \\
\hline $7^{0}$ & 4,2211 & 293,7 & 0 & $138 \rightarrow 150(6 \%), 143 \rightarrow 148(39 \%), 144 \rightarrow 149(39 \%), 147 \rightarrow 151(7 \%)$ \\
\hline & & & --- & 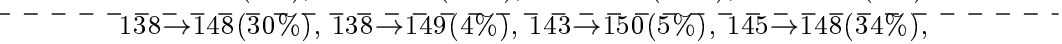 \\
\hline $8^{\mathrm{O}}$ & 4,2625 & 290,9 & 0,3487 & $145 \rightarrow 149(4 \%), 146 \rightarrow 148(13 \%), 147 \rightarrow 149(3 \%)$ \\
\hline-- & & & & 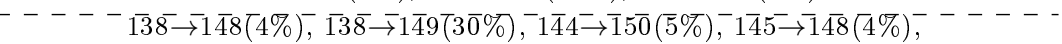 \\
\hline $9^{0}$ & 4,2625 & 290,9 & 0,3487 & $145 \rightarrow 149(34 \%), 146 \rightarrow 149(13 \%), 147$ \\
\hline & & & & $------{ }_{14} \overline{5} \rightarrow 148(1 \overline{0} \%),{ }_{1} 145 \rightarrow \overline{1} 4 \overline{9}(\overline{1} 3 \%), \overline{1} 4 \overline{6} \rightarrow 148(2 \overline{5} \%),-------$ \\
\hline $10^{\mathrm{O}}$ & 4,4078 & 281,3 & 0,7773 & $146 \rightarrow 149(34 \%), 147 \rightarrow 148(3 \%), 147 \rightarrow 149(2 \%)$ \\
\hline---- & & & --- & 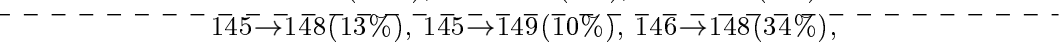 \\
\hline $11^{\underline{0}}$ & 4,4078 & 281,3 & 0,7773 & $146 \rightarrow 149(25 \%), 147 \rightarrow 148(2 \%), 147-$ \\
\hline--- & & & --- & -------- \\
\hline $12^{\underline{Q}}$ & 4,4390 & 279,3 & 0 & 135 \\
\hline---- & & & --- & ------- \\
\hline $13^{\mathrm{O}}$ & 4,4 & 279 & $\begin{array}{c}0 \\
--\end{array}$ & 13 \\
\hline $14^{\mathrm{O}}$ & 4,5 & 269,7 & 0 & $51(85 \%)$ \\
\hline--- & ---- & & --- & ------------- \\
\hline $15^{\mathrm{Q}}$ & 4,6347 & 267,5 & 0 & $147 \rightarrow 153(88 \%), 147$ \\
\hline & & & -- & $---\overline{1} 3 \overline{8} \overline{\overline{1}} \overline{15} \overline{3}(\overline{2 \%}), \overline{1} \overline{39} \rightarrow \overline{1} 5 \overline{0}(\overline{1} 0 \%), \overline{1} 4 \overline{0} \rightarrow$ \\
\hline $16^{0}$ & 4,7269 & 262,3 & 0 & 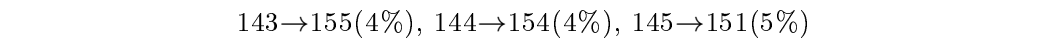 \\
\hline & & & -- & 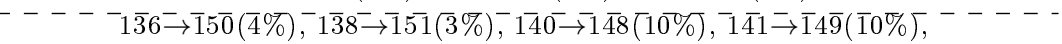 \\
\hline $17^{0}$ & 4,8122 & 257,7 & 0 & 143 \\
\hline & & & & -------- \\
\hline $18^{0}$ & 4,8253 & 257,0 & 0,0065 & $134 \rightarrow 148$ \\
\hline--- & & & & ---- \\
\hline $19^{\underline{0}}$ & 4,8455 & 255,9 & 0 & $134 \rightarrow 149(5$ \\
\hline & & & & $136 \rightarrow 149(8 \%), 138$ \\
\hline $20^{0}$ & 4,8499 & 255,6 & 0,0529 & $144 \rightarrow 153(3 \%), 145 \rightarrow 154(4 \%), 1$ \\
\hline & & & & $\overline{1} 3 \overline{6} \rightrightarrows \overline{14} \overline{8}(\overline{8} \%), \overline{1} \overline{38} \rightarrow \overline{1} 4 \overline{9}(\overline{9} \%),-1 \overline{3} 9 \rightarrow \overline{1} 4 \overline{8}(\overline{2} 4 \%$ \\
\hline $21^{0}$ & 4,8499 & 255,6 & 0,0529 & $143 \rightarrow 153(3 \%), 145 \rightarrow 155(4 \%), 14$ \\
\hline & & & --- & ---------- \\
\hline $22^{\underline{Q}}$ & 4,8 & 254,5 & 0 & $134 \rightarrow 149(37 \%), 135 \rightarrow 148(37 \%), 137 \rightarrow 151(5 \%), 147 \rightarrow 152(11 \%)$ \\
\hline--- & - & $--\overline{0}$ & $\begin{array}{c}--- \\
0\end{array}$ & 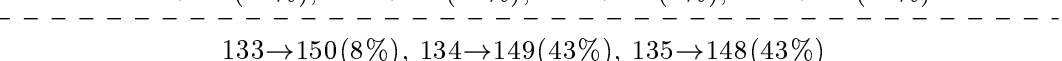 \\
\hline--- & & & --- & $-\ldots-\ldots-\ldots-\ldots-\ldots-\ldots-\ldots-\ldots-\ldots-\ldots$ \\
\hline $24^{\mathrm{O}}$ & 4,9 & 248,0 & 0 & $133 \rightarrow$ \\
\hline & & & & --------------------------------- \\
\hline $25^{\mathrm{O}}$ & 5,0332 & 246,3 & 0,0839 & $138 \rightarrow 149(3 \%), 145 \rightarrow 149(7 \%), 147 \rightarrow 154(62 \%), 147 \rightarrow 155(10 \%)$ \\
\hline--- & & & & \\
\hline $26^{0}$ & 5,0332 & 246,3 & 0,0839 & $138 \rightarrow 148(3 \%), 145 \rightarrow 14$ \\
\hline--- & & & ") & 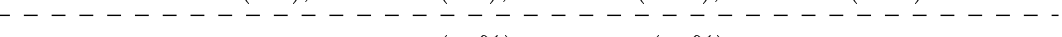 \\
\hline $27^{0}$ & 5,0639 & 244,8 & 0 & $143 \rightarrow 149(45 \%), 144 \rightarrow 148(45 \%)$ \\
\hline & & & -- & $------{ }_{13} 1 \rightarrow 149(4 \%), 132 \rightarrow 148(4 \%), \overline{13} 9 \rightarrow 151(3 \%)$ \\
\hline $28^{0}$ & 5,1213 & 242,1 & 0 & $140 \rightarrow 149(38 \%), 141 \rightarrow 148(38 \%), 147 \rightarrow 161(3 \%)$ \\
\hline-- & & & & ---------------- \\
\hline $29^{\underline{0}}$ & 5,1572 & 240,4 & 0 & $136 \rightarrow 150(3 \%), 140 \rightarrow 148(30 \%), 141 \rightarrow 149(30 \%), 143 \rightarrow 149(16 \%), 144 \rightarrow 148(16 \%)$ \\
\hline & & & & $-----\overline{1} 3 \overline{6} \rightarrow 149$ \\
\hline $30^{\mathrm{O}}$ & 5,2494 & 236,2 & 0,3021 & , $147 \rightarrow 155(3 \%)$ \\
\hline & & & & $-\overline{1} 3 \overline{6} \rightarrow 148(3 \%), \overline{1} 3 \overline{8} \rightrightarrows \overline{14} \overline{9}(3 \overline{5} \%), \overline{13} \overline{9} \rightarrow 148(27 \%)$, \\
\hline $31^{0}$ & 5,2494 & 236,2 & 0,3021 & $145 \rightarrow 1$ \\
\hline
\end{tabular}


Tabela C.4: Coordenadas das estruturas optimizadas de monômero e dímeros de $H_{2^{-}}$ Ftalocianina apresentados no decorrer da seção 3.2. O monômero foi obtido no nível B3LYP /6-31G* e os dímeros no nível wB97XD/6-31G*.

\begin{tabular}{|c|c|c|c|c|c|c|c|c|}
\hline \multirow[b]{2}{*}{ Átomo } & \multicolumn{2}{|l|}{ Monômero } & \multicolumn{3}{|c|}{ Dímero (a) } & \multicolumn{3}{|c|}{ Dímero (b) } \\
\hline & Y & I Z & $\mathrm{X}$ & Y & $\mathrm{Z}$ & $\mathrm{X}$ & Y & $\mathrm{Z}$ \\
\hline N1 & $\begin{array}{ccc}-2,37976177 & 2,40197616 \\
- & -\end{array}$ & $\begin{aligned} & 0,0 \\
- & -\end{aligned}$ & $\begin{array}{l}-2,313049 \\
-----\end{array}$ & $\begin{array}{l}\quad 3,361204 \\
\perp--\ldots\end{array}$ & $\begin{array}{l}-1,319577 \\
-\end{array}$ & $\begin{array}{r}-0,202383 \\
-\quad-\quad--\end{array}$ & $\begin{aligned} & -1,537086 \\
- & -\end{aligned}$ & $\begin{array}{l}-2,291041 \\
-\end{array}$ \\
\hline $\mathrm{C} 2$ & \begin{tabular}{l:l}
$-2,78921576$ & 1,14951709 \\
\hdashline
\end{tabular} & 0,0 & $-1,162976$ & 2,858101 & $-1,696897$ & $-0,220657$ & $-0,234101$ & $-2,173601$ \\
\hline $\mathrm{C} 3$ & \begin{tabular}{l:l}
$-1,09354618$ & 2,76368792 \\
\hdashline
\end{tabular} & 0,0 & $-3,356309$ & 2,615326 & $-0,960374$ & 0,728721 & $-2,309381$ & $-1,728079$ \\
\hline N4 & \begin{tabular}{l:l}
$-2,02526499$ & 0,00000000 \\
\hdashline
\end{tabular} & 0,0 & $-0,807487$ & 1,538562 & $-1,805487$ & 0,654914 & 0,577374 & $-1,499804$ \\
\hline N5 & \begin{tabular}{l|l}
0,00000000 & 1,94978006
\end{tabular} & 0,0 & $-3,440500$ & 1,262462 & | $-0,932964$ & 1,777080 & $-1,923212$ & $-0,967057$ \\
\hline $\mathrm{C} 6$ & \begin{tabular}{l|l}
$-4,17450390$ & 0,71197304
\end{tabular} & 0,0 & 0,002479 & $\begin{array}{l}----- \\
3,627333\end{array}$ & $-2,094148$ & $-1,206161$ & 0,643453 & $-2,778060$ \\
\hline & & & & & & & & \\
\hline $\begin{array}{l}\mathrm{C} 7 \\
----\end{array}$ & 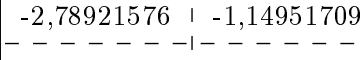 & $\begin{array}{rl}1 & 0,0 \\
-1 & --\end{array}$ & $\begin{array}{c}0,483842 \\
------\end{array}$ & $\begin{array}{l}+1,379811 \\
+-----\end{array}$ & $\begin{array}{l}\mid-2,233991 \\
\vdash--\ldots\end{array}$ & $\begin{array}{r}0,337043 \\
-----.\end{array}$ & $\begin{array}{r}1,905001 \\
-\mid----\end{array}$ & $\begin{array}{l}-1,626565 \\
+----\ldots\end{array}$ \\
\hline $\mathrm{C} 8$ & $\begin{array}{rll}-4,17450390 & \text { । } & -0,71197304\end{array}$ & 0,0 & 1,016812 & $\begin{array}{l}2,716357 \\
+\end{array}$ & $-2,425162$ & $-0,865782$ & $\begin{array}{r}1,960426 \\
-\end{array}$ & $\begin{array}{r}-2,439099 \\
-\end{array}$ \\
\hline $\begin{array}{c}\mathrm{C} 9 \\
---\end{array}$ & $\begin{array}{r}1,09354618 \\
\hdashline\end{array}$ & $\begin{array}{l}0,0 \\
- \\
-\end{array}$ & $-4,691179$ & $\begin{array}{l}\mid \\
\perp \\
\perp-\ldots\end{array}$ & $\left\{\begin{array}{l}-0,498286 \\
-[-\ldots\end{array}\right.$ & $\begin{array}{r}2,435996 \\
-\ldots-\ldots\end{array}$ & $\begin{array}{r}-3,060090 \\
-\end{array}$ & $\begin{array}{l}-0,600049 \\
-\end{array}$ \\
\hline $\begin{array}{r}\mathrm{C} 10 \\
--\end{array}$ & \begin{tabular}{c:c}
$-0,69706304$ & 4,17592108 \\
\hdashline & -
\end{tabular} & $\begin{aligned} 0,0 \\
- \\
-\end{aligned}$ & $-4,613653$ & $\begin{array}{l}\quad 3,230206 \\
\perp-\ldots\end{array}$ & $\begin{array}{l}-0,527558 \\
-\end{array}$ & $\begin{array}{r}0,687259 \\
-\quad-\ldots-\end{array}$ & $\begin{aligned} & -3,764608 \\
- & -\end{aligned}$ & \begin{tabular}{l}
$-1,876149$ \\
\hdashline-1
\end{tabular} \\
\hline C11 & \begin{tabular}{l:r}
0,69706304 & 4,17592108 \\
\hdashline-0.04
\end{tabular} & $\begin{array}{l}0,0 \\
- \\
-\end{array}$ & $-5,466533$ & 2,167431 & \begin{tabular}{l}
$-0,229126$ \\
\hdashline$-\ldots$
\end{tabular} & 1,784322 & $\begin{array}{l}-4,244687 \\
-\end{array}$ & \begin{tabular}{l}
$-1,163007$ \\
\hdashline-10
\end{tabular} \\
\hline $\mathrm{N} 12$ & $2,37976177 \quad 2,40197616$ & 0,0 & $-5,219662$ & $-0,252405$ & $-0,324125$ & 3,487348 & $-3,163210$ & 0,197224 \\
\hline $\mathrm{C} 13$ & $-1,09354618,-2,76368792$ & 0,0 & 0,609052 & $-0,943578$ & $-2,284139$ & 2,052618 & 2,836226 & $-0,366264$ \\
\hline & $-------1^{-}-----$ & & & & & & & \\
\hline $\begin{array}{r}\mathrm{C} 14 \\
---\end{array}$ & $\begin{array}{l}2,78921576 \\
-\end{array}$ & 0,0 & $-4,569910$ & $-1,370077$ & $-0,559951$ & $\begin{array}{r}4,048018 \\
------\end{array}$ & $-2,130883$ & $\begin{array}{r}0,791199 \\
-\end{array}$ \\
\hline $\begin{array}{r}\mathrm{N} 15 \\
---\end{array}$ & 2,025264999 । 0,00000000 & 0,0 & $-3,281389$ & $-1,527096$ & $-0,996994$ & 3,727902 & $-0,805424$ & 0,673723 \\
\hline N16 & $\begin{array}{c}0,00000000 \\
-\end{array}$ & $\begin{array}{rl}1 & 0,0 \\
-1 & -\end{array}$ & $-0,644728$ & $\begin{array}{l}-1,248586 \\
+\ldots\end{array}$ & $\begin{array}{l}-1,867618 \\
-\ldots-\ldots\end{array}$ & 2,658851 & $\begin{array}{r}1,703814 \\
-\mid-\ldots-\ldots\end{array}$ & $\begin{array}{r}\quad 0,056399 \\
-\end{array}$ \\
\hline $\begin{array}{r}\mathrm{H} 17 \\
---\end{array}$ & 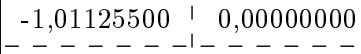 & $\begin{aligned} & 0,0 \\
- & -\end{aligned}$ & $-1,434051$ & $\begin{array}{l}0,768455 \\
+\end{array}$ & $\mid \begin{array}{l}-1,604351 \\
-\end{array}$ & 1,449984 & $\begin{array}{r}0,240622 \\
-\end{array}$ & $\begin{array}{l}-0,970856 \\
-\end{array}$ \\
\hline $\mathrm{H} 18$ & $1,01125500 \quad 0,00000000$ & 0,0 & $-2,653647$ & $-0,754926$ & $-1,186889$ & 2,982783 & $-0,455381$ & $\begin{array}{r}0,084290 \\
\hdashline\end{array}$ \\
\hline $\mathrm{C} 19$ & $\begin{array}{l:l}-0,69706304 & -4,17592108 \\
& -\end{array}$ & 0,0 & 1,381599 & $-2,155788$ & $\begin{array}{l}-2,568836 \\
-\end{array}$ & 2,717505 & $\begin{array}{r}4,025345 \\
-\end{array}$ & $\begin{array}{r}0,168875 \\
\hdashline\end{array}$ \\
\hline $\mathrm{C} 20$ & $1,09354618,-2,76368792$ & 0,0 & $-0,738869$ & $-2,605676$ & $-1,867984$ & 3,673107 & 2,084843 & $\begin{array}{r}0,881440 \\
\hdashline\end{array}$ \\
\hline $\mathrm{C} 21$ & $2,78921576 \quad-1,14951709$ & 0,0 & $-2,937725$ & $-2,844343$ & $-1,145135$ & 4,511695 & $-0,007474$ & 1,463844 \\
\hline $\mathrm{N} 22$ & \begin{tabular}{l|l}
2,37976177 & $-2,40197616$
\end{tabular} & 0,0 & $-1,790131$ & $-3,347771$ & 540677 & 4,507089 & 1,305758 & 1,555796 \\
\hline $\mathrm{C} 23$ & $\begin{array}{lll}0,69706304 & -4,17592108\end{array}$ & & 0,518380 & | $-3,218954$ & $-2,302653$ & 3,753955 & 3,545193 & 0,969120 \\
\hline $\begin{array}{r}\mathrm{C} 24 \\
-\end{array}$ & \begin{tabular}{c|c}
$-1,43165451$ & $-5,36356865$
\end{tabular} & 0,0 & 2,678091 & $-2,369825$ & $-3,020466$ & 2,482294 & । 5,385754 & $\begin{array}{r}0,025671 \\
-\end{array}$ \\
\hline $\begin{array}{l}--- \\
\mathrm{C} 25\end{array}$ & 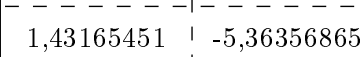 & & $\begin{array}{c}----- \\
0,918762\end{array}$ & 37803 & - - - - - & 4,598983 & । 4,408572 & 1,653620 \\
\hline $\mathrm{C} 26$ & 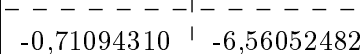 & 0,0 & $\begin{array}{l}----- \\
3,084214\end{array}$ & I $-3,6$ & ' $-3,195336$ & 3,328262 & & 0,706093 \\
\hline & $------1----$ & & & & & & & \\
\hline $\mathrm{C} 27$ & \begin{tabular}{c:c}
0,71094310 & $-6,56052482$ \\
\hdashline & -
\end{tabular} & 0,0 & 2,216395 & $-4,758195$ & $-2,926065$ & 4,371673 & 5,774287 & 1,509545 \\
\hline $\mathrm{C} 28$ & $4,17450390 \quad-0,71197304$ & 0,0 & $-4,107836$ & $-3,614023$ & $-0,774570$ & 5,406923 & $-0,895222$ & 2,174188 \\
\hline $\mathrm{C} 29$ & $\begin{array}{l:l}4,17450390 & 0,71197304\end{array}$ & 0,0 & $-5,113302$ & $-2,704959$ & $-0,408696$ & 5,125241 & 205119 & 1,751782 \\
\hline C30 & $5,37152270 \quad,-1,43296748$ & 0,0 & 32047 & $-4,990513$ & $-0,739985$ & 6,397317 & -0 & 3,126140 \\
\hline C31 & $5,37152270,1,43296748$ & 0,0 & $-6,370274$ & $-3,148313$ & 04229 & & & 2,276153 \\
\hline C32 & $\begin{array}{lll}- & - & - \\
6,56409299 & \text { I } & 0,69706996\end{array}$ & 0,0 & $-6,589171$ & & & 6,795689 & | $-3,04$ & 223350 \\
\hline
\end{tabular}




\begin{tabular}{|c|c|c|c|c|c|c|c|c|}
\hline \multirow[b]{2}{*}{ Átomo } & \multicolumn{2}{|l|}{ Monômero } & \multicolumn{3}{|c|}{ Dímero (a) } & \multicolumn{3}{|c|}{ Dímero (b) } \\
\hline & $\mathrm{Y}$ & I Z & $\mathrm{X}$ & Y & Z & $\mathrm{X}$ & $\mathrm{Y}$ & Z \\
\hline $\begin{array}{r}\text { C33 } \\
-- \\
\end{array}$ & \begin{tabular}{c:c}
6,56409299 & $-0,69706996$ \\
\hdashline-1 & -
\end{tabular} & $\begin{aligned} & 0,0 \\
- & -\end{aligned}$ & $\begin{array}{l}-5,580919 \\
-----\end{array}$ & $\begin{array}{l}1 \\
-5,427465 \\
1\end{array}$ & $\begin{array}{l}-0,329593 \\
-\end{array}$ & $\begin{array}{r}7,083312 \\
-\quad-\quad-\end{array}$ & $\begin{array}{l}-1,729621 \\
-\end{array}$ & $\begin{array}{l}13,643006 \\
- \\
-\end{array}$ \\
\hline $\begin{array}{r}\mathrm{C} 34 \\
---\end{array}$ & \begin{tabular}{c:c}
$-5,37152270$ & $-1,43296748$ \\
\hdashline-1, & -
\end{tabular} & $\begin{aligned} & 0,0 \\
- & -\end{aligned}$ & $\begin{array}{r}2,265494 \\
--\ldots-\ldots\end{array}$ & $\begin{array}{l}3,152722 \\
-\end{array}$ & $\begin{array}{l}-2,865076 \\
-\end{array}$ & $\begin{array}{l}-1,644116 \\
-\quad---\end{array}$ & $\begin{array}{r}3,037012 \\
- \\
-\end{array}$ & $\begin{array}{l}-2,856504 \\
-\end{array}$ \\
\hline $\begin{array}{r}\mathrm{C} 35 \\
---\end{array}$ & \begin{tabular}{l:l}
1,43165451 & 5,36356865 \\
\hdashline-1 & - \\
\hdashline
\end{tabular} & 0,0 & $\begin{array}{l}-6,764712 \\
--\ldots--\end{array}$ & $\begin{array}{l}2,383407 \\
-\end{array}$ & $\begin{array}{l}0,216273 \\
-\end{array}$ & $\begin{array}{r}2,033316 \\
-\ldots-\ldots\end{array}$ & $\begin{array}{r}-5,607253 \\
-\end{array}$ & $\begin{array}{l}-1,052338 \\
-\end{array}$ \\
\hline $\begin{array}{r}\mathrm{C} 36 \\
--\end{array}$ & \begin{tabular}{c:c}
$-5,37152270$ & 1,43296748 \\
\hdashline & -
\end{tabular} & 0,0 & $\begin{array}{r}0,209697 \\
-\ldots-\ldots\end{array}$ & 5,002169 & $-2,189773$ & $\begin{array}{l}-2,324320 \\
-\quad-\ldots\end{array}$ & 0,360804 & $\begin{array}{l}-3,557123 \\
-\end{array}$ \\
\hline $\begin{array}{r}\mathrm{C} 37 \\
---\end{array}$ & 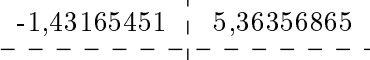 & 0,0 & $\begin{array}{l}-5,025902 \\
--\ldots-\end{array}$ & 4,550099 & $-0,392443$ & $\begin{array}{l}-0,206070 \\
-\end{array}$ & $\begin{array}{r}-4,622626 \\
-\end{array}$ & $-2,504361$ \\
\hline $\begin{array}{r}\mathrm{C} 38 \\
--\ldots\end{array}$ & $\begin{array}{c}-6,56409299 \\
-0,69706996 \\
-\end{array}$ & $\begin{aligned} & 0,0 \\
-1 & -\end{aligned}$ & $\begin{array}{r}2,468976 \\
-\ldots-\ldots\end{array}$ & $\begin{array}{l}4,520697 \\
+---\end{array}$ & $-2,960770$ & $\begin{array}{l}-2,764867 \\
-\ldots-\ldots\end{array}$ & $\begin{array}{r}2,754861 \\
-\end{array}$ & $\begin{array}{r}-3,624749 \\
-\end{array}$ \\
\hline $\begin{array}{r}\mathrm{C} 39 \\
--\end{array}$ & 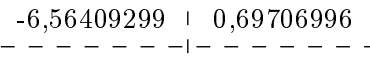 & $\begin{array}{cc}1 & 0,0 \\
-1 & -\end{array}$ & $\begin{array}{l}1,452643 \\
-----\end{array}$ & $\begin{array}{l}1 \quad 5,434708 \\
+----\end{array}$ & $\begin{array}{l}1 \\
-2,62 \\
\vdash-\end{array}$ & $\begin{array}{l}-3,098099 \\
-\quad-\quad--\end{array}$ & $\begin{aligned} & \text { I } 1,434324 \\
&-\mid---\end{aligned}$ & 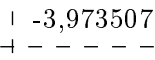 \\
\hline $\begin{array}{r}\mathrm{C} 40 \\
--\end{array}$ & \begin{tabular}{c|c}
0,71094310 & 6,56052482 \\
\hdashline
\end{tabular} & $\begin{array}{rl}1 & 0,0 \\
-1 & -\end{array}$ & $\begin{array}{l}-7,182997 \\
-\ldots-\ldots\end{array}$ & $\begin{array}{l}1 \quad 3,703380 \\
+-----\end{array}$ & $\begin{array}{l}0,35 \\
\vdash--\end{array}$ & $\begin{array}{r}1,144998 \\
-\ldots-\ldots\end{array}$ & $\begin{aligned} & -6,473421 \\
-1 & -\end{aligned}---$ & $\begin{array}{l}-1,682197 \\
- \\
-\end{array}$ \\
\hline $\begin{array}{r}\mathrm{C} 41 \\
--\end{array}$ & \begin{tabular}{c:c}
$-0,71094310$ & 6,56052482 \\
\hdashline & -
\end{tabular} & $\begin{aligned} & 0,0 \\
- & -\end{aligned}$ & $\begin{array}{l}-6,325367 \\
--\ldots--\end{array}$ & 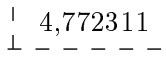 & $L_{-} 0,05$ & $\begin{array}{r}0,038808 \\
-\quad-\ldots-\end{array}$ & $\begin{array}{r}1 \\
-1 \\
-\end{array}$ & $\begin{array}{ll} & -2,3 \\
\lrcorner & -\end{array}$ \\
\hline $\begin{array}{r}\mathrm{H} 42 \\
---\end{array}$ & \begin{tabular}{c:c}
$-2,50386154$ & 5,36063505 \\
\hdashline$-1-2$ & -
\end{tabular} & $\begin{aligned} & 0,0 \\
- & -\end{aligned}$ & $\begin{array}{l}-4,353857 \\
-\ldots-\ldots\end{array}$ & & \begin{tabular}{l}
$-0,62$ \\
\hdashline--
\end{tabular} & $\begin{array}{l}-1,068615 \\
-\ldots-\ldots\end{array}$ & $\begin{aligned} & -4,235 \\
- & -\end{aligned}$ & \\
\hline $\begin{array}{r}\mathrm{H} 43 \\
-\ldots\end{array}$ & \begin{tabular}{c|c}
1,24367587 & 7,50771515 \\
\hdashline-1 & -
\end{tabular} & \begin{aligned} 0,0 \\
\hdashline-1\end{aligned} & $\begin{array}{l}-8,191444 \\
-\ldots-\ldots\end{array}$ & $\begin{array}{l}3,913405 \\
-\end{array}-$ & $\begin{array}{l}0,697834 \\
-\end{array}$ & $\begin{array}{r}1,304729 \\
-\quad-\quad--\end{array}$ & $\begin{aligned} & -7,545 \\
- & -\end{aligned}$ & $\begin{array}{l}-1 \\
-1\end{array}$ \\
\hline $\begin{array}{r}\mathrm{H} 44 \\
--\end{array}$ & \begin{tabular}{c:c}
2,50386154 & 5,36063505 \\
\hdashline & -
\end{tabular} & 0,0 & $\begin{array}{l}-7,420778 \\
--\ldots--\end{array}$ & 1,549864 & 0,445121 & $\begin{array}{r}2,883741 \\
-\quad-\ldots-\end{array}$ & $\begin{array}{r}-5,972233 \\
-\end{array}$ & -0, \\
\hline $\begin{array}{r}\mathrm{H} 45 \\
--\end{array}$ & $\begin{array}{c}-5,36043094 \\
-\end{array}$ & 0,0 & $\begin{array}{l}-0,581679 \\
-----\end{array}$ & 5,698090 & $-1,932635$ & $\begin{array}{l}-2,582363 \\
---\ldots\end{array}$ & $-0,664121$ & $-3,8$ \\
\hline $\begin{array}{r}\mathrm{H} 46 \\
--\end{array}$ & $\begin{array}{c}-7,51025308 \\
-\end{array}$ & $\begin{array}{rl}1 & 0,0 \\
-1 & -1\end{array}$ & $\begin{array}{r}1,647884 \\
-----\end{array}$ & $\begin{array}{l}6,498888 \\
+\end{array}$ & 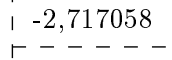 & $\begin{array}{l}-3,995454 \\
-\quad-\quad--\end{array}$ & $\begin{array}{r}1,252848 \\
-\end{array}$ & $\begin{array}{l}1-4,5 \\
7--1\end{array}$ \\
\hline $\begin{array}{r}\mathrm{H} 47 \\
---\end{array}$ & $\begin{array}{c}-5,36043094 \quad 1 \quad-2,51819255 \\
-- \\
-\end{array}$ & $\begin{array}{rl}1 & 0,0 \\
-1 & -\end{array}$ & $\begin{array}{r}3,037482 \\
-----\end{array}$ & $\begin{array}{l}1 \quad 2,437184 \\
+----\end{array}$ & $\begin{array}{l}-3,127515 \\
-----\end{array}$ & $\begin{array}{l}-1,386543 \\
-\quad-\ldots-\end{array}$ & 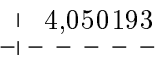 & $\begin{array}{l}1-2,5 \\
+\end{array}-$ \\
\hline $\begin{array}{r}\mathrm{N} 48 \\
---\end{array}$ & 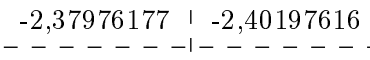 & $\begin{array}{rl}1 & 0,0 \\
-1 & -\end{array}$ & $\begin{array}{r}1,140232 \\
-\quad-\quad--\end{array}$ & $\begin{array}{l}1 \quad 0,2658 \\
+\quad--\end{array}$ & $\begin{array}{l}1-2,45 \\
\vdash--\end{array}$ & $\begin{array}{r}0,970620 \\
-\quad-\quad-\quad-\end{array}$ & $\begin{array}{c}1 \quad 2,9 \\
-1-2\end{array}$ & 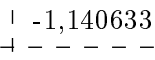 \\
\hline $\begin{array}{r}\mathrm{H} 49 \\
--\ldots\end{array}$ & 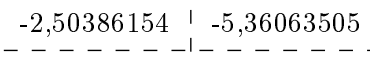 & $\begin{aligned} & 0,0 \\
- & -\end{aligned}$ & $\begin{array}{l}3,340 \\
-\end{array}$ & & $\begin{array}{l}{ }^{\prime}-3,23 \\
\llcorner--\end{array}$ & $\begin{array}{r}1,664452 \\
-\ldots-\ldots\end{array}$ & $\begin{array}{rl}1 & 5,7 \\
-1 & -\end{array}$ & $\perp-0$ \\
\hline $\begin{array}{r}\mathrm{H} 50 \\
-\end{array}$ & \begin{tabular}{c|c}
$-1,24367587$ & $-7,50771515$ \\
\hdashline$-1-1$ & -
\end{tabular} & $\begin{aligned} & 0,0 \\
- & -\end{aligned}$ & $\begin{array}{r}4,089747 \\
-\ldots-\ldots\end{array}$ & $\begin{array}{l}1 \\
1 \\
1\end{array}-3,898$ & $\begin{array}{l}\begin{array}{l}-3,547457 \\
-\end{array}-[--\end{array}$ & $\begin{array}{r}3,178532 \\
-\ldots+-\end{array}$ & $\begin{array}{r}\quad 7,328390 \\
-1 \\
-\end{array}$ & $\begin{aligned} & 0,617153 \\
- & -\end{aligned}$ \\
\hline $\begin{array}{r}\mathrm{H} 51 \\
-\_-\end{array}$ & \begin{tabular}{c:c}
2,50386154 & $-5,36063505$ \\
\hdashline & -
\end{tabular} & $\begin{array}{l}0,0 \\
- \\
-\end{array}$ & 0,238430 & $\begin{array}{l}-5,356963 \\
-\end{array}$ & $-2,266217$ & $\begin{array}{r}5,401434 \\
-\ldots \ldots\end{array}$ & 4,025696 & 2,275940 \\
\hline $\begin{array}{r}\mathrm{H} 52 \\
--\end{array}$ & $\begin{array}{r}5,36043094 \\
\hdashline \ldots \ldots \ldots\end{array}$ & 0,0 & $\begin{array}{l}-3,548118 \\
-\ldots-\ldots\end{array}$ & $\begin{array}{l}-5,682821 \\
-\end{array}$ & $\begin{array}{l}-1,027749 \\
-\end{array}$ & $\begin{array}{r}6,608541 \\
-\ldots-\ldots\end{array}$ & 0,371964 & 3,443453 \\
\hline $\begin{array}{r}\mathrm{H} 53 \\
--\end{array}$ & \begin{tabular}{r|l}
7,51025308 & $-1,24423498$ \\
\hdashline-1 & -
\end{tabular} & 0,0 & $\begin{array}{l}-5,790901 \\
-\ldots-\ldots\end{array}$ & $-6,492130$ & $-0,290877$ & $\begin{array}{l}7,857366 \\
-\ldots-\ldots\end{array}$ & $-1,570694$ & 4,387704 \\
\hline $\begin{array}{r}\mathrm{H} 54 \\
--\end{array}$ & \begin{tabular}{c|c}
5,36043094 & 2,51819255 \\
- & -
\end{tabular} & 0,0 & $\begin{array}{l}-7,139435 \\
--1--\end{array}$ & $-2,436429$ & 0,284084 & $\begin{array}{r}5,585414 \\
-\quad-\quad--\end{array}$ & $-4,304496$ & $\begin{array}{r}1,944921 \\
-\end{array}$ \\
\hline $\begin{array}{r}\mathrm{H} 55 \\
---\end{array}$ & 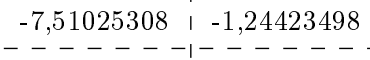 & $\begin{array}{rl}1 & 0,0 \\
-1 & --\end{array}$ & $\begin{array}{r}3,427308 \\
-\quad----\end{array}$ & $\begin{array}{l}4,898457 \\
+-----\end{array}$ & $-3,303601$ & $\begin{array}{r}-3,413410 \\
-\quad-\quad-\ldots\end{array}$ & $\begin{array}{r}3,564368 \\
-\end{array}$ & $\begin{array}{l}-3,945368 \\
- \\
-\end{array}$ \\
\hline $\begin{array}{r}\mathrm{H} 56 \\
---\end{array}$ & 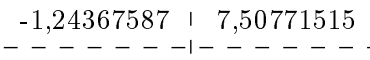 & 0,0 & $\begin{array}{l}-6,687205 \\
--\ldots--\end{array}$ & $\begin{array}{l}15,789702 \\
+-----\end{array}$ & {$\left[\begin{array}{l}0,169365 \\
-\end{array}-\right.$} & $\begin{array}{l}-0,638517 \\
-\quad-\ldots-\end{array}$ & $\begin{array}{r}1 \\
-6,692404 \\
-1\end{array}-\ldots$ & $\begin{aligned} & -2,871076 \\
- & -\end{aligned}-\ldots$ \\
\hline H57 & 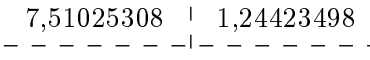 & $\begin{aligned} & 0,0 \\
-1 & -\end{aligned}$ & $\begin{array}{l}-7,555393 \\
-----\end{array}$ & $\begin{array}{l}1 \\
-4,896984 \\
+\end{array}$ & 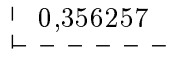 & $\begin{array}{r}7,353903 \\
-----\end{array}$ & $\begin{aligned} &-3,870484 \\
&-1- \\
&-\end{aligned}$ & $\begin{array}{l}1 \\
3,653566 \\
-----\end{array}$ \\
\hline H58 & \begin{tabular}{c|c}
1,24367587 & $-7,50771515$ \\
\hdashline
\end{tabular} & $\begin{aligned} 0,0 \\
- \\
-\end{aligned}$ & $\begin{array}{r}2,567056 \\
-\ldots-\ldots\end{array}$ & 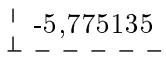 & $\left\{\begin{array}{l}-3,076022 \\
\llcorner \\
-\end{array}\right.$ & $\begin{array}{r}5,012764 \\
-\ldots-\ldots\end{array}$ & $\begin{array}{r}6,481905 \\
- \\
-\end{array}$ & $\begin{array}{r}2,027354 \\
\perp-\_-\_\end{array}$ \\
\hline $\begin{array}{r}\text { N59 } \\
--\end{array}$ & - & & $\begin{array}{l}1,790143 \\
-\ldots \ldots-\end{array}$ & $\begin{array}{l}\quad 3,347775 \\
1 \\
-\end{array}-$ & $\begin{array}{l}1,540663 \\
-\end{array}$ & $\begin{array}{l}-1,800127 \\
-\ldots-\ldots\end{array}$ & $\begin{aligned} & -3,214901 \\
- & -\end{aligned}$ & $\begin{array}{r}0,236943 \\
- \\
-\end{array}$ \\
\hline $\begin{array}{r}\mathrm{C} 60 \\
---\end{array}$ & - & 1 & $\begin{array}{r}2,937718 \\
-\ldots-\ldots\end{array}$ & $\begin{array}{l}2,844353 \\
-\end{array}$ & $\begin{array}{l}1,145125 \\
-\end{array}$ & $\begin{array}{c}-0,938602 \\
-\end{array}$ & $\begin{array}{r}-2,551829 \\
-\end{array}$ & $\begin{array}{r}0,964205 \\
-\end{array}$ \\
\hline $\mathrm{C} 61$ & & & 0,738851 & 2,605676 & 1,867966 & $-2,777527$ & $-2,630666$ & $-0,456117$ \\
\hline N62 & 1 & $1-$ & 3,281351 & 1,527107 & 0,996953 & $-0,834794$ & $\begin{array}{l}-1,194161 \\
\end{array}$ & 1,129930 \\
\hline N63 & i & - & 0,644684 & $\begin{array}{l}T,---- \\
1,248612\end{array}$ & {$\left[\begin{array}{l}1,867663 \\
1,---\end{array}\right.$} & $-3,128307$ & | $-1,323708$ & $-0,463189$ \\
\hline $\mathrm{C} 64$ & - & $1-$ & 4,107867 & I 3,613997 & I 0,774538 & 0,128879 & I $-3,141676$ & I 1,752122 \\
\hline
\end{tabular}




\begin{tabular}{|c|c|c|c|c|c|c|c|}
\hline \multirow[b]{2}{*}{ Átomo } & Monômero & \multicolumn{3}{|c|}{ Dímero (a) } & \multicolumn{3}{|c|}{ Dímero (b) } \\
\hline & $\begin{array}{l:l:l}X & Y & Z\end{array}$ & $\mathrm{X}$ & $\mathrm{Y}$ & Z & $\mathrm{X}$ & $\mathrm{Y}$ & Z \\
\hline $\begin{array}{r}\mathrm{C} 65 \\
---\end{array}$ & $\begin{array}{l:l}-1 & - \\
-- & -\end{array}-$ & $\begin{array}{r}4,569871 \\
--\ldots\end{array}$ & $\begin{array}{l}1,370015 \\
\perp-\end{array}$ & $\begin{array}{l}\mathbf{1} 0,559944 \\
-2----\end{array}$ & $\begin{array}{c}0,208024 \\
-\quad-\quad--\end{array}$ & $\begin{array}{l}1 \\
- \\
-\end{array}$ & $\begin{array}{r}1,946777 \\
-\end{array}$ \\
\hline $\mathrm{C} 66$ & $\begin{array}{l:l}-1 & - \\
- & -\end{array}$ & 5,113298 & $\begin{array}{r}2,704899 \\
-\end{array}$ & 0,408668 & 0,835902 & $\begin{array}{r}-2,092764 \\
-\end{array}$ & $\begin{array}{r}2,357555 \\
-\end{array}$ \\
\hline $\mathrm{C} 67$ & $-\begin{array}{l:l}- & - \\
- & -\end{array}$ & $-0,609112$ & 0,943589 & 2,284152 & $-4,218339$ & $-1,212214$ & $-1,272371$ \\
\hline $\mathrm{C} 68$ & $\begin{array}{r:ll}-1 & - \\
- & -\end{array}$ & $-0,518385$ & 3,218971 & 2,302630 & $-3,653026$ & $-3,418080$ & $-1,324501$ \\
\hline C69 & 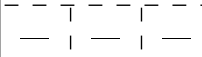 & $\begin{array}{l}----- \\
-1,381629\end{array}$ & $\begin{array}{l}T--- \\
2,155827\end{array}$ & $\begin{array}{l}\ulcorner---- \\
2,568801\end{array}$ & $-4,575164$ & $\begin{array}{l}----- \\
-2,511106\end{array}$ & $\begin{array}{l}7---- \\
-1,847933\end{array}$ \\
\hline N70 & $\begin{array}{r}-7--1-- \\
-1-1-1-\end{array}$ & $\begin{array}{l}----- \\
-1,140262\end{array}$ & $\begin{array}{l}T----- \\
-0,265766\end{array}$ & $\begin{array}{l}\ulcorner----- \\
2,453065\end{array}$ & $-4,920364$ & $\begin{array}{l}----- \\
-0,119869\end{array}$ & $\begin{array}{l}7----- \\
1-1,546128\end{array}$ \\
\hline--- & $\begin{array}{l}-++-1-- \\
-1-1-1-\end{array}$ & $\begin{array}{l}----- \\
4,691072\end{array}$ & $\begin{array}{l}+------ \\
-0,954080\end{array}$ & $\begin{array}{l}\vdash---- \\
10,498278\end{array}$ & $-0,072530$ & $1,---$ & 1,972174 \\
\hline $\mathrm{C} 72$ & $\begin{array}{r}-+--1-- \\
-1-1-\end{array}$ & $\begin{array}{l}----- \\
-0,483922\end{array}$ & $\begin{array}{l}+---- \\
-1,379797\end{array}$ & $\begin{array}{l}---- \\
2,234074\end{array}$ & $-4,592671$ & $\begin{array}{l}-1---- \\
1,075737\end{array}$ & $\begin{array}{l}-1--- \\
-1,109045\end{array}$ \\
\hline N73 & $\begin{array}{r}-+-1-- \\
-1-1-1-\end{array}$ & $\begin{array}{r}----- \\
0,807369\end{array}$ & $\begin{array}{l}-1,-- \\
-1,538598\end{array}$ & $\begin{array}{ll}- & - \\
1,805519\end{array}$ & $\begin{array}{l}---- \\
-3,519366\end{array}$ & $\begin{array}{r}1,--- \\
1,426190 \\
-\end{array}$ & $\begin{array}{l}----- \\
-0,333535 \\
-\end{array}$ \\
\hline N74 & $-:-1:-$ & 3,440458 & $-1,262522$ & 0,933028 & $-1,180249$ & 1,561060 & 1,201058 \\
\hline H75 & $\begin{array}{l:l:c}--1 & --- \\
- & - & -\end{array}$ & $\begin{array}{l}----- \\
2,653567\end{array}$ & 0 & 1,186856 & $\begin{array}{l}---- \\
-1,464662\end{array}$ & $\begin{array}{ll}-0,521966 \\
-10\end{array}$ & $\begin{array}{r}-10- \\
0,708872\end{array}$ \\
\hline--- & $\begin{array}{l:l:c}--1 & -- \\
- & - & -\end{array}$ & $\begin{array}{c}----- \\
1,433943\end{array}$ & $\begin{array}{l}-0,768520 \\
-0,0\end{array}$ & 1,604368 & $-2,846428$ & 0,758512 & 0,023480 \\
\hline $\begin{array}{l}--- \\
\mathrm{C} 77\end{array}$ & $\begin{array}{r:r:r}--1 & -- \\
- & -1 & -\end{array}$ & $\begin{array}{c}----- \\
5,466463\end{array}$ & $\begin{array}{l}T-\ldots \\
-2,167504\end{array}$ & $\begin{array}{l}--\cdots \\
0,229240\end{array}$ & $\begin{array}{l}---- \\
0,366993\end{array}$ & $\begin{array}{r}---- \\
2,768284\end{array}$ & $\begin{array}{r}---- \\
2,450513\end{array}$ \\
\hline $\mathrm{C} 78$ & $\begin{array}{l}--7--1-- \\
-1\end{array}$ & $\begin{array}{l}----- \\
3356187\end{array}$ & $T-----$ & $\Gamma----$ & $\begin{array}{l}----- \\
-1497219\end{array}$ & $\begin{array}{l}---- \\
-1- \\
2886953\end{array}$ & $7----$ \\
\hline & $--+--1--$ & & & & & $\begin{array}{l}12,000903 \\
-1-----\end{array}$ & $7-----$ \\
\hline $\begin{array}{l}\mathrm{C} 79 \\
--\end{array}$ & $\begin{array}{c}-1-1- \\
--+-1-\end{array}$ & $\begin{array}{r}1,162841 \\
-----\end{array}$ & $\begin{array}{r}1 \\
-2,858132 \\
+-\end{array}$ & $\begin{array}{l}1,696912 \\
- \\
-\end{array}$ & $\begin{array}{c}-3,438647 \\
-\ldots-\ldots-\end{array}$ & 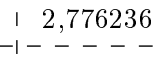 & $\begin{array}{r}-0,134483 \\
-+-\end{array}$ \\
\hline N80 & $-1-1-$ & 2,312925 & I $-3,361236$ & I 1,319560 & $-2,526042$ & 3,451772 & | 0,532309 \\
\hline C81 & $\begin{array}{l}-+--1-- \\
-1-1-\end{array}$ & $\begin{array}{c}----- \\
4.613562\end{array}$ & $\begin{array}{l}+------ \\
-3,230269\end{array}$ & $\begin{array}{l}----- \\
0,527612\end{array}$ & $-0 .---$ & $\begin{array}{r}-1---- \\
3.684499\end{array}$ & $\begin{array}{l}4----- \\
1 \\
1\end{array}$ \\
\hline & $--\perp--1--$ & & & & & $-1+----$ & $\perp-1,--$ \\
\hline C82 & $-:-1-$ & 6,764688 & $-2,383478$ & $-0,216032$ & 1,423106 & 3,172284 & 3,255085 \\
\hline $\mathrm{C} 83$ & $-:-1-$ & 5,025824 & $-4,550162$ & 0,392532 & $-0,419522$ & 5,044689 & 2,164473 \\
\hline $\mathrm{C} 84$ & $\begin{array}{lll}-1 & --1 \\
- & -\end{array}$ & $\begin{array}{c}----- \\
7,182978\end{array}$ & $\begin{array}{l}---- \\
-3.703457\end{array}$ & $\begin{array}{l}--- \\
53478\end{array}$ & $\begin{array}{l}---- \\
1.548008\end{array}$ & $\begin{array}{l}--- \\
4.535567\end{array}$ & $\begin{array}{c}--- \\
3,505833\end{array}$ \\
\hline & $--\frac{1}{1}--\frac{1}{1}-$ & & & & & & \\
\hline $\begin{array}{r}\mathrm{C} 85 \\
--- \\
-\end{array}$ & $-1-1-$ & 6,325321 & $-4,772376$ & $-0,052470$ & 0,640557 & 5,457425 & 2,967327 \\
\hline $\mathrm{C} 86$ & $-1-1-$ & $-0,002612$ & $-3,627333$ & 2,094170 & $-4,569229$ & 3,357287 & $\begin{array}{ll}-0,825997 \\
\end{array}$ \\
\hline & $--\top--1--$ & & & & & $-i_{1}---$ & \\
\hline $\begin{array}{r}\text { C87 } \\
---\end{array}$ & $\begin{array}{c}-1-1= \\
--+-1-\end{array}$ & $\begin{array}{l}-1,016919 \\
-\ldots \ldots\end{array}$ & $\begin{array}{r}-2,716331 \\
+\end{array}$ & $\begin{array}{l}1 \quad 2,425224 \\
-\ldots \ldots\end{array}$ & $\begin{array}{l}-5,283325 \\
-\ldots-\ldots-\end{array}$ & $\begin{array}{r}2,307121 \\
-\end{array}$ & - $-1,425432$ \\
\hline C88 & $-1-1-$ & $-0,209872$ & $-5,002173$ & 2,189756 & $-4,964671$ & 4,685130 & $\begin{array}{ll}-0,990687 \\
\end{array}$ \\
\hline & & & & & & & \\
\hline $\begin{array}{r}\text { C89 } \\
-----\end{array}$ & $\begin{aligned} &-1-1-1- \\
&--1--1-\end{aligned}$ & $\begin{array}{l}-2,265620 \\
-\ldots-\ldots\end{array}$ & $\begin{array}{l}-3,152694 \\
+-\end{array}$ & $\begin{array}{l}\mathbf{1} 2,865110 \\
\left\llcorner--_{-}\right.\end{array}$ & $\begin{array}{l}-6,411913 \\
-\quad-\quad-\quad-.\end{array}$ & $\begin{array}{r}\mathrm{I} 2,557806 \\
-\mathrm{I}-\end{array}$ & $\begin{array}{r}\quad-2,206699 \\
- \\
-\end{array}$ \\
\hline C90 & $-: \begin{array}{c}-1 \\
-\end{array}-$ & $-2,469126$ & $-4,520661$ & 2,960793 & $-6,801561$ & 3,877093 & $-2,369316$ \\
\hline C91 & $-:-1-$ & $-1,452808$ & $-5,434692$ & 2,625867 & $-6,085606$ & 4,930736 & $-1,766589$ \\
\hline $\mathrm{C} 92$ & $-1-1-$ & 6,370281 & 3,148203 & $-0,004261$ & 1,930156 & $-2,339853$ & 3,182021 \\
\hline $\mathrm{C} 93$ & $-\begin{array}{l:l}- & -\end{array}-$ & $-2,678125$ & 2,369908 & 3,020390 & $-5,564577$ & $-2,918791$ & $-2,734848$ \\
\hline C94 & $\begin{aligned}-1 & -1 \\
-1 & -1\end{aligned}$ & $\begin{array}{c}----- \\
4,332108\end{array}$ & 4,990474 & 0,739926 & 0,505 & & 9 \\
\hline & & & & & & & \\
\hline C95 & $-1-1-$ & $-0,918730$ & | 4,537838 & I 2,474946 & $-3,684034$ & । $-4,765308$ & । $-1,664502$ \\
\hline C96 & $-1-1-$ & 6,589224 & 4,515568 & | $-0,039956$ & 2,301770 & $-3,662838$ & | 3,372349 \\
\hline
\end{tabular}




\begin{tabular}{|c|c|c|c|c|c|c|c|}
\hline \multirow[b]{2}{*}{ Átomo } & Monômero & \multicolumn{3}{|c|}{ Dímero (a) } & \multicolumn{3}{|c|}{ Dímero (b) } \\
\hline & $X \quad Y \quad I \quad Z$ & $\mathrm{X}$ & $\mathrm{Y}$ & $\mathrm{Z}$ & $\mathrm{X}$ & $\mathrm{Y}$ & Z \\
\hline $\mathrm{C} 97$ & 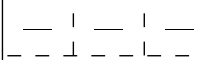 & 5,581002 & $\begin{array}{r}5,427385 \\
-\end{array}$ & 0,329528 & 1,600904 & $-4,713317$ & I 2,755120 \\
\hline $\mathrm{C} 98$ & $\begin{array}{r:l}-1 & - \\
- & -\end{array}$ & $-3,084207$ & $\begin{array}{l}3,689576 \\
-\end{array}$ & 3,195270 & $-5,598962$ & \begin{tabular}{l}
$-4,265941$ \\
\hdashline-
\end{tabular} & $-3,082034$ \\
\hline C99 & $\begin{array}{r:l}-1 & - \\
- & -\end{array}$ & $-2,216349$ & $\begin{array}{l}4,758264 \\
\end{array}$ & 2,926045 & $-4,671001$ & $\begin{array}{l}-5,177295 \\
-\end{array}$ & $\begin{array}{l}-2,554618 \\
-\end{array}$ \\
\hline H100 & $-\begin{array}{l:l}1 & - \\
- & -\end{array}$ & $-0,238371$ & 5,356976 & 2,266197 & $-2,956713$ & $-5,457848$ & $-1,252592$ \\
\hline H101 & $--7--1$ & $-4,089739$ & 3,899078 & 3,547370 & $-6,356123$ & $-4,621973$ & $-3,774433$ \\
\hline H102 & $\begin{array}{l:l}--1 & --- \\
-1 & -1\end{array}$ & $-3,340340$ & $\begin{array}{l}----- \\
1,536579\end{array}$ & $\begin{array}{l}----- \\
3,231060\end{array}$ & $-6,279495$ & $\begin{array}{l}--1 \\
-2,207441\end{array}$ & $\begin{array}{l}7---- \\
-3,135744\end{array}$ \\
\hline H103 & $\begin{array}{r}--1--1 \\
-1-1-\end{array}$ & 3,548200 & $\begin{array}{l}T,- \\
5,682811\end{array}$ & 1,027668 & $-0,032384$ & $\begin{array}{l}-5,269529 \\
-\end{array}$ & 1,443601 \\
\hline H104 & $\begin{array}{r}-1--1 \\
-1-1- \\
-1-1-\end{array}$ & $\begin{array}{l}----- \\
5,791014\end{array}$ & $\begin{array}{l}T----- \\
6,492043\end{array}$ & 0,290793 & 1,930459 & $\begin{array}{l}----- \\
-5,735148\end{array}$ & $\begin{array}{l}7---- \\
12,915932\end{array}$ \\
\hline $\begin{array}{l}--- \\
\mathrm{H} 105\end{array}$ & $\begin{array}{r}-+1--1-- \\
-1-1-1-\end{array}$ & $\begin{array}{c}----- \\
7,139425\end{array}$ & $\begin{array}{l}+------ \\
2,436292\end{array}$ & $-0,284097$ & 2,475155 & $-1,520015$ & $\begin{array}{l}7---- \\
13,638700\end{array}$ \\
\hline $\begin{array}{l}--- \\
\text { N106 }\end{array}$ & $\begin{array}{r}--+--1-- \\
-1-1-\end{array}$ & $\begin{array}{l}----- \\
5,219582\end{array}$ & $\begin{array}{l}+----- \\
+0,252343\end{array}$ & $\begin{array}{l}\vdash----- \\
\end{array} 0,324130$ & $\begin{array}{l}---- \\
0,579374\end{array}$ & $\begin{array}{r}---- \\
0,347829\end{array}$ & $\begin{array}{l}-1---- \\
\text { I } 2,325052\end{array}$ \\
\hline---- & $--+--1--$ & & & & & & \\
\hline $\mathrm{H} 107$ & $\begin{array}{r}-1-1 \\
--\end{array}-$ & $\begin{array}{r}7,420768 \\
-\end{array}$ & -1,549935 & $-0,444839$ & 2,129624 & $\begin{array}{r}2,450253 \\
-1-\ldots\end{array}$ & $\begin{array}{l}3,651415 \\
\lrcorner\end{array}$ \\
\hline $\mathrm{H} 108$ & $\begin{array}{r:l}-1 & -1 \\
-- & -\end{array}$ & 8,191452 & $-3,913478$ & $-0,697496$ & 2,372782 & $\begin{array}{r}4,895682 \\
-\end{array}$ & \lrcorner$_{-} 4,112505$ \\
\hline H109 & $\begin{array}{l}-1 \\
-1-1 \\
-\end{array}$ & $\begin{array}{r}4,353769 \\
--\ldots--\end{array}$ & $\begin{array}{l}-5,368590 \\
\perp-\ldots\end{array}$ & $\begin{array}{l}0,628734 \\
-\end{array}$ & $-1,126445$ & $\begin{array}{r}5,752252 \\
\hdashline\end{array}$ & $\begin{array}{r}1,743637 \\
-\end{array}$ \\
\hline H110 & $\begin{array}{l:l}-1 & - \\
- & -\end{array}$ & 0,581483 & $-5,698102$ & 1,932569 & $-4,402294$ & 5,487901 & $-0,525497$ \\
\hline H111 & $-:-1-$ & $-1,648063$ & $-6,498870$ & 2,717071 & $-6,421981$ & 5,952091 & $-1,917139$ \\
\hline $\mathrm{H} 112$ & $-1-1-$ & $-3,037614$ & $-2,437150$ & 3,127511 & $-6,952084$ & 1,738718 & $-2,669871$ \\
\hline H113 & $\begin{array}{l:l}-1 & - \\
-1 & -1\end{array}$ & 7,555466 & ( 4,896834 & $-0,356285$ & 3,163800 & $-3,890449$ & 3,991885 \\
\hline $\mathrm{H} 114$ & $-1-1-$ & $-2,566970$ & I 5,775215 & 3,076042 & $-4,729869$ & $-6,221769$ & I $-2,846442$ \\
\hline H115 & $-1-1-$ & $-3,427470$ & $-4,898410$ & 3,303607 & $-7,675182$ & । 4,108976 & $-2,971144$ \\
\hline H116 & $-1-1-$ & 6,687163 & | $-5,789768$ & I $-0,169153$ & 0,777237 & । 6,514740 & | 3,173234 \\
\hline
\end{tabular}




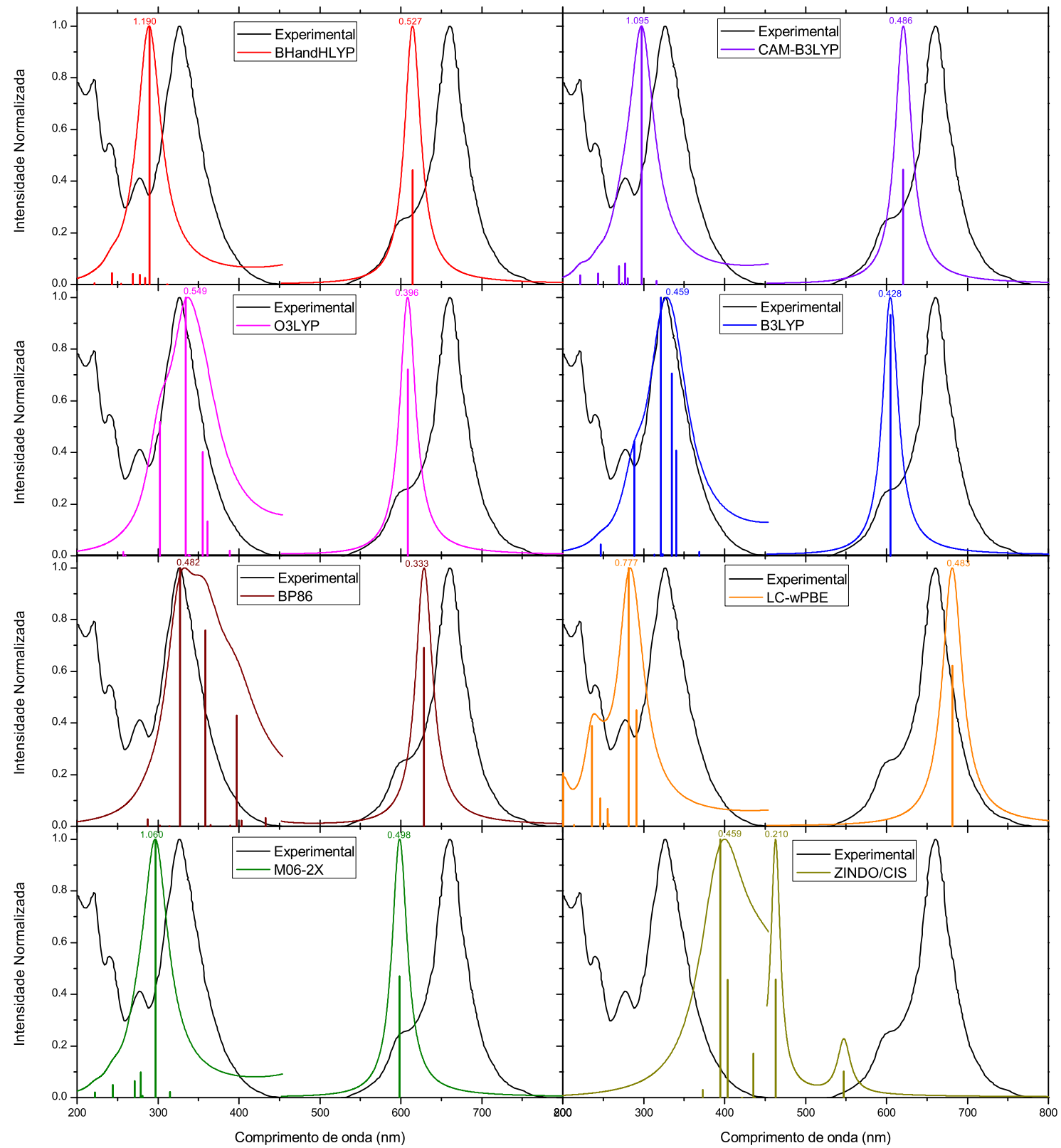

Figura C.7: Comparação de resultados para a $Z n$-Ftalocianina isolada. O espectro experimental foi retirado de [29]. Mostramos os picos teóricos e a convolução dos picos obtidos utilizando. Veja que amplificamos as curvas na região de 420 a $800 \mathrm{~nm}$, porém os picos teóricos não foram amplificados. Como pode ser visto em [29], a absorbância máxima na região do visível é 0,288 e na região ultravioleta é 0,251 . 


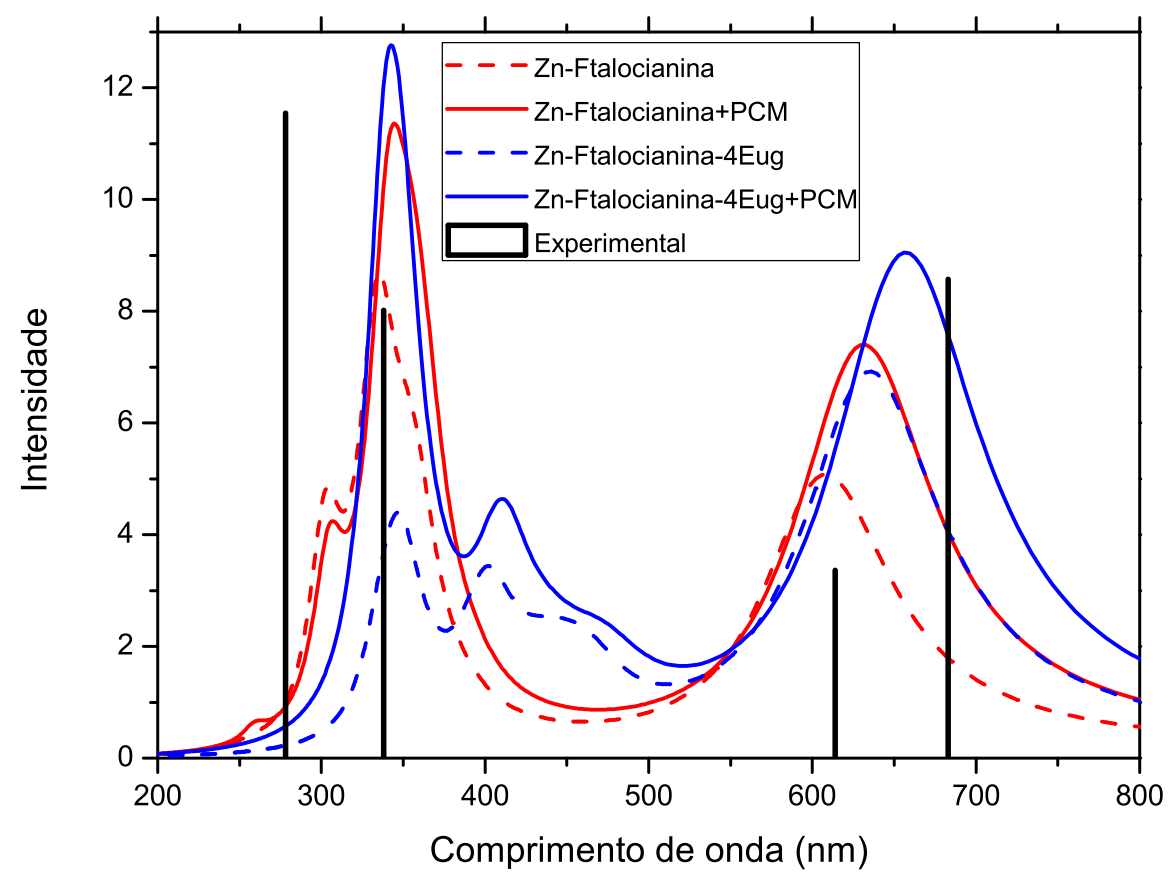

Figura C.8: Cálculo do espectro de absorção da molécula Ftalocianina complexada com Zinco, com e sem os quatro Eugenóis substituintes, e com e sem a inclusão de efeitos de solvente. Os cálculos foram feitos no nível O3LYP $/ 6-31+\mathrm{G}^{*}$. Os efeitos de solvente em meio Clorofórmio, quando incluídos, foram incluídos utilizando o modelo PCM. O resultado experimental do espectro de absorção em Clorofórmio também é apresentado e foi retirado de [93]. Nesta figura optamos por não normalizar as curvas, apenas as barras referentes ao espectro experimental. 


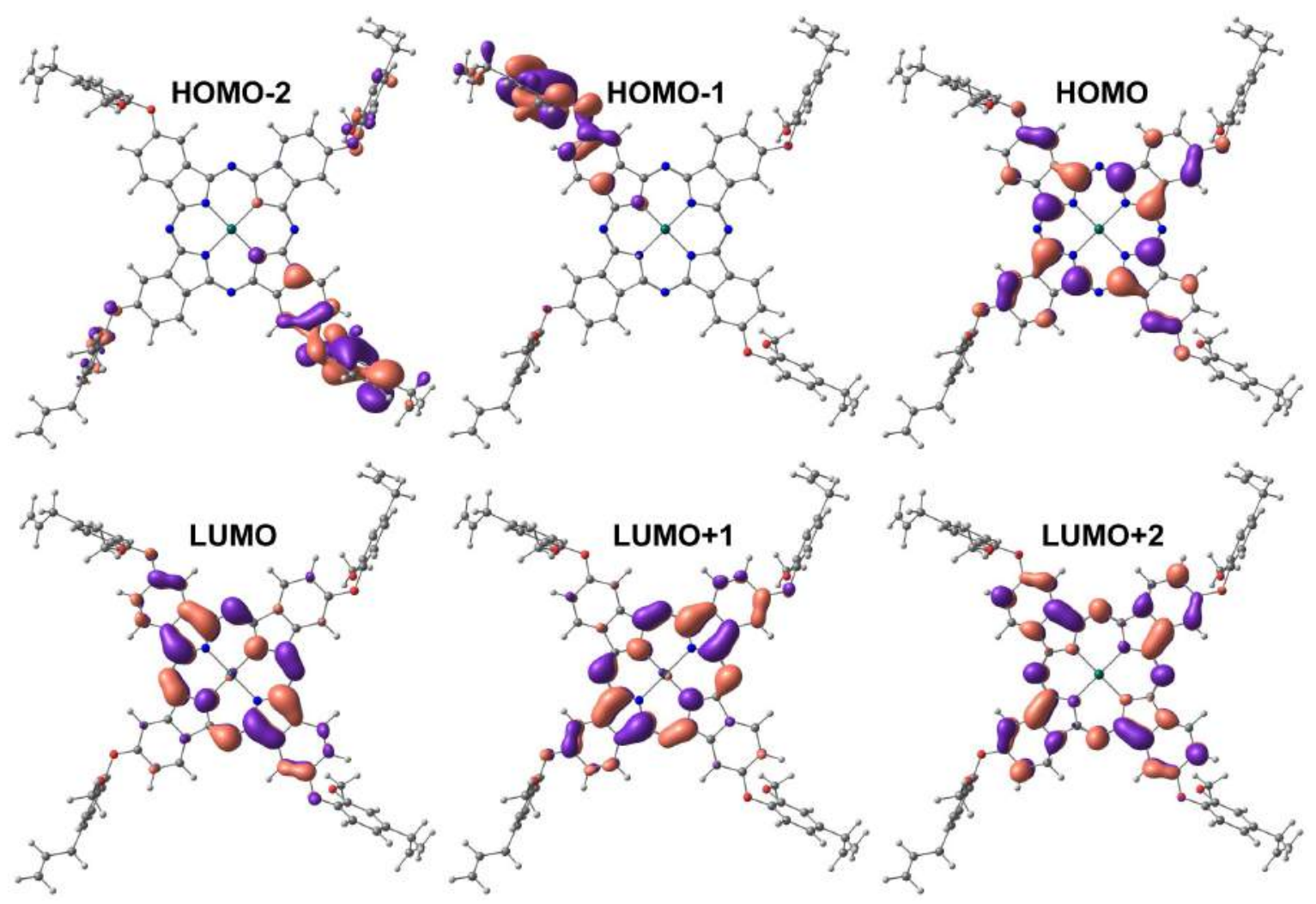

Figura C.9: Orbitais Moleculares da molécula Ftalocianina complexada com Zinco com quatro Eugenóis substituintes, obtidos no nível O3LYP/6-31+G*, em meio Clorofórmio utilizando o modelo PCM. 


\section{Apêndice D}

\section{Parametrizações das Dinâmicas Clássicas}

Neste apêndice são apresentados os arquivos de topologia e de inicialização da simulação, já no formato do programa GROMACS, utilizados nas dinâmicas clássicas para as moléculas $\mathrm{H}_{2}$-Porfirina e $\mathrm{H}_{2}$-Ftalocianina. Os resultados e análises dessas dinâmicas são apresentados no capítulo 3 .

\section{D.1 Parametrização da $H_{2}$-Porfirina}

\section{D.1.1 Arquivo de topologia}

É apresentado em seguida o arquivo *.top, no formato de arquivo de topologia do programa GROMACS [73-75], que contém os parâmetros da parametrização feita para a $H_{2}$-Porfirina baseada no campo de força GROMOS [68] com o conjunto de parâmetros 53A6 [69]. Os valores dos comprimentos de ligação, ângulos, e diedros fornecidos pela parametrização foram modificados para os valores obtidos para a estrutura optimizada, que foi obtida no nível B3LYP $/ 6-31+\mathrm{G}(\mathrm{d}, \mathrm{p})$ (ver início da seção 3.1). Os valores das cargas atômicas também foram modificados por valores obtidos a partir de um cálculo CHelpG no nível B3LYP $/ 6-31+\mathrm{G}^{* *}$ para a geometria optimizada. São 
apresentados também os valores modificados das constantes de força para reproduzir melhor a dinâmica $a b$ initio (ver subseção 3.1.5.4). Os rótulos dos átomos usados nesta parametrização são apresentados na figura 3.2 .

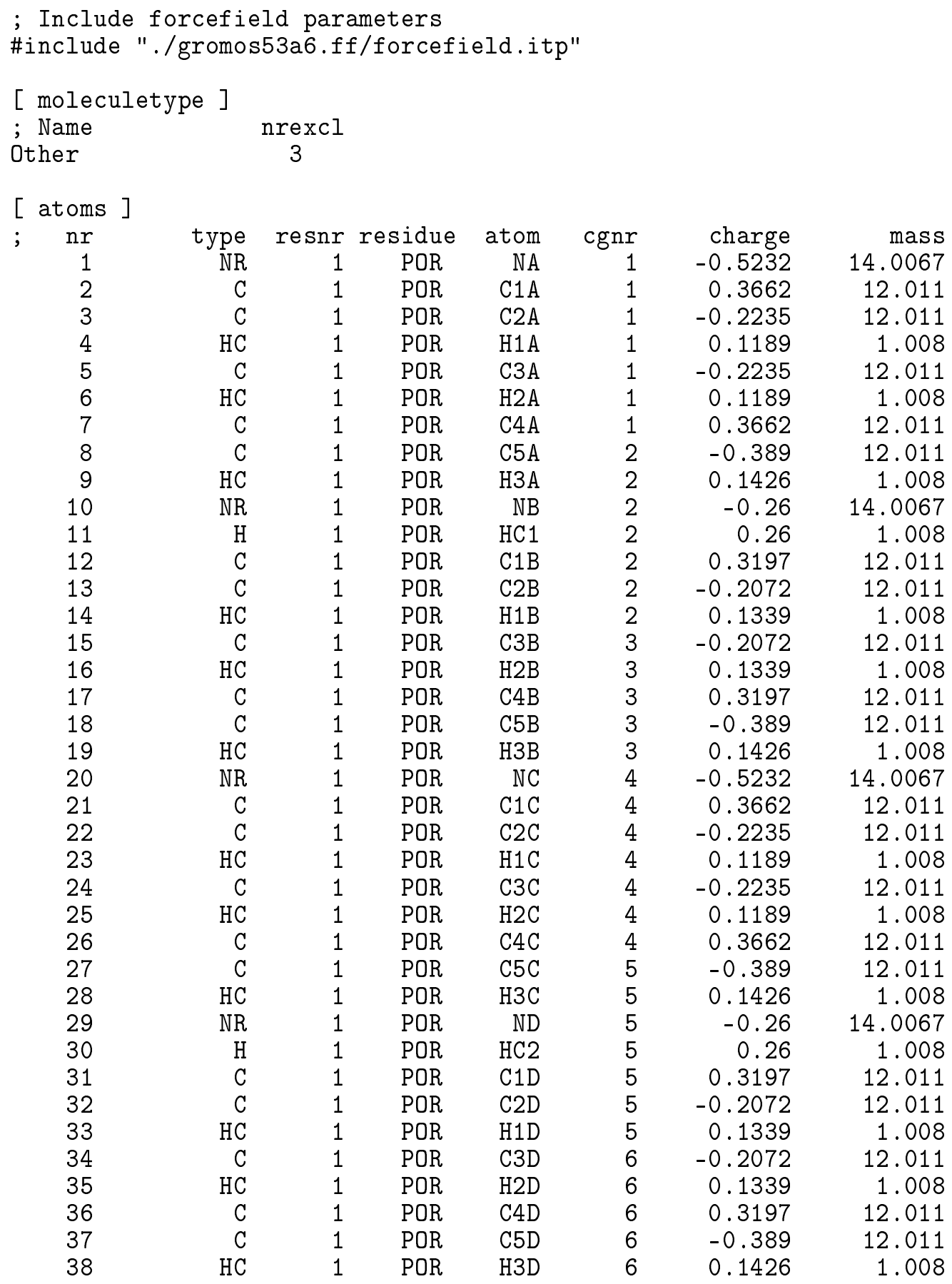




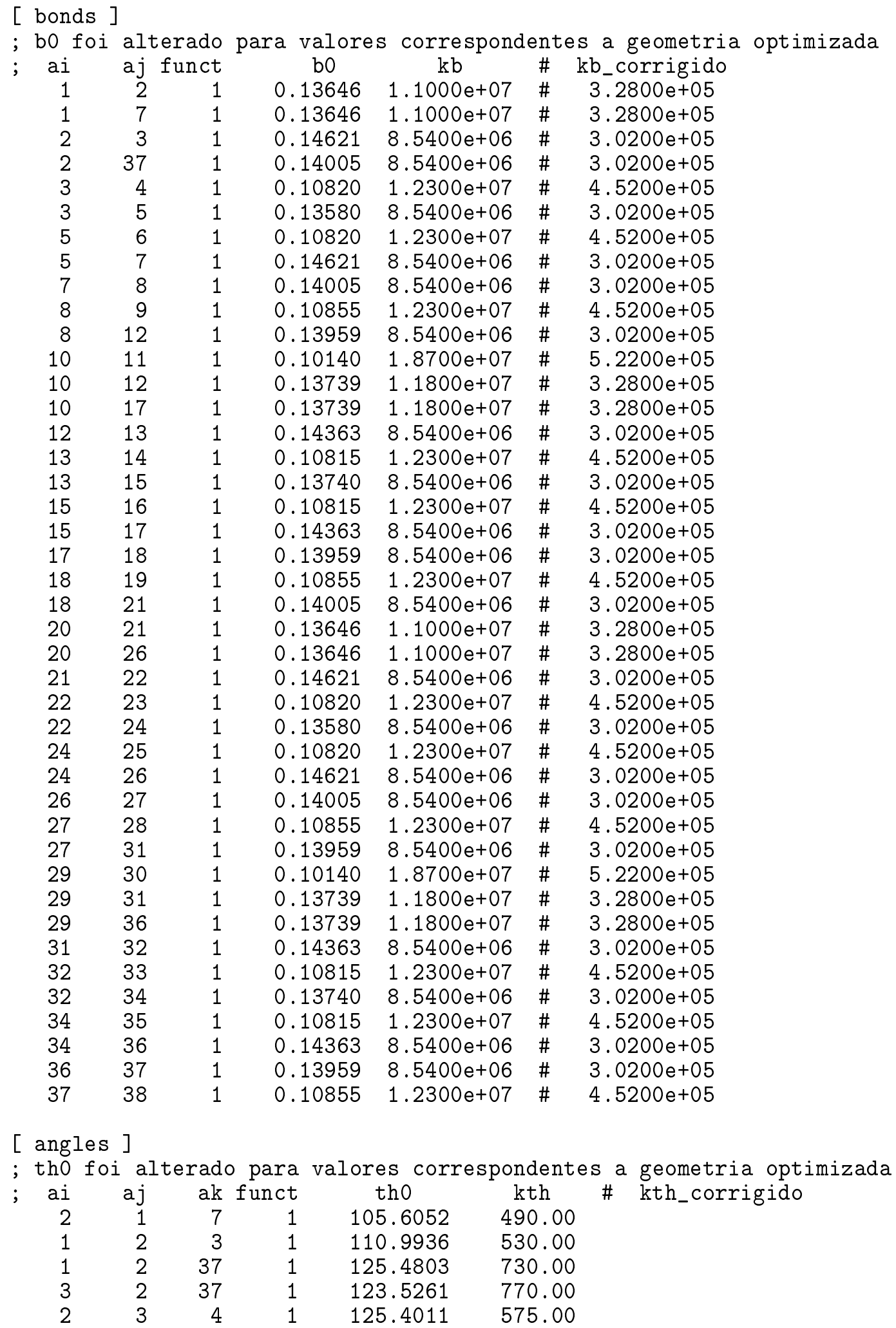




\begin{tabular}{|c|c|c|c|c|c|c|c|}
\hline 2 & 3 & 5 & 1 & 106.2038 & 465.00 & & \\
\hline 4 & 3 & 5 & 1 & 128.3952 & 575.00 & & \\
\hline 3 & 5 & 6 & 1 & 128.3952 & 575.00 & & \\
\hline 3 & 5 & 7 & 1 & 106.2038 & 465.00 & & \\
\hline 6 & 5 & 7 & 1 & 125.4011 & 575.00 & & \\
\hline 1 & 7 & 5 & 1 & 110.9936 & 530.00 & & \\
\hline 1 & 7 & 8 & 1 & 125.4803 & 730.00 & & \\
\hline 5 & 7 & 8 & 1 & 123.5261 & 770.00 & & \\
\hline 7 & 8 & 9 & 1 & 116.9685 & 465.00 & & \\
\hline 7 & 8 & 12 & 1 & 127.1722 & 640.00 & & \\
\hline 9 & 8 & 12 & 1 & 115.8593 & 465.00 & & \\
\hline 11 & 10 & 12 & 1 & 124.5923 & 575.00 & \# & 209.00 \\
\hline 11 & 10 & 17 & 1 & 124.5923 & 575.00 & \# & 209.00 \\
\hline 12 & 10 & 17 & 1 & 110.8154 & 465.00 & & \\
\hline 8 & 12 & 10 & 1 & 125.5579 & 730.00 & & \\
\hline 8 & 12 & 13 & 1 & 127.8559 & 770.00 & & \\
\hline 10 & 12 & 13 & 1 & 106.5862 & 465.00 & & \\
\hline 12 & 13 & 14 & 1 & 124.3188 & 575.00 & & \\
\hline 12 & 13 & 15 & 1 & 108.0061 & 465.00 & & \\
\hline 14 & 13 & 15 & 1 & 127.6752 & 575.00 & & \\
\hline 13 & 15 & 16 & 1 & 127.6752 & 575.00 & & \\
\hline 13 & 15 & 17 & 1 & 108.0061 & 465.00 & & \\
\hline 16 & 15 & 17 & 1 & 124.3188 & 575.00 & & \\
\hline 10 & 17 & 15 & 1 & 106.5862 & 465.00 & & \\
\hline 10 & 17 & 18 & 1 & 125.5579 & 730.00 & & \\
\hline 15 & 17 & 18 & 1 & 127.8559 & 770.00 & & \\
\hline 17 & 18 & 19 & 1 & 115.8593 & 465.00 & & \\
\hline 17 & 18 & 21 & 1 & 127.1722 & 640.00 & & \\
\hline 19 & 18 & 21 & 1 & 116.9685 & 465.00 & & \\
\hline 21 & 20 & 26 & 1 & 105.6052 & 490.00 & & \\
\hline 18 & 21 & 20 & 1 & 125.4803 & 730.00 & & \\
\hline 18 & 21 & 22 & 1 & 123.5261 & 770.00 & & \\
\hline 20 & 21 & 22 & 1 & 110.9936 & 530.00 & & \\
\hline 21 & 22 & 23 & 1 & 125.4011 & 575.00 & & \\
\hline 21 & 22 & 24 & 1 & 106.2038 & 465.00 & & \\
\hline 23 & 22 & 24 & 1 & 128.3952 & 575.00 & & \\
\hline 22 & 24 & 25 & 1 & 128.3952 & 575.00 & & \\
\hline 22 & 24 & 26 & 1 & 106.2038 & 465.00 & & \\
\hline 25 & 24 & 26 & 1 & 125.4011 & 575.00 & & \\
\hline 20 & 26 & 24 & 1 & 110.9936 & 530.00 & & \\
\hline 20 & 26 & 27 & 1 & 125.4803 & 730.00 & & \\
\hline 24 & 26 & 27 & 1 & 123.5261 & 770.00 & & \\
\hline 26 & 27 & 28 & 1 & 116.9685 & 465.00 & & \\
\hline 26 & 27 & 31 & 1 & 127.1722 & 640.00 & & \\
\hline 28 & 27 & 31 & 1 & 115.8593 & 465.00 & & \\
\hline 30 & 29 & 31 & 1 & 124.5923 & 575.00 & \# & 209.00 \\
\hline 30 & 29 & 36 & 1 & 124.5923 & 575.00 & \# & 209.00 \\
\hline 31 & 29 & 36 & 1 & 110.8154 & 465.00 & & \\
\hline 27 & 31 & 29 & 1 & 125.5579 & 730.00 & & \\
\hline 27 & 31 & 32 & 1 & 127.8559 & 770.00 & & \\
\hline 29 & 31 & 32 & 1 & 106.5862 & 465.00 & & \\
\hline 31 & 32 & 33 & 1 & 124.3188 & 575.00 & & \\
\hline 31 & 32 & 34 & 1 & 108.0061 & 465.00 & & \\
\hline 33 & 32 & 34 & 1 & 127.6752 & 575.00 & & \\
\hline
\end{tabular}




$\begin{array}{rlllll}32 & 34 & 35 & 1 & 127.6752 & 575.00 \\ 32 & 34 & 36 & 1 & 108.0061 & 465.00 \\ 35 & 34 & 36 & 1 & 124.3188 & 575.00 \\ 29 & 36 & 34 & 1 & 106.5862 & 465.00 \\ 29 & 36 & 37 & 1 & 125.5579 & 730.00 \\ 34 & 36 & 37 & 1 & 127.8559 & 770.00 \\ 2 & 37 & 36 & 1 & 127.1722 & 640.00 \\ 2 & 37 & 38 & 1 & 116.9685 & 465.00 \\ 36 & 37 & 38 & 1 & 115.8593 & 465.00\end{array}$

[ dihedrals ]

$\begin{array}{rrrrrrrr}\text {; } & \text { aj } & \text { ak } & \text { al funct } & & & \\ 1 & 2 & 37 & 36 & 1 & 180.000 & 41.8 & 2 \\ 1 & 7 & 8 & 12 & 1 & 180.000 & 41.8 & 2 \\ 7 & 8 & 12 & 10 & 1 & 180.000 & 41.8 & 2 \\ 10 & 17 & 18 & 21 & 1 & 180.000 & 41.8 & 2 \\ 17 & 18 & 21 & 20 & 1 & 180.000 & 41.8 & 2 \\ 20 & 26 & 27 & 31 & 1 & 180.000 & 41.8 & 2 \\ 26 & 27 & 31 & 29 & 1 & 180.000 & 41.8 & 2 \\ 29 & 36 & 37 & 2 & 1 & 180.000 & 41.8 & 2\end{array}$

[ dihedrals ]

$\begin{array}{rrrrrrr}\text { ai } & \text { aj } & \text { ak } & \text { al } \text { funct } & & \\ 1 & 7 & 5 & 3 & 2 & 0.0 & 167.42309 \\ 1 & 2 & 3 & 5 & 2 & 0.0 & 167.42309 \\ 2 & 37 & 1 & 3 & 2 & 0.0 & 167.42309 \\ 2 & 1 & 7 & 5 & 2 & 0.0 & 167.42309 \\ 2 & 3 & 5 & 7 & 2 & 0.0 & 167.42309 \\ 2 & 36 & 38 & 37 & 2 & 0.0 & 167.42309 \\ 3 & 2 & 5 & 4 & 2 & 0.0 & 167.42309 \\ 3 & 2 & 1 & 7 & 2 & 0.0 & 167.42309 \\ 5 & 3 & 7 & 6 & 2 & 0.0 & 167.42309 \\ 5 & 8 & 1 & 7 & 2 & 0.0 & 167.42309 \\ 8 & 7 & 12 & 9 & 2 & 0.0 & 167.42309 \\ 8 & 13 & 10 & 12 & 2 & 0.0 & 167.42309 \\ 10 & 11 & 17 & 12 & 2 & 0.0 & 167.42309 \\ 10 & 17 & 15 & 13 & 2 & 0.0 & 167.42309 \\ 10 & 12 & 13 & 15 & 2 & 0.0 & 167.42309 \\ 12 & 10 & 17 & 15 & 2 & 0.0 & 167.42309 \\ 12 & 13 & 15 & 17 & 2 & 0.0 & 167.42309 \\ 13 & 12 & 15 & 14 & 2 & 0.0 & 167.42309 \\ 13 & 16 & 17 & 15 & 2 & 0.0 & 167.42309 \\ 13 & 12 & 10 & 17 & 2 & 0.0 & 167.42309 \\ 15 & 18 & 10 & 17 & 2 & 0.0 & 167.42309 \\ 17 & 19 & 21 & 18 & 2 & 0.0 & 167.42309 \\ 18 & 22 & 20 & 21 & 2 & 0.0 & 167.42309 \\ 20 & 26 & 24 & 22 & 2 & 0.0 & 167.42309 \\ 20 & 21 & 22 & 24 & 2 & 0.0 & 167.42309 \\ 20 & 24 & 27 & 26 & 2 & 0.0 & 167.42309 \\ 21 & 23 & 24 & 22 & 2 & 0.0 & 167.42309 \\ 21 & 20 & 26 & 24 & 2 & 0.0 & 167.42309 \\ 21 & 22 & 24 & 26 & 2 & 0.0 & 167.42309 \\ 22 & 25 & 26 & 24 & 2 & 0.0 & 167.42309 \\ 22 & 21 & 20 & 26 & 2 & 0.0 & 167.42309\end{array}$




$\begin{array}{lllllll}27 & 28 & 26 & 31 & 2 & 0.0 & 167.42309 \\ 29 & 27 & 32 & 31 & 2 & 0.0 & 167.42309 \\ 29 & 36 & 34 & 32 & 2 & 0.0 & 167.42309 \\ 29 & 31 & 32 & 34 & 2 & 0.0 & 167.42309 \\ 31 & 29 & 36 & 34 & 2 & 0.0 & 167.42309 \\ 31 & 32 & 34 & 36 & 2 & 0.0 & 167.42309 \\ 32 & 33 & 31 & 34 & 2 & 0.0 & 167.42309 \\ 32 & 31 & 29 & 36 & 2 & 0.0 & 167.42309 \\ 34 & 35 & 32 & 36 & 2 & 0.0 & 167.42309 \\ 36 & 34 & 29 & 37 & 2 & 0.0 & 167.42309\end{array}$

[ system ]

; Name

H2-PORPHYRIN

[ molecules ]

; Compound

Other

\section{D.1.2 Arquivo de inicialização da dinâmica}

É apresentado em seguida o arquivo *.mdp, no formato de arquivo de inicialização do programa GROMACS [73-75], para a dinâmica feita para o monômero de $H_{2^{-}}$ Porfirina. Maiores informações e a descrição de cada palavra-chave (keyword) desse arquivo podem ser encontradas no manual do GROMACS [74].

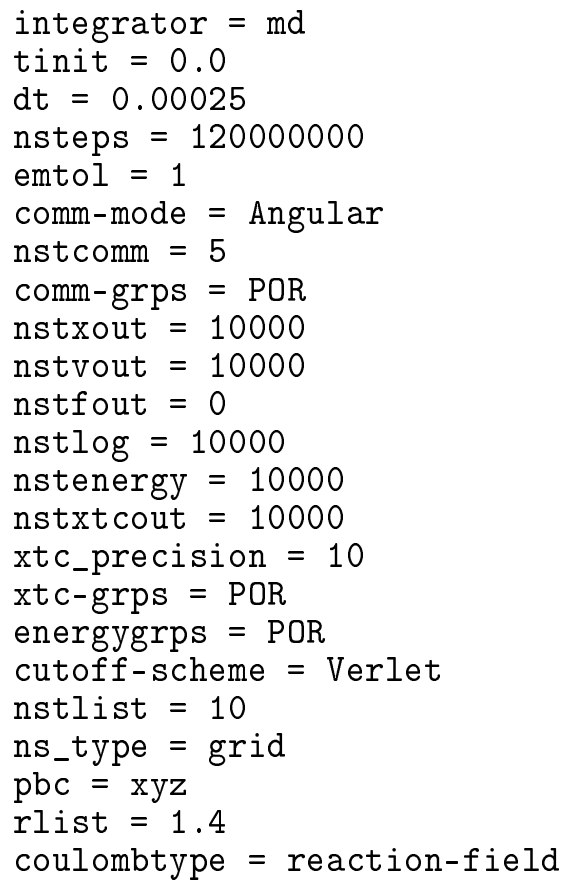




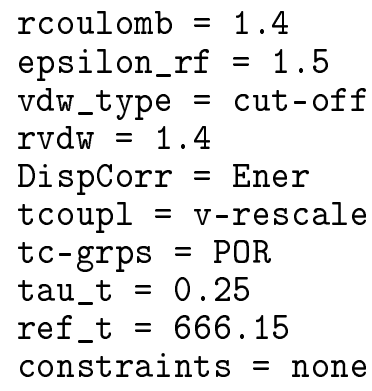

\section{D.2 Parametrização da $H_{2}$-Ftalocianina}

\section{D.2.1 Arquivo de topologia}

É apresentado em seguida o arquivo *.top, no formato de arquivo de topologia do programa GROMACS [73-75], que contém os parâmetros da parametrização feita para a $H_{2}$-Ftalocianina baseada no campo de força GROMOS [68] com o conjunto de parâmetros 53A6 [69]. Os valores dos comprimentos de ligação, ângulos, e diedros fornecidos pela parametrização foram modificados para os valores obtidos para a estrutura optimizada, que foi obtida no nível B3LYP $/ 6-31+\mathrm{G}^{*}$ (ver início da seção 3.2). Os valores das cargas atômicas também foram modificados por valores obtidos a partir de um cálculo CHelpG no nível B3LYP $/ 6-31+\mathrm{G}^{* *}$ para a geometria optimizada. Os rótulos dos átomos usados nesta parametrização são apresentados na figura 3.20.

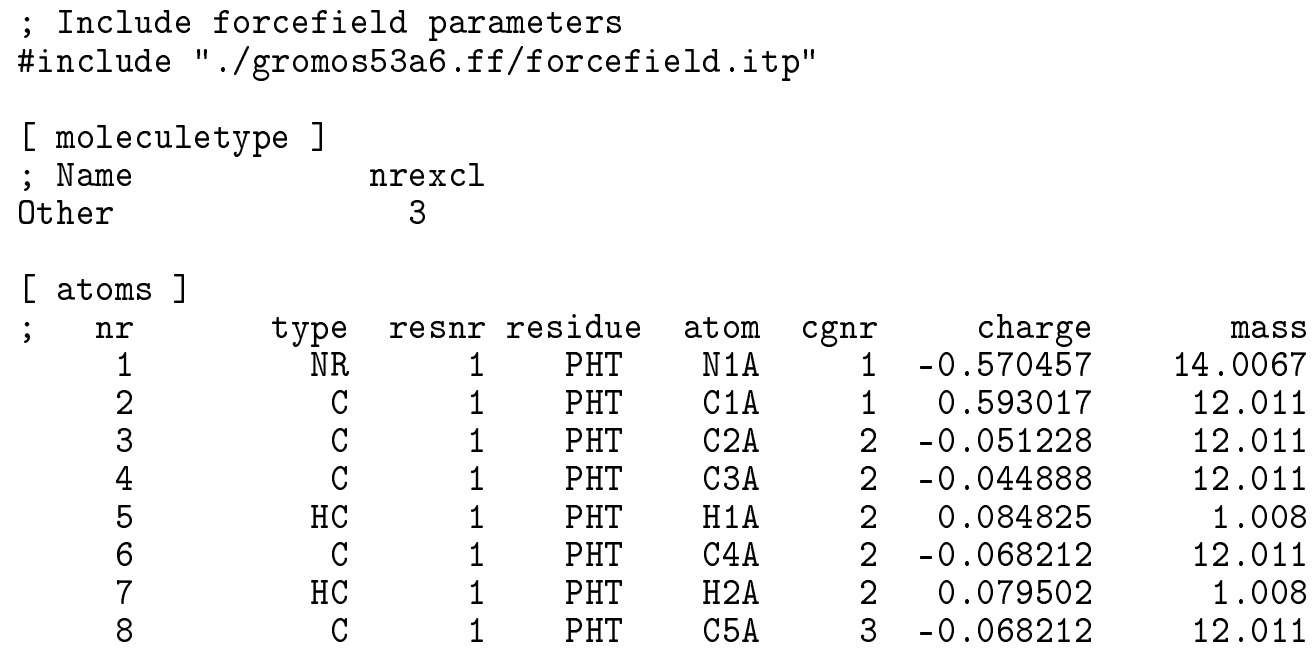




\begin{tabular}{|c|c|c|c|c|c|c|c|}
\hline 9 & $\mathrm{HC}$ & 1 & PHT & $\mathrm{H} 3 \mathrm{~A}$ & 3 & 0.079502 & 1.008 \\
\hline 10 & $\mathrm{C}$ & 1 & PHT & $\mathrm{C} 6 \mathrm{~A}$ & 3 & -0.044888 & 12.011 \\
\hline 11 & $\mathrm{HC}$ & 1 & PHT & $\mathrm{H} 4 \mathrm{~A}$ & 3 & 0.084825 & 1.008 \\
\hline 12 & C & 1 & PHT & C7A & 3 & -0.051228 & 12.011 \\
\hline 13 & C & 1 & PHT & $\mathrm{C} 8 \mathrm{~A}$ & 1 & 0.593017 & 12.011 \\
\hline 14 & NR & 1 & PHT & $\mathrm{N} 2 \mathrm{~A}$ & 1 & -0.615577 & 14.0067 \\
\hline 15 & NR & 1 & PHT & N1B & 4 & -0.380823 & 14.0067 \\
\hline 16 & $\mathrm{H}$ & 1 & PHT & $\mathrm{HC} 1$ & 4 & 0.251155 & 1.008 \\
\hline 17 & C & 1 & PHT & C1B & 4 & 0.430592 & 12.011 \\
\hline 18 & $\mathrm{C}$ & 1 & PHT & $\mathrm{C} 2 \mathrm{~B}$ & 4 & -0.057969 & 12.011 \\
\hline 19 & C & 1 & PHT & C3B & 5 & -0.079537 & 12.011 \\
\hline 20 & $\mathrm{HC}$ & 1 & PHT & $\mathrm{H} 1 \mathrm{~B}$ & 5 & 0.09038 & 1.008 \\
\hline 21 & C & 1 & PHT & C4B & 5 & -0.089043 & 12.011 \\
\hline 22 & $\mathrm{HC}$ & 1 & PHT & $\mathrm{H} 2 \mathrm{~B}$ & 5 & 0.078199 & 1.008 \\
\hline 23 & $\mathrm{C}$ & 1 & PHT & C5B & 6 & -0.089043 & 12.011 \\
\hline 24 & $\mathrm{HC}$ & 1 & PHT & H3B & 6 & 0.078199 & 1.008 \\
\hline 25 & C & 1 & PHT & C6B & 6 & -0.079537 & 12.011 \\
\hline 26 & $\mathrm{HC}$ & 1 & PHT & $\mathrm{H} 4 \mathrm{~B}$ & 6 & 0.09038 & 1.008 \\
\hline 27 & C & 1 & PHT & C7B & 4 & -0.057969 & 12.011 \\
\hline 28 & $\mathrm{C}$ & 1 & PHT & C8B & 4 & 0.430592 & 12.011 \\
\hline 29 & NR & 1 & PHT & $\mathrm{N} 2 \mathrm{~B}$ & 4 & -0.615577 & 14.0067 \\
\hline 30 & NR & 1 & PHT & $\mathrm{N} 1 \mathrm{C}$ & 7 & -0.570457 & 14.0067 \\
\hline 31 & $\mathrm{C}$ & 1 & PHT & $\mathrm{C} 1 \mathrm{C}$ & 7 & 0.593017 & 12.011 \\
\hline 32 & C & 1 & PHT & $\mathrm{C} 2 \mathrm{C}$ & 8 & -0.051228 & 12.011 \\
\hline 33 & $\mathrm{C}$ & 1 & PHT & C3C & 8 & -0.044888 & 12.011 \\
\hline 34 & $\mathrm{HC}$ & 1 & PHT & $\mathrm{H} 1 \mathrm{C}$ & 8 & 0.084825 & 1.008 \\
\hline 35 & $\mathrm{C}$ & 1 & PHT & $\mathrm{C} 4 \mathrm{C}$ & 8 & -0.068212 & 12.011 \\
\hline 36 & $\mathrm{HC}$ & 1 & PHT & $\mathrm{H} 2 \mathrm{C}$ & 8 & 0.079502 & 1.008 \\
\hline 37 & C & 1 & PHT & $\mathrm{C} 5 \mathrm{C}$ & 9 & -0.068212 & 12.011 \\
\hline 38 & $\mathrm{HC}$ & 1 & PHT & $\mathrm{H} 3 \mathrm{C}$ & 9 & 0.079502 & 1.008 \\
\hline 39 & C & 1 & PHT & $\mathrm{C} 6 \mathrm{C}$ & 9 & -0.044888 & 12.011 \\
\hline 40 & $\mathrm{HC}$ & 1 & PHT & $\mathrm{H} 4 \mathrm{C}$ & 9 & 0.084825 & 1.008 \\
\hline 41 & C & 1 & PHT & C7C & 9 & -0.051228 & 12.011 \\
\hline 42 & C & 1 & PHT & $\mathrm{C} 8 \mathrm{C}$ & 7 & 0.593017 & 12.011 \\
\hline 43 & NR & 1 & PHT & $\mathrm{N} 2 \mathrm{C}$ & 7 & -0.615577 & 14.0067 \\
\hline 44 & NR & 1 & PHT & N1D & 10 & -0.380823 & 14.0067 \\
\hline 45 & $\mathrm{H}$ & 1 & PHT & $\mathrm{HC} 2$ & 10 & 0.251155 & 1.008 \\
\hline 46 & C & 1 & PHT & C1D & 10 & 0.430592 & 12.011 \\
\hline 47 & C & 1 & PHT & C2D & 10 & -0.057969 & 12.011 \\
\hline 48 & $\mathrm{C}$ & 1 & PHT & C3D & 11 & -0.079537 & 12.011 \\
\hline 49 & $\mathrm{HC}$ & 1 & PHT & H1D & 11 & 0.09038 & 1.008 \\
\hline 50 & $\mathrm{C}$ & 1 & PHT & C4D & 11 & -0.089043 & 12.011 \\
\hline 51 & $\mathrm{HC}$ & 1 & PHT & $\mathrm{H} 2 \mathrm{D}$ & 11 & 0.078199 & 1.008 \\
\hline 52 & C & 1 & PHT & C5D & 12 & -0.089043 & 12.011 \\
\hline 53 & $\mathrm{HC}$ & 1 & PHT & H3D & 12 & 0.078199 & 1.008 \\
\hline 54 & C & 1 & PHT & C6D & 12 & -0.079537 & 12.011 \\
\hline 55 & $\mathrm{HC}$ & 1 & PHT & $\mathrm{H} 4 \mathrm{D}$ & 12 & 0.09038 & 1.008 \\
\hline 56 & C & 1 & PHT & C7D & 10 & -0.057969 & 12.011 \\
\hline 57 & C & 1 & PHT & C8D & 10 & 0.430592 & 12.011 \\
\hline 58 & NR & 1 & PHT & N2D & 10 & -0.615577 & 14.0067 \\
\hline
\end{tabular}

[ bonds ]

; b0 foi alterado para valores correspondentes a geometria optimizada ; ai aj funct bo $\mathrm{kb}$ 


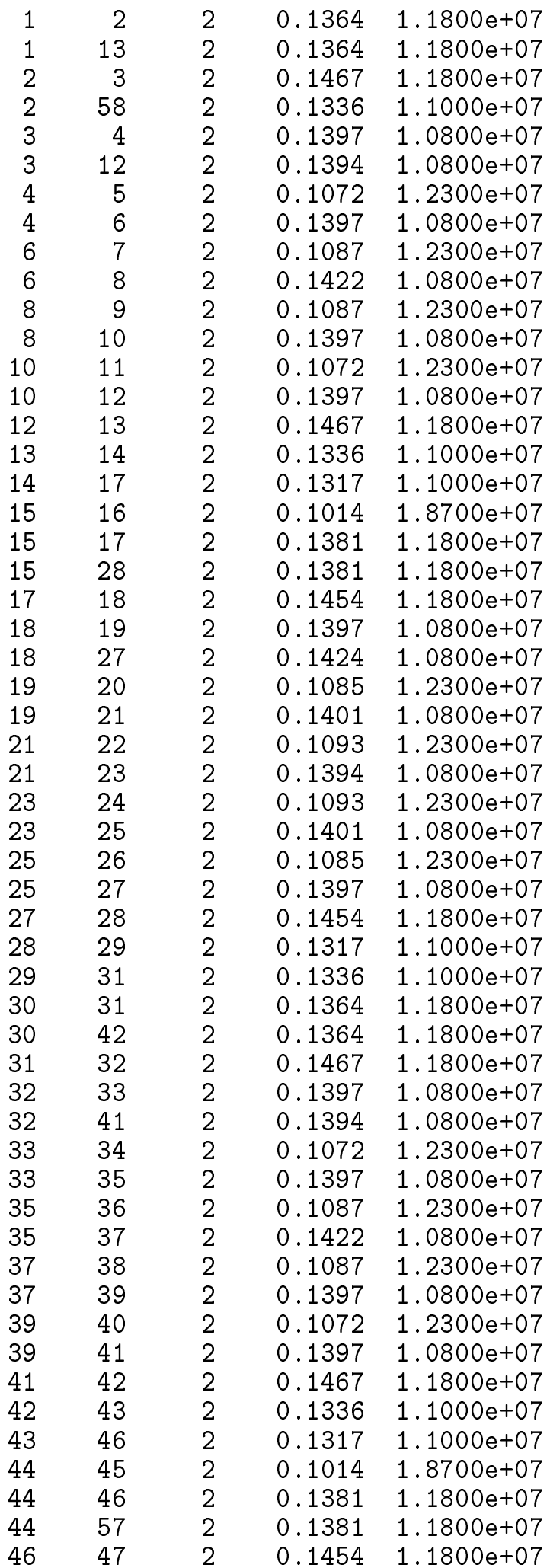




$\begin{array}{lllll}47 & 48 & 2 & 0.1397 & 1.0800 \mathrm{e}+07 \\ 47 & 56 & 2 & 0.1424 & 1.0800 \mathrm{e}+07 \\ 48 & 49 & 2 & 0.1085 & 1.2300 \mathrm{e}+07 \\ 48 & 50 & 2 & 0.1401 & 1.0800 \mathrm{e}+07 \\ 50 & 51 & 2 & 0.1093 & 1.2300 \mathrm{e}+07 \\ 50 & 52 & 2 & 0.1394 & 1.0800 \mathrm{e}+07 \\ 52 & 53 & 2 & 0.1093 & 1.2300 \mathrm{e}+07 \\ 52 & 54 & 2 & 0.1401 & 1.0800 \mathrm{e}+07 \\ 54 & 55 & 2 & 0.1085 & 1.2300 \mathrm{e}+07 \\ 54 & 56 & 2 & 0.1397 & 1.0800 \mathrm{e}+07 \\ 56 & 57 & 2 & 0.1454 & 1.1800 \mathrm{e}+07 \\ 57 & 58 & 2 & 0.1317 & 1.1000 \mathrm{e}+07\end{array}$

[ angles ]

; th0 foi alterado para valores correspondentes a geometria optimizada

- ai aj ak funct th0

$2-1 \quad 13$

106.70

$\mathrm{kth}$

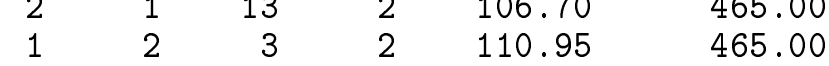

$\begin{array}{llllll}1 & 2 & 58 & 2 & 127.63 & 730.00\end{array}$

$\begin{array}{llllll}3 & 2 & 58 & 2 & 121.43 & 770.00\end{array}$

$\begin{array}{llllll}2 & 3 & 4 & 2 & 132.55 & 760.00\end{array}$

$\begin{array}{llllll}2 & 3 & 12 & 2 & 105.70 & 465.00\end{array}$

$\begin{array}{llllll}4 & 3 & 12 & 2 & 121.74 & 560.00\end{array}$

$\begin{array}{llllll}3 & 4 & 5 & 2 & 121.58 & 505.00\end{array}$

$\begin{array}{llllll}3 & 4 & 6 & 2 & 117.19 & 560.00\end{array}$

$121.22 \quad 505.00$

$119.57 \quad 505.00$

$121.06 \quad 560.00$

$119.37 \quad 505.00$

$119.37 \quad 505.00$

$121.06 \quad 560.00$

$119.57 \quad 505.00$

$121.22 \quad 505.00$

$117.19 \quad 560.00$

$121.58 \quad 505.00$

$121.74 \quad 560.00$

$105.70 \quad 465.00$

$132.55 \quad 760.00$

$110.95 \quad 560.00$

$127.63 \quad 730.00$

$121.43 \quad 770.00$

$123.81 \quad 640.00$

$123.60 \quad 575.00$

$123.60 \quad 575.00$

$112.80 \quad 465.00$

$128.31 \quad 730.00$

$125.63 \quad 770.00$

$106.06 \quad 465.00$

$131.40 \quad 760.00$

$107.54 \quad 465.00$

$121.06 \quad 560.00$

$120.43 \quad 505.00$

$117.24 \quad 560.00$

$122.33 \quad 505.00$ 


\begin{tabular}{|c|c|c|c|c|c|}
\hline 19 & 21 & 22 & 2 & 118.27 & 505.0 \\
\hline 19 & 21 & 23 & 2 & 121.69 & 560.0 \\
\hline 22 & 21 & 23 & 2 & 120.04 & 505. \\
\hline 21 & 23 & 24 & 2 & 120.04 & 505.0 \\
\hline 21 & 23 & 25 & 2 & 121.69 & 560.0 \\
\hline 24 & 23 & 25 & 2 & 118.27 & $505 . c$ \\
\hline 23 & 25 & 26 & 2 & 122.33 & 505. \\
\hline 23 & 25 & 27 & 2 & 117.24 & 560. \\
\hline 26 & 25 & 27 & 2 & 120.43 & $505 . c$ \\
\hline 18 & 27 & 25 & 2 & 121.06 & 560.0 \\
\hline 18 & 27 & 28 & 2 & 107.54 & 465.0 \\
\hline 25 & 27 & 28 & 2 & 131.40 & 760. \\
\hline 15 & 28 & 27 & 2 & 106.06 & 465.0 \\
\hline 15 & 28 & 29 & 2 & 128.31 & 730.0 \\
\hline 27 & 28 & 29 & 2 & 125.63 & 770.0 \\
\hline 28 & 29 & 31 & 2 & 123.81 & 640.0 \\
\hline 31 & 30 & 42 & 2 & 106.70 & $465 . c$ \\
\hline 29 & 31 & 30 & 2 & 127.63 & 465.0 \\
\hline 29 & 31 & 32 & 2 & 121.43 & 730.0 \\
\hline 30 & 31 & 32 & 2 & 110.95 & 770.0 \\
\hline 31 & 32 & 33 & 2 & 132.55 & 760.0 \\
\hline 31 & 32 & 41 & 2 & 105.70 & 465.0 \\
\hline 33 & 32 & 41 & 2 & 121.74 & 560.0 \\
\hline 32 & 33 & 34 & 2 & 121.58 & 505.0 \\
\hline 32 & 33 & 35 & 2 & 117.19 & 560.0 \\
\hline 34 & 33 & 35 & 2 & 121.22 & 505.0 \\
\hline 33 & 35 & 36 & 2 & 119.57 & 505.0 \\
\hline 33 & 35 & 37 & 2 & 121.06 & 560.0 \\
\hline 36 & 35 & 37 & 2 & 119.37 & 505.0 \\
\hline 35 & 37 & 38 & 2 & 119.37 & 505.0 \\
\hline 35 & 37 & 39 & 2 & 121.06 & 560.0 \\
\hline 38 & 37 & 39 & 2 & 119.57 & 505.0 \\
\hline 37 & 39 & 40 & 2 & 121.22 & 505.0 \\
\hline 37 & 39 & 41 & 2 & 117.19 & 560.0 \\
\hline 40 & 39 & 41 & 2 & 121.58 & 505.0 \\
\hline 32 & 41 & 39 & 2 & 121.74 & 560.0 \\
\hline 32 & 41 & 42 & 2 & 105.70 & 465.0 \\
\hline 39 & 41 & 42 & 2 & 132.55 & 760.0 \\
\hline 30 & 42 & 41 & 2 & 110.95 & 560.0 \\
\hline 30 & 42 & 43 & 2 & 127.63 & 730.0 \\
\hline 41 & 42 & 43 & 2 & 121.43 & 770.0 \\
\hline 42 & 43 & 46 & 2 & 123.81 & 640.0 \\
\hline 45 & 44 & 46 & 2 & 123.60 & 575.0 \\
\hline 45 & 44 & 57 & 2 & 123.60 & 575.0 \\
\hline 46 & 44 & 57 & 2 & 112.80 & 465.0 \\
\hline 43 & 46 & 44 & 2 & 128.31 & 730.0 \\
\hline 43 & 46 & 47 & 2 & 125.63 & 770 \\
\hline 44 & 46 & 47 & 2 & 106.06 & $465 . c$ \\
\hline 46 & 47 & 48 & 2 & 131.40 & 760.0 \\
\hline 46 & 47 & 56 & 2 & 107.54 & 465.0 \\
\hline 48 & 47 & 56 & 2 & 121.06 & 560.0 \\
\hline 47 & 48 & 49 & 2 & 120.43 & $505 . c$ \\
\hline 47 & 48 & 50 & 2 & 117.24 & 560.0 \\
\hline 49 & 48 & 50 & 2 & 122.33 & 505. \\
\hline
\end{tabular}




$\begin{array}{rlllll}48 & 50 & 51 & 2 & 118.27 & 505.00 \\ 48 & 50 & 52 & 2 & 121.69 & 560.00 \\ 51 & 50 & 52 & 2 & 120.04 & 505.00 \\ 50 & 52 & 53 & 2 & 120.04 & 505.00 \\ 50 & 52 & 54 & 2 & 121.69 & 560.00 \\ 53 & 52 & 54 & 2 & 118.27 & 505.00 \\ 52 & 54 & 55 & 2 & 122.33 & 505.00 \\ 52 & 54 & 56 & 2 & 117.24 & 560.00 \\ 55 & 54 & 56 & 2 & 120.43 & 505.00 \\ 47 & 56 & 54 & 2 & 121.06 & 560.00 \\ 47 & 56 & 57 & 2 & 107.54 & 465.00 \\ 54 & 56 & 57 & 2 & 131.40 & 760.00 \\ 44 & 57 & 56 & 2 & 106.06 & 465.00 \\ 44 & 57 & 58 & 2 & 128.31 & 730.00 \\ 56 & 57 & 58 & 2 & 125.63 & 770.00 \\ 2 & 58 & 57 & 2 & 123.81 & 640.00\end{array}$

[ dihedrals ]

$\begin{array}{rrrrrrr}\text {;i } & \text { aj } & \text { ak } & \text { al funct } & & \\ 1 & 2 & 58 & 57 & 1 & 180.000 & 41 . \\ 1 & 13 & 14 & 17 & 1 & 180.000 & 41.8 \\ 13 & 14 & 17 & 15 & 1 & 180.000 & 41 . \\ 15 & 28 & 29 & 31 & 1 & 180.000 & 41 . \\ 28 & 29 & 31 & 30 & 1 & 180.000 & 41 . \\ 30 & 42 & 43 & 46 & 1 & 180.000 & 41 . \\ 42 & 43 & 46 & 44 & 1 & 180.000 & 41 . \\ 44 & 57 & 58 & 2 & 1 & 180.000 & 41 . \\ \text { [ihedrals }] & & & & & \\ \text { ai } & \text { aj } & \text { ak } & \text { al funct } & & \\ 1 & 3 & 58 & 2 & 2 & 0.0 & 167.42309 \\ 1 & 13 & 12 & 3 & 2 & 0.0 & 167.42309 \\ 1 & 2 & 3 & 12 & 2 & 0.0 & 167.42309 \\ 2 & 1 & 13 & 12 & 2 & 0.0 & 167.42309 \\ 2 & 3 & 12 & 13 & 2 & 0.0 & 167.42309 \\ 3 & 4 & 6 & 8 & 2 & 0.0 & 167.42309 \\ 3 & 12 & 10 & 8 & 2 & 0.0 & 167.42309 \\ 3 & 2 & 4 & 12 & 2 & 0.0 & 167.42309 \\ 3 & 2 & 1 & 13 & 2 & 0.0 & 167.42309 \\ 4 & 3 & 5 & 6 & 2 & 0.0 & 167.42309 \\ 4 & 3 & 12 & 10 & 2 & 0.0 & 167.42309 \\ 4 & 6 & 8 & 10 & 2 & 0.0 & 167.42309 \\ 6 & 4 & 7 & 8 & 2 & 0.0 & 167.42309 \\ 6 & 4 & 3 & 12 & 2 & 0.0 & 167.42309 \\ 6 & 8 & 10 & 12 & 2 & 0.0 & 167.42309 \\ 8 & 6 & 9 & 10 & 2 & 0.0 & 167.42309 \\ 10 & 12 & 8 & 11 & 2 & 0.0 & 167.42309 \\ 10 & 3 & 13 & 12 & 2 & 0.0 & 167.42309 \\ 13 & 1 & 12 & 14 & 2 & 0.0 & 167.42309 \\ 15 & 18 & 14 & 17 & 2 & 0.0 & 167.42309 \\ 15 & 28 & 27 & 18 & 2 & 0.0 & 167.42309 \\ 15 & 17 & 18 & 27 & 2 & 0.0 & 167.42309 \\ 15 & 16 & 17 & 28 & 2 & 0.0 & 167.42309 \\ 17 & 15 & 28 & 27 & 2 & 0.0 & 167.42309\end{array}$

$41.8 \quad 2$

$41.8 \quad 2$

$41.8 \quad 2$

$41.8 \quad 2$

$41.8 \quad 2$

$41.8 \quad 2$

$41.8 \quad 2$

$41.8 \quad 2$




\begin{tabular}{|c|c|c|c|c|c|c|}
\hline 17 & 18 & 27 & 28 & 2 & 0.0 & 167.42309 \\
\hline 18 & 19 & 21 & 23 & 2 & 0.0 & 167.42309 \\
\hline 18 & 27 & 25 & 23 & 2 & 0.0 & 167.42309 \\
\hline 18 & 17 & 19 & 27 & 2 & 0.0 & 167.42309 \\
\hline 18 & 17 & 15 & 28 & 2 & 0.0 & 167.42309 \\
\hline 19 & 18 & 20 & 21 & 2 & 0.0 & 167.42309 \\
\hline 19 & 18 & 27 & 25 & 2 & 0.0 & 167.42309 \\
\hline 19 & 21 & 23 & 25 & 2 & 0.0 & 167.42309 \\
\hline 21 & 19 & 22 & 23 & 2 & 0.0 & 167.42309 \\
\hline 21 & 19 & 18 & 27 & 2 & 0.0 & 167.42309 \\
\hline 21 & 23 & 25 & 27 & 2 & 0.0 & 167.42309 \\
\hline 23 & 21 & 24 & 25 & 2 & 0.0 & 167.42309 \\
\hline 25 & 27 & 23 & 26 & 2 & 0.0 & 167.42309 \\
\hline 25 & 18 & 28 & 27 & 2 & 0.0 & 167.42309 \\
\hline 28 & 15 & 27 & 29 & 2 & 0.0 & 167.42309 \\
\hline 30 & 32 & 29 & 31 & 2 & 0.0 & 167.42309 \\
\hline 30 & 42 & 41 & 32 & 2 & 0.0 & 167.42309 \\
\hline 30 & 31 & 32 & 41 & 2 & 0.0 & 167.42309 \\
\hline 31 & 30 & 42 & 41 & 2 & 0.0 & 167.42309 \\
\hline 31 & 32 & 41 & 42 & 2 & 0.0 & 167.42309 \\
\hline 32 & 33 & 35 & 37 & 2 & 0.0 & 167.42309 \\
\hline 32 & 41 & 39 & 37 & 2 & 0.0 & 167.42309 \\
\hline 32 & 31 & 33 & 41 & 2 & 0.0 & 167.42309 \\
\hline 32 & 31 & 30 & 42 & 2 & 0.0 & 167.42309 \\
\hline 33 & 32 & 34 & 35 & 2 & 0.0 & 167.42309 \\
\hline 33 & 32 & 41 & 39 & 2 & 0.0 & 167.42309 \\
\hline 33 & 35 & 37 & 39 & 2 & 0.0 & 167.42309 \\
\hline 35 & 33 & 36 & 37 & 2 & 0.0 & 167.42309 \\
\hline 35 & 33 & 32 & 41 & 2 & 0.0 & 167.42309 \\
\hline 35 & 37 & 39 & 41 & 2 & 0.0 & 167.42309 \\
\hline 37 & 35 & 38 & 39 & 2 & 0.0 & 167.42309 \\
\hline 39 & 41 & 37 & 40 & 2 & 0.0 & 167.42309 \\
\hline 39 & 32 & 42 & 41 & 2 & 0.0 & 167.42309 \\
\hline 42 & 30 & 41 & 43 & 2 & 0.0 & 167.42309 \\
\hline 44 & 47 & 43 & 46 & 2 & 0.0 & 167.42309 \\
\hline 44 & 57 & 56 & 47 & 2 & 0.0 & 167.42309 \\
\hline 44 & 46 & 47 & 56 & 2 & 0.0 & 167.42309 \\
\hline 44 & 45 & 46 & 57 & 2 & 0.0 & 167.42309 \\
\hline 46 & 44 & 57 & 56 & 2 & 0.0 & 167.42309 \\
\hline 46 & 47 & 56 & 57 & 2 & 0.0 & 167.42309 \\
\hline 47 & 48 & 50 & 52 & 2 & 0.0 & 167.42309 \\
\hline 47 & 56 & 54 & 52 & 2 & 0.0 & 167.42309 \\
\hline 47 & 46 & 48 & 56 & 2 & 0.0 & 167.42309 \\
\hline 47 & 46 & 44 & 57 & 2 & 0.0 & 167.42309 \\
\hline 48 & 47 & 49 & 50 & 2 & 0.0 & 167.42309 \\
\hline 48 & 47 & 56 & 54 & 2 & 0.0 & 167.42309 \\
\hline 48 & 50 & 52 & 54 & 2 & 0.0 & 167.42309 \\
\hline 50 & 48 & 51 & 52 & 2 & 0.0 & 167.42309 \\
\hline 50 & 48 & 47 & 56 & 2 & 0.0 & 167.42309 \\
\hline 50 & 52 & 54 & 56 & 2 & 0.0 & 167.42309 \\
\hline 52 & 50 & 53 & 54 & 2 & 0.0 & 167.42309 \\
\hline 54 & 56 & 52 & 55 & 2 & 0.0 & 167.42309 \\
\hline 54 & 47 & 57 & 56 & 2 & 0.0 & 167.42309 \\
\hline 57 & 44 & 56 & 58 & 2 & 0.0 & 167.42309 \\
\hline
\end{tabular}


[ system ]

; Name

H2-PHTHALOCYANINE

[ molecules ]

; Compound

Other

\#mols

1

\section{D.2.2 Arquivo de inicialização da dinâmica}

É apresentado em seguida o arquivo *.mdp, no formato de arquivo de inicialização do programa GROMACS [73-75], para a dinâmica feita para o monômero de $H_{2^{-}}$ Ftalocianina. Maiores informações e a descrição de cada palavra-chave (keyword) desse arquivo podem ser encontradas no manual do GROMACS [74].

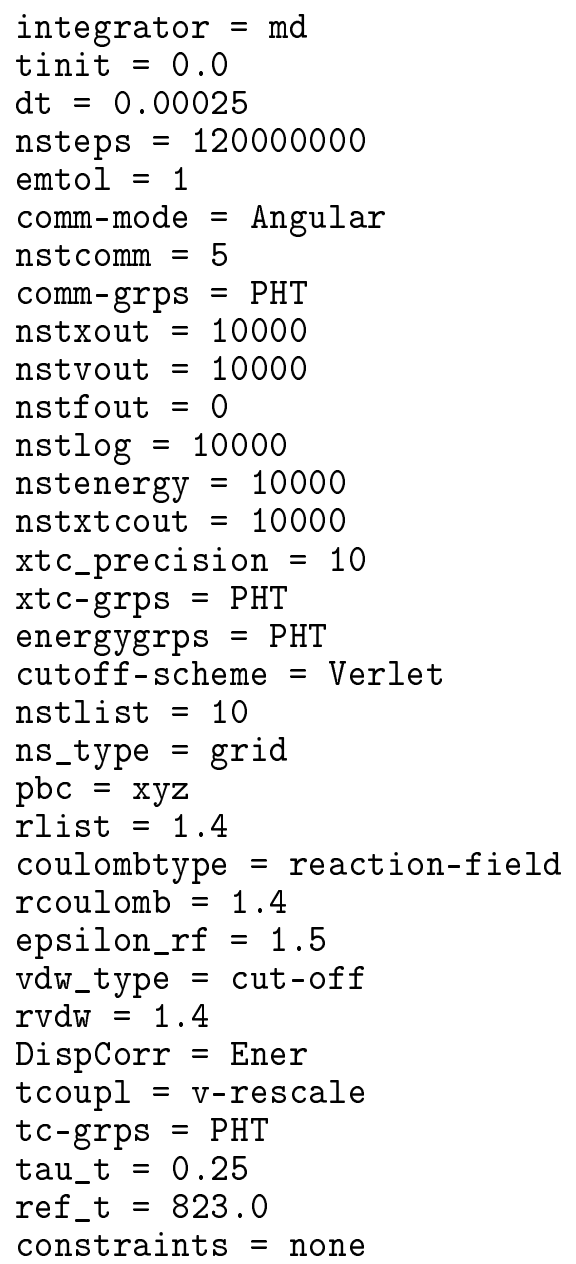




\section{Apêndice E \\ Publicação}

- Free base phthalocyanine: Influence of thermal effects and dimerization on the electronic absorption spectrum, Benedito J.C. Cabral, Vinícius Wilian D. Cruzeiro, Kaline Coutinho e Sylvio Canuto, Chem. Phys. Lett., 595, 97 (2014).

Este artigo é apresentado nas próximas páginas. 


\title{
Free base phthalocyanine: Influence of thermal effects and dimerization on the electronic absorption spectrum
}

\author{
Benedito J.C. Cabral ${ }^{\mathrm{a}, \mathrm{b}, \mathrm{c}, *},{\text { Vinícius Wilian D. } \text { Cruzeiro }^{\mathrm{c}} \text {, Kaline Coutinho }}^{\mathrm{c}}$, Sylvio Canuto ${ }^{\mathrm{c}}$ \\ ${ }^{a}$ Grupo de Física Matemática da Universidade de Lisboa, Av. Professor Gama Pinto 2, 1649-003 Lisboa, Portugal

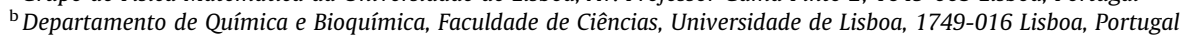 \\ ${ }^{\mathrm{c}}$ Instituto de Física da Universidade de São Paulo, CP 66318, 05314-970 São Paulo, SP, Brazil
}

\section{A R T I C L E I N F O}

\section{Article history:}

Received 19 December 2013

In final form 28 January 2014

Available online 3 February 2014

\begin{abstract}
A B S T R A C T
Theoretical results for the electronic properties of the free base phthalocyanine monomeric and dimeric species are presented. The binding energy for the most stable dimer (a parallel-displaced structure) is $12 \mathrm{kcal} / \mathrm{mol}$. The calculations of the electronic excitation spectrum rely on the analysis of structures generated by Born-Oppenheimer Molecular Dynamics at $500 \pm 4 \mathrm{~K}$ (monomer) and $700 \pm 4 \mathrm{~K}$ (dimer). The results for the absorption spectrum illustrate the importance of taking into account thermal broadening and dimerization. The $\mathrm{Q}_{x}-\mathrm{Q}_{y}$ band splitting is $\sim 40 \mathrm{~nm}$ in reasonable agreement with the experimental value of $64 \mathrm{~nm}$ at $T=783 \mathrm{~K}$.
\end{abstract}

(C) 2014 Elsevier B.V. All rights reserved.

\section{Introduction}

There is an increasing interest in the design of supramolecular structures for organic photovoltaics and artificial photosynthesis [1-5]. A particularly important class of species playing a central role in these fields are porphyrins and phthalocyanines $[6,1,3,2,7]$. However, for these species, some fundamental aspects such as electronic absorption, dynamics of excitonic propagation and charge transfer [8] are still not well understood [9]. One problem of interest concerns the role played by thermal effects and the associated structural distortions of the phthalocyanine skeleton on their electronic properties. Actually, the experimental absorption spectra for the metal free phthalocyanine and their complexes with several different metallic species [10] are, in many cases, for gas samples at temperatures above $500 \mathrm{~K}[10,11]$. Thermal effects are therefore of fundamental importance to discuss, for example, the location of the protons in the internal cavity of the free base phthalocyanine, a subject that was related to the anomaly of the free base phtalocyanine electronic spectrum relative to metallized species $[10,12]$. This anomaly was characterized by a $Q_{x}-Q_{y}$ band splitting and by broadening of the $Q_{x}$ band with temperature [10]. Other issue that deserves a special attention concerns the role played by aggregation, specifically, dimer formation on the electronic properties of phthalocyanines.

* Corresponding author at: Grupo de Física Matemática da Universidade de Lisboa, Av. Professor Gama Pinto 2, 1649-003 Lisboa, Portugal.

E-mail address: ben@cii.fc.ul.pt (B.J.C. Cabral).
Aggregation of large aromatic moieties is driven by dispersion interactions [13-16]. Therefore a correct description of these interactions is essential to determine the structures and electronic properties of porphyrins and phthalocyanines aggregates. Theoretical progress in the description of dispersion interactions has been recently accomplished by including empirical corrections for the dispersion interaction energy in density functional theory methods [17-19] which can be applied to very large supramolecular complexes [19].

Several works on the electronic properties of phthalocyanines $[20,12,21,24-27,22,23]$ and phthalocyanine dimers [28] were reported. The present Letter, is however, dedicated to the study of the dynamics and role played by thermal effects on the electronic properties of metal free phthalocyanine. Focus is placed on the relationship between the dynamics of phtalocyanine skeleton, aggregation (dimer formation) $[29,30]$ and the electronic absorption spectrum of free base phthalocyanine. The adopted theoretical approach is based on the sequential analysis of the electronic properties for structures generated by Born-Oppenheimer Molecular Dynamics (BOMD). The presentation is organized as follows. Initially, the adopted theoretical procedures are described. This is followed by a discussion on the properties of gas-phase optimized structures. Results relying on the sequential Born-Oppenheimer/ electronic structure calculations at temperatures close to the experimental conditions are then discussed. Finally, the conclusions stress the importance of taking into account aggregation and thermal effects to investigate the electronic properties of phthalocyanines. 


\section{Computational details}

The free base phthalocyanine monomer and dimers A and B (see Figure 1) were optimized with the CP2K program [31]. The hybrid Gaussian and plane-wave method GPW [32] as implemented in the QUICKSTEP module [33] was adopted. Goedecker, Teter, and Hutter (GTH) norm-conserving pseudopotentials [34] were used for representing the core electrons and only valence electrons were explicitly included in the quantum mechanical density functional theory (DFT) calculations for the geometry optimizations and BOMD. DFT calculations were carried with the Perdew-Burke-Ernzerhof (PBE) exchange-correlation functional [35] (the PBE calculations with the GTH pseudopotentials will be represented as PBE[GTH]). An empirical correction to dispersion interactions (D3) proposed by Grimme et al. [18] was added to the PBE functional for the geometry optimizations and BOMD. We adopted the GPW approach, where Kohn-Sham orbitals are expanded into atom-centered double-zeta-valence-polarization (DZVP) gaussian-type orbital functions, whereas the electron density is represented with an auxiliary plane-wave basis-set. A charge density cutoff of $280 \mathrm{Ry}$ was used for the auxiliary basis-set and the self-consistent-field energy threshold for calculating the electronic density was $10^{-7}$ Hartree. Geometry optimizations (monomer, and dimers A and B) and BOMD (monomer and dimer-A) were carried in a cubic cell of $22 \AA$. Non-periodic boundary conditions with the MartynaTuckerman Poisson solver [36] were adopted. Binding energies of phthalocyanine dimers relying on all electron single-point energy calculations with $\mathrm{CP} 2 \mathrm{~K}$ optimized geometries are also reported. These calculations were carried out with the ORCA program [37].

BOMD was performed in the canonical ensemble with a velocity scaling thermostat [38] and target temperatures $T$ of $500 \mathrm{~K}$ (monomer) and $700 \mathrm{~K}$ (dimer-A). In contrast with the results for gasphase optimized structures these high values of $T$ ( $500 \mathrm{~K}$ for the monomer and $700 \mathrm{~K}$ for the dimer) allows us to discuss thermal effects on the structure and electronic properties of free base phtalocyanine and the temperature for the dynamics of the dimer (700 K) is close to the experimental one ( $T=783 \mathrm{~K}$ ) [10]. A timestep of $0.5 \mathrm{fs}$ was used. The total time of the BOMD run was $14 \mathrm{ps}(28,000$ steps $)$. The final average temperatures were $499 \pm 4$ (monomer) and $698 \pm 4 \mathrm{~K}$ (dimer-A). A given number of configurations (equally separated in time) from the last $6 \mathrm{ps}$ of the BOMD run were selected for the analysis of the structure and calculation of the electronic excitation spectra by using time dependent density functional theory (TDDFT). A long-range correction scheme (LC) proposed by likura et al., [39] was added to the PBE functional (LC-PBE) for TDDFT calculations. The choice of the LC-PBE functional was driven by a series of benchmarks with different functionals (see Supplementary Material). It was verified that $Q_{x}-Q_{y}$
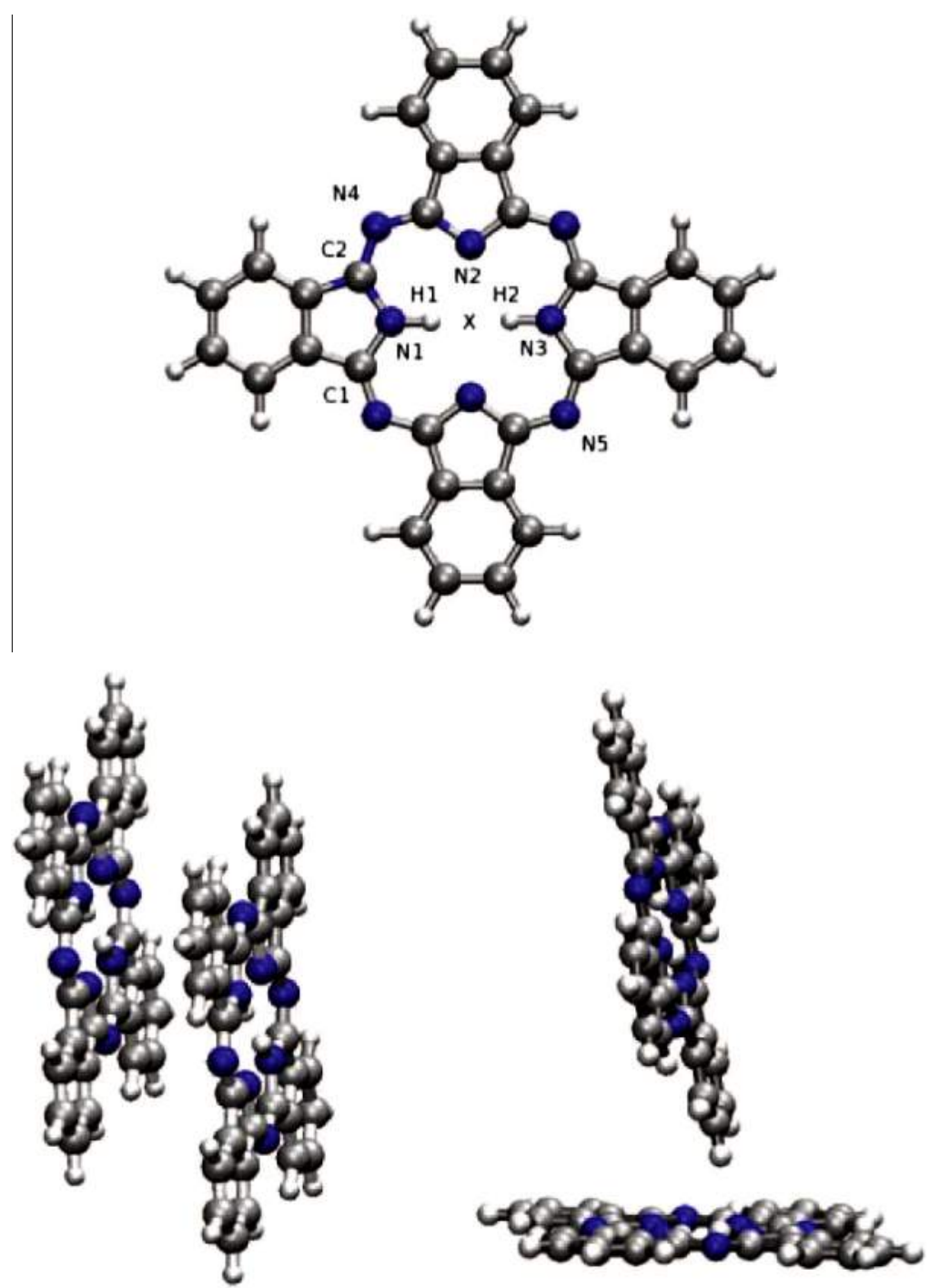

Figure 1. Optimized structures for the monomer (top) and dimers $\mathrm{A}$ (bottom left) and $\mathrm{B}$ (bottom right) of the free base phthalocyanine. For the monomer the $\mathrm{N}-\mathrm{H}$ bond distance is $1.02 \AA$ and the $\mathrm{N}_{4} \mathrm{~N}_{5} \mathrm{H}_{2}$ angle is $15.7^{\circ}$. 
band splitting, a fingerprint of the free base phthalocyanine absorption spectrum [10], was semi-quantitatively reproduced by using the LC-PBE functional. The choice of the LC-PBE is also supported by a recent investigation on the performance of several exchange-correlation functionals for predicting excitation energies of organic molecules [40]. Excitation energies calculated with several methods are presented in Supplementary Material. Considering the size of the system and the number of configurations needed to ensure statistical convergence of the spectra (see below) excitation energies were calculated with the Sttutgart-Dresden pseudopotentials [41] and the Dunning's D95 basis-set [42,43]. TDDFT calculations were carried out with the GAUSSIAN-09 program [44].

The calculations of the spectra were carried out by using a subset of the configurations generated by BOMD. It was therefore important to investigate the convergence of the excitation energies with the number of configurations $(N)$ included in the calculations. Figure 2 (bottom panel) shows the behaviour of the first (low energy region) and 30th (high energy region) excitations with $N$. These results are for the dimer-A and clearly indicate that convergence for low energy excitations are attained for $N \gtrsim 70$ configurations. Convergence for the high energy excitation is observed for $N \gtrsim 20$. Convergence of the oscillator strength $\mathrm{f}$ with $N$ is also illustrated in the top panels of Figure 2 and follows the same trends observed for the excitation energies. Sequential analysis of the configurations generated by BOMD will be mainly focused on the calculations of the low energy excitation spectra. To represent the spectra, TDDFT excitation energies and oscillator strengths were convoluted by a Lorentzian distribution of $0.05 \mathrm{eV}$ width.

\section{Results and discussion}

\subsection{Gas-phase optimized structures, binding energies, and electronic spectrum}

The PBE-D3[GTH]/TZVP optimized structures for the $D_{2 h}$ monomer and dimers $A$ and $B$ of the free base phthalocyanine are shown in Figure 1. Dimer-A is a parallel displaced structure of $C_{i}$ symmetry with a distance of $4.58 \AA$ between the two monomeric planes. The center-of-mass of each monomer will be denoted by $X$ and the $\mathrm{X}-\mathrm{X}$ distance by $\mathrm{d}(\mathrm{X}-\mathrm{X})$, which is $5.9 \AA$ for dimer-A. The relative displacement of the monomeric planes is $3.02 \AA$. Dimer- $B$ is a perpendicular tilted structure and $\mathrm{d}(\mathrm{X}-\mathrm{X})$ is $10.1 \AA$. The tilt angle, calculated as the angle between the $\mathrm{X}-\mathrm{X}$ line and the monomeric
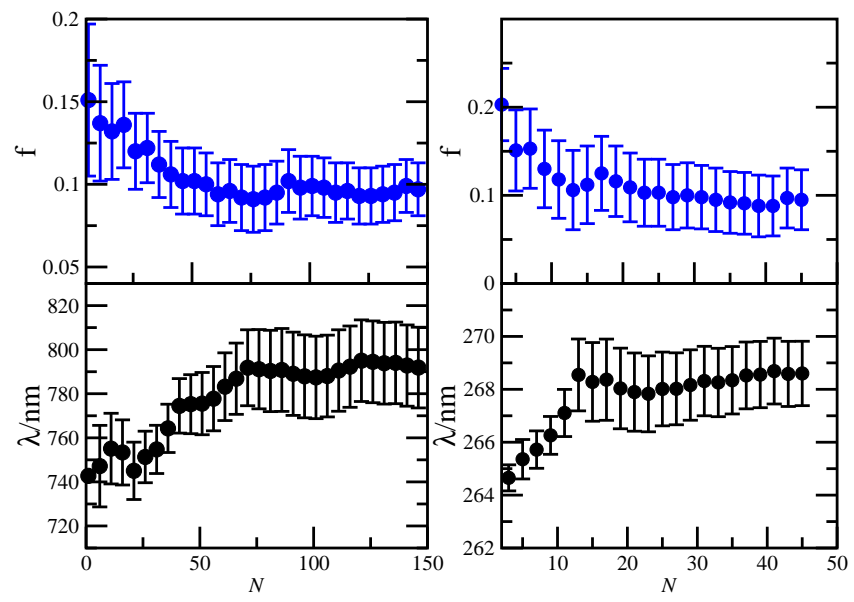

Figure 2. Convergence of the excitation energies (bottom) and oscillator strengths (top) with the number $N$ of configurations from BOMD for dimer-A for the 1st (left) and 30th (right) excitations. plane is 12.0 degrees. The optimized structures of the free base phthalocyanine keep some similarity with optimized structures for van der Waals complexes including benzene and naphtalene $[45,16]$. The dimer-A parallel displaced structure is also similar to that one proposed for the $\pi$-stacked Zn-porphyrin dimer [13].

Binding energies (BEs) are reported in Table 1 . The binding energy for the most stable dimer (dimer-A) is $11.3 \mathrm{kcal} / \mathrm{mol}$ at the PBE[GTH]-D3/TZVP level and no basis-set superposition error (BSSE) correction. It is in reasonable agreement with the all electron PBE-D3/TZVP calculation (12.2 kcal/mol). For dimer-A, corrections to BSSE are small with the TZVP $(0.81 \mathrm{kcal} / \mathrm{mol})$ and QZVP $(0.27 \mathrm{kcal} / \mathrm{mol})$ basis-sets. Our best estimates for the binding energies rely on all electron PBE-D3/QZVP calculations and include corrections to BSSE. They are 11.9 and $4.86 \mathrm{kcal} / \mathrm{mol}$ for dimers A and $B$, respectively. Therefore, our results indicate that dimer-A (a parallell displaced structure) is much more stable than dimer-B (a perpendicular structure). We are not aware of theoretical calculations for the binding energies of phthalocyanine dimers. Binding energies of van der Waals complexes were, however, the subject of several works $[13,16,19]$. The binding energy for a parallel displaced structure of the $\mathrm{Zn}$-porphyrin dimer was reported as $11.7 \pm 2.4 \mathrm{kcal} / \mathrm{mol}$ [13]. It is known that theoretical estimates of binding energies for systems stabilized by dispersion interactions are dependent on the adopted theoretical approach [16]. However, the present DFT estimates are based on the introduction of an empirical correction for the dispersion interaction [17]. In addition, recent benchmarks of dispersion interactions using DFT on large supramolecular systems [19] support the adequacy of the presently adopted approach to investigate binding energies of phthalocyanines dimers. Vibrational energy corrections to the binding energies were not taken into consideration and it is assumed that their inclusion will not change significantly our conclusions concerning the BEs and relative energies of the dimers. However, a discussion on the $\mathrm{N}-\mathrm{H}$ stretching frequency in the phthalocyanine internal cavity is presented in the next section.

The absorption spectra for the optimized structures of the phthalocyanine monomer and dimers A and B are presented in Figure 3. A total number of 20 and 40 excitation energies were calculated for the optimized structures of the monomer and dimers, respectively. Data for the peak positions and oscillator strengths are also gathered in Table 2. For dimer-A the two lowest excitation energies are $697.7 \mathrm{~nm}$ and $665.7 \mathrm{~nm}$. These transitions are forbidden (oscillator strength close to zero). The next two excitations of dimer-A (649.4 $\mathrm{nm}$ and $611.4 \mathrm{~nm}$ ) are displaced to higher energies in comparison with the results for the monomer $(667.5 \mathrm{~nm}$ and $631.8 \mathrm{~nm}$ ). In contrast with dimer-A, the low energy excitation region $(\lambda>500 \mathrm{~nm})$ of dimer-B shows two nearly degenerate excitations $(677.6 \mathrm{~nm} ; 669.8 \mathrm{~nm}$ and $638.7 \mathrm{~nm} ; 631.9 \mathrm{~nm})$ which correspond to similar localized excitations on each monomer.

Table 1

Binding energies $(\mathrm{kcal} / \mathrm{mol})$ for dimers $\mathrm{A}$ and $\mathrm{B}$ of free base phthalocyanine. Geometry optimized at the PBE[GTH]-D3/TZVP level. Binding energies without corrections to BSSE are shown in parentheses.

\begin{tabular}{lll}
\hline & Dimer A & Dimer B \\
\hline PBE[GTH]-D3/TZVP & $(11.26)$ & $(5.51)$ \\
PBE-D3/TZVP $^{\mathrm{b}}$ & $11.99(12.80)$ & $4.92(5.25)$ \\
PBE-D3/QZVP $^{\text {b }}$ & $11.94(12.21)$ & $4.86(4.94)$ \\
\hline
\end{tabular}

a Geometry optimization with GTH [34] pseudopotentials.

b Single-point energy calculation with all the electrons and geometry optimized at the PBE[GTH]-D3/TZVP level. The binding energy with BSSE correction for a phthalocyanine dimer with monomers 1 and 2 was estimated as: $\Delta E=E_{12}^{12}[12]-E_{1}^{12}[12]-E_{2}^{12}[12]$, where $E_{\mathrm{i}}^{12}[12]$ denotes the energy of the monomer $i$ $(i=1,2)$ calculated with the basis-set of the dimer (12) in the geometry of the dimer [12]. The relaxation energy contribution for each monomer $\Delta E_{R}=E_{1}^{1}[12]-E_{1}^{1}[1]$ was neglected. 


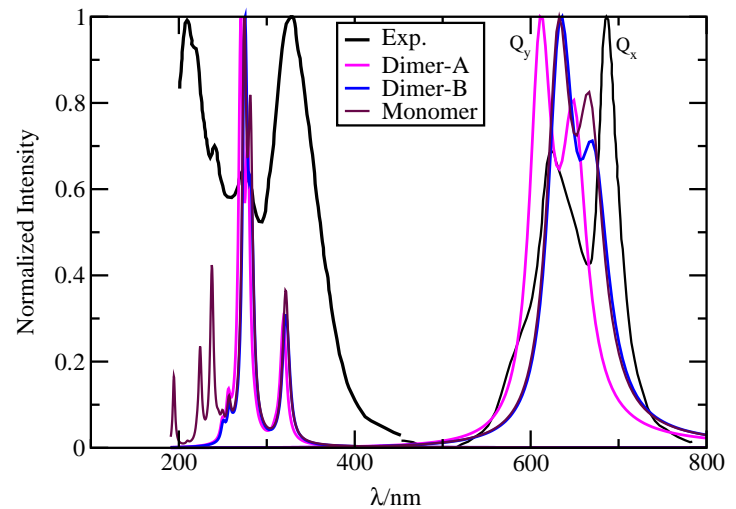

Figure 3. Excitation spectra for the optimized structures of the monomer and dimers A and B: comparison with experiment.

Table 2

Excitation energies ( $\mathrm{nm}$ ) and oscillator strengths (in parentheses) for the gas-phase phthalocyanine monomer and dimers A and B. Average values and rmsd calculated from BOMD configurations for the monomer and dimer-A are shown in italics.

\begin{tabular}{llll}
\hline Monomer & Dimer-A $^{\text {a }}$ & Dimer-B & Exp. $^{\text {b }^{\prime}}$ \\
\hline $667.5(0.41)$ & $649.4(0.66)$ & $677.6(0.21) ; 669.8(0.47)$ & $686.0\left(\mathrm{Q}_{x}\right)$ \\
$696 \pm 10$ & $674 \pm 10$ & & \\
$631.7(0.55)$ & $611.4(0.89)$ & $638.7(0.37)) ; 631.9(0.77)$ & $622.5\left(\mathrm{Q}_{y}\right)$ \\
$656 \pm 10$ & $633 \pm 10$ & & \\
$321.5(0.48)$ & $318.9(0.67)$ & $323.8(0.34) ; 320.8(0.58)$ & $340.0(\mathrm{~B})$ \\
& $278.4(1.38)$ & $283.4(0.43) ; 281.6(0.87)$ & \\
$281.6(0.89)$ & $270.8(0.95) ;$ & $275.9(1.18) ; 274.6(1.49)$ & \\
$274.4(1.19)$ & $270.2(1.21)$ & & $280 ; 270(\mathrm{~N})$ \\
$257.0(0.08)$ & $256.2(0.16)$ & $257.6(0.11)$ & \\
$237.6(0.54)$ & & & $240.0(\mathrm{~L})$ \\
$224.2(0.29)$ & & & $220 ; 210(\mathrm{C})$ \\
\hline
\end{tabular}

a The two lowest excitation energies of the gas-phase optimized structure of dimer-A ( $C_{i}$ symmetry) are $697.7 \mathrm{~nm}$ and $665.7 \mathrm{~nm}$. These transitions are forbidden by symmetry.

b Experimental values from Edwards and Gouterman [10].

Moreover, these excitation energies are quite similar to those calculated for the isolated monomer.

In comparison with the data for the optimized structures the experimental spectra is characterized by an intense peak near $686 \mathrm{~nm}\left(\mathrm{Q}_{x}\right)$ and by the extension of the absorption region into the low energy region above $700 \mathrm{~nm}$. Other difference concerns the $\mathrm{Q}_{x}-\mathrm{Q}_{y}$ splitting that is $\sim 38 \mathrm{~nm}$ for dimers $\mathrm{A}$ and $\mathrm{B}$, whereas the experimental value is $\sim 64 \mathrm{~nm}$. A good agreement between theoretical predictions and experiment for the peak positions associated with the different high energy bands is also observed.

It should be expected that inclusion of thermal effects improve the theoretical results in comparison with experiment. However, considering the significant difference between the binding energies of dimers A and B $(7.0 \mathrm{kcal} / \mathrm{mol})$, Born-Oppenheimer Molecular Dynamics were only carried out for the monomer $(500 \pm 4 \mathrm{~K})$ and dimer-A $(700 \pm 4 \mathrm{~K})$.

\subsection{Thermal effects on the electronic absorption}

The role played by structural distortions of the free base phthalocyanine skeleton induced by thermal effects on the electronic properties is of fundamental importance to understand the electronic absorption spectra of these species $[10,12]$. Some specific features characterizing the electronic spectra of free base phthalocyanines are a strong dependence of the $Q_{x}-Q_{y}$ splitting on the environment as well as the anomalous broadening of the $\mathrm{Q}_{y}$ band with temperature [10]. In addition, porphyrins [46] and phthalocyanines [47] exhibit a great flexibility and deviations from planarity.
It should be expected that these effects are even more important at high temperatures such as the ones where the electronic absorption spectra were measured [10] thus stressing the role played by thermal effects on the electronic properties of phatalocyanines. To investigate the relationship between structural distortions of the free base phthalocyanine skeleton and their influence on the electronic properties we first defined a set of geometric parameters. Then we followed their time evolution accordingly to the Born-Oppenheimer dynamics. By adopting thresholds for these geometric parameters we can investigate the electronic spectra for a subset of configurations corresponding to specific structural distortions.

To discuss the relationship between the $\mathrm{Q}_{x}-\mathrm{Q}_{y}$ splitting and the internal $\mathrm{H}$ atoms position in the phthalocyanine central cavity we defined the angles $\mathrm{NNH}$ between two outer $\mathrm{N}$ atoms of the macrocycle and one hydrogen atom (this angle is defined by the N4N5H2 or N5N4H1 atoms of Figure 1). Figure 4 illustrates the time evolution of NNH predicted by the BOMD of the phthalocyanine monomer. When the two NNH angles are less than $10^{\circ}$ the structure of the internal cavity of the phthalocyanine monomer keeps some similarity with the bridge configuration proposed by Schaffer and Gouterman [12] (it should be observed that only $\lesssim 2 \%$ of the total BOMD configurations satisfy this criterion). In a bridge configuration, it is assumed that the each proton $\left(\mathrm{H}_{1}, \mathrm{H}_{2}\right)$ is shared by two neighbor $\mathrm{N}$ nuclei of the central cavity $[10,12]$. In agreement with Schaffer and Gouterman [12] the present results indicate that distortions of the internal cavity leading to structures similar to a bridge configuration effectively contribute to increase the $Q_{x}-Q_{y}$ splitting. This is illustrated in Figure 5, where we compare the spectrum for the NNH threshold value with the full average spectrum for the monomer without no geometric constraints (BOMD) and also with the experimental data [10]. The inset panel of Figure 5 shows the dependence of the $\mathrm{Q}_{x}-\mathrm{Q}_{y}$ splitting on the NNH angle. The black squares represent the averages for a set of $\mathrm{NNH}$ values in a $0.5^{\circ}$ interval. Circles are the maxima and minima values in the same interval. These results indicate a correlation between the splitting and the proton positions. Moreover, it appears that when $\mathrm{NNH}$ is $\lesssim 8.5^{\circ}$ the $\mathrm{Q}_{x}-\mathrm{Q}_{y}$ splitting is around $120 \mathrm{~nm}$ and for larger NNH the splitting is around $70 \mathrm{~nm}$. Although the $\mathrm{Q}_{x}-\mathrm{Q}_{y}$ splitting is increased for nearly bridged configurations, these configurations are present in small number and do not contribute in a significant way to determine the average spectrum of free base phthalocyanine. In addition, $Q_{x}$ for these configurations is strongly red-shifted relative to the average spectrum and experimental data. Based on the present results it seems more reasonable to assume that the observed $Q_{x}-Q_{y}$ splitting is mainly determined by a complex set of structural distortions induced by thermal effects.

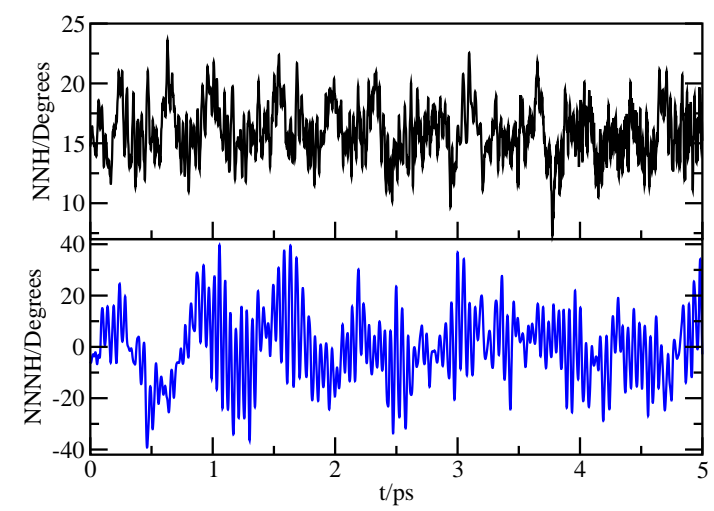

Figure 4. Time evolution of NNNH dihedral angle and NNH angle (see Figure 1) for the phthalocyanine monomer. 


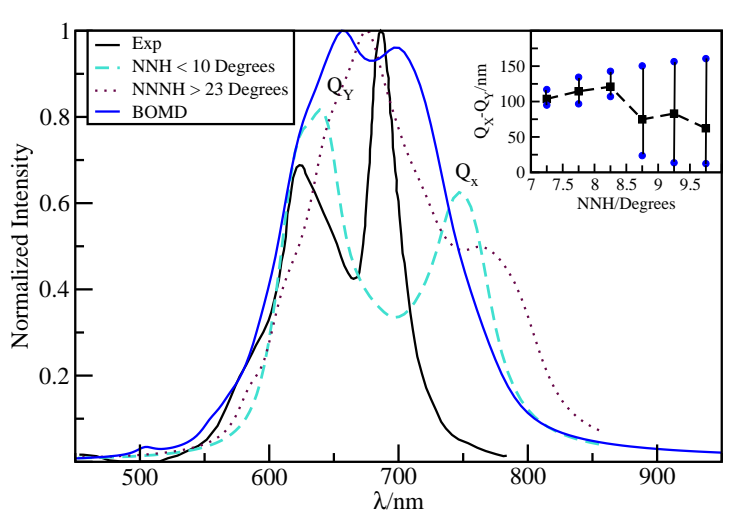

Figure 5. Influence of structural distortions on the low-energy absorption spectrum of free base phthalocyanine monomer. The inset panel illustrates the dependence of the $\mathrm{Q}_{x}-\mathrm{Q}_{y}$ splitting on the $\mathrm{NNH}$ angle (see Figure 1 ).
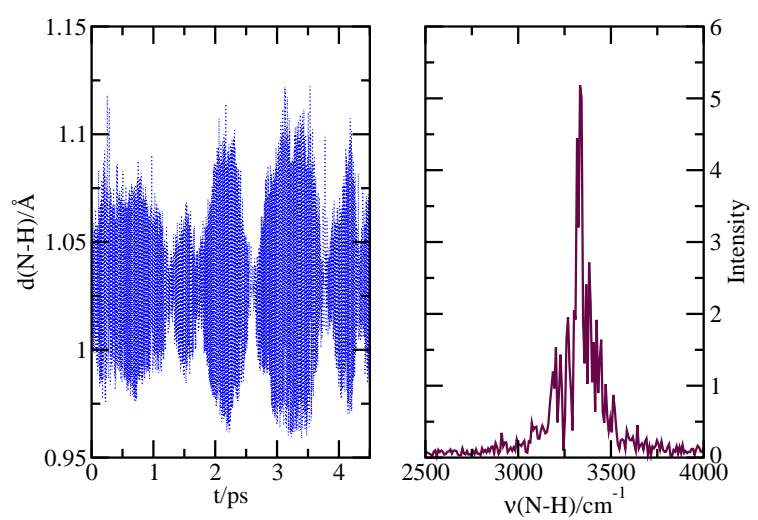

Figure 6. Time evolution of the NH bond in the central cavity (left) and frequency distribution (right) in the phthalocyanine monomer.

Deviations of the $\mathrm{H}$ atoms in the internal cavity from the NNN plane can be discussed by defining a dihedral NNNH angle involving two pyrroles and one aza group (this angle is defined by the N1N2N3H2 or N3N2N1H1 atoms in Figure 1). The time evolution of NNNH is shown in Figure 4 (bottom panel). We adopted the convention that significant deviations from planarity $(\mathrm{NNNH} \sim 0$ ) take place when at least one of the NNNH angles fulfills the condition abs $(\mathrm{NNNH})>23^{\circ}$. The excitation spectrum for the subset of configurations satisfying this criterion is also shown in Figure 5. These configurations contribute to reinforce an absorption peak at $\sim 680 \mathrm{~nm}$. In contrast with the results for the full average spectrum, the absorption peak at $\sim 640 \mathrm{~nm}$ is not observed and a shoulder in the low energy region close to $750 \mathrm{~nm}$ is now present. Therefore, deviations of NNNH from planarity in the internal cavity of the free base phthalocyanine contribute to enhance electronic absorption at lower energies.

The time evolution of the $\mathrm{N}-\mathrm{H}$ bond $[\mathrm{d}(\mathrm{N}-\mathrm{H})(\mathrm{t})]$ in the internal cavity of the phthalocyanine dimer-A is illustrated in Figure 6 (left panel). The average value is $1.03 \pm 0.03 \AA$, which can be compared with the $\mathrm{N}-\mathrm{H}$ bond distance observed for the gas-phase optimized structure $(1.02 \AA)$. The right panel shows the distribution of the $v(\mathrm{~N}-\mathrm{H})$ stretching frequency that was calculated as the Fourier transform of the average velocity autocorrelation function defined as $C_{A A}(t)=<A(t) A\left(t_{i}\right) / A\left(t_{i}\right) A\left(t_{i}\right)>$ where $A=\frac{d x}{d t}, t_{i}$ a time origin, and $x=\mathrm{d}(\mathrm{N}-\mathrm{H})$. A similar procedure was recently applied to calculate the vibrational frequencies of chlorophyll- $\mathrm{c}_{2}$ in liquid methanol [48]. This distribution shows a peak near $3300 \mathrm{~cm}^{-1}$, which is the value observed for the $\mathrm{N}-\mathrm{H}$ stretching frequency in different systems [49].

The structural dynamics of the phthalocyanine dimer will reflect thermal effects as well as the dispersion interactions between the monomers. The time evolution of $\mathrm{d}(\mathrm{X}-\mathrm{X})$, the distance between the nomomers center-of-mass $\mathrm{X}$, is represented in Figure 7 for a 4 ps window. These distances are in the 4.5-5.5 $\AA$ range and their distribution is associated with significant distortions of the phthalocyanine skeleton. Deviations of the phtalocyanine fragments involving the pyrrole group from the planar situation observed in the monomeric optimized structure can be estimated through the introduction of a dihedral angle ( $\mathrm{CCH}-\mathrm{X})$ between the $\mathrm{CCH}$ plane of pyrrole and the $\mathrm{H}-\mathrm{X}$ vector $(\mathrm{C} 1 \mathrm{C} 2 \mathrm{H} 1$ atoms of Figure 1 and the coordinate $\mathrm{X}$ ). When $\mathrm{CCH}-\mathrm{X}= \pm 180^{\circ}$ for one specific pyrrole fragment, an orientation similar to the planar situation can be assumed. The time evolution of this angle is also shown in Figure 7 (bottom panel) and the results show deviations of up to $\sim 60^{\circ}$ from the planar situation. Actually, different criteria can be defined to discuss the distortions of the phthalocyanine skeleton relative to the gas-phase optimized structure and the qualitative nature of the present analysis should be stressed.

The low-energy electronic excitation spectra for the monomer and dimer-A of phthalocyanine calculated by using a selected set of 140 configurations generated by BOMD is shown in Figure 8, where they are compared with the spectra for the optimized structures (monomer and dimer) and with experiment. Average values calculated by using BOMD configurations are also gathered in Table 2. Comparison between the results for the monomer (at $T=500 \pm 4 \mathrm{~K}$ ) and dimer (at $T=700 \pm 4 \mathrm{~K}$ ) shows a good agreement. The theoretical $\mathrm{Q}_{x}-\mathrm{Q}_{y}$ splitting for both the monomer and dimer is $\sim 40 \pm 14 \mathrm{~nm}$, which is $\sim 24 \mathrm{~nm}$ below the experimental value $(63.5 \mathrm{~nm})$ [10]. For both the monomer and dimer, thermal effects lead to a shift to lower energies and to a significant broadening of the spectra. It should be noticed that structural distortions induced by thermal effects may contribute to broad of the low energy band of dimer-A. The two lowest excitation energies of the optimized gas-phase dimer-A are forbidden by symmetry (see Table 2). However, they become allowed for the structures generated by BOMD.

In general, a good agreement with experiment is observed for the results relying on averages over BOMD configurations. In addition, our results suggest that the main features characterizing the low energy range of the electronic absorption spectrum of free base phthalocyanine may be interpreted by assuming the presence in the vapour phase of dimeric species stabilized by dispersion interactions. The influence of dimers in the absorption spectra of phthalocyanines was discussed by Dhami et al. [30]. Some

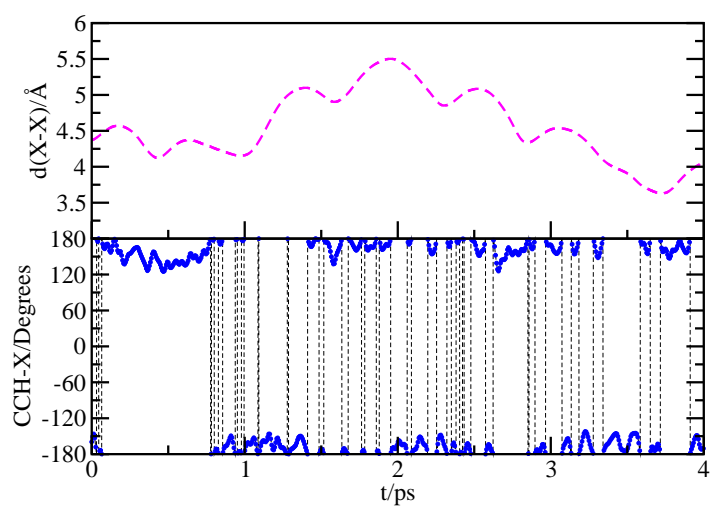

Figure 7. Time evolution of the distance between the phthalocyanine center-ofmass for dimer-A (top); time evolution of the $\mathrm{CCH}-\mathrm{X}$ dihedral angle for the monomer in dimer-A (see $\mathrm{C}_{1} \mathrm{C}_{2} \mathrm{H}_{1}-\mathrm{X}$ of Figure 1 ). 


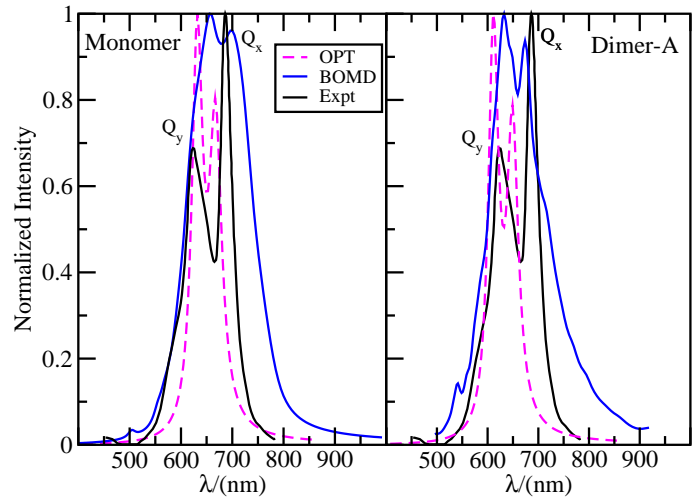

Figure 8. Low energy electronic absorption spectra for the monomer and dimer-A. Comparison with BOMD, optimized structures and experimental data.

particular features associated with dimerization are the broadening of the $\mathrm{Q}_{y}$ band and the presence a new band at the red edge of the spectrum. Our results are in keeping with these experimental findings [30].

\section{Conclusions}

The role played by thermal effects and dimerization on the electronic properties of free base phthalocyanine was investigated through a sequential BOMD/TDDFT approach. Our results for the binding energies of phthalocyanine dimers, mainly for the parallel displaced dimer-A, bound by $12 \mathrm{kcal} / \mathrm{mol}$, indicate that this species could be present even at the high temperature $(776 \mathrm{~K})$ at which the experimental absorption spectrum was measured [10]. This conclusion is supported by the good agreement between the theoretical excitation spectrum for dimer-A and the experimental data. Thermal effects lead to important distortions of the phthalocyanine skeleton at high temperatures. The distortions are characterized by deviations from the planarity characterizing the gas-phase optimized structures. The theoretical spectra of free base phthalocyanine, for both the monomer and dimer-A are significantly broadened in the low energy region in comparison with the experimental data [10].

In agreement with previous investigations on the relationship between the proton's position in the internal cavity of phthalocyanine and the Q-band splitting, it was verified that structures similar to the bridged structures proposed by Schaefer and Gouterman [12] lead to a significant $Q_{x}-Q_{y}$ splitting. However, these structures are present only in a small fraction of the total BOMD configurations. Consequently, our results suggest that the Q-band splitting in free base phthalocyanine is enhanced by thermal effects and it is actually determined by a complex set of structural distortions.

\section{Acknowledgements}

Partially supported by FCT (Portugal), CNPq, CAPES, FAPESP, INCT-FCX and nBioNet (Brazil). BJCC gratefully acknowledges support from the Universidade de São Paulo through a research grant.

\section{Appendix A. Supplementary data}

Supplementary data associated with this article can be found, in the online version, at http://dx.doi.org/10.1016/j.cplett.2014. 01.047 .

\section{References}

[1] M.G. Walter, A.B. Rudine, C.C. Wamser, J. Porphyrins Phtalocya. 14 (2010) 759.

[2] F. Ito et al., J. Phys. Chem. A 110 (2006) 12734.

[3] T. Inabe, H. Tajima, Chem. Rev. 104 (2004) 553.

[4] A. Uetomo, M. Kozaki, S. Suzuki, K.-I. Yamanaka, O. Ito, K. Okada, J. Am. Chem. Soc. 133 (2011) 13276

[5] J.G. Woller, J.K. Hannestad, B. Albinsson, J. Am. Chem. Soc. 135 (2013) 2759.

[6] J.R. Darwent, P. Douglas, A. Harriman, G. Porter, M.C. Richoux, Chem. Rev. 44 (1982) 83.

[7] A. Takeda, T. Oku, A. Suzuki, Y. Yamasaki, J. Mod. Phys. 2 (2011) 966.

[8] K. Kilså, J. Kajanus, A.N. Macpherson, J. Mårtensson, B. Albinsson, J. Am. Chem. Soc. 123 (2001) 3069.

[9] Y. Shirota, H. Kageyama, Chem. Rev. 107 (2007) 953.

[10] L. Edwards, M. Gouterman, J. Mol. Spectrosc. 33 (1970) 292.

[11] L. Edwards, D.H. Dolphin, M. Gouterman, A.D. Adler, J. Mol. Spectrosc. 38 (1971) 16.

[12] A.M. Schaffer, M. Gouterman, Theoret. Chim. Acta 25 (1972) 62.

[13] C.A. Hunter, J.K.M. Sanders, J. Am. Chem. Soc. 112 (1990) 5525.

[14] K.S. Kim, P. Tarakeshwar, J.Y. Lee, Chem. Rev. 100 (2000) 4145.

[15] K. Müller-Dethlefs, P. Hobza, Chem. Rev. 100 (2000) 143.

[16] Y. Jung, M. Head-Gordon, Phys. Chem. Chem. Phys. 8 (2006) 2831.

[17] S. Grimme, J. Comput. Chem. 27 (2006) 1787.

[18] S. Grimme, J. Antony, S. Ehrlich, J. Chem. Phys. 132 (2010) 154104

[19] T. Risthaus, S. Grimme, J. Chem. Theory Comput. 9 (2013) 1580.

[20] N.S. Hush, I.S. Woolsey, Mol. Phys. 21 (1971) 465

[21] E. Orti, J.L. Bredas, C. Clarisse, J. Chem. Phys. 92 (1990) 1228.

[22] P. Toman, S. Nespurek, K. Yakushi, J. Porphyr. Phtalocya. 6 (2002) 556.

[23] M.G. Vivas, L. de Boni, L. Gaffo, C.R. Mendonça, Dyes Pigments 101 (2014) 338.

[24] K. Toyota, J.-Y. Hasegawa, H. Nakatsuji, J. Phys. Chem. A 101 (1997) 446

[25] D.P. Piet, D. Danovich, H. Zuilhof, E.J.R. Sudhölter, J. Chem. Soc. Perkin Trans. 2 (1999) 1653.

[26] T.-T. Lu, M. Xiang, H.-L. Wang, T.-J. He, D.-M. Chen, J. Mol. Struct. (Theochem.) 860 (2008) 141.

[27] R. Fukuda, M. Ehara, H. Nakatsuji, J. Chem. Phys. 133 (2010) 144316.

[28] M.M. Mikolajczyk, R. Zalesny, Z. Czyznikowska, P. Toman, J. Leszczynski, W. Bartkowiak, J. Mol. Model. 17 (2011) 2143.

[29] D. Phillips, S. Dhami, R. Ostler, Z. Petrasek, Prog. React. Kinet. Mec. 28 (2003) 299.

[30] S. Dhami, A.J. de Mello, G. Rumble, S.M. Bishop, D. Philips, A. Beeby, Photochem. Photobio. 61 (1995) 341.

[31] http://cp2k.berlios.de, 2011.

[32] G. Lippert, J. Hutter, M. Parrinello, Mol. Phys. 92 (1997) 477.

[33] J. VandeVondele, M. Krack, F. Mohemed, M. Parrinello, T. Chassaing, J. Hutter, Comput. Phys. Commun. 167 (2005) 103.

[34] S. Goedecker, M. Teter, J. Hutter, Phys. Rev. B 54 (1996) 1703.

[35] J. Perdew, K. Burke, M. Ernzerhof, Phys. Rev. Lett. 77 (1996) 3865.

[36] G.J. Martyna, M.E. Tuckerman, J. Chem. Phys. 110 (1999) 2810.

[37] F. Neese, ORCA - An ab initio, Density Functional and Semiempirical Program Package, Version 2.9.1, University of Bonn, 2012.

[38] G. Bussi, D. Donadio, M. Parrinello, J. Chem. Phys. 126 (2007) 014101.

[39] H. Iikura, T. Tsuneda, T. Yanai, K. Hirao, J. Chem. Phys. 115 (2001) 3540.

[40] D. Jacquemin, V. Wathelet, E.A. Perpete, C. Adamo, J. Chem. Theory Comput. 5 (2009) 2420.

[41] M. Dolg, U. Wedig, H. Stoll, H. Preuss, J. Chem. Phys. 86 (1987) 866.

[42] T.H. Dunning Jr., P.J. Hay, in: H.F. Schaefer III (Ed.), Modern Theoretical Chemistry, vol. 3, Plenum, New York, 1976, p. 1.

[43] T.H. Dunning Jr., J. Chem. Phys. 90 (1989) 1007.

[44] M.J. Frisch et al., Gaussian 09, Revision A.1, Gaussian Inc, Wallingford, CT, 2009.

[45] M. Pitoňak, P. Neogrady, J. Řezáč, P. Jurečka, M. Urban, P. Hobza, J. Chem. Theory Comput. 4 (2008) 1829.

[46] T.A. Hamor, W.S. Caughey, J.L. Hoard, J. Am. Chem. Soc. 87 (1965) 2305.

[47] C.J. Brown, J. Chem. Soc. 2488 (1968) 2494.

[48] B.J.C. Cabral, K. Coutinho, S. Canuto, J. Chem. Phys. 138 (2013) 225102.

[49] N.G. Mirkin, S. Krimm, J. Phys. Chem. A 108 (2004) 5438. 
Benchmarking for the $\mathbf{Q}$ bands of the absorption spectrum of $\mathbf{H 2}-\mathrm{Phth}$ alocyanine. The basis set used in the TD calculations were $6-31+G^{*}$.

\begin{tabular}{clccc}
\hline System & \multicolumn{1}{c}{ Method } & $\lambda_{Q_{x}}$ (nm) & $\lambda_{Q_{y}} \mathbf{( n m )}$ & $\begin{array}{c}\Delta \lambda_{Q_{x}-Q_{y}} \\
(\mathbf{n m})\end{array}$ \\
\hline Monomer & TD/BHandHLYP & 620 & 616 & 4 \\
& TD/CAM- & 632 & 621 & 11 \\
& B3LYP & & & \\
& TD/O3LYP & 614 & 610 & 4 \\
& TD/B3LYP & 610 & 607 & 3 \\
& TD/BP86 & 635 & 631 & 4 \\
& TD/LC-wPBE & 713 & 674 & 39 \\
& TD/M06-2X & 608 & 597 & 11 \\
& ZINDO/CIS & 766 & 713 & 53 \\
\hline Dimer A & TD/B3LYP & 607 & 597 & 10 \\
& TD/LC-wPBE & 705 & 657 & 48 \\
Dimer B & TD/B3LYP & 622 & 610 & 12 \\
& TD/LC-wPBE & 731 & 679 & 52 \\
\hline Experimental & & 684 & 620 & 64 \\
\hline
\end{tabular}

